$\therefore$ Catalysts

\title{
Nanomaterials
}

for Environmental

Purification and

Energy Conversion

Edited by

Ewa Kowalska, Agata Markowska-Szczupak and Marcin Janczarek Printed Edition of the Special Issue Published in Catalysts 
Nanomaterials for Environmental Purification and Energy Conversion 



\section{Nanomaterials for Environmental Purification and Energy Conversion}

Special Issue Editors

Ewa Kowalska

Agata Markowska-Szczupak

Marcin Janczarek 
Special Issue Editors

Ewa Kowalska

Hokkaido University

Japan

Marcin Janczarek

Poznan University of Technology

Poland
Agata Markowska-Szczupak

West Pomeranian University of Technology

Poland

\section{Editorial Office}

MDPI

St. Alban-Anlage 66

4052 Basel, Switzerland

This is a reprint of articles from the Special Issue published online in the open access journal Catalysts (ISSN 2073-4344) from 2017 to 2019 (available at: https: / / www.mdpi.com/journal/catalysts/special_ issues/nano_envi_puri)

For citation purposes, cite each article independently as indicated on the article page online and as indicated below:

LastName, A.A.; LastName, B.B.; LastName, C.C. Article Title. Journal Name Year, Article Number, Page Range.

ISBN 978-3-03921-814-1 (Pbk)

ISBN 978-3-03921-815-8 (PDF)

Cover image courtesy of Kunlei Wang.

(c) 2019 by the authors. Articles in this book are Open Access and distributed under the Creative Commons Attribution (CC BY) license, which allows users to download, copy and build upon published articles, as long as the author and publisher are properly credited, which ensures maximum dissemination and a wider impact of our publications.

The book as a whole is distributed by MDPI under the terms and conditions of the Creative Commons license CC BY-NC-ND. 


\section{Contents}

About the Special Issue Editors $\ldots \ldots \ldots \ldots \ldots \ldots \ldots$ vii

Ewa Kowalska, Agata Markowska-Szczupak and Marcin Janczarek

Nanomaterials for Environmental Purification and Energy Conversion

Reprinted from: catalysts 2019,9 , 855, doi:10.3390/catal9100855 . . . . . . . . . . . . . 1

Zhongwei Fu, Yuehong Yu, Zhen Li, Dongmei Han, Shuanjin Wang, Min Xiao and Yuezhong Meng

Surface Reduced $\mathrm{CeO}_{2}$ Nanowires for Direct Conversion of $\mathrm{CO}_{2}$ and Methanol to Dimethyl

Carbonate: Catalytic Performance and Role of Oxygen Vacancy

Reprinted from: catalysts 2018, 8, 164, doi:10.3390/catal8040164

Ali Hafizi and Mohammad Reza Rahimpour

Inhibiting $\mathrm{Fe}-\mathrm{Al}$ Spinel Formation on a Narrowed Mesopore-Sized $\mathrm{MgAl}_{2} \mathrm{O}_{4}$ Support as a Novel Catalyst for $\mathrm{H}_{2}$ Production in Chemical Looping Technology

Reprinted from: catalysts 2018, 8, 27, doi:10.3390/catal8010027 . . . . . . . . . . . . . . .

Sanaz Daneshmand-Jahromi, Mohammad Reza Rahimpour, Maryam Meshksar and Ali Hafizi

Hydrogen Production from Cyclic Chemical Looping Steam Methane Reforming over Yttrium Promoted Ni/SBA-16 Oxygen Carrier

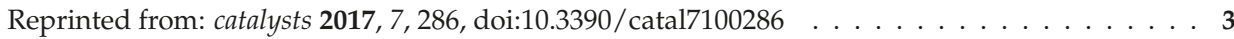

Jinxin Zou, Lei Wang and Peijun Ji

Promoting the Synthesis of Ethanol and Butanol by Salicylic Acid

Reprinted from: catalysts 2017, 7, 295, doi:10.3390/catal7100295

Fang Li, Qin Xia, Qianxun Cheng, Mingzhi Huang and Yanbiao Liu

Conductive Cotton Filters for Affordable and Efficient Water Purification

Reprinted from: catalysts 2017, 7, 291, doi:10.3390/catal7100291 . . . . . . . . . . . . . . .

Yuki Wakisaka, Daiki Kido, Hiromitsu Uehara, Qiuyi Yuan, Satoru Takakusagi, Yohei Uemura, Toshihiko Yokoyama, Takahiro Wada, Motohiro Uo, Tomohiro Sakata, Oki Sekizawa, Tomoya Uruga, Yasuhiro Iwasawa and Kiyotaka Asakura

A Demonstration of $\mathrm{Pt} \mathrm{L}_{3}$-Edge EXAFS Free from Au L $\mathrm{L}_{3}$-Edge Using Log-Spiral Bent Crystal Laue Analyzers

Reprinted from: catalysts 2018, 8, 204, doi:10.3390/catal8050204

Rita Giovannetti, Elena Rommozzi, Marco Zannotti and Chiara Anna D'Amato

Recent Advances in Graphene Based $\mathrm{TiO}_{2}$ Nanocomposites $\left(\mathrm{GTiO}_{2} \mathrm{Ns}\right)$ for Photocatalytic Degradation of Synthetic Dyes

Reprinted from: catalysts $2017,7,305$, doi:10.3390/catal7100305 . . . . . . . . . . . . .

Yebin Guan, Ming Xia, Alessandro Marchetti, Xiaohong Wang, Weicheng Cao, Hanxi Guan and Xueqian Kong

Photocatalytic Reduction of $\mathrm{CO}_{2}$ from Simulated Flue Gas with Colored Anatase

Reprinted from: catalysts 2018, 8, 78, doi:10.3390/catal8020078 . . . . . . . . . . . . . 113

Tongyao Wang, Ming Xia and Xueqian Kong

The Pros and Cons of Polydopamine-Sensitized Titanium Oxide for the Photoreduction of $\mathrm{CO}_{2}$ Reprinted from: catalysts 2018, 8, 215, doi:10.3390/catal8050215 . . . . . . . . . . . . . 124 
Agata Markowska-Szczupak, Paulina Rokicka, Kunlei Wang, Maya Endo, Antoni Waldemar Morawski and Ewa Kowalska

Photocatalytic Water Disinfection under Solar Irradiation by D-Glucose-Modified Titania

Reprinted from: catalysts 2018, 8,316, doi:10.3390/catal8080316 . . . . . . . . . . . . . . 134

Marcin Janczarek, Kunlei Wang and Ewa Kowalska

Synergistic Effect of $\mathrm{Cu}_{2} \mathrm{O}$ and Urea as Modifiers of $\mathrm{TiO}_{2}$ for Enhanced Visible Light Activity

Reprinted from: catalysts 2018,8, 240, doi:10.3390/catal8060240 . . . . . . . . . . . . . . . . 150

Anna Gołąbiewska, Micaela Checa-Suárez, Marta Paszkiewicz-Gawron, Wojciech Lisowski, Edyta Raczuk, Tomasz Klimczuk,Żaneta Polkowska, Ewelina Grabowska,

Adriana Zaleska-Medynska and Justyna Łuczak

Highly Active $\mathrm{TiO}_{2}$ Microspheres Formation in the Presence of Ethylammonium Nitrate Ionic Liquid

Reprinted from: catalysts 2018, 8, 279, doi:10.3390/catal8070279 . . . . . . . . . . . . . . . 162

Magda Kozak, Paweł Mazierski, Joanna Żebrowska, Marek Kobylański, Tomasz Klimczuk, Wojciech Lisowski, Grzegorz Trykowski, Grzegorz Nowaczyk and

Adriana Zaleska-Medynska

Electrochemically Obtained $\mathrm{TiO}_{2} / \mathrm{Cu}_{x} \mathrm{O}_{y}$ Nanotube Arrays Presenting a Photocatalytic Response in Processes of Pollutants Degradation and Bacteria Inactivation in Aqueous Phase Reprinted from: catalysts 2018, 8, 237, doi:10.3390/catal8060237 . . . . . . . . . . . . . 179

Huanhuan Wang, Peijiang Zhou, Rui Guo, Yifei Wang, Hongju Zhan and Yunfei Yuan

Synthesis of Rectorite $/ \mathrm{Fe}_{3} \mathrm{O}_{4} / \mathrm{ZnO}$ Composites and Their Application for the Removal of Methylene Blue Dye

Reprinted from: catalysts 2018,8, 107, doi:10.3390/catal8030107 . . . . . . . . . . . . . . . . . 199

Hui Liu, An Wang, Quan Sun, Tingting Wang and Heping Zeng

$\mathrm{Cu}$ Nanoparticles/Fluorine-Doped Tin Oxide (FTO) Nanocomposites for Photocatalytic $\mathrm{H}_{2}$

Evolution under Visible Light Irradiation

Reprinted from: catalysts 2017, 7,385, doi:10.3390/catal7120385 . . . . . . . . . . . . 217

Raluca Dumitru, Florica Manea, Cornelia Păcurariu, Lavinia Lupa, Aniela Pop,

Adrian Cioablă, Adrian Surdu and Adelina Ianculescu

Synthesis, Characterization of Nanosized $\mathrm{ZnCr}_{2} \mathrm{O}_{4}$ and Its Photocatalytic Performance in the

Degradation of Humic Acid from Drinking Water

Reprinted from: catalysts 2018, 8, 210, doi:10.3390/catal8050210 . . . . . . . . . . . . . . . 230

Chentao Hou, Wenli Liu and Jiaming Zhu

Synthesis of $\mathrm{NaOH}-$ Modified $\mathrm{TiOF}_{2}$ and Its Enhanced Visible Light Photocatalytic Performance on RhB

Reprinted from: catalysts 2017, 7, 243, doi:10.3390/catal7080243 . . . . . . . . . . . . . . 245 


\section{About the Special Issue Editors}

Ewa Kowalska is a leader of Research Cluster for Plasmonic Photocatalysis in Institute for Catalysis (ICAT), Hokkaido University. She received her Ph.D. in chemical technology from Gdansk University of Technology, Poland in 2004. After completing Marie Skłodowska-Curie fellowships in France (Paris-sud University; 2002-2003) and in Germany (FAU University, Erlangen and Ulm University; 2009-2012) and postdoctoral fellowships in Japan (Hokkaido University; JSPS: 2005-2007 and GCOE: 2007-2009), she joined ICAT as an associate professor in 2012. Her current work focuses on heterogeneous photocatalysis, environmental protection, plasmonic nanomaterials, vis-responsive photocatalysts and anti-microbial properties of nanomaterials.

Agata Markowska-Szczupak was born in Szczecin in 1972, and graduated from Faculty of Environmental Science and Fisheries, University of Warmia and Mazury in Olsztyn. She completed a doctoral school at University of Agriculture in Szczecin and obtained a Ph.D. in plant genetics in 2001. She became an associate professor at Faculty of Chemical Technology and Engineering (West Pomeranian University of Technology in Szczecin) after obtaining habilitation (D.Sc.) in chemical engineering in 2014. From December 2018 she works as professor at the same Faculty.

Marcin Janczarek received his Ph.D. in chemical technology from Gdansk University Technology, Poland in 2005, where he mainly conducted his research until 2016. He also worked at University of Erlangen-Nurnberg, Germany (2003-2004) and Hokkaido University (2011-1013, 2016-2017). He obtained habilitation (D.Sc.) in chemical technology in 2019. Currently, he is an associate professor at Poznan University of Technology. His research interests include heterogeneous photocatalysis, materials engineering, and technologies for purification of water and air. 



\title{
Editorial \\ Nanomaterials for Environmental Purification and Energy Conversion
}

\author{
Ewa Kowalska ${ }^{1, *}$, Agata Markowska-Szczupak ${ }^{2}$ and Marcin Janczarek ${ }^{3}$ \\ 1 Institute for Catalysis (ICAT), Hokkaido University, N21 W10, Sapporo 001-0021, Japan \\ 2 Faculty of Chemical Technology and Engineering, West Pomeranian University of Technology in Szczecin, \\ 70-322 Szczecin, Poland; Agata.Markowska@zut.edu.pl \\ 3 Institute of Chemical Technology and Engineering, Faculty of Chemical Technology, Poznan University of \\ Technology, 60-965 Poznan, Poland; marcin.janczarek@put.poznan.pl \\ * Correspondence: kowalska@cat.hokudai.ac.jp; Tel.: +81-11-706-9130
}

Received: 10 October 2019; Accepted: 12 October 2019; Published: 14 October 2019

Nanomaterials, engineered structures of which a single unit is sized (in at least one dimension) between 1 to $100 \mathrm{~nm}$, are probably the fastest growing market in the world. Although, nanotechnology is still a new discipline (proposed by Richard Feynman's talk "There's Plenty of Room at the Bottom" in 1959; and named by Norio Taniguchi in 1974), nanomaterials have already been commercialized for various purposes, including medicine, food, cosmetics, technology, and industry, as well as human and environmental health. A lot of studies on the preparation of more efficient, stable, and safe nanomaterials have been performed each year, as clearly shown by the growing number of published papers (Figure 1). Although, nanomaterials are extremely important for industrial and household purposes, it should be pointed out that properties of nanomaterials differ substantially from those of bulk materials of the same composition, resulting in high reactivity. Accordingly, possible undesirable effects might cause harmful interactions with the environment, living organisms, and humans and their parts (e.g., influence on structural integrity and functions of essential proteins, enzymes, and DNA), and thus have the potential to generate toxicity $[1,2]$. Therefore, possible negative impacts of novel materials (toxicity) must be also considered in the design of efficient, but also safe products. It is believed that most importantly, for future human development, nanomaterials/nanotechnology could be used to solve three of the top ten of humanity's problems (proposed by Prof. Smalley [3]), i.e., environment, water, and energy (which is critical for the rest of the problems). It is known that nanomaterials might be used for purification of water and air [4-6], wastewater treatment [7-10], microorganisms' inactivation [11-13], and energy conversion to the electricity and fuels [14-16].

Therefore, the special issue of Catalysts has been announced to discuss the progress of recent research on synthesis, properties, and applications of nanomaterials for environmental purification and energy conversion. This Special Issue was mainly dedicated as a platform for the contributions from The Symposium on Nanomaterials for Environmental Purification and Energy Conversion (SNEPEC), which was held in Sapporo, Japan in February 2018 (http://www.cat.hokudai.ac.jp/icat-nepec/). The contributions from those who could not attend SNEPEC were also welcomed. The Symposium covered a broad range of topics focusing on the exceptional role of catalytic nanomaterials in solving environmental and energy problems of modern societies. Accordingly, the Special Issue "Nanomaterials for Environmental Purification and Energy Conversion" is a collection of 17 papers, including 16 research papers and one review. Eleven papers present heterogeneous photocatalysis for efficient degradation of organic pollutants (phenol [17,18], 2-propanol [19], dyes [20-22], humic acid [23]), inactivation of microorganisms (Escherichia coli, Staphylococcus epidermidis [24], Bacillus subtilis, and Clostridium sp. [18]), $\mathrm{H}_{2}$ evolution [25], and $\mathrm{CO}_{2}$ reduction [26,27]. Six other papers focus on conventional catalysis ("dark" reactions), reporting efficient $\mathrm{H}_{2}$ production [28,29], synthesis of ethanol and butanol [30], direct conversion of $\mathrm{CO}_{2}$ and methanol to dimethyl carbonate [31], water purification [32], and advanced 
characterization of catalysts by X-ray absorption fine structure (EXAFS) spectroscopy [33]. The majority of studies have been performed with particulate catalysts (nanoparticles (NPs)), but organized nanostructures, such as nanotubes $\left(\mathrm{TiO}_{2} / \mathrm{Cu}_{\mathrm{x}} \mathrm{O}_{\mathrm{y}}[18]\right.$, carbon nanotubes (CNTs) $\left.[30,32]\right)$ and nanowires $\left(\mathrm{CeO}_{2}[31]\right)$ have also been used.

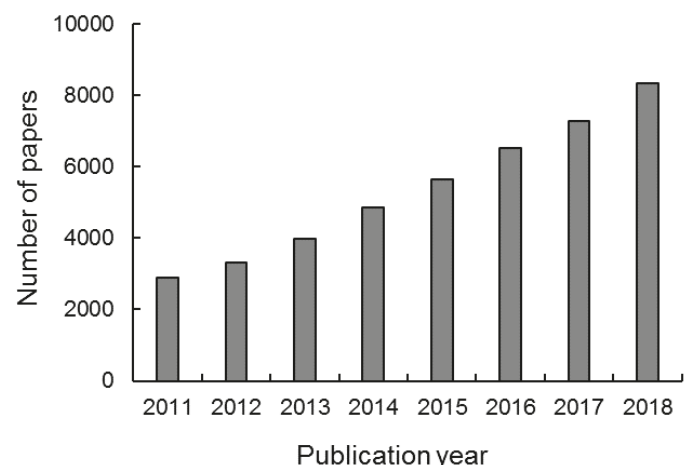

Figure 1. Number of papers published annually on nanomaterials (searched in Web of Science using "nanomaterials", 9 October 2019).

Fu et al. prepared $\mathrm{CeO}_{2}$ nanowires by the advanced solvothermal method for direct catalytic synthesis of dimethyl carbonate from $\mathrm{CO}_{2}$ and methanol [31]. They found that the surface reduction under $\mathrm{H}_{2}$ atmosphere formed acidic/alkaline sites on the catalyst surface, and thus significantly improved catalytic activity, reducing the activation energy barrier from 74.7 to $41.9 \mathrm{~kJ} / \mathrm{mol}$. Complex catalytic studies were performed by Hafizi and Rahimpour for catalytic $\mathrm{H}_{2}$ production [28]. The effect of alumina and $\mathrm{Mg}-\mathrm{Al}$ spinel as the support for the formation of $\mathrm{Fe}_{2} \mathrm{O}_{3}$ catalyst was investigated. The $\mathrm{Fe}_{2} \mathrm{O}_{3}-\mathrm{MgAl}_{2} \mathrm{O}_{4}$ with narrowed mesopore-sized $(2.3 \mathrm{~nm})$ was successfully synthesized as an ultra-pure lattice oxygen transport medium. Furthermore, Daneshmand-Jahromi et al. analyzed the role of yttrium promoted $\mathrm{Ni} / \mathrm{SBA}-16$ as an oxygen carrier in steam methane reforming [29]. The reaction temperature, $\mathrm{Y}$ and $\mathrm{Ni}$ loading, steam/carbon molar ration, and lifetime of the oxygen carrier were investigated. The best catalytic activity was obtained for mesoporous silica (SBA-16) modified with $25 \mathrm{wt} \% \mathrm{Ni}$ and $2.5 \mathrm{wt} \% \mathrm{Y}$, resulting in $99.83 \% \mathrm{CH}_{4}$ conversion and $85.34 \% \mathrm{H}_{2}$ production.

The synthesis of ethanol and butanol from synthesis gas on multiwalled carbon nanotubes (MWCNTs) functionalized with salicylic acid and impregnated with copper-cobalt catalyst was proposed by Zou et al. [30]. It was found that salicylic acid did not only functionalize carbon nanotubes, but also promoted the synthesis of ethanol and butanol, instead of methanol. Moreover, the surface properties of MWCNTs were crucial for efficient alcohol synthesis, i.e., the best activity was obtained with MWCNTs of $30 \mathrm{~nm}$ diameter. Carbon nanotubes (CNTs) were also used for efficient water purification by $\mathrm{Li}$ et al. [32]. The conductive cotton filter anodes were fabricated by a facile dying method to incorporate CNTs as filters. The developed filtration device achieved physical adsorption of organic compounds (ferrocyanide, methyl orange dye, and antibiotic tetracycline), and additionally, an application of external potential resulted in chemical oxidation of pollutants. The CNTs amount, total cell potential, and surfactant were key parameters affecting the electrochemical oxidation. It was proposed that the conductive cotton filter might be efficiently used for low-cost and energy-saving water purification. This very important research was reported by Wakisaka et al. who demonstrated the extended X-ray absorption fine structure (EXAFS) spectroscopy as an efficient technique to characterize $\mathrm{Pt}-\mathrm{Au}$ fuel cell catalysts [33]. Previously, range-extended EXAFS was only achieved in high-energy resolution fluorescence detected XAFS (HERFD-XAFS). The presented results confirmed the feasibility of the range-extended EXAFS using the bent crystal Laue analyzer (BCLA) for fuel cells models containing Pt and Au. 
Most papers discussed photocatalytic reactions on nanomaterials (heterogeneous photocatalysis). Titania (titanium(IV) oxide, $\mathrm{TiO}_{2}$ ) is one of the most well-known and widely studied photocatalysts, due to its advantages, such as high activity, stability, low-cost, and nontoxicity (excluding toxicity of nanomaterials), as also confirmed in this issue (seven papers [17-19,21,24,26,27]). However, titania has two main shortcomings, i.e., recombination of charge carriers (typical for all semiconductors) and inactivity under visible light irradiation (due to wide bandgap). Therefore, various studies have been performed to improve photocatalytic performance of titania. The comprehensive review by Giovannetti et al. on recent advances in graphene-based $\mathrm{TiO}_{2}$ nanocomposites for synthetic dye degradation shows the increasing potential of titania photocatalysts based on graphene matrix, in the field of extending the light absorption of $\mathrm{TiO}_{2}$ from UV into the visible light range of radiation [21]. In this regard, the idea of titania modification is strongly present in the papers collected in the issue, e.g., titania surface modification with copper oxides $\left(\mathrm{Cu}_{2} \mathrm{O}[19]\right.$ and $\left.\mathrm{Cu}_{x} \mathrm{O}_{y}[18]\right)$, organic compounds (glucose [24] and urea [19]), polymers (polydopamine [27]), graphene [21], carbon/nitrogen [17], and titania doping (self-doped or hydrogenated) [34]. All kinds of modifications resulted in enhanced activity under either UV, visible light or solar radiation. Guan et al. prepared and characterized the colored core-shell structure of $\mathrm{TiO}_{2} @ \mathrm{TiO}_{2-x}$ [26]. They reported visible light activity of this material towards $\mathrm{CO}_{2}$ reduction under a simulated flue gas system. Visible light-induced photoreduction of $\mathrm{CO}_{2}$ was also conducted with polydopamine-sensitized $\mathrm{TiO}_{2}$ by Wang et al. [27]. The successful titania modifications with D-glucose was achieved by Markowska-Szczupak et al. [24], where the photocatalytic activities of suspended and immobilized photocatalysts were compared. In this study, it was shown for the first time that titania modification with monosaccharides could be efficient for water disinfection, and the immobilization of the photocatalyst on the concrete discs might be a prospective method for public water supplies and water storage tanks (as exemplified for a home aquarium in Figure 2a). The synergistic effect was observed by Janczarek et al. for titania bi-modification with urea (formed poly(amino-s-triazine) [35]) and $\mathrm{Cu}_{2} \mathrm{O}$ [19]. Two types of possible mechanisms of visible light activity were proposed, i.e., the type II heterojunction and Z-scheme. An important issue was the morphological form of the photocatalytic material based on titania. Golabiewska et al. prepared highly active microspheres in the presence of ionic liquid and Kozak et al. designed $\mathrm{TiO}_{2} / \mathrm{Cu}_{\mathrm{x}} \mathrm{O}_{\mathrm{y}}$ nanotubes with visible light activity in the degradation of organic pollutants and bacteria inactivation. It was proposed that these nanotubes could be efficiently used for environmental purification under natural solar radiation, as shown on the journal cover (Figure $2 b$ ).

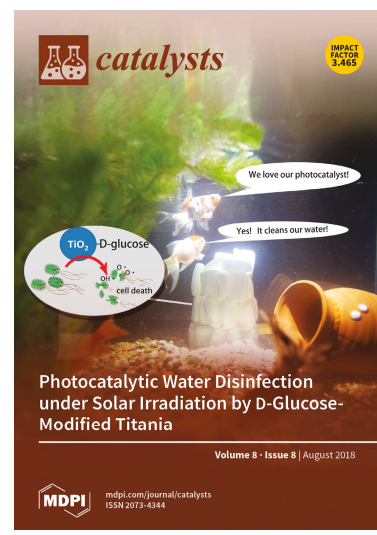

(a)

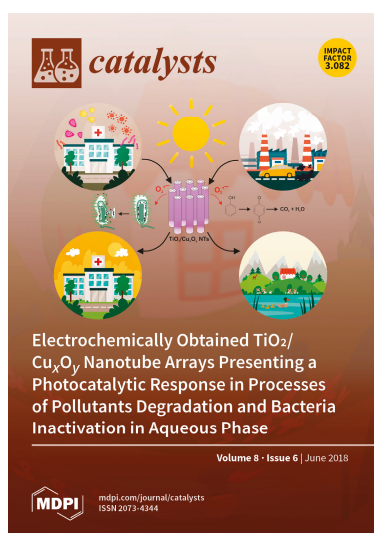

(b)

Figure 2. Journal covers of Catalysts showing possible applications of (a) modified titania with D-glucose for water tanks; volume 8, issue 8 (https://res.mdpi.com/data/covers/catalysts/big_cover-catalysts-v8i8.png) [24] and (b) $\mathrm{TiO}_{2} / \mathrm{Cu}_{\mathrm{x}} \mathrm{O}_{\mathrm{y}}$ nanotube arrays for environmental purification; volume 8 , issue 6 (https://res.mdpi.com/data/covers/catalysts/big_cover-catalysts-v8-i6.png) [18]. 
It should be pointed that also other semiconductors have been used successfully for environmental applications, such as $\mathrm{ZnO}$ [36], graphitic carbon nitride (g-C3N4) [37], $\mathrm{WO}_{3}$ [10], $\mathrm{BiVO}_{4}$ [38], and $\mathrm{SrTiO}_{3}$ [39], and some of them exhibited higher activity than that of titania even under UV irradiation [40-42]. Accordingly, the photocatalytic activity of other semiconductors has also been discussed in this special issue, such as $\mathrm{ZnCr}_{2} \mathrm{O}_{4}$ [23], $\mathrm{TiOF}_{2}$ (modified with $\mathrm{NaOH}$ ) [20], $\mathrm{SnO}_{2}$ (fluorine-doped $\mathrm{SnO}_{2}$ (FTO), surface modified with $\mathrm{Cu} \mathrm{NPs}$ ) [25], and rectorite $/ \mathrm{Fe}_{3} \mathrm{O}_{4} / \mathrm{ZnO}$ [22]. Wang et al. prepared rectorite/ $\mathrm{Fe}_{3} \mathrm{O}_{4} / \mathrm{ZnO}$ composities with photocatalytic and magnetic properties enabling efficient photocatalyst separation after reaction [22]. Liu et al. obtained $\mathrm{Cu} / \mathrm{fluorine}$-doped tin oxide nanocomposites $(\mathrm{Cu} / \mathrm{FTO})$ dedicated to visible light-induced hydrogen production and photocurrent generation [25]. The high stability during recycling (24-h irradiation) should be considered as high advantage of this material. The nanosized $\mathrm{ZnCr}_{2} \mathrm{O}_{4}$ was synthesized by Dumitru et al. by thermolysis of a new $\mathrm{Zn}(\mathrm{II})-\mathrm{Cr}$ (III) oxalate coordination compound [23]. The photocatalyst was much more efficient for humic acid degradation than simple photolysis $(7 \%)$, reaching $60 \%$ degradation after $3 \mathrm{~h}$ of $\mathrm{UV}$ irradiation. Finally, $\mathrm{TiOF}_{2}$ modified with $\mathrm{NaOH}$ of network structure was prepared via a modified low-temperature solvothermal method by Hou et al., and efficiently used for Rhodamine B degradation [20].

In conclusion, the significant role of catalytic nanomaterials in environmental remediation, energy production, and chemical synthesis systems has been discussed in the collected papers. We do believe that the SNEPEC symposium and this associated Special Issue have provided further insights to this area. We are looking forward to seeing how things will be progressed at the next SNEPEC symposium (July 2020).

Finally, we thank all authors for their valuable contributions, without which this special issue would not have been possible. We would like to express our sincerest thanks also to the editorial team of Catalysts for their kind support, advice, and fast responses.

Acknowledgments: Institute for Catalysis (ICAT), Hokkaido University is highly acknowledged for excellent support in organizing and hosting the Symposium on Nanomaterials for Environmental Purification and Energy Conversion (SNEPEC), 20-21 February 2018.

Conflicts of Interest: The authors declare no conflict of interest.

\section{References}

1. Nel, A.; Xia, T.; Mädler, L.; Li, N. Toxic Potential of Materials at the Nanolevel. Science 2006, 311, $622-627$. [CrossRef] [PubMed]

2. Nel, A.E.; Mädler, L.; Velegol, D.; Xia, T.; Hoek, E.M.V.; Somasundaran, P.; Klaessig, F.; Castranova, V.; Thompson, M. Understanding biophysicochemical interactions at the nano-bio interface. Nat. Mater. 2009, 8, 543-557. [CrossRef] [PubMed]

3. Smalley, R.E. Nanotechnology, Energy and People; MIT Forum: River Oaks, TX, USA, 2003.

4. Hoffmann, M.R.; Martin, S.T.; Choi, W.; Bahnemann, D.W. Environmental Applications of Semiconductor Photocatalysis. Chem. Rev. 1995, 95, 69-96. [CrossRef]

5. Verbruggen, S.W.; Keulemans, M.; Goris, B.; Blommaerts, N.; Bals, S.; Martens, J.A.; Lenaerts, S. Plasmonic 'rainbow' photocatalyst with broadband solar light response for environmental applications. Appl. Catal. B Environ. 2016, 188, 147-153. [CrossRef]

6. Alfano, O.; Bahnemann, D.; Cassano, A.; Dillert, R.; Goslich, R. Photocatalysis in water environments using artificial and solar light. Catal. Today 2000, 58, 199-230. [CrossRef]

7. Herrmann, J.-M.; Disdier, J.; Pichat, P.; Malato, S.; Blanco, J. $\mathrm{TiO}_{2}$-based solar photocatalytic detoxification of water containing organic pollutants. Case studies of 2,4-dichlorophenoxyaceticacid (2,4-D) and of benzofuran. Appl. Catal. B Environ. 1998, 17, 15-23. [CrossRef]

8. Wang, Z.-H.; Zhuang, Q.-X. Photocatalytic reduction of pollutant $\mathrm{Hg}(\mathrm{II})$ on doped $\mathrm{WO}_{3}$ dispersion. J. Photochem. Photobiol. A Chem. 1993, 75, 105-111. [CrossRef]

9. Li Puma, G.L.; Khor, J.N.; Brucato, A. Modeling of an Annular Photocatalytic Reactor for Water Purification: Oxidation of Pesticides. Environ. Sci. Technol. 2004, 38, 3737-3745. [CrossRef] 
10. Abe, R.; Takami, H.; Murakami, N.; Ohtani, B. Pristine Simple Oxides as Visible Light Driven Photocatalysts: Highly Efficient Decomposition of Organic Compounds over Platinum-Loaded Tungsten Oxide. J. Am. Chem. Soc. 2008, 130, 7780-7781. [CrossRef]

11. Guillard, C.; Bui, T.-H.; Felix, C.; Moules, V.; Lina, B.; Lejeune, P. Microbiological disinfection of water and air by photocatalysis. Comptes Rendus Chim. 2008, 11, 107-113. [CrossRef]

12. Markowska-Szczupak, A.; Wang, K.; Rokicka, P.; Endo, M.; Wei, Z.; Ohtani, B.; Morawski, A.W.; Kowalska, E. The effect of anatase and rutile crystallites isolated from titania P25 photocatalyst on growth of selected mould fungi. J. Photochem. Photobiol. B Boil. 2015, 151, 54-62. [CrossRef] [PubMed]

13. Markowska-Szczupak, A.; Ulfig, K.; Morawski, A. The application of titanium dioxide for deactivation of bioparticulates: An overview. Catal. Today 2011, 169, 249-257. [CrossRef]

14. Fujishima, A.; Honda, K. Electrochemical Photolysis of Water at a Semiconductor Electrode. Nature 1972, 238, 37-38. [CrossRef] [PubMed]

15. O'Regan, B.; Graetzel, M. A low-cost, high-efficiency solar cell based on dye-sensitized colloidal titanium dioxide films. Nature 1991, 353,737-740. [CrossRef]

16. Abe, R. Recent progress on photocatalytic and photoelectrochemical water splitting under visible light irradiation. J. Photochem. Photobiol. C Photochem. Rev. 2010, 11, 179-209. [CrossRef]

17. Gołąbiewska, A.; Checa-Suárez, M.; Paszkiewicz-Gawron, M.; Lisowski, W.; Raczuk, E.; Klimczuk, T.;

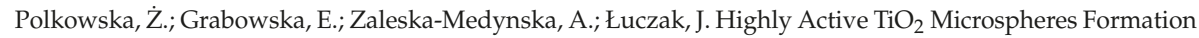
in the Presence of Ethylammonium Nitrate Ionic Liquid. Catalysts 2018, 8, 279.

18. Kozak, M.; Mazierski, P.; Zebrowska, J.; Kobylański, M.; Klimczuk, T.; Lisowski, W.; Trykowski, G.; Nowaczyk, G.; Zaleska-Medynska, A. Electrochemically Obtained $\mathrm{TiO}_{2} / \mathrm{Cu}_{\mathrm{x}} \mathrm{O}_{\mathrm{y}}$ Nanotube Arrays Presenting a Photocatalytic Response in Processes of Pollutants Degradation and Bacteria Inactivation in Aqueous Phase. Catalysts 2018, 8, 237. [CrossRef]

19. Janczarek, M.; Wang, K.; Kowalska, E. Synergistic Effect of $\mathrm{Cu}_{2} \mathrm{O}$ and Urea as Modifiers of $\mathrm{TiO}_{2}$ for Enhanced Visible Light Activity. Catalysts 2018, 8, 240. [CrossRef]

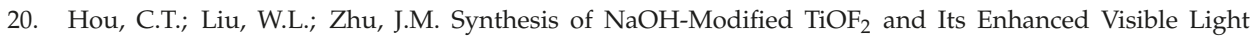
Photocatalytic Performance on RhB. Catalysts 2017, 7, 243. [CrossRef]

21. Giovannetti, R.; Rommozzi, E.; Zannotti, M.; D'Amato, C.A. Recent Advances in Graphene Based $\mathrm{TiO}_{2}$ Nanocomposites $\left(\mathrm{GTiO}_{2} \mathrm{Ns}\right)$ for Photocatalytic Degradation of Synthetic Dyes. Catalysts 2017, 7, 305. [CrossRef]

22. Wang, H.; Zhou, P.; Guo, R.; Wang, Y.; Zhan, H.; Yuan, Y. Synthesis of Rectorite/ $\mathrm{Fe}_{3} \mathrm{O}_{4} / \mathrm{ZnO}$ Composites and Their Application for the Removal of Methylene Blue Dye. Catalysts 2018, 8, 107. [CrossRef]

23. Dumitru, R.; Manea, F.; Păcurariu, C.; Lupa, L.; Pop, A.; Cioablă, A.; Surdu, A.; Ianculescu, A. Synthesis, Characterization of Nanosized $\mathrm{ZnCr}_{2} \mathrm{O}_{4}$ and Its Photocatalytic Performance in the Degradation of Humic Acid from Drinking Water. Catalysts 2018, 8, 210. [CrossRef]

24. Markowska-Szczupak, A.; Rokicka, P.; Wang, K.; Endo, M.; Morawski, A.W.; Kowalska, E. Photocatalytic Water Disinfection under Solar Irradiation by d-Glucose-Modified Titania. Catalysts 2018, 8, 316. [CrossRef]

25. Liu, H.; Wang, A.; Sun, Q.; Wang, T.; Zeng, H. Cu Nanoparticles/Fluorine-Doped Tin Oxide (FTO) Nanocomposites for Photocatalytic $\mathrm{H}_{2}$ Evolution under Visible Light Irradiation. Catalysts 2017, 7, 385. [CrossRef]

26. Guan, Y.; Xia, M.; Marchetti, A.; Wang, X.; Cao, W.; Guan, H.; Kong, X. Photocatalytic Reduction of $\mathrm{CO}_{2}$ from Simulated Flue Gas with Colored Anatase. Catalysts 2018, 8, 78. [CrossRef]

27. Wang, T.; Xia, M.; Kong, X. The Pros and Cons of Polydopamine-Sensitized Titanium Oxide for the Photoreduction of $\mathrm{CO}_{2}$. Catalysts 2018, 8, 215. [CrossRef]

28. Hafizi, A.; Rahimpour, M.R. Inhibiting Fe-Al Spinel Formation on a Narrowed Mesopore-Sized $\mathrm{MgAl}_{2} \mathrm{O}_{4}$ Support as a Novel Catalyst for $\mathrm{H}_{2}$ Production in Chemical Looping Technology. Catalysts 2018, 8, 27. [CrossRef]

29. Daneshmand-Jahromi, S.; Rahimpour, M.R.; Meshksar, M.; Hafizi, A. Hydrogen Production from Cyclic Chemical Looping Steam Methane Reforming over Yttrium Promoted Ni/SBA-16 Oxygen Carrier. Catalysts 2017, 7, 286. [CrossRef]

30. Zou, J.; Wang, L.; Ji, P. Promoting the Synthesis of Ethanol and Butanol by Salicylic Acid. Catalysts 2017, 7, 295.

31. Fu, Z.; Yu, Y.; Li, Z.; Han, D.; Wang, S.; Xiao, M.; Meng, Y. Surface Reduced $\mathrm{CeO}_{2}$ Nanowires for Direct Conversion of $\mathrm{CO}_{2}$ and Methanol to Dimethyl Carbonate: Catalytic Performance and Role of Oxygen Vacancy. Catalysts 2018, 8, 164. [CrossRef] 
32. Li, F.; Xia, Q.; Cheng, Q.; Huang, M.; Liu, Y. Conductive Cotton Filters for Affordable and Efficient Water Purification. Catalysts 2017, 7, 291. [CrossRef]

33. Wakisaka, Y.; Kido, D.; Uehara, H.; Yuan, Q.; Takakusagi, S.; Uemura, Y.; Yokoyama, T.; Wada, T.; Uo, M.; Sakata, T.; et al. A Demonstration of Pt L3-Edge EXAFS Free from Au L3-Edge Using Log-Spiral Bent Crystal Laue Analyzers. Catalysts 2018, 8, 204. [CrossRef]

34. Tsang, C.H.A.; Li, K.; Zeng, Y.; Zhao, W.; Zhang, T.; Zhan, Y.; Xie, R.; Leung, D.Y.; Huang, H. Titanium oxide based photocatalytic materials development and their role of in the air pollutants degradation: Overview and forecast. Environ. Int. 2019, 125, 200-228. [CrossRef] [PubMed]

35. Mitoraj, D.; Kisch, H. The Nature of Nitrogen-Modified Titanium Dioxide Photocatalysts Active in Visible Light. Angew. Chem. Int. Ed. 2008, 47, 9975-9978. [CrossRef] [PubMed]

36. Bandara, J.; Tennakone, K.; Jayatilaka, P. Composite tin and zinc oxide nanocrystalline particles for enhanced charge separation in sensitized degradation of dyes. Chemosphere 2002, 49, 439-445. [CrossRef]

37. Maeda, K.; Wang, X.; Nishihara, Y.; Lu, D.; Antonietti, M.; Domen, K. Photocatalytic Activities of Graphitic Carbon Nitride Powder for Water Reduction and Oxidation under Visible Light. J. Phys. Chem. C 2009, 113, 4940-4947. [CrossRef]

38. Kohtani, S.; Makino, S.; Kudo, A.; Tokumura, K.; Ishigaki, Y.; Matsunaga, T.; Nikaido, O.; Hayakawa, K.; Nakagaki, R. Photocatalytic degradation of 4-n-nonylphenol under irradiation from solar simulator: comparison between $\mathrm{BiVO}_{4}$ and $\mathrm{TiO}_{2}$ photocatalysts. Chem. Lett. 2002, 7, 660-661. [CrossRef]

39. Niishiro, R.; Kudo, A. Development of Visible-Light-Driven $\mathrm{TiO}_{2}$ and $\mathrm{SrTiO}_{3}$ Photocatalysts Doped with Metal Cations for $\mathrm{H}_{2}$ or $\mathrm{O}_{2}$ Evolution. Solid State Phenom. 2010, 162, 29-40. [CrossRef]

40. Shafaei, A.; Nikazar, M.; Arami, M. Photocatalytic degradation of terephthalic acid using titania and zinc oxide photocatalysts: Comparative study. Desalination 2010, 252, 8-16. [CrossRef]

41. Khodja, A.A.; Sehili, T.; Pilichowski, J.-F.; Boule, P. Photocatalytic degradation of 2-phenylphenol on $\mathrm{TiO}_{2}$ and $\mathrm{ZnO}$ in aqueous suspensions. J. Photochem. Photobiol. A Chem. 2001, 141, 231-239. [CrossRef]

42. Lizama, C.; Freer, J.; Baeza, J.; Mansilla, H.D. Optimized photodegradation of Reactive Blue 19 on $\mathrm{TiO}_{2}$ and ZnO suspensions. Catal. Today 2002, 76, 235-246. [CrossRef]

(C) 2019 by the authors. Licensee MDPI, Basel, Switzerland. This article is an open access article distributed under the terms and conditions of the Creative Commons Attribution (CC BY) license (http://creativecommons.org/licenses/by/4.0/). 


\title{
Article \\ Surface Reduced $\mathrm{CeO}_{2}$ Nanowires for Direct Conversion of $\mathrm{CO}_{2}$ and Methanol to Dimethyl Carbonate: Catalytic Performance and Role of Oxygen Vacancy
}

\author{
Zhongwei Fu ${ }^{\dagger}$, Yuehong $\mathrm{Yu}^{\dagger}{ }^{+}$, Zhen Li, Dongmei Han, Shuanjin Wang, Min Xiao * and \\ Yuezhong Meng * \\ The Key Laboratory of Low-Carbon Chemistry \& Energy Conservation of Guangdong Province/State Key \\ Laboratory of Optoelectronic Materials and Technologies, Sun Yat-sen University, No. 135, Xingang Xi Road, \\ Guangzhou 510275, China; fuzhw@mail2.sysu.edu.cn (Z.F.); yuyueh@mail2.sysu.edu.cn (Y.Y.); \\ lizh63@mail2.sysu.edu.cn (Z.L.); handongm@mail.sysu.edu.cn (D.H.); wangshj@mail.sysu.edu.cn (S.W.) \\ * Correspondence: stsxm@mail.sysu.edu.cn (M.X.); mengyzh@mail.sysu.edu.cn (Y.M.); \\ Tel.: +86-20-8411-4113 (Y.M.) \\ + These authors have contributed equally to this work.
}

Received: 14 March 2018; Accepted: 4 April 2018; Published: 19 April 2018

\begin{abstract}
Ultralong $1 \mathrm{D} \mathrm{CeO} 2$ nanowires were synthesized via an advanced solvothermal method, surface reduced under $\mathrm{H}_{2}$ atmosphere, and first applied in direct synthesis of dimethyl carbonate (DMC) from $\mathrm{CO}_{2}$ and $\mathrm{CH}_{3} \mathrm{OH}$. The micro morphologies, physical parameters of nanowires were fully investigated by transmission electron microscopy (TEM), X-ray diffraction (XRD), $\mathrm{N}_{2}$ adsorption, $\mathrm{X}$-ray photoelectron spectrum (XPS), and temperature-programmed desorption of ammonia/carbon dioxide $\left(\mathrm{NH}_{3}-\mathrm{TPD} / \mathrm{CO}_{2}-\mathrm{TPD}\right)$. The effects of surface oxygen vacancy and acidic/alkaline sites on the catalytic activity was explored. After reduction, the acidic/alkaline sites of $\mathrm{CeO}_{2}$ nanowires can be dramatically improved and evidently raised the catalytic performance. $\mathrm{CeO}_{2}$ nanowires reduced at $500{ }^{\circ} \mathrm{C}\left(\mathrm{CeO}_{2} \_\mathrm{NW} \_500\right)$ exhibited notably superior activity with DMC yield of $16.85 \mathrm{mmol} \mathrm{gcat}^{-1}$. Furthermore, kinetic insights of initial rate were carried out and the apparent activation energy barrier of $\mathrm{CeO}_{2} \mathrm{NW}_{-} 500$ catalyst was found to be $41.9 \mathrm{~kJ} / \mathrm{mol}$, much tiny than that of $\mathrm{CeO}_{2} \mathrm{NW}$ catalyst $(74.7 \mathrm{KJ} / \mathrm{mol})$.
\end{abstract}

Keywords: dimethyl carbonate; carbon dioxide; ceria nanowires; oxygen vacancy

\section{Introduction}

As an environmentally benign compound and unique intermediate of versatile chemical products, dimethyl carbonate (DMC) is widely applied in polymer industry and pharmaceutical as well as detergent, surfactant, and softener additives [1,2]. In addition, DMC is important raw material when serving as a non-toxic substitute for poisonous phosgene and dimethyl sulfate in sustainable chemistry of carbonylation, methylation, and polymer synthesis [3,4]. As an additive, DMC can improve the octane number and oxygen content of fuels, thereby enhancing its antiknock [1]. Furthermore, DMC can be used as a cleaning solvent in coating paints and the important composition of electrolyte [5]. Considering the wide applications, DMC is known as the "new cornerstone" for synthesis chemistry nowadays and lots of efforts have been made in finding appropriate routes to meet the demand of DMC industrial production since it is far from satisfaction until now. Several approaches including the methanolysis of phosgene [6], the oxidative carbonylation of methanol [7], the transesterification of alkene carbonates [8], and the alcoholysis of urea [3], have been developed, but it is still limited with strict operation conditions, highly toxicity, and corrosivity up to now. 
Using carbon dioxide $\left(\mathrm{CO}_{2}\right)$ in DMC synthesis is particularly attractive since $\mathrm{CO}_{2}$ is known as a recyclable and naturally abundant raw materials for the production of plentiful chemical reagents. Meanwhile, the emissions of $\mathrm{CO}_{2}$ have significantly increased and contributed to global warming, thus the utilization of $\mathrm{CO}_{2}$ has attracted more and more attention in the last decades [9,10]. In this regard, the direct synthesis of DMC from $\mathrm{CO}_{2}$, and methanol (Scheme 1) is considered as one of the most attractive and effective methods since such an approach is environmentally benign not only for reduction of greenhouse gas emissions but also for development of a new carbon resource [11,12]. However, such a sustainable route also exists significant challenges due to facts including the highly thermodynamically stability of $\mathrm{CO}_{2}$, as well as the kinetically inert and deactivation of catalysts induced by water formation in the reaction process [13-15].

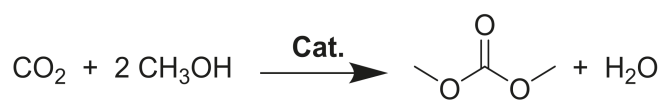

Scheme 1. Direct synthesis of DMC from $\mathrm{CO}_{2}$ and methanol.

Several methods, such as adding co-reagents and dehydrants in the reaction systems, have been developed [16,17]. Furthermore, some new technologies, such as photo-assistant [14], electro-assistant [18], membrane separation [19], and supercritical $\mathrm{CO}_{2}$ technology [20,21] have been introduced to boost the production of DMC in former reports. Even then, the reactions are preferred at strict conditions and the yield of DMC is relatively low. Though the efforts to these approaches are devoted today, the explorations of advanced heterogeneous catalysts are still regarded as the most effective route [22-24]. In particular, $\mathrm{CeO}_{2}$ based catalysts have been transplanted in the direct synthesis of DMC and show much better catalytic activity as an excellent heterogeneous catalyst $[25,26]$. Plenty of references has employed $\mathrm{CeO}_{2}$ as competent catalysts in $\mathrm{DMC}$ formation involving dehydration [27]. Furthermore, previously studies have revealed that the different crystal facets exposed on the surface of $\mathrm{CeO}_{2}$ nanostructures were strongly controlled by its morphology, leading to differential physicochemical properties and further effecting the catalytic performance [28]. In this context, 1D structured $\mathrm{CeO}_{2}$ nanorods catalyst demonstrated superior DMC yield $(0.906 \mathrm{mmol} \mathrm{DMC} / \mathrm{mmol} \mathrm{cat})$ from $\mathrm{CO}_{2}$ and methanol when compared to $\mathrm{CeO}_{2}$ nanocubes $(0.582 \mathrm{mmol} \mathrm{DMC} / \mathrm{mmol}$ cat $)$ and $\mathrm{CeO}_{2}$ nano-octahedrons $\left(0.120 \mathrm{mmol} \mathrm{DMC} / \mathrm{mmol}\right.$ cat) $[25,29]$. However, major drawbacks of $\mathrm{CeO}_{2}$ nanorods are the extremely low yield and high cost of hydrothermal method, preventing it from being used in practical applications [30]. In the meantime, the low aspect ratio of nanorods limits the specific surface area of catalysts, which would affect the catalytic performance further $[25,26]$.

In this respect, we were especially interested in new trials for ultralong $1 \mathrm{D} \mathrm{CeO}_{2}$ nanostructure. Furthermore, oxygen deficiency of the $\mathrm{CeO}_{2}$ based catalyst has been proved playing important roles in $\mathrm{CO}_{2}$ and methanol activation in former research [26,31]. Thus, we conducted further research on surface reduced $\mathrm{CeO}_{2}$ nanowires catalyst. Herein, $\mathrm{CeO}_{2}$ nanowires with a diameter of $10 \mathrm{~nm}$ and an aspect ratio of more than 50 was successfully prepared by the refluxing approach established by Yu et al. [32] and then simply surface reduced under hydrogen atmospheres, followed by their application in the direct synthesis of DMC from $\mathrm{CO}_{2}$ and methanol. Moreover, the influence of surface oxygen-deficiency and acid-basic sites were fully investigated. The catalytic recyclability was also detected. Finally, we conducted a detailed kinetic investigation for the direct formation of DMC in an autoclave reactor over catalysts.

\section{Results and Discussion}

\subsection{Morphology and Microstructure of the Prepared Catalysts}

$\mathrm{CeO}_{2}$ nanowires catalyst was prepared using a solvothermal method in a mixed water/ethanol solvents $(\mathrm{v} / \mathrm{v}=1: 1)$. Figure $1 \mathrm{a}, \mathrm{b}$ show the morphology of the unreduced $\mathrm{CeO}_{2}$ nanowires catalyst, 
exhibiting an intact nanowire structure with an average length of around $500 \mathrm{~nm}$ and a uniform diameter of less than $10 \mathrm{~nm}$. After reduced with $\mathrm{H}_{2}$, the nanowire structure was kept undestroyed, and the size of nanowires has made almost no change (Figure 1c). The crystal structures of $\mathrm{CeO}_{2}$ nanowires catalysts were investigated by XRD, and the spectra are shown in Figure 2. For unreduced $\mathrm{CeO}_{2}$ nanowires, the diffraction peaks of $2 \theta$ can be ascribed to the fluorite-structured $\mathrm{CeO}_{2}$ (JCPDS $34-0394,28.6^{\circ}(111), 33.1^{\circ}(200), 47.6^{\circ}(220)$, and $\left.56.4^{\circ}(311)\right)$. After reduction under $\mathrm{H}_{2}$ atmosphere as a function of temperature $\left(450-700^{\circ} \mathrm{C}\right)$, the spectra of nanowires remained almost unchanged, indicating that the crystalline stucture of the nanowires was not destroyed.
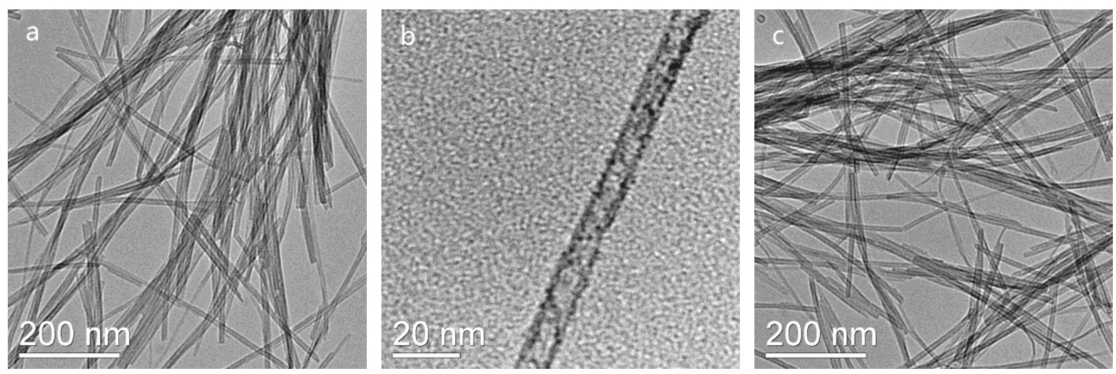

Figure 1. TEM images of $(\mathbf{a}, \mathbf{b}) \mathrm{CeO}_{2} \_\mathrm{NW}$, and (c) $\mathrm{CeO}_{2} \_\mathrm{NW} \_500$.

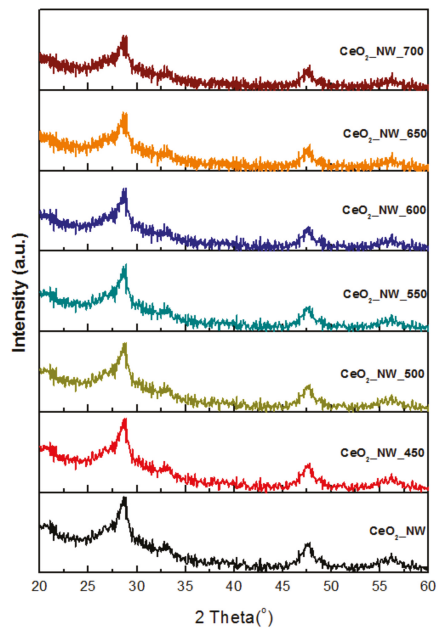

Figure 2. XRD patterns of $\mathrm{CeO}_{2}$ nanowires reduced by $\mathrm{H}_{2}$ as a function of temperature $\left(450-700{ }^{\circ} \mathrm{C}\right)$.

Physical and chemical parameters of the as-prepared catalysts are summarized in Table 1. The specific surface area of the nanowires was acquired from BET method and seemed to decrease slightly from $116.33 \mathrm{~m}^{2} \mathrm{~g}^{-1}$ to $98.1 \mathrm{~m}^{2} \mathrm{~g}^{-1}$ upon increasing the reduction temperature up to $500{ }^{\circ} \mathrm{C}$, indicating that the low-temperature reduction only can influence the specific surface area within tolerable extent. When elevating the reduction temperature, specific surface area of reduced $\mathrm{CeO}_{2}$ nanowires drops abruptly, which inevitably lead to the covered up of efficient active sites and eventually cause the worse catalytic performance.

Further investigation on the surface acidic/alkaline properties of as-prepared catalysts was acquired by $\mathrm{NH}_{3} / \mathrm{CO}_{2}$-TPD. The amount of moderate acidic and alkaline sites is also summarized in Table 1. For $\mathrm{CeO}_{2} \_\mathrm{NW} \_450$ and $\mathrm{CeO}_{2} \_\mathrm{NW} \_500$, more plentiful moderately acidic and alkaline sites are 
generated with the elevating of reduction temperature, which is bond to benefit the DMC formation according to former research. [33] While for other nanowires reduced under higher temperature, the amount of moderate acidity and alkalinity lessens. It can be ascribe to the fast-declining specific surface area upon elevating the reduction temperature, and then result in the covered up of efficient active sites. $\mathrm{CeO}_{2} \_\mathrm{NW} 500$ was determined to possess both the richest acidity and alkalify, which is mainly because of the enriching of oxygen vacancy on catalysts surface, further providing much richer active sites when compared to unreduced nanowires.

Table 1. Textural data of as-prepared catalysts basing on BET, XRD, and XPS investigation.

\begin{tabular}{ccccc}
\hline \multirow{2}{*}{ Catalysts } & \multirow{2}{*}{ BET Surface Area $\left(\mathbf{m}^{\mathbf{2}} \mathbf{g}^{-\mathbf{1}}\right)$} & \multicolumn{2}{c}{ Sites Amount $\left(\mu \mathbf{m o l ~ g}^{-\mathbf{1}}\right)$} & \multirow{2}{*}{ Oxygen Vacancy $(\%)$} \\
\cline { 3 - 4 } & & Moderate Acidity & Moderate Alkalify & \\
\hline $\mathrm{CeO}_{2}$ NW & 116.3 & 82 & 25 & 5.1 \\
$\mathrm{CeO}_{2}$ NW_450 & 104.9 & 282 & 52 & 20.5 \\
$\mathrm{CeO}_{2}$ NW_500 & 98.1 & 235 & 65 & 22.7 \\
$\mathrm{CeO}_{2}$ NW_550 & 70.4 & 192 & 48 & 25.1 \\
$\mathrm{CeO}_{2}$ NW_600 & 55.2 & 171 & 47 & 27.3 \\
$\mathrm{CeO}_{2}$ NW_650 & 42.5 & 115 & 39 & 31.2 \\
$\mathrm{CeO}_{2}$ _NW_700 & 28.7 & & & \\
\hline
\end{tabular}

Surface chemical state of prepared catalysts was investigated by XPS. Based on the calculated result, the XPS result forecasts that the oxygen vacancy on the surface of as-prepared nanowires varies along the reduction temperature from 5.1\% in $\mathrm{CeO}_{2} \_\mathrm{NW}$ to $31.2 \%$ in $\mathrm{CeO}_{2} \_\mathrm{NW} \_700$. Due to the Ce valent state partly shift from +4 to +3 , reduction of $\mathrm{CeO}_{2}$ nanowires leads to the formation of oxygen vacancy on the catalyst surface.

Based on the aforesaid result, a certain relationship between the surface active sites (mainly the moderate acidic and alkaline sites), specific surface area and surface oxygen vacancy was established. Both the moderate acidic and alkaline sites showed a linear relationship contrast specific surface area multiply surface oxygen vacancy (Figure 3). The combination of TPD, XPS, and BET reveals that the oxygen vacant structure of nanowires contributes to the formation of moderately acidic and basic sites, which is also influenced by the specific surface area.

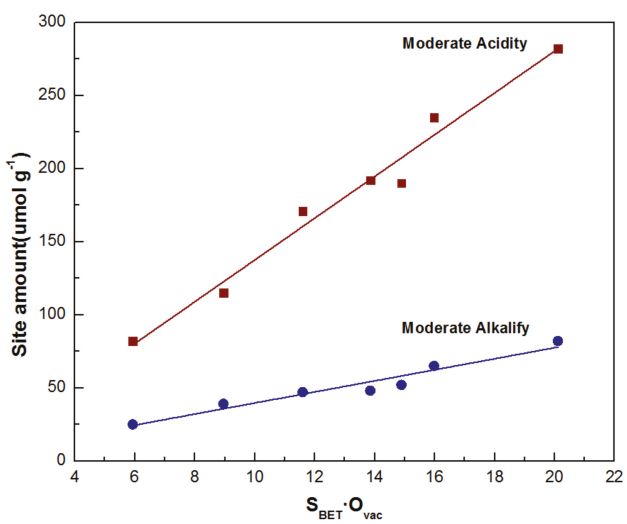

Figure 3. Liner relationship of moderate acidic/alkaline sites contrast specific surface area and surface oxygen vacancy.

\subsection{Catalytic Performance}

The effects of reduction temperature for nanowires on the catalytic activity were probed and the catalytic reaction was conducted in a stainless autoclave micro-reactor with high-speed stirring. 
The DMC yield of as-prepared catalysts with different catalysts are demonstrated in Figure 4 and serves as the basis for original selection of reduction temperatures.

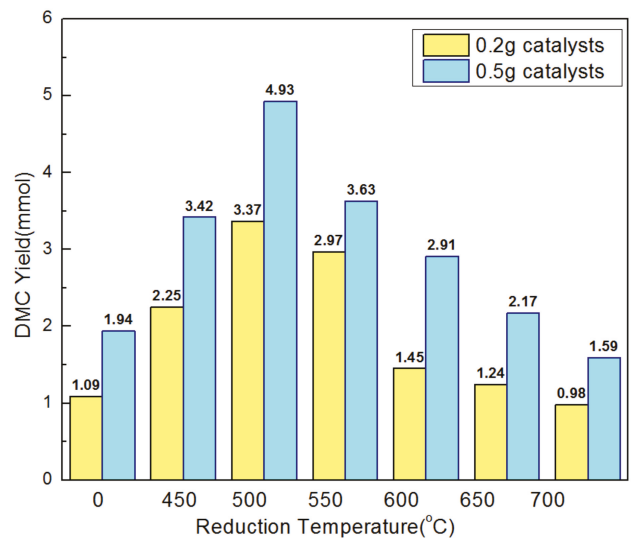

Figure 4. Effects of reduction temperature on the DMC yield over as-prepared nanowires. Reaction conditions: Methanol $500 \mathrm{mmol}$; catalysts $0.2 \mathrm{~g}$ or $0.5 \mathrm{~g}$; $\mathrm{CO}_{2}$ pressure $5 \mathrm{MPa}$; temperature $120{ }^{\circ} \mathrm{C}$; reaction time $5 \mathrm{~h}$.

Unreduced $\mathrm{CeO}_{2}$ nanowires $\left(\mathrm{CeO}_{2} \_\mathrm{NW}\right)$ catalyst obtained much inferior DMC yield when compared with the surface reduced $\mathrm{CeO}_{2}$ nanowires $\left(\mathrm{CeO}_{2} \_\mathrm{NW} \_\mathrm{x}\right)$. DMC yield enhanced with elevating the reduction temperature of $\mathrm{CeO}_{2}$ nanowires, reached a maximum at $500{ }^{\circ} \mathrm{C}$ and then declined with further temperature rise. We observed the catalytic performance of all nanowires catalysts with loading amount of $0.2 \mathrm{~g}$ and $0.5 \mathrm{~g}$ respectively. The reaction found to reach saturated and catalytic performance was influenced by leveling effect when loading $0.5 \mathrm{~g}$ catalyst, while the catalyst was efficiently utilized at $0.2 \mathrm{~g}$. Among the catalysts examined, $\mathrm{CeO}_{2} \_\mathrm{NW} \_500$ catalyst achieves excellent DMC yield of $16.85 \mathrm{mmol}_{\text {gcat }}{ }^{-1}$, superior than the catalytic activity of $\mathrm{CeO}_{2} \mathrm{NW}$ catalyst $\left(5.45 \mathrm{mmol} \mathrm{gcat}^{-1}\right)$ under the same condition. Associating with the specific surface area of as-prepared catalysts, $\mathrm{CeO}_{2} \_\mathrm{NW} \_\mathrm{x}(\mathrm{x}>500)$ catalysts with tinier surface area proof inferior catalytic activity, illustrating that the catalytic performance is directly related to the specific surface area of as-prepared catalysts. Smaller specific surface area necessarily leads to the covering of efficient active sites and causes lower catalytic activity $[34,35]$.

Further research on direct synthesis of DMC from $\mathrm{CO}_{2}$ and methanol over $\mathrm{CeO}_{2}$ NW_500 was conducted. The effects of different catalytic conditions was fully investigated. Figure 5 shows the DMC amount with different reaction time and reaction temperatures over $\mathrm{CeO}_{2} \_\mathrm{NW} \_500$ catalysts catalyst. The generation rate of the destination product DMC enhanced when elevated the catalytic temperature, while the final yield of DMC constantly decreased due to the limitations of thermodynamic and generation of side product. Under $140{ }^{\circ} \mathrm{C}$, the yield of DMC reached the maximum value at $75 \mathrm{~min}$, and then seemed to be almost unchanged. However, the formation amount of DMC even trends increasing after $5 \mathrm{~h}$ at $120^{\circ} \mathrm{C}$.

Further investigation for the recyclability of $\mathrm{CeO}_{2} \mathrm{NW}_{-} 500$ was carried out and the used nanowires catalyst was thermal reduced under $\mathrm{H}_{2}$ atmosphere before re-catalyze the direct synthesis of DMC under the same reaction conditions. BET specific surface area and catalytic performance of the recovered $\mathrm{CeO}_{2}$ NW__500 catalysts are demonstrated in Figure 6. Both specific surface area and the catalytic performance were found mildly falling as the number of reuses accumulates, which is on account of the slight surface collapse during the retreatment of the catalysts. Anyway, $\mathrm{CeO}_{2} \mathrm{NW}_{-} 500$ shows favorable stability for the direct formation of $\mathrm{DMC}$ from $\mathrm{CO}_{2}$ and methanol. 


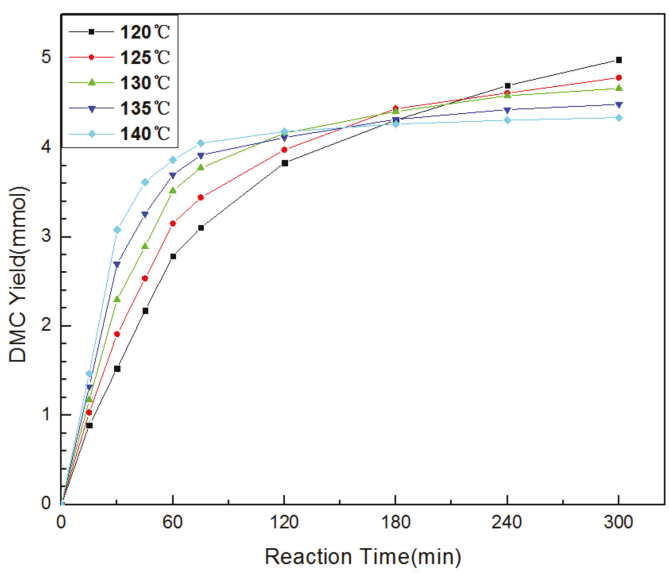

Figure 5. Effects of reaction temperature of nanowires on the catalytic performance for DMC formation. Reaction conditions: Methanol $500 \mathrm{mmol} ; \mathrm{CeO}_{2} \_\mathrm{NW} \_500$ catalysts $0.5 \mathrm{~g}$; $\mathrm{CO}_{2}$ pressure $5 \mathrm{MPa}$.

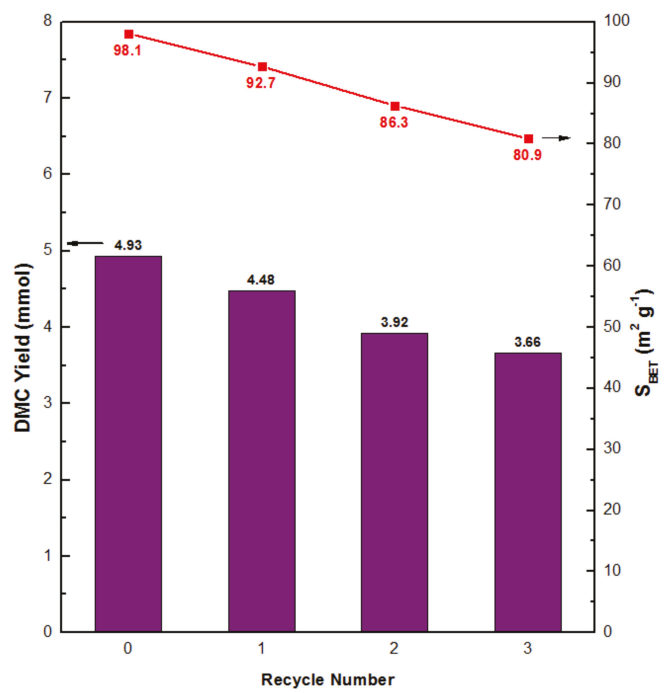

Figure 6. Recyclability study of $\mathrm{CeO}_{2} \_\mathrm{NW} \_500$ catalyst for the direct synthesis of $\mathrm{DMC}$ from $\mathrm{CO}_{2}$ and methanol. Reaction conditions: Methanol $500 \mathrm{mmol}$; catalysts $0.5 \mathrm{~g} ; \mathrm{CO}_{2}$ pressure $5 \mathrm{MPa}$; temperature $120{ }^{\circ} \mathrm{C}$; reaction time $5 \mathrm{~h}$.

\subsection{Kinetic Analysis}

Initial rate kinetic insights in the direct synthesis of $\mathrm{DMC}$ over $\mathrm{CeO}_{2} \mathrm{NW}_{-} 500$ catalyst were conducted. Based on the result of Figure 5, the yield data within 60 min was selected as the initial rate region. In addition, similar initial reaction was carried out on $\mathrm{CeO}_{2} \_\mathrm{NW}$ and compared with that of $\mathrm{CeO}_{2} \_\mathrm{NW} \_500$. The linear fitting of Arrhenius plot in Figure 7 gives a slope at $-5.04( \pm 0.41)$, indicating the apparent activation energy at $41.9 \pm 3.4 \mathrm{~kJ} / \mathrm{mol}$ for $\mathrm{CeO}_{2} \_\mathrm{NW} 500$ catalyst, which is lower than $\mathrm{CeO}_{2} \mathrm{NW}$ catalyst $(74.7 \mathrm{~kJ} / \mathrm{mol})$. It suggests that the surface reduction of $\mathrm{CeO}_{2}$ nanowires has reduced the activation energy barriers and improved the catalytic performance by enriching the surface active sites. 


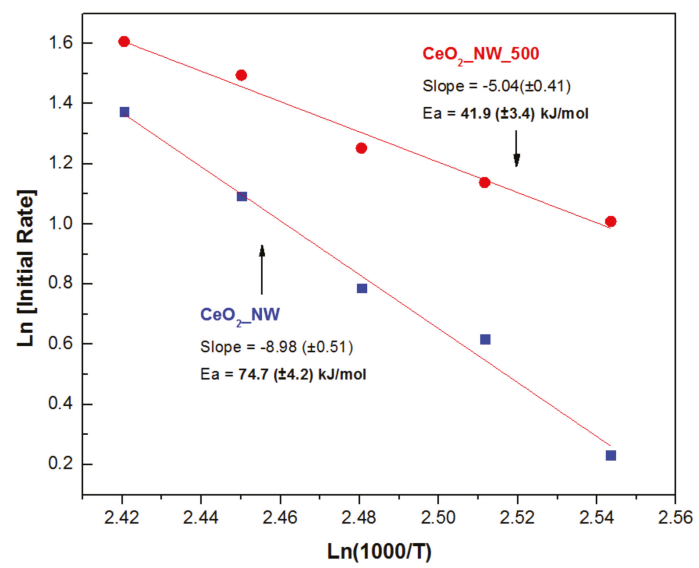

Figure 7. Arrhenius plot for direct synthesis of $\mathrm{DMC}$ over $\mathrm{CeO}_{2} \_\mathrm{NW} \_500$ and $\mathrm{CeO}_{2} \_\mathrm{NW}$ catalyst.

Furthermore, based on the former proposed mechanism for the direct synthesis of DMC, surface adsorption and activation of $\mathrm{CO}_{2}$ and methanol occurs on the alkaline sites and acidic sites, respectively [36]. As a consequence, the inferior catalytic performance of unreduced $\mathrm{CeO}_{2} \mathrm{NW}$ catalyst in this study should mainly ascribe to much poorer surface acidic and alkaline sites. While for $\mathrm{CeO}_{2} \_\mathrm{NW} \_\mathrm{x}$ catalysts, more abundant moderately acidic and alkaline sites generate along with the surface reduction process, thus resulting in more favorable catalytic performance than $\mathrm{CeO}_{2} \mathrm{NW}$. Figure 8 shows the Ln-Ln curves of initial rate for each catalysts contrast the concentration of moderately acidic/alkaline sites. There is a positive liner relationship of these parameters, suggesting the initial rates of this reaction influenced by the activation of both $\mathrm{CO}_{2}$ and methanol. This result corresponds to the deduction of Langmuir-Hinshelwood mechanism [37,38].

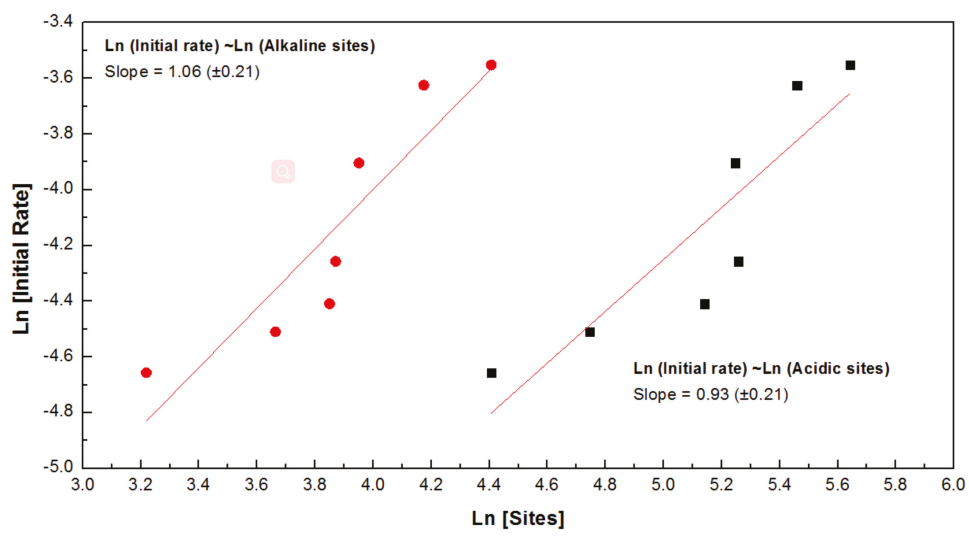

Figure 8. Kinetics study of the initial rate of DMC production contrast acidic/alkaline sites. Reaction conditions: Methanol $500 \mathrm{mmol}$; catalysts $0.2 \mathrm{~g}$; $\mathrm{CO}_{2}$ pressure $5 \mathrm{MPa}$; temperature $120^{\circ} \mathrm{C}$; reaction time $60 \mathrm{~min}$. 


\section{Materials and Methods}

\subsection{Materials}

Cerium (III) nitrate hexahydrate $\mathrm{Ce}\left(\mathrm{NO}_{3}\right)_{3} \cdot 6 \mathrm{H}_{2} \mathrm{O}$, methanol, and dimethyl carbonate (DMC) were purchased from Aladdin Co., Ltd. (Shanghai, China). Ammonium hydroxide $\mathrm{NH}_{3} \cdot \mathrm{H}_{2} \mathrm{O}(25$ wt \%) and ethanol was purchased from Guangdong Chemical Reagent Factory (Guangzhou, China). All the reactants were of analytical purity and used without any further treatment.

High purity $\mathrm{CO}_{2}(>99.9999 \%)$ and $\mathrm{H}_{2}(>99.999 \%)$ were obtained from Guangqi Gas Co., Ltd. (Guangzhou, China).

\subsection{Catalysts Preparation}

Ceria nanowires catalyst was prepared using a solvothermal method in a mixed water/ethanol solvents [32]. Briefly, stoichiometric $\mathrm{Ce}\left(\mathrm{NO}_{3}\right)_{3} \cdot 6 \mathrm{H}_{2} \mathrm{O}$ was dissolved in a flash with water/ethanol mixed solution $(\mathrm{v} / \mathrm{v}=1: 1)$, following by oil bath heating up to $140{ }^{\circ} \mathrm{C}$. Then the $\mathrm{NH}_{3} \cdot \mathrm{H}_{2} \mathrm{O}$ was added into the flash and the reaction mixture was refluxed for $12 \mathrm{~h}$ under stirring. After cooling to room temperature, the resulting mixture was separated by centrifugation. Afterward, the solid product was bathed with a mixture of ethanol and water $(\mathrm{v} / \mathrm{v}=1: 1)$ for several times. After that, the pre-synthesized nanowires were freeze-dried in a lyophilizer (Four-Ring Science Instrument Plant Beijing Corporation, Beijing, China) at a vacuity of 3 mbar and a frigorific temperature of $-40{ }^{\circ} \mathrm{C}$. Finally, as-prepared nanowires catalyst were thermal reduced under $\mathrm{H}_{2}$ atmosphere for $4 \mathrm{~h}$. The samples were named after $\mathrm{CeO}_{2} \_\mathrm{NW}$ and $\mathrm{CeO}_{2} \_\mathrm{NW} \_\mathrm{x}$, in which $\mathrm{x}$ represented the reduced temperature.

\subsection{Catalyst Characterization}

Micromorphology measurement was carried out on a transmission electron microscope (TEM, JSM-2010HR, JEOL Ltd., Tokyo, Japan) at a high voltage of 200 kV. Samples were ultrasonic dispersed into ethanol absolute, and then dropwise loaded onto the micro copper grid, followed by drying under air condition at room temperature.

Powder X-ray diffraction (XRD) was measured on a XRD diffractometer (Dmax 2200, Rigaku Ltd., Tokyo, Japan) at a scan rate of $5^{\circ} / \mathrm{min}$. High voltage of $40 \mathrm{kV}$ and current of $30 \mathrm{~mA}$ were employed in this measurement and $\mathrm{Cu} \mathrm{K} \alpha$ radiation target $(\lambda=0.154178 \mathrm{~nm})$ was used.

$\mathrm{N}_{2}$ adsorption characterization was acquired on a nitrogen adsorption apparatus (ASAP-2020, Micrometrics Ltd., Cumming, GA, USA) and the specific surface area was calculated through the Brunauer-Emmett-Teller method from the adsorption results. Samples were pre-treated under nitrogen atmosphere at $200{ }^{\circ} \mathrm{C}$ for $2 \mathrm{~h}$. After cooling, $\mathrm{N}_{2}$ at a flow rate of $110 \mathrm{~mL} / \mathrm{min}$ was adsorbed on the samples surface in a $U$ tube surrounded by liquid nitrogen.

Temperature programmed desorption (TPD) was conducted on a chemical adsorption apparatus (Chem-BET 3000, Quantachrome Ltd., Boynton Beach, FL, USA). Firstly, samples were pre-treated under nitrogen atmosphere at $200{ }^{\circ} \mathrm{C}$ for $1 \mathrm{~h}$. Then, a mixture standard gas of $10 \% \mathrm{CO}_{2} / 90 \% \mathrm{~N}_{2}$ or $10 \% \mathrm{NH}_{3} / 90 \% \mathrm{~N}_{2}$ saturated with the samples for $30 \mathrm{~min}$ at a flow rate of $60 \mathrm{~mL} / \mathrm{min}$ in a U tube. After that, surface physical adsorption of $\mathrm{CO}_{2}$ or $\mathrm{NH}_{3}$ was dislodged by bathing with $30 \% \mathrm{~N}_{2} / 70 \% \mathrm{He}$ standard gas for $2 \mathrm{~h}$ at a flow rate of $50 \mathrm{~mL} / \mathrm{min}$. Then, the samples were thermal treated under $\mathrm{N}_{2} / \mathrm{He}$ $30 \% \mathrm{~N}_{2} / 70 \%$ He from room temperature up to $600{ }^{\circ} \mathrm{C}$ with $8{ }^{\circ} \mathrm{C} / \mathrm{min}$ heating rate. Finally, the total desorption of $\mathrm{NH}_{3} / \mathrm{CO}_{2}$ was determined through back-titration method. $\mathrm{HCl} / \mathrm{NaOH}(0.01 \mathrm{~mol} / \mathrm{L})$ was employed as an adsorbent for $\mathrm{NH}_{3} / \mathrm{CO}_{2}, \mathrm{NaOH} / \mathrm{HCl}(0.01 \mathrm{~mol} / \mathrm{L})$ was served as titrant together with a mixed indicator reagent, which consisted of bromocresol green ethanol solution ( $1 \%$, 3 equivalent volumes) and methyl red ethanol solution (2\%, 1 equivalent volume) [39].

X-ray photoelectron spectrum (XPS) was acquired on an X-ray photoelectron spectrometer (ESCALAB250, Thermo Fisher Scientific Ltd., Waltham, MA, USA) with a scan survey of 1100-0 eV binding energy range. Monochromatized Al-Ka source at $1486.6 \mathrm{eV}$ and $150 \mathrm{w}$ was applied in the 
characterization with a voltage of $15 \mathrm{kV}$. Surface oxygen vacancy can be roughly calculated according to the equation

$$
O_{V a c}(\%)=\frac{C(C e)-0.5 C(O)}{C(C e)}
$$

\subsection{Catalytic Performance Measurement}

Direct synthesis of DMC from $\mathrm{CO}_{2}$ and methanol was carried out in a stainless steel autoclave with a volume of $50 \mathrm{~mL}$ and high-velocity stirring. As-prepared catalyst and a certain amount of absolute methanol were added into the reactor, following be purging $\mathrm{CO}_{2}$ for several times to evacuate the air inside and obtained the strict oxygen-free and water-free condition. Reaction pressure of $\mathrm{CO}_{2}$ was set at $5 \mathrm{MPa}$ and the reaction was conducted at $120^{\circ} \mathrm{C}$ for $5 \mathrm{~h}$ if no otherwise specified. The final products were measured and quantified by a gas chromatograph (GC-7900II, Techcomp Ltd., Beijing, China) equipped with a flame ionization detector (FID) after filtrating with PES membrane with a pore size of $0.45 \mathrm{um}$.

\section{Conclusions}

Ultralong $1 \mathrm{D} \mathrm{CeO}_{2}$ nanowires were synthesized via an advanced solvothermal method, surface reduced under $\mathrm{H}_{2}$ atmosphere, and firstly applied in direct synthesis of dimethyl carbonate (DMC) from $\mathrm{CO}_{2}$ and $\mathrm{CH}_{3} \mathrm{OH}$. The influences of reduction temperatures for the nanowires and different operating conditions for the catalysis reactivity were fully explored. The catalysis reactivity of ceria nanowires was founded to be greatly improved after surface reduction by generating more surface acidic-alkaline sites. Among the catalysts investigated, $\mathrm{CeO}_{2} \_\mathrm{NW} 500$ obtains the most favorable catalytic activity for DMC formation than $\mathrm{CeO}_{2} \_\mathrm{NW}$ and all of the other $\mathrm{CeO}_{2} \_\mathrm{NW} \_x$ catalysts. Under optimal reaction conditions, $\mathrm{CeO}_{2} \_\mathrm{NW} \_500$ catalyst achieves the best catalysis reactivity with DMC yield of $16.85 \mathrm{mmol}_{\text {gcat }}{ }^{-1}$ in an autoclave reactor. Based on the approach of initial rates method, the kinetic insight were conducted for the direct synthesis of DMC over $\mathrm{CeO}_{2} \mathrm{NW}_{2} 500$ catalyst and the activation energy barrier is determined to be $41.9 \mathrm{~kJ} / \mathrm{mol}$, tinier than $74.7 \mathrm{~kJ} / \mathrm{mol}$ for unreduced $\mathrm{CeO}_{2}$ nanowires. Moreover, a certain relationship between the initial rate and the surface acidity/alkalify was found, which is identical to the deduction of former proposed Langmuir-Hinshelwood mechanism where the initial rates of this reaction are influenced by the activation of both $\mathrm{CO}_{2}$ and methanol.

Acknowledgments: The authors would like to thank the National Natural Science Foundation of China (grant no. 21376276, 21643002), Guangdong Province Sci. \& Tech. Bureau (grant no. 2017B090901003, 2016B010114004, 2016A050503001), and Fundamental Research Funds for the Central Universities (171gjc37) for financial support of this work.

Author Contributions: Zhongwei Fu, Yuezhong Meng, Min Xiao, Dongmei Han, and Shuanjin Wang conceived and designed the experiments; Zhongwei Fu performed the experiments; Zhongwei Fu and Yuehong Yu analyzed the data; Zhen Li and Yuehong Yu contributed analysis tools; Zhongwei Fu wrote the paper.

Conflicts of Interest: The authors declare no conflict of interest.

\section{References}

1. And, M.A.P.; Christopher, L.M. Review of dimethyl carbonate (DMC) manufacture and its characteristics as a fuel additive. Energy Fuels 1997, 11, 2-29.

2. Ono, Y. Catalysis in the production and reactions of dimethyl carbonate, an environmentally benign building block. Appl. Catal. A Gen. 1997, 155, 133-166. [CrossRef]

3. Santos, B.A.V.; Silva, V.M.T.M.; Loureiro, J.M.; Rodrigues, A.E. Review for the direct synthesis of dimethyl carbonate. Chem. Rev. 2015, 1, 214-229. [CrossRef]

4. Keller, N.; Rebmann, G.; Keller, V. Catalysts, mechanisms and industrial processes for the dimethylcarbonate synthesis. J. Mol. Catal. A Chem. 2010, 317, 1-18. [CrossRef]

5. Tundo, P.; Selva, M. The chemistry of dimethyl carbonate. Acc. Chem. Res. 2002, 35, 706. [CrossRef] [PubMed] 
6. Chaturvedi, D.; Mishra, N.; Mishra, V. Various approaches for the synthesis of organic carbamates. Curr. Org. Synth. 2007, 4, 308-320. [CrossRef]

7. King, S.T. Reaction mechanism of oxidative carbonylation of methanol to dimethyl carbonate in cu-y zeolite. J. Catal. 1996, 161, 530-538. [CrossRef]

8. Bhanage, B.M.; Fujita, S.; Ikushima, Y.; Torii, K.; Arai, M. Synthesis of dimethyl carbonate and glycols from carbon dioxide, epoxides and methanol using heterogeneous mg containing smectite catalysts: Effect of reaction variables on activity and selectivity performance. Green Chem. 2003, 5, 71-75. [CrossRef]

9. Zhao, G.; Huang, X.; Wang, X.; Wang, X. Progress in catalyst exploration for heterogeneous $\mathrm{CO}_{2}$ reduction and utilization: A critical review. J. Mater. Chem. A 2017, 41, 21625-21649. [CrossRef]

10. Olajire, A.A. Recent advances in the synthesis of covalent organic frameworks for $\mathrm{CO}_{2}$ capture. J. $\mathrm{CO}_{2}$ Util. 2017, 17, 137-161. [CrossRef]

11. Fu, Z.; Meng, Y. Research Progress in the Phosgene-Free and Direct Synthesis of Dimethyl Carbonate From $\mathrm{CO}_{2}$ and Methanol; Springer International Publishing: Berlin/Heidelberg, Germany, 2016.

12. Garciaherrero, I.; Cuéllarfranca, R.M.; Alvarezguerra, M.; Irabien, A.; Azapagic, A. Environmental assessment of dimethyl carbonate production: Comparison of a novel electrosynthesis route utilizing $\mathrm{CO}_{2}$ with a commercial oxidative carbonylation process. ACS Sustain. Chem. Eng. 2016, 4, 2088-2097. [CrossRef]

13. Fang, S.; Fujimoto, K. Direct synthesis of dimethyl carbonate from carbon dioxide and methanol catalyzed by base. Appl. Catal. A Gen. 1996, 142, L1-L3. [CrossRef]

14. Wang, X.J.; Xiao, M.; Wang, S.J.; Lu, Y.X.; Meng, Y.Z. Direct synthesis of dimethyl carbonate from carbon dioxide and methanol using supported copper $(\mathrm{Ni}, \mathrm{V}, \mathrm{O})$ catalyst with photo-assistance. J. Mol. Catal. A Chem. 2007, 278, 92-96. [CrossRef]

15. Han, D.; Wang, S.; Meng, Y.; Chen, Y.; Lu, Y.; Xiao, M. Porous diatomite-immobilized cu-ni bimetallic nanocatalysts for direct synthesis of dimethyl carbonate. J. Nanomater. 2012, 2012, 8.

16. Eta, V.; Mäkiarvela, P.; Murzin, D.Y.; Salmi, T.; Mikkola, J.P. Synthesis of dimethyl carbonate from methanol and carbon dioxide: The effect of dehydration. Ind. Eng. Chem. Res. 2009, 49, 9609-9617. [CrossRef]

17. Lin, C.M.; Shen, D.P.; You, Y.U.; Ming-Xian, X.U. Catalysts and dehydration agents of one-pot synthesis of dimethyl carbonate. J. Zhejiang Univ. Technol. 2013, 13, 329-331.

18. Zhou, Y.; Fu, Z.; Wang, S.; Xiao, M.; Han, D.; Meng, Y. Electrochemical synthesis of dimethyl carbonate from $\mathrm{CO}_{2}$ and methanol over carbonaceous material supported dbu in a capacitor-like cell reactor. RSC Adv. 2016, 6, 40010-40016. [CrossRef]

19. Mengers, H.J. Membrane reactors for the direct conversion of $\mathrm{CO}_{2}$ to dimethyl carbonate. Clin. Nephrol. 2015, 33, 1653-1659.

20. Ballivet-Tkatchenko, D.; Ligabue, R.A.; Plasseraud, L. Synthesis of dimethyl carbonate in supercritical carbon dioxide. Braz. J. Chem. Eng. 2006, 23, 111-116. [CrossRef]

21. Hong, S.T.; Park, H.S.; Lim, J.S.; Lee, Y.W.; Anpo, M.; Kim, J.D. Synthesis of dimethyl carbonate from methanol and supercritical carbon dioxide. Res. Chem. Intermed. 2006, 32, 737-747. [CrossRef]

22. Bian, J.; Xiao, M.; Wang, S.; Lu, Y.; Meng, Y. Direct synthesis of dmc from $\mathrm{CH}_{3}$ oh and $\mathrm{CO}_{2}$ over v -doped cu-ni/ac catalysts. Catal. Commun. 2009, 10, 1142-1145. [CrossRef]

23. Chen, H.; Wang, S.; Xiao, M.; Han, D.; Yixin, L.U.; Meng, Y. Direct synthesis of dimethyl carbonate from coand choh using $0.4 \mathrm{~nm}$ molecular sieve supported cu-ni bimetal catalyst. Chin. J. Chem. Eng. 2012, 20, 906-913. [CrossRef]

24. Zhang, M.; Xiao, M.; Wang, S.; Han, D.; Lu, Y.; Meng, Y. Cerium oxide-based catalysts made by template-precipitation for the dimethyl carbonate synthesis from carbon dioxide and methanol. J. Clean. Prod. 2015, 103, 847-853. [CrossRef]

25. Wang, S.; Zhao, L.; Wang, W.; Zhao, Y.; Zhang, G.; Ma, X.; Gong, J. Morphology control of ceria nanocrystals for catalytic conversion of $\mathrm{CO}_{2}$ with methanol. Nanoscale 2013, 5, 5582-5588. [CrossRef] [PubMed]

26. Fu, Z.; Zhong, Y.; Yu, Y.; Long, L.; Xiao, M.; Han, D.; Wang, S.; Meng, Y. TiO ${ }_{2}$-doped $\mathrm{CeO}_{2}$ nanorod catalyst for direct conversion of $\mathrm{CO}_{2}$ and $\mathrm{CH}_{3} \mathrm{OH}$ to dimethyl carbonate: Catalytic performance and kinetic study. ACS Omega 2018, 3, 198-207. [CrossRef]

27. Honda, M.; Sonehara, S.; Yasuda, H.; Nakagawa, Y.; Tomishige, K. Heterogeneous $\mathrm{CeO}_{2}$ catalyst for the one-pot synthesis of organic carbamates from amines, $\mathrm{CO}_{2}$ and alcohols. Green Chem. 2011, 13, 3406-3413. [CrossRef] 
28. Sun, C.; Li, H.; Zhang, H.; Wang, Z.; Chen, L. Controlled synthesis of ceo2 nanorods by a solvothermal method. Nanotechnology 2005, 16, 1454. [CrossRef]

29. Zhao, S.Y.; Wang, S.P.; Zhao, Y.J.; Ma, X.B. An in situ infrared study of dimethyl carbonate synthesis from carbon dioxide and methanol over well-shaped $\mathrm{CeO}_{2}$. Chin. Chem. Lett. 2017, 28, 65-69. [CrossRef]

30. Vantomme, A.; Yuan, Z.Y.; Du, G.; Su, B.L. Surfactant-assisted large-scale preparation of crystalline $\mathrm{CeO}_{2}$ nanorods. Langmuir ACS J. Surf. Colloids 2005, 21, 1132. [CrossRef] [PubMed]

31. Watanabe, S.; Ma, X.; Song, C. Characterization of structural and surface properties of nanocrystalline $\mathrm{TiO}_{2}-\mathrm{CeO}_{2}$ mixed oxides by XRD, XPS, TPR, and TPD. J. Phys. Chem.C 2009, 113, 14249-14257. [CrossRef]

32. Yu, X.F.; Liu, J.W.; Cong, H.P.; Xue, L.; Arshad, M.N.; Albar, H.A.; Sobahi, T.R.; Gao, Q.; Yu, S.H. Templateand surfactant-free synthesis of ultrathin $\mathrm{CeO}_{2}$ nanowires in a mixed solvent and their superior adsorption capability for water treatment. Chem. Sci. 2015, 6, 2511. [CrossRef] [PubMed]

33. Li, A.; Pu, Y.; Li, F.; Luo, J.; Zhao, N.; Xiao, F. Synthesis of dimethyl carbonate from methanol and $\mathrm{CO}_{2}$ over fe-zr mixed oxides. J. CO $\mathrm{CO}_{2}$ Util. 2017, 19, 33-39. [CrossRef]

34. Li, H.; Jiao, X.; Li, L.; Zhao, N.; Xiao, F.; Wei, W.; Sun, Y.; Zhang, B. Synthesis of glycerol carbonate by direct carbonylation of glycerol with $\mathrm{CO}_{2}$ over solid catalysts derived from $\mathrm{zn} / \mathrm{al} / \mathrm{la}$ and $\mathrm{zn} / \mathrm{al} / \mathrm{la} / \mathrm{m}(\mathrm{m}=\mathrm{li}, \mathrm{mg}$ and zr) hydrotalcites. Catal. Sci. Technol. 2015, 5, 989-1005. [CrossRef]

35. Cosimo, J.I.D.; DiEz, V.K.; Xu, M.; Iglesia, E.; Apestegu1A, C.R. Structure and surface and catalytic properties of mg-al basic oxides. J. Catal. 1998, 178, 499-510. [CrossRef]

36. Jung, K.T.; Bell, A.T. An in situ infrared study of dimethyl carbonate synthesis from carbon dioxide and methanol over zirconia. J. Catal. 2001, 204, 339-347. [CrossRef]

37. Tomishige, K.; Ikeda, Y.; Sakaihori, T.; Fujimoto, K. Catalytic properties and structure of zirconia catalysts for direct synthesis of dimethyl carbonate from methanol and carbon dioxide. J. Catal. 2000, 192, 355-362. [CrossRef]

38. Marin, C.M.; Li, L.; Bhalkikar, A.; Doyle, J.E.; Zeng, X.C.; Cheung, C.L. Kinetic and mechanistic investigations of the direct synthesis of dimethyl carbonate from carbon dioxide over ceria nanorod catalysts. J. Catal. 2016, 340, 295-301. [CrossRef]

39. Jin, D.; Jing, G.; Hou, Z.; Yan, G.; Lu, X.; Zhu, Y.; Zheng, X. Microwave assisted in situ synthesis of usy-encapsulated heteropoly acid (hpw-usy) catalysts. Appl. Catal. A Gen. 2009, 352, 259-264. [CrossRef] 
Article

\title{
Inhibiting Fe-Al Spinel Formation on a Narrowed Mesopore-Sized $\mathrm{MgAl}_{2} \mathrm{O}_{4}$ Support as a Novel Catalyst for $\mathrm{H}_{2}$ Production in Chemical Looping Technology
}

\author{
Ali Hafizi and Mohammad Reza Rahimpour* \\ Department of Chemical Engineering, Shiraz University, Shiraz 71345, Iran; hafizi@shirazu.ac.ir \\ * Correspondence: rahimpor@shirazu.ac.ir
}

Received: 13 October 2017; Accepted: 29 December 2017; Published: 15 January 2018

\begin{abstract}
In this paper, the structure of $\mathrm{Al}_{2} \mathrm{O}_{3}$ is modified with magnesium to synthesize $\mathrm{MgAl}_{2} \mathrm{O}_{4}$ as an oxygen carrier $(\mathrm{OC})$ support. The surface properties and structural stability of the modified support are improved by the incorporation of magnesium in the structure of the support and additionally by narrowing the pore size distribution (about $2.3 \mathrm{~nm}$ ). Then, iron oxide is impregnated on both an $\mathrm{Al}_{2} \mathrm{O}_{3}$ support and a $\mathrm{MgAl}_{2} \mathrm{O}_{4}$ support as the oxygen transfer active site. The XRD results showed the formation of solely $\mathrm{Fe}_{2} \mathrm{O}_{3}$ on the $\mathrm{MgAl}_{2} \mathrm{O}_{4}$ support, while both $\mathrm{Fe}_{2} \mathrm{O}_{3}$ and $\mathrm{Fe}_{3} \mathrm{O}_{4}$ are detected in the synthesized $\mathrm{Fe}_{2} \mathrm{O}_{3}-\mathrm{Al}_{2} \mathrm{O}_{3}$ structure. The synthesized samples are investigated in chemical looping cycles, including $\mathrm{CO}$ reduction (as one of the most important side reactions of chemical looping reforming), at different temperatures $\left(300-500{ }^{\circ} \mathrm{C}\right.$ ) and oxidation with steam at $700{ }^{\circ} \mathrm{C}$ for hydrogen production. The obtained results showed the inhibition of $\mathrm{Fe}-\mathrm{Al}$ spinel formation in the structure of the $\mathrm{Fe}_{2} \mathrm{O}_{3}-\mathrm{MgAl}_{2} \mathrm{O}_{4}$ OC. In addition, $\mathrm{H}_{2}$ with a purity higher than $98 \%$ is achievable in oxidation of the $\mathrm{OC}$ with steam. In addition, the activity and crystalline change of the $\mathrm{Fe}_{2} \mathrm{O}_{3}-\mathrm{MgAl}_{2} \mathrm{O}_{4} \mathrm{OC}$ is investigated after 20 reduction-oxidation cycles.
\end{abstract}

Keywords: chemical looping; oxygen carrier; hydrogen production; narrow pore size distribution; $\mathrm{Fe}_{2} \mathrm{O}_{3}$ dispersion; texture modification

\section{Introduction}

The production of hydrogen (as an energy carrier) from primary resources, such as methane and water, is industrially developed [1-4]. Hydrogen with high purity can be applied in different applications, such as fuel cells. Nevertheless, most hydrogen production processes need further purification with the purpose of preventing electrode poisoning [5]. One-step pure hydrogen production has attracted attention during the past few years [6,7]. The chemical looping technique (CLT) is known as a novel process for hydrogen production from different sources. Chemical looping processes are based on the transportation of lattice oxygen from an oxidizing solid environment to a reducing environment in two interconnected reactors called the "fuel reactor" and the "oxidation reactor" as indicated in Figure $1[8,9]$. The principal reactions involved in the chemical looping steam methane reforming (CL-SMR) process are as follows [10,11]:

Fuel reactor:

$$
\mathrm{CH}_{4}+\mathrm{Me}_{x} \mathrm{O}_{y} \rightarrow \mathrm{CO}+2 \mathrm{H}_{2}+\mathrm{Me}_{x} \mathrm{O}_{y-1}
$$

Oxidation reactor:

$$
\mathrm{H}_{2} \mathrm{O}+\mathrm{Me} e_{x} \mathrm{O}_{y-1} \rightarrow \mathrm{H}_{2}+\mathrm{Me}_{x} \mathrm{O}_{y}
$$


The in-situ oxidation of carbon monoxide is one of the most important side reactions to progress the reaction network toward pure hydrogen. Carbon monoxide can be used as a reducing agent and the steam is used as an oxidant as indicated in the following reactions:

$$
\mathrm{CO}+\mathrm{Me}_{x} \mathrm{O}_{y} \rightarrow \mathrm{CO}_{2}+\mathrm{Me}_{x} \mathrm{O}_{y-1}
$$

Therefore, hydrogen with high purity could be obtained in both the oxidation and reduction periods of chemical looping cycles, which is depicted in Figure 1.

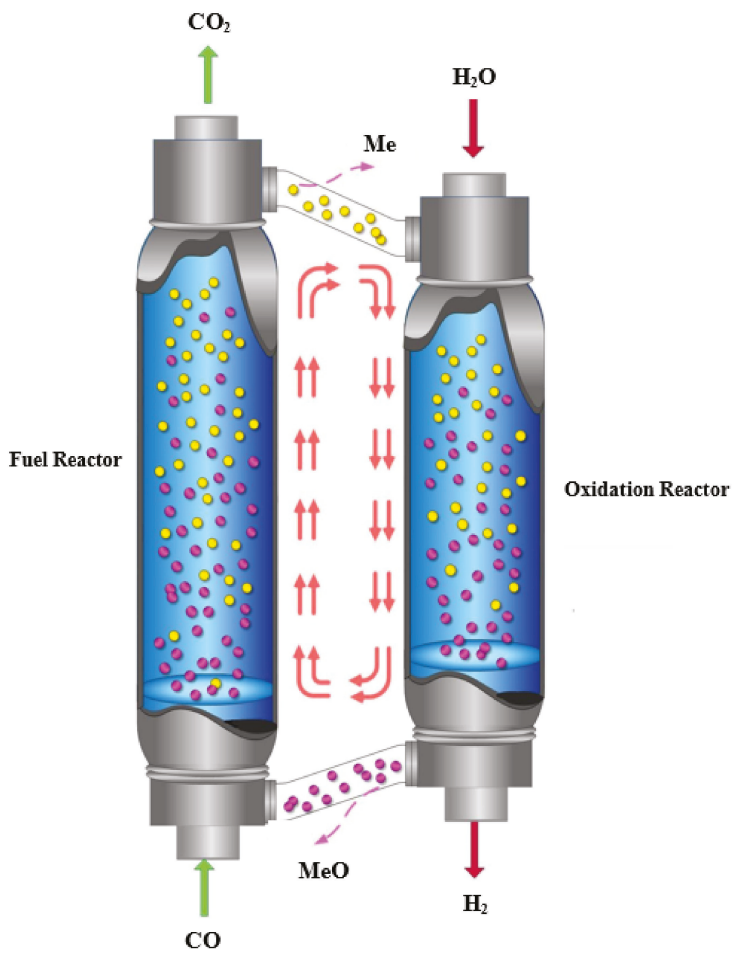

Figure 1. Conceptual scheme of chemical looping reforming technology.

The selection of an appropriate oxygen carrier $(\mathrm{OC})$ has a significant impact on the reaction performance of this process. Recently, the application of metal oxides as oxygen transfer media have attracted much attention [11-13]. The lattice oxygen released from these composites has the advantage of being pure in addition to transferring lattice oxygen intelligently. The selection of a suitable OC seems to be of great importance in large-scale use. The oxygen carrier must have sufficient oxygen transport capacity, high reactivity, easy oxygen release, sorption properties, agglomeration resistance, a low cost, no environmental impact, and high chemical and mechanical stability $[14,15]$. One of the major challenges in the large-scale usage of oxygen transfer materials is the development of a stable OC in continuous alternating cycles of reduction and oxidation without deactivation. $\mathrm{Fe}_{2} \mathrm{O}_{3}$ is known as one of the best candidates among different metal oxides because of its low cost, high thermal resistance, and its thermodynamic tendency toward $\mathrm{H}_{2}$ production [11]. In an iron-based OC, the oxygen is mainly supplied from the reduction of hematite to magnetite $\left(\mathrm{Fe}_{2} \mathrm{O}_{3} \rightarrow \mathrm{Fe}_{3} \mathrm{O}_{4} \rightarrow \mathrm{Fe}_{0.947} \mathrm{O}\right)$ in the presence of oxygen demandant for the first cycle. The first step of the reaction occurs faster than other iron oxide reduction reactions. The reoxidation reaction $\left(\mathrm{Fe}_{0.947} \mathrm{O}+\mathrm{H}_{2} \mathrm{O} \rightarrow \mathrm{H}_{2}+\mathrm{Fe}_{3} \mathrm{O}_{4}\right)$ occurs by passing steam 
over the OC bed at high temperatures in order to regenerate the reacted OC. The oxidation of the reduced oxygen carrier $\left(\mathrm{Fe}_{0.947} \mathrm{O}\right)$ with steam for the production of hydrogen is thermodynamically limited. Thus, magnetite $\left(\mathrm{Fe}_{3} \mathrm{O}_{4}\right)$ could be formed after oxidization with steam $[16,17]$.

The active metal oxide should be supported on an appropriate material that can effectively increase the surface area and availability of active metal oxides, improves the OC's structural properties, and subsequently increases its reactivity [18]. $\mathrm{Al}_{2} \mathrm{O}_{3}$ is known as one of the best catalysts and oxygen carrier supports owing to its high stability (chemical and mechanical) and considerably higher melting temperature [18]. However, the imperfect formation of iron-alumina spinel $\left(\mathrm{FeAl}_{2} \mathrm{O}_{4}\right)$ is an important phenomenon that occurs at high temperatures. Furthermore, the transformation of primary formed iron oxide particles to $\mathrm{Fe}_{3} \mathrm{O}_{4}$ on the support surface is the other defect of aluminum oxide as the $\mathrm{OC}$ support [11]. The formation of $\mathrm{FeAl}_{2} \mathrm{O}_{4}$ in the $\mathrm{OC}$ structure could deactivate the iron oxides and slow down the rate and capacity of oxygen transference.

Despite these well-known problems, many efforts have been made to enhance the activity and stability of an iron-based oxygen carrier. There are several ways currently being applied to reach this purpose, such as applying various types of supports with enhanced structural and textural properties [19-21], and the application of different promoters and inhibitors are the most important efforts to solve these drawbacks [22-27].

With the purpose of suppressing the carbon deposition and improving its catalytic activity, a wide diversity of promoters, such as lanthanum, cerium, magnesium, and calcium, have been incorporated into the structure of the support [28-30]. Li et al. [28] assessed ceria-promoted Ni/SBA-15 catalysts for ethanol steam reforming. The results showed that the incorporation of $\mathrm{CeO}_{2}$ could effectively control the size of Ni particles via strong metal-support interaction. Hafizi et al. [11] examined a Ca-promoted $\mathrm{Fe} / \mathrm{Al}_{2} \mathrm{O}_{3}$ oxygen carrier in the chemical looping reforming of methane during the redox cycles. The obtained results showed the interaction of the calcium promoter and the alumina support for the improvement of an iron-based oxygen carrier with an inhibition of coke deposition. Ce-SBA-15-supported nickel catalysts were synthesized by Wang et al. [31] and applied for the dry reforming of methane. The results revealed that the cerium incorporated into the skeleton of the SBA-15 promoted the dispersion of nano-sized Ni particles and prohibited carbon formation.

The addition of magnesium to $\mathrm{Al}_{2} \mathrm{O}_{3}$ could effectively prevent the formation of $\mathrm{Fe}-\mathrm{Al}$ spinel and improve the stability of the support at higher reaction temperatures by forming $\mathrm{MgAl}_{2} \mathrm{O}_{4}$ [8,31]. Furthermore, a rearrangement of the support's crystalline structure and a regulation of its pore size in a narrow distribution range with magnesium addition could effectively increase the OC's activity and stability. On the other hand, it could effectively control the coke deposition during reforming processes due to the nature of the $\mathrm{Mg}$ promoter.

This study investigates the effect of alumina and $\mathrm{Mg}-\mathrm{Al}$ spinel as the support for the formation of $\mathrm{Fe}_{2} \mathrm{O}_{3}$. In addition, a narrowing of the oxygen carrier's pore size in the range of 2-3 nm is expected in order to control the coke deposition. The activity and feasibility of synthesized OC in the chemical looping process, including $\mathrm{CO}$ oxidation and hydrogen production in alternating cycles, were investigated at different temperatures. The crystalline phase transformation in the reduction-oxidation process is examined on the successfully synthesized $\mathrm{Fe}_{2} \mathrm{O}_{3}-\mathrm{MgAl}_{2} \mathrm{O}_{4}$ as an ultra-pure lattice oxygen transport medium.

\section{Results and Discussion}

\subsection{Sample Characterization}

The XRD patterns of $\mathrm{Al}_{2} \mathrm{O}_{3}, \mathrm{Fe}_{2} \mathrm{O}_{3}-\mathrm{Al}_{2} \mathrm{O}_{3}$, and $\mathrm{Fe}_{2} \mathrm{O}_{3}-\mathrm{MgAl}_{2} \mathrm{O}_{4}$ are shown in Figure 2a. The patterns were identified by the typical peaks of iron oxides, alumina, magnesium oxide, and spinel phases considering the JCPDS data bank. The XRD results suggest that the $\mathrm{MgAl}_{2} \mathrm{O}_{4}$ support could help the formation of pure $\mathrm{Fe}_{2} \mathrm{O}_{3}$, while alumina disperses iron on its surface in both the $\mathrm{Fe}^{2+}$ and $\mathrm{Fe}^{3+}$ forms. 
The $\mathrm{Fe}_{2} \mathrm{O}_{3}$ could be clearly assigned at $2 \theta=24.3^{\circ}, 33.4^{\circ}, 35.8^{\circ}, 49.7^{\circ}, 62.7^{\circ}, 64.3^{\circ}$, and $89^{\circ}$ in the XRD patterns of $\mathrm{Fe}_{2} \mathrm{O}_{3}-\mathrm{Al}_{2} \mathrm{O}_{3}$ and $\mathrm{Fe}_{2} \mathrm{O}_{3}-\mathrm{MgAl}_{2} \mathrm{O}_{4}$ according to JCPDS No. 01-084-0308. The formation of $\mathrm{MgAl}_{2} \mathrm{O}_{4}$ spinel is clear in the $\mathrm{Mg}$-modified $\mathrm{OC}$, and significantly inhibits the formation of iron alumina spinel. The diffraction peak at $37.6^{\circ}$ for the (110) plane, $46^{\circ}$ for the (111) plane, and $66.4^{\circ}$ for the (211) plane of $\mathrm{Al}_{2} \mathrm{O}_{3}$ shifts about $0.4-0.8^{\circ}$ to left in the Mg-promoted OC, representing the presence of $\mathrm{MgAl}_{2} \mathrm{O}_{4}$ spinel (JCPDS No. 01-073-2210) shown in Figure 2a. The four peaks located at $19.25^{\circ}, 36.9^{\circ}$, $42.5^{\circ}$, and $66.3^{\circ}$ match well with $\mathrm{MgAl}_{2} \mathrm{O}_{4}$. Furthermore, $\mathrm{Mg}$ or $\mathrm{MgO}$ species are not detected in the modified OC, which suggests the complete transformation of $\mathrm{Mg}$ to its spinel form. The XRD pattern of $\mathrm{Fe}_{2} \mathrm{O}_{3}-\mathrm{MgAl}_{2} \mathrm{O}_{4}$ after 20 reduction-oxidation cycles showed no iron-alumina spinel $\left(\mathrm{FeAl}_{2} \mathrm{O}_{4}\right)$ formation (Figure $2 \mathrm{~b}$ ) at high reaction temperatures during the process (JCPDS No. 01-086-2320). However, our previous study on $\mathrm{Fe}_{2} \mathrm{O}_{3}-\mathrm{Al}_{2} \mathrm{O}_{3}$ or $\mathrm{Fe}_{2} \mathrm{O}_{3}-\mathrm{CaO}-\mathrm{Al}_{2} \mathrm{O}_{3}$ oxygen transfer materials showed the formation of $\mathrm{FeAl}_{2} \mathrm{O}_{4}$ or $\mathrm{CaFe}_{2} \mathrm{O}_{4}$ in the $\mathrm{OC}$ structure after using it in the chemical looping process [11].
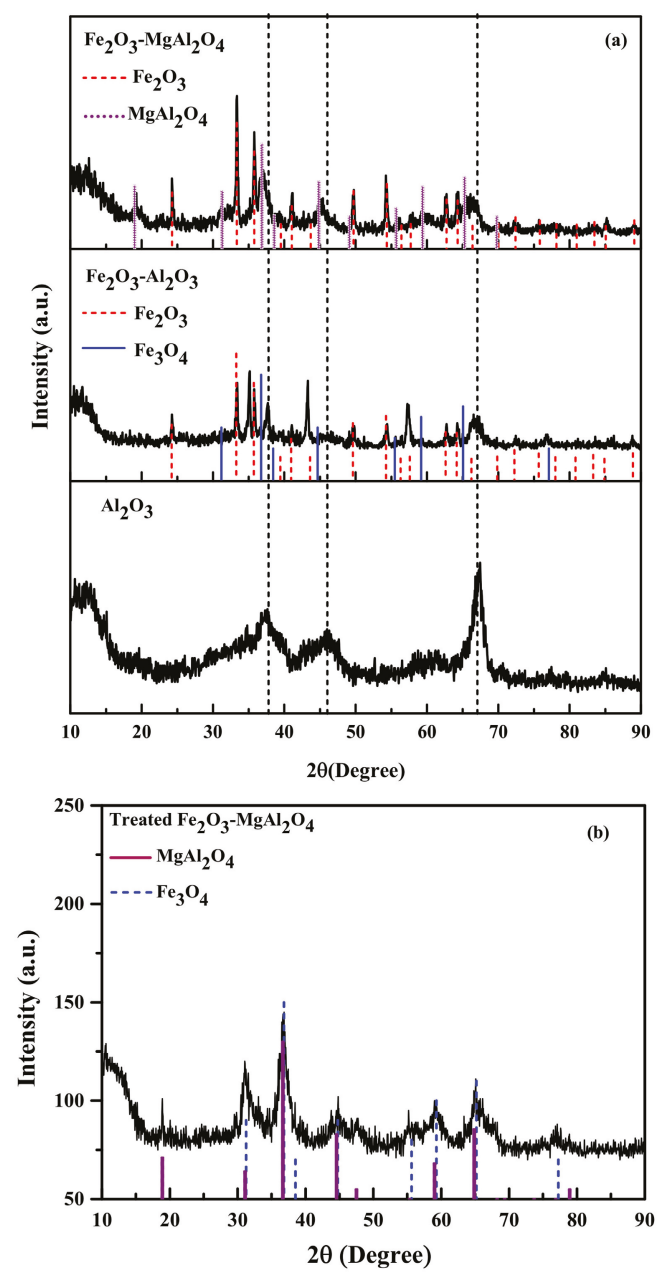

Figure 2. XRD patterns of (a) $\mathrm{Al}_{2} \mathrm{O}_{3}, \mathrm{Fe}_{2} \mathrm{O}_{3}-\mathrm{Al}_{2} \mathrm{O}_{3}$, and $\mathrm{Fe}_{2} \mathrm{O}_{3}-\mathrm{MgAl}_{2} \mathrm{O}_{4}$; (b) treated $\mathrm{Fe}_{2} \mathrm{O}_{3}-\mathrm{MgAl}_{2} \mathrm{O}_{4}$ in 20 redox cycles analyzed after the oxidation reaction. 
Table 1 presents the physical properties, including Brunauer-Emmett-Teller (BET) surface area, pore volume average, pore size distribution, and energy dispersive $\mathrm{X}$-ray Spectroscopy (EDX) results, of the synthesized OC samples. The BET surface area of the $\mathrm{Fe}_{2} \mathrm{O}_{3}-\mathrm{Al}_{2} \mathrm{O}_{3}$ is $174.3 \mathrm{~m}^{2} \mathrm{~g}^{-1}$, while the surface area of the $\mathrm{Fe}_{2} \mathrm{O}_{3}-\mathrm{MgAl}_{2} \mathrm{O}_{4}$ oxygen carrier shows a reduction to $113.1 \mathrm{~m}^{2} \mathrm{~g}^{-1}$. This reduction is due to the change of alumina structure and sequential calcinations that can result in pore blockage, sintering, and structural destruction. The reduction in pore volume from 0.416 to $0.389 \mathrm{~cm}^{3} \mathrm{~g} \mathrm{r}^{-1} \mathrm{can}$ verify the reduction in surface area of the Mg-modified sample.

Table 1. Structural properties of the fresh and used samples.

\begin{tabular}{|c|c|c|c|c|c|c|c|c|}
\hline Sample & $\begin{array}{c}\mathrm{Fe}^{\mathrm{a}} \\
\left(w \mathrm{t}^{\%}\right)\end{array}$ & $\begin{array}{c}\mathrm{Mg}^{\mathrm{a}} \\
\text { (wt \%) }\end{array}$ & $\begin{array}{c}\mathrm{Al}^{\mathrm{a}} \\
(\mathrm{wt} \%)\end{array}$ & $\begin{array}{c}C^{a} \\
\left(w t^{\%}\right)\end{array}$ & $\begin{array}{c}\mathrm{O}^{\mathrm{a}} \\
\left(w \mathrm{wt}^{\%}\right)\end{array}$ & $\begin{array}{c}\text { BET Surface } \\
\text { Area }\left(\mathrm{m}^{2} \mathrm{~g}^{-1}\right)\end{array}$ & $\begin{array}{l}\text { Average Pore } \\
\text { Size (nm) }\end{array}$ & $\begin{array}{l}\text { Pore Volume } \\
\left(\mathrm{cm}^{3} \mathrm{~g}^{-1}\right)\end{array}$ \\
\hline $\begin{array}{c}\text { Fresh } \\
\mathrm{Fe}_{2} \mathrm{O}_{3}-\mathrm{Al}_{2} \mathrm{O}_{3}\end{array}$ & 17.72 & - & 39.82 & - & 42.46 & 174.3 & 4.3 & 0.416 \\
\hline $\begin{array}{c}\text { Fresh } \\
\mathrm{Fe}_{2} \mathrm{O}_{3}-\mathrm{MgAl}_{2} \mathrm{O}_{4}\end{array}$ & 16.42 & 10.81 & 21.94 & - & 50.83 & 113.1 & 2.3 & 0.389 \\
\hline $\begin{array}{l}\text { Used } \\
\mathrm{Fe}_{2} \mathrm{O}_{3}-\mathrm{Al}_{2} \mathrm{O}_{3}\end{array}$ & 16.97 & - & 40.01 & 5.83 & 37.29 & - & - & - \\
\hline $\begin{array}{c}\text { Used } \\
\mathrm{Fe}_{2} \mathrm{O}_{3}-\mathrm{MgAl}_{2} \mathrm{O}_{4}\end{array}$ & 14.86 & $9.25 \mathrm{a}$ & $\begin{array}{l}33.46 \\
\text { ured by }\end{array}$ & X. 1.20 & $\begin{array}{l}41.23 \\
\text { inauer- }\end{array}$ & imett-Tēller. & - & - \\
\hline
\end{tabular}

Figure 3 shows the Barrett-Joyner-Halenda (BJH) pore size distribution of both the $\mathrm{Fe}_{2} \mathrm{O}_{3}-\mathrm{Al}_{2} \mathrm{O}_{3}$ and $\mathrm{Fe}_{2} \mathrm{O}_{3}-\mathrm{MgAl}_{2} \mathrm{O}_{4}$ oxygen carriers. Since the average pore size distribution of the $\mathrm{Fe}_{2} \mathrm{O}_{3}-\mathrm{Al}_{2} \mathrm{O}_{3}$ is $4.3 \mathrm{~nm}$, the distribution peak shows a wide range of pores (about 2-20 nm). On the other hand, the sharp peak of the $\mathrm{Fe}_{2} \mathrm{O}_{3}-\mathrm{MgAl}_{2} \mathrm{O}_{4}$ indicated in this figure confirms a narrow pore size distribution centered at $2.3 \mathrm{~nm}$. Consequently, modifying the $\mathrm{OC}$ alumina support by $\mathrm{Mg}$ could effectively regulate the pore size distribution in a narrow range.

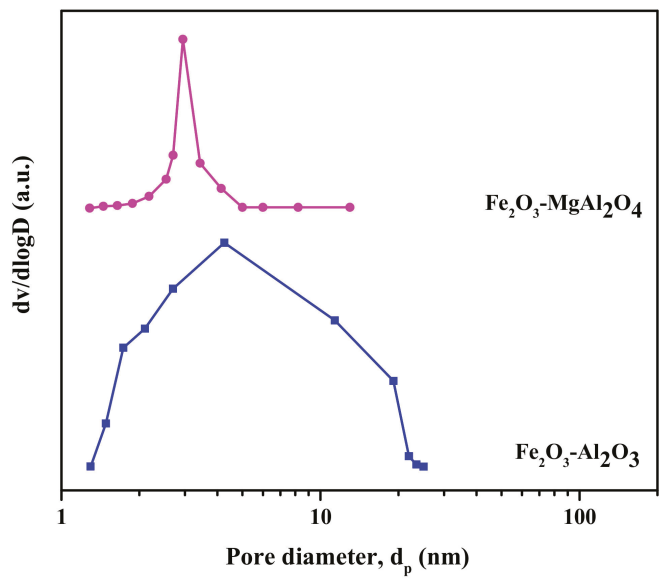

Figure 3. Pore size distributions of $\mathrm{Fe}_{2} \mathrm{O}_{3}-\mathrm{Al}_{2} \mathrm{O}_{3}$ and $\mathrm{Fe}_{2} \mathrm{O}_{3}-\mathrm{MgAl}_{2} \mathrm{O}_{4}$.

Field emission scanning electron microscopy (FESEM) micrographs of the prepared $\mathrm{Al}_{2} \mathrm{O}_{3}$, $\mathrm{Fe}_{2} \mathrm{O}_{3}-\mathrm{Al}_{2} \mathrm{O}_{3}$, and $\mathrm{Fe}_{2} \mathrm{O}_{3}-\mathrm{MgAl}_{2} \mathrm{O}_{4}$ samples are presented in Figure $4 \mathrm{a}-\mathrm{c}$. The synthesized blank alumina has a uniform aggregated surface as indicated in Figure $4 \mathrm{a}$, and the distribution of $\mathrm{Fe}_{2} \mathrm{O}_{3}-\mathrm{Al}_{2} \mathrm{O}_{3}$ particles is indicated in Figure $4 \mathrm{~b}$. On the other hand, the $\mathrm{Fe}_{2} \mathrm{O}_{3}-\mathrm{MgAl}_{2} \mathrm{O}_{4} \mathrm{OC}$ has approximately uniformly dispersed aggregated $\mathrm{Fe}_{2} \mathrm{O}_{3}$ particles (Figure 4c). A comparison of the FESEM graphs of both $\mathrm{OC}$ samples indicates that the structure of the $\mathrm{Fe}_{2} \mathrm{O}_{3}-\mathrm{Al}_{2} \mathrm{O}_{3}$ seems to have higher porosity than that of the $\mathrm{Fe}_{2} \mathrm{O}_{3}-\mathrm{MgAl}_{2} \mathrm{O}_{4}$. The FESEM-EDX results of the used $\mathrm{Fe}_{2} \mathrm{O}_{3}-\mathrm{MgAl}_{2} \mathrm{O}_{4}$ 
OC shown in Figure 4d and Table 1 revealed coke deposition of about $1.2 \mathrm{wt} \%$. In addition, the slight aggregation of $\mathrm{OC}$ nanoparticles that is demonstrated in this figure could be due to the high oxidation temperature. The TEM image of the prepared $\mathrm{Fe}_{2} \mathrm{O}_{3}-\mathrm{MgAl}_{2} \mathrm{O}_{4} \mathrm{OC}$ is shown in Figure $4 \mathrm{e}$ to examine the dispersion and size of iron oxide particles on the surface of the $\mathrm{Mg}-\mathrm{Al}$ spinel. Nevertheless, the image shows the agglomeration of iron oxide particles with a diameter range of about $40-50 \mathrm{~nm}$.
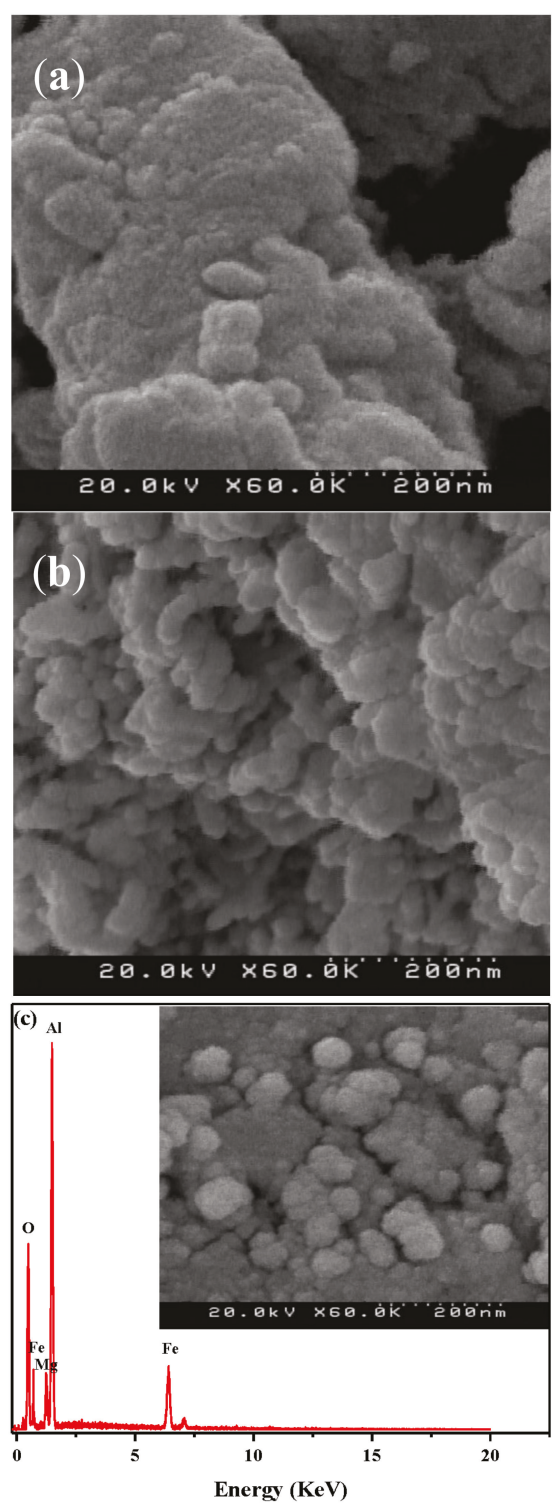

Figure 4. Cont. 

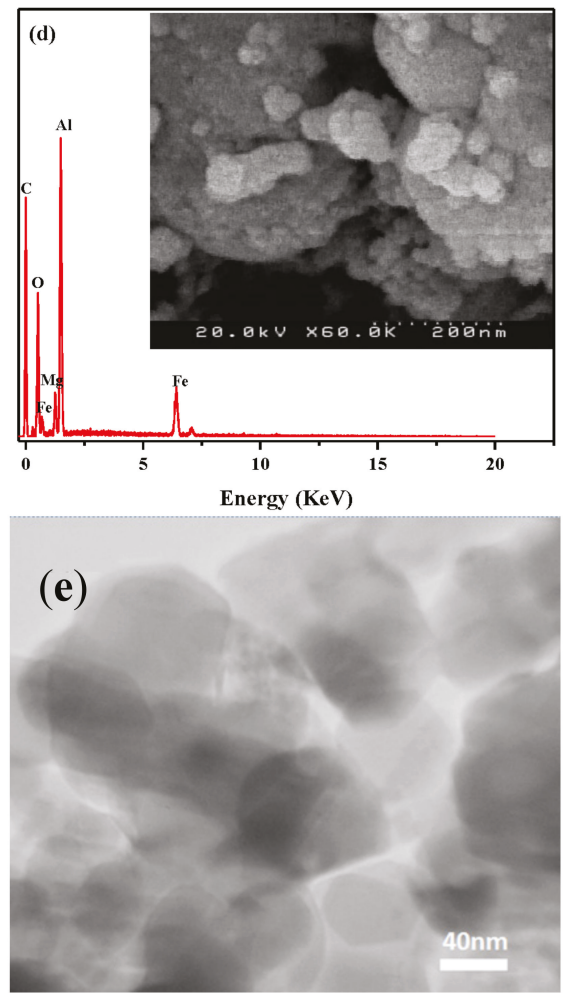

Figure 4. FESEM and EDX of blank $\mathrm{Al}_{2} \mathrm{O}_{3}$ (a); fresh $\mathrm{Fe}_{2} \mathrm{O}_{3}-\mathrm{Al}_{2} \mathrm{O}_{3}$ (b); fresh $\mathrm{Fe}_{2} \mathrm{O}_{3}-\mathrm{MgAl}_{2} \mathrm{O}_{4}$ (c); and used $\mathrm{Fe}_{2} \mathrm{O}_{3}-\mathrm{MgAl}_{2} \mathrm{O}_{4}$ (d) and TEM of $\mathrm{Fe}_{2} \mathrm{O}_{3}-\mathrm{MgAl}_{2} \mathrm{O}_{4}$ (e).

\subsection{Activity Results}

The catalytic activity of not-modified and modified OC was evaluated in chemical looping CO oxidation, where $\mathrm{CO}$ is oxidized to $\mathrm{CO}_{2}$ in the reduction period and $\mathrm{H}_{2}$ is produced in the oxidation section. Figure 5 represents the effect of reduction temperature $\left(300-500{ }^{\circ} \mathrm{C}\right)$ on average $\mathrm{CO}$ conversion. In addition, the purity of produced hydrogen in the oxidation section at $700{ }^{\circ} \mathrm{C}$ for each relevant reduction temperature is shown in this figure. The results show the positive effect of reduction temperature on $\mathrm{CO}$ conversion for both samples. For instance, the $\mathrm{CO}$ conversion is increased from about $45.3 \%$ to $98.3 \%$ using the $\mathrm{Fe}_{2} \mathrm{O}_{3}-\mathrm{Al}_{2} \mathrm{O}_{3}$ oxygen carrier. On the other hand, the conversion of carbon monoxide is $48.2 \%, 75.7 \%, 91.3 \%, 95.2 \%$, and $96.6 \%$ at $300,350,400,450$, and $500{ }^{\circ} \mathrm{C}$, respectively. The improvement in $\mathrm{CO}$ conversion with temperature for both samples is related to the surface activation of iron oxide for oxygen transfer to the reducing agent at elevated temperatures. However, the related $\mathrm{H}_{2}$ purity in the oxidation section is decreased with a further increase in reduction temperature. In addition to improving the activity of the $\mathrm{OC}$, increasing the reduction temperature facilitates coke formation on its surface. CO disproportionation is an important side reaction that leads to the formation of coke through the following equation [32,33]:

$$
2 \mathrm{CO} \rightarrow \mathrm{C}+\mathrm{CO}_{2}
$$

The coke is oxidized in the oxidation section with steam to $\mathrm{CO}$ and $\mathrm{CO}_{2}$ that reduce the purity of produced hydrogen. For example, in the oxidation step related to the reduction temperature of $400{ }^{\circ} \mathrm{C}$, 
hydrogen with about $98.5 \%$ purity is produced, while oxidation of OC treated in lower reduction temperatures results in the $\mathrm{H}_{2}$ purity of $100 \%$ (Figure $5 \mathrm{~b}$ ). In addition, the $\mathrm{CO}$ conversion of about $91.3 \%$ is achieved at $400{ }^{\circ} \mathrm{C}$ in the reduction period.
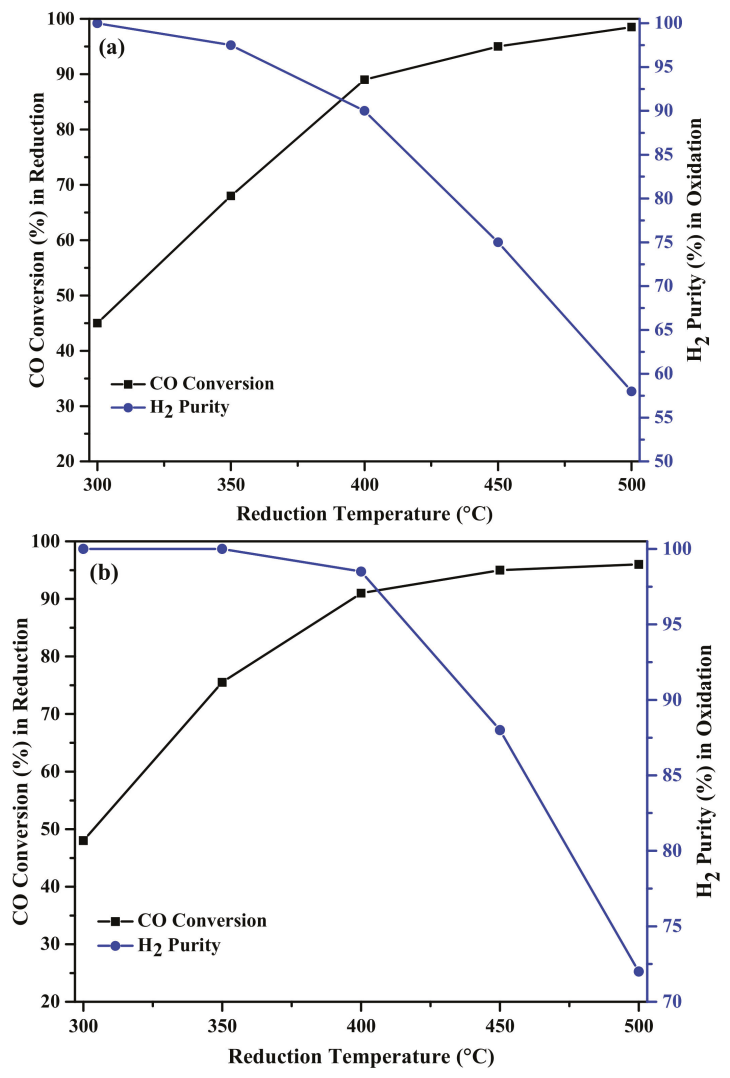

Figure 5. Carbon monoxide conversion at different reduction temperatures and hydrogen purity in the oxidation section using (a) the $\mathrm{Fe}_{2} \mathrm{O}_{3}-\mathrm{Al}_{2} \mathrm{O}_{3}$ oxygen carrier and (b) the $\mathrm{Fe}_{2} \mathrm{O}_{3}-\mathrm{MgAl}_{2} \mathrm{O}_{4}$ oxygen carrier.

With the aim of investigating the effect of an $\mathrm{Mg}$ promoter on the stability of the synthesized oxygen carriers, the performance of $\mathrm{Fe}_{2} \mathrm{O}_{3}-\mathrm{Al}_{2} \mathrm{O}_{3}$ and $\mathrm{Fe}_{2} \mathrm{O}_{3}-\mathrm{MgAl}_{2} \mathrm{O}_{4}$ was tested through 20 consecutive reduction-oxidation cycles. Therefore, the variation of $\mathrm{CO}$ conversion in the reduction period at $400{ }^{\circ} \mathrm{C}$ and the hydrogen purity in the oxidation step over the cycles were determined as shown in Figure 6a,b. The results for the $\mathrm{Fe}_{2} \mathrm{O}_{3}-\mathrm{Al}_{2} \mathrm{O}_{3}$ oxygen carrier revealed a reduction in $\mathrm{CO}$ conversion from $89.9 \%$ to $83.5 \%$ during 20 redox cycles (about $7 \%$ ). In addition, the hydrogen purity in the oxidation step is reduced during the cycles (Figure 6a). These behaviors could be mainly due to the deposition of coke on the surface of the oxygen carrier in the reduction step that reduces the purity of produced hydrogen in the oxidation section. However, the crystalline change and destruction in the structure of the oxygen carrier at a high redox temperature has a negative effect on the durability of the sample. On the other hand, the Mg-promoted oxygen carrier $\left(\mathrm{Fe}_{2} \mathrm{O}_{3}-\mathrm{MgAl}_{2} \mathrm{O}_{4}\right)$ showed a $0.7 \%$ reduction in activity through the first five cycles and remained approximately constant over the rest of cycles. The hydrogen purity in the oxidation section is firstly 97.7 and increased to $98.8 \%$ in the fifth cycle and remained constant. The improvement in $\mathrm{H}_{2}$ purity seems to be due to the coke inhibition in 
the reduction cycles. This phenomenon is related to the reduction of emitted gases produced from the catalyst's decoking simultaneous with hydrogen production in the reaction between metal and water.
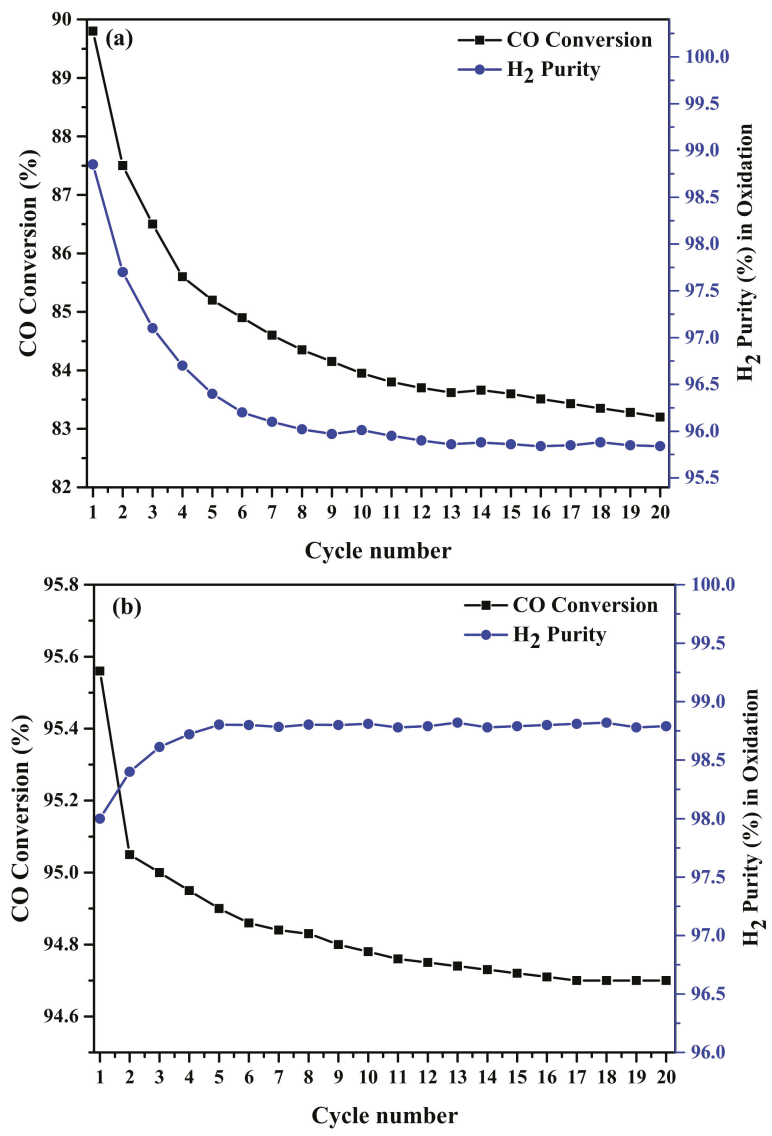

Figure 6. Life time of (a) $\mathrm{Fe}_{2} \mathrm{O}_{3}-\mathrm{Al}_{2} \mathrm{O}_{3}$ and (b) $\mathrm{Fe}_{2} \mathrm{O}_{3}-\mathrm{MgAl}_{2} \mathrm{O}_{4}$ oxygen carriers during 20 redox cycles.

In order to better investigate the durability results of the two samples, the $\mathrm{CO}$ conversion and hydrogen purity of the first, second, fifth, tenth, and twentieth cycles at $400{ }^{\circ} \mathrm{C}$ are demonstrated in Figures 7 and 8. The reduction in $\mathrm{CO}$ conversion during each cycle could be related to the reduction in the lattice oxygen of surface active sites with reduction time and coke deposition on the surface. The reduction in $\mathrm{CO}$ conversion in the tenth and twentieth cycles compared to the previous cycles shows a continuous reduction in the activity of the oxygen carrier (Figure 7a). On the other hand, the activity of the Mg-promoted sample in Figure 8a revealed that the conversion remained approximately constant after cycle 5 . The purity of the produced hydrogen in the oxidation step of both samples increased during the step time to reach $100 \%$ (Figures 7 and $8 b$ ). The increase in hydrogen purity could be due to the coke decomposition during the process. The higher purity of the produced hydrogen using the $\mathrm{Fe}_{2} \mathrm{O}_{3}-\mathrm{MgAl}_{2} \mathrm{O}_{4}$ oxygen carrier compared to that using the $\mathrm{Fe}_{2} \mathrm{O}_{3}-\mathrm{Al}_{2} \mathrm{O}_{3}$ oxygen carrier is due to the lower coke deposition. 

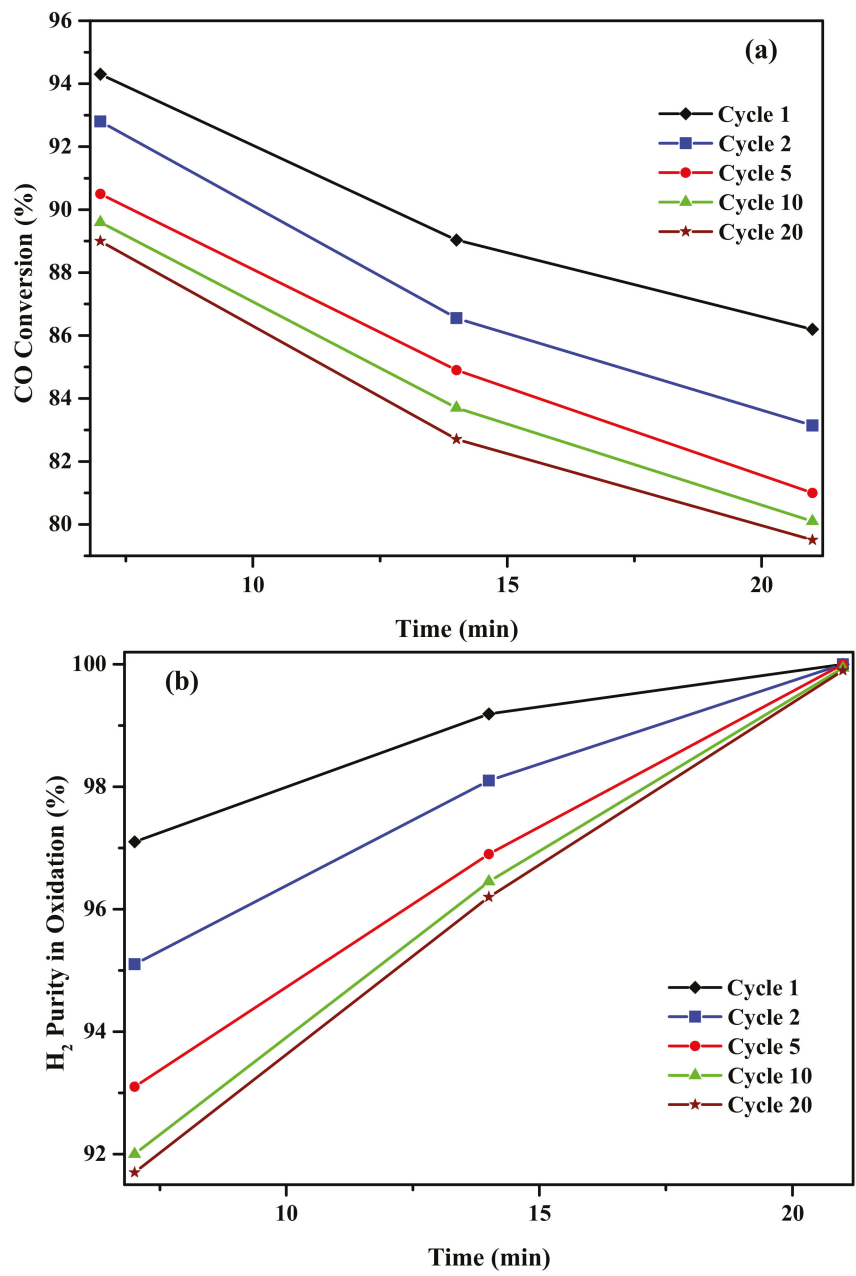

Figure 7. (a) The $\mathrm{CO}$ conversion and (b) hydrogen purity in the oxidation step with time for the $\mathrm{Fe}_{2} \mathrm{O}_{3}-\mathrm{Al}_{2} \mathrm{O}_{3}$ oxygen carrier at $400{ }^{\circ} \mathrm{C}$ (in the reduction step) for different cycles. 

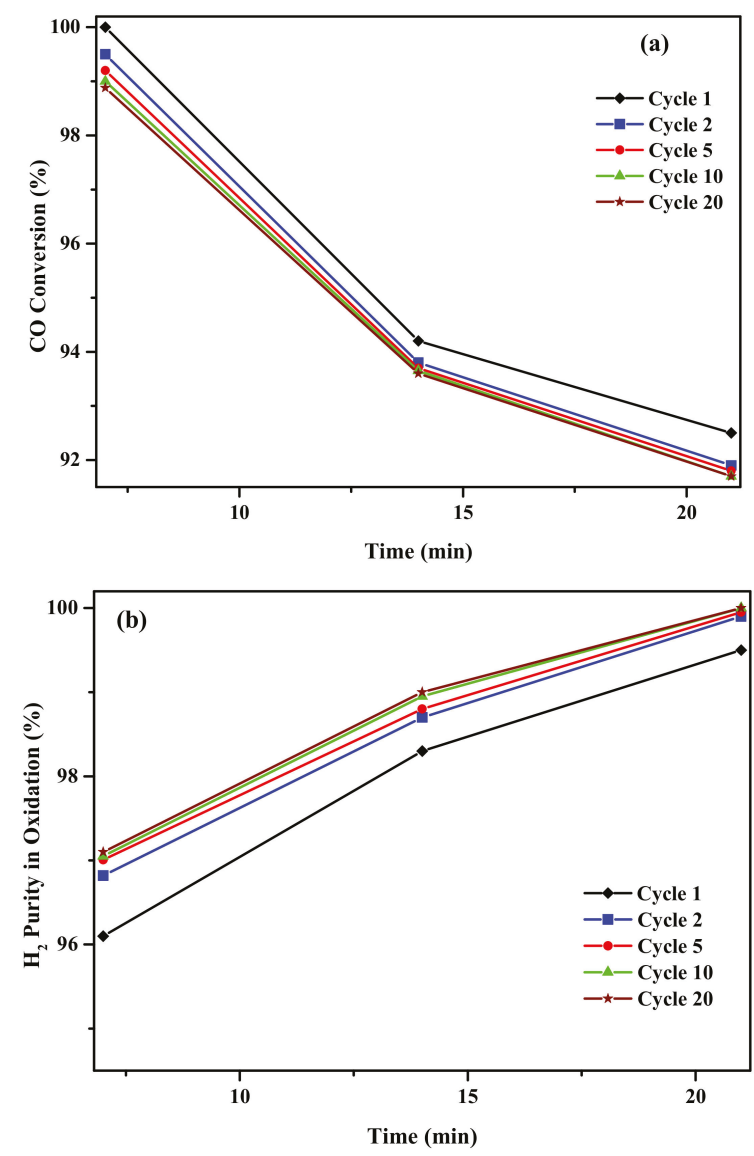

Figure 8. (a) The $\mathrm{CO}$ conversion and (b) hydrogen purity in the oxidation step with time for the $\mathrm{Fe}_{2} \mathrm{O}_{3}-\mathrm{MgAl}_{2} \mathrm{O}_{4}$ oxygen carrier at $400{ }^{\circ} \mathrm{C}$ (in the reduction step) for different cycles.

\section{Experimental Methods}

\subsection{Oxygen Carrier Preparation}

The OC support affects the performance of oxygen transference, and both alumina and magnesia-alumina spinels were applied as the support for iron oxide. The $\mathrm{Fe}_{2} \mathrm{O}_{3}-\mathrm{MgAl}_{2} \mathrm{O}_{4}$ oxygen transfer material was synthesized using a two-step sequential wetness impregnation method. $\mathrm{MgAl}_{2} \mathrm{O}_{4}$ spinel was prepared by adding a solution of magnesium acetate $(0.2 \mathrm{M})$ to previously synthesized alumina $\left(\mathrm{Al}_{2} \mathrm{O}_{3}\right.$ was synthesized by the precipitation method). Prior to impregnation, the slurry was sonicated in a bath-type ultrasound at $30^{\circ} \mathrm{C}$ for better incorporation of magnesium precursor into the pores' alumina structure, followed by vacuum impregnation at $80{ }^{\circ} \mathrm{C}$ in a rotary evaporator. After that, the sample was dried at $70{ }^{\circ} \mathrm{C}$ in a vacuum oven for $10 \mathrm{~h}$. The resulting paste was calcined at $600{ }^{\circ} \mathrm{C}$ for $2 \mathrm{~h}$ in flowing air. After that, the prepared $\mathrm{MgAl}_{2} \mathrm{O}_{4}$ was used as the support for the preparation of $\mathrm{Fe}_{2} \mathrm{O}_{3}-\mathrm{Al}_{2} \mathrm{O}_{3}$ or $\mathrm{Fe}_{2} \mathrm{O}_{3}-\mathrm{MgAl}_{2} \mathrm{O}_{4}$ samples. For this purpose, a $0.5 \mathrm{M}$ solution of $\mathrm{Fe}\left(\mathrm{NO}_{3}\right)_{2} \cdot 6 \mathrm{H}_{2} \mathrm{O}$ (Merck KGaA, Darmstadt, Germany) was added to the as-prepared $\mathrm{MgAl}_{2} \mathrm{O}_{4}$ or $\mathrm{Al}_{2} \mathrm{O}_{3}$ supports with continuous sonication in a bath ultrasound for $15 \mathrm{~min}$. Subsequently, the impregnated oxygen carrier was dried at $80^{\circ} \mathrm{C}$ for $12 \mathrm{~h}$ in a vacuum oven followed by calcination at $800^{\circ} \mathrm{C}$ for $2 \mathrm{~h}$. 


\subsection{Oxygen Carrier Characterization}

Textual properties, including specific surface area, pore volume, and average pore diameter of the as-prepared samples, were calculated according to the Brunauer-Emmett-Teller (BET) method by $\mathrm{N}_{2}$ adsorption-desorption isotherms. The specific surface area of the oxygen carriers was measured by BET tests using a (ASAP-2020, Micromeritics, Norcross, GA, USA) gas adsorption apparatus. The Barrett-Joyner-Halenda (BJH) method was implemented to calculate the pore size distributions according to the adsorption branches of the isotherms. The freshly calcined samples were degassed with nitrogen at $200^{\circ} \mathrm{C}$ for $3 \mathrm{~h}$ prior to the BET test.

The morphology of the synthesized samples was analyzed by an energy dispersive X-ray Spectroscopy (EDX)-equipped field emission scanning electron microscope using a HITACHI S-4160 apparatus (Hitachi, Ltd., Chiyoda, Tokyo, Japan). In addition, a Philips CM30 operated at $300 \mathrm{kV}$ was applied for transmission electron microscopy (TEM) (Philips, Andover, MA, USA). The phase composition and crystallinity of the oxygen transfer materials were analyzed by means of X-ray powder diffraction (XRD; Bruker, D8 Advance, Karlsruhe, Germany) using $\mathrm{Cu} \mathrm{K} \alpha$ radiation and operated at $40 \mathrm{kV}$ and $40 \mathrm{~mA}$. The support and oxygen carriers were scanned with $0.05^{\circ} / \mathrm{s}$ resolution to collect the spectra $2 \theta$ between $10^{\circ}$ and $90^{\circ}$ at ambient temperature.

\subsection{Process Activity}

In order to evaluate the structural resistance and crystalline transformation of $\mathrm{MgAl}_{2} \mathrm{O}_{4}$-supported $\mathrm{Fe}_{2} \mathrm{O}_{3}$ as an oxygen carrier, a series of cyclic reduction-oxidation tests were performed at different reduction temperatures $\left(300-500{ }^{\circ} \mathrm{C}\right)$. Hereinafter, the term "cycle" means a reduction cycle involving the reduction of the oxygen carrier with carbon monoxide, followed by oxidation with steam. In the reduction step, carbon monoxide diluted in Ar was fed to the reactor for $21 \mathrm{~min}$ and the effluent gas was analyzed continuously. Afterwards, the reduced OC was treated with steam for $21 \mathrm{~min}$ in order to reoxidize the sample and hydrogen production simultaneously. Each step in a cycle is dissociated with pure $\mathrm{Ar}$ for $20 \mathrm{~min}$ in order to drive all of the remaining gases out of the reactor. After 20 reduction-oxidation cycles, the residue oxygen transfer material was examined by the XRD technique.

The activity tests of the chemical looping process were conducted in a fixed-bed reactor with an inner diameter of $16 \mathrm{~mm}$ and height of $1000 \mathrm{~mm}$ filled with $1 \mathrm{~g}$ of finely powdered oxygen carrier with a 100-200 mesh size (Figure 9). The gas streams, including argon (Ar, $100 \mathrm{~mL} \cdot \mathrm{min}^{-1}$ ) as carrier gas and carbon monoxide $\left(\mathrm{CO}, 100 \mathrm{~mL} \cdot \mathrm{min}^{-1}\right)$ as reactant, were passed through two distinct mass flow controllers (MFC-Unit instruments, model UFC 1661, Yorba Linda, CA, USA) before mixing in the gas mixer. Deionized water was injected into the evaporator with an HPLC pump (Gilson, 307, Middleton, WI, USA) to generate steam. The generated steam was mixed with Ar in a heat-traced pipeline. The products of the reactor were passed through a condenser in order to liquefy the steam and separate them from the gaseous stream. Finally, the products and the unreacted gas streams were analyzed using an online Bruker 450 gas chromatograph (GC-Bruker, 450 series, Billerica, MA, USA) system. The data were collected after one complete cycle in order to ensure the structural stability of the oxygen carriers at a high process temperature. 


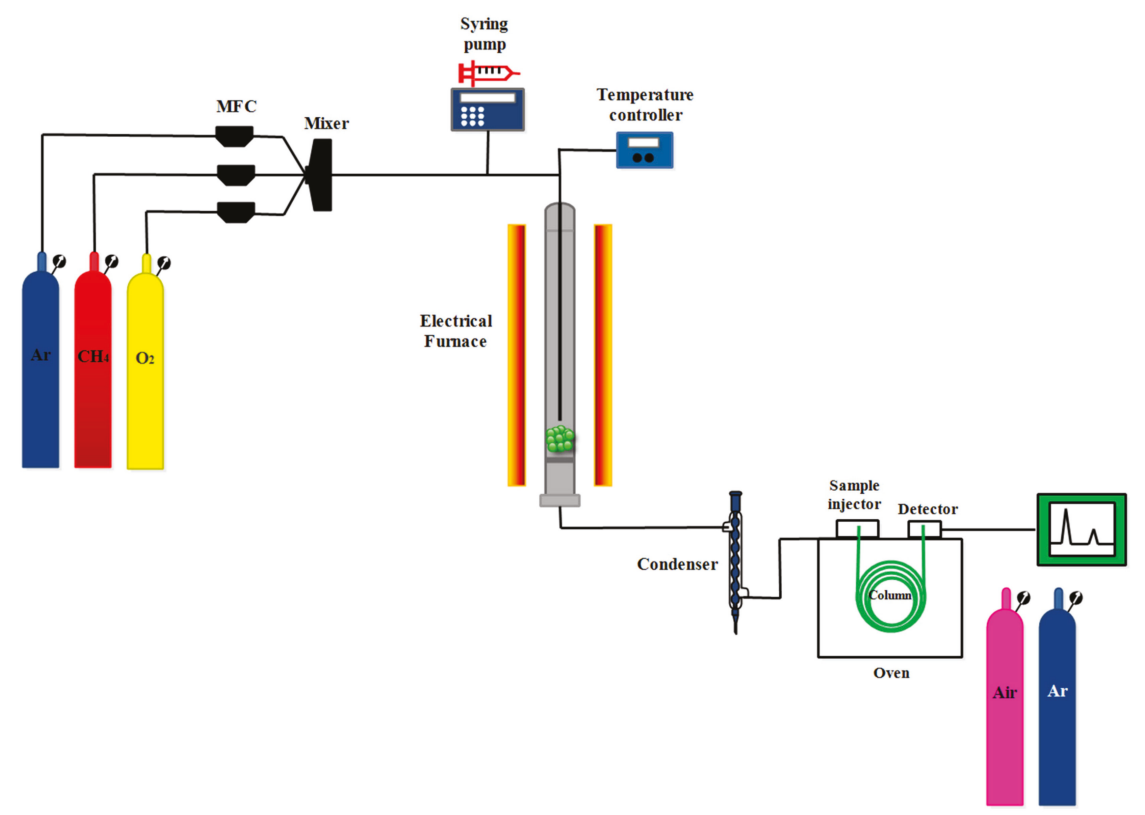

Figure 9. Reactor system for chemical looping hydrogen production.

$\mathrm{CO}$ conversion in the reduction section $\left(\mathrm{X}_{\mathrm{CO}}\right)$ was calculated for evaluating the activity of catalyst-sorbents in the chemical looping hydrogen production process according to the following equations.

$$
\mathrm{X}_{\mathrm{CO}}=\frac{\left(\mathrm{F}_{\mathrm{CO}_{\text {in }}}\right)-\left(\mathrm{F}_{\mathrm{CO}_{\text {out }}}\right)}{\left(\mathrm{F}_{\mathrm{CO}_{\text {in }}}\right)} * 100
$$

where $\mathrm{F}_{\mathrm{CO}}$ in and $\mathrm{F}_{\mathrm{CO}_{\text {out }}}$ represent the inlet and outlet molar flow rates of carbon monoxide $\left(\mathrm{mol} \cdot \mathrm{min}^{-1}\right)$, respectively.

\section{Conclusions}

In summary, iron oxide was impregnated on a magnesium-modified alumina support for the transference of pure lattice oxygen. The synthesized $\mathrm{MgAl}_{2} \mathrm{O}_{4}$ with a narrow pore size distribution centered at $2.3 \mathrm{~nm}$ revealed a better performance on the formation of $\mathrm{Fe}_{2} \mathrm{O}_{3}$ on the support's surface in comparison with $\mathrm{Al}_{2} \mathrm{O}_{3}$. However, the higher lattice oxygen transfer capacity could be attained using $\mathrm{Fe}_{2} \mathrm{O}_{3}-\mathrm{MgAl}_{2} \mathrm{O}_{4}$ as an oxygen carrier, which is due to the inhibition of $\mathrm{Fe}-\mathrm{Al}$ spinel formation. It means that more iron oxides are exposed to transfer lattice oxygen to feed carbon monoxides (for $\mathrm{Fe}_{2} \mathrm{O}_{3}-\mathrm{MgAl}_{2} \mathrm{O}_{4} \mathrm{OC}$ ) in the fuel reactor compared to $\mathrm{Fe}_{2} \mathrm{O}_{3}-\mathrm{Al}_{2} \mathrm{O}_{3}$ with more iron atoms associated in spinel of $\mathrm{Fe}-\mathrm{Al}$. In addition, the characterization results of the $\mathrm{Fe}_{2} \mathrm{O}_{3}-\mathrm{MgAl}_{2} \mathrm{O}_{4}$ sample showed the agglomeration of particles with a diameter of about $40-50 \mathrm{~nm}$. The modified OC was applied in chemical looping $\mathrm{CO}$ oxidation cycles. The obtained results revealed that increasing the reduction temperature to higher than $400{ }^{\circ} \mathrm{C}$ accelerates coke formation on the OC's surface. The conversion of deposited coke in the oxidation section reduced the purity of produced hydrogen in the oxidation section. A CO conversion of $91.3 \%$ and hydrogen purity of about $98.5 \%$ were achieved in the reduction $\left(400^{\circ} \mathrm{C}\right)$ and oxidation periods, respectively. 
Author Contributions: A.H. conceived and designed the experiments, performed the experiments, performed the catalyst synthesis, and analyzed the data; M.R.R. contributed reagents/materials/analysis tools and participated in the analysis and interpretation of the characterization results; and A.H. and M.R.R. wrote the paper.

Conflicts of Interest: The authors declare no conflict of interest.

\section{References}

1. Sarshar, Z.; Kleitz, F.; Kaliaguine, S. Novel oxygen carriers for chemical looping combustion: $\mathrm{La}_{1-\mathrm{x}} \mathrm{CexBO}_{3}$ ( $\mathrm{B}=\mathrm{Co}, \mathrm{Mn}$ ) perovskites synthesized by reactive grinding and nanocasting. Energy Environ. Sci. 2012, 4, 4258-4269. [CrossRef]

2. Hafizi, A.; Rahimpour, M.R.; Hassanajili, S. Hydrogen production via chemical looping steam methane reforming process: Effect of cerium and calcium promoters on the performance of $\mathrm{Fe}_{2} \mathrm{O}_{3} / \mathrm{Al}_{2} \mathrm{O}_{3}$ oxygen carrier. Appl. Energy 2016, 165, 685-694. [CrossRef]

3. Mohsenzadeh, A.; Richards, T.; Bolton, K. DFT study of the water gas shift reaction on $\mathrm{Ni}(111), \mathrm{Ni}(100)$ and Ni(110) surfaces. Surf. Sci. 2016, 644, 53-63. [CrossRef]

4. Tang, Q.-L.; Chen, Z.-X.; He, X. A theoretical study of the water gas shift reaction mechanism on $\mathrm{Cu}(111)$ model system. Surf. Sci. 2009, 603, 2138-2144. [CrossRef]

5. Alihoseinzadeh, A.; Khodadadi, A.A.; Mortazavi, Y. Enhanced catalytic performance of Au/CuO-ZnO catalysts containing low $\mathrm{CuO}$ content for preferential oxidation of carbon monoxide in hydrogen-rich streams for PEMFC. Int. J. Hydrogen Energy 2014, 39, 2056-2066. [CrossRef]

6. Tosti, S.; Zerbo, M.; Basile, A.; Calabrò, V.; Borgognoni, F.; Santucci, A. Pd-based membrane reactors for producing ultra-pure hydrogen: Oxidative reforming of bio-ethanol. Int. J. Hydrogen Energy 2013, 38, 701-707. [CrossRef]

7. Akbari-Emadabadi, S.; Rahimpour, M.R.; Hafizi, A.; Keshavarz, P. Promotion of Ca-Co bifunctional catalyst/sorbent with yttrium for hydrogen production in modified chemical looping steam methane reforming. Catalysts 2017, 7, 270. [CrossRef]

8. Liu, W.; Ismail, M.; Dunstan, M.T.; Hu, W.; Zhang, Z. Fennell PS Inhibiting the interaction between FeO and $\mathrm{Al}_{2} \mathrm{O}_{3}$ during chemical looping production of hydrogen. RSC Adv. 2015, 5, 1759-1771. [CrossRef]

9. Akbari-Emadabadi, S.; Rahimpour, M.R.; Hafizi, A.; Keshavarz, P. Production of hydrogen-rich syngas using $\mathrm{Zr}$ modified Ca-Co bifunctional catalyst-sorbent in chemical looping steam methane reforming. Appl. Energy 2017, 206, 51-62. [CrossRef]

10. Alirezaei, I.; Hafizi, A.; Rahimpour, M.R. Syngas production in chemical looping reforming process over $\mathrm{ZrO}_{2}$ promoted Mn-based catalyst. J. $\mathrm{CO}_{2}$ Util. 2017, 23, 105-116. [CrossRef]

11. Hafizi, A.; Rahimpour, M.R.; Hassanajili, S. Calcium promoted $\mathrm{Fe} / \mathrm{Al}_{2} \mathrm{O}_{3}$ oxygen carrier for hydrogen production via cyclic chemical looping steam methane reforming process. Int. J. Hydrogen Energy 2015, 40, 16159-16168. [CrossRef]

12. Zhu, X.; Sun, L.; Zheng, Y.; Wang, H.; Wei, Y.; Li, K. $\mathrm{CeO}_{2}$ modified $\mathrm{Fe}_{2} \mathrm{O}_{3}$ for the chemical hydrogen storage and production via cyclic water splitting. Int. J. Hydrogen Energy 2014, 39, 13381-13388. [CrossRef]

13. Alirezaei, I.; Hafizi, A.; Rahimpour, M.R.; Raeissi, S. Application of zirconium modified Cu-based oxygen carrier in chemical looping reforming. J. $\mathrm{CO}_{2}$ Util. 2016, 14, 112-121. [CrossRef]

14. Ortiz, M.; de Diego, L.F.; Abad, A.; García-Labiano, F.; Gayán, P.; Adánez, J. Catalytic Activity of Ni-Based Oxygen-Carriers for Steam Methane Reforming in Chemical-Looping Processes. Energy Fuels 2012, 26, 791-800. [CrossRef]

15. Forutan, H.; Karimi, E.; Hafizi, A.; Rahimpour, M.R.; Keshavarz, P. Expert representation chemical looping reforming: A comparative study of $\mathrm{Fe}, \mathrm{Mn}, \mathrm{Co}$ and $\mathrm{Cu}$ as oxygen carriers supported on $\mathrm{Al}_{2} \mathrm{O}_{3}$. J. Ind. Eng. Chem. 2015, 21, 900-911. [CrossRef]

16. Hacker, V.; Faleschini, G.; Fuchs, H.; Fankhauser, R.; Simader, G.; Ghaemi, M.; Spreitz, B.; Friedrich, M. Usage of biomass gas for fuel cells by the SIR process. J. Power Sources 1998, 71, 226-230. [CrossRef]

17. Hacker, V.; Fankhauser, R.; Faleschini, G.; Fuchs, H.; Friedrich, K.; Muhr, M.; Kordesch, K. Hydrogen production by steam-iron process. J. Power Sources 2000, 86, 531-535. [CrossRef]

18. Hafizi, A.; Rahimpour, M.R.; Hassanajili, S. High purity hydrogen production via sorption enhanced chemical looping reforming: Application of $22 \mathrm{Fe}_{2} \mathrm{O}_{3} / \mathrm{MgAl}_{2} \mathrm{O}_{4}$ and $22 \mathrm{Fe}_{2} \mathrm{O}_{3} / \mathrm{Al}_{2} \mathrm{O}_{3}$ as oxygen carriers and cerium promoted $\mathrm{CaO}$ as $\mathrm{CO}_{2}$ sorbent. Appl. Energy 2016, 169, 629-641. [CrossRef] 
19. Li, F.; Sun, Z.; Luo, S.; Fan, L.S. Ionic diffusion in the oxidation of iron-Effect of support and its implications to chemical looping applications. Energy Environ. Sci. 2011, 4, 876-880. [CrossRef]

20. Xu, B.-Q.; Wei, J.-M.; Wang, H.-Y.; Sun, K.-Q.; Zhu, Q.-M. Nano-MgO: Novel preparation and application as support of Ni catalyst for $\mathrm{CO}_{2}$ reforming of methane. Catal. Today 2001, 68, 217-225. [CrossRef]

21. Kambolis, A.; Matralis, $\mathrm{H}$.; Trovarelli, A.; Papadopoulou, C. Ni/CeO $-\mathrm{ZrO}_{2}$ catalysts for the dry reforming of methane. Appl. Catal. A Gen. 2010, 377, 16-26. [CrossRef]

22. Hafizi, A.; Rahimpour, M.R.; Hassanajili, S. Hydrogen production by chemical looping steam reforming of methane over Mg promoted iron oxygen carrier: Optimization using design of experiments. J. Taiwan Inst. Chem. Eng. 2016, 62, 140-149. [CrossRef]

23. Rezaei, M.; Alavi, S.; Sahebdelfar, S.; Bai, P.; Liu, X.; Yan, Z.-F. $\mathrm{CO}_{2}$ reforming of $\mathrm{CH}_{4}$ over nanocrystalline zirconia-supported nickel catalysts. Appl. Catal. B Environ. 2008, 77, 346-354. [CrossRef]

24. Wang, N.; Yu, X.; Shen, K.; Chu, W.; Qian, W. Synthesis, characterization and catalytic performance of $\mathrm{MgO}-$ coated Ni/SBA-15 catalysts for methane dry reforming to syngas and hydrogen. Int. J. Hydrogen Energy 2013, 38, 9718-9731. [CrossRef]

25. Laosiripojana, N.; Sutthisripok, W.; Assabumrungrat, S. Synthesis gas production from dry reforming of methane over $\mathrm{CeO}_{2}$ doped $\mathrm{Ni} / \mathrm{Al}_{2} \mathrm{O}_{3}$ : Influence of the doping ceria on the resistance toward carbon formation. Chem. Eng. J. 2005, 112, 13-22. [CrossRef]

26. Huang, L.; Xie, J.; Chen, R.; Chu, D.; Chu, W.; Hsu, A.T. Effect of iron on durability of nickel-based catalysts in auto-thermal reforming of ethanol for hydrogen production. Int. J. Hydrogen Energy 2008, 33, 7448-7456. [CrossRef]

27. Hafizi, A.; Jafari, M.; Rahimpour, M.R.; Hassanajili, S. Experimental investigation of sorption enhanced chemical looping reforming for high purity hydrogen production using $\mathrm{CeO}_{2}-\mathrm{CaO} \mathrm{CO}_{2}$ sorbent and $15 \mathrm{Fe}-5 \mathrm{Ca} / \mathrm{Al}_{2} \mathrm{O}_{3}$ oxygen carrier. J. Taiwan Inst. Chem. Eng. 2016, 65, 185-196. [CrossRef]

28. Li, D.; Zeng, L.; Li, X.; Wang, X.; Ma, H.; Assabumrungrat, S.; Gong, J. Ceria-promoted Ni/SBA-15 catalysts for ethanol steam reforming with enhanced activity and resistance to deactivation. Appl. Catal. B Environ. 2015, 176, 532-541. [CrossRef]

29. Jabbour, K.; Massiani, P.; Davidson, A.; Casale, S.; Hassan, N. Ordered mesoporous "one-pot" synthesized $\mathrm{Ni}-\mathrm{Mg}(\mathrm{Ca})-\mathrm{Al}_{2} \mathrm{O}_{3}$ as effective and remarkably stable catalysts for combined steam and dry reforming of methane (CSDRM). Appl. Catal. B Environ. 2017, 201, 527-542. [CrossRef]

30. Jiang, B.; Dou, B.; Wang, K.; Song, Y.; Chen, H.; Zhang, C.; Xu, Y.; Li, M. Hydrogen production from chemical looping steam reforming of glycerol by Ni based Al-MCM-41 oxygen carriers in a fixed-bed reactor. Fuel 2016, 183, 170-176. [CrossRef]

31. Ren, B.; Zhang, L.; Tang, C.; Dong, L.; Li, J. Construction of hierarchical $\mathrm{MgAl}_{2} \mathrm{O}_{4}$ spinel as catalytic supports. Mater. Lett. 2015, 159, 204-206. [CrossRef]

32. Damyanova, S.; Pawelec, B.; Arishtirova, K.; Fierro, J. Ni-based catalysts for reforming of methane with $\mathrm{CO}_{2}$. Int. J. Hydrogen Energy 2012, 37, 15966-15975. [CrossRef]

33. Wang, P.; Tanabe, E.; Ito, K.; Jia, J.; Morioka, H.; Shishido, T.; Takehira, K. Filamentous carbon prepared by the catalytic pyrolysis of $\mathrm{CH}_{4}$ on $\mathrm{Ni} / \mathrm{SiO}_{2}$. Appl. Catal. A Gen. 2002, 231, 35-44. [CrossRef]

(C) 2018 by the authors. Licensee MDPI, Basel, Switzerland. This article is an open access article distributed under the terms and conditions of the Creative Commons Attribution (CC BY) license (http:/ / creativecommons.org/licenses/by/4.0/). 


\title{
Article \\ Hydrogen Production from Cyclic Chemical Looping Steam Methane Reforming over Yttrium Promoted Ni/SBA-16 Oxygen Carrier
}

\author{
Sanaz Daneshmand-Jahromi, Mohammad Reza Rahimpour *, Maryam Meshksar and Ali Hafizi \\ Department of Chemical Engineering, Shiraz University, Shiraz 71345, Iran; \\ Sanaz.daneshmand@yahoo.com (S.D.-J.); Meshksar.maryam@gmail.com (M.M.); hafizi@shirazu.ac.ir (A.H.) \\ * Correspondence: rahimpor@shirazu.ac.ir
}

Academic Editors: Ewa Kowalska, Marcin Janczarek and Agata Markowska-Szczupak

Received: 3 September 2017; Accepted: 22 September 2017; Published: 25 September 2017

\begin{abstract}
In this work, the modification of Ni/SBA-16 oxygen carrier (OC) with yttrium promoter is investigated. The yttrium promoted Ni-based oxygen carrier was synthesized via co-impregnation method and applied in chemical looping steam methane reforming (CL-SMR) process, which is used for the production of clean energy carrier. The reaction temperature $\left(500-750{ }^{\circ} \mathrm{C}\right)$, Y loading (2.5-7.4 wt. \%), steam/carbon molar ratio (1-5), Ni loading (10-30 wt. \%) and life time of OCs over 16 cycles at $650{ }^{\circ} \mathrm{C}$ were studied to investigate and optimize the structure of OC and process temperature with maximizing average methane conversion and hydrogen production yield. The synthesized OCs were characterized by multiples techniques. The results of X-ray powder diffraction (XRD) and energy dispersive $X$-ray spectroscopy (EDX) of reacted OCs showed that the presence of $Y$ particles on the surface of OCs reduces the coke formation. The smaller NiO species were found for the yttrium promoted $\mathrm{OC}$ and therefore the distribution of Ni particles was improved. The reduction-oxidation (redox) results revealed that 25Ni-2.5Y/SBA-16 OC has the highest catalytic activity of about $99.83 \%$ average $\mathrm{CH}_{4}$ conversion and $85.34 \% \mathrm{H}_{2}$ production yield at reduction temperature of $650^{\circ} \mathrm{C}$ with the steam to carbon molar ratio of 2 .
\end{abstract}

Keywords: chemical looping reforming of methane; yttrium promoted oxygen carrier; SBA-16; hydrogen production

\section{Introduction}

Fast depletion of conventional fossil fuel sources and increasing concerns over the global warming phenomenon due to the emissions of greenhouse gases especially carbon dioxide, initiated various researchers for the production of clean energies [1-6]. $\mathrm{H}_{2}$ has been widely identified as a favorable clean energy carrier because of its non-polluting nature and high specific energy density (120.7 kJ/g) [7-9]. Recently, hydrogen can be produced by applying novel techniques with lower cost [9-11]. Reforming of fossil fuels, photo-catalytic water splitting, electrolysis and biomass gasification are hydrogen production technologies $[9,12-15]$. Steam methane reforming (SMR) is the most commonly used process in industry for the generation of $\mathrm{H}_{2}[16,17]$. However, SMR is energy intensive process and needs high level of capital investment that is not economically $[18,19]$. As an alternative method, chemical looping steam methane reforming (CL-SMR) process was proposed in order to overcome these drawbacks $[20,21]$. In this process the necessity of the gas separation is eliminated since the produced gas is not diluted with $\mathrm{N}_{2}$ [22,23]. A typical CL-SMR scheme consists of two interconnected reactors where there is no direct mixing of fuel and air as indicated in Figure 1. Methane is partially oxidized to syngas $\left(\mathrm{H}_{2}\right.$ and $\left.\mathrm{CO}\right)$ in the fuel reactor, while the metal oxide $\left(\mathrm{Me}_{x} \mathrm{O}_{y}\right)$ used as an oxygen 
carrier (OC) is reduced to $\mathrm{Me}_{x} \mathrm{O}_{y-1}$. The principle reactions that are involved in the fuel reactor are as follows:

$$
\begin{gathered}
\mathrm{CH}_{4}+\mathrm{Me}_{x} \mathrm{O}_{y} \rightarrow \mathrm{Me}_{x} \mathrm{O}_{y-s}+\mathrm{sCO}+2 \mathrm{H}_{2} \\
\mathrm{CO}+\mathrm{H}_{2} \mathrm{O} \leftrightarrow \mathrm{H}_{2}+\mathrm{CO}_{2}
\end{gathered}
$$

Then air is applied to re-oxidized the reduced OC at high temperature in the air reactor through the following reaction:

$$
2 \mathrm{Me}_{x} \mathrm{O}_{y-s}+\mathrm{sO}_{2} \rightarrow \mathrm{Me}_{x} \mathrm{O}_{y}
$$

Selection and development of an appropriate oxygen carrier is one of the most essential issues in CL-SMR process. The OC needs to possess adequate stability over multiple reduction-oxidation (redox) cycles. It also should have high methane conversion and selectivity to syngas, negligible coke deposition, high oxygen transfer rate and considerable strength to agglomeration, attrition, fragmentation and other chemical and mechanical degeneration types $[2,19,22,24]$.

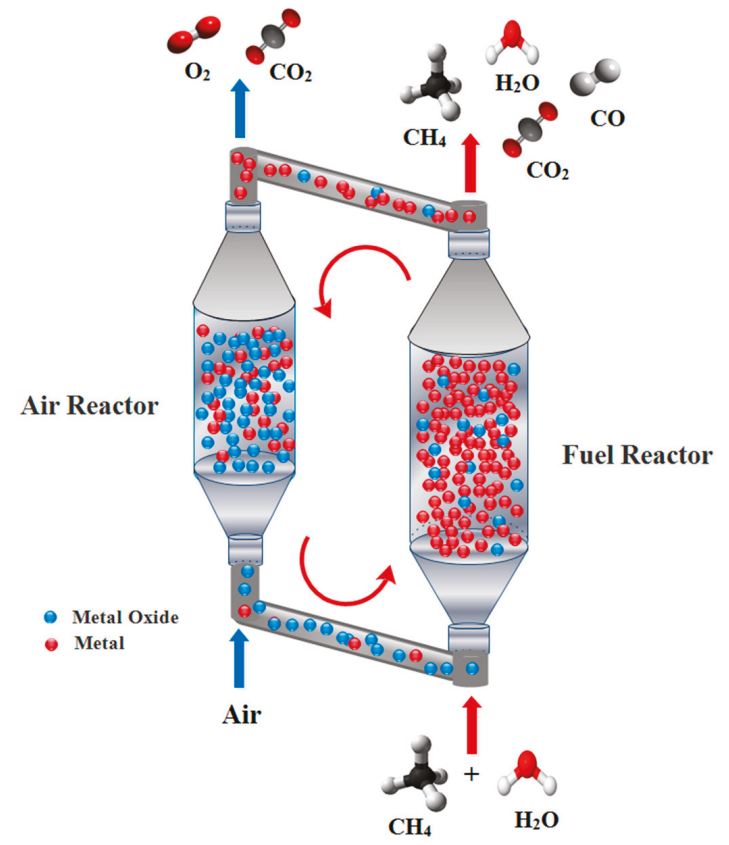

Figure 1. The schematic of CL-SMR reactor for synthesis gas production.

Among the various oxygen carriers, nickel-based OCs are the most promising and attractive candidate as active phase for CL-SMR process because of their high activity and selectivity toward $\mathrm{H}_{2}$ production. Also, they have wide availability and low cost compared to noble metal materials $[25,26]$. However, Ni-based systems generally suffer from severe deactivation caused by coke deposition and/or thermal sintering of the metallic phases due to their low tammann temperature (863 K) [27-29]. Therefore, some approaches have been applied in order to enhance the catalytic performance and durability of nickel-based materials in reforming reactions.

The first strategy is using a support with appropriate structural and textural properties that improves Ni dispersion over the carrier surface and inhibits the agglomeration of Ni nanoparticles [30,31]. Previous experiments have shown that the size of nickel particles have remarkable influence on its catalytic activity. Ni particles with sizes of several nanometers could supply more active Ni surface and could excellently 
reduce the graphite coke deposition [32-34]. Dispersing Ni particles on suitable supports such as porous silica can control the size of metallic Ni particles [35-39].

Silica-based mesoporous materials (e.g., SBA-n, MCM-48, MCM-41) have attracted much attention in many areas of material science and technology such as separations, adsorptions and catalysis [40,41]. They have shown good characteristics because of their high specific surface area, controllable pore size and pore volume. MCM-41 and SBA-15 have a uniform two-dimensional hexagonal ordered mesopore channel structure. However, the weak interaction between Ni nanoparticles and these kinds of supports leads nickel metallic particles to diffuse out of the mesoporous silica channels at elevated temperature [42]. Therefore, using three-dimensional cubic SBA-16 as a support of Ni-based material is an alternative way in order to enhance metal-support interaction. Santa Barbara Amorphous 16 (SBA-16) silica, has been known as an outstanding support for Ni-based materials due to its thick pore walls, excellent hydrothermal and thermal stability, high specific surface area and uniform pore size distribution [43].

Another popular strategy in order to avoid carbon formation and/or stabilizing Ni nanoparticles in the channels of two dimensional mesoporous silica is the utilization of promotional oxides such as $\mathrm{Ce}_{2} \mathrm{O}_{3}, \mathrm{La}_{2} \mathrm{O}_{3}, \mathrm{CaO}, \mathrm{MgO}$ and $\mathrm{Y}_{2} \mathrm{O}_{3}$ [44-48]. Li et al. [46] prepared Ce promoted $\mathrm{Ni} / \mathrm{SiO}_{2}$ catalyst using co-impregnation method and applied for producing syngas in the combined partial oxidation of methane with $\mathrm{CO}_{2}$ reforming. The results revealed that nickel-based catalyst has better performance in the presence of cerium promoter. Qian et al. [47] assessed Ni/SBA-15 catalysts with La promoter for dry reforming reaction. They have proved that highly dispersed La led to an increase of the $\mathrm{CO}_{2}$ conversion.

It was reported that the presence of $\mathrm{Y}_{2} \mathrm{O}_{3}$ particles reduces the metal particle size and prevents the coke formation due to high surface oxygen mobility. Shi et al. [49] have been investigated the performance of $\mathrm{Y}_{2} \mathrm{O}_{3}$ promoted $\mathrm{Pd} / \mathrm{Al}_{2} \mathrm{O}_{3}$ in dry $\left(\mathrm{CO}_{2}\right)$ reforming of $\mathrm{CH}_{4}$. They concluded that the addition of yttrium to $\mathrm{Pd} / \mathrm{Al}_{2} \mathrm{O}_{3}$ suppressed carbon formation and maintained $\mathrm{Pd}$ particle size below $10 \mathrm{~nm}$. Furthermore, the oxygen species mobility increased in the presence of $\mathrm{Y}_{2} \mathrm{O}_{3}$ promoter. Li et al. [50] applied sol gel method to synthesize 0-9\%Y-NiO/SBA-15 catalysts and tested them in dry reforming of $\mathrm{CH}_{4}$ process. The obtained results showed that the stronger interaction between support and metallic nickel particles is created as a result of $\mathrm{Y}_{2} \mathrm{O}_{3}$ promoter addition. Also, 9\% Y-NiO/SBA-15 showed low coke deposition and remarkable catalytic activity through dry methane reforming reaction.

Based on the above consideration, three-dimensional cubic SBA-16 material was applied as a support in order to synthesize Ni-based oxygen carriers in this research, and yttrium promoter was introduced to enhance the catalytic activity in CL-SMR process. Besides, some characteristics were employed for investigating the effect of yttrium addition on the catalytic and structural properties of $\mathrm{NiO}-\mathrm{Y}_{2} \mathrm{O}_{3} /$ SBA-16 oxygen carrier.

\section{Results and Discussion}

\subsection{Sample Characterization}

\subsubsection{X-ray Powder Diffraction (XRD) Study}

Figure 2 displays the wide angle XRD diffraction patterns of fresh $25 \mathrm{Ni} / \mathrm{SBA}-16$ and $25 \mathrm{Ni}-2.5 \mathrm{Y} / \mathrm{SBA}-16$ oxygen carriers. Five well-resolved peaks at $2 \theta=37.3^{\circ}, 43.3^{\circ}, 62.9^{\circ}, 75.4^{\circ}$ and $79.4^{\circ}$, ascribable respectively to (111), (200), (220), (311) and (222) crystal planes of cubic nickel oxide (cod No. 01-078-0643), are observed for both samples. The crystallite sizes of the nickel particles were calculated using the Debye Scherrer's equation [51]. The results showed that the size of NiO crystallite of $25 \mathrm{Ni}-2.5 \mathrm{Y} / \mathrm{SBA}-16$ oxygen carrier is smaller than that of $25 \mathrm{Ni} / \mathrm{SBA}-16$ (Table 1 ). This suggests that the presence of $\mathrm{Y}_{2} \mathrm{O}_{3}$ led to the formation of $\mathrm{NiO}$ species with smaller size, which caused better dispersion of $\mathrm{NiO}$ particles on the surface of SBA-16 support. According to 01-083-0927 reference pattern code, $\mathrm{Y}_{2} \mathrm{O}_{3}$ is observed in $25 \mathrm{Ni}-2.5 \mathrm{Y} / \mathrm{SBA}-16$ sample at peaks of $2 \theta=20.5^{\circ}, 33.8^{\circ}, 48.5^{\circ}, 54.7^{\circ}$ and $85.9^{\circ}$. 


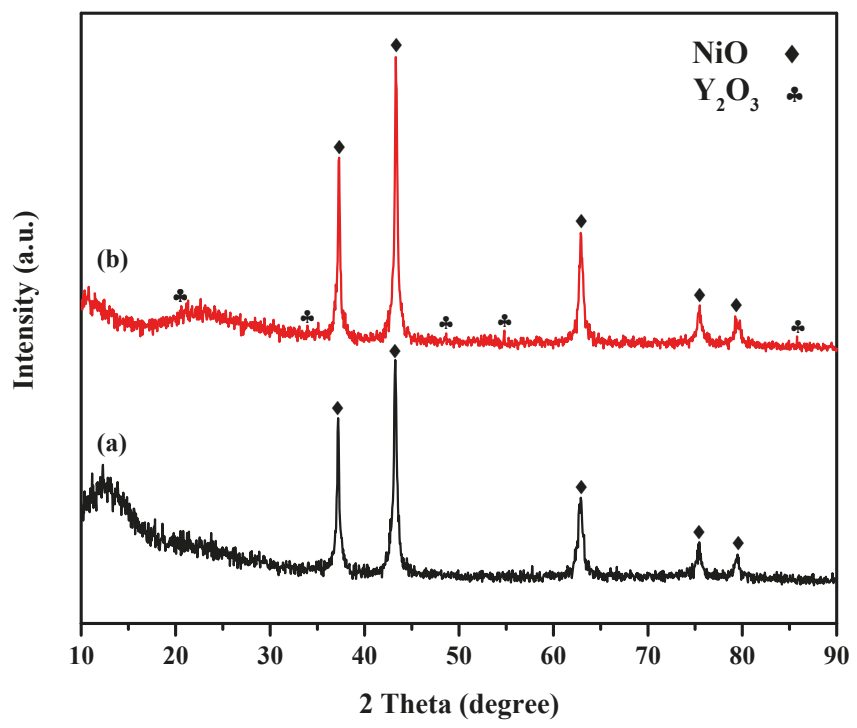

Figure 2. XRD patterns of (a) 25Ni/SBA-16 and (b) 25Ni-2.5Y/SBA-16.

Table 1. Structure properties of the prepared samples.

\begin{tabular}{ccccc}
\hline Samples & BET Surface Area $\left(\mathbf{m}^{2} / \mathbf{g}\right)$ & Pore Diameter $(\mathbf{n m})$ & ${\text { Pore Volume }\left(\mathbf{c m}^{\mathbf{3}} / \mathbf{g}\right)}$ & Crystal Size $^{\mathbf{a}}(\mathbf{n m})$ \\
\hline SBA-16 & 743.93 & 3.30 & 0.38 & - \\
25Ni/SBA-16 & 321.99 & 3.68 & 0.25 & 42.91 \\
25Ni-2.5Y/SBA-16 & 363.09 & 3.59 & 0.26 & 34.34 \\
\hline
\end{tabular}

${ }^{a}$ Crystal size of $\mathrm{NiO}$ calculated using the Debye Scherrer equation $(\mathrm{d}=0.89 \lambda / \beta \cos \theta)$.

\subsection{2. $\mathrm{N}_{2}$ Adsorption-Desorption Isotherms}

Nitrogen-physisorption analyses of pure SBA-16, 25Ni/SBA-16 and 25Ni-2.5Y/SBA-16 are shown in Figure 3a. As reported by IUPAC classification, all these prepared samples demonstrated type IV isotherm patterns with a $\mathrm{H} 2$ hysteresis loop at a range of about $\mathrm{P} / \mathrm{P}_{0}=0.4-0.7$, which represents the mesoporous hexagonal materials with cage like structure. This confirms that the mesoporous structure of SBA-16 is well preserved after impregnation of nickel active sites and yttrium promoters. However, the amount of adsorbed nitrogen is decreased upon impregnation of nickel and yttrium particles and therefore some porosity loss would be expected. The pore size distribution of pure SBA-16, 25Ni/SBA-16 and 25Ni-2.5Y/SBA-16 samples are obtained by BJH method and depicted in Figure $3 \mathrm{~b}$. All materials present sharp and narrow pore size distribution peaks, indicative of uniform mesopore structure. The mesopores of SBA- 16 and $25 \mathrm{Ni}-2.5 \mathrm{Y} / \mathrm{SBA}-16$ samples possess a pore size of about $3.5 \mathrm{~nm}$, while it is about $3.9 \mathrm{~nm}$ for $25 \mathrm{Ni} / \mathrm{SBA}-16$ oxygen carrier $[52,53]$.

The major characteristics obtained by the nitrogen adsorption experiments are exhibited in Table 1 . It can be clearly observed that after the addition of nickel active sites and yttrium promoter to the surface of SBA-16, the pore volume and specific surface area decreased significantly. These declines are due to the partial pore blocking caused by $\mathrm{NiO}$ and $\mathrm{Y}_{2} \mathrm{O}_{3}$ species posited on the surface of the SBA-16 support $[54,55]$. However, the pore volume and specific surface area of $25 \mathrm{Ni}-2.5 \mathrm{Y} / \mathrm{SBA}-16$ sample are higher than $25 \mathrm{Ni} / \mathrm{SBA}-16$ oxygen carrier, which showed that yttrium promoter developed the surface area of $25 \mathrm{Ni} / \mathrm{SBA}-16$ oxygen carrier and therefore improved the dispersion of Ni nanoparticles on the SBA-16 support $[56,57]$. Also, the addition of yttrium oxide to the oxygen carrier disperses fine $\mathrm{NiO}$ particles through the structure of SBA-16 support and inhibits the agglomeration of Ni active sites 
and pore blockage. Thus, the Brunauer-Emmett-Teller (BET) surface area of yttrium promoted oxygen carrier is higher than that of non-promoted $25 \mathrm{Ni} / \mathrm{SBA}-16$ oxygen carrier.
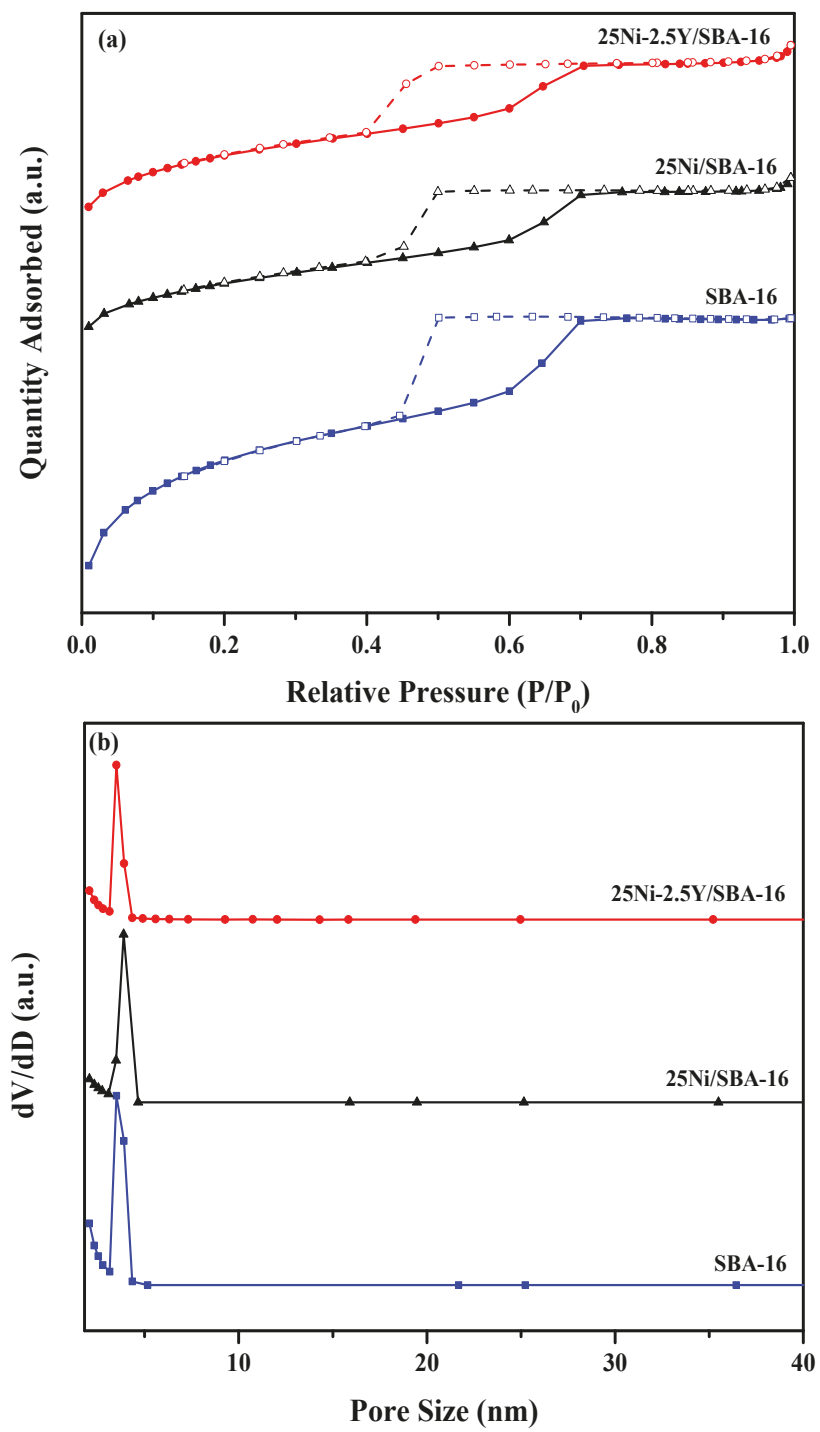

Figure 3. (a) $\mathrm{N}_{2}$ adsorption/desorption isotherms and (b) Pore size distribution of: SBA-16, $25 \mathrm{Ni} / \mathrm{SBA}-16$ and $25 \mathrm{Ni}-2.5 \mathrm{Y} / \mathrm{SBA}-16$.

\subsubsection{Field Emission Scanning Electron Microscopy (FESEM) Analysis}

The FESEM analysis was performed to evaluate the surface morphology of some samples. The FESEM micrographs of 25Ni-2.47Y/SBA-16 and 25Ni/SBA-16 oxygen carriers before CL-SMR process are dedicated in Figure 4. As exhibited in this figure, SBA-16 possesses 3-dimentional cubic and solid mesoporous structure. 


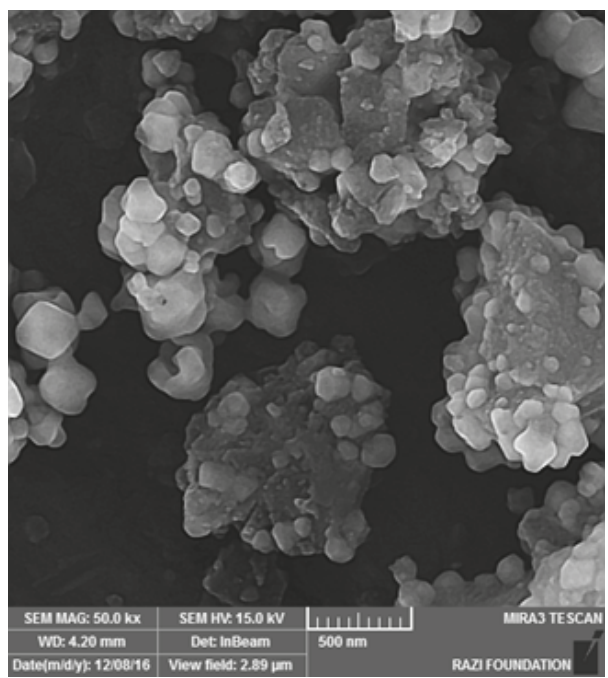

(a)

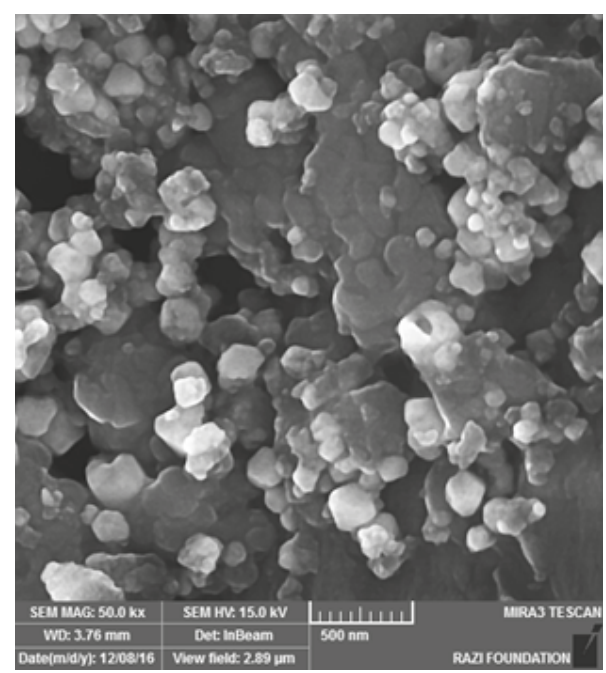

(b)

Figure 4. FESEM images of fresh (a) 25Ni/SBA-16 and (b) 25Ni-2.5Y/SBA-16 oxygen carriers.

\subsection{Effect of Yttrium Weight Percentage and Temperature on the Catalytic Activity}

To investigate the catalytic activity of different yttrium promoted Ni-based oxygen carriers, the samples with different $\mathrm{Y}$ percentages are synthesized and tested in CL-SMR process. The yttrium weight percentage was changed from 0 to $7.4 \mathrm{wt}$. \% in different reaction temperatures $\left(500-750{ }^{\circ} \mathrm{C}\right)$ with the steam to carbon molar ratio of 1.5. As depicted in Figure 5a, the methane conversion increases with the rise of temperature, reflecting the endothermic nature of steam methane reforming process. Therefore, high temperature is favorable for increasing the methane conversion $[58,59]$. The yttrium free oxygen carrier (20Ni/SBA-16) showed the lowest methane conversion in all the temperature range studied. The performance of this oxygen carrier is greatly improved by the addition of yttrium to the support especially at lower reaction temperatures. As discussed previously in the result of XRD, the promotion of oxygen carrier with yttrium led to the better dispersion of nickel nanoparticles. Thus, the oxygen transfer rate is improved in these samples. For instance, by adding $2.5 \mathrm{wt}$. \% yttrium to the oxygen carrier, the average methane conversion is increased from $56.37 \%$ to $93.13 \%$ at the reduction temperature of $550^{\circ} \mathrm{C}$. It can be clearly observed that $20 \mathrm{Ni}-2.5 \mathrm{Y} / \mathrm{SBA}-16$ oxygen carrier had the highest catalytic activity and further increase of yttrium loading has negative effect on methane conversion. In addition, as indicated in Figure $5 b$, hydrogen production yield is increased by raising the reaction temperature. The average hydrogen yield of $20 \mathrm{Ni}-2.5 \mathrm{Y} / \mathrm{SBA}-16$ oxygen carrier is increased from $69.13 \%$ to $85.66 \%$ by increasing the temperature from 500 to $750{ }^{\circ} \mathrm{C}$. The highest average hydrogen yield is achieved by $20 \mathrm{Ni}-2.5 \mathrm{Y} / \mathrm{SBA}-16$ oxygen carrier. Consequently, 20Ni-2.5Y/SBA- 16 has better proficiency and higher activity according to the results of methane conversion and average hydrogen yield.

In addition to high activity and hydrogen yield, it is important to reduce the coke deposition as the main effect of adding yttrium promoter. Thus, the energy dispersive X-ray spectroscopy (EDX) analysis is carried out for the used samples with different yttrium contents.

The EDX analysis of used 20Ni-2.5Y/SBA-16, 20Ni-3.7Y/SBA-16 and 20Ni-7.4Y/SBA-16 oxygen carriers are presented in Figure 6a-c. As shown in this figure, carbon (C) element is detected in addition to $\mathrm{Si}, \mathrm{O}, \mathrm{Ni}$ and $\mathrm{Y}$ elements on the surface of all these used OCs. For 20Ni-7.4Y/SBA-16 OC, the coke deposited became less because of higher amount of $\mathrm{Y}_{2} \mathrm{O}_{3}$ particles on the surface of OC. As demonstrated in Figure $6 \mathrm{~b}, \mathrm{c}$, the amount of $\mathrm{Y}$ element for these two OCs is much lower than that 
the theoretical value, indicating the coverage of $\mathrm{Y}_{2} \mathrm{O}_{3}$ species by $\mathrm{NiO}$ nanoparticles on the surface of SBA-16. As a result, yttrium particles that are covered by $\mathrm{NiO}$ particles cannot inhibit the coke by releasing oxygen easily. Therefore, in spite of higher amount of yttrium in the synthesized mixture of 20Ni-3.7/SBA-16 OC compared with 20Ni-2.5Y/SBA-16, the coke deposited is approximately equal due to the similar amount of $\mathrm{Y}_{2} \mathrm{O}_{3}$ particles on the surface of the support. Although the carbon deposited on the 20Ni-2.5Y/SBA-16 OC was approximately higher than other OCs, the catalytic activity of this oxygen carrier was much better especially at lower temperature (Figure 5). Therefore, the yttrium weight percentage of 2.5 is the best yttrium loading on the surface of oxygen carrier.
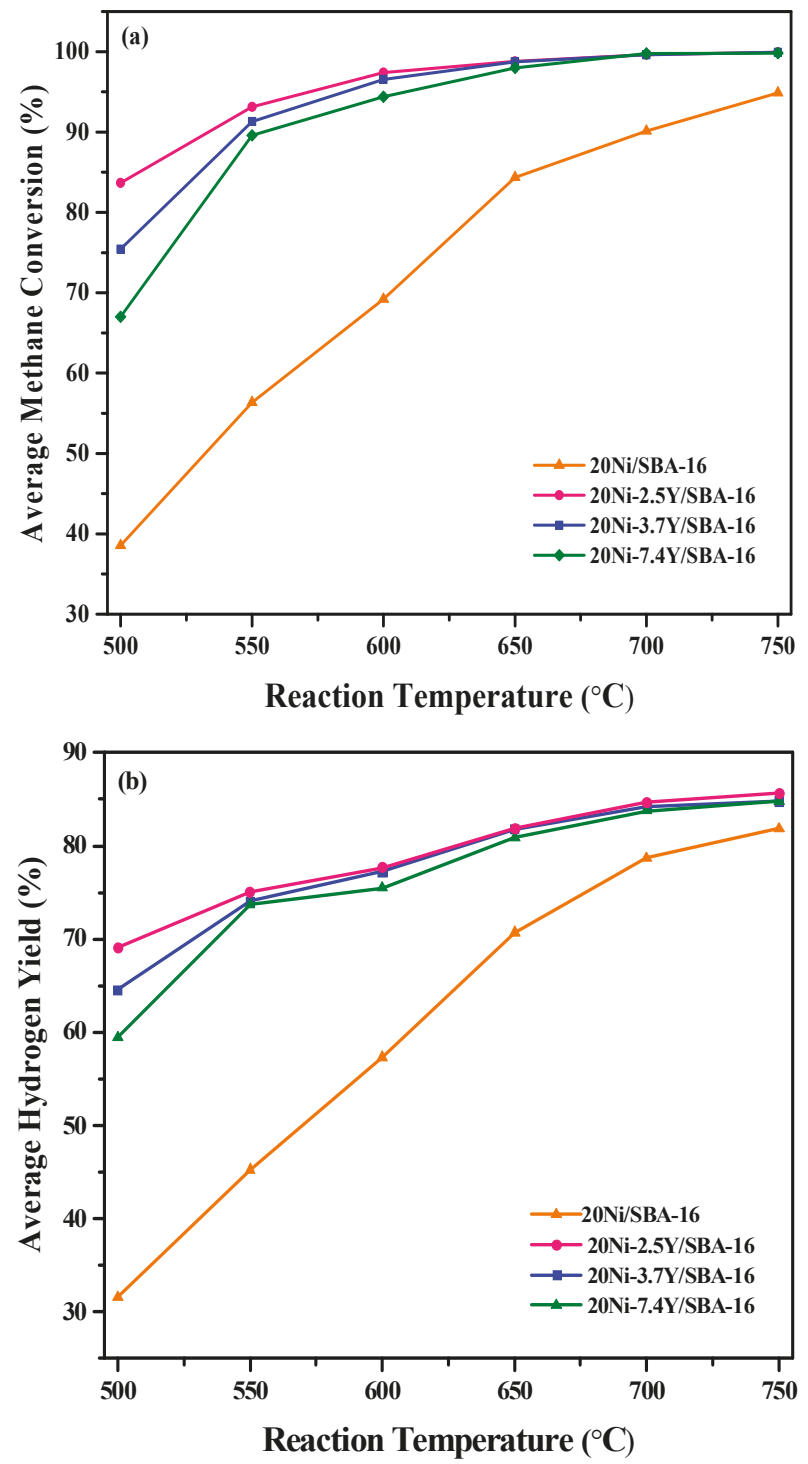

Figure 5. The effect of $Y$ weight percentage and different reduction temperature on (a) Average methane conversion and (b) Average hydrogen yield of 20Ni-yY/SBA-16 oxygen carriers. 

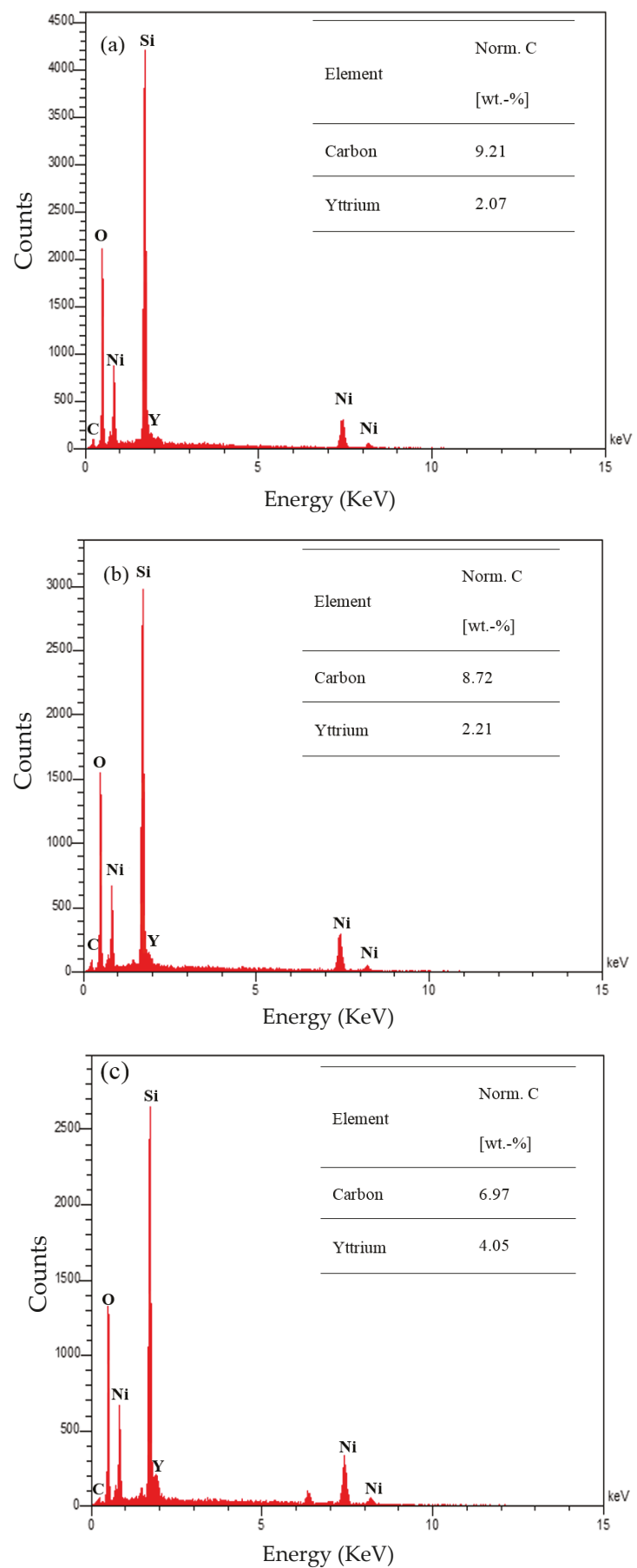

Figure 6. EDX of used (a) 20Ni-2.5Y/SBA-16; (b) 20Ni-3.7Y/SBA-16 and (c) 20Ni-7.4Y/SBA-16 oxygen carriers after 16 redox cycles at $650{ }^{\circ} \mathrm{C}$. 


\subsection{Life Time Investigation of Different Yttrium Weight Percentage}

To investigate the influence of different yttrium weight percentage on the life time of oxygen carrier, the synthesized samples were tested during 16 oxidation/reduction cycles at the temperature of $650{ }^{\circ} \mathrm{C}$ with the steam to methane molar ratio of 1.5. Figure 7 demonstrates the average methane conversion and average hydrogen yield of 20Ni/SBA-16, 20Ni-2.5Y/SBA-16, 20Ni-3.7Y/SBA-16 and 20Ni-7.4Y/SBA-16 oxygen carriers. As shown in Figure 7, the average methane conversion and the average hydrogen yield of promoted oxygen carriers are higher than yttrium free sample during the cycles. It confirms the result obtained in the characterization section, which indicated the better distribution of nickel particles on the surface of support. In addition, it shows the higher oxygen mobility in the presence of yttrium promoter. The results revealed that the average $\mathrm{CH}_{4}$ conversion and average $\mathrm{H}_{2}$ yield of $20 \mathrm{Ni}-2.5 \mathrm{Y} / \mathrm{SBA}-16$ oxygen carrier are higher than other promoted oxygen carriers in most of successive redox cycles. It is noteworthy to say that the methane conversion of $99.21 \%$ and the average hydrogen yield of $84.87 \%$ were achieved using $20 \mathrm{Ni}-2.5 \mathrm{Y} / \mathrm{SBA}-16$ oxygen carrier. Therefore, according to Figure 7a,b, 20Ni-2.5Y/SBA-16 oxygen carrier has highest stability compared with other oxygen carriers and also as demonstrated before, this oxygen carrier has higher activity and better proficiency. Therefore, the yttrium weight percentage of 2.5 is detected as the optimum yttrium loading.
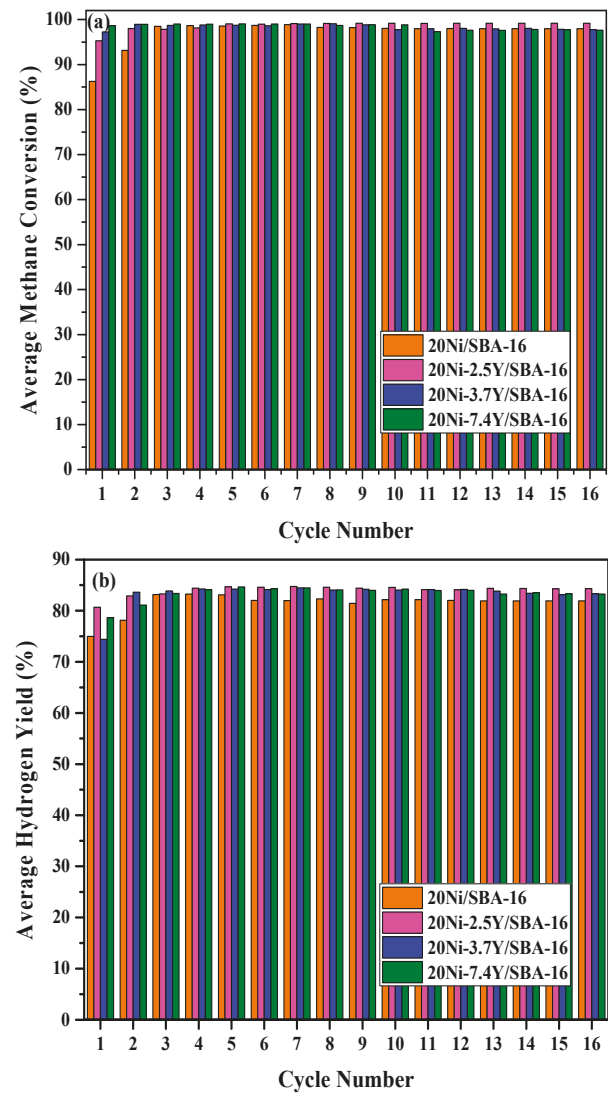

Figure 7. The Life time of 20Ni-yY/SBA-16 oxygen carriers at $650^{\circ} \mathrm{C}$ : (a) Average methane conversion and (b) Average hydrogen yield. 


\subsection{Effect of Steam/Carbon Molar Ratio on the Catalytic Performance}

Figure 8 shows the average methane conversion and hydrogen yield at various steam to methane molar ratio $(1,1.5,2,3,4$ and 5$)$ at $650{ }^{\circ} \mathrm{C}$ using $20 \mathrm{Ni}-2.5 \mathrm{Y} / \mathrm{SBA}-16$ oxygen carrier. The S/C molar ratio is a significant parameter to determine reaction pathway of $\mathrm{CH}_{4}$ and distribution of product in the CL-SMR process. Using large excess steam is undesirable, since high operating expenditures are required $[60,61]$. As demonstrated in this figure, by increasing the $\mathrm{H}_{2} \mathrm{O} / \mathrm{CH}_{4}$ ratio to 2 , the $\mathrm{CH}_{4}$ conversion and hydrogen yield were increased to $99.44 \%$ and $85.48 \%$, respectively and further increase of $\mathrm{H}_{2} \mathrm{O} / \mathrm{CH}_{4}$ ratio, caused slight negative effect on the activity of OC due to the pore blockage of oxygen carriers at higher steam to carbon molar ratios $[62,63]$. Therefore, the optimum average $\mathrm{CH}_{4}$ conversion and $\mathrm{H}_{2}$ yield were obtained at steam to carbon molar ratio of 2 .

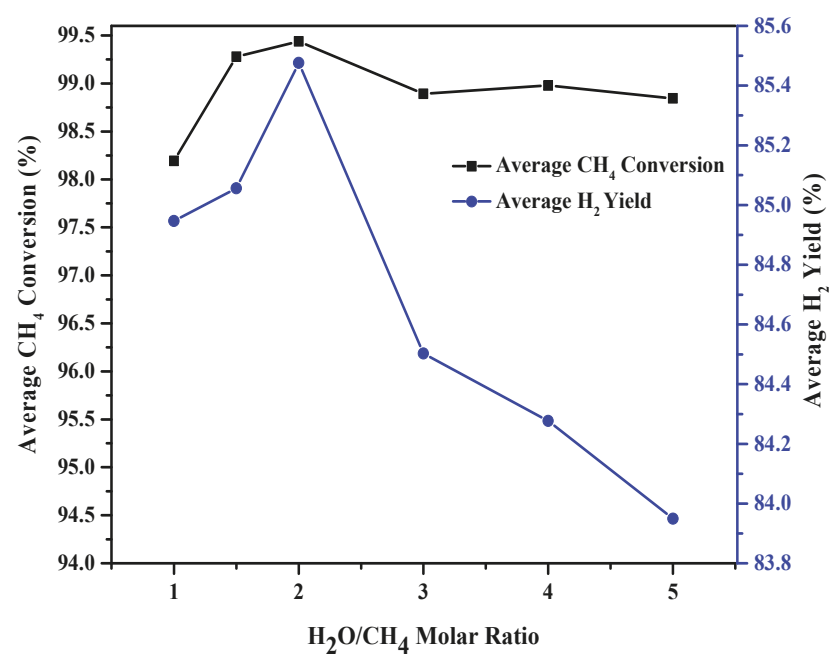

Figure 8. Average methane conversion and hydrogen yield of $20 \mathrm{Ni}-2.5 \mathrm{Y} / \mathrm{SBA}-16$ oxygen carrier at $650{ }^{\circ} \mathrm{C}$ for different $\mathrm{H}_{2} \mathrm{O} / \mathrm{CH}_{4}$ molar ratio.

\subsection{Effect of Ni Loading Percentage and Temperature on the Catalytic Activity}

In order to detect the optimum nickel weight percentage, $x N i-2.5 Y / S B A-16(x=10,15,20$, $25,30 \mathrm{wt}$. \%) oxygen carriers were synthesized and investigated in CL-SMR process in various reduction temperatures $\left(500-750^{\circ} \mathrm{C}\right)$ with steam to carbon molar ratio of 2 . The methane conversion during the cycle time and average hydrogen yield in different temperature are plotted in Figure 9. Because Ni loading percentage has great effect on the catalyst activity, its variation with time at different temperatures is plotted in Figure 9. As demonstrated in this figure, 25Ni-2.5Y/SBA-16 OC revealed the highest catalytic activity and average $\mathrm{H}_{2}$ yield in all temperature range. The average methane conversion of $25 \mathrm{Ni}-2.5 \mathrm{Y} / \mathrm{SBA}-16 \mathrm{OC}$ is about $91.09 \%$ at $500{ }^{\circ} \mathrm{C}$ (Figure 9a) and increased to $100 \%$ at $700{ }^{\circ} \mathrm{C}$ (Figure $9 \mathrm{~b}$ ). In addition, the average hydrogen yield increased from about $78.05 \%$ to $85.33 \%$ with temperature rise from 500 to $650^{\circ} \mathrm{C}$ using this OC. Actually, the performance of OCs with different nickel loadings displayed a maximum with raising the nickel content up to $25 \%$ and further increase of nickel loading percentage results in the reduction of $\mathrm{CH}_{4}$ conversion. The improvement of methane conversion with $\mathrm{Ni}$ loading percentage could be due to the more available lattice oxygen by increasing the $\mathrm{NiO}$ molecules. Afterwards the reduction in the activity is related to the agglomeration tendency of nickel particles at higher Ni weight percentage [48]. It can be concluded from Figure 9 that at higher reduction temperature the difference between catalytic activity and hydrogen production yield of $x N i-2.5 Y / S B A-16(x=10,15,20,25,30 \mathrm{wt}$. \%) oxygen carriers are less significant. 


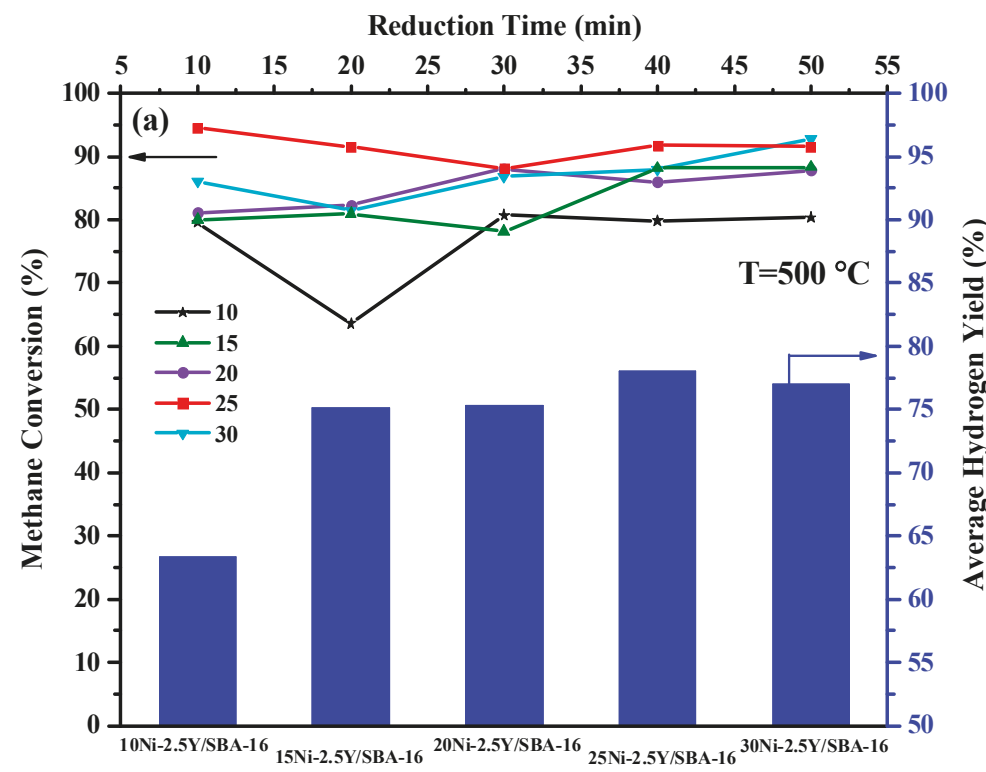

Type of Oxyge Carrier

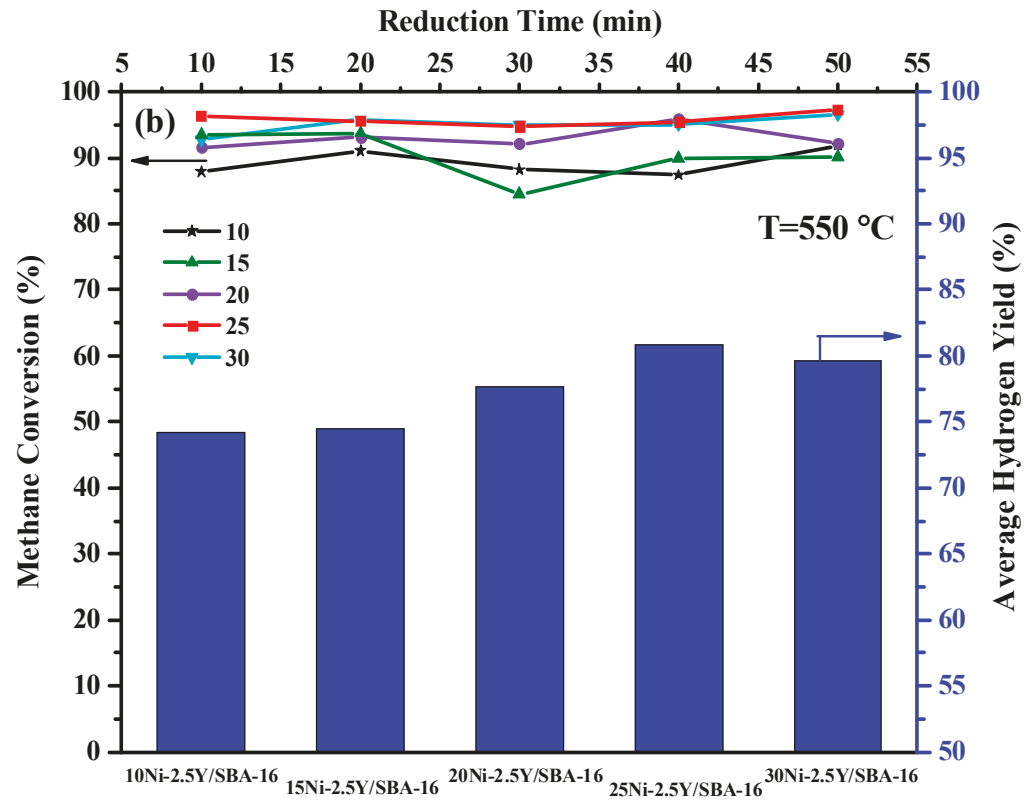

Type of Oxygen Carrier

Figure 9. Cont. 


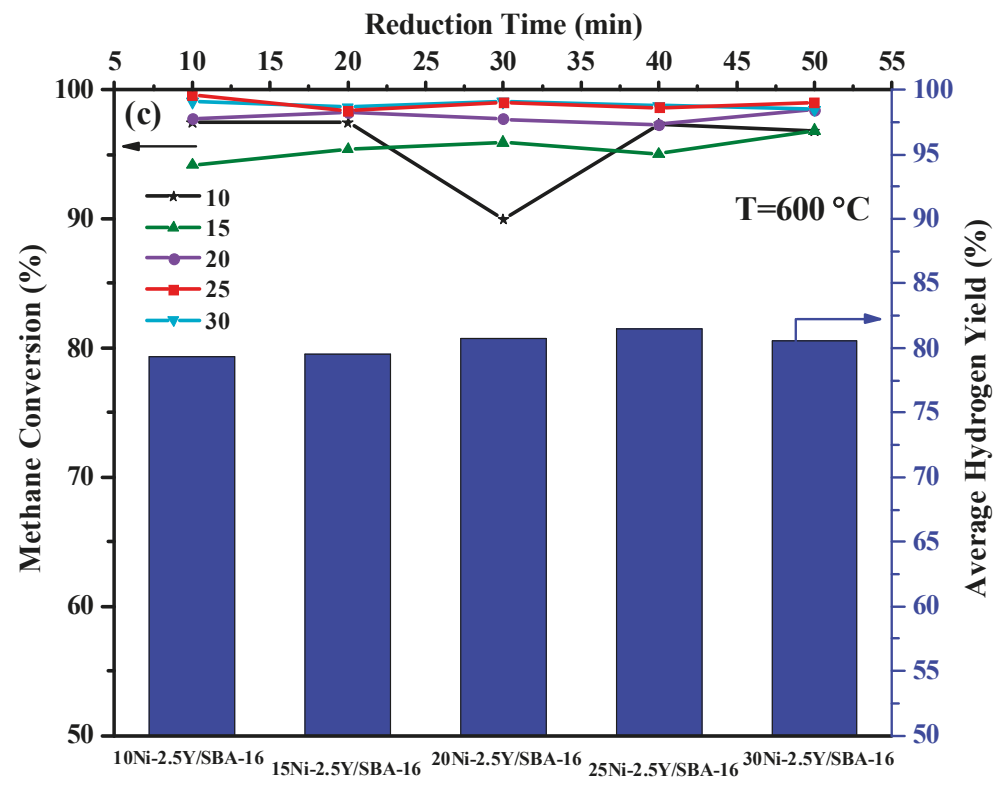

Type of Oxygen Carrier

Reduction Time (min)

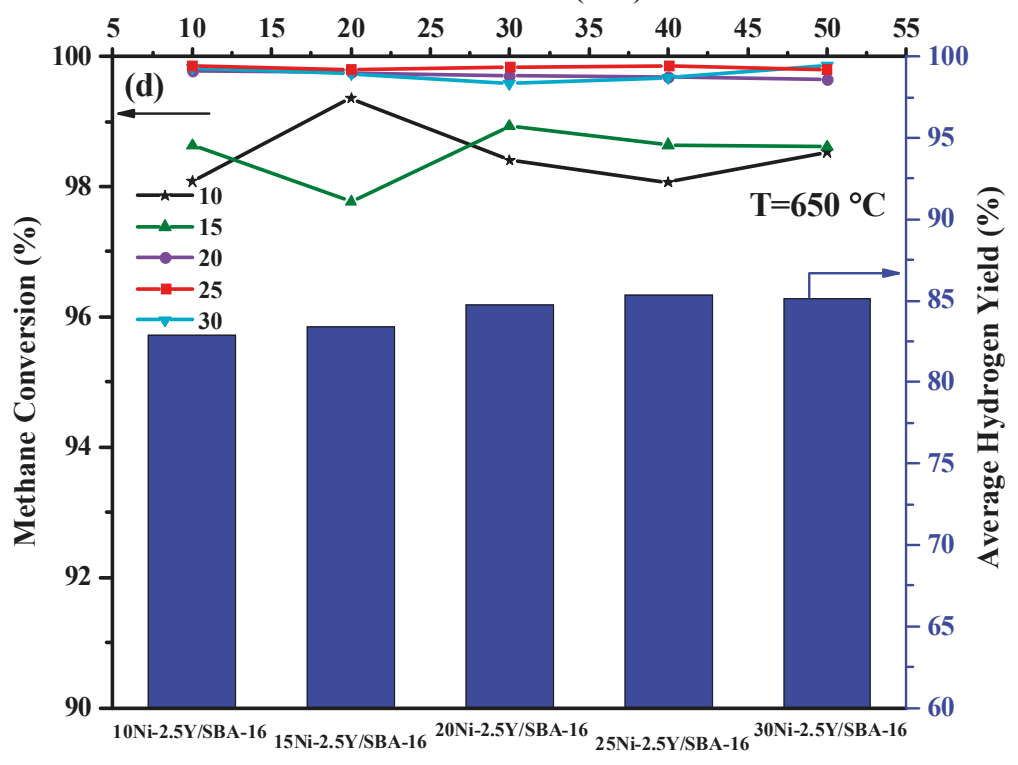

Type of Oxygen Carrier

Figure 9. Cont. 


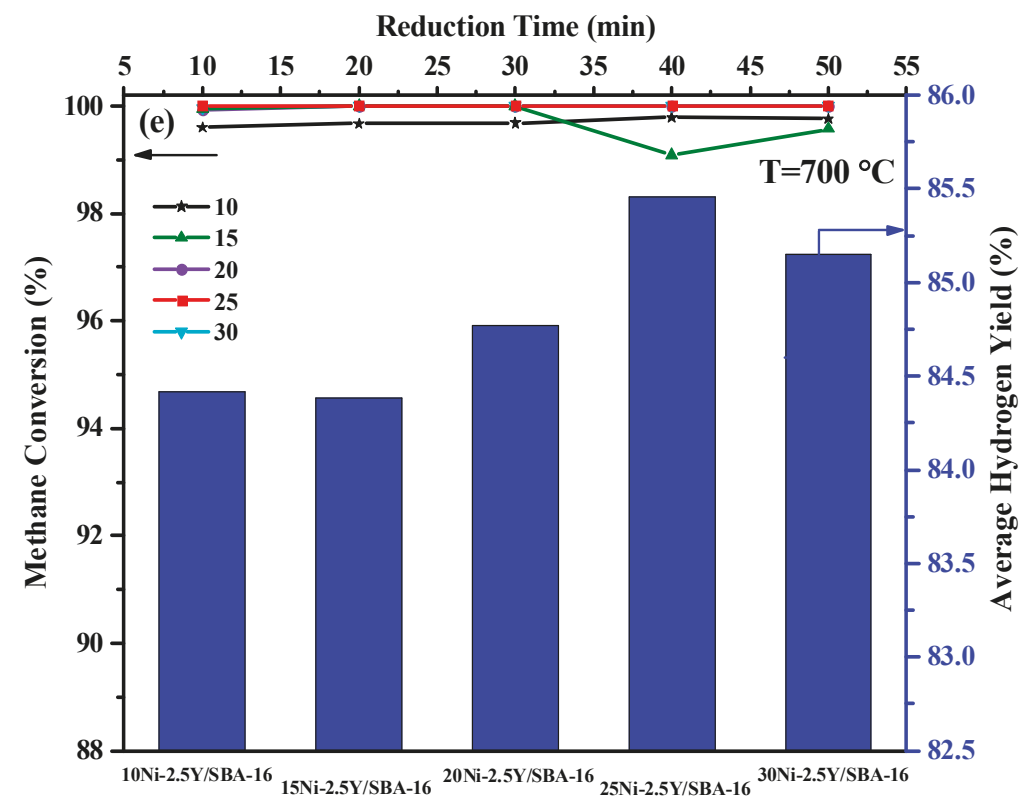

Type of Oxygen Carrier

Reduction Time (min)

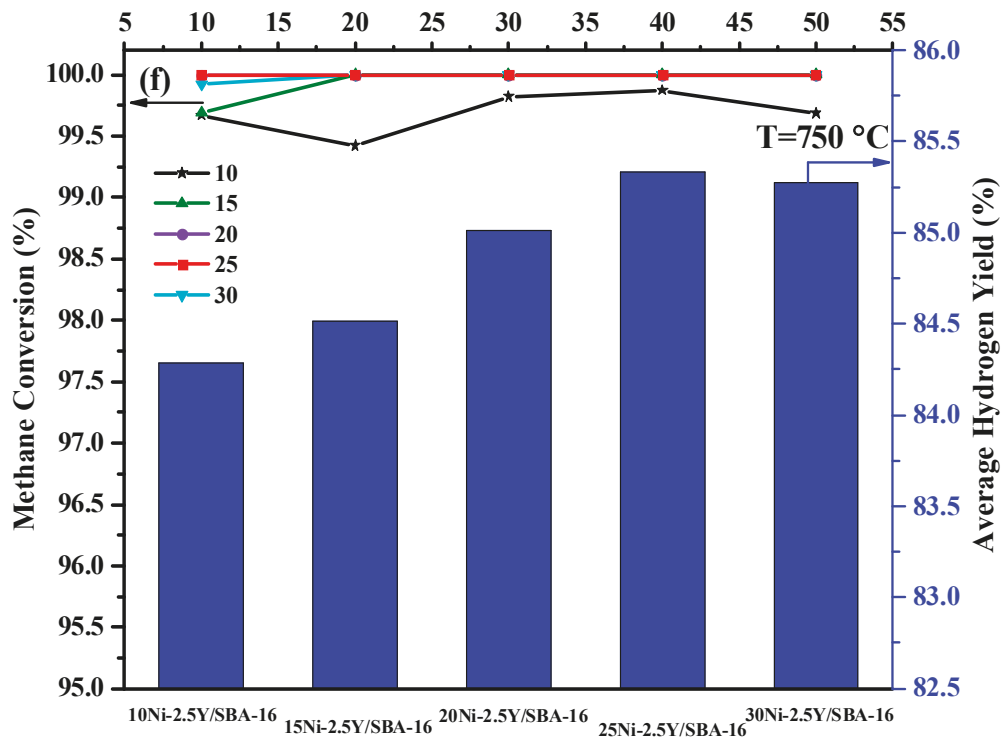

Type of Oxygen Carrier

Figure 9. The effect of $\mathrm{Ni}$ weight percentage on the methane conversion and average hydrogen yield of $\mathrm{xNi}-2.5 \mathrm{Y} / \mathrm{SBA}-16$ oxygen carriers at reduction temperature of (a) $500{ }^{\circ} \mathrm{C}$; (b) $550{ }^{\circ} \mathrm{C}$; (c) $600{ }^{\circ} \mathrm{C}$; (d) $650{ }^{\circ} \mathrm{C}$; (e) $700{ }^{\circ} \mathrm{C}$ and (f) $750{ }^{\circ} \mathrm{C}$. 


\subsection{Life Time of $25 \mathrm{Ni} / \mathrm{SBA}-16$ and $25 \mathrm{Ni}-2.5 \mathrm{Y} / \mathrm{SBA}-16$ Oxygen Carriers}

In order to investigate the effect of yttrium promoter on the durability of samples, $25 \mathrm{Ni} / \mathrm{SBA}-16$ and $25 \mathrm{Ni}-2.5 \mathrm{Y} / \mathrm{SBA}-16$ oxygen carriers were examined over 16 oxidation-reduction cycles at $650{ }^{\circ} \mathrm{C}$ with steam to carbon molar ration of 2 . As represented in Figure 10, the average $\mathrm{CH}_{4}$ conversion and $\mathrm{H}_{2}$ production yield of promoted oxygen carrier is higher than that of yttrium free OC during cycles. A slight variation of methane conversion observed during the cycles and no sensible activity loss was detected over the 16 redox cycles for $25 \mathrm{Ni}-2.5 \mathrm{Y} / \mathrm{SBA}-16 \mathrm{OC}$. The highest $\mathrm{CH}_{4}$ conversion of about $99 \%$ and $\mathrm{H}_{2}$ yield of about $85 \%$ were achieved during the cycles at $650{ }^{\circ} \mathrm{C}$ using this OC. This can be due to better distribution of nickel nanoparticles on the surface of oxygen carrier in yttrium promoted OC according to XRD result. Therefore, oxygen transfer rate is improved in the presence of yttrium promoter. As shown in this figure, the average methane conversion and hydrogen production yield of non-promoted oxygen carrier increased during first six cycles. Then they decreased with slight slope in the next three cycles and after that remained constant. Coke formation on the surface of 25Ni/SBA-16 and/or agglomeration of $\mathrm{Ni}$ particles can be the result of this reduction in the catalytic activity [19].

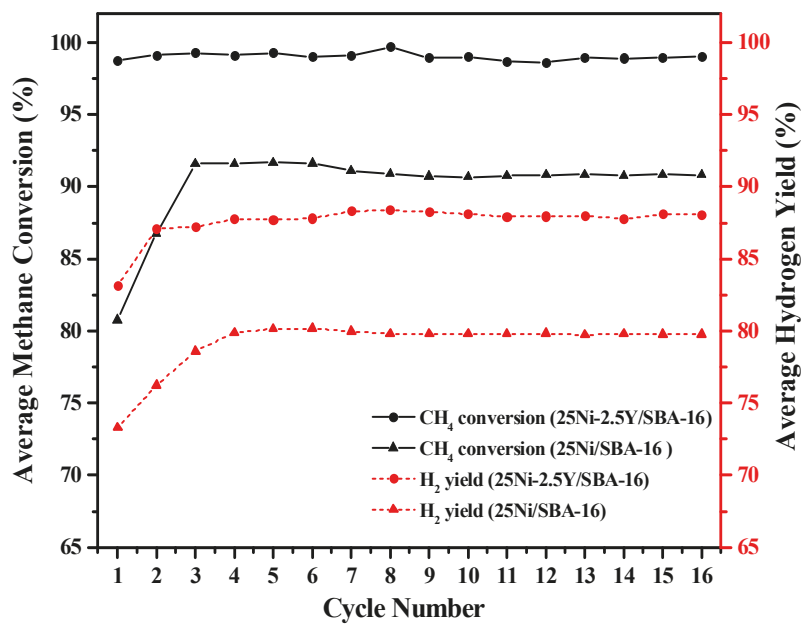

Figure 10. Life time of $25 \mathrm{Ni} / \mathrm{SBA}-16$ and $25 \mathrm{Ni}-2.5 \mathrm{Y} / \mathrm{SBA}-16$ oxygen carriers during 16 cycles at $650{ }^{\circ} \mathrm{C}$.

Table 2 shows the BET surface area, total pore volume and average pore size of 25Ni-2.5Y/SBA-16 and $25 \mathrm{Ni} / \mathrm{SBA}-16$ oxygen carriers after 16 redox cycles. Specific surface area and pore volume of both samples were decreased significantly due to sintering and blocking the pores during CL-SMR process at high temperature of $650^{\circ} \mathrm{C}$. In addition, coke formation on the surface of oxygen carrier in reduction section can effectively decrease the specific surface area of samples [1]. It is noteworthy that the presence of yttrium on the surface of support leads to lower reduction in pore volume and specific surface area of $25 \mathrm{Ni}-2.5 \mathrm{Y} / \mathrm{SBA}-16$ compared to $25 \mathrm{Ni} / \mathrm{SBA}-16 \mathrm{OC}$.

Table 2. Structure characteristics of the spent $25 \mathrm{Ni} / \mathrm{SBA}-16$ and $25 \mathrm{Ni}-2.5 \mathrm{Y} / \mathrm{SBA}-16$ oxygen carriers after 16 redox cycles at $650{ }^{\circ} \mathrm{C}$.

\begin{tabular}{cccc}
\hline Oxygen Carrier & BET Surface Area $\left(\mathrm{m}^{2} / \mathrm{g}\right)$ & Pore Diameter $(\mathrm{nm})$ & Pore Volume $\left(\mathrm{cm}^{3} / \mathrm{g}\right)$ \\
\hline $25 \mathrm{Ni} / \mathrm{SBA}-16$ & 58.26 & 4.78 & 0.08 \\
$25 \mathrm{Ni}-2.5$ Y SBA-16 & 144.04 & 3.99 & 0.15 \\
\hline
\end{tabular}


The XRD patterns of $25 \mathrm{Ni} / \mathrm{SBA}-16$ and $25 \mathrm{Ni}-2.5 \mathrm{Y} / \mathrm{SBA}-16$ oxygen carriers after 16 redox cycles are depicted in Figure 11. Both samples show the diffraction peaks of nickel at $2 \theta$ value of $44.5^{\circ}, 51.8^{\circ}$ and $76.4^{\circ}$ which respectively correspond to (111), (200) and (220) planes. This indicates that nickel oxide was reduced to metallic Ni during CL-SMR process. $\mathrm{Y}_{2} \mathrm{O}_{3}$ is observed in $25 \mathrm{Ni}-2.5 \mathrm{Y} / \mathrm{SBA}-16$ sample at peak of $2 \theta=79.7^{\circ}$. The carbon diffraction peak observed at $44.5^{\circ}$ for both samples was less pronounced in the case of $25 \mathrm{Ni}-2.5 \mathrm{Y} / \mathrm{SBA}-16$ oxygen carrier. It was reported that the presence of yttrium oxide enhanced the oxygen vacancies on the surface of support and promoted the mobility of oxygen so the carbon can be removed more easily over the yttrium promoted oxygen carrier [62]. Also, the peak at $2 \theta=43.8^{\circ}$ can be assigned to carbon for $25 \mathrm{Ni} / \mathrm{SBA}-16$ sample (cod. No. 00-050-1084). The formation of $\mathrm{NiCO}_{3}$ spinel in yttrium free oxygen carrier $(25 \mathrm{Ni} / \mathrm{SBA}-16)$ is evident at the diffraction peak of $43.4^{\circ}$ according to 00-012-0771 reference pattern code.
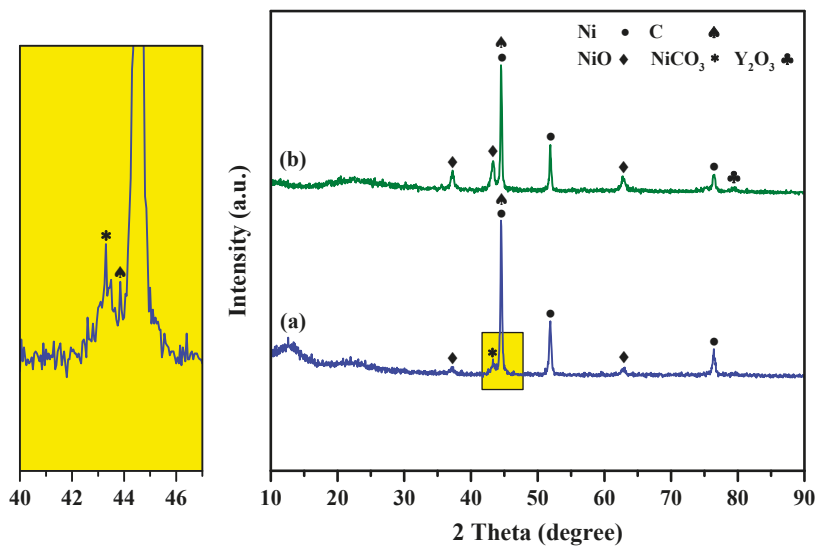

Figure 11. XRD patterns of (a) 25Ni/SBA-16 and (b) 25Ni-2.5Y/SBA-16 oxygen carriers.

Figure 12 shows the EDX analysis and FESEM images of spent 25Ni/SBA-16 and $25 \mathrm{Ni}-2.5 \mathrm{Y} / \mathrm{SBA}-16 \mathrm{OCs}$ in 16 redox cycles. As mentioned in this figure, $\mathrm{C}, \mathrm{O}, \mathrm{Ni}, \mathrm{Si}$ and $\mathrm{Y}$ atoms are presented in these OCs and the $\mathrm{C}$ element which represents the coke deposited on the SBA-16 support, was reduced from $10.61 \%$ to $4.93 \%$ on the $25 \mathrm{Ni}-2.5 \mathrm{Y} / \mathrm{SBA}-16 \mathrm{OC}$. This can be due to the presence of $\mathrm{Y}_{2} \mathrm{O}_{3}$ species that have the ability to form oxycarbonate for oxidizing the surface carbon [64]. The FESEM images indicate the formation of Ni active sites with appropriate distribution on the surface of yttrium promoted OC which enhanced the catalytic activity.

The results presented in this paper demonstrated a better performance of Ni/SBA-16 OC with yttrium promoter compared with other oxygen carriers used previously in CL-SMR process. The average methane conversion of about $99.8 \%$ was achieved at $650{ }^{\circ} \mathrm{C}$ using $25 \mathrm{Ni}-2.5 \mathrm{Y} / \mathrm{SBA}-16$ oxygen carrier in the present work, while Belhadi et al. [65] obtained the methane conversion of about $72.0 \%$ and $88.0 \%$ at $700{ }^{\circ} \mathrm{C}$ using nickel based $\mathrm{ZrO}_{2}$ and $\mathrm{La}_{2} \mathrm{O}_{3}$ supports, respectively. As a comparison with Ni-based catalysts in SMR process, Wan et al. [66] achieved the methane conversion of $99.5 \%$ at $800{ }^{\circ} \mathrm{C}$ using $\mathrm{Ce}_{x} \mathrm{Zr}_{1-\mathrm{x}} \mathrm{O}_{2}$ promoted Ni/SBA-15 catalyst. Furthermore, Rakass et al. [67] tested unsupported nickel powder catalyst for SMR and the methane conversion of $98.0 \%$ was achieved at $700{ }^{\circ} \mathrm{C}$. 

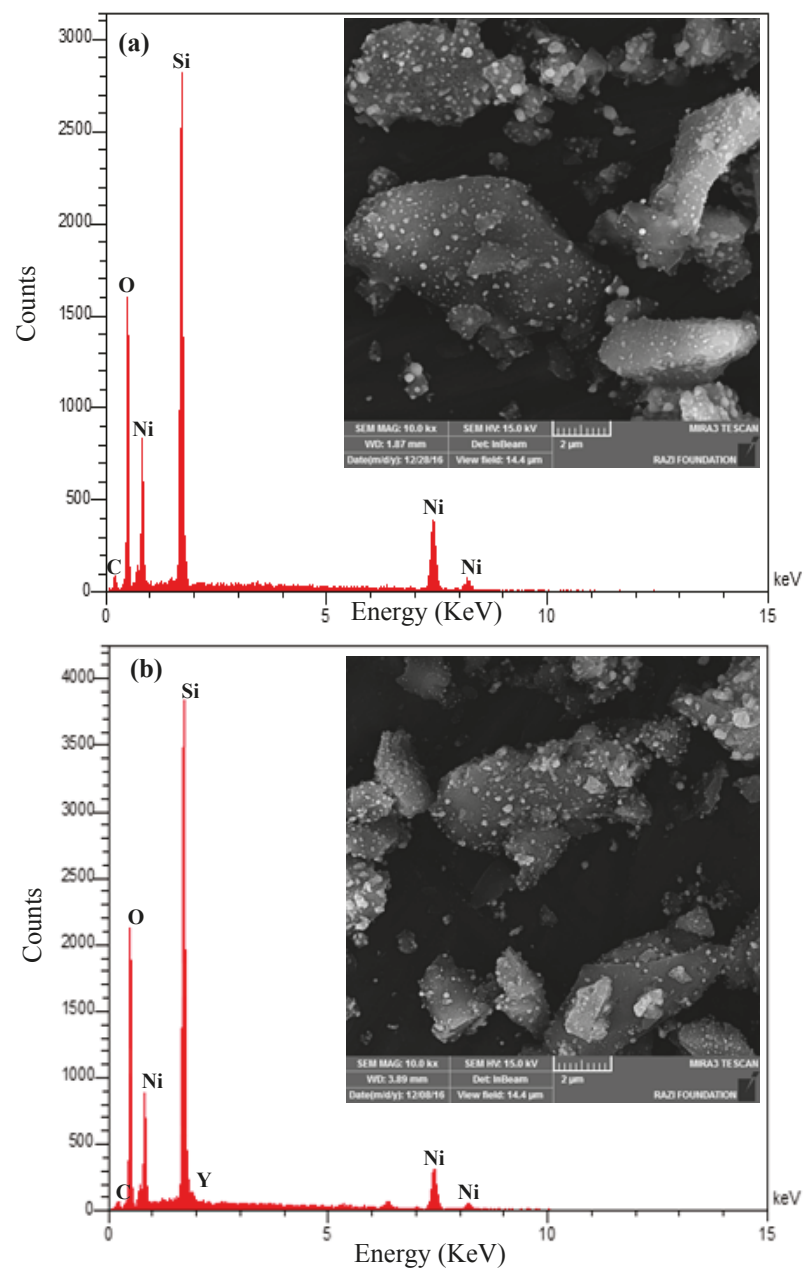

Figure 12. EDX and FESEM analysis of used (a) 25Ni/SBA-16 and (b) 25Ni-2.5Y/SBA-16 oxygen carriers.

\section{Experimental Methods}

\subsection{Oxygen Carrier Preparation}

SBA-16 support was synthesized using triblock copolymer Pluronic F127 $\left(\mathrm{EO}_{106} \mathrm{PO}_{70} \mathrm{EO}_{106}\right.$, $\mathrm{Mw}=12,600$, Aldrich, St. Louis, MO, USA) as the structure-directing agent and tetraethyl orthosilicate (TEOS, Merck, Kenilworth, NJ, USA) as the silica source by means of hydrothermal method. In a typical synthesis, $1.15 \mathrm{~g}$ F127 was dissolved in $\mathrm{HCl}$ (37 wt. \%) and de-ionized water under vigorous stirring at $40{ }^{\circ} \mathrm{C}$. Then, TEOS and butanol were added dropwise to the above solution. After stirring the mixture for $27 \mathrm{~h}$ at $40{ }^{\circ} \mathrm{C}$, it was transferred to the Teflon-lined autoclave and heated at $100{ }^{\circ} \mathrm{C}$ for two days. The solid product was recovered, washed with de-ionized water and ethanol for several times and dried at $100{ }^{\circ} \mathrm{C}$ for one day. Calcination was occurred at $550{ }^{\circ} \mathrm{C}$ for $6 \mathrm{~h}$ with a heating rate of $4{ }^{\circ} \mathrm{C} / \mathrm{min}$ to remove the organic compounds of template and the formation of mesoporous structure of cubic SBA-16. It was used as a supporting material for Ni-Y/SBA-16 oxygen carrier. 
Final stage of preparation procedure was performed by co-impregnation of SBA-16 support with nickel nitrate and yttrium nitrate solutions. For this purpose, the separated solution of $\mathrm{Y}\left(\mathrm{NO}_{3}\right)_{3} \cdot 6 \mathrm{H}_{2} \mathrm{O}$ (Merck) and $\mathrm{Ni}\left(\mathrm{NO}_{3}\right)_{2} \cdot 6 \mathrm{H}_{2} \mathrm{O}$ (Merck) were added simultaneously to the support at $40{ }^{\circ} \mathrm{C}$. The solution was stirred for $5 \mathrm{~h}$ at $40^{\circ} \mathrm{C}$ in order to better diffusion of nickel and yttrium precursors into the pores of SBA-16. The impregnated OCs were dried at $100{ }^{\circ} \mathrm{C}$ for $15 \mathrm{~h}$ and then calcined at $650{ }^{\circ} \mathrm{C}$ for $3 \mathrm{~h}$. The solid product designated as $x$ Ni-yY/SBA-16 where $x=10,15,20,25 \& 30 \mathrm{wt}$. \% and $y=0,2.5,3.7 \& 7.4 \mathrm{wt}$. \%.

\subsection{Oxygen Carrier Characterization}

The synthesized OCs were characterized before and after reduction section in order to study their structural and catalytic properties via different techniques. The XRD patterns were collected on a powder Bruker D8 Advance Germany instrument equipped with $\mathrm{Cu} \mathrm{K} \alpha$ source at $40 \mathrm{kV}$ and $40 \mathrm{~mA}$ in the range of $2 \theta=10^{\circ}-90^{\circ}$ with a step size of $0.05^{\circ}$. In order to measure the specific surface area, BET method was applied by $\mathrm{N}_{2}$ adsorption/desorption isotherms using ASPA-2020 Instrument (Norcross, GA, USA). All the synthesized samples were degassed at $250{ }^{\circ} \mathrm{C}$ with nitrogen. The pore size distribution and the cumulative pore volume were achieved by the Barret-Joyner-Halenda $(\mathrm{BJH})$ method from the desorption branches of $\mathrm{N}_{2}$ isotherms. FESEM images were recorded on a HITAGHI S-4160 system equipped with an EDX spectroscopy.

\subsection{Process Activity}

Gas-solid reactions consist of redox multi-cycles were done in a cylindrical stainless steel reactor which has an inner diameter of $16 \mathrm{~mm}$ with $1000 \mathrm{~mm}$ height. The fixed-bed reactor was inserted into a vertical electrical furnace and a k-type thermocouple posited at the center of the OC bed to monitor the temperature of the catalytic bed during the process. In each activity test, $1 \mathrm{~g}$ of freshly synthesized powdered OC (mesh size: 100-200 $\mu \mathrm{m}$ ) was packed on a thin porous layer in the middle of the reformer reactor. Deionized water was injected to the evaporator with syringe pump to generate steam. In the reduction step, the reactant gas streams $\left(\mathrm{CH}_{4}\right.$ as reactant and Ar as carrier gas) were controlled through two distinct mass flow controllers (MFCs) and mixed with steam before the reactor entrance. The reduction section was carried out by changing temperature from 500 to $750{ }^{\circ} \mathrm{C}$ at atmospheric pressure for $50 \mathrm{~min}$. The feed mixture entered the bed at the reaction temperature and reacted with lattice oxygen of solid OCs. In the oxidation step, the stream of $20 \mathrm{vol} \% \mathrm{O}_{2}$ diluted in Ar

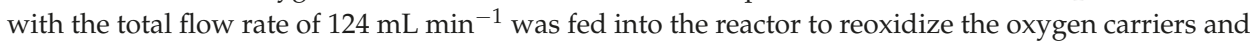
removing the deposited carbon. The oxidation and reduction periods were dissociated by purging Ar for $3 \mathrm{~min}$. The products of the reactor were passed through a condenser in order to liquefy the steam from gaseous product. Finally, the product and unreacted gas streams were analyzed using an online Bruker 450 gas chromatograph (GC) system every ten minutes. This means that the outlet gas was analyzed five times for each temperature. It is noteworthy to say that the first sample injection was carried out $10 \mathrm{~min}$ after the beginning of the reaction. Thus, the short transient state period is passed and it could be in the steady state section. Figure 13 indicates the schematic of the designated reactor applied for investigating the performance of oxygen carriers. Methane conversion $\left(\mathrm{X}_{\mathrm{CH}_{4}}\right)$ and hydrogen production yield $\left(\mathrm{y}_{\mathrm{H}_{2}}\right)$ were calculated as follows:

$$
\begin{gathered}
\mathrm{X}_{\mathrm{CH}_{4}}=\frac{\left(\text { moles of } \mathrm{CH}_{4}\right)_{\text {in }}-\left(\text { moles of } \mathrm{CH}_{4}\right)_{\text {out }}}{\left(\text { moles of } \mathrm{CH}_{4}\right)_{\text {in }}} \times 100 \\
\mathrm{y}_{\mathrm{H}_{2}}=\frac{\left(\text { moles of } \mathrm{H}_{2}\right)_{\text {out }}}{2 *\left(\text { moles of } \mathrm{CH}_{4}\right)_{\text {in }}} \times 100
\end{gathered}
$$




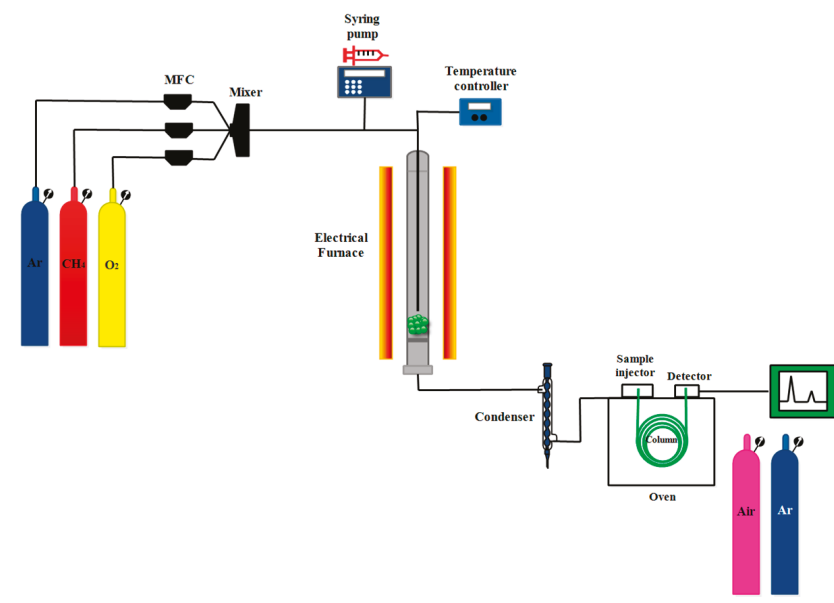

Figure 13. Reactor system for CL-SMR.

\section{Conclusions}

Structural characterization and catalytic activity of yttrium promoted Ni-based oxygen carriers were examined in chemical looping steam methane reforming process to produce synthesis gas. The oxygen carriers were synthesized via co-impregnation method and the effect of Ni loading (10-30 wt. \%), Y weight percentage (0-7.4 wt. \%), reaction temperature $\left(500-750{ }^{\circ} \mathrm{C}\right)$, steam to methane molar ratio (1-5) and life time of oxygen carriers over 16 redox cycles were successfully investigated. The reduction temperature revealed significant effect on $\mathrm{CH}_{4}$ conversion and $\mathrm{H}_{2}$ production yield of all prepared samples. The reaction temperature of $650{ }^{\circ} \mathrm{C}$ and $\mathrm{H}_{2} \mathrm{O} / \mathrm{CH}_{4}$ molar ratio of 2 were the optimum reduction condition using $25 \mathrm{Ni}-60 \mathrm{Y} / \mathrm{SBA}-16$ oxygen carrier to achieve $99.83 \%$ methane conversion and $85.34 \%$ hydrogen yield. The characterization results showed that better dispersion of $\mathrm{Ni}$ active sites, higher specific surface area and lower coke deposited were achieved using yttrium as a promoter on the surface of oxygen carrier. Thus, the catalytic activity and long-term stability of OCs were improved after the addition of yttrium promoter on SBA-16 support.

Author Contributions: S.D.-J., M.M. and A.H. conceived and designed the experiments; S.D.-J. and M.M performed the experiments; S.D.-J. and M.M. performed catalyst synthesis; S.D.-J., M.M. and A.H. analyzed the data; M.R.R. contributed reagents/materials/analysis tools; M.R.R. participated in the analysis and interpretation of characterization results; and S.D.-J. and M.M. wrote the paper.

Conflicts of Interest: The authors declare no conflict of interest.

\section{References}

1. Hafizi, A.; Rahimpour, M.R.; Hassanajili, S. Calcium promoted $\mathrm{Fe} / \mathrm{Al}_{2} \mathrm{O}_{3}$ oxygen carrier for hydrogen production via cyclic chemical looping steam methane reforming process. Int. J. Hydrogen Energy 2015, 40, 16159-16168. [CrossRef]

2. Hafizi, A.; Rahimpour, M.R.; Hassanajili, S. Hydrogen production by chemical looping steam reforming of methane over $\mathrm{Mg}$ promoted iron oxygen carrier: Optimization using design of experiments. J. Taiwan Inst. Chem. Eng. 2016, 62, 140-1409. [CrossRef]

3. Karimi, E.; Forutan, H.; Saidi, M.; Rahimpour, M.R.; Shariati, A. Experimental study of chemical-looping reforming in a fixed-bed reactor: Performance investigation of different oxygen carriers on $\mathrm{Al}_{2} \mathrm{O}_{3}$ and $\mathrm{TiO}_{2}$ support. Energy Fuels 2014, 28, 2811-2820. [CrossRef]

4. Frusteri, F.; Freni, S.; Spadaro, L.; Chiodo, V.; Bonura, G.; Donato, S.; Cavallaro, S. $\mathrm{H}_{2}$ production for MC fuel cell by steam reforming of ethanol over $\mathrm{MgO}$ supported $\mathrm{Pd}, \mathrm{Rh}, \mathrm{Ni}$ and Co catalysts. Catal. Commun. 2004, 5 , 611-615. [CrossRef] 
5. Wang, Y.; Chen, M.; Liang, T.; Yang, Z.; Yang, J.; Liu, S. Hydrogen generation from catalytic steam reforming of acetic acid by Ni/attapulgite catalysts. Catalysts 2016, 6, 172. [CrossRef]

6. Du, Y.-L.; Wu, X.; Cheng, Q.; Huang, Y.-L.; Huang, W. Development of Ni-based catalysts derived from hydrotalcite-like compounds precursors for synthesis gas production via methane or ethanol reforming. Catalysts 2017, 7, 70. [CrossRef]

7. Midilli, A.; Ay, M.; Dincer, I.; Rosen, M. On hydrogen and hydrogen energy strategies: I: Current status and needs. Renew. Sustain. Energy Rev. 2005, 9, 255-271. [CrossRef]

8. Momirlan, M.; Veziroglu, T.N. The properties of hydrogen as fuel tomorrow in sustainable energy system for a cleaner planet. Int. J. Hydrogen Energy 2005, 30, 795-802. [CrossRef]

9. Holladay, J.D.; Hu, J.; King, D.L.; Wang, Y. An overview of hydrogen production technologies. Catal. Today 2009, 139, 244-260. [CrossRef]

10. Abbasi, M.; Farniaei, M.; Rahimpour, M.R.; Shariati, A. Enhancement of Hydrogen Production and Carbon Dioxide Capturing in a Novel Methane Steam Reformer Coupled with Chemical Looping Combustion and Assisted by Hydrogen Perm-Selective Membranes. Energy Fuels 2013, 27, 5359-5372. [CrossRef]

11. Akbari-Emadabadi, S.; Rahimpour, M.R.; Hafizi, A.; Keshavarz, P. Production of hydrogen-rich syngas using Zr modified Ca-Co bifunctional catalyst-sorbent in chemical looping steam methane reforming. Appl. Energy 2017, 206, 51-62. [CrossRef]

12. Schädel, B.T.; Duisberg, M.; Deutschmann, O. Steam reforming of methane, ethane, propane, butane, and natural gas over a rhodium-based catalyst. Catal. Today 2009, 142, 42-51. [CrossRef]

13. Basagiannis, A.; Verykios, X. Catalytic steam reforming of acetic acid for hydrogen production. Int. J. Hydrogen Energy 2007, 32, 3343-3355. [CrossRef]

14. Armor, J. Catalysis and the hydrogen economy. Catal. Lett. 2005, 101, 131-135. [CrossRef]

15. Chaubey, R.; Sahu, S.; James, O.O.; Maity, S. A review on development of industrial processes and emerging techniques for production of hydrogen from renewable and sustainable sources. Renew. Sustain. Energy Rev. 2013, 23, 443-462. [CrossRef]

16. Forutan, H.; Karimi, E.; Hafizi, A.; Rahimpour, M.R.; Keshavarz, P. Expert representation chemical looping reforming: A comparative study of $\mathrm{Fe}, \mathrm{Mn}, \mathrm{Co}$ and $\mathrm{Cu}$ as oxygen carriers supported on $\mathrm{Al}_{2} \mathrm{O}_{3}$. J. Ind. Eng. Chem. 2015, 21, 900-911. [CrossRef]

17. Rydén, M.; Arjmand, M. Continuous hydrogen production via the steam-iron reaction by chemical looping in a circulating fluidized-bed reactor. Int. J. Hydrogen Energy 2012, 37, 4843-4854. [CrossRef]

18. Zhu, X.; Wei, Y.; Wang, H.; Li, K. Ce-Fe oxygen carriers for chemical-looping steam methane reforming. Int. J. Hydrogen Energy 2013, 38, 4492-4501. [CrossRef]

19. Hafizi, A.; Rahimpour, M.R.; Hassanajili, S. Hydrogen production via chemical looping steam methane reforming process: Effect of cerium and calcium promoters on the performance of $\mathrm{Fe}_{2} \mathrm{O}_{3} / \mathrm{Al}_{2} \mathrm{O}_{3}$ oxygen carrier. Appl. Energy 2016, 165, 685-694. [CrossRef]

20. Moghtaderi, B. Review of the recent chemical looping process developments for novel energy and fuel applications. Energy Fuels 2011, 26, 15-40. [CrossRef]

21. Solunke, R.D.; Veser, G.T. Hydrogen production via chemical looping steam reforming in a periodically operated fixed-bed reactor. Ind. Eng. Chem. Res. 2010, 49, 11037-11044. [CrossRef]

22. Hafizi, A.; Rahimpour, M.R.; Hassanajili, S. High purity hydrogen production via sorption enhanced chemical looping reforming: Application of $22 \mathrm{Fe}_{2} \mathrm{O}_{3} / \mathrm{MgAl}_{2} \mathrm{O}_{4}$ and $22 \mathrm{Fe}_{2} \mathrm{O}_{3} / \mathrm{Al}_{2} \mathrm{O}_{3}$ as oxygen carriers and cerium promoted $\mathrm{CaO}$ as $\mathrm{CO}_{2}$ sorbent. Appl. Energy 2016, 169, 629-641. [CrossRef]

23. Rahimpour, M.R.; Hesami, M.; Saidi, M.; Jahanmiri, A.; Farniaei, M.; Abbasi, M. Methane Steam Reforming Thermally Coupled with Fuel Combustion: Application of Chemical Looping Concept as a Novel Technology. Energy Fuels 2013, 27, 2351-2362. [CrossRef]

24. Alirezaei, I.; Hafizi, A.; Rahimpour, M.R.; Raeissi, S. Application of zirconium modified Cu-based oxygen carrier in chemical looping reforming. J. $\mathrm{CO}_{2}$ Util. 2016, 14, 112-121. [CrossRef]

25. Zafar, Q.; Mattisson, T.; Gevert, B. Redox investigation of some oxides of transition-state metals $\mathrm{Ni}, \mathrm{Cu}, \mathrm{Fe}$, and $\mathrm{Mn}$ supported on $\mathrm{SiO}_{2}$ and $\mathrm{MgAl}_{2} \mathrm{O}_{4}$. Energy Fuels 2006, 20, 34-44. [CrossRef]

26. Adanez, J.; Abad, A.; Garcia-Labiano, F.; Gayan, P.; Luis, F. Progress in chemical-looping combustion and reforming technologies. Prog. Energy Comb. Sci. 2012, 38, 215-282. [CrossRef]

27. Trimm, D.L. Catalysts for the control of coking during steam reforming. Catal. Today 1999, 49, 3-10. [CrossRef] 
28. Van Dillen, A.J.; Terörde, R.J.; Lensveld, D.J.; Geus, J.W.; De Jong, K.P. Synthesis of supported catalysts by impregnation and drying using aqueous chelated metal complexes. J. Catal. 2003, 216, 257-264. [CrossRef]

29. Zhong, X.; Xie, W.; Wang, N.; Duan, Y.; Shang, R.; Huang, L. Dolomite-Derived Ni-Based Catalysts with Fe Modification for Hydrogen Production via Auto-Thermal Reforming of Acetic Acid. Catalysts 2016, 6, 85. [CrossRef]

30. Xu, B.-Q.; Wei, J.-M.; Wang, H.-Y.; Sun, K.-Q.; Zhu, Q.-M. Nano-MgO: Novel preparation and application as support of Ni catalyst for $\mathrm{CO}_{2}$ reforming of methane. Catal. Today 2001, 68, 217-225. [CrossRef]

31. Kambolis, A.; Matralis, H.; Trovarelli, A.; Papadopoulou, C. Ni/CeO $-\mathrm{ZrO}_{2}$ catalysts for the dry reforming of methane. Appl. Catal. A Gen. 2010, 377, 16-26. [CrossRef]

32. Kim, J.-H.; Suh, D.J.; Park, T.-J.; Kim, K.-L. Effect of metal particle size on coking during $\mathrm{CO}_{2}$ reforming of $\mathrm{CH}_{4}$ over Ni-alumina aerogel catalysts. Appl. Catal. A Gen. 2000, 197, 191-200. [CrossRef]

33. Bengaard, H.S.; Nørskov, J.K.; Sehested, J.; Clausen, B.; Nielsen, L.; Molenbroek, A.; Rostrup-Nielsen, J. Steam reforming and graphite formation on Ni catalysts. J. Catal. 2002, 209, 365-384. [CrossRef]

34. Bradford, M.; Vannice, M. $\mathrm{CO}_{2}$ reforming of $\mathrm{CH}_{4}$. Catal. Rev. 1999, 41, 1-42. [CrossRef]

35. Takahashi, R.; Sato, S.; Sodesawa, T.; Tomiyama, S. $\mathrm{CO}_{2}$-reforming of methane over $\mathrm{Ni} / \mathrm{SiO}_{2}$ catalyst prepared by homogeneous precipitation in sol-gel-derived silica gel. Appl. Catal. A Gen. 2005, 286, 142-147. [CrossRef]

36. Zhang, M.; Ji, S.; Hu, L.; Yin, F.; Li, C.; Liu, H. Structural characterization of highly stable Ni/SBA-15 catalyst and its catalytic performance for methane reforming with $\mathrm{CO}_{2}$. Chin. J. Catal. 2006, 27, 777-781. [CrossRef]

37. Liu, D.; Quek, X.Y.; Cheo, W.N.E.; Lau, R.; Borgna, A.; Yang, Y. MCM-41 supported nickel-based bimetallic catalysts with superior stability during carbon dioxide reforming of methane: Effect of strong metal-support interaction. J. Catal. 2009, 266, 380-390. [CrossRef]

38. Liu, Z.; Zhou, J.; Cao, K.; Yang, W.; Gao, H.; Wang, Y.; Li, H. Highly dispersed nickel loaded on mesoporous silica: One-spot synthesis strategy and high performance as catalysts for methane reforming with carbon dioxide. Appl. Catal. B Environ. 2012, 125, 324-330. [CrossRef]

39. Li, L.; He, S.; Song, Y.; Zhao, J.; Ji, W.; Au, C.-T. Fine-tunable Ni@ porous silica core-shell nanocatalysts: Synthesis, characterization, and catalytic properties in partial oxidation of methane to syngas. J. Catal. 2012, 288, 54-64. [CrossRef]

40. Carrero, A.; Calles, J.; Vizcaíno, A. Hydrogen production by ethanol steam reforming over Cu-Ni/SBA-15 supported catalysts prepared by direct synthesis and impregnation. Appl. Catal. A Gen. 2007, 327, 82-94. [CrossRef]

41. Klimova, T.; Calderón, M.; Ramírez, J. Ni and Mo interaction with Al-containing MCM-41 support and its effect on the catalytic behavior in DBT hydrodesulfurization. Appl. Catal. A Gen. 2003, 240, 29-40. [CrossRef]

42. Zhang, S.; Muratsugu, S.; Ishiguro, N.; Tada, M. Ceria-doped Ni/SBA-16 catalysts for dry reforming of methane. ACS Catal. 2013, 3, 1855-1864. [CrossRef]

43. Kantorovich, D.; Haviv, L.; Vradman, L.; Landau, M. Behaviour of $\mathrm{NiO}$ and $\mathrm{NiO}$ pohases at high loadings, in SBA-15 and SBA-16 mesoporous silica matrices. Stud. Surf. Sci. Catal. 2005, 156, 147-154. [CrossRef]

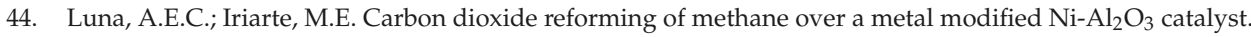
Appl. Catal. A Gen. 2008, 343, 10-15. [CrossRef]

45. Hu, Y.H.; Ruckenstein, E. The characterization of a highly effective $\mathrm{NiO} / \mathrm{MgO}$ solid solution catalyst in the $\mathrm{CO}_{2}$ reforming of $\mathrm{CH}_{4}$. Catal. Lett. 1997, 43, 71-77. [CrossRef]

46. $\mathrm{Li}, \mathrm{B}$.; $\mathrm{Xu}, \mathrm{X}$.; Zhang, S. Synthesis gas production in the combined $\mathrm{CO}_{2}$ reforming with partial oxidation of methane over Ce-promoted $\mathrm{Ni} / \mathrm{SiO}_{2}$ catalysts. Int. J. Hydrogen Energy 2013, 38, 890-900. [CrossRef]

47. Qian, L.; Ma, Z.; Ren, Y.; Shi, H.; Yue, B.; Feng, S.; Shen, J.; Xie, S. Investigation of La promotion mechanism on Ni/SBA-15 catalysts in $\mathrm{CH}_{4}$ reforming with $\mathrm{CO}_{2}$. Fuel 2014, 122, 47-53. [CrossRef]

48. Meshksar, M.; Daneshmand-Jahromi, S.; Rahimpour, M.R. Synthesis and characterization of cerium promoted $\mathrm{Ni} / \mathrm{SBA}-16$ oxygen carrier in cyclic chemical looping steam methane reforming. J. Taiwan Inst. Chem. Eng. 2017, 76, 73-82. [CrossRef]

49. Shi, C.; Zhang, P. Effect of a second metal ( $\mathrm{Y}, \mathrm{K}, \mathrm{Ca}, \mathrm{Mn}$ or $\mathrm{Cu})$ addition on the carbon dioxide reforming of methane over nanostructured palladium catalysts. Appl. Catal. B Environ. 2012, 115, 190-200. [CrossRef]

50. Li, J.; Xia, C.; Au, C.; Liu, B. $\mathrm{Y}_{2} \mathrm{O}_{3}$-promoted NiO/SBA-15 catalysts highly active for $\mathrm{CO}_{2} / \mathrm{CH}_{4}$ reforming. Int. J. Hydrogen Energy 2014, 39, 10927-10940. [CrossRef] 
51. Yogamalar, R.; Srinivasan, R.; Vinu, A.; Ariga, K.; Bose, A.C. X-ray peak broadening analysis in ZnO nanoparticles. Solid State Commun. 2009, 149, 1919-1923. [CrossRef]

52. Kaneko, K. Determination of pore size and pore size distribution. J. Membr. Sci. 1994, 96, 59-89. [CrossRef]

53. Cohan, L.H. Hysteresis and the Capillary Theory of Adsorption of Vapors1. J. Am. Chem. Soc. 1944, 66, 98-105. [CrossRef]

54. Tsoncheva, T.; Linden, M.; Areva, S.; Minchev, C. Copper oxide modified large pore ordered mesoporous silicas for ethyl acetate combustion. Catal. Commun. 2006, 7, 357-361. [CrossRef]

55. Rodrıuez-Castellón, E.; Dıaz, L.; Braos-Garcıa, P.; Mérida-Robles, J.; Maireles-Torres, P.; Jiménez-López, A.; Vaccari, A. Nickel-impregnated zirconium-doped mesoporous molecular sieves as catalysts for the hydrogenation and ring-opening of tetralin. Appl. Catal. A Gen. 2003, 240, 83-94. [CrossRef]

56. Yamazaki, T.; Kikuchi, N.; Katoh, M.; Hirose, T.; Saito, H.; Yoshikawa, T.; Wada, M. Behavior of steam reforming reaction for bio-ethanol over $\mathrm{Pt} / \mathrm{ZrO}_{2}$ catalysts. Appl. Catal. B Environ. 2010, 99, 81-88. [CrossRef]

57. Profeti, L.P.; Dias, J.A.; Assaf, J.M.; Assaf, E.M. Hydrogen production by steam reforming of ethanol over Ni-based catalysts promoted with noble metals. J. Power Sources 2009, 190, 525-533. [CrossRef]

58. De Diego, LF.; Ortiz, M.; García-Labiano, F.; Adánez, J.; Abad, A.; Gayán, P. Synthesis gas generation by chemical-looping reforming using a Nibased oxygen carrier. Energy Procedia 2009, 1, 3-10. [CrossRef]

59. Akbari-Emadabadi, S.; Rahimpour, M.R.; Hafizi, A.; Keshavarz, P. Promotion of Ca-Co bifunctional catalyst/sorbent with yttrium for hydrogen production in modified chemical looping steam methane reforming. Catalysts 2017, 7, 270. [CrossRef]

60. Antzara, A.; Heracleous, E.; Bukur, D.B.; Lemonidou, A.A. Thermodynamic analysis of hydrogen production via chemical looping steam methane reforming coupled with in situ $\mathrm{CO}_{2}$ capture. Int. J. Greenh. Gas Control 2015, 32, 115-128. [CrossRef]

61. Adiya, Z.I.; Dupont, V.; Mahmud, T. Chemical equilibrium analysis of hydrogen production from shale gas using sorption enhanced chemical looping steam reforming. Fuel Process. Technol. 2017, 159, 128-144. [CrossRef]

62. Silva, J.M.; Soria, M.A.; Madeira, L.M. Thermodynamic analysis of Glycerol Steam Reforming for hydrogen production with in situ hydrogen and carbon dioxide separation. J. Power Sources 2015, 273, 423-430. [CrossRef]

63. He, H.; Dai, H.; Wong, K.W.; Au, C. $\mathrm{RE}_{0.6} \mathrm{Zr}_{0.4-\mathrm{x}} \mathrm{Y}_{\mathrm{x}} \mathrm{O}_{2}(\mathrm{RE}=\mathrm{Ce}, \mathrm{Pr} ; \mathrm{x}=0$, 0.05) solid solutions: An investigation on defective structure, oxygen mobility, oxygen storage capacity, and redox properties. Appl. Catal. A Gen. 2003, 251, 61-74. [CrossRef]

64. Oemar, U.; Hidajat, K.; Kawi, S. Role of catalyst support over PdO-NiO catalysts on catalyst activity and stability for oxy-CO $\mathrm{CO}_{2}$ reforming of methane. Appl. Catal. A Gen. 2011, 402, 176-187. [CrossRef]

65. Belhadi, A.; Trari, M.; Rabia, C.; Cherifi, O. Methane steam reforming on supported nickel based catalysts. effect of oxide $\mathrm{ZrO}_{2}, \mathrm{La}_{2} \mathrm{O}_{3}$ and nickel composition. Open J. Phys. Chem. 2013, 3, 89-96. [CrossRef]

66. Wan, H.; Li, X.; Ji, S.; Huang, B.; Wang, K.; Li, C. Effect of Ni loading and $\mathrm{Ce}_{\mathrm{x}} \mathrm{Zr}_{\mathrm{i}-\mathrm{x}} \mathrm{O}_{2}$ promoter on Ni-based SBA-15 catalysts for steam reforming of methane. J. Nat. Gas Chem. 2007, 16, 139-147. [CrossRef]

67. Rakass, S.; Oudghiri-Hassani, H.; Rowntree, P.; Abatzoglou, N. Steam reforming of methane over unsupported nickel catalysts. J. Power Sources 2006, 158, 485-496. [CrossRef]

(c) 2017 by the authors. Licensee MDPI, Basel, Switzerland. This article is an open access article distributed under the terms and conditions of the Creative Commons Attribution (CC BY) license (http:/ / creativecommons.org/licenses/by/4.0/). 


\title{
Article \\ Promoting the Synthesis of Ethanol and Butanol by Salicylic Acid
}

\author{
Jinxin Zou, Lei Wang and Peijun Ji * \\ Department of Chemical Engineering, Beijing University of Chemical Technology, Beijing 100029, China; \\ Jinxin_zhou@outlook.com (J.Z.); wanglei410@outlook.com (L.W.) \\ * Correspondence: jipj@mail.buct.edu.cn; Tel.: +86-010-6442-3254
}

Received: 3 September 2017; Accepted: 22 September 2017; Published: 1 October 2017

\begin{abstract}
Multiwalled carbon nanotubes (MWCNTs) were functionalized with salicylic acid (SA). The copper-cobalt catalyst was impregnated on the SA functionalized MWCNTs (SA-MWCNTs). The catalyst copper-cobalt/SA-MWCNTs was used to catalyze the synthesis of alcohols from synthesis gas. Salicylic acid can promote the synthesis of ethanol and butanol from synthesis gas, thus reducing the synthesis of methanol. This work demonstrated that salicylic acid not only can be used to functionalize carbon nanotubes, but also can enhance the production of ethanol and butanol from synthesis gas. On the other hand, the copper-cobalt catalyst supported on MWCNTs of $30 \mathrm{~nm}$ in diameter can synthesize more ethanol and butanol than supported on MWCNTs of 15 and $50 \mathrm{~nm}$ in diameter, indicating that the diameter of MWCNTs also has an effect on the synthesis of alcohols.
\end{abstract}

Keywords: alcohols; salicylic acid; multiwalled carbon nanotubes; synthesis gas

\section{Introduction}

The conversion of synthesis gas producing higher alcohols as fuel benefits sustainable development [1]. Investigation on catalysts with a higher selectivity and yield has been continuously carried out [2,3]. Researchers are focusing on heterogeneous catalysts rather than on homogeneous ones, as homogeneous catalysts are difficult to recycle. Metals including $\mathrm{Re}, \mathrm{Ru}, \mathrm{Rh}, \mathrm{Co}, \mathrm{Cu}$, and Mo have been extensively used for preparing heterogeneous catalysts for the conversion of synthesis gas [4-8]. Re, Ru, and Rh are noble metals and are effective for catalyzing the synthesis of alcohols [4-7]. However, these metals are expensive. In contrast, $\mathrm{Co}, \mathrm{Cu}$, and $\mathrm{Mo}$ are much cheaper than the noble metals $[8,9]$. The non-noble metal based catalysts are being paid much attention [10-13]. For preparing a heterogeneous catalyst, one or several metals are deposited or impregnated on a support [13]. Particle sizes and the distribution of the particles are affected by catalyst supports.

With a large surface area, good thermal conductivity, strong mechanical strength, and excellent electrical properties, carbon nanotubes (CNTs) have been investigated as supports for preparing Rh, $\mathrm{Co}, \mathrm{Cu}$, and Mo-based catalysts $[5,14,15]$. CO hydrogenation is facilitated by carbon nanotubes and the formation of ethanol is promoted on Rh/CNTs [16]. A relatively higher activity and space yield of higher alcohols can be achieved by the metals supported on carbon nanotubes. The high catalysis efficiency is ascribed to that the metals interacted with carbon nanotubes, on the other hand the metal particles were well distributed on the supports [14]. In addition, carbon nanotubes are capable of adsorbing hydrogen gas. This facilitates the interaction of the hydrogen with the metals.

In this work, multiwalled carbon nanotubes (MWCNTs) have been functionalized with salicylic acid (SA), then copper and cobalt have been deposited on the SA functionalized MWCNTs (SA-MWCNTs). The aim of this research is to investigate the effect of salicylic acid on the synthesis of higher alcohols from synthesis gas. The catalyst copper-cobalt/SA-MWCNTs have been used to catalyze the synthesis of higher alcohols, especially ethanol and butanol, from synthesis gas, 
as ethanol and butanol not only can be used as fuels but also can be used as feedstocks for producing chemicals $[17,18]$. The effect of the diameter of MWCNTs and salicylic acid on the conversion of syngas and the selectivity of higher alcohols, especially ethanol and butanol, have been investigated.

\section{Results and Discussion}

\subsection{Characterization of the Copper-Cobalt/SA-MWCNTs Catalyst}

For the characterization of the copper-cobalt/SA-MWCNTs catalyst, the MWCNTs with a diameter of about $30 \mathrm{~nm}$ were used. Figure 1a shows the transmission electron microscope (TEM) image of purified MWCNTs, which exhibited a smooth surface. In contrast, the catalyst copper-cobalt/SA-MWCNT exhibited nanosize particles on its surface (Figure 1b) due to the deposition of copper-cobalt particles. Figure $1 \mathrm{~b}$ shows that the nanoparticles (copper-cobalt oxides) were well distributed on the surface of SA-MWCNT. The aromatic ring of salicylic acid can have a strong interaction with the wall of MWCNTs. Thus, salicylic acid can be used to functionalize MWCNTs though adsorption. The SA functionalized MWCNTs (SA-MWCNTs) possess functional hydroxyl and carboxyl groups. These groups can interact strongly with copper and cobalt. This facilitates the deposition of copper and cobalt on SA-MWCNTs.

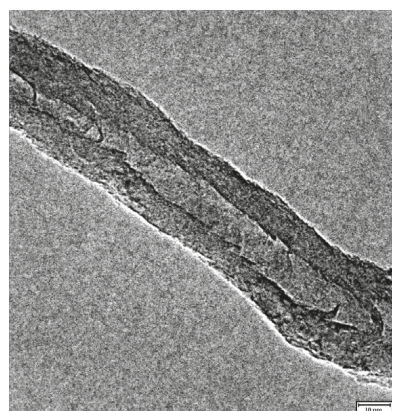

(a)

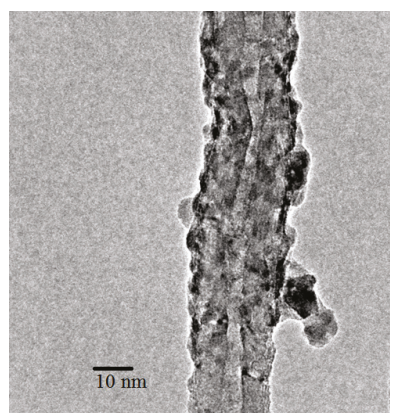

(b)

Figure 1. Transmission electron microscope (TEM) images for purified multiwalled carbon nanotubes (MWCNT) (a) and the catalyst copper-cobalt/SA-MWCNT (b).

The X-ray diffraction (XRD) pattern of the catalyst is shown in Figure 2. Supplementary Materials Figure $\mathrm{S} 1$ shows the XRD patterns for SA-MWCNTs and purified MWCNTs. In Figure 2, peak 1 is for MWCNTs, and the peaks indicated by 2,3, and 4 correspond to crystalline structures of the oxidized metals. Using the JCPDS chemical spectra data bank [19], the peaks were recognized representing $\mathrm{CuO}, \mathrm{Cu}_{\mathrm{x}} \mathrm{Co}_{3-\mathrm{x}} \mathrm{O}$, and $\mathrm{Cu}_{2} \mathrm{O}$, respectively. The XRD pattern indicates the interaction between cobalt and copper species in the catalyst. This is possibly ascribed to that copper and cobalt ions can interact with salicylic acid of SA-MWCNTs, and further interacted with each other.

The spectra of X-ray photoelectron spectroscopy (XPS) for the catalyst are presented in Figure 3a,b. Supplementary Materials Figure S2 shows the XPS spectra for SA-MWCNTs and purified MWCNTs. The parent peak in Figure 3 was deconvoluted into three peaks. Figure 3a shows the XPS spectra for the copper states. The two peaks at 933.3 and $934.6 \mathrm{eV}$ are ascribed to $\mathrm{Cu}(\mathrm{I})$ and $\mathrm{Cu}$ (II) oxides [20], respectively. The peak at $943.2 \mathrm{eV}$ is ascribed to the satellite peak for the $\mathrm{Cu}(\mathrm{II})$ oxide. Figure 3a demonstrates two oxidation states of $\mathrm{Cu}(\mathrm{I})$ and $\mathrm{Cu}(\mathrm{II})$ for copper in the catalyst. Figure $3 \mathrm{~b}$ shows the spectra for different cobalt states. The two peaks at 780 and $781.5 \mathrm{eV}$ are ascribed to $\mathrm{Co}$ (III) oxide and $\mathrm{Co}(\mathrm{II})$ oxide [21], respectively, and the peak at $787.4 \mathrm{eV}$ is due to the satellite peak for the $\mathrm{Co}(\mathrm{II})$ oxide. The results demonstrate the two oxidation states of $\mathrm{Co}(\mathrm{II})$ and $\mathrm{Co}(\mathrm{III})$ for cobalt in the catalyst. Figure 3 further confirms the interaction of copper and cobalt after bring supported on SA-MWCNTs. 
Figure 4 shows the temperature programmed reduction (TPR) profile for copper-cobalt/SA-MWCNTs. Supplementary Materials Figure S3 shows the TPR profile for SA-MWCNTs. In Figure 4, there are two prominent peaks at 278 and $363{ }^{\circ} \mathrm{C}$. They are acribed to the reduction of $\mathrm{Cu}^{2+}$ to $\mathrm{Cu}$. The right shoulder $\left(450-636{ }^{\circ} \mathrm{C}\right)$ is ascribed to the reduction of $\mathrm{Co}^{2+}$ to $\mathrm{Co}$.

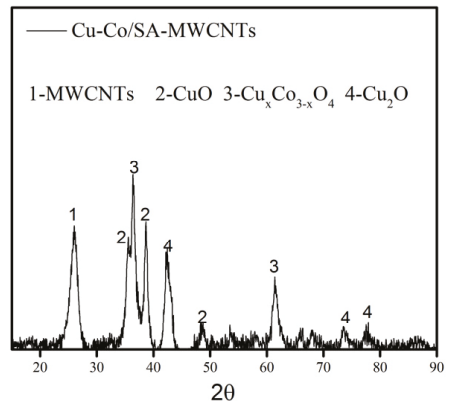

Figure 2. X-ray diffraction (XRD) pattern for the catalyst copper-cobalt/SA-MWCNTs.
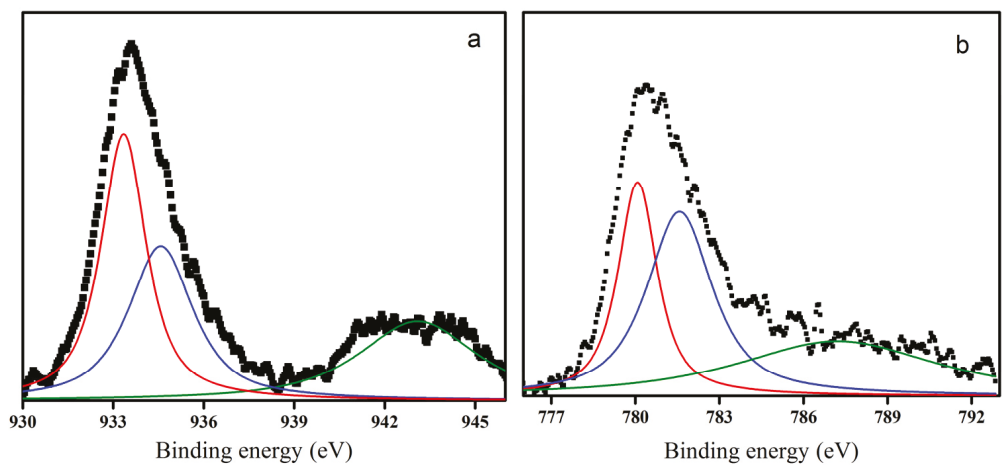

Figure 3. (a) XPS spectra of Cu 2p region of the catalyst; (b) XPS spectra of Co 2p region of the catalyst.

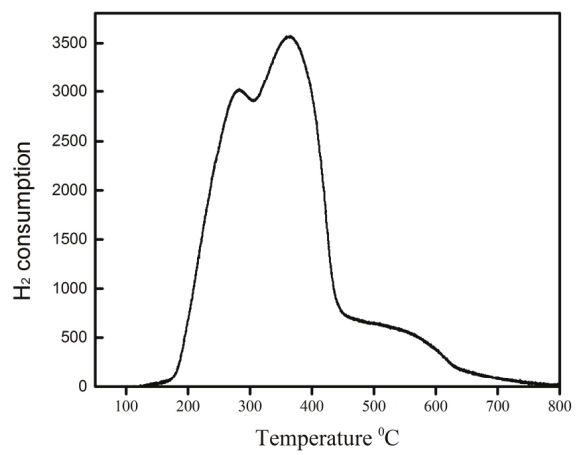

Figure 4. Temperature programmed reduction (TRP) profile for copper-cobalt/SA-MWCNTs.

\subsection{Alcohol Synthesis from Syngas}

Experimental results showed that both the purified MWCNTs and SA-MWCNTs cannot catalyze the reaction of synthesis of alcohols from syngas. That is no alcohols were produced when using 
the carbon nanotubes as catalysts. Prior to evaluating the catalyst copper-cobalt/SA-MWCNTs and studying the efffect of salicylic acid on the production of alcohols, the effect of purification of MWCNTs and diameter of MWCNTs were first investigated. MWCNTs were purified by refluxing in $\mathrm{HNO}_{3}$. Copper-cobalt supported on the purified MWCNTs has exhibited a better conversion of syngas and selectivity of ethanol and butanol than the copper-cobalt supported on the non-purified MWCNTs (Figure 5). The result showed that for preparing copper-cobalt based catalyst, MWCNTs should be purified. The residues on non-purified carbon nanotubes are amorphous carbon [22]. Amorphous carbon on the surface of MWCNTs not only affects the interaction of SA with the wall of MWCNTs, but also affects the deposition of copper and cobalt. This is the reason that using non-purified MWCNTs has exhibited a lower alcohol production than using purified MWCNTs. The effect of the diameter of MWVNTs on the synthesis of alcohols was also investigated (Figure 6). Using the MWCNTs with a diameter of $30 \mathrm{~nm}$, the conversion of syngas (Figure 6a) and selectivity for the alcohols of ethanol + butanol (Figure 6b) are larger than the MWCNTs with diameters of $15 \mathrm{~nm}$ and $50 \mathrm{~nm}$, indicating that the MWCNTs of $30 \mathrm{~nm}$ in diameter are better as supports for preparing the copper-cobalt based catalyst. The diameter of carbon nanotubes can roughly reflect the surface area of carbon nanotubes. Possibly, the carbon nanotubes with a diameter of about $30 \mathrm{~nm}$ can provide an appropriate surface area. When investigating the effect of salicylic acid on the synthesis of alcohols, salicylic acid was added to the reaction solutions according to predetermined weight ratios. Figure 7 shows the effect of salicylic acid on the production of alcohols. With increasing the ratio of salicylic acid to MWCNTs, the conversion of syngas and the selectivity toward to ethanol and butanol are increased. The optimal ratio is 0.3 , at which the syngas conversion and the selectivity toward ethanol and butanol have reached highest values.
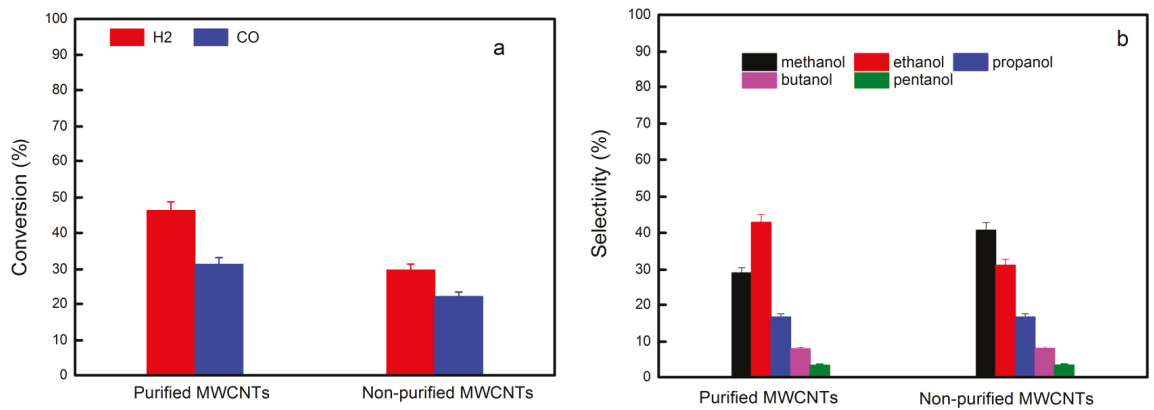

Figure 5. Effect of purification of MWCNTs on the synthesis of alcohols. Conversion of syngas (a) and Selectivity of alcohols (b).
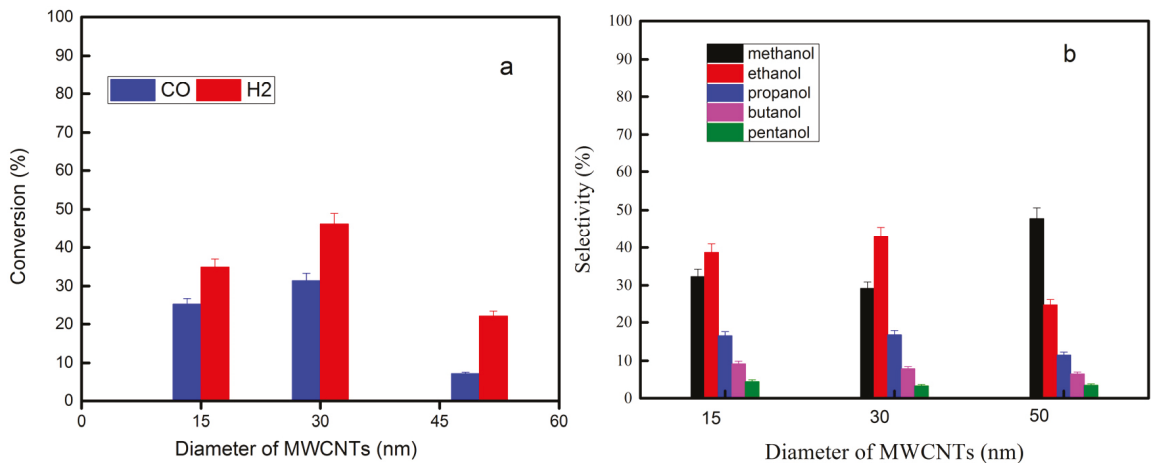

Figure 6. Effect of the diameter of MWCNTs on the syngas conversion (a) and alcohol selectivity (b). 

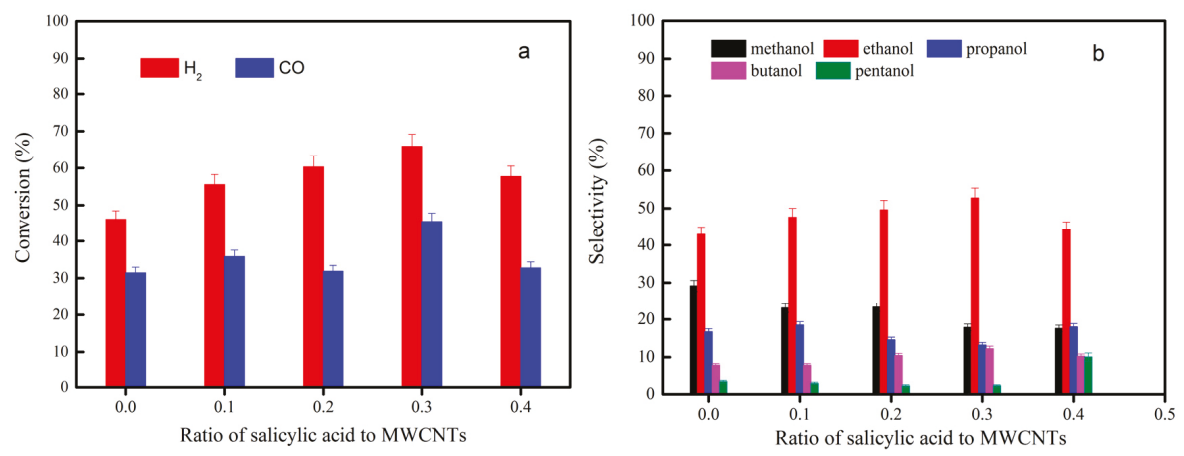

Figure 7. Effect of salicylic acid on the syngas conversion (a) and alcohol selectivity (b).

\section{Experimental Section}

\subsection{Materials}

Multiwalled carbon nanotubes (MWCNTs, diameters $15 \pm 5 \mathrm{~nm}, 30 \pm 10 \mathrm{~nm}, 50 \pm 10 \mathrm{~nm}$ ) were obtained from Nacen Nanotechnologies Inc. (Shenzhen, China). Salicylic acid (SA), ethanol, propanol, butanol, pentanol, $\mathrm{Cu}\left(\mathrm{NO}_{3}\right)_{2} 3 \mathrm{H}_{2} \mathrm{O}$, and $\mathrm{Co}-\left(\mathrm{NO}_{3}\right)_{2} 6 \mathrm{H}_{2} \mathrm{O}$ were obtained from Sinopharm Chemical Reagent Co. (Shanghai, China). All chemicals were of analytical reagent grade.

\subsection{Catalyst Preparation}

MWCNTs were refluxed in $\mathrm{HNO}_{3}(2.5 \mathrm{M})$ at $70{ }^{\circ} \mathrm{C}$ for $10 \mathrm{~h}$. Then, the MWCNTs suspensions were filtered by a $450 \mathrm{~nm}$ polycarbonate membrane. The purified MWCNTs were then mixed with the salicylic acid solutions with different concentrations. The mixtures were sonicated for $20 \mathrm{~min}$. Then, salicylic acid functionalized MWCNTs (SA-MWCNTs) were filtered through a $450 \mathrm{~nm}$ polycarbonate membrane and rinsed with deionized water. The collected SA-MWCNTs were dried at $70{ }^{\circ} \mathrm{C}$ under vacuum.

The catalyst copper-cobalt/SA-MWCNTs was prepared as follows. $800 \mathrm{mg}$ of SA-MWCNTs were dispersed in $200 \mathrm{~mL}$ of deionized water by sonication for $5 \mathrm{~min}$. Then, the solution (115 mL) containing $\mathrm{Cu}\left(\mathrm{NO}_{3}\right)_{2} 3 \mathrm{H}_{2} \mathrm{O}(10.2 \mathrm{mg} / \mathrm{mL})$ and $\mathrm{Co}\left(\mathrm{NO}_{3}\right)_{2} 6 \mathrm{H}_{2} \mathrm{O}(12.3 \mathrm{mg} / \mathrm{mL})$, was added and sonicated for $3 \mathrm{~min}$. After $50 \mathrm{~min}$ incubation, the mixture was dried at $50^{\circ} \mathrm{C}$ under vacuum. The dried catalyst was calcined at $450{ }^{\circ} \mathrm{C}$ for $3 \mathrm{~h}$ by introducing nitrogen at a flow rate of $160 \mathrm{~mL} / \mathrm{min}$. The amounts of copper and cobalt deposited on MWCNTs-SA were determined using atomic absorption spectrometer (Model GGX-6). The concentrations of the metal ions in the stock solutions and in the residue solutions were measured. The difference between the concentrations was used to calculate the amount of copper and cobalt deposited on the support. The copper loading was finally determined to be $0.263 \mathrm{mg} \mathrm{Cu} / \mathrm{mg}$ MWCNTs and that of cobalt was $0.271 \mathrm{mg} \mathrm{Co} / \mathrm{mg}$ MWCNTs.

\subsection{Catalyst Characterization}

SA-MWCNTs and copper-cobalt/SA-MWCNTs were imaged by transmission electron microscopy (TEM) using a Hitachi H-800 system (Shanghai, China). Samples were first dispersed in ethanol by ultrasonication. Then the suspensions were dropped onto a carbon-coated copper grid. The X-ray diffraction (XRD) patterns of the catalysts were obtained with a diffractometer (Rigaku D/Max 2500 $\mathrm{VBZ}+/ \mathrm{PC}$, Gu target at $35 \mathrm{kV}, 30 \mathrm{~mA}$ ) (Shanghai, China). The diffractograms were obtained by scanning at a rate of $2 \theta=1^{\circ} / \mathrm{min}$, the range was from $2 \theta=5^{\circ}$ to $2 \theta=90^{\circ}$. TPD/R/O 1100 (Shanghai, China) was used to record temperature programmed reduction (TPR) spectra for the catalysts, using a gas mixture of $10 \%$ hydrogen in argon. The flow rate was controlled at $30 \mathrm{~mL} / \mathrm{min}$. The samples 
were heated up to $800{ }^{\circ} \mathrm{C}$ at a heating rate of $5{ }^{\circ} \mathrm{C} / \mathrm{min}$. A thermal conductivity detector was used to monitor the sample pretreatment, adsorption, and desorption. A Thermo VG ESCALAB250 X-ray photoelectron spectrometer (Beijing, China) was used to obtain X-ray photoelectron spectroscopy (XPS) spectra for the catalysts. The measurements were carried out at a pressure of $2 \times 10^{-9} \mathrm{~Pa}$ using $\mathrm{Mg}$ $\mathrm{K} \alpha \mathrm{X}$-ray as the excitation source.

\subsection{Alcohol Synthesis from Syngas}

The reactions were carried out in a fixed bed microreactor with a length of $500 \mathrm{~mm}$ and $9 \mathrm{~mm}$ in diameter. A temperature controller was used to control the temperature of the microreactor. Introducing the gases $\mathrm{H}_{2}, \mathrm{CO}$, and $\mathrm{N}_{2}$ at certain rates to the reactor was controlled by mass flow controllers. In all of the reactions, nitrogen was used as an internal standard gas. The copper-cobalt/SA-MWCNTs catalyst (1.5 g) was placed in the reactor bed. The reactor was heated up to $300{ }^{\circ} \mathrm{C}$ at a rate of $3{ }^{\circ} \mathrm{C} / \mathrm{min}$. The catalyst copper-cobalt/SA-MWCNTs was reduced in situ at $300{ }^{\circ} \mathrm{C}$ for $15 \mathrm{~h}$, and the flow rate of $\mathrm{H}_{2}$ was controlled at $50 \mathrm{~mL} / \mathrm{min}$. Then, synthesis gas $\left(\mathrm{H}_{2} / \mathrm{CO}\right.$ ratio of 1.0) with a flow rate of $92 \mathrm{~mL} / \mathrm{min}$ was introduced. The reactor pressure was controlled at $5 \mathrm{MPa}$. The composition of effluent gas stream was determined by an online GC-2014C Shimadzu Gas Chromatograph (Beijing, China), which was equipped with a TCD detector and a Porapak Q column. The produced alcohols were analyzed off-line using a FID detector and a PEG-20 M capillary column.

\section{Conclusions}

Salicylic acid has been used to functionalize multiwalled carbon nanotubes. SA-MWCNTs were used as supports for preparing copper-cobalt based catalyst. The catalyst copper-cobalt/SA-MWCNTs was used to catalyze the synthesis of alcohols from synthesis gas. Salicylic acid can promote the synthesis of ethanol and butanol from synthesis gas, reducing the synthesis of methanol. For preparing the copper-cobalt based catalyst, purified MWCNTs are better than non-purified MWCNTs, and the diameter of MWCNTs also has an effect on the alcohol production. The copper-cobalt catalyst supported on MWCNTs of $30 \mathrm{~nm}$ in diameter can synthesize more ethanol and butanol than supported on MWCNTs of 15 and $50 \mathrm{~nm}$ in diameter, indicating that the diameter of MWCNTs also has an effect on the synthesis of alcohols. This work demonstrated that salicylic acid not only can be used to functionalize carbon nanotubes, but also can enhance the production of ethanol and butanol from synthesis gas.

Supplementary Materials: The following are available online at www.mdpi.com/2073-4344/7/10/295/s1. Figure S1: XRD pattern for purified MWCNTs and SA-MWCNTs, Figure S2: XPS spectra for purified MWCNTs and SA-MWCNTs; Figure S3: TRP profile for SA-MWCNTs.

Acknowledgments: This work was supported by the National Science Foundation of China (21476023).

Author Contributions: Peijun Ji provided the idea and design for the study; Jinxin Zou and Lei Wang performed the experiments; Jinxin Zou drafted the manuscript; Peijun Ji revised it.

Conflicts of Interest: The authors declare no conflict of interest.

\section{References}

1. Xiong, H.; Jewell, L.L.; Coville, N.J. Shaped Carbons As Supports for the Catalytic Conversion of Syngas to Clean Fuels. ACS Catal. 2015, 5, 2640-2658. [CrossRef]

2. Yue, Y.; Ma, X.; Gong, J. An Alternative Synthetic Approach for Efficient Catalytic Conversion of Syngas to Ethanol. Acc. Chem. Res. 2014, 47, 1483-1492. [CrossRef] [PubMed]

3. Kim, T.W.; Kleitz, F.; Jun, J.W.; Chae, H.J.; Kim, C.U. Catalytic conversion of syngas to higher alcohols over mesoporous perovskite catalysts. J. Ind. Eng. Chem. 2017, 51, 196-205. [CrossRef]

4. Wang, J.; Liu, Z.; Zhang, R.; Wang, B. Ethanol Synthesis from Syngas on the Stepped Rh(211) Surface: Effect of Surface Structure and Composition. J. Phys. Chem. C 2014, 118, 22691-22701. [CrossRef] 
5. Surisetty, V.R.; Dalai, A.K.; Kozinski, J. Effect of Rh Promoter on MWCNT Supported Alkali Modified $\mathrm{MoS}_{2}$ Catalysts for Higher Alcohols Synthesis from CO Hydrogenation. Appl. Catal. A 2010, 381, 282-288. [CrossRef]

6. Lopez, L.; Velasco, J.; Montes, V.; Marinas, A.; Cabrera, S.; Boutonnet, M.; Järås, S. Synthesis of Ethanol from Syngas over Rh/MCM-41 Catalyst: Effect of Water on Product Selectivity. Catalysts 2015, 5, 1737-1755. [CrossRef]

7. Subramani, V.; Gangwal, S.K. A Review of Recent Literature to Search for an Efficient Catalytic Process for the Conversion of Syngas to Ethanol. Energy Fuels 2008, 22, 814-839. [CrossRef]

8. Zhao, L.; Li, W.; Zhou, J.; Mu, X.; Fang, K. One-step synthesis of $\mathrm{Cu}$ Co alloy/ $\mathrm{Mn}_{2} \mathrm{O}_{3} \mathrm{Al}_{2} \mathrm{O}_{3}$ composites and their application in higher alcoholsynthesis from syngas. Int. J. Hydrogen Energy 2017, 42, 17414-17424. [CrossRef]

9. Gupta, M.; Smith, M.L.; Spivey, J.J. Heterogeneous Catalytic Conversion of Dry Syngas to Ethanol and Higher Alcohols on Cu-Based Catalysts. ACS Catal. 2011, 1, 641-656. [CrossRef]

10. Zuo, Z.J.; Wang, L.; Yu, L.M.; Han, P.D.; Huang, W. Experimental and Theoretical Studies of Ethanol Synthesis from Syngas over CuZnAl Catalysts without Other Promoters. J. Phys. Chem. C 2014, 118, 12890-12898. [CrossRef]

11. Yang, Q.; Cao, A.; Kang, N.; Ning, H.; Wang, J.; Liu, Z.T.; Liu, Y. Bimetallic Nano Cu-Co Based Catalyst for Direct Ethanol Synthesis from Syngas and Its Structure Variation with Reaction Time in Slurry Reactor. Ind. Eng. Chem. Res. 2017, 56, 2889-2898. [CrossRef]

12. Morrill, M.R.; Thao, N.T.; Shou, H.; Davis, R.J.; Barton, D.G.; Ferrari, D.; Agrawal, P.K.; Jones, K.W. Origins of Unusual Alcohol Selectivities over Mixed MgAl Oxide-Supported $\mathrm{K} / \mathrm{MoS}_{2}$ Catalysts for Higher Alcohol Synthesis from Syngas. ACS Catal. 2013, 3, 1665-1675. [CrossRef]

13. Hensley, J.E.; Lovestead, T.M.; Christensen, E.; Dutta, A.; Bruno, T.J.; McCormick, R. Compositional Analysis and Advanced Distillation Curve for Mixed Alcohols Produced via Syngas on a K-CoMoSx Catalyst. Energy Fuels 2013, 27, 3246-3260. [CrossRef]

14. Surisetty, V.R.; Dalai, A.K.; Kozinski, J. Synthesis of higher alcohols from synthesis gas over Co-promoted alkali-modified $\mathrm{MoS}_{2}$ catalysts supported on MWCNTs. Appl. Catal. A Gen. 2010, 385, 153-162. [CrossRef]

15. Dong, X.; Liang, X.L.; Li, H.Y.; Lin, G.D.; Zhang, P.; Zhang, H.B. Preparation and characterization of carbon nanotube-promoted Co-Cu catalyst for higher alcohol synthesis from syngas. Catal. Today 2009, 147, 158-165. [CrossRef]

16. Sims, A.; Jeffers, M.; Talapatra, S.; Mondal, K.; Pokhrel, S.; Liang, L.; Zhang, X.; Elias, A.L.; Sumpter, B.G.; Meunier, V.; et al. Hydro-deoxygenation of $\mathrm{CO}$ on functionalized carbon nanotubes for liquid fuels production. Carbon 2017, 121, 274-284. [CrossRef]

17. Pomalaza, G.; Capron, M.; Ordomsky, V.; Dumeignil, F. Recent Breakthroughs in the Conversion of Ethanol to Butadiene. Catalysts 2016, 6, 203. [CrossRef]

18. Kim, M.; Park, J.; Kannapu, H.P.R.; Suh, Y.W. Cross-Aldol Condensation of Acetone and n-Butanol into Aliphatic Ketones over Supported Cu Catalysts on Ceria-Zirconia. Catalysts 2017, 7, 249. [CrossRef]

19. Eswaramoorthi, I.; Sundaramurthy, V.; Das, N.; Dalai, A.K.; Adjaye, J. Application of Multi-Walled Carbon Nanotubes as Efficient Support to Nimo Hydrotreating Catalyst. Appl. Catal. A 2008, 339, 187-195. [CrossRef]

20. Contarin, S.; Kevan, L. X-ray Photoelectron Spectroscopic Study of Copper-Exchanged X-and Y-Type Sodium Zeolites: Resolution of Two Cupric Ion Components and Dependence on Dehydration and X-Irradiation. J. Phys. Chem. 1986, 90, 1630-1632. [CrossRef]

21. Ernst, B.; Bensaddik, A.; Hilaire, L.; Chaumette, P.; Kiennemann, A. Study on a Cobalt Silica Catalyst during Reduction and Fischer-Tropsch Reaction: In Situ EXAFS Compared to XPS and XRD. Catal. Today 1998, 39, 329-341. [CrossRef]

22. Rinaldi, A.; Frank, B.; Su, D.S.; Hamid, S.B.A.; Schlögl, R. Facile Removal of Amorphous Carbon from Carbon Nanotubes by Sonication. Chem. Mater. 2011, 23, 926-928. [CrossRef]

(C) 2017 by the authors. Licensee MDPI, Basel, Switzerland. This article is an open access article distributed under the terms and conditions of the Creative Commons Attribution (CC BY) license (http:/ / creativecommons.org/licenses/by/4.0/). 


\title{
Article \\ Conductive Cotton Filters for Affordable and Efficient Water Purification
}

\author{
Fang $\mathrm{Li}^{1,2}$, Qin Xia ${ }^{1}$, Qianxun Cheng ${ }^{1}$, Mingzhi Huang ${ }^{3}$ and Yanbiao Liu ${ }^{1,2, *}$ \\ 1 School of Environmental Science and Engineering, Donghua University, Shanghai 201620, China; \\ lifang@mail.dhu.edu.cn (F.L.); rachel.q.xia@gmail.com (Q.X.); chengqianxun@dhu.edu.cn (Q.C.) \\ 2 Textile Pollution Controlling Engineering Centre of Ministry of Environmental Protection, \\ Shanghai 201620, China \\ 3 Department of Water Resources and Environment, Guangdong Provincial Key Laboratory of Urbanization \\ and Geo-Simulation, Sun Yat-sen University, Guangzhou 510275, China; huangmzh6@mail.sysu.edu.cn \\ * Correspondence: yanbiaoliu@dhu.edu.cn; Tel.: +86-021-67792545
}

Received: 12 September 2017; Accepted: 26 September 2017; Published: 29 September 2017

\begin{abstract}
It is highly desirable to develop affordable, energy-saving, and highly-effective technologies to alleviate the current water crisis. In this work, we reported a low-cost electrochemical filtration device composing of a conductive cotton filter anode and a Ti foil cathode. The device was operated by gravity feed. The conductive cotton filter anodes were fabricated by a facile dying method to incorporate carbon nanotubes (CNTs) as fillers. The CNTs could serve as adsorbents for pollutants adsorption, as electrocatalysts for pollutants electrooxidation, and as conductive additives to render the cotton filters highly conductive. Cellulose-based cotton could serve as low-cost support to 'host' these CNTs. Upon application of external potential, the developed filtration device could not only achieve physically adsorption of organic compounds, but also chemically oxide these compounds on site. Three model organic compounds were employed to evaluate the oxidative capability of the device, i.e., ferrocyanide (a model single-electron-transfer electron donor), methyl orange ( $\mathrm{MO}$, a common recalcitrant azo-dye found in aqueous environments), and antibiotic tetracycline (TC, a common antibiotic released from the wastewater treatment plants). The devices exhibited a maximum electrooxidation flux of $0.37 \mathrm{~mol} / \mathrm{h} / \mathrm{m}^{2}$ for $5.0 \mathrm{mmol} / \mathrm{L}$ ferrocyanide, of $0.26 \mathrm{~mol} / \mathrm{h} / \mathrm{m}^{2}$ for $0.06 \mathrm{mmol} / \mathrm{L} \mathrm{MO}$, and of $0.9 \mathrm{~mol} / \mathrm{h} / \mathrm{m}^{2}$ for $0.2 \mathrm{mmol} / \mathrm{L} \mathrm{TC}$ under given experimental conditions. The effects of several key operational parameters (e.g., total cell potential, CNT amount, and compound concentration) on the device performance were also studied. This study could shed some light on the good design of effective and affordable water purification devices for point-of-use applications.
\end{abstract}

Keywords: conductive cotton filter; carbon nanotubes; low-cost; water purification; gravity feed

\section{Introduction}

One of the grand challenges of 21st century is to provide affordable and clean water to meet human needs. However, rapid industrial development, fast population growth, and global climate change have caused serious water pollution we are currently facing [1]. During the past few decades, numerous efforts have been devoted to developing feasible and sustainable technologies to alleviate the water crisis. To be mentioned are technologies such as membrane separations (e.g., reverse osmosis, RO) [2,3] and advanced oxidation processes (AOPs, e.g., UV-ozone and photocatalysis) [4-8]. Many of them only have limited success. For example, the efficacy of both RO and AOPs could be negatively affected by natural organic matters (NOM) due to membrane fouling and oxidant scavenging $[9,10]$. High energy consumption and high cost also restrict the wide application of other 
promising technologies such as electrodialysis. Therefore, it is highly desirable to develop efficient, affordable, scalable, and energy-saving water treatment devices and technologies.

Electrochemical oxidation has proven to be effective for the decomposition of organic pollutants and the key to this technology is a high-performance electrocatalyst [11-13]. In recent years, carbon-based materials have been widely applied as electrode materials for electrochemical processes. Among these newly developed electrode materials, carbon nanotubes (CNTs) are especially attractive due to their large specific surface area $\left(50-500 \mathrm{~m}^{2} / \mathrm{g}\right)$, excellent electrical conductivity $\left(10^{4}-10^{6} \mathrm{~S} / \mathrm{m}\right)$, and desirable chemical resistivity and stability [14-17]. A highly porous CNT membrane or filter can be easily fabricated via vacuum filtration. These filters can be used for the removal of pollutants by physical adsorption [18]. A electrochemical CNT filter could bring this concept one step further by not only physically adsorb the pollutants but also electrochemically oxide the pollutants in situ [19]. However, most of the reported CNT filters are generally $<10 \mathrm{~cm}$ in diameter and further upscaling of these CNT filters is challenging [20]. Another approach to utilize CNTs is to construct 3D macrostructures. For example, a CNT sponge synthesized by CVD method exhibits excellent rejection performance for several organic solvents and oils with different densities (e.g., ethanol, hexane, ethylene glycol, gasoline, and pump oil) [21]. The harsh synthesis conditions have, however, limited significantly the wide application of this promising design [22]. Also, the CNTs can be used as conductive fillers to boost the electrical conductivity of a designed composite. For example, Schoen et al. previously developed a composite filter material based on three one-dimensional (1D) materials, i.e., silver nanowires, CNTs, and cellulose cotton fibers. The fabricated composite filter could inactivate $>98 \%$ of bacteria within only several seconds via electroporation [23]. To obtain a high-performance CNTs-based composite, an ideal support material is also of significance [24]. Among various support materials reported so far, the cotton-based support has attracted extensive interest from the community due to their desirable characteristics like mechanically and chemically robust, highly porous, readily available, and cheap [25]. Some reported cotton/CNTs composite materials have been used as electrode materials for supercapacitor [26] and sensor applications [27]. To the best of our knowledge, there are very limited reports on the simultaneous adsorption and electro-oxidation of organic pollutants using $3 \mathrm{D}$ conductive cotton filters in a continuous flow filtration design.

In this study, an efficient electrochemical water purification technology based on conductive cotton filters was developed. The composite filter can be fabricated via a facile and scalable dying method. In particular, the CNTs served as adsorbents and electrocatalysts for pollutant adsorption and electrooxidation. The device was operated by gravity feed (Figure 1a), so that the operation cost could be further decreased. The performance of the device was evaluated using three selected model compounds, e.g., ferrocyanide (a model single-electron-transfer electron donor), methyl orange (MO, a common recalcitrant azo-dye found in aqueous environments), and antibiotic tetracycline (TC, a common antibiotic released from the wastewater treatment plants). The effects of key operational parameters on the device performance were systematically studied. The details of this investigation presented below. 

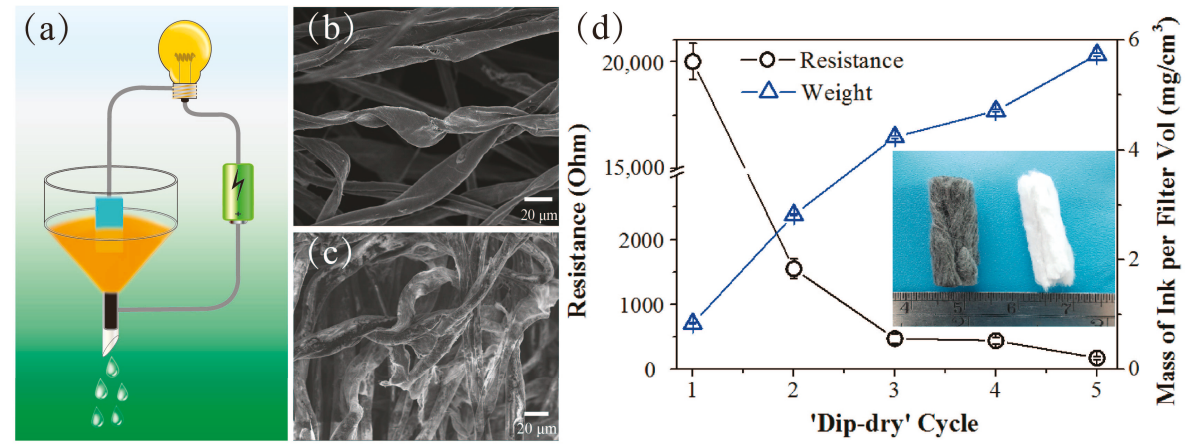

Figure 1. (a) Schematic illustration of the electrochemical cotton filtration device; FESEM images of (b) a pristine cotton and (c) a CNT-coated cotton filter; (d) change of filter resistance and weight of cotton filter as a function of 'dip-dry' cycles. The inset in (d) is digital pictures of a pristine cotton filter (white, right) and a CNT-coated cotton filter (black, left).

\section{Results and Discussion}

\subsection{Fabrication of Conductive Cotton Filters}

The conductive cotton filters were fabricated by a facile dying method. The CNT, SDBS, and cotton are key components for this design. The CNT could serve as high-performance sorbent and electrocatalyst for pollutants adsorption and electrooxidation. It could also facilitate the cotton as a conductive electrode material. Firstly, three different surfactants-polyvinyl pyrrolidone (PVP), sodium dodecyl sulphate (SDS), and SDBS—-were employed to disperse CNTs in DI- $\mathrm{H}_{2} \mathrm{O}$. While only $10 \mathrm{mg} \mathrm{mL}^{-1}$ of SDBS could successfully disperse CNTs and a homogeneous solution can be obtained after 15 min probe sonication treatment. Visible agglomerates can be witnessed when using PVP and SDS of the same concentration. This finding suggests that SDBS is an ideal surfactant to facilitate the dispersion of CNT in aqueous solution via $\pi-\pi$ interaction between the SDBS benzene rings and the aromatic structure of CNTs [28]. Thus, SDBS could provide good protection for CNTs to avoid agglomeration. Moreover, the SDBS could serve as a 'bridge' to connect CNTs with cotton, by bonding CNT with benzene ring moieties and bonding with the hydroxyl-groups of cotton cellulose fibers via van der Waals forces and/or hydrogen. The cotton could serve as macro-porous and low-cost support materials to 'host' these CNTs [29,30]. The CNTs might interwine each other to further enhance the stability of the as-fabricated 3D cotton filters. In a typical fabrication process, $100 \mathrm{mg}$ cotton sample was immersed into a freshly-prepared CNT ink solution (composed of $1.5 \mathrm{mg} / \mathrm{mL}$ CNTs and $10 \mathrm{mg} / \mathrm{mL}$ SDBS), followed by a drying process at $120{ }^{\circ} \mathrm{C}$ for $30 \mathrm{~min}$ to remove water residue. The inset in Figure $1 \mathrm{~d}$ compares the digital pictures of a pristine cotton (white, right) and a CNT-coated cotton (black, left). The black color provides supportive evidence for the successful CNT loading. Furthermore, field-emission scanning electron microscopy (FESEM) technique was employed to provide detailed morphological information. As displayed in Figure 1b,c, the pristine cotton sample showed a twisted and smooth fiber-like structure with an average fiber width of $\sim 50 \mu \mathrm{m}$ and an average pore size of $\sim 110 \mu \mathrm{m}$. However, the surface became much rougher after CNT loading. A magnified image showed that the CNTs were distributed uniformly onto the cellulose fiber surface (Figure S1, Supplementary Materials). This data provides supportive evidence for the successful loading of CNT onto the cotton. Also, by varying the 'dip-dry' cycles and CNT content in the ink, the loading amounts of CNTs onto the cotton as well as the electrical conductivity of the as-fabricated filters can be controlled (Figure S2, Supplementary Materials). For example, as shown in Figure 1d, the accumulated ink mass adsorbed per volume of the cotton increased from $0.85 \mathrm{mg} / \mathrm{cm}^{3}$ (one 'dip-dry' cycle, by dividing the filter weight gain with the filter volume) to $5.74 \mathrm{mg} / \mathrm{cm}^{3}$ (five 'dip-dry' cycles) when using a $1.5 \mathrm{mg} / \mathrm{mL}$ 
CNT ink. This indicates a quantitative sorption of conductive nanotubes onto the cotton surface. Meanwhile, as expected, the sheet resistance of the cotton filter samples decreased significantly from $20,000 \pm 850 \Omega$ to $170 \pm 30 \Omega$, mainly due to the continuous increase of highly conductive CNTs within the cotton filters. As a simple demonstration of the electrical conductivity, an LED lamp connected to a direct current (DC) power supply ( $4.0 \mathrm{~V}$ applied voltage) can be easily powered through the as-fabricated conductive cotton filters (Figure S3, Supplementary Materials). Given that the CNT loading amount became rather limited over five 'dip-dry' cycles, hence, this number was chosen for all subsequent experiments.

\subsection{Electron Transfer}

The electrochemical performance of a conductive cotton filter was firstly evaluated using ferrocyanide $\left(\mathrm{F}_{\mathrm{e}}(\mathrm{CN})_{6}^{4-}\right)$ as model electron donor. The unique characteristics of single-electron transfer and negligible adsorption of ferrocyanide make it suitable candidate for electron transfer experiment [31,32]. The oxidation of ferrocyanide can be described by Equation (1).

$$
\mathrm{Fe}(\mathrm{CN})_{6}^{3-}+\mathrm{e}^{-} \rightarrow \mathrm{Fe}(\mathrm{CN})_{6}^{4-}, E_{0}=0.139 \mathrm{~V} \text { vs. } \mathrm{Ag} / \mathrm{AgCl}
$$

Figure 2 shows the change of electrooxidation flux of ferrocyanide as a function of applied anode potential and ferrocyanide concentrations. At an anode potential range of $0.15-0.4 \mathrm{~V}(\mathrm{vs} . \mathrm{Ag} / \mathrm{AgCl}$ ), a linear relationship between electrooxidation flux of ferrocyanide and applied anode potential can be observed for all influent concentrations. Voltage-independent plateaus were achieved for all cases when anode potential above $0.4 \mathrm{~V}$ (vs. $\mathrm{Ag} / \mathrm{AgCl}$ ). This finding indicates the mass transport limitations. At an anode potential of $0.4 \mathrm{~V}$, the electrooxidation rate of ferrocyanide was $0.037,0.106,0.145$, and $0.373 \mathrm{~mol} / \mathrm{h} / \mathrm{m}^{2}$ for $0.2,0.5,1.0$, and $5.0 \mathrm{mmol} / \mathrm{L}$ ferrocyanide, respectively. The electrooxidation flux increased up to 10-fold by increasing the influent concentration and interval electrode convection. This value was lower than a reported graphene-CNT composite filter (e.g., 15-fold) [32]. The reason may be due to a much thinner thickness of the graphene-CNT filter $(10 \mu \mathrm{m}$ vs. $2.5 \mathrm{~cm})$ and, hence, an increased transport resistance of ferrocyanide ions in the current design. As only one electron transfer was involved to oxide ferrocyanide to ferricyanide, the maximum electron transfers at an applied anode potential of $0.4 \mathrm{~V}$ (vs. Ag/ AgCl) were calculated to be $1 \times 10^{14}, 3 \times 10^{14}, 1 \times 10^{15} \mathrm{e} / \mathrm{s}$ for $0.2,0.5,1.0$, and $5.0 \mathrm{mmol} / \mathrm{L}$ ferrocyanide, respectively.

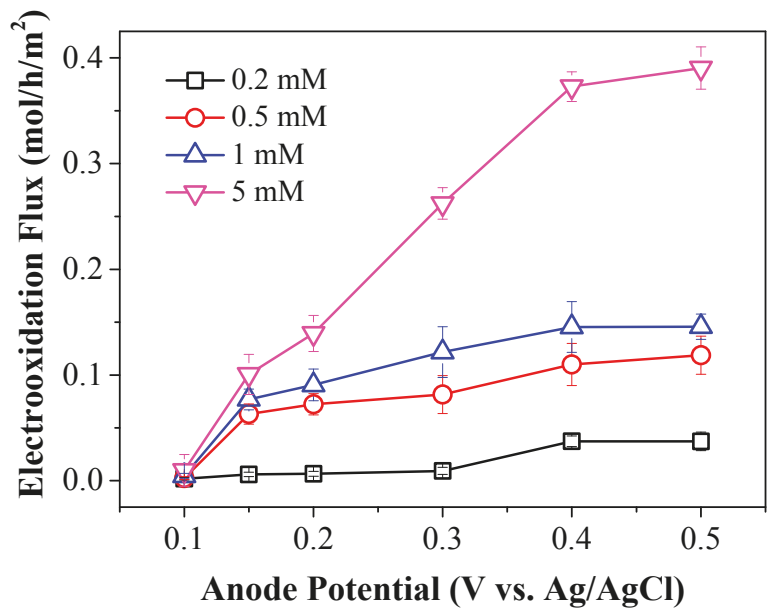

Figure 2. Concentration-dependent oxidation of ferrocyanide using an electrochemical cotton filter. Experimental conditions: $[\mathrm{CNT}]_{\text {ink }}=1.5 \mathrm{mg} / \mathrm{mL},\left[\mathrm{Na}_{2} \mathrm{SO}_{4}\right]=10 \mathrm{mmol} / \mathrm{L}$, and flow rate $=1.5 \mathrm{~mL} / \mathrm{min}$. 


\subsection{Performance of the Cotton Filter towards MO Removal}

To further evaluate the feasibility of the as-fabricated conductive cotton filters for organic pollutants degradation, methyl orange (MO) was selected as a typical recalcitrant organic compound in aqueous environment. Firstly, the MO sorption process on a conductive cotton filter was examined by breakthrough curve analysis in the absence of electrochemistry. As displayed in Figure S4 (Supplementary Materials), the sorption behavior of cotton filters fabricated with different CNT concentrations varies significantly. The effluent $\mathrm{MO}$ concentration flow through the cotton filters fabricated by a $0.5 \mathrm{mg} / \mathrm{mL}$ and a $1.0 \mathrm{mg} / \mathrm{mL}$ CNT ink solution increased sharply at the initial 5-10 min and then maintained a stable concentration. For the cotton filter fabricated by a $1.5 \mathrm{mg} / \mathrm{mL} \mathrm{CNT}$ ink, the effluent increased at a gentle slope in the first $18 \mathrm{~min}$ and then showed a steeper increase before breakthrough occurs. The cotton filter MO sorption capacity was $53.5 \mathrm{mg} / \mathrm{g}, 1.8$ times higher than a pure CNT filter reported previously [33]. This increased sorption capacity observed in this study are likely due to the contribution of MO sorption by the cotton support. However, the limited area of the cotton filter results in an absolute sorption capacity that is relatively low and in turn MO breakthrough occurs within $1 \mathrm{~h}$. Thus, further experiments were conducted to electrochemically degrade the adsorbed $\mathrm{MO}$ molecules and to regenerate adsorption sites.

The electrooxidative filtration of MO was evaluated as a function of total cell potential and CNT loading onto the cotton filters as displayed in Figure 3a. The MO oxidation flux increased with increasing total cell potential to a maximum of $0.26 \pm 0.02 \mathrm{~mol} / \mathrm{h} / \mathrm{m}^{2}$ at $3.5 \mathrm{~V}$ for the cotton filter fabricated using a $1.5 \mathrm{mg} / \mathrm{mL}$ CNT ink. Further increase of the total cell potential to $4.0 \mathrm{~V}$ did not improve the device performance due to other side reactions (e.g., water oxidation) occurred at this condition, resulting in the loss of electrochemical activity. Moreover, increased electrolytic gas bubble formation at a higher potential may block some active sites on the filter surface, or even degrade the filter integrity to some extent. It is of note that the optimal total cell potential of $3.5 \mathrm{~V}$ for $\mathrm{MO}$ electrooxidation was higher than that of a CNT electrochemical filter (e.g., $2.5 \mathrm{~V})$. This difference may be due to an increased filter resistance $(\sim 175 \Omega$ vs. $\sim 50 \Omega$ ) and a reduced CNT content ( 7 mg vs. $30 \mathrm{mg}$ ) of the cotton filters reported in this work. The increased resistance of the as-fabricated cotton filters may increase the resistance for the transport of electrons, so that an increased overpotential may be needed to overcome this barrier. Moreover, the CNT content in the ink is another important factor for the electro-oxidative process. As expected, the MO electrooxidation flux was increased with CNT amount for all cases. For example, at a given total cell potential of $3.5 \mathrm{~V}$, the $\mathrm{MO}$ electrooxidation flux was $0.15,0.23$, and $0.26 \mathrm{~mol} / \mathrm{h} / \mathrm{m}^{2}$ for CNT ink concentration of $0.5 \mathrm{mg} / \mathrm{mL}, 1.0 \mathrm{mg} / \mathrm{mL}$, and $1.5 \mathrm{mg} / \mathrm{mL}$, respectively. Since more $\mathrm{CNT}$ loading will lead to more active sites for the sorption and electrooxidation of MO molecules and increase the electrical conductivity of the as-fabricated filters (or decreased electron transport resistance). The $0.26 \mathrm{~mol} / \mathrm{h} / \mathrm{m}^{2}$ electrooxidation flux of $\mathrm{MO}$ in a single pass through the cotton filter is of note since the device was running by gravity feed. These data suggest the potential of a cost-effective, energy-saving, and facile method for the efficient removal of organic compounds from water.

Open circuit potential measurements over a range of cell potentials for the device was conducted with a cotton filter anode, a Ti cathode, $[\mathrm{MO}]_{\text {in }}=0.06 \mathrm{mmol} / \mathrm{L}$ and $\left[\mathrm{Na}_{2} \mathrm{SO}_{4}\right]=10 \mathrm{mmol} / \mathrm{L}$. As shown in Figure $3 \mathrm{~b}$, a total cell potential of $3.0 \mathrm{~V}$ was required to achieve a high enough anode potential $(>+0.8 \mathrm{~V}$ vs. $\mathrm{Ag} / \mathrm{AgCl}$ ) for $\mathrm{MO}$ oxidation as determined by the cyclic voltammogram measurement [33]. At a total cell potential of $4 \mathrm{~V}$, the anode potential was as high as $1.5 \mathrm{~V}$ vs. Ag/ AgCl which has exceeded the water oxidation potential of $1.23 \mathrm{~V}$ (vs. standard hydrogen electrode, SHE). This finding supports the change of $\mathrm{MO}$ electrooxidation flux with total cell potential as shown in Figure 3a.

The re-usability of the cotton filters is of great significance towards practical applications. Hence, additional experiments to evaluate the regeneration performance of the cotton filters were conducted. As shown in Figure 3c, the cotton filter exhibits an initial MO oxidation flux of $0.27 \mathrm{~mol} / \mathrm{h} / \mathrm{m}^{2}$ and a MO removal efficiency of $>98 \%$ in the first $30 \mathrm{~min}$, which then slightly decreased in the following few hours. The decrement in MO oxidation can be due to the MO oxidation byproducts and/or 
precipitates accumulated onto the filter surface. This hypothesis was further confirmed by the SEM characterization results of the cotton filter after running. As shown in the inset, certain polydispersed nanoparticles and/or precipitates were observed on the cotton surface that might eventually foul the cotton filter. These materials could be organic polymers and/or inorganic sodium persulfate [34]. The build-up of polymer/precipitates may cause some adverse effects on the oxidative performance of the filter by blocking the active centers of the filter, significantly increasing resistance to water and electron transfer, thus reducing the reaction kinetics and electrochemistry. To eliminate the contribution of MO degradation by the possibly produced persulfate precipitates, another control experiment was conducted by mixing $0.1-5 \mathrm{mmol} / \mathrm{L}$ persulfate with $0.06 \mathrm{mmol} / \mathrm{L} \mathrm{MO}$. The results show that the $\mathrm{MO}$ concentration changed negligible $(<0.4 \%)$ for all cases. This finding supports the conclusion that the MO removal was mainly due to the electrooxidation by the filter. A $100 \mathrm{~mL}$ of $1 \mathrm{~mol} / \mathrm{L} \mathrm{HCl}$ : ethanol mixture $(50: 50 \mathrm{vol} \%)$ washing of the cotton filter was found to be effective to restore the initial electrooxidation flux. An average electrooxidation flux of $0.2 \mathrm{~mol} / \mathrm{h} / \mathrm{m}^{2}$ was achieved for the next two running cycles. Also, the lack of breakthrough during the $8 \mathrm{~h}$ continuous running at $3.5 \mathrm{~V}$ total cell potential suggests that the primary removal mechanism during electrochemical filtration is oxidative degradation rather than physical adsorption. These data suggest the potential of a cost-effective, energy-saving, and facile method for the efficient removal of organic compounds from water.

(a)

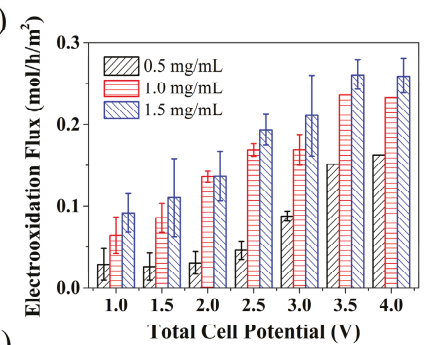

(b)

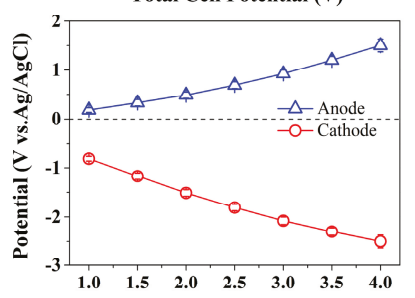

(c)

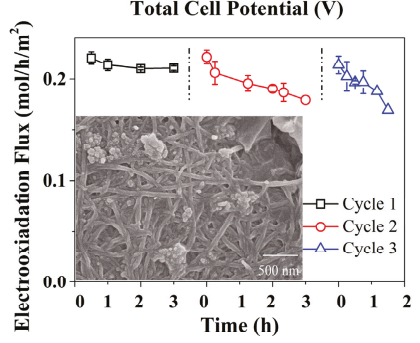

Figure 3. MO electrooxidation flux (a) and open-circuit potential (b) as a functional total cell potential. Experimental conditions: $[\mathrm{MO}]_{\text {in }}=0.06 \mathrm{mmol} / \mathrm{L},\left[\mathrm{Na}_{2} \mathrm{SO}_{4}\right]=10 \mathrm{mmol} / \mathrm{L},[\mathrm{CNT}]_{\text {ink }}=1.5 \mathrm{mg} / \mathrm{mL}$, and flow rate $=1.5 \mathrm{~mL} / \mathrm{min}$; The regeneration performance of a cotton filter. The filter was washed with a $100 \mathrm{~mL}$ of $1 \mathrm{~mol} / \mathrm{L} \mathrm{HCl}$ : ethanol mixture (50:50 vol \%) without electrochemistry before a next running cycle. The inset in (c) is SEM image of a cotton filter after $4 \mathrm{~h}$ of continuous operation. 


\subsection{Performance of the Cotton Filter towards TC Removal}

The $0.26 \mathrm{~mol} / \mathrm{h} / \mathrm{m}^{2}$ electrooxidation flux of $\mathrm{MO}$ in a single pass through the cotton filter is of note since the device was running under gravity feed. This also reveals the potential of a low-cost and energy-saving route for water purification. To further explore the potential for the treatment of other emerging organic contaminants, the as-fabricated conductive cotton filter was further challenged with a typical emerging contaminant, i.e., antibiotic tetracycline (TC, $0.2 \mathrm{mmol} / \mathrm{L}$ ). TC is one of the commonly detected antibiotics in water and the wastewater treatment plant was considered as one major point sources for TC pollution. Control experiments in the absence of applied cell potential can only adsorb physically the TC molecules until all sorption sites were occupied after $70 \mathrm{~min}$, i.e., adsorption saturation (Figure S5, Supplementary Materials). Figure 4a compares the TC electrooxidation flux as a function of total cell potential. The TC electrooxidation flux increased with increasing total cell potential from $1.0 \mathrm{~V}$ to $2.0 \mathrm{~V}$ with an electrooxidation flux of $0.9 \pm 0.1 \mathrm{~mol} / \mathrm{h} / \mathrm{m}^{2}$ for the cotton filter fabricated with a $1.5 \mathrm{mg} / \mathrm{mL}$ CNT ink. The TC electrooxidation flux changed negligibly with further increase in the total cell potential until 3.0 V. This finding can be explained by the open-circuit measurements as displayed in Figure $4 \mathrm{~b}$. At a total cell potential of $1.5 \mathrm{~V}$, the anode potential was determined to be $0.7 \pm 0.06 \mathrm{~V}$ (vs. $\mathrm{Ag} / \mathrm{AgCl}$ ), which is high enough to oxide $\mathrm{TC}$ molecules (e.g., dimethylamine group of $\mathrm{TC}$ at $0.5 \mathrm{~V}$ vs. $\mathrm{Ag} / \mathrm{AgCl}$ ) [35]. It is of note that the maximum TC electrooxidation kinetics was $2.0 \mathrm{~V}$, which was quite different with that of MO. For example, an optimal total cell potential for MO electrooxidation was $3.5 \mathrm{~V}$, while only $2.0 \mathrm{~V}$ was required for TC electrooxidation. This finding could be explained by their different molecular structures and physicochemical properties. TC is an amphoteric molecule with multiple functional groups/moieties (e.g., phenol, amino, alcohol, diketone). Moreover, compared with MO, the TC molecules tend to adsorb onto the $s p^{2}$-conjugated CNT sidewalls due to its relatively strong van der Waals, $\pi-\pi$, and cation $-\pi$ interactions [35]. A recent report has demonstrated that TC has significant 3D molecular curvature and tend to adsorb onto the CNT surface until monolayer formation [35]. The LC-MS characterization results suggest that the characteristic TC peak observed in the influent solution was decreased by $63 \%$ and $96 \%$ at a total cell potential of $1.0 \mathrm{~V}$ and $2.0 \mathrm{~V}$, respectively, indicates that the parent TC molecules has been degraded. TC was spiked into real surface water samples to further challenge the cotton filter. The results show that the TC electrooxidation flux decreased by $35 \%$ compared with that of model electrolyte solution. The lower conductivity $(1408 \mu \mathrm{S} / \mathrm{cm}$ vs. $6289 \mu \mathrm{S} / \mathrm{cm})$ and complex natural reservoir organic matrix (background chemical oxygen demand, $\mathrm{COD}=47.1 \mathrm{mg} / \mathrm{L}$ ) may account for the significant decrease in electrooxidation kinetics. The energy consumption of the developed electrochemical cotton filter technology for TC treatment is calculated at an applied total cell potential of $2.0 \mathrm{~V}$, by assuming 31 electrons transferred per TC molecule, to be $1.2 \mathrm{kWh} / \mathrm{kg}$ COD (The COD used here is the theoretical COD). This value is comparative with state-of-the-art electrochemical oxidation processes with an energy consumption in the range of $5-100 \mathrm{kWh} / \mathrm{kg}$ COD [36-39]. Alternatively, the energy per volume treated is calculated to be only $0.05 \mathrm{kWh} / \mathrm{m}^{3}$. The gravity feed could further save the pumping energy which was constantly required for conventional membrane separation processes, especially for some high pressure-driven membrane separation process like RO. Of course, the energy consumed for MO electrooxidation should be higher than that of TC, since a larger total cell potential will be required to achieve efficient MO degradation (e.g., $3.5 \mathrm{~V}$ vs. 2.0 V). The energy per MO volume treated is calculated to be $0.19 \mathrm{kWh} / \mathrm{m}^{3}, 3.7$ times higher than that of TC. The experimental results have demonstrated that the cotton filter clogging caused by the accumulation of precipitates/polymers may greatly limit the practical applications of the developed device towards the treatment of real water samples. Hence, further studies will be necessary to enhance the electrooxidative capability and to address the filter regeneration issues. Additionally, the ubiquitous presence of dissolved natural organic matters may negatively affect the efficacy and efficiency of the device toward practical applications. Since there are only limited active sites available on the cotton filter surface, the pollutant concentration effect on the device performance also deserves future investigation. Especially for the treatment of trace 
organic contaminants, e.g., antibiotic tetracycline, their environmental concentration should be taken into consideration in future studies.
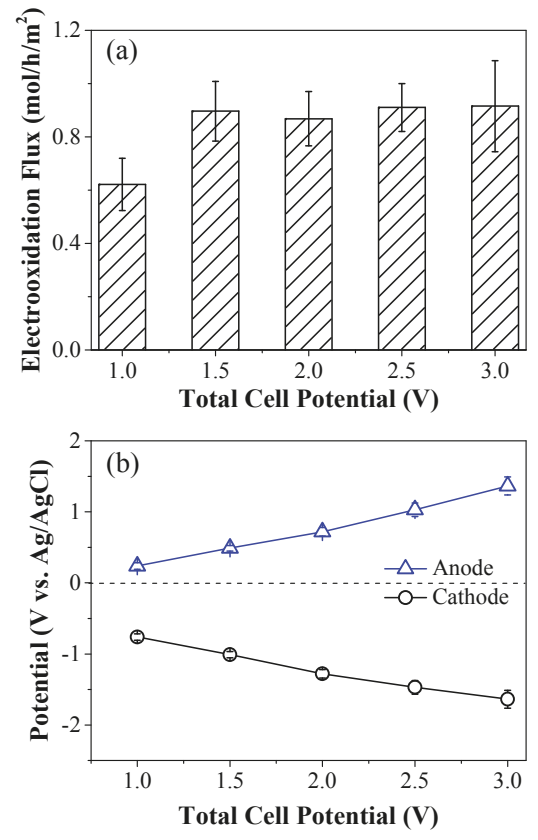

Figure 4. TC electrooxidation flux (a) and open-circuit potential (b) as a functional total cell potential. Experimental conditions: $[\mathrm{CNT}]_{\text {ink }}=1.5 \mathrm{mg} / \mathrm{mL},[\mathrm{TC}]_{\text {in }}=0.2 \mathrm{mmol} / \mathrm{L},\left[\mathrm{Na}_{2} \mathrm{SO}_{4}\right]=10 \mathrm{mmol} / \mathrm{L}$, and flow rate $=1.5 \mathrm{~mL} / \mathrm{min}$.

\section{Materials and Methods}

\subsection{Materials}

Multiwalled carbon nanotube networks (CNTs, $<\mathrm{d}>=15 \mathrm{~nm}$ and $<\mathrm{l}>=100 \mu \mathrm{m}$ ) were purchased from NanoTechLabs (Buckeye Composites, Yadkinville, NC, USA). Medical absorbent cottons were purchased from supermarket. Sodium sulfate $\left(\mathrm{Na}_{2} \mathrm{SO}_{4}, \geq 99.0 \%\right)$, methyl orange $(\mathrm{MO}$, $\mathrm{C}_{14} \mathrm{H}_{14} \mathrm{~N}_{3} \mathrm{NaO}_{3} \mathrm{~S}$, ACS reagent, dye content 85\%), tetracycline (TC, $\mathrm{C}_{22} \mathrm{H}_{24} \mathrm{~N}_{2} \mathrm{O}_{8} \cdot \times \mathrm{H}_{2} \mathrm{O}, \geq 98.0 \%$ ), hydrochloric acid $(\mathrm{HCl}, \geq 37 \%)$, ethanol (anhydrous, denatured), potassium hexacyanoferrate (II) trihydrate $\left(\mathrm{K}_{4} \mathrm{Fe}(\mathrm{CN})_{6} \cdot 3 \mathrm{H}_{2} \mathrm{O}\right)$, and sodium dodecyl benzene sulfonate (SDBS) were purchased from Sigma-Aldrich (St. Louis, MO, USA). Deionized water used in the experiments was produced by using a Milli-Q ultrapure water system (Millipore, Billerica, MA, USA).

\subsection{Fabrication of Conductive Cotton Filter}

Firstly, the CNT ink was prepared by adding a certain amount of CNTs $(0.5-1.5 \mathrm{mg} / \mathrm{mL})$ and a $10 \mathrm{mg} / \mathrm{mL}$ SDBS to deionized water. The mixture was then bath sonicated (KQ3200E bath sonicator, Kunshan, China) for $10 \mathrm{~min}$ and probe sonicated (Branson SFX150 sonifier, St. Louis, MO, USA) for another $15 \mathrm{~min}$ to improve the CNT dispensability in water. A facile dying method was used to load CNTs onto the cellulose fiber-based cotton samples. In a typical fabrication process, $100 \mathrm{mg}$ cotton sample was immersed into a freshly-prepared CNT ink for $5 \mathrm{~min}$, following $30 \mathrm{~min}$ of drying in an oven (at $120^{\circ} \mathrm{C}$ ). Before drying, the cotton sample was pressed with finger to remove extra SDBS surfactant until no visible bubbles were observed and washed with DI water. Due to the strong 
absorption capability, the CNT ink was quickly coated onto the cotton. By varying the 'dip-dry' cycles and CNT content in the ink, different amounts of CNTs can be loaded onto the cellulose fibers of cotton. We assume the CNT ink coated uniformly onto the cotton surface. The mass of the loaded CNTs can be obtained from the mass difference before and after the dipping and drying of the cotton samples. The loading of CNTs onto the cotton could significantly boost the electrical conductivity of the as-fabricated filter. Finally, the conductive cotton filters (with $2.0 \mathrm{~cm}$ in the funnel and $0.5 \mathrm{~cm}$ connect to the power supply) were transferred into a plastic funnel (bottom diameter of $0.8 \mathrm{~cm}$, funnel volume of $85 \mathrm{~mL}$ ) for electrochemical filtration applications.

\subsection{Electrochemical Filtration Device}

The electrochemical filtration experiments were conducted using a conductive cotton filter (with a length of $2.5 \mathrm{~cm})$ as anode, a Ti foil $(2 \times 5 \mathrm{~cm})$ as cathode, and $10 \mathrm{mmol} / \mathrm{L} \mathrm{Na}_{2} \mathrm{SO}_{4}$ as background electrolyte. The solution passed through the conductive cotton filter by only gravity feed. In a typical experiment of electrochemical filtration of methyl orange (MO), $0.06 \mathrm{mmol} / \mathrm{L} \mathrm{MO}$, and $10 \mathrm{mmol} / \mathrm{L}$ $\mathrm{Na}_{2} \mathrm{SO}_{4}$ were first flowed through the filter in the absence of applied voltage to achieve adsorption saturation of the filter, which could exclude the contribution of physical sorption to pollutants removal. Unless noted, the volume treated was $200 \mathrm{~mL}$. Due to the limited space in the funnel, the solution was topped up every $15 \mathrm{~min}$ to maintain the 'driving force' (i.e., gravity). Then, an Agilent E3646A DC power supply was used to provide the voltage to induce the electro-oxidation of the pollutants. The effluent was collected at specific time intervals. Water flux was measured in a similar way by replacing the organic solution with $\mathrm{DI}-\mathrm{H}_{2} \mathrm{O}$. When challenging with the organic solution, the flux will decrease to some extent due to the accumulation of precipitates and/or polymers on the filter surface. To evaluate the regeneration performance of the conductive cotton filters, a $100 \mathrm{~mL}$ of ethanol and $1 \mathrm{~mol} / \mathrm{L} \mathrm{HCl}$ mixture (50:50 vol \%) was passed through the filter without electrochemistry after the MO electrochemical filtration. This could help to remove the organic residues from the filter surface. The oxidation flux was calculated by the Equation (2)

$$
\text { Elextrooxidation Flux }=\frac{\left(C_{\text {in }}-C_{\text {out }}\right)(\mathrm{mol} / \mathrm{L}) \times \text { flow rate }(\mathrm{L} / \mathrm{h})}{\text { effective filter area }\left(\mathrm{m}^{2}\right)}
$$

where $C_{\text {in }}$ is the initial influent compound concentration and $C_{\text {out }}$ is the compound concentration after passing through the cotton filter. The effluent samples were collected after applying the external potential for $20 \mathrm{~min}$. All these measurements were repeated at least three times for reproducibility.

\subsection{Characterizations}

The morphology of the as-fabricated conductive cotton filters was examined by a JEOL JSM-6700F filed-emission scanning electron microscopy (FESEM) (Carl Zeiss Supra55VP, Oberkochen, Germany). Micrographs were analyzed with ImageJ software (Bethesda, MD, USA) to get the average interfiber pore size of the as-fabricated filters, which was obtained from the average of at least 100 measurements from three FESEM images. The electrochemical characterizations of the samples were conducted on a CHI660E electrochemical workstation (Shanghai Chenhua Instrument Co. Ltd., Shanghai, China) using a three-electrode system. A conductive cotton filter, an $\mathrm{AgCl} / \mathrm{Ag}$ electrode and a Ti foil served as working electrode, reference electrode and counter electrode, respectively. For the open-circuit voltage measurements, an Agilent E3646A DC power (Santa Clara, CA, USA) supply was used to provide an applied voltage of 0 to $4 \mathrm{~V}$. The concentration of ferricyanide and methyl orange (MO) was determined by a Shimadzu UV-1800 UV-vis photometer (Kyoto, Japan) at their maximum absorbance values of $425 \mathrm{~nm}$ and $462 \mathrm{~nm}$, respectively. The concentration of tetracycline (TC) was determined by using an Agilent 1290 UHPLC system (Waldbronm, Germany) coupled with 6540 quadrupole-time of flight (Q-TOF) mass detector equipped with a dual jet stream electrospray ionization source. 


\section{Conclusions}

In conclusion, an affordable and effective electrochemical cotton-based filtration device for water treatment was developed. The CNT amount, total cell potential and surfactant were identified to be key parameters affecting the device performance. Moreover, the efficient electrooxidation of ferrocyanide, methyl orange, and antibiotic tetracycline suggest that the electrochemical cotton filters have good potential for water purification applications. Overall, the experiment results presented in this study quantitatively exemplified the advantages of a conductive cotton filter for water purification in a low-cost and energy-saving manner.

Supplementary Materials: The following are available online at www.mdpi.com/2073-4344/7/10/291/s1; Figure S1: FESEM images of conductive cotton filters fabricated using $[\mathrm{CNT}]_{\text {ink }}=1.5 \mathrm{mg} / \mathrm{mL}$; Figure S2: Variation of filter resistance of as-fabricated cotton filters with CNT ink concentrations; Figure S3: Demonstration of a CNT cotton filter acts as a conducting path in the emission of an LED indicative lamp under applied voltage of $4 \mathrm{~V}$; Figure S4: MO breakthrough curve under conditions of $[\mathrm{MO}]_{\text {in }}=0.06 \mathrm{mmol} / \mathrm{L},\left[\mathrm{Na}_{2} \mathrm{SO}_{4}\right]=10 \mathrm{mmol} / \mathrm{L}$, and flow rate $=1.5 \mathrm{~mL} / \mathrm{min}$; Figure S5. TC breakthrough curves under conditions of $[\mathrm{TC}]_{\text {in }}=0.2 \mathrm{mmol} / \mathrm{L},\left[\mathrm{Na}_{2} \mathrm{SO}_{4}\right]=$ $10 \mathrm{mmol} / \mathrm{L}$, and flow rate $=1.5 \mathrm{~mL} / \mathrm{min}$.

Acknowledgments: This work was financially supported by the National Natural Science Foundation of China (No.51478099 and No. 51208206) and National Key Research and Development Program of China (No. 2016YFC0400501). Y.L. thanks Donghua University for the start-up grant (No. 113-07-005710).

Author Contributions: F.L. and Y.B.L. conceived and designed the experiments; Q.X. and Q.C. performed the experiments; M.Z.H. and Q.X. analyzed the data; Y.B.L. wrote the paper.

Conflicts of Interest: The authors declare no conflict of interest.

\section{References}

1. Zodrow, K.R.; Li, Q.; Buono, R.M.; Chen, W.; Daigger, G.; Dueñas-Osorio, L.; Elimelech, M.; Huang, X.; Jiang, G.; Kim, J.-H.; et al. Advanced materials, technologies, and complex systems analyses: Emerging opportunities to enhance urban water security. Environ. Sci. Technol. 2017, 51, 10274-10281. [CrossRef] [PubMed]

2. Zhang, R.; Liu, Y.; He, M.; Su, Y.; Zhao, X.; Elimelech, M.; Jiang, Z. Antifouling membranes for sustainable water purification: Strategies and mechanisms. Chem. Soc. Rev. 2016, 45, 5888-5924. [CrossRef] [PubMed]

3. Madaeni, S.S.; Ghaemi, N.; Rajabi, H. 1-Advances in Polymeric Membranes for Water Treatment, in Advances in Membrane Technologies for Water Treatment; Woodhead Publishing: Oxford, UK, 2015; pp. 3-41.

4. Liu, Y.; Zhang, Y.; Wang, L.; Yang, G.; Shen, F.; Deng, S.; Zhang, X.; He, Y.; Hu, Y.; Chen, X. Fast and large-scale anodizing synthesis of pine-cone $\mathrm{TiO}_{2}$ for solar-driven photocatalysis. Catalysts 2017, 7, 229. [CrossRef]

5. O'Shea, K.E.; Dionysiou, D.D. Advanced oxidation processes for water treatment. J. Phys. Chem. Lett. 2012, 3 , 2112-2113. [CrossRef]

6. Deng, Y.; Zhao, R. Advanced oxidation processes (AOPs) in wastewater treatment. Curr. Pollution Rep. 2015, 1, 167-176. [CrossRef]

7. Lazar, M.; Varghese, S.; Nair, S. Photocatalytic water treatment by titanium dioxide: Recent updates. Catalysts 2012, 2, 572-601. [CrossRef]

8. Santos, M.C.; Elabd, Y.A.; Jing, Y.; Chaplin, B.P.; Fang, L. Highly porous $\mathrm{Ti}_{4} \mathrm{O}_{7}$ reactive electrochemical water filtration membranes fabricated via electrospinning/electrospraying. AIChE J. 2016, 62, 508-524. [CrossRef]

9. Ikehata, K.; Jodeiri Naghashkar, N.; Gamal El-Din, M. Degradation of aqueous pharmaceuticals by ozonation and advanced oxidation processes: A review. Ozone Sci. Eng. 2006, 28, 353-414. [CrossRef]

10. Kim, K.-J.; Jang, A. Fouling characteristics of NOM during the ceramic membrane microfiltration process for water treatment. Desalination Water Treat. 2016, 57, 9034-9042. [CrossRef]

11. Chaplin, B.P. Critical review of electrochemical advanced oxidation processes for water treatment applications. Environ. Sci. Process. Impacts 2014, 16, 1182-1203. [CrossRef] [PubMed]

12. Anglada, Á.; Urtiaga, A.; Ortiz, I. Contributions of electrochemical oxidation to waste-water treatment: Fundamentals and review of applications. J. Chem. Technol. Biotechnol. 2009, 84, 1747-1755. [CrossRef]

13. Chen, G. Electrochemical technologies in wastewater treatment. Sep. Purif. Technol. 2004, 38, 11-41. [CrossRef]

14. Popov, V.N. Carbon nanotubes: Properties and application. Mater. Sci. Eng. R 2004, 43, 61-102. [CrossRef] 
15. Wu, J.; Gerstandt, K.; Zhang, H.; Liu, J.; Hinds, B.J. Electrophoretically induced aqueous flow through single-walled carbon nanotube membranes. Nat. Nanotechnol. 2012, 7, 133-139. [CrossRef] [PubMed]

16. De Volder, M.F.L.; Tawfick, S.H.; Baughman, R.H.; Hart, A.J. Carbon nanotubes: Present and future commercial applications. Science 2013, 339, 535-539. [CrossRef] [PubMed]

17. Liu, Y.; Zheng, Y.; Du, B.; Nasaruddin, R.R.; Chen, T.; Xie, J. Golden carbon nanotube membrane for continuous flow catalysis. Ind. Eng. Chem. Res. 2017, 56, 2999-3007. [CrossRef]

18. Liu, H.; Zuo, K.; Vecitis, C.D. Titanium dioxide-coated carbon nanotube network filter for rapid and effective arsenic sorption. Environ. Sci. Technol. 2014, 48, 13871-13879. [CrossRef] [PubMed]

19. Gao, G.; Zhang, Q.; Hao, Z.; Vecitis, C.D. Carbon nanotube membrane stack for flow-through sequential regenerative electro-Fenton. Environ. Sci. Technol. 2015, 49, 2375-2383. [CrossRef] [PubMed]

20. Liu, Y.; Xie, J.; Ong, C.N.; Vecitis, C.D.; Zhou, Z. Electrochemical wastewater treatment with carbon nanotube filters coupled with in situ generated $\mathrm{H}_{2} \mathrm{O}_{2}$. Environ. Sci. Water Res. Technol. 2015, 1, 769-778. [CrossRef]

21. Gui, X.; Wei, J.; Wang, K.; Cao, A.; Zhu, H.; Jia, Y.; Shu, Q.; Wu, D. Carbon Nanotube Sponges. Adv. Mater. 2010, 22, 617-621. [CrossRef] [PubMed]

22. Li, X.; Xue, Y.; Zou, M.; Zhang, D.; Cao, A.; Duan, H. Direct oil recovery from saturated carbon nanotube sponges. ACS Appl. Mater. Interfaces 2016, 8, 12337-12343. [CrossRef] [PubMed]

23. Schoen, D.T.; Schoen, A.P.; Hu, L.; Kim, H.S.; Heilshorn, S.C.; Cui, Y. High speed water sterilization using one-dimensional nanostructures. Nano Lett. 2010, 10, 3628-3632. [CrossRef] [PubMed]

24. Arash, B.; Wang, Q.; Varadan, V.K. Mechanical properties of carbon nanotube/polymer composites. Sci. Rep. 2014, 4, 6479. [CrossRef] [PubMed]

25. Makowski, T.; Kowalczyk, D.; Fortuniak, W.; Jeziorska, D.; Brzezinski, S.; Tracz, A. Superhydrophobic properties of cotton woven fabrics with conducting 3D networks of multiwall carbon nanotubes, MWCNTs. Cellulose 2014, 21, 4659-4670. [CrossRef]

26. Pasta, M.; La Mantia, F.; Hu, L.; Deshazer, H.D.; Cui, Y. Aqueous supercapacitors on conductive cotton. Nano Res. 2010, 3, 452-458. [CrossRef]

27. Wang, Z.; Huang, Y.; Sun, J.; Huang, Y.; Hu, H.; Jiang, R.; Gai, W.; Li, G.; Zhi, C. Polyurethane/Cotton/Carbon Nanotubes Core-Spun Yarn as High Reliability Stretchable Strain Sensor for Human Motion Detection. ACS Appl. Mater. Interfaces 2016, 8, 24837-24843. [CrossRef] [PubMed]

28. Islam, M.F.; Rojas, E.; Bergey, D.M.; Johnson, A.T.; Yodh, A.G. High weight fraction surfactant solubilization of single-wall carbon nanotubes in water. Nano Lett. 2003, 3, 269-273. [CrossRef]

29. Qi, H.; Liu, J.; Mäder, E. Smart cellulose fibers coated with carbon nanotube networks. Fibers 2014, 2, 295. [CrossRef]

30. Rahman, M.J.; Mieno, T. Conductive cotton textile from safely functionalized carbon nanotubes. J. Nanomater. 2015, 2015. [CrossRef]

31. Liu, H.; Liu, J.; Liu, Y.; Bertoldi, K.; Vecitis, C.D. Quantitative 2D electrooxidative carbon nanotube filter model: Insight into reactive sites. Carbon 2014, 80, 651-664. [CrossRef]

32. Liu, Y.; Dustin Lee, J.H.; Xia, Q.; Ma, Y.; Yu, Y.; Lanry Yung, L.Y.; Xie, J.; Ong, C.N.; Vecitis, C.D.; Zhou, Z. A graphene-based electrochemical filter for water purification. J. Mater. Chem. A 2014, 2, 16554-16562. [CrossRef]

33. Vecitis, C.D.; Gao, G.; Liu, H. Electrochemical carbon nanotube filter for adsorption, desorption, and oxidation of aqueous dyes and anions. J. Phys. Chem. C 2011, 115, 3621-3629. [CrossRef]

34. Gao, G.; Pan, M.; Vecitis, C.D. Effect of the oxidation approach on carbon nanotube surface functional groups and electrooxidative filtration performance. J. Mater. Chem. A 2015, 3, 7575-7582. [CrossRef]

35. Liu, Y.; Liu, H.; Zhou, Z.; Wang, T.; Ong, C.N.; Vecitis, C.D. Degradation of the common aqueous antibiotic tetracycline using a carbon nanotube electrochemical filter. Environ. Sci. Technol. 2015, 49, 7974-7980. [CrossRef] [PubMed]

36. Avlonitis, S.A.; Kouroumbas, K.; Vlachakis, N. Energy consumption and membrane replacement cost for seawater RO desalination plants. Desalination 2003, 157, 151-158. [CrossRef]

37. Lee, Y.; Gerrity, D.; Lee, M.; Gamage, S.; Pisarenko, A.; Trenholm, R.A.; Canonica, S.; Snyder, S.A.; von Gunten, U. Organic contaminant abatement in reclaimed water by $\mathrm{UV} / \mathrm{H}_{2} \mathrm{O}_{2}$ and a combined process consisting of $\mathrm{O}_{3} / \mathrm{H}_{2} \mathrm{O}_{2}$ followed by $\mathrm{UV} / \mathrm{H}_{2} \mathrm{O}_{2}$ : Prediction of abatement efficiency, energy consumption, and byproduct formation. Environ. Sci. Technol. 2016, 50, 3809-3819. [CrossRef] [PubMed] 
38. Zou, S.; Yuan, H.; Childress, A.; He, Z. Energy consumption by recirculation: A missing parameter when evaluating forward osmosis. Environ. Sci. Technol. 2016, 50, 6827-6829. [CrossRef] [PubMed]

39. Xiao, H.; Wu, M.; Zhao, G. Electrocatalytic oxidation of cellulose to gluconate on carbon aerogel supported gold nanoparticles anode in alkaline medium. Catalysts 2016, 6, 5. [CrossRef]

(c)

(C) 2017 by the authors. Licensee MDPI, Basel, Switzerland. This article is an open access article distributed under the terms and conditions of the Creative Commons Attribution (CC BY) license (http://creativecommons.org/licenses/by/4.0/). 
Article

\title{
A Demonstration of $\mathrm{Pt} \mathrm{L}_{3}$-Edge EXAFS Free from $\mathrm{Au}$ $\mathrm{L}_{3}$-Edge Using Log-Spiral Bent Crystal Laue Analyzers
}

\author{
Yuki Wakisaka ${ }^{1, *}$, Daiki Kido ${ }^{1}$, Hiromitsu Uehara ${ }^{1}$, Qiuyi Yuan ${ }^{1}$, Satoru Takakusagi ${ }^{1}$, \\ Yohei Uemura $^{2}$, Toshihiko Yokoyama ${ }^{2}$, Takahiro Wada ${ }^{3}$, Motohiro Uo ${ }^{3}$, Tomohiro Sakata ${ }^{4}$, \\ Oki Sekizawa ${ }^{4,5}$, Tomoya Uruga ${ }^{4,5}$, Yasuhiro Iwasawa ${ }^{4}$ and Kiyotaka Asakura ${ }^{1, *}$ \\ 1 Institute for Catalysis, Hokkaido University, Hokkaido 001-0021, Japan; d-kido@eis.hokudai.ac.jp (D.K.); \\ uehara@oeic.hokudai.ac.jp (H.U.); qy.qiuyiyuan@gmail.com (Q.Y.); takakusa@cat.hokudai.ac.jp (S.T.) \\ 2 Institute for Molecular Science, Aichi 444-8585, Japan; y-uemura@ims.ac.jp (Y.U.); yokoyama@ims.ac.jp (T.Y.) \\ 3 Graduate School of Medical and Dental Sciences, Tokyo Medical and Dental University, Tokyo 113-8549, \\ Japan; wada.abm@tmd.ac.jp (T.W.); uo.abm@tmd.ac.jp (M.U.) \\ 4 Innovation Research Center for Fuel Cells, The University of Electro-Communications, Tokyo 182-8585, \\ Japan; s-tomohiro@uec.ac.jp (T.S.); sekizawa@uec.ac.jp (O.S.); urugat@spring8.or.jp (T.U.); \\ iwasawa@pc.uec.ac.jp (Y.I.) \\ 5 Japan Synchrotron Radiation Research (JASRI), Hyogo 679-5148, Japan \\ * Correspondence: ywkskhkd@gmail.com (Y.W.); askr@cat.hokudai.ac.jp (K.A.); Tel.: +81-11-706-9113(K.A.)
}

Received: 30 March 2018; Accepted: 8 May 2018; Published: 13 May 2018

\begin{abstract}
Pt-Au nanostructures are important and well-studied fuel cell catalysts for their promising catalytic performance. However, a detailed quantitative local structure analysis, using extended X-ray absorption fine structure (EXAFS) spectroscopy, have been inhibited by interference between Pt and $\mathrm{Au} \mathrm{L}_{3}$-edges. In this paper, $\mathrm{Pt} \mathrm{L}_{3}$-edge XAFS analysis, free of $\mathrm{Au} \mathrm{L}_{3}$ edge, is demonstrated for a Pt-Au reference sample using a low-cost log-spiral bent crystal Laue analyzer (BCLA). This method facilitates the EXAFS structural analysis of Pt-Au catalysts, which are important to improve fuel cell catalysts.
\end{abstract}

Keywords: Pt-Au; XAFS; BCLA

\section{Introduction}

Platinum is one of the key elements for catalytic reactions in fuel cells. Although there are many studies in which authors suggest different methodologies to replace Pt with others low-cost metals, it is still difficult to substitute the catalytic performance of Pt. A practical approach, combining different metals with Pt have widely been adopted to reduce the amount of Pt and improve its activity and durability. Among those, $\mathrm{Au}$ is one of the interesting metals due to its superior oxygen-reduction-reaction activity and durability reported in Pt-Au nanostructures, where the Pt (shell)-Au (core) structures and the effect of Au decoration on the edges of Pt surfaces are used as a fuel cell catalyst [1-5]. Hence, it is essential to understand the local structures of both Pt and $\mathrm{Au}$ in an atomic scale to elucidate the mechanism of the catalytic reactions in Pt-Au nanostructures. Extended X-ray absorption fine structure (extended XAFS or EXAFS) spectroscopy is a suitable and widely-used method to investigate the local atomic structures of fuel-cell catalysts because of its atomic selectivity and applicability to nanoparticles under electrochemical environments [6]. However, in case of Pt-Au system, it is difficult to obtain a Pt $\mathrm{L}_{3}$-edge EXAFS sufficient for its analysis due to the interference between $\mathrm{Pt}$ and $\mathrm{Au}$, which are only separated by $\sim 350 \mathrm{eV}$, so that $\mathrm{Au} \mathrm{L}_{3}$-edge appears at $\sim 9.6 \AA^{-1}$ in Pt $\mathrm{L}_{3}$-edge EXAFS [7,8]. Although the problem can be solved by measuring K-edge XAFS, where Pt and Au K-edges are separated by 
$\sim 2300 \mathrm{eV}[9,10]$, the information in the long-range order is limited by the lifetime broadening, and $\mathrm{Pt}$ $\mathrm{L}_{3}$-edge EXAFS measurement is preferable.

Glatzel et al. first demonstrated that EXAFS spectra sufficient for analysis under the existence of interfering absorption edges, called range-extended EXAFS, could be obtained by taking advantage of high-energy-resolution fluorescence detected XAFS (HERFD-XAFS) using crystal analyzers with an energy resolution of $\sim 1 \mathrm{eV}[11,12]$. It was shown that HERFD-XAFS was not only useful for capturing the detailed structures of the X-ray absorption near edge structure spectra but also capable of obtaining the range extended EXAFS. Recently, this method was applied to the feasibility study of Pt $\mathrm{L}_{3}$-edge EXAFS in the presence of $\mathrm{Au}$ [13]. In this paper, we demonstrated that range-extended $\mathrm{Pt} \mathrm{L}_{3}$-edge EXAFS can also be obtained under the existence of Au using a log-spiral bent crystal Laue analyzer (BCLA) [14]. Although the energy resolution of BCLA (>10 eV [15]) is generally less than the resolution of crystal analyzers used in HERFD-XAFS $(\sim 1 \mathrm{eV})$, the energy reolution of the BCLA is sufficiently small for discriminating Au fluorescence from Pt. On the other hand, adopting BCLA, one can expect a lower cost for experimental arrangement compared to HERFD-XAFS. Moreover, the emission energy scan of BCLA can be achieved by a vertical scan because it approximately corresponds to the change in the incident angle of the X-ray against the crystal face. These characteristics may facilitate the application of the BCLA to the range-extended EXAFS of Pt-Au catalysts.

\section{Results}

Figure 1 shows the emission X-ray intensity from a diluted Pt-Au reference sample measured through a BCLA moved to the vertical direction. The incident $\mathrm{X}$-ray energy was $12.1 \mathrm{keV}$, which was corresponding to the energy above the $\mathrm{Au} \mathrm{L}_{3}$-edge. All four fluorescent peaks ( $\mathrm{Pt} \mathrm{L}_{\alpha 2}, \mathrm{Pt} \mathrm{L}_{\alpha 1}, \mathrm{Au} \mathrm{L} \mathrm{L}_{\alpha 2}$, $\mathrm{Au} \mathrm{L}_{\alpha 1}$ ) were well resolved, and it is confirmed that there was a clear correspondence between the accepted X-ray fluorescent energy and the vertical position of the BCLA. Au fluorescent peaks were smaller compared to the expected molar ratio of the sample ( $\mathrm{Pt} / \mathrm{Au}=\sim 1 / 10)$; a solid-state detector (SSD) was used within the range of interest, only including the entire $\mathrm{Pt} \mathrm{L}_{\alpha}$ peaks. According to the full width half maximum (FWHM) of the $\mathrm{Pt}_{\alpha 1}$ peak, the energy resolution is $\sim 30 \mathrm{eV}$ for this experimental arrangement.

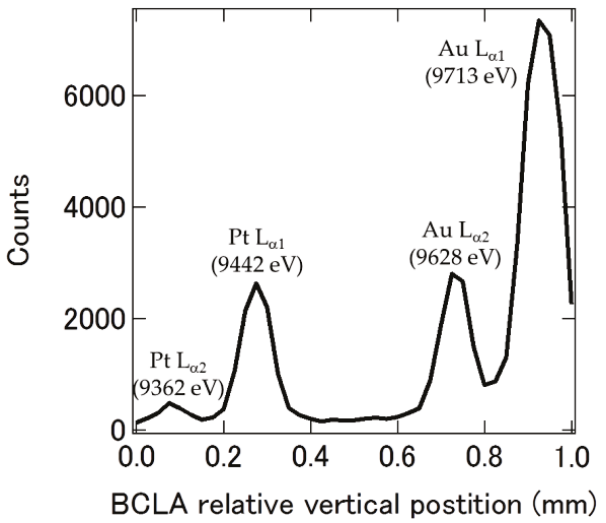

Figure 1. Emission X-ray intensity from a diluted Pt-Au sample measured through a BCLA moved to the vertical direction. Four peaks were assigned as $\mathrm{Pt}_{\alpha 2}, \mathrm{Pt} \mathrm{L}_{\alpha 1}, \mathrm{Au} \mathrm{L}_{\alpha 2}, \mathrm{Au} \mathrm{L}_{\alpha 1}$, from lower to higher positions of the BCLA.

Figure 2 shows the normalized XAFS spectra of a concentrated Pt-Au reference sample measured in a transmission mode and a fluorescence mode with the BCLA. The edge heights of the raw spectrum were 1 and 7.31.1 for $\mathrm{Pt}$ and $\mathrm{Au}$, respectively. It was clearly observed by the transmission spectrum 
that the sample contained 10 times more $\mathrm{Au}$ than Pt. In the fluorescence mode, apparently, no $\mathrm{Au}$ signal was observed due to the BCLA. However, the Pt fluorescence signal abruptly decreased at the $\mathrm{Au} \mathrm{L}_{3}$-edge; the incident $\mathrm{X}$-rays were absorbed by the abundant $\mathrm{Au}$ atoms. Consequently, $\mathrm{Pt}$ atoms were less excited $[11,16]$. This effect can be avoided by a sufficient dilution of the sample.

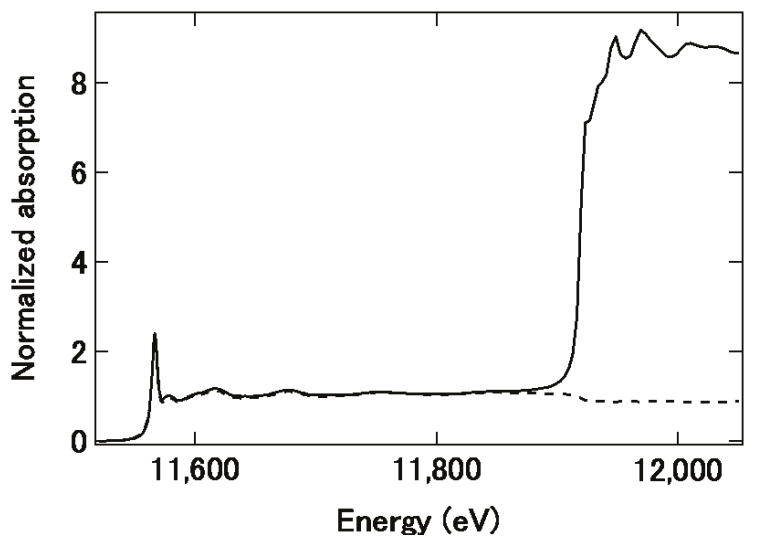

Figure 2. XAFS spectra of the concentrated Pt-Au reference sample measured in transmission (solid line) and fluorescence mode (dashed line) with the BCLA. The spectrum was normalized by the edge height of $\mathrm{Pt}=1$.

Figure 3a shows the XAFS spectrum of the diluted Pt-Au reference sample (see Materials and Methods) measured in the fluorescence mode with the BCLA. The edge heights of the raw data for this diluted sample measured in transmission mode was 0.007 for $\mathrm{Pt}$ and 0.05 for $\mathrm{Au}$, respectively. As expected, no clear anomaly was observed near the region of $\mathrm{Au} \mathrm{L}_{3}$-edge, when the interference of Auand $\mathrm{Pt}_{3}$-edge EXAFS could be removed. Figure $3 \mathrm{~b}$ shows the $k^{3} \chi$ plot with an accumulation time of less than $30 \mathrm{~min}$. For comparison, the $\mathrm{Pt}_{\mathrm{t}} \mathrm{L}_{3}$ transmission XAFS spectrum of a standard sample $\left(\mathrm{PtCl}_{4}\right)$ measured at Beam line (BL)14B2 in Super Photon ring-8 GeV (SPring-8) was overlaid as a red dashed line (see Figure $3 b$ ). There is a good agreement up to $\sim 12 \AA^{-1}$. No clear edge was found even in this $k^{3} \chi$ plot. Here, we demonstrated that $\mathrm{Pt} \mathrm{L}_{3}$-edge EXAFS spectra, free of $\mathrm{Au} \mathrm{L}_{3}$-edge, could be obtained using a considerable amount of $\mathrm{Au}$ in BCLA.
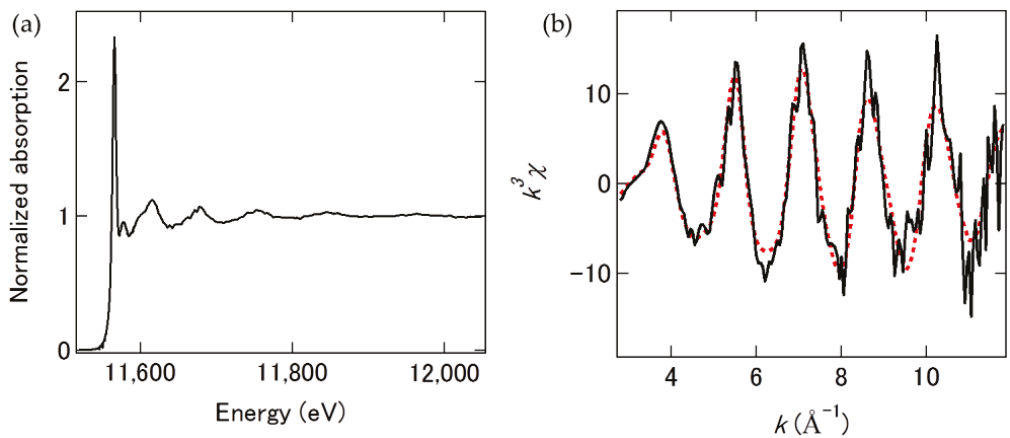

Figure 3. (a): Fluorescence XAFS spectrum of the diluted Pt-Au reference sample measured with the BCLA. The spectrum was normalized by the edge height of $\mathrm{Pt}=1 ;(\mathbf{b}): k^{3} \chi$ EXAFS spectra of the diluted $\mathrm{Pt}$-Au reference sample measured at BL36XU (black solid line) and of the standard sample $\mathrm{PtCl}_{4}$ (red dashed line) measured at BL14B2. 


\section{Discussion}

Previously, range-extended EXAFS was only achieved in HERFD-XAFS. In this work, we have successfully demonstrated the range-extended EXAFS analysis using BCLA is possible. BCLA has several advantages mentioned above compared to HERFD-XAFS method. In addition, the crystal alignment is quite simple. It is mainly achieved by a vertical scan followed by a precise two-dimensional linear scan of the BCLA $[15,17]$. The only constraint is the vertical size of the incident X-ray beam. In this study, it was $\sim 50 \mu \mathrm{m}$, though this condition is not fixed, depending on the energy difference between the measuring $(\mathrm{Pt})$ and interfering ( $\mathrm{Au}$ ) fluorescent $\mathrm{X}$-rays (see Figure 1).

HERFD-XAFS is, in general, a powerful technique to detect the subtle spectral changes in X-ray absorption near to edge regions. By applying this technique to Pt catalysts in fuel cells, various adsorbates on Pt and its oxidation states have been discussed [18-20]. HERFD-XAFS can not be achieved by using the BCLA because of their moderate energy resolution larger than the core-hole lifetime broadening. However, this is preferable in case of direct comparison between the spectra measured in the transmission and the fluorescence mode using BCLA; which should have the same energy resolutions.

\section{Materials and Methods}

The concentrated $\mathrm{Pt}-\mathrm{Au}$ reference sample was made by mixing $\mathrm{PtCl}_{4}$ and $\mathrm{AuCl}$ powder. The mixture was then ground in a mortar and pestle together with BN (boron nitride) powder and pressed into a pellet with a size of $1 \mathrm{~mm}$ thick and $10 \mathrm{~mm}$ diameter. The Pt and Au concentration was $\mathrm{Pt} / \mathrm{Au} \sim 1 / 10$ and the $\mathrm{Pt} \mathrm{L}_{3}$-edge step $(\Delta \mu \mathrm{t})$ was $\sim 0.1$. The diluted Pt-Au reference sample was made diluting the concentrated Pt-Au pellet by $\sim 1 / 20$ with additional BN powder.

The XAFS measurements were performed at BL36XU in SPring-8 (JASRI, Koto, Japan). The beam size of the incident $X$-rays was focused to $\sim 50 \mu \mathrm{m}$ (vertical) $\times \sim 500 \mu \mathrm{m}$ (horizontal) by using 4 focusing mirrors equipped in the beamline. The photon flux was $\sim 2 \times 10^{13}$ photons $/ \mathrm{s}$, but it was reduced to $\sim 2 \times 10^{12}$ photons/s for the diluted Pt-Au sample using an $\mathrm{Al}$ attenuator. Ion chambers were used for the transmission measurement. A commercial BCLA (0095, FMB Oxford, UK) and a 25-element Ge SSD (Canberra, Coneticcut , USA) or a pixel-array detector (PILATUS 300K-W; Dectris, Baden-Daettwil, Switzerland) were used for detecting fluorescent X-rays. The sample and the BCLA/SSD (or PILATUS) were placed in the $45^{\circ} / 45^{\circ}$ arrangement. The shaping time of the SSD was set to $0.5 \mu \mathrm{s}$, which resulted in an SSD energy resolution of $400 \mathrm{eV}$. The region of interest in the SSD was 9.09-9.76 keV. Thus, the Au fluorescence effect cannot fully suppress after the $\mathrm{Au} \mathrm{L}_{3}$-edge. The commercial BCLA was linearly scanned in two dimensions to find their optimum position so that the $\mathrm{Pt} \mathrm{L}_{\alpha 1}$ fluorescent $\mathrm{X}$-ray intensity became maximum in the multi-element SSD. Only the detector of elements in the multi-element SSD, which sufficiently suppressed $A u L_{\alpha}$ fluorescent X-rays, was used for the spectral analyses [21].

\section{Conclusions}

$\mathrm{Pt} \mathrm{L}_{3}$-edge XAFS analysis, free from $\mathrm{Au} \mathrm{L}_{3}$-edge, was demonstrated here for the first time using BCLA; a low-cost and high-sensitive crystal analyzers, which facilitates detail EXAFS analyses for $\mathrm{Pt}-\mathrm{Au}$ fuel cell catalysts. Our results confirm the feasibility of the range-extended EXAFS using BCLA, we apply this technique to two interesting fuel cell models containing Pt and Au; Au-Pt-Co-N nanoparticles deposited on a highly oriented pyrolytic graphite [22] and monolayer Pt deposited on Au thin film with $60 \mathrm{~nm}$ thickness on a Si (100) substrate [23]. We will soon report these results.

Author Contributions: Y.W., H.U., and K.A. conceived, designed, and performed the experiments; D.K., Q.Y., Y.U., and T.W. performed the experiments; Y.W., S.T., M.U., T.Y., T.U., Y.I., and K.A. discussed the results; T.S., O.S., and T.U. supported the experiments; Y.W. analyzed the data; Y.W. and K.A. wrote the paper.

Acknowledgments: The authors would like to express their gratitude to the New Energy and Industrial Technology Development Organization (NEDO) Polymer Electrolyte Fuel Cell project for their financial support. We would like to thank Hiroyuki Asakura for discussing the range-extended EXAFS results of Pt-Au. T.W. and Y.U. were supported by the Cooperative Research Program of Institute for Catalysis, Hokkaido University. The XAFS 
measurements at SPring- 8 were performed under project number 2016A7902 and 2016B7902. XAFS spectrum of standard sample $\mathrm{PtCl}_{4}$ is utilized by SPring-8 BL14B2 XAFS database (2014S0000-000523). This work was supported by the Technical Division of Institute for Catalysis, Hokkaido University.

Conflicts of Interest: The authors declare no conflict of interest.

\section{References}

1. Kristian, N.; Wang, X. Pt shell-Au core/C electrocatalyst with a controlled shell thickness and improved Pt utilization for fuel cell reactions. Electrochem. Commun. 2008, 10, 12-15. [CrossRef]

2. Shuangyin, W.; Noel, K.; Sanping, J.; Xin, W. Controlled synthesis of dendritic Au@Pt core-shell nanomaterials for use as an effective fuel cell electrocatalyst. Nanotechnology 2009, 20, 025605. [CrossRef]

3. Xiu, C.; Shengnan, W.; Scott, J.; Zhibing, C.; Zhenghua, W.; Lun, W.; Li, Y. The deposition of Au-Pt core-shell nanoparticles on reduced graphene oxide and their catalytic activity. Nanotechnology 2013, 24, 295402. [CrossRef]

4. Dai, Y.; Chen, S. Oxygen Reduction Electrocatalyst of Pt on Au Nanoparticles through Spontaneous Deposition. ACS Appl. Mater. Interfaces 2015, 7, 823-829. [CrossRef] [PubMed]

5. Takahashi, S.; Chiba, H.; Kato, T.; Endo, S.; Hayashi, T.; Todoroki, N.; Wadayama, T. Oxygen reduction reaction activity and structural stability of $\mathrm{Pt}-\mathrm{Au}$ nanoparticles prepared by arc-plasma deposition. Phys. Chem. Chem. Phys. 2015, 17, 18638-18644. [CrossRef] [PubMed]

6. Iwasawa, Y.; Asakura, K.; Tada, M. XAFS Techniques for Catalysts, Nanomaterials, and Surfaces; Springer: New York, NY, USA, 2016.

7. Nagamatsu, S.; Arai, T.; Yamamoto, M.; Ohkura, T.; Oyanagi, H.; Ishizaka, T.; Kawanami, H.; Uruga, T.; Tada, M.; Iwasawa, Y. Potential-Dependent Restructuring and Hysteresis in the Structural and Electronic Transformations of $\mathrm{Pt} / \mathrm{C}, \mathrm{Au}($ Core)-Pt(Shell)/C, and Pd(Core)-Pt(Shell)/C Cathode Catalysts in Polymer Electrolyte Fuel Cells Characterized by in Situ X-ray Absorption Fine Structure. J. Phys. Chem. C 2013, 117, 13094-13107.

8. Yuan, Q.; Takakusagi, S.; Wakisaka, Y.; Uemura, Y.; Wada, T.; Ariga, H.; Asakura, K. Polarization-dependent Total Reflection Fluorescence X-ray Absorption Fine Structure (PTRF-XAFS) Studies on the Structure of a Pt Monolayer on Au(111) Prepared by the Surface-limited Redox Replacement Reaction. Chem. Lett. 2017, 46, 1250-1253. [CrossRef]

9. Kaito, T.; Mitsumoto, H.; Sugawara, S.; Shinohara, K.; Uehara, H.; Ariga, H.; Takakusagi, S.; Hatakeyama, Y.; Nishikawa, K.; Asakura, K. K-Edge X-ray Absorption Fine Structure Analysis of Pt/Au Core-Shell Electrocatalyst: Evidence for Short Pt-Pt Distance. J. Phys. Chem. C 2014, 118, 8481-8490. [CrossRef]

10. Kaito, T.; Mitsumoto, H.; Sugawara, S.; Shinohara, K.; Uehara, H.; Ariga, H.; Takakusagi, S.; Asakura, K. A new spectroelectrochemical cell for in situ measurement of $\mathrm{Pt}$ and $\mathrm{Au}$ K-edge X-ray absorption fine structure. Rev. Sci. Instrum. 2014, 85, 084104. [CrossRef] [PubMed]

11. Glatzel, P.; de Groot, F.M.F.; Manoilova, O.; Grandjean, D.; Weckhuysen, B.M.; Bergmann, U.; Barrea, R. Range-extended EXAFS at the \$L $\$$ edge of rare earths using high-energy-resolution fluorescence detection: A study of La in LaOCl. Phys. Rev. B 2005, 72, 014117. [CrossRef]

12. Yano, J.; Pushkar, Y.; Glatzel, P.; Lewis, A.; Sauer, K.; Messinger, J.; Bergmann, U.; Yachandra, V. High-Resolution Mn EXAFS of the Oxygen-Evolving Complex in Photosystem II: Structural Implications for the Mn4Ca Cluster. J. Am. Chem. Soc. 2005, 127, 14974-14975. [CrossRef] [PubMed]

13. Asakura, H.; Kawamura, N.; Mizumaki, M.; Nitta, K.; Ishii, K.; Hosokawa, S.; Teramura, K.; Tanaka, T. A feasibility study of "range-extended" EXAFS measurement at the Pt L3-edge of $\mathrm{Pt} / \mathrm{Al}_{2} \mathrm{O}_{3}$ in the presence of $\mathrm{Au}_{2} \mathrm{O}_{3}$. J. Anal. At. Spectrom. 2018, 33, 84-89. [CrossRef]

14. Zhong, Z.; Chapman, L.D.; Bunker, B.A.; Bunker, G.B.; Fischetti, R.; Segre, C.U. A bent Laue analyzer for fluorescence EXAFS detection. J. Synchrotron Radiat. 1999, 6, 212-214. [CrossRef] [PubMed]

15. Kujala, N.G.; Karanfil, C.; Barrea, R.A. High resolution short focal distance Bent Crystal Laue Analyzer for copper K edge X-ray absorption spectroscopy. Rev. Sci. Instrum. 2011, 82, 063106. [CrossRef] [PubMed]

16. Bianchini, M.; Glatzel, P. A tool to plan photon-in/photon-out experiments: Count rates, dips and self-absorption. J. Synchrotron Radiat. 2012, 19, 911-919. [CrossRef] [PubMed]

17. Karanfil, C.; Bunker, G.; Newville, M.; Segre, C.U.; Chapman, D. Quantitative performance measurements of bent crystal Laue analyzers for X-ray fluorescence spectroscopy. J. Synchrotron Radiat. 2012, 19, 375-380. [CrossRef] [PubMed] 
18. Friebel, D.; Viswanathan, V.; Miller, D.J.; Anniyev, T.; Ogasawara, H.; Larsen, A.H.; O'Grady, C.P.; Nørskov, J.K.; Nilsson, A. Balance of Nanostructure and Bimetallic Interactions in Pt ModelFuel Cell Catalysts: In Situ XAS and DFT Study. J. Am. Chem. Soc. 2012, 134, 9664-9671. [CrossRef] [PubMed]

19. Merte, L.R.; Behafarid, F.; Miller, D.J.; Friebel, D.; Cho, S.; Mbuga, F.; Sokaras, D.; Alonso-Mori, D.; Weng, T.-C.; Nordlund, D.; et al. Electrochemical Oxidation of Size-Selected Pt Nanoparticles Studied Using in Situ High-Energy-Resolution X-ray Absorption Spectroscopy. ACS Catal. 2012, 2, 2371-2376. [CrossRef]

20. Cui, Y.-T.; Harada, Y.; Niwa, H.; Hatanaka, T.; Nakamura, N.; Ando, M.; Yoshida, T.; Ishii, K.; Matsumura, D.; Oji, H.; et al. Wetting Induced Oxidation of Pt-based Nano Catalysts Revealed by In Situ High Energy Resolution X-ray Absorption Spectroscopy. Sci. Rep. 2017, 7, 1482. [CrossRef] [PubMed]

21. Wakisaka, Y.; Iwasaki, Y.; Uehara, H.; Mukai, S.; Kido, D.; Takakusgi, S.; Uemura, Y.; Wada, T.; Yuan, Q.; Sekizawa, O.; et al. Approach to Highly Sensitive XAFS by Means of Bent Crystal Laue Analyzers. J. Surf. Sci. Soc. Jpn. 2017, 38, 378-383. [CrossRef]

22. Takahashi, S.; Takahashi, N.; Todoroki, N.; Wadayama, T. Dealloying of Nitrogen-Introduced Pt-Co Alloy Nanoparticles: Preferential Core-Shell Formation with Enhanced Activity for Oxygen Reduction Reaction. ACS Omega 2016, 1, 1247-1252. [CrossRef]

23. Liu, Y.; Hangarter, C.M.; Garcia, D.; Moffat, T.P. Self-terminating electrodeposition of ultrathin Pt films on Ni: An active, low-cost electrode for $\mathrm{H}_{2}$ production. Surf. Sci. 2015, 631, 141-154. [CrossRef]

(C) 2018 by the authors. Licensee MDPI, Basel, Switzerland. This article is an open access article distributed under the terms and conditions of the Creative Commons Attribution (CC BY) license (http:/ / creativecommons.org/licenses/by/4.0/). 


\title{
Recent Advances in Graphene Based $\mathrm{TiO}_{2}$ Nanocomposites $\left(\mathrm{GTiO}_{2} \mathrm{Ns}\right)$ for Photocatalytic Degradation of Synthetic Dyes
}

\author{
Rita Giovannetti *, Elena Rommozzi, Marco Zannotti and Chiara Anna D'Amato \\ School of Science and Technology, Chemistry Division, University of Camerino, Via S. Agostino 1, \\ 62032 Camerino, Italy; elena.rommozzi@unicam.it (E.R.); marco.zannotti@unicam.it (M.Z.); \\ chiaraanna.damato@unicam.it (C.A.D.) \\ * Correspondence: rita.giovannetti@unicam.it; Tel.: +39-0737-402272
}

Academic Editors: Ewa Kowalska, Marcin Janczarek and Agata Markowska-Szczupak Received: 24 August 2017; Accepted: 10 October 2017; Published: 16 October 2017

\begin{abstract}
Synthetic dyes are widely used in textile, paper, food, cosmetic, and pharmaceutical industries. During industrial processes, some of these dyes are released into the wastewater and their successive release into rivers and lakes produces serious environmental problems. $\mathrm{TiO}_{2}$ is one of the most widely studied and used photocatalysts for environmental remediation. However, it is mainly active under UV-light irradiation due to its band gap of $3.2 \mathrm{eV}$, while it shows low efficiency under the visible light spectrum. Regarding the exploration of $\mathrm{TiO}_{2}$ activation in the visible light region of the total solar spectrum, the incorporation of carbon nanomaterials, such as graphene, in order to form carbon- $\mathrm{TiO}_{2}$ composites is a promising area. Graphene, in fact, has a large surface area which makes it a good adsorbent for organic pollutants removal through the combination of electrostatic attraction and $\pi-\pi$ interaction. Furthermore, it has a high electron mobility and therefore it reduces the electron-hole pair recombination, improving the photocatalytic activity of the semiconductor. In recent years, there was an increasing interest in the preparation of graphene-based $\mathrm{TiO}_{2}$ photocatalysts. The present short review describes the recent advances in $\mathrm{TiO}_{2}$ photocatalyst coupling with graphene materials with the aim of extending the light absorption of $\mathrm{TiO}_{2}$ from UV wavelengths into the visible region, focusing on recent progress in the design and applications in the photocatalytic degradation of synthetic dyes.
\end{abstract}

Keywords: titanium dioxide; graphene; photocatalysis; visible light; dyes

\section{Introduction}

One of the biggest problems that the world is facing today is environmental pollution, which increases every year and causes serious and irreparable damage to the Earth [1]. Therefore, environmental protection and a new approach in environmental remediation are important factors for a real improvement in quality of life and for sustainable development.

In recent years, a large number of research activities have been dedicated to environmental protection and remediation as a consequence of special attention from social, political, and legislative authorities, which has led to the delivery of very stringent regulations for the environment [2].

Due to industrialization and the lack of effective treatments of the effluents at the source, a severe deterioration of freshwater resources caused by the release of a wide range of hazardous substances into water bodies has occurred. Of these substances, synthetic dyes represent a large group and therefore deserve particular attention, due to the high quantity-more than 800,000 tons-that is produced annually worldwide [3]. About one third of these is released into receiving waters every year through industrial wastewater discharges [4], which may have a severe influence on both the environment 
and human health, affecting photosynthetic activity as well as dissolved oxygen concentration, and therefore causing serious ecologic problems [5].

Dyes present high toxicity, are carcinogenic and mutagenic in nature, and can also result in bioaccumulation in the food chain [6]. Because their origin is synthetic, these compounds are very stable in the presence of light and biodegradation [7]. Furthermore, very low concentrations of these are easily visible in contaminated waters; therefore, the total effect of the presence of dyes in the water ecosystem is both environmentally and aesthetically unacceptable.

Taking account of these considerations, there is an urgent need to develop new methods for the treatment of industrial wastewater containing synthetic dyes.

In recent years, photocatalysis studies have focused on the use of semiconductor materials as photocatalysts for environmental remediation. Semiconductor photocatalysis is a versatile, low-cost, and environmentally friendly treatment technology for many pollutants $[8,9]$, and the use of heterogeneous photocatalysis is an emerging application in water decontamination.

Within a great number of oxide semiconductors, $\mathrm{TiO}_{2}$ is the most widely used as promising photocatalyst, demonstrating a very important role in environmental remediation [10,11], solar energy [12], and other fields [13,14] due to its nontoxicity, low cost, corrosion resistance, abundant resources, and high photocatalytic efficiency [15-17].

A high number of studies concerning $\mathrm{TiO}_{2}$ regard wastewater treatments [18-21] and, in many cases, total mineralization of pollutants without any waste disposal problem have been published [22]. On the other hand, the practical applications of this technique are limited to a narrow excitation wavelength because of a large band gap energy $(3.2 \mathrm{eV})$, high recombination rate of the photo-produced electron-hole pair, and poor adsorption capacity [23-25]. In recent decades, various attempts have been applied to improve the catalytic efficiency of $\mathrm{TiO}_{2}[18,26,27]$.

Due to its wide band-gap, $\mathrm{TiO}_{2}$ is active only under UV-light irradiation; considering that the percentage of UV-light is less than $5 \%$ of the total incident solar spectrum on the Earth, in recent years research has focused on extending the light absorption of $\mathrm{TiO}_{2}$ under visible light. The research goal of $\mathrm{TiO}_{2}$ photocatalysis, as for other semiconductors, is represented by the combination of $\mathrm{TiO}_{2}$ with other nanomaterials to achieve both visible light activation and adsorption capacity improvement, with the simultaneous limitation of the electron-hole recombination rate. For this reason, to improve the photocatalytic performances in the use of $\mathrm{TiO}_{2}$, different approaches have been investigated, such as the use of co-catalysts, and loading with noble metal particles, dye, metallic or non-metallic doping [28-36]. Recently, enhancements of the photocatalytic activity of $\mathrm{TiO}_{2}$ by visible light have been also demonstrated by the modification of $\mathrm{TiO}_{2}$ with carbonaceous substances such as fullerenes, carbon nanotubes, and graphene to form carbon- $\mathrm{TiO}_{2}$ composites [37-40].

In particular, graphene nanomaterials in combination with $\mathrm{TiO}_{2}$ highlight new prospectives in the field of photocatalysis for their large specific surface area, flexible structure, extraordinary mobility of charge carriers at room temperature, high thermal and electrical conductivities, and high chemical stability [41-48], emerging as one of the most promising materials for enhancing the photocatalytic performance in the new generation of photocatalysts [49-56].

In this short review, the recent research advances in graphene- $\mathrm{TiO}_{2}$ employed in photocatalysis are presented with the aim of extending the light absorption of $\mathrm{TiO}_{2}$ from $\mathrm{UV}$ wavelengths into the visible region, as well as increasing the photocatalytic activity of the compound, focusing on the applications of synthetic dye degradation.

\section{Graphene Materials: Concepts and Properties}

Graphene $(G)$ is the term used to indicate carbon atoms tightly packed in a plane monolayer into a two-dimensional (2D) "honeycomb lattice" that represents the building block for all graphitic materials such as fullerenes, nanotubes, and graphite [48,57].

The isolation of graphene from graphite in 2003, by Prof. Andre Geim and Prof. Kostya Novoselov, which was the first paper published in Science in 2004 [42] and was awarded the Nobel Prize in Physics 
in 2010, has fascinated and revolutionized the scientific community [42,58,59]. This is due to graphene's notable properties and to the high range of applications that these properties offer to technologies such as energy storage and photocatalysis [60-67].

The IUPAC commission proposed the term "graphene" to substitute the older term "graphite layers", which was inappropriate in the research of two-dimensional (2D) monolayers of carbon atoms because the three-dimensional (3D) stacking structure is identified as "graphite" [59].

After the first report on graphene, which was obtained manually by mechanical cleavage with a Scotch tape sample of graphite, various techniques developed to produce thin graphitic films have been reported $[55,68,69]$. These can be divided into two main groups: bottom-up and top-down methods [55,69], as schematized in Figure 1.

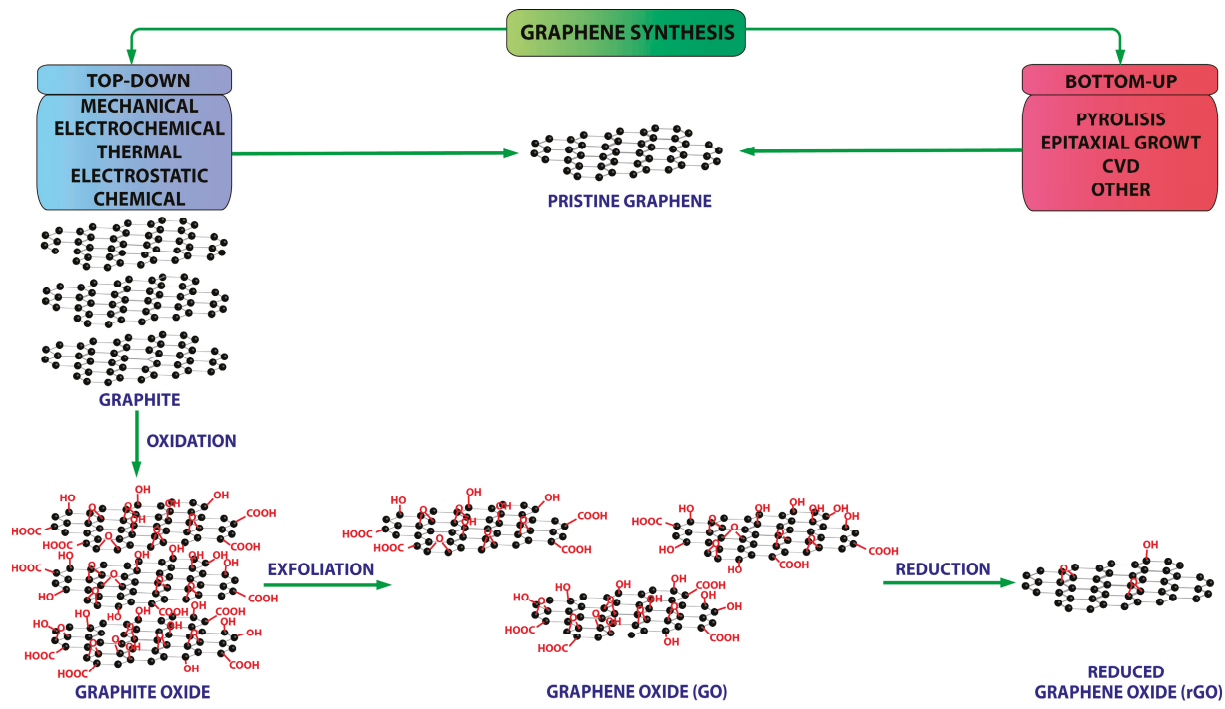

Figure 1. Schematic graphene synthesis: top-down and bottom-up methods.

In the bottom-up growth of graphene sheets (Table 1), the synthesis of graphene [70] can be obtained via epitaxial growth [71-73], chemical vapor deposition (CVD) [74-82], electrochemical reduction of $\mathrm{CO}$ and $\mathrm{CO}_{2}[83,84]$, arc discharge [85,86], unzipping carbon nanotubes [70,87], organic synthesis [88], and pyrolysis [89-91].

The top-down approach (Table 2) offers considerable economic advantages over bottom-up methods [92,93], producing high quality graphene. In this case, the graphene is derived from the exfoliation of graphite, from mechanical [42,94-97], electrochemical expansion [98-100], thermal [101], electrostatic deposition [102], and chemical synthesis [103-105]. Some other techniques are unzipping nanotube [106-108] and microwave synthesis [109,110], or by chemical and/or thermal graphene oxide (GO) reduction [111]. This last method allows the production of low-cost and large-scale graphene, though with oxygen-containing groups and defects [112,113]. Much interest is directed at the study of proceedings to obtain graphene in the form of highly reduced graphene oxide (rGO) $[114,115]$ or chemically modified graphene $[116,117]$ from the oxidation and exfoliation of graphite and successive chemical reduction. 
Table 1. Graphene synthesis with the bottom-up approach.

\begin{tabular}{|c|c|c|c|c|}
\hline & & Results & Highlight & Refs. \\
\hline \multirow{3}{*}{ Epitaxial growth } & - & General & Experimental and theoretical aspect & [71] \\
\hline & - & $\begin{array}{l}\text { Flower defects and effects of } \\
\mathrm{G} \text { grown on } \mathrm{SiC} \text { substrate }\end{array}$ & $\begin{array}{l}\text { Enhancements in the electronic properties of } \\
\text { G-based devices }\end{array}$ & [72] \\
\hline & - & $\begin{array}{l}\text { G nanoribbons (GNR) on } \\
\text { surface facets of } \mathrm{SiC}(0001)\end{array}$ & $\begin{array}{l}\text { Influence of the substrate step height on the } \\
\text { energy barrier }\end{array}$ & [73] \\
\hline \multirow{9}{*}{$\begin{array}{l}\text { Chemical vapor } \\
\text { deposition (CVD) }\end{array}$} & - & $\begin{array}{l}\text { Large-size, single-crystal, } \\
\text { twisted bilayer G }\end{array}$ & $\begin{array}{l}\text { Raman spectra measured as a function of the } \\
\text { rotation angle }\end{array}$ & [74] \\
\hline & - & G & Review: challenges and future perspective & [75] \\
\hline & - & $\mathrm{G}$ on $\mathrm{Ni}$ and $\mathrm{Cu}$ substrates & Representative applications & {$[76]$} \\
\hline & - & $\begin{array}{l}200 \mathrm{~mm} \mathrm{G} \text { on } \\
\mathrm{Ge}(001) / \mathrm{Si}(001) \text { wafers }\end{array}$ & Absence of metallic contaminations & [77] \\
\hline & - & Multilayer G films & $\begin{array}{l}\text { Educational experiments: economical, safe, and simple } \\
\text { technique in } 30-45 \mathrm{~min}\end{array}$ & [78] \\
\hline & - & $\begin{array}{l}\text { Large-scale } \mathrm{G} \text { films on thin } \\
\text { Ni layers }\end{array}$ & $\begin{array}{l}\text { Two methods to shape and transfer films to } \\
\text { specific substrates }\end{array}$ & [79] \\
\hline & - & $\begin{array}{l}\text { Monolayer G films on } \\
\mathrm{SiC}(0001)\end{array}$ & Ex-situ graphitization in argon atmosphere & [80] \\
\hline & - & $\begin{array}{l}\text { Centimeter-scale single- to } \\
\text { few-layer } \mathrm{G} \text { on Ni foils }\end{array}$ & Efficient roll-to-roll process & [81] \\
\hline & - & N-doped graphene & $\begin{array}{l}\text { N-type behavior useful to modulate } \\
\text { G electrical properties }\end{array}$ & [82] \\
\hline \multirow{2}{*}{$\begin{array}{l}\text { Electrochemical } \\
\text { reduction of } \mathrm{CO} \\
\text { and } \mathrm{CO}_{2}\end{array}$} & - & $\begin{array}{l}\text { Several types of } \\
\text { nanocarbons of } \\
\text { controlled shape }\end{array}$ & Direct reaction of $\mathrm{CO}_{2}$ with $\mathrm{Mg}$ metal & [83] \\
\hline & - & G flakes & $\begin{array}{l}\text { Room-temperature synthesis method on copper foil } \\
\text { from different carbon sources using external charges }\end{array}$ & [84] \\
\hline \multirow{2}{*}{ Arc discharge } & - & Few-layered G & $\begin{array}{l}\text { The reactivity of buffer gases (helium, oxygen-helium, } \\
\text { and hydrogen-helium) is the key factor }\end{array}$ & [85] \\
\hline & - & Few-layered G & $\begin{array}{l}\text { Different mechanisms in the presence and absence of } \\
\mathrm{TiO}_{2} \text { and } \mathrm{ZnO} \text { catalysts }\end{array}$ & [86] \\
\hline \multirow{2}{*}{$\begin{array}{c}\text { Unzipping } \\
\text { carbon-nanotubes } \\
\text { (CNT) }\end{array}$} & - & Chemical-free G & $\begin{array}{l}\text { Radial and shear loading unzipping modes with } \\
\text { cryomill method at } 150 \mathrm{~K}\end{array}$ & {$[70]$} \\
\hline & - & G nanoribbons & $\begin{array}{l}\text { Linear longitudinal opening of the Multi Wall } \\
\text { CNT (MWCNT) }\end{array}$ & [87] \\
\hline \multirow[t]{2}{*}{ Organic synthesis } & - & $\begin{array}{l}\text { Two-dimensional } \\
\text { G nanoribbons }\end{array}$ & $\begin{array}{l}\text { Highly ordered monolayers (2D crystal) of larger } \\
\text { G ribbons }\end{array}$ & [88] \\
\hline & - & General description & Pyrolysis of organic matter & {$[89]$} \\
\hline \multirow[t]{2}{*}{ Pyrolysis } & - & $\begin{array}{l}\text { Metal-free catalyst of } \\
\text { G sheets }\end{array}$ & Spray pyrolysis of iron carbonyl and pyridine & {$[90]$} \\
\hline & - & $\begin{array}{l}\text { G nanoporous with high } \\
\text { specific surface area }\end{array}$ & $\begin{array}{l}\text { Spray pyrolysis at different temperatures, graphene } \\
\text { oxide-based precursor, nitrogen carrier gas }\end{array}$ & {$[91]$} \\
\hline
\end{tabular}


Table 2. Graphene synthesis with the top-down approach.

\begin{tabular}{|c|c|c|c|c|}
\hline & & Results & Highlight & Refs. \\
\hline \multirow{5}{*}{ Mechanical } & - & $\begin{array}{l}\text { Monocrystalline } \\
\text { graphitic films }\end{array}$ & $\begin{array}{l}\text { Exfoliation of small mesas of highly oriented } \\
\text { pyrolytic graphite }\end{array}$ & [42] \\
\hline & - & G & Review: general description & {$[94]$} \\
\hline & - & G sheets & $\begin{array}{l}\text { Dispersion and exfoliation of graphite in } \\
\text { N-methyl-pyrrolidone }\end{array}$ & [95] \\
\hline & - & $\begin{array}{l}\text { Stably single-layer } \mathrm{G} \text { sheets } \\
\text { in organic solvents }\end{array}$ & Exfoliation-reintercalation-expansion of graphite & [96] \\
\hline & - & G nanoplatelet & Thin films on a low-density polyethylene substrate & [97] \\
\hline \multirow{3}{*}{$\begin{array}{l}\text { Electrochemical } \\
\text { expansion }\end{array}$} & - & Functional G sheets & $\begin{array}{l}\text { Hyperexpanded graphite by electrolysis in a } \mathrm{Li}+ \\
\text { containing electrolyte and in situ electrochemical } \\
\text { diazonium functionalization }\end{array}$ & [98] \\
\hline & - & G flakes & $\begin{array}{l}\text { Cathodic graphite expansion in dimethylformamide } \\
\text { (DMF) and functionalization by reducing aryl } \\
\text { diazonium salts in organic solution }\end{array}$ & [99] \\
\hline & - & G & $\begin{array}{l}\text { Exfoliation temperature increase from } 25 \text { to } 95^{\circ} \mathrm{C} \\
\text { reuslt in decrease of defects and increase of thermal } \\
\text { stability (with } \mathrm{H}_{2} \mathrm{O}_{2} \text { addition) }\end{array}$ & [100] \\
\hline \multirow{3}{*}{ Chemical synthesis } & - & G & Review: general description & [103] \\
\hline & - & Carbon nanoscrolls & $\begin{array}{l}\text { Low-temperature, catalyst-free graphite intercalation } \\
\text { with alkali metals }\end{array}$ & [104] \\
\hline & - & $\begin{array}{l}\text { G and chemically } \\
\text { modified G }\end{array}$ & From colloidal suspensions & [105] \\
\hline \multirow{3}{*}{ Unzipping nanotube } & - & Few-layer nanoribbons & $\begin{array}{l}\text { Mechanical sonication and gas-phase oxidation in } \\
\text { organic solvent of multiwalled carbon nanotubes }\end{array}$ & [106] \\
\hline & - & G nanoribbons & $\begin{array}{l}\text { Lengthwise cutting of MWCNTs by a solution-based } \\
\text { oxidative process }\end{array}$ & [107] \\
\hline & - & G nanoribbons & $\begin{array}{l}\text { Plasma etching of CNT partly embedded in a } \\
\text { polymer film }\end{array}$ & [108] \\
\hline Microwave synthesis & - & $\begin{array}{l}\text { Flower-like G on hexagonal } \\
\text { boron nitride crystals (h-BN) }\end{array}$ & $\begin{array}{l}\text { Microwave G growth on polymethyl methacrylate } \\
\text { (PMMA)-coated h-BN flakes }\end{array}$ & $\begin{array}{l}{[109]} \\
{[110]}\end{array}$ \\
\hline $\begin{array}{l}\text { Chemical and/or } \\
\text { thermal graphene oxide } \\
\text { (GO) reduction }\end{array}$ & - & $\begin{array}{l}\text { Polylactic acid } \\
\text { (PLA)/rGO nanocomposites }\end{array}$ & $\begin{array}{l}\text { Glucose and polhyvinilpyrrolidone (PVP) reduction } \\
\text { of GO mixed with PLA }\end{array}$ & [111] \\
\hline Reduction & - & $\begin{array}{l}\text { rGO } \\
\text { rGO }\end{array}$ & $\begin{array}{l}\text { Two different reducing mixed reagents: } \mathrm{HI} / \mathrm{NH} \text { and } \\
\mathrm{NH} / \mathrm{HI} \text {. Review: } 50 \text { types of reducing agents }\end{array}$ & $\begin{array}{l}{[114]} \\
{[115]}\end{array}$ \\
\hline Other & - & $\begin{array}{l}\text { G } \\
\text { G networks }\end{array}$ & $\begin{array}{l}\text { Review: different sizes and chemical compositions. } \\
\text { Controlled segregation of } \mathrm{G} \text { chemically modified on } \\
\text { liquid interfaces }\end{array}$ & $\begin{array}{l}{[116]} \\
{[117]}\end{array}$ \\
\hline
\end{tabular}

The strong oxidation of graphite produces bulk solid graphite oxide that can be exfoliated in water or other suitable organic solvents to form GO [118-120]; several recent reviews report the synthesis of graphite oxide [121-123]. Graphite oxide can be prepared with Brodie [124], Staudenmaier [125], and Hummer's [126] methods. The synthetic technique and the extent of the reaction influence the degree of graphite oxidation; the most oxidized graphite oxide is produced with the Staudenmaier method, but this reaction may take several days. However, because both Staudenmaier and Brodie methods generate highly toxic $\mathrm{ClO}_{2}$ gas that can decompose in air violently; thus, the most widely used method to prepare graphite oxide is Hummer's method.

With Hummer's method, the GO is prepared by exfoliating graphite oxide obtained from the oxidation of graphite powder with strong chemical oxidants, such as $\mathrm{HNO}_{3}, \mathrm{KMnO}_{4}$, and $\mathrm{H}_{2} \mathrm{SO}_{4}[112,113,126]$. GO can be successively reduced to graphene by the partial restoration of the $\mathrm{sp}^{2}$ - hybridization by thermal [127], chemical [128], electrochemical [129], photothermal [130], 
photocatalytic [69,131], sonochemical [132,133], and microwave reduction methods [134]. The high number of oxygen-containing groups of the obtained GO product permits the interaction with the cations, providing important reactive molecules for the nucleation and growth of nanoparticles and therefore the formation of various graphene-based composites.

\section{The Photocatalytic Process: Fundamentals of Graphene- $-\mathrm{TiO}_{2}$ Photocatalysts}

Photocatalysis is based on the activation of a semiconductor (SC) by the sun or artificial light. When an SC material is irradiated with photons whose energy is higher or equal to its band gap energy, a promotion of an electron from the valence band (VB) to the conduction band (CB) occurs with the concomitant generation of a hole in the valence band VB [135].

In a water system, oxygen adsorbed on the surface of the semiconductor acts as an electron acceptor, while the adsorbed water molecules and hydroxyl anions act as electron donors, leading to the formation of a very powerful oxidizing ${ }^{\bullet} \mathrm{OH}$ radical. The electrons react with oxygen molecules to form the superoxide anion, $\mathrm{O}_{2}{ }^{\bullet}$. In the presence of a contaminant organic molecule (M), adsorbed on the catalyst surface, the ${ }^{\bullet} \mathrm{OH}$ radical is the primary oxidant that reacts to produce adducts, followed by the fragmentation of the molecular structure into several intermediates species until the total mineralization of contaminant is completed with the formation of $\mathrm{CO}_{2}$ and $\mathrm{H}_{2} \mathrm{O}$ [136-138].

The successful of photocatalytic process is therefore strictly dependent on the competition between the reaction of the electron with water on the SC surface and the electron-hole recombination process that releases heat or radiation.

The overall process can be described by the following reactions:

- electron-hole pair generation :

$$
S C+h v \rightarrow S C\left(e_{C B}^{-}+h_{V B}^{+}\right)
$$

- hydroxil radicals formation:

$$
\mathrm{SC}\left(h_{V B}^{+}\right)+\mathrm{H}_{2} \mathrm{O}_{a d s} \rightarrow \mathrm{SC}+\bullet \mathrm{OH}_{a d s}+\mathrm{H}_{a d s}^{+}
$$

- superoxyde formation from electrons in $C B$ and oxygen :

$$
\mathrm{SC}\left(e_{\mathrm{CB}}^{-}\right)+\mathrm{O}_{2 \text { ads }} \rightarrow \mathrm{SC}+\mathrm{O}_{2 a d s}^{-}
$$

- adsorption of $M$ on catalyst :

$$
S C\left(h_{V B}^{+}\right)+M_{a d s} \rightarrow S C+M_{a d s}^{+}
$$

- the hydroxyl radical is the primary oxidant :

$$
\mathrm{OH}_{\text {ads }}+\mathrm{M}_{\text {ads }} \rightarrow \text { intermediate products } \rightarrow \mathrm{CO}_{2}+\mathrm{H}_{2} \mathrm{O}
$$

As an example, Khan et al. [23] defined the different intermediate degradation products of Methyl Orange by using $\mathrm{TiO}_{2}$ photocatalysts that are resumed in Figure 2. The reported compounds are derived from the reaction of ${ }^{\bullet} \mathrm{OH}$ radicals with the final mineralization in $\mathrm{CO}_{2}$ and water.

It is important to consider that, because the photocatalytic process is strictly dependent on the kinetics of charge carriers and redox reactions, the knowledge of the electronic processes that occur at the level of the SC surface are of great importance. In the SC, the oxidation fromphotogenerated holes and the reduction fromphotogenerated electrons may occur simultaneously and, to keep the photocatalyst electrically neutral, should occur at the same rate.

The photocatalytic activity is greatly limited by electron-hole recombination, and therefore several methods are used to increase the efficiency of charge carrier separation and therefore to improve the photocatalytic performance of the SC photocatalyst [139-141]. In this context, the combination of graphene with the SC photocatalyst represents an innovative strategy [55,69,142]. 


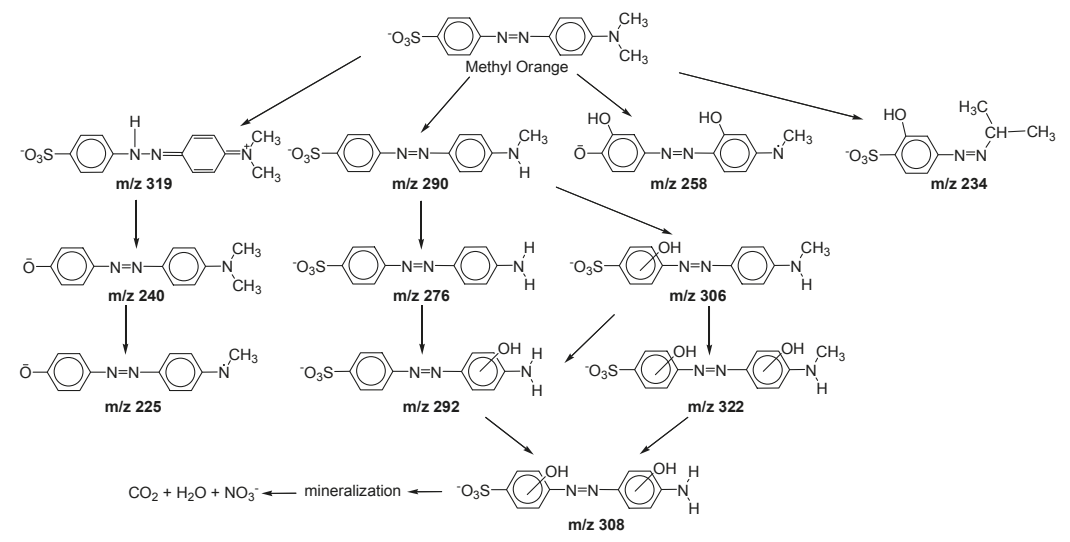

Figure 2. Proposed photodegradation mechanism of Methyl Orange [23].

Titanium dioxide (TiO2) is generally considered the best SC material that can be used as a photocatalyst $[18,139,143]$, showing almost all of the required properties for an efficient photocatalytic process, except for activity under visible light irradiation.

From these considerations, $\mathrm{TiO} 2 /$ graphene nanocomposites $\left(\mathrm{GTiO}_{2} \mathrm{Ns}\right)$ are widely used for photocatalytic applications, exploiting their potential in environmental applications.

The effective role of $\mathrm{G}$ in a photocatalytic event on $\mathrm{GTiO}_{2} \mathrm{Ns}$ has not been completely investigated, or is not completely understood. In order to explain the possible mechanism, the light source (UV or VIS light) and the presence/absence of dye molecules, or rather the presence of a compound able to absorb visible light, are fundamental.

When the target molecule does not adsorb light and is efficiently adsorbed on the photocatalyst surface:

(1) UV light excitation of $\mathrm{GTiO}_{2} \mathrm{Ns}$ photogenerates the electron-hole pairs and the electrons are then injected into graphene due to its more positive Fermi level [144]. This process is favored by the position of the work function of graphene that is $-4.42 \mathrm{eV}$, with respect the conduction band

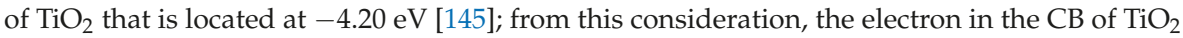
is injected to $\mathrm{G}$. Graphene scavengesphotogenerated electrons by dissolved oxygen; facilitates the hole-electron separation, reducing the recombination of e-(CB) and the holes (VB); and, due to its high carrier mobility, accelerates the electron transport, thus enhancing the photocatalytic performance $[142,146]$.

(2) When the operational mechanism takes place via visible light, the electron transfer of thephotogenerated electron is promoted from the $G$ photoexcited state and then delocalized to the $\mathrm{TiO}_{2}$ surface. M.T Silva et al. indicated, by rGO photoluminescence study, that the photogenerated electrons under Vis or NIR laser can be transferred to the surface of $\mathrm{TiO}_{2}$ with a consequent quenching of photoluminescence; also in this case, charge recombination is inhibited with a consequent increasing of photocatalytic activity under visible light [147]. It is important to know that the presence of $\mathrm{G}$ in $\mathrm{GTiO}_{2} \mathrm{Ns}$ photocatalyst produces a red shift in the absorption, reducing its band gap and thus extending the photoresponse to a longer wavelength [148]. The explanation of visible light activation in the $\mathrm{GTiO}_{2} \mathrm{Ns}$ composites is not clear, but it is possible to attribute this phenomena to the sensitization of $\mathrm{TiO}_{2}$ due to the presence of graphene $[147,149,150]$. In this case, in the visible light excitation of $\mathrm{GTiO}_{2} \mathrm{Ns}$, graphene absorbs the light, and the photoexcited electrons in high energy $\mathrm{G}$ states are delocalized into the $\mathrm{CB}$ of the $\mathrm{TiO}_{2}$ surface with the dissipation of excess energy due to electron vibrational interaction [151]; successively electrons 
react with oxygen, resulting in the formation of superoxide radicals. In Figure 3, the activation mechanisms of $\mathrm{GTiO}_{2} \mathrm{Ns}$ under UV and visible light are reported.

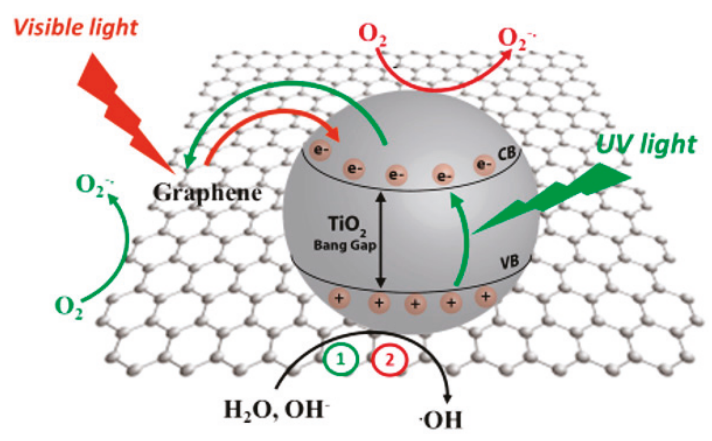

Figure 3. Mechanisms of $\mathrm{UV}$ and visible light activation of $\mathrm{TiO}_{2}$ with $\mathrm{G}$.

When a dye (D) as a target molecule is efficiently adsorbed onto the photocatalyst surface, the UV mechanism is the same as that reported before (1) while, under visible light, different activation pathways can be found. In this case, the dye acts both as a sensitizer for visible-activation and as a pollutant during the photocatalytic process, promoting the electron transfer from the excited dye molecules state to the $\mathrm{TiO}_{2} \mathrm{CB}$ while $\mathrm{G}$ acts as an electron scavenger, as in the UV mechanism [147].

The other possible pathway under visible light involves $G$ which acts as visible light sensitizer promoting the electron transfer to the $\mathrm{TiO}_{2} \mathrm{CB}$ (as in 2) [152-154] (Figure 4). This process is less probable due to the competition between $\mathrm{G}$ and $\mathrm{D}$ as light sensitizers, but in any case is possible.

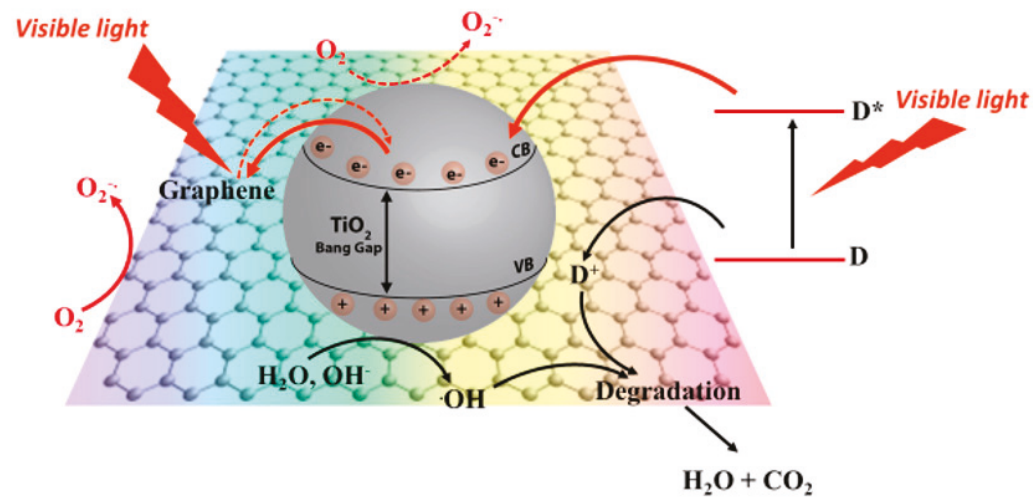

Figure 4. Mechanisms of $\mathrm{UV}$ and visible light activation of $\mathrm{TiO}_{2}$ with $\mathrm{G}$ in the presence of dye (D).

\section{Preparation Methods of $\mathrm{GTiO}_{2} \mathrm{Ns}$}

According to the facts that graphene doping of $\mathrm{TiO}_{2}$ generally contributes to the bathochromic shift of the absorption band, hinders the recombination of $\mathrm{h}^{+} / \mathrm{e}^{-}$by transferring the photoexcited electron to the graphene surface, which also enhances the surface area of $\mathrm{TiO}_{2}$ for better adsorptive properties [155], the investigation of $\mathrm{GTiO}_{2} \mathrm{Ns}$ photoactivity under visible light seems to be crucial. The improvement of performance due to the presence of $\mathrm{G}$ in $\mathrm{GTiO}_{2} \mathrm{Ns}$ photocatalyst is primarily attributed to the extension of the light absorption range, the increase of absorptivity, and the efficient charge separation and transportation. With $\mathrm{GTiO}_{2} \mathrm{Ns}$ photocatalyst, the rate of $\mathrm{h}^{+} / \mathrm{e}^{-}$recombination 
after light excitation decreases [156], while the charge transfer rate of electrons increases in addition to the surface-adsorption of chemical species thanks to $\pi-\pi$ interactions [157].

However, the properties $\mathrm{GTiO}_{2} \mathrm{Ns}$ and different operational parameters, such as the characteristics of substrates, UV-vis or Vis light irradiation, etc., can affect the photocatalytic efficiency [157].

$\mathrm{GTiO}_{2} \mathrm{Ns}$ can be generally categorized into three kinds: $\mathrm{TiO}_{2}$-mounted activated graphene [92], graphene-doped $\mathrm{TiO}_{2}$, and graphene-coated $\mathrm{TiO}_{2}$ [158]. Each of these types exhibits good photocatalytic activity. In order to improve the efficiency, the surface properties of graphene could be adjusted via chemical modification, which facilitates its use in composite materials $[156,159,160]$.

$\mathrm{GTiO}_{2} \mathrm{Ns}$ can be generally realized in two different ways by "ex situ hybridization" or "in situ crystallization". In Figure 5, a schematic representation of ex situ hybridization and in situ crystallization in the synthesis of $\mathrm{GTiO}_{2} \mathrm{NPs}$ is reported.

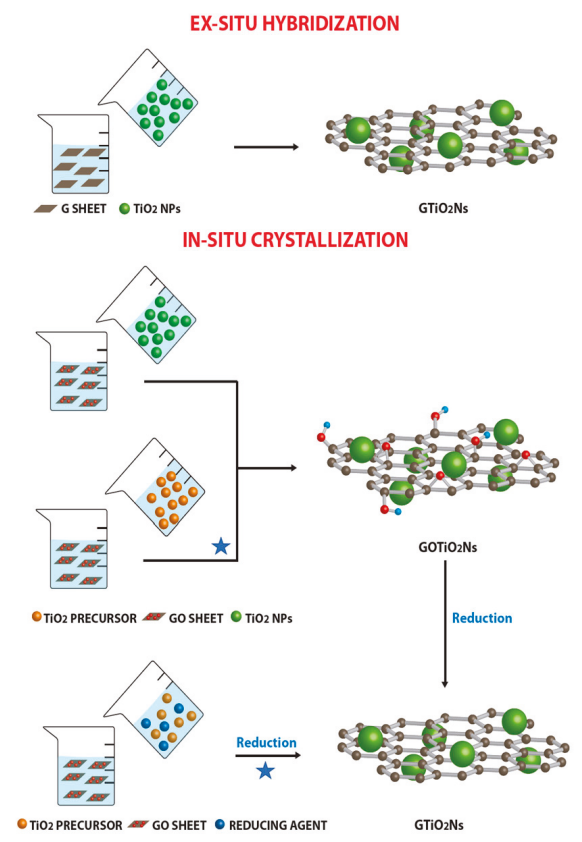

Figure 5. Schematic representation of ex situ hybridization and in situ crystallization in the synthesis of $\mathrm{GTiO}_{2} \mathrm{Ns}$.

Ex situ hybridization (Table 3) involves the mixing of graphene dispersions with pre-synthesized $\mathrm{TiO}_{2}$ nanoparticles $\left(\mathrm{TiO}_{2} \mathrm{NPs}\right.$ ) [147]. To enhance their solubility and improve the quality of $\mathrm{GTiO}_{2} \mathrm{Ns}$ composites, before mixing, $\mathrm{TiO}_{2} \mathrm{NPs}$ and/or graphene sheets can be functionalized by covalent $\mathrm{C}-\mathrm{C}$ coupling $[59,161]$ or non-covalent $\pi-\pi$ stacking reactions [162]. For example, Morawski et al. [163] prepared a visible light-active $\mathrm{TiO}_{2}$-reduced $\mathrm{GO}$ photocatalyst by mechanically mixing $\mathrm{TiO}_{2}$ with an appropriate mass ratio of reduced GO in 1-butyl alcohol and successive ultrasonication. Yong Liu et al. [164] prepared a graphene aqueous dispersion by sonicating a mixture of graphene raw materials with polyvinylpyrrolidone (PVP) as surfactant and a suspension of $\mathrm{TiO}_{2}$ by dispersing $\mathrm{TiO}_{2}$ powder in deionized water with ultrasonication. In this preparation, graphene- $\mathrm{TiO}_{2}$ composite material was obtained by simple mechanical mixing and sonication using anhydrous ethanol to improve the wettability of the dispersion, while spray-coating was carried out both on polycarbonate and on rubber substrates to facilitate the testing of photocatalytic performance. Ramesh Raliya et al. [165] also 
prepared nanomaterial/composite solutions by mixing GO at different concentration ratios to $\mathrm{TiO}_{2}$ and tested their effects on photocatalytic performance.

However, with ex situ hybridization, in some cases it is possible to obtain a low-density and non-uniform coverage of nanostructures by $\mathrm{G}$ sheets [113,166-169].

The most common strategy to synthetize $\mathrm{GTiO}_{2} \mathrm{Ns}$ nanocomposites is represented by in situ crystallization (Table 3). In this case, GO or rGO are usually used as starting materials for the presence of oxygen-containing functional groups on their surface. In fact, they act as a nucleation point for grooving and anchoring semiconductor nanocrystals. The successive reduction of GO generates $\mathrm{GTiO}_{2} \mathrm{Ns}$ with homogeneous distribution on $2 \mathrm{D}$ nanosheets, thereby promoting the direct interaction between semiconductor nanocrystals and G. For this reason, various methods, such as mixing, hydrothermal/solvothermal methods, sol-gel, electrochemical deposition, combustion, microwave, photo-assisted reduction, and self-assemble approaches, can be applied for the synthesis of $\mathrm{GTiO}_{2} \mathrm{Ns}[66,170,171]$.

In the mixing method (M), GO and semiconductors are mixed with stirring and ultrasonication in order to obtain the exfoliation of $\mathrm{GO}$ and, successively, $\mathrm{GO} / \mathrm{TiO}_{2}$ product with uniform distribution; in a second step the reduction of GO is performed [51,172-175].

A strong mixing and the best chemical interaction between $\mathrm{GO}$ and $\mathrm{TiO}_{2}$ can be obtained by applying the sol-gel method (SG). As an example, Zhang et al. [176] used a sol-gel method to prepare a series of $\mathrm{TiO}_{2}$ and graphene sheet composites by using tetrabutyl titanate and graphite oxide and the obtained precursors were calcinated at $450{ }^{\circ} \mathrm{C}$ for $2 \mathrm{~h}$ under air or nitrogen atmospheres. Zabihi et al. [177] prepared photocatalytic composite thin films of $\mathrm{GTiO}_{2} \mathrm{Ns}$ with a low-temperature synthetic process by using $\mathrm{G}$ dispersion and titanium isopropoxide bis (acetylacetonate) solution by using a sol-gel chemical method. Spin- and spray-coating was successively used for films deposition; the use of ultrasonic vibration demonstrated a positive effect from both sol-gel and deposition processes that produced rutile and anatase nanoparticles inclused in a matrix of few-layered graphene thin film.

Gopalakrishnan et al. [178] prepared $\mathrm{TiO}_{2}$-reduced $\mathrm{GO}$ nanocomposites in situ from the incorporation of $\mathrm{TiO}_{2}$ sol into $\mathrm{GO}$ sheets and the successive solvothermal method without the addiction of any chemicals. Shao et al. [179] reported a novel so-called gel-sol process for the synthesis of $\mathrm{TiO}_{2}$ nanorods combining rGO composites by utilizing the triethanolamine as a shape controller and under specific conditions. The as-fabricated hybrid composites presented distinct advantages over the traditional methods in terms of the well-confined $\mathrm{TiO}_{2}$ morphology and the formation of Ti-C bonds between $\mathrm{TiO}_{2}$ nanoroads and rGO simultaneously. Long et al. [180] used the hydrothermal method to prepare efficient visible light active $\mathrm{GTiO}_{2} \mathrm{Ns}$ by using a $\mathrm{GO}$ suspension and $\mathrm{TiO}_{2}$ sol with undergrown $\mathrm{TiO}_{2}$ nanoparticles at $413 \mathrm{~K}$. The study of obtained materials demonstrated high chemical interaction at the interface of GO sheets and the polymeric Ti-O-Ti structure that facilitated the retaining of more alkoxyl groups; the induced crystal disorders and oxygen vacancies contributed positively to the performance of the obtained photocatalyst.

In the hydrothermal/solvothermal methods (HD/SD), semiconductor nanoparticles or their precursors are loaded on $\mathrm{GO}$ sheets that are successively reduced to $\mathrm{GGO}$ involving reactions under controlled temperature and or pressure. For example, Hao Zhang et al. [181] obtained a $\mathrm{GTiO}_{2} \mathrm{Ns}_{\text {(P25) }}$ nanocomposite photocatalyst with a high adsorptivity of dyes and a greater light absorption range by using a one-step hydrothermal reaction obtaining both GO reduction and P25 cover. Hu et al. [182] successfully synthesized different structures of $\mathrm{TiO}_{2}$-graphene composites through the hydrothermal reaction by using GO and different titanium sources in hydrothermal conditions. The results showed the larger interfacial contact between $\mathrm{TiO}_{2}$ and $\mathrm{G}$, in addition to the greater surface area of the poriferous composite. Hamandi et al. [183] studied the influence of the photocatalytic performance of $\mathrm{TiO}_{2}$ nanotubes (NT) resulting from the addition of $\mathrm{GO}$. $\mathrm{TiO}_{2}$ nanotubes were prepared using alkaline hydrothermal treatment of $\mathrm{TiO}_{2} \mathrm{P} 25$ followed by calcination at $400{ }^{\circ} \mathrm{C}$ under air, while GO-NT composites were obtained by the wet impregnation of the as-prepared $\mathrm{TiO}_{2}$ nanotubes onto graphene oxide before reduction under $\mathrm{H}_{2}$ at $200^{\circ} \mathrm{C}$. Sijia et al. [184] synthesized a novel composite photocatalyst, 
reduced graphene oxide (rGO)-modified superlong $\mathrm{TiO}_{2}$ nanotubes with a length of about $500 \mathrm{~nm}$, by an improved hydrothermal process and a heating reflux method.

A hybrid nanocomposite containing nanocrystalline $\mathrm{TiO}_{2}$ and graphene-related materials ( $\mathrm{GO}$ and rGO) was prepared from Kusiak et al. [185] by using the hydrothermal method under elevated pressure. In this preparation, the presence of graphitic carbon depends on temperature, the type of modification method, and the preparation conditions, obtaining multilayer GO flakes in comparison to rGO flakes. This multilayer character produced the most intensive time resolved microwave conductivity signals under both UV and visible illumination for materials modified with $\mathrm{GO}$, indicating that more electrons are induced in the conduction band of hybrid nanocomposites. $\mathrm{Li}$ et al. [186] synthesized reduced graphene oxide- $\mathrm{TiO}_{2}\left(\mathrm{rGO}-\mathrm{TiO}_{2}\right)$ composites with a sandwich-like structure by using a simple solvothermal method. Hemraj et al. [187] synthesized nanocrystalline anatase $\mathrm{TiO}_{2}$-GO nanocomposites by two steps with the initial preparation of anatase $\mathrm{TiO}_{2} \mathrm{NPs}$ by a simple sol-gel method and the successive decoration of GO on its surface by using a facile solvothermal method. Ju Hu et al. [188] synthesized $\mathrm{TiO}_{2} /$ reduced graphene oxide nanocomposites by using a one-step surfactant-assisted hydrothermal method. Compared with the control $\mathrm{TiO}_{2} / \mathrm{rGO}$ nanocomposite, $\mathrm{TiO}_{2} / \mathrm{rGO}-\mathrm{X}(\mathrm{X}=$ sodium dodecyl benzene sulfonate, Triton $\mathrm{X}-100$, and acetyl trimethyl ammonium bromide) presented excellent photocatalytic activity. The study indicated that the surfactant-assisted hydrothermal method is an effective approach to improve the structure, morphology, and photocatalytic performance of $\mathrm{TiO}_{2} / \mathrm{rGO}$ composites.

Semiconductor nanostructures can be electrolytically deposited on the surface of graphene-based substrates, at low temperature condition, from an aqueous solution containing the semiconductor. For example, Ming-Zheng Ge et al. [189] adopted both electrodeposition and carbonation methods to deposit rGO films on $\mathrm{TiO}_{2}$ nanotubes obtained with two-step electrochemical anodization. Recently, Guimaraes de Oliveira et al. [190] used the electrochemical method to deposite $\mathrm{GTiO}_{2} \mathrm{Ns}_{\text {composite }}$ film on a Ti substrate by using GO and Ti(IV) aqueous solution, demonstrating a photocatalytic activity almost twice as high as that observed for the $\mathrm{TiO}_{2}$ only film.

The microwave-assisted strategy, in this context, addresses the synthesis of semiconductor nanomaterials of a controlled size and shape. For example, Shanmugama et al. [191] synthesized $\mathrm{GTiO}_{2} \mathrm{Ns}$ nanocomposites by a novel surfactant-free, environmentally friendly one-pot in situ microwave method. This method leads to the uniform distribution of $\mathrm{TiO}_{2}$ nanoparticles on $\mathrm{G}$ sheets with the binding nature of $\mathrm{TiO}_{2}$. Wang et al. [192] reduced GO with both direct and microwave-assisted reduction in the presence of Ti powders, showing that the microwave effect decreased the reduction time. In this case, Ti ions derived from the reaction of Ti powder with GO were hydrolytically transferred to $\mathrm{TiO}_{2}$ with the formation of $\mathrm{rGO}-\mathrm{TiO}_{2}$, which was proven to be an active material in the removal of methylene blue. Yang et al. [193] prepared nanocomposites of $\mathrm{TiO}_{2}$ and $\mathrm{rGO}$, with a fast and simple microwave irradiation method by the reaction of graphene-oxide and commercial $\mathrm{TiO}_{2}$ nanoparticles in water/ethanol solvent, examining different microwave powers with different time intervals. The effect of time and power on absorption wavelength and the creation of defects in the graphene layer was examined, obtaining an optimum irradiation time in which the nanocomposite presented the highest absorption wavelength (the smallest band gap), and the optimum value for microwave power in which the nanocomposite had the lowest number of defects. First, GO was prepared using a modified Hummer's method, and then $\mathrm{TiO}_{2}$ and the mixture of water/ethanol and graphene-oxide (GO) was used for the hydrolysis of $\mathrm{TiO}_{2}$, followed by its mounting on graphene-oxide. In this way, microwave irradiation reduced $\mathrm{GO}$ to graphene with the formation of $\mathrm{TiO}_{2} / \mathrm{rGO}$ nanocomposites.

Other methods have been investigated, such as that proposed by Pu et al. [194] regarding the synthesis of $\mathrm{TiO}_{2}-\mathrm{rGO}$ nanocomposites, conducted simultaneously with the photoreduction (PR) of GO nanosheets in a simple $\mathrm{GO}$ and $\mathrm{TiO}_{2}$ ethanol system, demonstrating a facile and environmentally friendly strategy for the in situ preparation of the $\mathrm{TiO}_{2}-\mathrm{rGO}$ hybrid "dyade". In Table 3, the principal synthesis methods of $\mathrm{GTiO}_{2} \mathrm{Ns}$ are summarized. 
Table 3. The synthesis methods of Graphene Based $\mathrm{TiO}_{2}$ nanocomposites.

\begin{tabular}{|c|c|c|c|c|}
\hline \multicolumn{5}{|c|}{ Ex-Situ Hybridization } \\
\hline Photocatalyst & Synthetic Route & Starting Graphite & Starting Semiconductor & Refs. \\
\hline $\mathrm{rGO} / \mathrm{TiO}_{2}$ & $\begin{array}{l}\text { Mechanical mixing and } \\
\text { ultrasonication }\end{array}$ & rGO & $\begin{array}{l}\mathrm{TiO}_{2} \mathrm{NPs} \text { in } \\
\text { 1-butyl alcohol }\end{array}$ & [163] \\
\hline $\mathrm{G} / \mathrm{TiO}_{2}$ & $\begin{array}{l}\text { Mechanical mixing and } \\
\text { ultrasonication }\end{array}$ & $\mathrm{G}$ in $\mathrm{PVP} /$ water & $\begin{array}{l}\mathrm{TiO}_{2} \mathrm{NPs} \text { anatase } \\
\text { in water }\end{array}$ & [164] \\
\hline $\mathrm{GO} / \mathrm{TiO}_{2}$ & Mechanical mixing & GO & Titanium isopropoxide & [165] \\
\hline \multicolumn{5}{|l|}{ In-Situ Crystallization } \\
\hline \multirow[t]{2}{*}{$\mathrm{rGO} / \mathrm{TiO}_{2}$} & $\begin{array}{l}\text { M with GO and PR } \\
\text { reduction }\end{array}$ & GO & $\mathrm{TiO}_{2} \mathrm{NPs}$ & [174] \\
\hline & $\mathrm{M}$ and $\mathrm{GO}$ and ST reduction & GO & $\mathrm{TiO}_{2} \mathrm{NPs}$ & [175] \\
\hline $\mathrm{G} / \mathrm{TiO}_{2}$ & ST & GO & Tetrabutyl titanate & [145] \\
\hline $\mathrm{G} / \mathrm{TiO}_{2}$ & SG & $\mathrm{rGO}$ & Titanium isopropoxide & [146] \\
\hline $\mathrm{G} / \mathrm{TiO}_{2}$ & HD & GO & P25 & [147] \\
\hline $\mathrm{rGO} / \mathrm{TiO}_{2}$ & SG & GO & Tetrabutyl titanate & [176] \\
\hline $\mathrm{G} / \mathrm{TiO}_{2}$ & SG & G dispersion & Titanium isopropoxide & [177] \\
\hline $\mathrm{rGO} / \mathrm{TiO}_{2}$ & Solvothermal SG & GO sheets & $\mathrm{TiO}_{2}$ sol & [178] \\
\hline $\mathrm{rGO} / \mathrm{TiO}_{2}$ & SG & GO & Titanium isopropoxide & [179] \\
\hline $\mathrm{G} / \mathrm{TiO}_{2}$ & $\mathrm{HD}$ & GO suspension & $\mathrm{TiO}_{2}$ sol & [180] \\
\hline $\mathrm{G} / \mathrm{TiO}_{2}$ & one-step HD & GO water/ethanol & $\mathrm{TiO}_{2}$ & [181] \\
\hline $\mathrm{G} / \mathrm{TiO}_{2}$ & $\mathrm{HD}$ & GO & Different Ti sources & [182] \\
\hline $\mathrm{G} / \mathrm{TiO}_{2}$ & $\begin{array}{l}\text { Wet impregnation and } \\
\text { thermal reduction }\left(\mathrm{H}_{2}\right)\end{array}$ & GO & $\begin{array}{l}\mathrm{TiO}_{2} \text { nanotubes from } H D \\
\text { of } \mathrm{TiO}_{2} \mathrm{P} 25\end{array}$ & [183] \\
\hline rGO superlong $\mathrm{TiO}_{2}$ & HD and heating reflux & GO & Super long $\mathrm{TiO}_{2}$ & [184] \\
\hline $\begin{array}{l}\mathrm{GO} \text { and } \mathrm{rGO} / \mathrm{TiO}_{2} \\
\text { (nanocristals) }\end{array}$ & Elevated pressure HD & $\mathrm{GO}$ and $\mathrm{rGO}$ & $\mathrm{TiO}_{2}$ & [185] \\
\hline $\begin{array}{l}\mathrm{rGO} / \mathrm{TiO}_{2} \\
\text { sandwich-like } \\
\text { structure }\end{array}$ & $\mathrm{HD} / \mathrm{ST}$ & rGO & Butyl titanate & [186] \\
\hline $\begin{array}{l}\text { nanocrystalline } \\
\text { anatase } \mathrm{TiO}_{2} \text {-GO }\end{array}$ & SG and GO decoration by ST & GO & Anatase $\mathrm{TiO}_{2} \mathrm{NPs}$ by $S G$ & [187] \\
\hline $\begin{array}{l}\mathrm{TiO}_{2} / \mathrm{rGO}-\mathrm{X} \\
\text { nanocomposites }\end{array}$ & $\begin{array}{l}\text { One-step surfactant } \\
(\mathrm{X}) \text {-assisted HD }\end{array}$ & GO & $\mathrm{TiO}_{2}(\mathrm{P} 25)$ & [188] \\
\hline $\begin{array}{l}\text { rGO films on } \mathrm{TiO}_{2} \\
\text { nanotubes }\end{array}$ & $\begin{array}{l}\text { Two-step ED and } \\
\text { carbonation techniques }\end{array}$ & rGO & $\begin{array}{l}\text { Two-step anodized } \mathrm{TiO}_{2} \\
\text { nanotubes from Ti foils }\end{array}$ & [189] \\
\hline $\begin{array}{l}\text { Ti plate deposited } \mathrm{TiO}_{2} \\
\text { and GO film }\end{array}$ & ED & $\begin{array}{l}\text { GO from } \\
\text { nanographite }\end{array}$ & $\begin{array}{l}\text { Ti plate and } \mathrm{K}_{2} \mathrm{TiF}_{6} \\
\text { aqueous solution }\end{array}$ & [190] \\
\hline $\mathrm{G} / \mathrm{TiO}_{2}$ & MW & GO & $\mathrm{TiCl}_{4}$ & [191] \\
\hline $\mathrm{rGO} / \mathrm{TiO}_{2}$ & MW & GO & Ti powder & [192] \\
\hline $\mathrm{rGO} / \mathrm{TiO}_{2}$ & MW & GO & $\mathrm{TiO}_{2} \mathrm{NPs}$ & [193] \\
\hline $\mathrm{rGO} / \mathrm{TiO}_{2}$ & PR & GO & $\mathrm{TiO}_{2} \mathrm{NPs}$ & [194] \\
\hline $\mathrm{rGO} / \mathrm{TiO} 2$ & PR & GO & Colloidal $\mathrm{TiO}_{2}$ & [156] \\
\hline
\end{tabular}

\section{Photocatalytic Degradation of Dyes with $\mathrm{GTiO}_{2} \mathrm{Ns}$}

Dye molecules, which are solubilized during several application processes, present different colors derived from the selective absorption of light. Coloring properties of dyes depend on their chemical structure consisting of two fundamental components: the chromophore and the auxochrome. The chromophore is a covalently unsaturated group, which is responsible for the color production 
for the absorption in the UV or visible region; the auxochrome is supplementary to the chromophore, and influences the solubility in water and the affinity towards a particular support [195]. Concerning their uses, dyes can be anionic, cationic, and non-ionic; anionic dyes are divided into direct, acid, and reactive dyes, while cationic dyes are basic [196]. Water treatments by using $\mathrm{GTiO}_{2} \mathrm{Ns}$ in the photocatalytic degradations of dyes became very important due to the danger of dyes as environmental pollutants [142].

Methylene blue (MB) was first prepared by Caro in 1876 as an aniline-derived dye for textiles, and is largely used as a water-soluble cationic dye in the dyeing of paper, wood, plastic, silk, and cotton, as well as in scientific research and pharmaceutical industries [197,198]. Kyeong Min Cho et al. [8], to obtain MB photodegradation, used hydrothermal methods in the self-assembly of $\mathrm{TiO}_{2}$ precursors, $\mathrm{GO}$, and a surfactant to prepare $\mathrm{rGO}$ mesoporous $\mathrm{TiO}_{2}$; this material showed high photocatalytic performances in the MB degradation test, good ability in the charge separation, and a large surface area compared to typical $\mathrm{GTiO}_{2} \mathrm{Ns}$.

Hanan H. Mohamed [199] recently described the simultaneous photoassisted oxidation of MB by using new synthesized hierarchical structures of anatase $/$ rutile $\mathrm{TiO}_{2}$ microsphere-rGO nanocomposites. Interestingly, rutile/anatase phase transformation was observed upon changing the GO content. The synthesized nanocomposites showed enhanced photocatalytic activity for the dye degradation compared to pristine $\mathrm{TiO}_{2}$ nanoparticles that was attributed to the synergetic effect between anatase and rutile in the synthesized $\mathrm{TiO}_{2}$ microsphere composites. Also, Zhang et al. [200] synthesized graphene-supported mesoporous titania nanosheets $\left(\mathrm{GTiO}_{2} \mathrm{Ns}\right)$ by using liquid-phase exfoliated $\mathrm{G}$ as a template and sandwich-like G-silica as intermediates. $\mathrm{GTiO}_{2} \mathrm{Ns}$ showed a mesoporous structure formed by crystalline $\mathrm{TiO}_{2}$ nanoparticles anchored on $\mathrm{G}$ nanosheets that showed high surface areas. These characteristics significantly enhanced the photocatalytic activity of $\mathrm{TiO}_{2}$ in the $\mathrm{MB}$ degradation.

Najafi et al. [201] fabricated $\mathrm{TiO}_{2}-\mathrm{GO}$ nanocomposites with different nanowire and nanoparticle morphologies of $\mathrm{TiO}_{2}$ by using a one-step hydrothermal method. The different morphologies of $\mathrm{TiO}_{2}$ were grown on the surface of the GO sheets, previously synthesized by the modified Hummer's method. The obtained $\mathrm{TiO}_{2}$-GO nanocomposites showed a tetragonal structure and covalent bonds between $\mathrm{TiO}_{2}$ nanostructures and $\mathrm{GO}$ sheets. The best photodegradation rate of $\mathrm{MB}$ was found by using $\mathrm{TiO}_{2}$ nanowire-GO nanocomposites. Divya et al. [202] used microwave irradiation of different $\mathrm{GO}$ weights and tetrabutyl titanate in isopropyl alcohol to obtain $\mathrm{TiO}_{2}$ hybridation with the formation of $\mathrm{GTiO}_{2} \mathrm{Ns}$ nanocomposites. In this method, the irradiation with microwaves increase the temperature in a short time, favoring the $\mathrm{GO}$ reduction to $\mathrm{G}$ and the growth of $\mathrm{TiO}_{2}$ nanoparticles on the $\mathrm{G}$ surface. The obtained $\mathrm{GTiO}_{2} \mathrm{Ns}$ nanocomposites presented efficient electron conductivity in $\mathrm{G}$, therefore showing a reduced electron-hole recombination rate.

Another example is that of Sohail et al. [203], who prepared GO nanosheets by using a modified Hummer's technique with the successive conversion into particles by a spray-drying method. $\mathrm{TiO}_{2}$ nanoparticles were grown on the surface of GO particles to obtain $\mathrm{rGO}-\mathrm{TiO}_{2}$ nanocomposites that showed better photocatalytic activities upon the degradation of $\mathrm{MB}$ compared to pure $\mathrm{TiO}_{2}$, also showing in this case that $\mathrm{rGO}$ played an important role in the charge recombination to enhance the electron-hole separation.

Tseng et al. [204] studied a facile process to fabricate two-dimensional titania nanosheets (t-NS) by using $\mathrm{GO}$ as a support with in situ growth of anatase $\mathrm{TiO}_{2}$ on $\mathrm{GO}$ suspended in butanol by combining the sol-gel and solvothermal processes without further calcination. Significant amounts of MB molecules can easily be adsorbed on the intrinsic graphitic structure. An optimum rate of hole titration by ethylenediaminetetraacetic acid was essential to efficiently reduce the recombination of charge carriers and consequently produce more active radicals to decompose MB. The strong interaction between graphitic and titania structures, rather than the crystallite size of anatase, dominated the photoreduction capability of t-NS.

Similarly, Minella et al. [205] obtained $\mathrm{rGO}-\mathrm{TiO}_{2}$ and $\mathrm{rGO}-\mathrm{SiO}_{2}$ hybrid materials by reducing different quantities of $\mathrm{GO}$ with hydrazine in the presence of $\mathrm{TiO}_{2}$ and $\mathrm{SiO}_{2}$ nanoparticles; 
the photocatalytic activity of these nanomaterials was evaluated in the degradation of MB under both UV-vis and only visible light irradiation. The results showed that MB was strongly adsorbed on these new materials with an increase of degradation rates with respect to pristine semiconductors. The visible light degradation of MB was attributed to the dye-sensitization mechanism, while the UV-vis degradation was considered to be the typical semiconductor photocatalytic mechanism.

"Biphasic $\mathrm{TiO}_{2}$ nanoparticles" and their G nanocomposites were synthesized by Raja et al. [206] by the hydrothermal method. Introducing high surface area, G suppressed the electron-hole pair recombination rate in the nanocomposites. Further, the nanocomposites showed a red-shift of the absorption edge with a contraction of the band gap from $2.98 \mathrm{eV}$ to $2.85 \mathrm{eV}$. The characterization of photocatalytic activities under natural sunlight and UV-filtered sunlight irradiation revealed that the $\mathrm{GTiO}_{2} \mathrm{Ns}$ composite exhibited about a 15- and 3.5-fold increase in the degradability of Congo red and $\mathrm{MB}$ dyes, respectively, in comparison to pristine $\mathrm{TiO}_{2}$. The authors therefore developed a visible light active $\mathrm{G}$ composite catalyst that can degrade both cationic and anionic dyes, making it potentially useful in environmental remediation and water splitting applications under direct sunlight.

The ex situ hydrothermal method was proposed from Verma et al. [207] to synthesize rGO mixed $\mathrm{TiO}_{2}$ nano-composites. The study demonstrated that the cooperation between the optimal phase ratio of $\mathrm{TiO}_{2}$ (anatase/rutile) and rGO produced a positive system in the photocatalytic degradation test with $\mathrm{MB}$ other than antibacterial activity. Atchudan et al. [208] used a solvothermal method to prepare GO grafting $\mathrm{TiO}_{2}$ nanocomposites and studied it as a photoactive material under UV-light irradiation in the degradation of $\mathrm{MB}$ and methyl orange. The obtained degradation efficiency, compared with only $\mathrm{TiO}_{2}$, demonstrated the important function that $\mathrm{GO}$ played in the increase of performance due to the increase of light absorption and reducing charge recombination.

Darvishi et al. [209] instead used titanium butoxide (TBO) as a $\mathrm{TiO}_{2}$ precursor, commercial $\mathrm{TiO}_{2}$, and $\mathrm{GO}$ in a water/ethanol mixture to produce hydrolytically, and under microwave irradiation, $\mathrm{rGO}^{-\mathrm{TiO}_{2}}$ nanocomposites; these showed high conductive and light absorption properties, demonstrating an enhancement of photocatalytic MB degradation. In these nanocomposites, the content of $\mathrm{G}$ improved the photocatalytic performances of the photocatalysts.

An example of an eco-friendly method was studied by Rezaei et al. [210], who synthesized $\mathrm{TiO}_{2}$-graphene nanocomposites by the addition of the "blackberry juice" to GO as a reducing agent to produce rGO nano-sheets. The obtained $\mathrm{TiO}_{2}$ (anatase)-rGO materials exhibited an excellent photocatalytic activity toward $\mathrm{MB}$ degradation due to the enlarged surface area and the collaborative effect of rGO. Shanmugam et al. [191] synthesized $\mathrm{GTiO}_{2} \mathrm{Ns}$ nanocomposites by a surfactant-free, environmentally friendly one-pot in situ microwave method. $\mathrm{TiO}_{2}$ nanoparticles of $5-10 \mathrm{~nm}$ were distributed on the $\mathrm{G}$ sheets. The photocatalytic activity of pure $\mathrm{TiO}_{2}$ and $\mathrm{GTiO}_{2} \mathrm{Ns}_{\text {sanocomposites }}$ was studied under UV and visible light irradiation sources with MB. The studies revealed the highest degradation efficiency of $97 \%$ with UV light and $96 \%$ with visible light irradiation by using the $\mathrm{GTiO}_{2} \mathrm{Ns}$ photocatalyst, opening the possibility of using this material for industrial wastewater treatment.

The sol-gel technique was used by Rezaei [211], who prepared $\mathrm{GO}-\mathrm{TiO}_{2}$ nanocomposites by evaluating the photocatalytic activities of $\mathrm{MB}$ aqueous solution under sunlight irradiation. The results showed that the nanocomposite containing $9.0 \mathrm{wt} \%$ of GO had the highest photocatalytic performance in the MB degradation to either "single-phase anatase" or other composites containing different GO quantities. The improvement of the photocatalytic activity was attributed to the favorable effect of the distribution of $\mathrm{TiO}_{2}$ nanoparticles of less than $20 \mathrm{~nm}$ on $\mathrm{GO}$ sheets.

UV-assisted photocatalytic reduction of $\mathrm{GO}$ by $\mathrm{TiO}_{2}$ nanoparticles in ethanol was used by Charoensuk et al. [212] in the preparation of $\mathrm{rGO}^{-\mathrm{TiO}_{2}}$ nanocomposites. The photocatalytic activity of prepared $\mathrm{rGO} / \mathrm{TiO}_{2}$ and $\mathrm{GO} / \mathrm{TiO}_{2}$ nanocomposites was evaluated by the kinetics of the photocatalytic degradation of MB under UV irradiation. Significant roles in the MB photodegradation were played by important factors such as the bandgap, electron-hole recombination, characteristics of surface (area and functional groups), and adsorption capacity of nanocomposites. The results revealed that 
$\mathrm{rGO} / \mathrm{TiO}_{2}$ and $\mathrm{GO} / \mathrm{TiO}_{2}$ nanocomposites exhibited efficient charge separation, showing about $500 \%$ improvement of photocatalytic activity in $\mathrm{MB}$ photodegradation compared to pristine $\mathrm{TiO}_{2}$.

The solvothermal technique was used by Wang et al. [213], who prepared an efficient photocatalyst of nano $\mathrm{TiO}_{2}$-functionalized $\mathrm{GO}$ nanocomposites. This nanomaterial showed an quadruple increase in $\mathrm{MB}$ photodegradation activity with respect to that obtained by using the P25-graphene composite photocatalyst. Liu et al. [214] instead used an interesting impregnation-hydrothermal method to prepare highly distributed $\mathrm{TiO}_{2}$ nanoparticles with in situ growth on functional G (FG), which was before obtained by modifying $\mathrm{GO}$ by using triethanolamine. The obtained $\mathrm{FGTiO}_{2} \mathrm{Ns}$ photocatalyst showed better photocatalytic activity under UV light irradiation with respect to pure $\mathrm{TiO}_{2}$ and $\mathrm{GO}^{-} \mathrm{TiO}_{2}$ prepared by other similar methods, also revealing considerable photocatalytic skill under visible light irradiation.

A fruitful method to produce expanded exfoliated GO (EGO) was used by Baldissarelli et al. [215]. The use of ozone exposure and thermal treatment transformated the graphite surface to a G-like surface containing oxygen and $\mathrm{sp}^{3}$ carbon. The EGO, obtained through thermal treatment, produced, with the addition of $\mathrm{TiO}_{2}$ nanoparticles, photocatalytic $\mathrm{TiO}_{2}$-EGO nanocomposites that demonstrated higher activity with respect to that produced by the common Hummer's method. In particular, $\mathrm{TiO}_{2}-\mathrm{EGO}$ showed enhanced $\mathrm{MB}$ photodegradation under UV light compared to $\mathrm{TiO}_{2} \mathrm{P} 25$.

A new nanomaterial composed of ultrasmall $\mathrm{TiO}_{2}$ nanoparticles and $\mathrm{rGO}$ nanosheets was prepared by $\mathrm{Gu}$ et al. [216], who used glucosamine in alkaline conditions under hydrothermal treatment. In this synthesis, glucosamine regulated the growth and homogeneity of $\mathrm{TiO}_{2}$ nanoparticles dispersed on the $G$ structure, permitting the formation of the expected $\mathrm{GTiO}_{2} \mathrm{Ns}$ products, demonstrating that $\mathrm{TiO}_{2}$ nanoparticles about $13 \mathrm{~nm}$ in diameter were strongly anchored on $\mathrm{G}$. Different $\mathrm{GTiO}_{2} \mathrm{Ns}$ samples were calcined at several temperatures; in particular, the $\mathrm{GTiO}_{2} \mathrm{Ns}$ sample treated at $700{ }^{\circ} \mathrm{C}$ showed good photocatalytic activity in $\mathrm{MB}$ photodegradation compared to those produced at other calcination temperatures.

Moreover, Fan et al. [217] used the hydrothermal method to synthesize $\mathrm{TiO}_{2}$ nanospindles, which are featured by large exposed $\left\{\begin{array}{lll}0 & 0 & 1\end{array}\right\}$ facets, and then fabricated $\mathrm{TiO}_{2}$ nanospindles/reduced GO nanocomposites $\left(\mathrm{rGO}-\mathrm{TiO}_{2}\right)$. The photocatalytic activity in the photodegradation of $\mathrm{MB}$ showed an impressive photocatalytic enhancement of $\mathrm{rGO}-\mathrm{TiO}_{2}$ with respect to pure $\mathrm{TiO}_{2}$ nanospindles. In addition, Sun et al. [218] used a one-step in situ hydrothermal method to prepare chemically bonded $\mathrm{GTiO}_{2}$ nanorods hybrid composites with high dispersity by using $\mathrm{GO}$ and $\mathrm{TiO}_{2}(\mathrm{P} 25)$ as the starting materials without using reducing agents. Ultraviolet-visible diffuse reflectance measurements of the composites showed an enhanced light absorption and a red shift of absorption edge. When $\mathrm{GTiO}_{2} \mathrm{Ns}$ nanorods hybrid composites were used as photocatalysts, they showed an enhancement of photocatalytic performance in the photodegradation of $\mathrm{MB}$ under visible light irradiation compared to that of pristine $\mathrm{TiO}_{2}$ nanorods.

Rong et al. [219] prepared different $\mathrm{GTiO}_{2} \mathrm{Ns}$ photocatalysts with a simple hydrothermal method. First, GO (obtained from graphite oxidation) was dispersed in a water/ethanol solution with ultrasonic treatment, after which $\mathrm{TiO}_{2}$ was added and a thermal treatment at $120^{\circ}$ for $12 \mathrm{~h}$ was used. A series of $\mathrm{GTiO}_{2} \mathrm{Ns}$ photocatalysts obtained with different oxidation times (in the GO production from graphite) and GO contents were obtained. When these materials were applied to the photodegradation of MB under visible light irradiation, they exhibited excellent photocatalytic activities.

Gupta et al. [220] proposed a strategy to fabricate G quantum dots (GQDs) infilled $\mathrm{TiO}_{2}$ nanotube arrays hybrid structure (GQDs- $\left.\mathrm{TiO}_{2} \mathrm{NTAs}\right)$ for the application of $\mathrm{MB}$ degradation under UV light irradiation. In particular, anodic oxidation of a Ti sheet by using an impregnation method produced the fill of GQDs into $\mathrm{TiO}_{2}$ NTAs. The application of this material in the adsorption and photodegradation of MB in an aqueous solution under UV light irradiation showed high photocatalytic efficiency, which was attributed to the favorable visible light absorption and to efficiency in the transfer of photogenerated electrons from the $\mathrm{TiO}_{2} \mathrm{NTAs}$ to GQDs that produced large photoinduced charge separation. No less important was the strong adsorption capacity of the GQDs to MB molecules. 
GP-wrapped $\mathrm{TiO}_{2}\left(\mathrm{GwTiO}_{2}\right)$ hybrid material was fabricated by Ni et al. [221] with the simultaneous reduction and wrapping of $\mathrm{GO}$ on the surface of high-reactive anatase $\mathrm{TiO}_{2}$, based on the surface negatively charged property of $\mathrm{GO}$. $\mathrm{GwTiO}_{2}$ gave a strong red-shifted light absorption edge and a contracted bandgap compared to that of GP randomly supported $\mathrm{TiO}_{2}$; this behavior was attributed to the positive chemical interaction between $\mathrm{TiO}_{2}$ and $\mathrm{G}$. The photocatalytic $\mathrm{MB}$ degradation under a xenon lamp and visible light irradiation confirmed the best quality of this nanomaterial. Furthermore, Yang et al. [222] prepared $\mathrm{TiO}_{2} / \mathrm{G}$ porous composites with $\mathrm{rGO}$ by using a template of $\mathrm{G}$ microsphere colloidal crystals that showed high light absorbing properties, and good MB adsorption properties, other than a fast ability in the charge transportation and separation. These porous composites showed high degradation activities in MB degradation under visible light irradiation with a constant rate almost 6.5 times higher than that of P25 under the same conditions.

Also, Suave et al. [223] prepared photocatalytic $\mathrm{TiO}_{2}$ nanocomposites with different loads of ozonated graphene (OGn) and evaluated the performances in photocatalytic MB degradation and other dyes using UVC irradiation. Although the photocatalytic activity decreased with each cycle, it is possible to reuse the nanocomposite that facilitates its practical application for water treatment.

In Table 4, the different preparation methods of $\mathrm{GTiO}_{2} \mathrm{Ns}$ applied to $\mathrm{MB}$ photodegradation are listed.

Table 4. Photocatalytic applications of Graphene Based $\mathrm{TiO}_{2}$ nanocomposites in the degradation of Methylene Blue.

\begin{tabular}{|c|c|c|c|c|c|c|}
\hline Photoactive Nanomaterials & $\begin{array}{c}\text { Dye Conc. } \\
\text { (mg/L) }\end{array}$ & $\begin{array}{c}\text { Catalyst } \\
\text { Quantity (g/L) }\end{array}$ & $\begin{array}{l}\text { Light } \\
\text { Source }\end{array}$ & $\begin{array}{l}\text { Irradiation } \\
\text { Time (min) }\end{array}$ & $\begin{array}{c}\text { Degradation } \\
(\%)\end{array}$ & Refs. \\
\hline $\mathrm{G} / \mathrm{TiO}_{2}$ & 9.60 & 0.33 & Visible & 180 & 90 & [8] \\
\hline P25-G & 8.64 & 0.6 & UV & 60 & 85 & [199] \\
\hline P25-G & 8.64 & 0.6 & Visible & 60 & 65 & [199] \\
\hline $\mathrm{G} / \mathrm{TiO}_{2}$ & 10 & 0.6 & UV & 120 & 100 & [200] \\
\hline $\mathrm{G} / \mathrm{TiO}_{2}$ & 10 & 0.2 & UV & 40 & 85 & [202] \\
\hline $\mathrm{TiO}_{2} @ \mathrm{rGO}$ & - & 0.1 & UV & 120 & 92 & [203] \\
\hline $\mathrm{GO} / \mathrm{TiO}_{2}$ & 15 & 0.2 & UV & 350 & 92 & [204] \\
\hline $\mathrm{TiO}_{2}-\mathrm{G}$ & 0.13 & 0.5 & UV-Vis & 450 & 100 & [205] \\
\hline $\mathrm{rGO} / \mathrm{TiO}_{2}$ & 320 & 0.5 & Visible & 90 & 95 & [207] \\
\hline $\mathrm{TiO}_{2} / \mathrm{GO}$ & - & 0.2 & UV & 25 & 100 & [208] \\
\hline $\mathrm{TiO}_{2} / \mathrm{G}$ & 0.13 & 0.4 & UV & 60 & 96 & [209] \\
\hline $\mathrm{TiO}_{2} / \mathrm{G}$ & 3 & 0.48 & Visible & 90 & 100 & [210] \\
\hline $\mathrm{G} / \mathrm{TiO}_{2}$ & 3.2 & 0.2 & UV & 180 & 97 & [191] \\
\hline $\mathrm{G} / \mathrm{TiO}_{2}$ & 3.2 & 0.2 & Visible & 240 & 96 & [191] \\
\hline $\mathrm{TiO}_{2} / \mathrm{GO}$ & 3 & 0.48 & Visible & 60 & 94 & [211] \\
\hline $\mathrm{TiO}_{2} / \mathrm{GO}$ & 5 & 0.1 & UV & 40 & 93 & [213] \\
\hline $\mathrm{TiO}_{2} / \mathrm{GO}$ & 5 & 0.1 & Visible & 40 & 70 & [213] \\
\hline $\mathrm{TiO}_{2}$-Graphite Oxide & 10 & 0.5 & UV & 60 & 100 & [215] \\
\hline $\mathrm{TiO}_{2} / \mathrm{G}$ & 10 & 0.2 & UV & 20 & 97 & [216] \\
\hline $\mathrm{TiO}_{2} / \mathrm{rGO}$ & 10 & 0.17 & UV & 60 & 100 & [217] \\
\hline $\mathrm{G} / \mathrm{TiO}_{2}$ & 5 & 0.5 & Visible & 100 & 70 & [218] \\
\hline $\mathrm{TiO}_{2} / \mathrm{G}$ & 10 & 0.8 & Visible & 100 & 98.8 & [219] \\
\hline Graphene quantum dots $/ \mathrm{TiO}_{2}$ & 6.4 & - & UV & 180 & 100 & [220] \\
\hline $\mathrm{TiO}_{2} / \mathrm{GO}$ & 10 & 0.1 & UV & 180 & 100 & [221] \\
\hline $\mathrm{TiO}_{2} / \mathrm{G}$ & 10 & 0.01 & Visible & 150 & 100 & [222] \\
\hline $\mathrm{TiO}_{2} / \mathrm{G}$ & 10 & 0.5 & UV & 90 & 100 & [223] \\
\hline Graphene quantum dots $/ \mathrm{TiO}_{2}$ & 6.4 & - & UV & 180 & 100 & [220] \\
\hline
\end{tabular}

Methyl orange (MO) is a well-known anionic azo dye largely used in the textile, printing, paper, food, pharmaceutical, and research fields [224]. As an example, MO photodegradation was studied by Lavanya et al. [225], who combined novel reduced graphene oxide (rGO) with anatase/rutile mixed phase $\mathrm{TiO}_{2}$ nanofibers (MPTNFs), by using electrospinning and easy chemical methods, to enhance the photocatalytic performance. The photocatalytic activity in the photodegradation of MO showed a significant increase in the reaction rate for the synergistic effect of anatase/rutile mixed phase in one-dimensional nanostructures, and the electronic interaction between $\mathrm{TiO}_{2}$ and $\mathrm{rGO}$ that provided 
the improvement of electron transfer reduced the charge recombination for the enhancement of catalytic efficiency.

$\mathrm{Xu}$ et al. [63] used a two-step method to prepare G-pasted $\mathrm{TiO}_{2}$ spheres. In the first step, the total cover of the surface of $\mathrm{TiO}_{2}$ spheres with small GO sheets was obtained, while in the second step, GO was photocatalytically reducted in situ. G-pasted $\mathrm{TiO}_{2}$ spheres presented more interfaces between $\mathrm{G}$ and $\mathrm{TiO}_{2}$ with favorable interaction under the light irradiation compared to that of typical $\mathrm{GTiO}_{2} \mathrm{Ns}$ composites. As a result, these materials demonstrated higher photocatalytic activity in $\mathrm{MO}$ degradation.

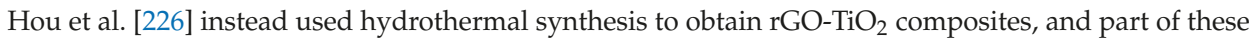
were successively calcined at $450{ }^{\circ} \mathrm{C}\left(\mathrm{CS}-\mathrm{rGO}-\mathrm{TiO}_{2}\right)$. Photocatalytic activities in the decomposition of $\mathrm{MO}$ under UV, visible, and solar light by using both $\mathrm{RGO}-\mathrm{TiO}_{2}$ and calcinated composites were tested. The amount of $\mathrm{G}$ apparently influenced the photocatalytic activities of both $\mathrm{rGO}-\mathrm{TiO}_{2}$ composites and CS-rGO-TiO ${ }_{2}$, which showed better photocatalytic activity compared to that of $\mathrm{rGO}-\mathrm{TiO}_{2}$. These results were due to the calcination that favored the oxidation of residual organics in the rGO- $\mathrm{TiO}_{2}$ and a better crystallization of $\mathrm{TiO}_{2}$ nanoparticles with smaller diameters.

Zhao et al. [227] synthetized three-dimensional nanocomposites with $\mathrm{TiO}_{2}$ nanotubes (TNTs) and rGO nanosheets by using the hydrothermal method. The obtained rGO/TNTs nanocomposites presented sufficient active sites and gave the path of good electron-transport. These nanomaterials showed better photocatalytic activity in MO degradation under UV-light irradiation with respect to traditional $\mathrm{TiO}_{2}$ nanotubes. Also, $\mathrm{Lu}$ et al. [228] combined $\mathrm{TiO}_{2}$ and $\mathrm{GO}$ and used $\mathrm{UV}$ irradiation to synthesize $\mathrm{rGO}-\mathrm{TiO}_{2}$ composites. The influence of $\mathrm{TiO}_{2}$ quantity and $\mathrm{UV}$ irradiation time on the rGO formation during the composite synthesis was investigated. The results demonstrated that a longer UV irradiation time corresponded to a higher reduction degree of GO, and therefore to a higher photodegradation efficiency of the composites in MO photodegradation. However, the results also showed that excessive UV irradiation times gave a negative effect on the photodegradation efficiency and therefore proposed a mechanism that correlated the reduction degree of GO with the photodegradation efficiency of composites.

Chemisorption and successive heating at different temperatures was applied by Xia et al. [229] to combine $\mathrm{TiO}_{2}$ in different anatase and rutile phases with $\mathrm{G}$ sheets. The photoactivities of these nanomaterials were tested by using $\mathrm{MO}$ under UV and visible light irradiation, demonstrating an enhanced respect to only $\mathrm{TiO}_{2}$. Notably, the different crystallite phases of $\mathrm{TiO}_{2}$ reacted with different behaviors under UV and visible light irradiation due to the different charge transfer mechanisms.

Another example was described by Ge et al. [230], who combined electrodeposition and carbonation techniques to obtain the deposition of rGO films on $\mathrm{TiO}_{2}$ nanotube arrays $\left(\mathrm{TiO}_{2} \mathrm{NTAs}\right)$; these materials, prepared in ethylene glycol by using two-step electrochemical anodization, showed an enhanced $\mathrm{MO}$ photocatalytic degradation with respect to both pristine $\mathrm{TiO}_{2} \mathrm{NTAs}$ and annealed $\mathrm{TiO}_{2}$ NTAs under the same conditions. The increase of efficiency in photocatalytic degradation was due to the increase of separation efficiency of photoinduced electrons and holes, to red-shift in the UV absorption and to the profitable adsorbent skill of rGO towards the MO dye.

$\mathrm{GTiO}_{2} \mathrm{Ns}$ nanocomposites were instead synthetized by Han et al. [231] by using the hydrothermal method and a successive annealing process. In this preparation, the loading of flocculent-like $\mathrm{TiO}_{2}$ nanostructures onto $\mathrm{G}$ sheets was obtained. The evaluation of photoelectrochemical activities and the photocatalytic degradation of $\mathrm{MO}$ under UV light irradiation showed that the flocculent-like $\mathrm{GTiO}_{2} \mathrm{Ns}$ composites presented the greatest photocatalytic activity compared to that of commercial anatase $\mathrm{TiO}_{2}$, due to the increase of light absorption and fruitful charge separation of the nanocomposite structure.

In order to synthesize rGO wrapped with anatase mesoporous $\mathrm{TiO}_{2}$ nanofibers, Lavanya et al. [232] used electrospinning and easy chemical methods. The interface between rGO and $\mathrm{TiO}_{2}$ nanofibers in these composites favored an efficient photogenerated charge carrier separation with an enhanced efficiency of photocatalytic MO degradation of $96 \%$ instead of only $43 \%$ of $\mathrm{TiO}_{2}$ nanofibers. Wang et al. [233] applied a low-temperature solvothermal method using graphite oxide and $\mathrm{TiCl}_{3}$ as precursors to prepare $\mathrm{GTiO}_{2} \mathrm{Ns}$ nanocomposites. During this solvothermal 
transformation, the synthesis of $\mathrm{TiO}_{2}$ nanoparticles and $\mathrm{G}$ formation occurred. Compared to only $\mathrm{TiO}_{2}$ nanoparticles, also in this case, the results revealed a greatly enhanced visible light photocatalytic MO degradation.

Athanasekou et al. [234] prepared $\mathrm{rGO}^{-\mathrm{TiO}_{2}}$ composite membranes for incorporation into a water purification device for the application in the hybrid photocatalytic/ultrafiltration process. For this, GO sheets were decorated with $\mathrm{TiO}_{2}$ nanoparticles and deposited into the pores of ultrafiltration mono-channel monoliths using the dip-coating technique and water filtration conducted in the dark, as well as UV and visible light irradiation. The obtained results, compared with that of standard nanofiltration, showed that the synergetic effects of GO on MO adsorption and photocatalytic degradation demonstrated that this material can be positively applied in nanofiltration technology.

Liu [235] prepared $\mathrm{rGO}^{-\mathrm{TiO}_{2}}$ with the hydrothermal method by using $\mathrm{GO}$ and $\mathrm{Ti}(\mathrm{OH})_{4}$ in ethanol/water. The results showed that $\mathrm{rGO}-\mathrm{TiO}_{2}$ presented a stratified structure composed of dispersed anatase $\mathrm{TiO}_{2}$ on the surface of rGO; the larger surface area of the composite was favorable for the $\mathrm{MO}$ absorption; in addition, the extension of the visible light region absorption range was observed. All these factors positively favored the photocatalytic performances of the composites in the photodegradation of $\mathrm{MO}$ under visible light irradiation with respect to that of pure $\mathrm{TiO}_{2}$.

In Table 5, the different preparation methods of $\mathrm{GTiO}_{2} \mathrm{Ns}$ applied in $\mathrm{MO}$ photodegradation are summarized.

Table 5. Photocatalytic applications of Graphene Based $\mathrm{TiO}_{2}$ nanocomposites in the degradation of Methyl Orange.

\begin{tabular}{|c|c|c|c|c|c|c|}
\hline Photoactive Nanomaterials & $\begin{array}{l}\text { Dye Conc. } \\
\text { (mg/L) }\end{array}$ & $\begin{array}{c}\text { Catalyst } \\
\text { Quantity }(\mathrm{g} / \mathrm{L})\end{array}$ & $\begin{array}{l}\text { Light } \\
\text { Source }\end{array}$ & $\begin{array}{l}\text { Irradiation } \\
\text { Time (min) }\end{array}$ & $\begin{array}{c}\text { Degradation } \\
(\%)\end{array}$ & Refs. \\
\hline $\begin{array}{c}\mathrm{rGO} / \mathrm{TiO}_{2} \text { (mix anatase/ } \\
\text { rutile nanofibers) }\end{array}$ & 10 & 0.4 & UV & 120 & 97 & [225] \\
\hline G-pasted $\mathrm{TiO}_{2}$ spheres & 12 & 0.5 & UV & 75 & 95 & [63] \\
\hline & \multirow{4}{*}{13} & 1 & UV & 60 & 88 & \multirow{4}{*}{ [226] } \\
\hline $\mathrm{GO} / \mathrm{TiO}_{2}$ & & 1 & Vis & 60 & 80 & \\
\hline \multirow{2}{*}{$\mathrm{rGO} / \mathrm{TiO}_{2}$} & & 1 & UV & 60 & 70 & \\
\hline & & 1 & Vis & 60 & 99 & \\
\hline $\mathrm{rGO} / \mathrm{TiO}_{2}$ anotube & 20 & 0.25 & UV & 210 & 100 & [227] \\
\hline $\mathrm{rGO} / \mathrm{TiO}_{2}$ & 10 & 0.5 & UV & 75 & 70 & [228] \\
\hline \multirow{2}{*}{$\mathrm{rGO} / \mathrm{TiO}_{2}$ mix anatasio/rutilio } & \multirow{2}{*}{6.55} & \multirow{2}{*}{0.6} & UV & 100 & 100 & \multirow{2}{*}{ [229] } \\
\hline & & & Vis & 100 & 50 & \\
\hline $\mathrm{G} / \mathrm{TiO}_{2} /$ Magnetite & 9.6 & 0.16 & UV & 90 & 99 & [230] \\
\hline Flocculent likeTiO $2 / G$ & 20 & 0.8 & UV & 60 & 70 & [231] \\
\hline $\mathrm{rGO} / \mathrm{TiO}_{2}$ nanofibers & 15 & 0.4 & UV & 120 & 100 & [232] \\
\hline $\mathrm{G} / \mathrm{TiO}_{2}$ & 10 & 0.6 & UV & 60 & 80 & [233] \\
\hline $\mathrm{TiO}_{2 /} / \mathrm{rGO}$ & 10 & 0.5 & Vis & 240 & 90 & [235] \\
\hline
\end{tabular}

In addition, other authors explored photocatalytic materials in the photodegradation of Rhodamine- $B$ (RB), which is a brilliant soluble basic dye, most used in the dyeing of various products of the textile industry such as cotton, silk, paper, leather, and others. Notably, RB imparts an intense color to polluted wastewaters derived from different industries and from scientific laboratories [236]. In particular, for RhB photodegradation, Chen Q. et al. [237] used electrospinning and the hydrothermal reaction in mixed ethanol/water solution to prepare nanocomposites composed from rGO and $\mathrm{TiO}_{2}$ nanotubes. In these nanocomposites, $\mathrm{TiO}_{2}$ nanotubes combined with $\mathrm{rGO}$ sheets between $\mathrm{Ti}-\mathrm{C}$ and Ti-O-C bonds and the absorption edge shifted to higher wavelengths, improving the visible light absorption with respect to pure $\mathrm{TiO}_{2}$ nanotubes. The measurements of photocatalytic activities 
regarding $\mathrm{RhB}$ photodegradation under xenon lamp irradiation showed that the highest photocatalytic activities were obtained when the rGO ratio increased to $10 \%$.

Furthermore, Chen Y. et al. [238] used a hydrothermal method to prepare rGO and $\mathrm{TiO}_{2}$ hybrid of 10-20 nm, by using $\mathrm{TiO}_{2}$ P25 nanoparticles and "liquid-exfoliated" GO. Also in this case, rGO-TiO 2 , compared to only $\mathrm{TiO}_{2}$, showed an increased photocatalytic RhB degradation under Xe lamp irradiation. The $\mathrm{rGO}-\mathrm{TiO}_{2}$ characterization confirmed the enhancement of photocatalytic and could be attributed to two reasons. The first was that rGO extended the path and lifetime of photogenerated electrons of $\mathrm{TiO}_{2}$, minimizing the recombination of electron-hole pairs. while the second was that $\mathrm{rG}$ expanded the light absorption spectrum versus the visible light range. These effects were explained by the change of the energy gap and the likelihood of the up-conversion photoluminescence mechanism.

Another example was reported by Wang et al. [239] about the immobilization of anatase $\mathrm{TiO}_{2}$ nanosheets on the magnetically actuated artificial cilia film by using rGO as the contact medium. The artificial cilia film was optimal in the immobilization of more powder of photocatalysts and, when used under s rotating magnetic field, exhibited an improvement of RhB degradation efficiency due to high mass transfer and to the efficiencies of photoproducts desorption. Biris et al. [240] synthesized core-shell nanostructural materials with multi-component architectures from $\mathrm{TiO}_{2}$ and layers of graphitic materials by application CVD for 5, 10, 30, and $45 \mathrm{~min}$ with methane as the carbon source. The reaction time linearly regulated the quantity of $\mathrm{G}$ shells covering the $\mathrm{TiO}_{2}$ surfaces, obtaining nanostructured materials with excellent stability and photocatalytic activity in the UV RhB degradation.

Moreover, Kim et al. [241] used synthesized composites of flower-like $\mathrm{TiO}_{2}$ spheres and $\mathrm{rGO}$ (FTS-G). First $\mathrm{TiO}_{2}$ spheres, with high specific surface area and good pore structure, and $\mathrm{rGO}$ without the use of strong reducing agents, were separately prepared; next, FTS-G were synthesized by using a solvothermal method. The photocatalytic performance of FTS-G was evaluated for RhB photodegradation under solar light irradiation, establishing that the rGO quantity was very important for the effects on photocatalytic activity. This preparation method could also be used to prepare other photocatalysts composed of flower-like $\mathrm{TiO}_{2}$ spheres with carbon materials. Liu et al. [242] prepared a photocatalyst based on $\mathrm{TiO}_{2}$ nanotubes and $\mathrm{rGO}$ with the hydrothermal method that was successively tested in the photocatalytic degradation of $\mathrm{RhB}$ under UV-light irradiation. Also with this photocatalyst, thanks to the introduction of $\mathrm{rGO}$ on $\mathrm{TiO}_{2}$ nanotubes, the adsorption capacity as well as the photocatalytic activity in RhB photodegradation increased compared to the same without rGO.

Sedghi et al. [243], by using Titanium(IV) chloride as a photocatalyst precursor, prepared different nanocomposites of porous and magnetic porous GO in the mix with $\mathrm{TiO}_{2}$ (anatase) and $\mathrm{TiO}_{2}$ (mix phase), respectively. Between these nanocomposites, the mix of $\mathrm{TiO}_{2}$ with magnetic porous GO showed enhanced efficiency in the RhB degradation under visible light irradiation compared with that of the other photocatalysts, obtaining 100\% degradation in less than $20 \mathrm{~min}$. Similarly, Zhang et al. [244] used the one-pot hydrothermal process, by using tetrabutyl titanate and GO, to prepare a series of self-assembled composites of anatase $\mathrm{TiO}_{2}$ nanocrystals and three-dimensional graphene aerogel. The obtained composites showed higher adsorption capacities and good visible light efficiency in the RhB photodegradation. The results of this study clarified that the chemical-physical properties of these composites could be attributed to their 3D nanoporous structure with high surface areas and to the contemporary action of $\mathrm{G}$ nanosheets and $\mathrm{TiO}_{2}$ nanoparticles.

An ultrasonication-assisted reduction process was used from $\mathrm{He}$ et al. [245] to produce rGO-- $\mathrm{TiO}_{2}$ nanocomposites. In this process, simultaneous $\mathrm{GO}$ reduction and $\mathrm{TiO}_{2}$ crystals formation were obtained; photocatalytic studies demonstrated that the quantities rGO in these nanocomposites influenced the RhB degradation efficiency under visible light irradiation. The obtained increase in the photocatalytic activity was attributed in this case to the harvesting under visible-light irradiation and to the efficiency in the separation of the photogenerated charge carriers, also obtaining an improvement in the photoelectric conversion efficiency. 
Fang et al. [246] exfoliated GO sheets from graphite and wrapped on the surfaces of polymer microspheres of about $2.5 \mu \mathrm{m}$ in diameter. Successively, the solvothermal method permitted the nucleation and growth of anatase $\mathrm{TiO}_{2}$ nanoparticles on the GO surfaces and the contemporary $\mathrm{GO}$ reduction to $\mathrm{rGO}$. The as-prepared GO-skined GO/polymer hybrid microspheres composites tested in the photocatalytic activity with $\mathrm{RhB}$ solutions gave 96\% degradation in 30 min under visible light irradiation, demonstrating an improvement with respect to commercial $\mathrm{TiO}_{2}$. The results were attributed to the favorable interactions between $\mathrm{rGO}$ of singular electrical conductivity and $\mathrm{TiO}_{2}$ nanoparticles.

Liang et al. [247] used a one-step hydrothermal approach to synthesize chemically bonded $\mathrm{TiO}_{2} / \mathrm{rGO}$ nanocomposites by using $\mathrm{Ti}\left(\mathrm{SO}_{4}\right)_{2}$ and $\mathrm{GO}$ as precursors and ethanol/water solvent as a reducing agent, obtaining well-dispersed $\mathrm{TiO}_{2}$ nanocrystals on the surface of $\mathrm{rGO}$ sheets with optimal interfacial contact. The obtained nanocomposites demonstrated higher photocatalytic activity with respect to only $\mathrm{TiO}_{2}$ nanoparticles and to a simple mixing of $\mathrm{TiO}_{2}$ and $\mathrm{rGO}$ samples in the $\mathrm{RhB}$ degradation which was attributed, also in this case, to the interaction between $\mathrm{TiO}_{2}$ and $\mathrm{rGO}$, with excellent electron trapping and transportation properties.

$\mathrm{Li}$ et al. [248] obtained different carbon materials- $\mathrm{TiO}_{2}$ hybrid nanostructures incorporated into $\mathrm{TiO}_{2}$, activated carbon, $\mathrm{G}$, carbon nanotubes, and fullerene by using a solvothermal method and thermal annealing. The relationships between the interactions of carbon materials with $\mathrm{TiO}_{2}$ nanoparticles, morphologies, structures, and increasing photodegradation performances in RhB degradation were clarified. The results of these photocatalysts were due to higher adsorption properties, the favorable formation of chemical bonds of Ti-O-C, reduced band gap, lower particle size, and charge-carrier qualities. In Table 6, the different preparation methods of $\mathrm{GTiO}_{2} \mathrm{Ns}$ applied in $\mathrm{RhB}$ photodegradation are listed.

Table 6. Photocatalytic applications of Graphene Based $\mathrm{TiO}_{2}$ nanocomposites in the degradation of Rhodamin B.

\begin{tabular}{|c|c|c|c|c|c|c|}
\hline Photoactive Nanomaterials & $\begin{array}{l}\text { Dye Conc. } \\
\text { (mg/L) }\end{array}$ & $\begin{array}{c}\text { Catalyst } \\
\text { Quantity }(\mathrm{g} / \mathrm{L})\end{array}$ & Light Source & $\begin{array}{l}\text { Irradiation } \\
\text { Time (min) }\end{array}$ & $\begin{array}{c}\text { Degradation } \\
(\%)\end{array}$ & Refs \\
\hline $\mathrm{TiO}_{2} / \mathrm{rGO}$ & 30 & 0.2 & Vis & 40 & 100 & {$[238]$} \\
\hline $\begin{array}{c}\mathrm{rGO} / \mathrm{TiO}_{2} \text { nanosheets } \\
\text { onmagnetically cilia film } \\
\mathrm{rGO} / \mathrm{TiO}_{2}-\mathrm{Au}\end{array}$ & 20 & 0.2 & UV & 180 & $\begin{array}{c}83 \\
100\end{array}$ & [239] \\
\hline Core-shell $\mathrm{TiO}_{2} / \mathrm{G}$ & 4.79 & 0.6 & UV & 270 & 100 & {$[240]$} \\
\hline Flower-like $\mathrm{TiO}_{2}$ sphere /rGO & 15 & 0.4 & Simulated solar & 120 & 100 & {$[241]$} \\
\hline $\mathrm{TiO}_{2}$ nanotubes $/ \mathrm{rGO}$ & 10 & 0.5 & UV & 20 & 100 & {$[242]$} \\
\hline $\mathrm{TiO}_{2} /$ magnetic porous GO & 10 & 0.1 & Vis & 20 & 100 & {$[243]$} \\
\hline $3 \mathrm{D} \mathrm{TiO}_{2} / \mathrm{G}$ aerogel & 20 & 0.2 & Visible light & 180 & 99 & {$[244]$} \\
\hline $\mathrm{TiO}_{2} / \mathrm{rGO}$ & 4.79 & 0.4 & Visible light & 180 & 100 & {$[245]$} \\
\hline $\mathrm{TiO}_{2} / \mathrm{rGO} /$ polymer & 8 & 0.2 & Visible light & 30 & 96 & {$[246]$} \\
\hline $\mathrm{TiO}_{2} / \mathrm{rGO}$ & 20 & 0.5 & UV & 30 & 100 & [247] \\
\hline $\mathrm{GTiO}_{2}$ & 5 & 0.5 & Visible light & 60 & 80 & {$[248]$} \\
\hline
\end{tabular}

Rhodamine 6G (Rh6G) is dark reddish-purple dye, mostly used in the textile industries, in biochemistry research laboratories, and in other applications. Rh6G is a non-volatile compound that presents high solubility in water causing skin, eye, and respiratory system irritations, and is also carcinogenic and poisonous to living organisms [249].

In order to obtain the photocatalytic degradation of Rh6G, Pu et al. [194] demonstrated a facile and environmentally friendly strategy for the simultaneous in situ preparation of the $\mathrm{rGO}-\mathrm{TiO}_{2}$ "dyade hybrid" obtained by the photoreduction of GO nanosheets in ethanolic solutions of GO and $\mathrm{TiO}_{2}$ (P25) mix. Successively, the photodegradation efficiency of the resultant composite by utilizing 
Rh6G as the target pollutant was systematically investigated. The obtained $\mathrm{rGO}-\mathrm{TiO}_{2}$ presented a significant enhancement in photo energy adsorption, leading to the effective photocatalytic degradation reactions which exhibited more than triple the higher photodegradation rate compared to commercial $\mathrm{TiO}_{2}(\mathrm{P} 25)$ nanoparticles.

Reactive Black 5 (RB5), which has two azo groups, belongs to the class of azo reactive dyes, which are abundantly used in textile industries for dyeing.

The photocatalytic degradation of RB5 was studied by Day et al. [250], who prepared different types of $\mathrm{GTiO}_{2} \mathrm{Ns}$ nanocomposites with $\mathrm{G}$ and P25 or Titanium (IV) n-butoxide as precursors by using the hydrothermal method. To investigate the differences of the photocatalytic properties of composites with various $\mathrm{TiO}_{2}$ shapes, nanotubes, nanosheets, and nanoparticles of $\mathrm{TiO}_{2}$ were prepared and combined with $\mathrm{G}$. The photocatalytic activities of these composites were tested in the degradation of RB5 under UV lamp irradiation, indicating that the differences in the $\mathrm{TiO}_{2}$ morphology and the characteristics of heterojunction between $\mathrm{G}$ and $\mathrm{TiO}_{2}$ played an important role in the photocatalytic abilities. The results demonstrated that these composites exhibited excellent adsorption capacity and higher photocatalytic activity with respect to P25, and that the photocatalytic activity of $\mathrm{GTiO}_{2} \mathrm{Ns}_{\mathrm{s}}$ nanosheets was higher than those of the other tested photocatalysts. Another example was proposed by Liang et al. [251], who obtained an increase of photocatalysis efficiency for $\mathrm{RB} 5$ by using $\mathrm{TiO}_{2}$ nanotubes and G nanocomposites prepared with the hydrothermal method. In particular, Zhang et al. [252] deciphered the mechanism of RB5 photodegradation, which was used as a model for other azo dyes by using $\mathrm{G}$-loaded $\mathrm{TiO}_{2}$ as a photocatalyst. They demonstrated that electronic transfer groups affect the degradability of azo dyes, that ${ }^{\bullet} \mathrm{OH}$ radicals are the major oxidized species, and that substituents with high electron-density in the dye structure were more favorably attacked by ${ }^{\bullet} \mathrm{OH}$ radicals.

The photodegradation of the non-biodegradable azo dye acid orange 7 (AO7) in aqueous solution

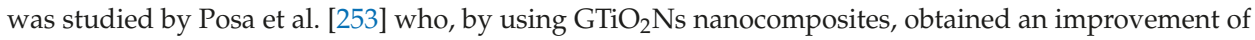
photocatalytic performance compared with that of pure $\mathrm{TiO}_{2}$, examining also the reusability of the photocatalyst. They suggested a reaction mechanism on the basis of the obtained results. Furthermore, Gao et al. [254] synthesized different $\mathrm{TiO}_{2}$ nanostructures: one-dimensional $\mathrm{TiO}_{2}$ nanotubes and nanowires, three-dimensional spheres assembled by nanoparticles and by nanosheets. The results of photodegradation activity in the AO7 degradation indicated that the photodegradation efficiency of $\mathrm{TiO}_{2}$ spheres assembled by nanosheets was the highest with respect to the other $\mathrm{TiO}_{2}$ nanostructures, while its specific surface area was lower than that of $\mathrm{TiO}_{2}$ nanotubes. The results were attributed to the highest light harvesting capacity under solar light derived from the multiple reflections of light, and from the hierarchical mesoporous structure. The last example regards the study of Muthirulan et al. [255], who fabricated $\mathrm{GTiO}_{2} \mathrm{Ns}$ by using a simple one-step chemical process, mixing $\mathrm{TiO}_{2}$ nanoparticles suspended in ethanol with $\mathrm{G}$ followed by ultrasonication and successive treatment in a rotary evaporator under vacuum. The dried $\mathrm{GTiO}_{2} \mathrm{Ns}$ showed improvement in the photocatalytic ability in the degradation of AO7 under both UV and solar light irradiations. The obtained results of photodegradation indicated that $\mathrm{GTiO}_{2} \mathrm{Ns}$ nanocomposites exhibited higher photocatalytic activity than that of $\mathrm{TiO}_{2}$, which was attributed to the role of $\mathrm{G}$ in the suppression of charge recombination and in the promotion of the charge transfer, permitting also a possible reaction pathway for the degradation of AO7.

\section{Conclusions}

In this short review, we have described the characteristics of both $\mathrm{TiO}_{2}$ semiconductors and graphene materials and reported several examples focusing on the recent progress in the design, synthesis, and applications of these $\mathrm{GTiO}_{2} \mathrm{Ns}$ nanocomposites used as photocatalysts in the photocatalytic degradation of synthetic dyes.

We have described the important effects of $\mathrm{G}$ in $\mathrm{GTiO}_{2} \mathrm{Ns}$ nanocomposites, as shown in Figure 6 . In fact, in conjunction with $\mathrm{TiO}_{2}$ nanomaterials, $\mathrm{G}$ can act as a co-adsorbent thanks to the increase of adsorption surface and to $\pi-\pi$ interactions with dye and as a sensitizer due to the electron transfer from 
the $\mathrm{G}$ photoexcited state, with delocalization and energy excess dissipation, to the $\mathrm{TiO}_{2}$ surface with the extension of the light absorption towards the visible region. Notably, both the functions of conductive materials and co-catalysts favor the stabilization of excited electrons, thus limiting the electron-hole recombination in the photocatalytic process. In addition to these properties, $\mathrm{TiO}_{2}$ band-gap narrowing due to the interaction between $\mathrm{TiO}_{2}$ and $\mathrm{G}$ was demonstrated.

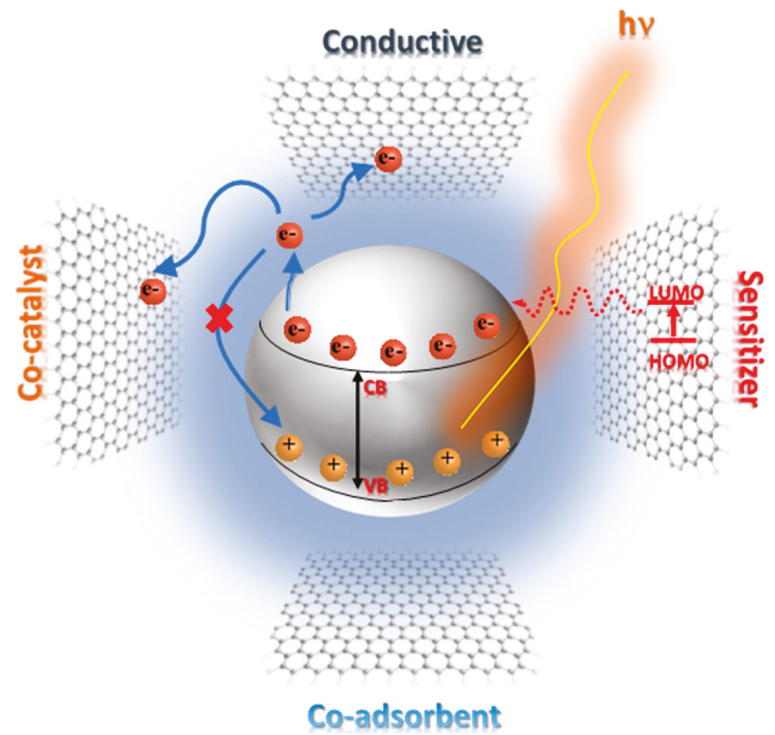

Figure 6. Schematic representation of the main features of graphene in the photocatalysis with $\mathrm{TiO}_{2}$.

Thanks to these features, in order to obtain the best benefit of graphene in the enhancment of the photoactivity of $\mathrm{TiO}_{2}$ nanomaterials, all of these factors that dominate the photocatalytic process must to be taken into consideration and optimized with the purpose of obtaining the best dye absorption and its complete mineralization.

Much research has been conducted regarding the photocatalytic degradation of synthetic dyes, and the high-quality results of these studies demonstrate that these materials could be promising for large-scale applications in wastewater depuration.

Acknowledgments: This work was partially supported from FAR Project NAMES: “Nanocomposite Materials for Energy and Environment Applications" of Camerino University.

Author Contributions: Rita Giovannetti organized and prepared the manuscript. Elena Rommozzi collected and analyzed the literature reports, Marco Zannotti, Chiara Anna D'Amato designed the figures and critically revised the manuscript.

Conflicts of Interest: The authors declare no conflict of interest.

\section{References}

1. Peirce, J.J.; Weiner, R.; Vesilind, P.A. Environmental Pollution and Control, 4th ed.; Elsevier: Oxford, UK, 1998; ISBN 978-0-7506-9899-3.

2. Andreozzi, R.; Caprio, V.; Insola, A.; Marotta, R. Advanced oxidation processes (AOP) for water purification and recovery. Catal. Today 1999, 53, 51-59. [CrossRef]

3. Chaukura, N.; Edna, C.; Murimba, E.C.; Gwenzi, W. Sorptive removal of methylene blue from simulated wastewater using biochars derived from pulp and paper sludge. Environ. Technol. Innov. 2017, 8, 132-140. [CrossRef] 
4. Solís, M.; Solís, A.; Inés Pérez, H.; Manjarrez, N.; Flores, M. Microbial decolouration of azo dyes: A review. Process. Biochem. 2012, 47, 1723-1748. [CrossRef]

5. Zhang, Z.; Yang, R.Y.; Gao, Y.S.; Zhao, Y.F.; Wang, J.Y.; Huang, L.; Guo, J.; Zhou, T.T.; Lu, P.; Guo, Z.H.; et al. Novel $\mathrm{Na}_{2} \mathrm{Mo}_{4} \mathrm{O}_{13} / \alpha-\mathrm{MoO}_{3}$ hybrid material as highly efficient CWAO catalyst for dye degradation at ambient conditions. Sci. Rep. 2014, 4, 6797-6809. [CrossRef] [PubMed]

6. Santhosh, C.; Velmurugan, V.; Jacob, G.; Jeong, S.K.; Grace, A.N.; Bhatnagar, A. Role of nanomaterials in water treatment applications: A review. Chem. Eng. J. 2016, 306, 1116-1137. [CrossRef]

7. Padikkaparambil, S.; Narayanan, B.; Yaakob, Z.; Viswanathan, S.; Tasirin, S.M. Au/TiO 2 reusable photocatalysts for dye degradation. Int. J. Photoenergy 2013, 2013. [CrossRef]

8. Cho, K.M.; Kim, K.H.; Choi, H.O.; Jung, H.T. A highly photoactive, visible-light-driven graphene/2D mesoporous $\mathrm{TiO}_{2}$ photocatalyst. Green Chem. 2015, 17, 3972-3978. [CrossRef]

9. Ibhadon, A.O.; Fitzpatrick, P. Heterogeneous photocatalysis: Recent advances and applications. Catalysts 2013, 3, 189-218. [CrossRef]

10. Wei, W.; Liu, D.; Wei, Z.; Zhu, Y. Short-range $\pi$ - $\pi$ stacking assembly on $\mathrm{P} 25 \mathrm{TiO}_{2}$ nanoparticle for enhanced visible-light photocatalysis. ACS Catal. 2017, 7, 652-663. [CrossRef]

11. Jiang, W.J.; Liu, Y.F.; Wang, J.; Zhang, M.; Luo, W.J.; Zhu, Y.F. Separation-free polyaniline $/ \mathrm{TiO}_{2} 3 \mathrm{D}$ hydrogel with high photocatalytic activity. Adv. Mater. Interfaces 2016, 3, 9.

12. Tatsuma, T.; Saitoh, S.; Ohko, Y.; Fujishima, A. $\mathrm{TiO}_{2}-\mathrm{WO}_{3}$ photoelectrochemical anticorrosion system with an energy storage ability. Chem. Mater. 2001, 13, 2838-2842. [CrossRef]

13. Sajan, C.P.; Wageh, S.; Al-Ghamdi, A.A.; Yu, J.G.; Cao, S.W. $\mathrm{TiO}_{2}$ nanosheets with exposed $\{001\}$ facets for photocatalytic applications. Nano Res. 2016, 9, 3-27. [CrossRef]

14. Chen, X.; Mao, S.S. Titanium dioxide nanomaterials: Synthesis, properties, modifications, and applications. Chem. Rev. 2007, 107, 2891-2959. [CrossRef] [PubMed]

15. Tong, H.; Ouyang, S.X.; Bi, Y.P.; Umezawa, N.; Oshikiri, M.; Ye, J.H. Nano-photocatalytic materials: Possibilities and challenges. Adv. Mater. 2012, 24, 229-251. [CrossRef] [PubMed]

16. Anpo, M.; Tackeuchi, M. The design and development of highly reactive titanium oxide photocatalysts operating under visible light irradiation. J. Catal. 2003, 216, 505-516. [CrossRef]

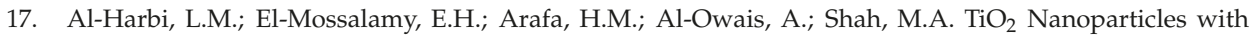
Tetra-pad Shape Prepared by an Economical and Safe Route at very Low Temperature. Mod. Appl. Sci. 2011, 5, 130-135. [CrossRef]

18. Giovannetti, R.; D'Amato, C.A.; Zannotti, M.; Rommozzi, E.; Gunnella, R.; Minicucci, M.; Di Cicco, A. Visible light photoactivity of polypropylene coated nano- $\mathrm{TiO}_{2}$ for dyes degradation in water. Sci. Rep. 2015, 2. [CrossRef] [PubMed]

19. Augugliaro, V.; Bellardita, M.; Loddo, V.; Palmisano, G.; Palmisano, L.; Yurdakal, S. Overview on oxidation mechanisms of organic compounds by $\mathrm{TiO}_{2}$ in heterogeneous photocatalysis. J. Photochem. Photobiol. C Photochem. Rev. 2012, 13, 224-245. [CrossRef]

20. Sud, D.; Kaur, P. Heterogeneous photocatalytic degradation of selected organophosphate pesticides: A review. Crit. Rev. Environ. Sci. Technol. 2012, 42, 2365-2407. [CrossRef]

21. Wang, J.L.; Xu, L.J. Advanced oxidation processes for wastewater treatment: Formation of hydroxyl radical and application. Crit. Rev. Environ. Sci. Technol. 2012, 42, 251-325. [CrossRef]

22. Hashimoto, K.; Irie, $\mathrm{H}$; Fujishima, $\mathrm{A}$. $\mathrm{TiO}_{2}$ photocatalysis: A historical overview and future prospects. Jpn. J. Appl. Phys. 2005, 12, 8269-8285. [CrossRef]

23. Sheikh, M.U.D.; Naikoo, G.A.; Thomas, M.; Bano, M.; Khan, F. Solar-assisted photocatalytic reduction of methyl orange azo dye over porous $\mathrm{TiO}_{2}$ nanostructures. New J. Chem. 2016, 40, 5483-5494. [CrossRef]

24. Zhang, N.; Zhang, Y.; Xu, Y.-J. Recent progress on graphene-based photocatalysts: Current status and future perspectives. Nanoscale 2012, 4, 5792-5813. [CrossRef] [PubMed]

25. Malato, S.; Fernández-Ibáñez, P.; Maldonado, M.I.; Blanco, J.; Gernjak, W. Decontamination and disinfection of water by solar photocatalysis: Recent overview and trends. Catal. Today 2009, 147, 1-59. [CrossRef]

26. Wang, W.K.; Chen, J.J.; Gao, M.; Huang, Y.X.; Zhang, X.; Yu, H.Q. Photocatalytic degradation of atrazine by boron-doped $\mathrm{TiO}_{2}$ with a tunable rutile/anatase ratio. Appl. Catal. B Environ. 2016, 195, 69-76. [CrossRef]

27. Hao, R.R.; Wang, G.H.; Tang, H.; Sun, L.L.; Xu, C.; Han, D.Y. Template-free preparation of macro/mesoporous g- $\mathrm{C}_{3} \mathrm{~N}_{4} / \mathrm{TiO}_{2}$ heterojunction photocatalysts with enhanced visible light photocatalytic activity. Appl. Catal. B Environ. 2016, 187, 47-58. [CrossRef] 
28. Gua, Y.; Xinga, M.; Zhang, J. Synthesis and photocatalytic activity of graphene based doped $\mathrm{TiO}_{2}$ nanocomposites. Appl. Surf. Sci. 2014, 319, 8-15. [CrossRef]

29. Zaleska, A. Doped-TiO ${ }_{2}$ : A review. Recent Pat. Eng. 2008, 2, 157-164. [CrossRef]

30. Yang, H.G.; Sun, C.H.; Qiao, S.Z.; Zou, J.; Liu, G.; Smith, S.C.; Cheng, H.M.; Lu, G.Q. Anatase TiO 2 single crystals with a large percentage of reactive facets. Nature 2008, 453, 638-641. [CrossRef] [PubMed]

31. Adán, C.; Bahamonde, A.; Fernández-García, M.; Martínez-Arias, A. Structure and activity of nanosized iron-doped anatase $\mathrm{TiO}_{2}$ catalysts for phenol photocatalytic degradation. Appl. Catal. B Environ. 2007, 72, 11-17. [CrossRef]

32. Cai, J.; Wu, X.; Li, S.; Zheng, F. Controllable location of Au nanoparticles as cocatalyst onto $\mathrm{TiO}_{2} @ \mathrm{CeO}_{2}$ nanocomposite hollow spheres for enhancing photocatalytic activity. Appl. Catal. B Environ. 2017, 201, $12-21$. [CrossRef]

33. Cheng, L.; Qiu, S.; Chen, J.; Shao, J.; Cao, S. A practical pathway for the preparation of $\mathrm{Fe}_{2} \mathrm{O}_{3}$ decorated $\mathrm{TiO}_{2}$ photocatalyst with enhanced visible-light photoactivity. Mater. Chem. Phys. 2017, 190, 53-61. [CrossRef]

34. Xie, Y.; Meng, Y.; Wu, M. Visible-light-driven self-cleaning SERS substrate of silver nanoparticles and graphene oxide decorated nitrogen-doped Titania nanotube array. Surf. Interface Anal. 2016, 48, 334-340. [CrossRef]

35. Xing, Z.; Zong, X.; Zhu, Y.; Chen, Z.; Bai, Y.; Wang, L. A nanohybrid of CdTe@CdS nanocrystals and Titania nanosheets with $\mathrm{p}-\mathrm{n}$ nanojunctions for improved visible light-driven hydrogen production. Catal. Today 2016, 264, 229-235. [CrossRef]

36. Hamzezadeh-Nakhjavani, S.; Tavakoli, O.; Akhlaghi, S.P.; Salehi, Z.; Esmailnejad-Ahranjani, P.; Arpanaei, A. Efficient photocatalytic degradation of organic pollutants by magnetically recoverable nitrogen-doped $\mathrm{TiO}_{2}$ nanocomposite photocatalysts under visible light irradiation. Environ. Sci. Pollut. Res. 2015, 22, 18859-18873. [CrossRef] [PubMed]

37. Qi, K.; Selvaraj, R.; Al Fahdi, T.; Al-Kindy, S.; Kim, Y.; Wang, G.-C.; Tai, C.-W.; Sillanpää, M. Enhanced photocatalytic activity of anatase- $\mathrm{TiO}_{2}$ nanoparticles by fullerene modification: A theoretical and experimental study. Appl. Surf. Sci. 2016, 387, 750-758. [CrossRef]

38. Qin, X.; He, F.; Chen, L.; Meng, Y.; Liu, J.; Zhao, N.; Huang, Y. Oxygen-vacancy modified $\mathrm{TiO}_{2}$ nanoparticles as enhanced visible-light driven photocatalysts by wrapping and chemically bonding with graphite-like carbon. RSC Adv. 2016, 6, 10887-10894. [CrossRef]

39. Rahbar, M.; Behpour, M. Multi-walled carbon nanotubes $/ \mathrm{TiO}_{2}$ thin layer for photocatalytic degradation of organic pollutant under visible light irradiation. J. Mater. Sci. Mater. Electron. 2016, 27, 8348-8355. [CrossRef]

40. Lin, L.; Wang, H.; Xu, P. Immobilized $\mathrm{TiO}_{2}$-reduced graphene oxide nanocomposites on optical fibers as high performance photocatalysts for degradation of pharmaceuticals. Chem. Eng. J. 2017, 310, 389-398. [CrossRef]

41. Stoller, M.D.; Park, S.; Zhu, Y.; An, J.; Ruoff, R.S. Graphene-based ultracapacitors. Nano Lett. 2008, 8, 3498-3502. [CrossRef] [PubMed]

42. Novoselov, K.S.; Geim, A.K.; Morozov, S.V.; Jiang, D.; Zhang, Y.; Dubonos, S.V.; Grigorieva, I.V.; Firsov, A.A Electric field effect in atomically thin carbon films. Science 2004, 306, 666-669. [CrossRef] [PubMed]

43. Balandin, A.A.; Ghosh, S.; Bao, W.; Calizo, I.; Teweldebrhan, D.; Miao, F.; Lau, C.N. Superior thermal conductivity of single-layer graphene. Nano Lett. 2008, 8, 902-907. [CrossRef] [PubMed]

44. Cheng, Y.; Zhou, S.; Hu, P.; Zhao, G.; Li, Y.; Zhang, X.; Han, W. Enhanced mechanical, thermal, and electric properties of graphene aerogels via supercritical ethanol drying and high-temperature thermal reduction. Sci. Rep. 2017, 7. [CrossRef] [PubMed]

45. Sun, W.; Du, A.; Gao, G.; Shen, J.; Wu, G. Graphene-templated carbon aerogels combining with ultra-high electrical conductivity and ultra-low thermal conductivity. Microporous Mesoporous Mater. 2017, 253, 71-79. [CrossRef]

46. Tran, V.-T.; Saint-Martin, J.; Dollfus, P.; Volz, S. Optimizing the thermoelectric performance of graphene nano-ribbons without degrading the electronic properties. Sci. Rep. 2017, 7. [CrossRef] [PubMed]

47. Wei, A.; Li, Y.; Li, Y.; Ye, H. Thermal characteristics of graphene nanosheet with graphane domains of varying morphologies. Comput. Mater. Sci. 2017, 138, 192-198. [CrossRef]

48. Geim, A.K.; Novoselov, K.S. The rise of graphene. Nat. Mater. 2007, 6, 183-191. [CrossRef] [PubMed]

49. Leary, R.; Westwood, A. Carbonaceous nanomaterials for the enhancement of $\mathrm{TiO}_{2}$ photocatalysis. Carbon 2011, 49, 741-772. [CrossRef] 
50. Hamandia, M.; Berhault, G.; Guillardb, C.; Kochkara, H. Influence of reduced graphene oxide on the synergism between rutileand anatase $\mathrm{TiO}_{2}$ particles in photocatalytic degradation of formic acid. Mol. Catal. 2017, 432, 125-130. [CrossRef]

51. Morales-Torres, S.; Pastrana-Martínez, L.M.; Figueiredo, J.L.; Faria, J.J.; Silva, A.M.T. Design of graphene-based $\mathrm{TiO}_{2}$ photocatalysts-A review. Environ. Sci. Pollut. Res. 2012, 19, 3676-3687. [CrossRef] [PubMed]

52. Adamu, H.; Dubey, P.; Anderson, J.A. Probing the role of thermally reduced graphene oxide in enhancing performance of $\mathrm{TiO}_{2}$ in photocatalytic phenol removal from aqueous environments. Chem. Eng. J. 2016, 284, 380-388. [CrossRef]

53. Giovannetti, R.; Rommozzi, E.; Zannotti, M.; D’Amato, C.A.; Ferraro, S.; Cespi, M.; Bonacucina, G.; Minicucci, M.; Di Cicco, A. Exfoliation of graphite into graphene in aqueous solution: An application as graphene $/ \mathrm{TiO}_{2}$ nanocomposite to improve visible light photocatalytic activity. RSC Adv. 2016, 6, 93048-93055. [CrossRef]

54. Truppi, A.; Petronella, F.; Placido, T.; Striccoli, M.; Agostiano, A.; Curri, M.L.; Comparelli, R. Visible-light-active $\mathrm{TiO}_{2}$-based hybrid nanocatalysts for environmental applications. Catalysts 2017, 7, 100. [CrossRef]

55. Xiang, Q.; Yu, J.; Jaroniec, M. Graphene-based semiconductor photocatalysts. Chem. Soc. Rev. 2012, 41, 782-796. [CrossRef] [PubMed]

56. Zhang, Y.; Tang, Z.R.; Fu, X.Y.; Xu, J. TiO 2 -graphene nanocomposites for gas-phase photocatalytic degradation of volatile aromatic pollutant: $\mathrm{Is}_{\mathrm{TiO}_{2}}$-graphene truly different from other $\mathrm{TiO}_{2}$-carbon composite materials? ACS Nano 2010, 4, 7303-7314. [CrossRef] [PubMed]

57. Surender Kumar, S. Complex Magnetic Nanostructures: Synthesis, Assembly and Applications; Springer: Cham, Switzerland, 2017.

58. Syväjärvi, M.; Tiwari, A. Graphene Materials: Fundamentals and Emerging Applications; Wiley: Hoboken, NJ, USA, 2015.

59. Singh, V.; Joung, D.; Zhai, L.; Das, S.; Khondaker, S.I.; Seal, S. Graphene based materials: Past, present and future. Progress Mater. Sci. 2011, 56, 1178-1271. [CrossRef]

60. Cong, H.-P.; Chena, J.-F.; Yu, S.-H. Graphene-based macroscopic assemblies and architectures: An emerging material system. Chem. Soc. Rev. 2014, 43, 7295-7325. [CrossRef] [PubMed]

61. Mahmood, N.; Zhang, C.; Yin, H.; Hou, Y. Graphene-based nanocomposites for energy storage and conversion in lithium batteries, supercapacitors and fuel cells. J. Mater. Chem. A 2014, 2, 15-32. [CrossRef]

62. Li, X.; Yu, J.; Wageh, S.; Al-Ghamdi, A.A.; Xie, J. Graphene in photocatalysis: A review. Small 2016, 12, 6640-6696. [CrossRef] [PubMed]

63. Xu, C.; Zhu, J.; Yuan, R.; Fu, X. More effective use of graphene in photocatalysis by conformal attachment of small sheets to $\mathrm{TiO}_{2}$ spheres. Carbon 2016, 96, 394-402. [CrossRef]

64. Zhu, J.; Yang, D.; Yin, Z.; Yan, Q.; Zhang, H. Graphene and graphene-based materials for energy storage applications. Small 2014, 10, 3480-3498. [CrossRef] [PubMed]

65. Piao, Y. Preparation of porous graphene-based nanomaterials for electrochemical energy storage devices. In Nano Devices and Circuit Techniques for Low-Energy Applications and Energy Harvesting; Kyung, C.M., Ed.; KAIST Research Series; Springer: Dordrecht, The Netherland, 2016.

66. Li, N.; Liu, G.; Zhen, C.; Li, F.; Zhang, L.; Cheng, H.M. Battery performance and photocatalytic activity of mesoporous anatase $\mathrm{TiO}_{2}$ nanospheres/graphene composites by template-free self-assembly. Adv. Funct. Mater. 2011, 21, 1717-1722. [CrossRef]

67. Maroni, F.; Raccichini, R.; Birrozzi, A.; Carbonari, G.; Tossici, R.; Croce, F.; Marassi, R.; Nobili, F. Graphene/silicon nanocomposite anode with enhanced electrochemical stability for lithium-ion battery applications. J. Power Sources 2014, 269, 873-882. [CrossRef]

68. Kaplas, T.; Kuzhir, P. Ultra-thin Graphitic Film: Synthesis and Physical Properties. Nanoscale Res. Lett. 2016, 11, 54. [CrossRef] [PubMed]

69. Allagui, A.; Abdelkareem, M.A.; Alawadhi, H.; Elwakil, A.S. Reduced graphene oxide thin film on conductive substrates by bipolar electrochemistry. Sci. Rep. 2016, 6. [CrossRef] [PubMed]

70. Bhuyan, M.S.A.; Uddin, M.N.; Islam, M.M.; Bipasha, F.A.; Hossain, S.S. Synthesis of graphene. Int. Nano Lett. 2016, 6, 65-83. [CrossRef] 
71. Tetlow, H.; de Boer, J.P.; Ford, I.J.; Vvedenskyb, D.D.; Coraux, J.; Kantorovich, L. Growth of epitaxial graphene: Theory and experiment. Phys. Rep. 2014, 542, 195-295. [CrossRef]

72. Cui, Y.; Zhang, H.; Chen, W.; Yang, Z.; Cai, Q. Structural evolution of flower defects and effects on the electronic structures of epitaxial graphene. J. Phys. Chem. C 2017, 121, 15282-15287. [CrossRef]

73. Galves, L.A.; Wofford, J.M.; Soares, G.V.; Jahn, U.; Pfüller, C.; Riechert, H.; Lopes, J.M.J. The effect of the $\mathrm{SiC}(0001)$ surface morphology on the growth of epitaxial mono-layer graphene nanoribbons. Carbon 2017, 115, 162-168. [CrossRef]

74. Ramnani, P.; Neupane, M.R.; Ge, S.; Balandin, A.A.; Lake, R.K.; Mulchandani, A. Raman spectra of twisted CVD bilayer graphene. Carbon 2017, 123, 302-306. [CrossRef]

75. Chena, X.; Zhangb, L.; Chena, S. Large area CVD growth of graphene. Synth. Met. 2015, 210, 95-108. [CrossRef]

76. Zhang, Y.; Zhang, L.; Zhou, C. Review of chemical vapor deposition of graphene and related applications. Acc. Chem. Res. 2013, 46, 2329-2339. [CrossRef] [PubMed]

77. Lukosius, M.; Dabrowski, J.; Kitzmann, J.; Fursenko, O.; Akhtar, F.; Lisker, M.; Lippert, G.; Schulze, S.; Yamamoto, Y.; Schubert, M.A.; et al. Metal-free CVD graphene synthesis on $200 \mathrm{~mm} \mathrm{Ge/Si(001)} \mathrm{substrates.}$ ACS Appl. Mater. Interfaces 2016, 8, 33786-33793. [CrossRef] [PubMed]

78. Robert, M.; Jacobberger, R.M.; Machhi, R.; Wroblewski, J.; Ben Taylor, B.; Anne Lynn Gillian-Daniel, A.L.; Arnold, M.S. Simple graphene synthesis via chemical vapor deposition. J. Chem. Educ. 2015, 92, 1903-1907.

79. Kim, K.S.; Zhao, Y.; Jang, H.; Lee, S.Y.; Kim, J.M.; Kim, K.S.; Ahn, J.H.; Kim, P.; Choi, J.Y.; Hong, B.H. Large-scale pattern growth of graphene films for stretchable transparent electrodes. Nature 2009, 457, 706-710. [CrossRef] [PubMed]

80. Emtsev, K.V.; Bostwick, A.; Horn, K.; Jobst, J.; Kellogg, G.L.; Ley, L.; McChesney, J.L.; Ohta, T.; Reshanov, S.A.; Rohrl, J.; et al. Towards wafer-size graphene layers by atmospheric pressure graphitization of silicon carbide. Nat. Mater. 2009, 8, 203-207. [CrossRef] [PubMed]

81. Juang, Z.Y.; Wu, C.Y.; Lu, A.Y.; Su, C.Y.; Leou, K.C.; Chen, F.R.; Tsai, C.H. Graphene synthesis by chemical vapor deposition and transfer by a roll-to-roll process. Carbon 2010, 48, 3169-3174. [CrossRef]

82. Wei, D.C.; Liu, Y.Q.; Wang, Y.; Zhang, H.L.; Huang, L.P.; Yu, G. Synthesis of N-doped graphene by chemical vapor deposition and its electrical properties. Nano Lett. 2009, 9, 1752-1758. [CrossRef] [PubMed]

83. Zhang, H.; Zhang, X.; Sun, X.; Ma, Y. Shape-controlled synthesis of nanocarbons through direct conversion of carbon dioxide. Sci. Rep. 2013, 3. [CrossRef] [PubMed]

84. Hajian, M.; Zareie, M.; Hashemiana, D.; Bahrami, M. Synthesis of graphene through direct decomposition of $\mathrm{CO}_{2}$. RSC Adv. 2016, 6, 73331-73335. [CrossRef]

85. Qin, B.; Zhang, T.; Chen, H.; Ma, Y. The growth mechanism of few-layer graphene in the arc discharge process. Carbon 2016, 102, 494-498. [CrossRef]

86. Poorali, M.S.; Bagheri-Mohagheghi, M.M. Synthesis and physical properties of multi-layered graphene sheets by Arc-discharge method with $\mathrm{TiO}_{2}$ and $\mathrm{ZnO}$ catalytic. J. Mater. Sci. Mater. Electron. 2017, 28, 6186-6193. [CrossRef]

87. Xiao, B.; Li, X.; Li, X.; Wang, B.; Langford, C.; Li, R.; Sun, X. Graphene Nanoribbons Derived from the Unzipping of Carbon Nanotubes: Controlled Synthesis and Superior Lithium Storage. J. Phys. Chem. C 2014, 118, 881-890. [CrossRef]

88. Yang, X.; Dou, X.; Rouhanipour, A.; Zhi, L.; Räder, H.J.; Mülle, K. Two-dimensional graphene nanoribbons. J. Am. Chem. Soc. 2008, 130, 4216-4217. [CrossRef] [PubMed]

89. Kharisov, B.I.; Kharissova, O.V. Synthesis of graphene by pyrolysis of organic matter. In Graphene Science Handbook: Fabrication Methods; Aliofkhazraei, M., Ali, N., Milne, W.I., Ozkan, C.S., Mitura, S., Gervasoni, J.L., Eds.; CRC Press: Boca Raton, FL, USA, 2016; pp. 345-360.

90. Zou, B.; Wang, X.X.; Huang, X.X.; Wang, J.N. Continuous synthesis of graphene sheets by spray pyrolysis and their use as catalysts for fuel cells. Chem. Commun. 2015, 51, 741-744. [CrossRef] [PubMed]

91. Jabari-Seresht, R.; Jahanshahi, M.; Rashidi, A.; Ghoreyshi, A.A. Fabrication and evaluation of nonporous graphene by a unique spray pyrolysis method. Chem. Eng. Technol. 2013, 36, 1550-1558. [CrossRef]

92. Khan, M.; Tahir, M.N.; Adil, S.F.; Khan, H.U.; Siddiqui, M.R.H.; Al-warthan, A.A.; Tremel, W. Graphene based metal and metal oxide nanocomposites: Synthesis, properties and their applications. J. Mater. Chem. A 2015, 3, 18753-18808. [CrossRef] 
93. Kim, H.; Abdala, A.A.; Macosko, C.W. Graphene/polymer nanocomposites. Macromolecules 2010, 43, 6515-6530. [CrossRef]

94. Yi, M.; Shen, Z. A review on mechanical exfoliation for the scalable production of graphene. J. Mater. Chem. A 2015, 3, 11700-11715. [CrossRef]

95. Hernandez, Y.; Nicolosi, V.; Lotya, M.; Blighe, F.M.; Sun, Z.Y.; De, S.; McGovern, I.T.; Holland, B.; Byrne, M.; Gunko, Y.K.; et al. High-yield production of graphene by liquid-phase exfoliation of graphite. Nat. Nanotechnol. 2008, 3, 563-568. [CrossRef] [PubMed]

96. Li, X.; Zhang, G.; Bai, X.; Sun, X.; Wang, X.; Wang, E.; Dai, H. Highly conducting graphene sheets and Langmuir-Blodgett films. Nat. Nanotechnol. 2008, 3, 538-542. [CrossRef] [PubMed]

97. Coscia, U.; Palomba, M.; Ambrosone, G.; Barucca, G.; Cabibbo, M.; Mengucci, P.; de Asmundis, R.; Carotenuto, G. A new micromechanical approach for the preparation of graphene nanoplatelets deposited on polyethylene. Nanotechnology 2017, 28. [CrossRef] [PubMed]

98. Zhong, Y.L.; Swager, T.M. Enhanced electrochemical expansion of graphite for in situ electrochemical functionalization. J. Am. Chem. Soc. 2012, 134, 17896-17899. [CrossRef] [PubMed]

99. Leroux, Y.R.; Jean-François Bergamini, J.-F.; Ababou, S.; Le Breton, J.-C.; Hapiot, P. Synthesis of functionalized few-layer graphene through fast electrochemical expansion of graphite. J. Electroanal. Chem. 2015, 753, 42-46. [CrossRef]

100. Hossaina, S.T.; Wanga, R. Electrochemical exfoliation of graphite: Effect of temperature and hydrogen peroxide addition. Electrochim. Acta 2016, 216, 253-260. [CrossRef]

101. McAllister, M.J.; Li, J.L.; Adamson, D.H.; Schniepp, H.C.; Abdala, A.A.; Liu, J.; Herrera-Alonso, M.; Milius, D.L.; Car, R.; Prudhomme, R.K.; et al. Single sheet functionalized graphene by oxidation and thermal expansion of graphite. Chem. Mater. 2007, 19, 4396-4404. [CrossRef]

102. Beidaghi, M.; Wang, Z.; Gu, L.; Wang, C. Electrostatic spray deposition of graphene nanoplatelets for high-power thin-film supercapacitor electrodes. J. Solid State Electrochem. 2012, 16, 3341-3348. [CrossRef]

103. Allen, M.J.; Tung, V.C.; Kaner, R.B. Honeycomb carbon: A review of graphene. Chem. Rev. 2010, 110, 132-145. [CrossRef] [PubMed]

104. Viculis, L.M.; Mack, J.J.; Kaner, R.B. A chemical route to carbon nanoscrolls. Science 2003, 299. [CrossRef] [PubMed]

105. Park, S.; Ruoff, R.S. Chemical methods for the production of graphenes. Nat. Nanotechnol. 2009, 4, 217-224. [CrossRef] [PubMed]

106. Jiao, L.Y.; Wang, X.R.; Diankov, G.; Wang, H.L.; Dai, H.J. Facile synthesis of high-quality graphene nanoribbons. Nat. Nanotechnol. 2010, 5, 321-325. [CrossRef] [PubMed]

107. Kosynkin, D.V.; Higginbotham, A.L.; Sinitskii, A.; Lomeda, J.R.; Dimiev, A.; Price, B.K.; Tour, J.M. Longitudinal unzipping of carbon nanotubes to form graphene nanoribbons. Nature 2009, 458, 872-876. [CrossRef] [PubMed]

108. Jiao, L.Y.; Zhang, L.; Wang, X.R.; Diankov, G.; Dai, H.J. Narrow graphene nanoribbons from carbon nanotubes. Nature 2009, 458, 877-880. [CrossRef] [PubMed]

109. Lin, T.; Liu, Z.; Zhou, M.; Bi, H.; Zhang, K.; Huang, F.; Wan, D.; Zhong, Y. Rapid microwave synthesis of graphene directly on h-BN with excellent heat dissipation performance. ACS Appl. Mater. Interfaces 2014, 6, 3088-3092. [CrossRef] [PubMed]

110. Xin, G.Q.; Hwang, W.; Kim, N.; Cho, S.M.; Chae, H. A graphene sheet exfoliated with microwave irradiation and interlinked by carbon nanotubes for high-performance transparent flexible electrodes. Nanotechnology 2010, 21. [CrossRef] [PubMed]

111. Shen, Y.; Jing, T.; Ren, W.; Zhang, J.; Jiang, Z.-G.; Yu, Z.-Z.; Dasari, A. Chemical and thermal reduction of graphene oxide and its electrically conductive polylactic acid nanocomposites. Compos. Sci. Technol. 2012, 72, 1430-1435. [CrossRef]

112. Cote, L.J.; Kim, F.; Huang, J. Langmuir-Blodgett assembly of graphite oxide single layers. J. Am. Chem. Soc. 2009, 131, 1043-1049. [CrossRef] [PubMed]

113. Loh, K.P.; Bao, Q.L.; Ang, P.K.; Yang, J.X. The chemistry of graphene. J. Mater. Chem. 2010, 20, 2277-2289. [CrossRef]

114. Moon, I.K.; Lee, J. Highly qualified reduced graphene oxides: The best chemical reduction. Chem. Commun. 2011, 47, 9681-9683. [CrossRef] [PubMed] 
115. Chua, C.K.; Pumera, M. Chemical reduction of graphene oxide: A synthetic chemistry viewpoint. Chem. Soc. Rev. 2014, 43, 291-312. [CrossRef] [PubMed]

116. Chen, L.; Hernandez, Y.; Feng, X.; Mullen, K. From nanographene and graphene nanoribbons to graphene sheets: Chemical synthesis. Angew. Chem. Int. Ed. Engl. 2012, 51, 7640-7654. [CrossRef] [PubMed]

117. Barg, S.; Perez, F.M.; Ni, N.; Pereira, P.V.; Maher, R.C.; Garcia-Tunon, E.; Eslava, S.; Agnoli, S.; Mattevi, C.; Saiz, E. Mesoscale assembly of chemically modified graphene into complex cellular networks. Nat. Commun. 2014, 5, 4328. [CrossRef] [PubMed]

118. Ruoff, R. Graphene: Calling all chemists. Nat. Nano 2008, 3, 10-11. [CrossRef] [PubMed]

119. Paredes, J.I.; Villar-Rodil, S.; Martinez-Alonso, A.; Tascon, J.M.D. Graphene oxide dispersions in organic solvents. Langmuir 2008, 24, 10560-10564. [CrossRef] [PubMed]

120. Bianco, A.; Cheng, H.-M.; Enoki, T.; Gogotsi, Y.; Hurt, R.H.; Koratkar, N.; Kyotani, T.; Monthioux, M.; Park, C.R.; Tascon, J.M.D.; et al. All in the graphene family-A recommended nomenclature for two dimensional carbon materials. Carbon 2013, 65, 1-6. [CrossRef]

121. Poh, H.L.; Sanek, F.; Ambrosi, A.; Zhao, G.; Sofer, Z.; Pumera, M. Graphenes prepared by Staudenmaier, Hofmann and Hummer's methods with consequent thermal exfoliation exhibit very different electrochemical properties. Nanoscale 2012, 4, 3515-3522. [CrossRef] [PubMed]

122. Compton, O.C.; Nguyen, S.T. Graphene oxide, highly reduced graphene oxide, and graphene: Versatile building blocks for carbon-based materials. Small 2010, 6, 711-723. [CrossRef] [PubMed]

123. Dreyer, D.R.; Park, S.; Bielawski, C.W.; Ruoff, R.S. The chemistry of graphene oxide. Chem. Soc. Rev. 2010, 39, 228-240. [CrossRef] [PubMed]

124. Brodie, B.C. On the atomic weight of graphite. Philos. Trans. R. Soc. Lond. 1859, 149, 249-259. [CrossRef]

125. Staudenmaier, L. Verfahren zur darstellung der graphitsaure. Ber. Dtsch. Chem. Ges. 1898, 31, 1481-1487. [CrossRef]

126. Hummers, W.S., Jr.; Offeman, R.E. Preparation of graphitic oxide. J. Am. Chem. Soc. 1958, 80, 1339. [CrossRef]

127. Schniepp, H.C.; Li, J.L.; McAllister, M.J.; Sai, H.; Herrera-Alonso, M.; Adamson, D.H.; Prud'homme, R.K.; Car, R.; Saville, D.A.; Aksay, I.A. Functionalized single graphene sheets derived from splitting graphite oxide. J. Phys. Chem. B 2006, 110, 8535-8539. [CrossRef] [PubMed]

128. Gao, X.F.; Jang, J.; Nagase, S. Hydrazine and thermal reduction of graphene oxide: Reaction mechanisms, product structures, and reaction design. J. Phys. Chem. C 2010, 114, 832-842. [CrossRef]

129. Ramesha, G.K.; Sampath, S. Electrochemical reduction of oriented graphene oxide films: An in situ Raman spectroelectrochemical study. J. Phys. Chem. C 2009, 113, 7985-7989. [CrossRef]

130. Abdelsayed, V.; Moussa, S.; Hassan, H.M.; Aluri, H.S.; Collinson, M.M.; El-Shall, M.S. Photothermal deoxygenation of graphite oxide with laser excitation in solution and graphene-aided increase in water temperature. J. Phys. Chem. Lett. 2010, 1, 2804-2809. [CrossRef]

131. Ng, Y.H.; Lightcap, I.V.; Goodwin, K.; Matsumura, M.; Kamat, P.V. To what extent do graphene scaffolds improve the photovoltaic and photocatalytic response of $\mathrm{TiO}_{2}$ nanostructured films? J. Phys. Chem. Lett. 2010, 1, 2222-2227. [CrossRef]

132. Golsheikh, A.M.; Lim, H.N.; Zakaria, R.; Huang, N.M. Sonochemical synthesis of reduced graphene oxide uniformly decorated with hierarchical ZnS nanospheres and its enhanced photocatalytic activities. RSC Adv. 2015, 5, 12726-12735. [CrossRef]

133. Vinodgopal, K.; Neppolian, B.; Lightcap, I.V.; Grieser, F.; Ashokkumar, M.; Kamat, P.V. Sonolytic design of graphene-Au nanocomposites. Simultaneous and sequential reduction of graphene oxide and $\mathrm{Au}(\mathrm{III})$. J. Phys. Chem. Lett. 2010, 1, 1987-1993. [CrossRef]

134. Voiry, D.; Yang, J.; Kupferberg, J.; Fullon, R.; Lee, C.; Jeong, H.Y.; Shin, H.S.; Chhowalla, M. High-quality graphene via microwave reduction of solution-exfoliated graphene oxide. Science 2016, 353, 1413-1416. [CrossRef] [PubMed]

135. Mills, A.; Le Hunte, S. An overview of semiconductor photocatalysis. J. Photochem. Photobiol. A 1997, 108, 1-35. [CrossRef]

136. Mahlambi, M.M.; Ngila, C.J.; Mamba, B.B. Recent developments in environmental photocatalytic degradation of organic pollutants: The case of Titanium dioxide nanoparticles-A review. J. Nanomater. 2015, 2015. [CrossRef]

137. Nosaka, Y.; Nosaka, A. Understanding hydroxyl radical $\left({ }^{\bullet} \mathrm{OH}\right)$ generation processes in photocatalysis. ACS Energy Lett. 2016, 1, 356-359. [CrossRef] 
138. Zhang, Y.; Tan, Y.; Stormer, H.L.; Kim, P. Experimental observation of the quantum Hall effect and Berry's phase in graphene. Nature 2005, 438, 201-204. [CrossRef] [PubMed]

139. Teh, C.M.; Mohamed, A.R. Roles of titanium dioxide and ion-doped titanium dioxide on photocatalytic degradation of organic pollutants (phenolic compounds and dyes) in aqueous solutions: A review. J. Alloys Compd. 2011, 509, 1648-1660. [CrossRef]

140. Hager, S.; Bauer, R. Heterogeneous photocatalytic oxidation of organics for air purification by near UV irradiated titanium dioxide. Chemosphere 1999, 38, 1549-1559. [CrossRef]

141. Faraldos, M.; Bahamonde, A. Environmental applications of titania-graphene photocatalysts. Catal. Today 2017, 285, 13-28. [CrossRef]

142. Upadhyay, R.K.; Soin, N.; Ro, S.S. Role of graphene/metal oxide composites as photocatalysts, adsorbents and disinfectants in water treatment: A review. RSC Adv. 2014, 4, 3823-3851. [CrossRef]

143. Fujishima, A.; Rao, T.N.; Tryk, D.A. Titanium dioxide photocatalysis. J. Photochem. Photobiol. C Photochem. Rev. 2000, 1, 1-21. [CrossRef]

144. Hu, G.; Tang, B. Photocatalytic mechanism of graphene/titanate nanotubes photocatalyst under visible-light irradiation. Mater. Chem. Phys. 2013, 138, 608-614. [CrossRef]

145. Cruz, M.; Gomez, C.; Duran-Valle, C.J.; Pastrana-Martínez, L.M.; Faria, J.L.; Silva, A.M.T.; Faraldosa, M.; Bahamondea, A. Bare $\mathrm{TiO}_{2}$ and graphene oxide $\mathrm{TiO}_{2}$ photocatalysts on the degradation of selected pesticides and influence of the water matrix. Appl. Surf. Sci. 2017, 416, 1013-1021. [CrossRef]

146. Wang, C.; Cao, M.; Wang, P.; Ao, Y.; Hou, J.; Qian, J. Preparation of graphene- $\mathrm{TiO}_{2}$ composites with enhanced photocatalytic activity for the removal of dye and Cr (VI). Appl. Catal. A Gen. 2014, 473, 83-89. [CrossRef]

147. Pastrana-Martínez, L.M.; Morales-Torres, S.; Likodimos, V.; José, L.; Figueiredo, J.L.; Faria, J.L.; Falaras, P.; Silva, A.M.T. Advanced nanostructured photocatalysts based on reduced graphene oxide- $\mathrm{TiO}_{2}$ composites for degradation of diphenhydramine pharmaceutical and methyl orange dye. Appl. Catal. B 2012, 123, 241-256. [CrossRef]

148. Liu, S.; Sun, H.; Liu, S.; Wang, S. Graphene facilitated visible light photodegradation of methylene blue over titanium dioxide photocatalysts. Chem. Eng. J. 2013, 214, 298-303. [CrossRef]

149. Zhang, L.-W.; Fu, H.-B.; Zhu, Y.-F. Efficient $\mathrm{TiO}_{2}$ photocatalysts from surface hybridization of $\mathrm{TiO}_{2}$ particles with graphite-like carbon. Adv. Funct. Mater. 2008, 18, 2180-2189. [CrossRef]

150. Ren, L.; Qi, X.; Liu, Y.; Huang, Z.; Wei, X.; Li, J.; Yang, L.; Zhong, J. Upconversion-P25-graphene composite as an advanced sunlight driven photocatalytic hybrid material. J. Mater. Chem. 2012, 22, 11765-11771. [CrossRef]

151. Long, R.; English, N.J.; Prezhdo, O.V. Photo-induced charge separation across the graphene- $\mathrm{TiO}_{2}$ interface is faster than energy losses: A time-domain ab initio analysis. J. Am. Chem. Soc. 2012, 134, 14238-14248. [CrossRef] [PubMed]

152. Rehman, S.; Ullah, R.; Butt, A.M.; Gohar, N.D. Strategies of making $\mathrm{TiO}_{2}$ and $\mathrm{ZnO}$ visible light active. J. Hazard. Mater. 2009, 170, 560-569. [CrossRef] [PubMed]

153. Wu, H.; Wu, X.-L.; Wang, Z.-M.; Aoki, H.; Kutsuna, S.; Keiko Jimura, K.; Hayashi, S. Anchoring titanium dioxide on carbon spheres for high-performancevisible light photocatalysis. Appl. Catal. B Environ. 2017, 207, 255-266. [CrossRef]

154. Warkhade, S.K.; Gaikwad, G.S.; Zodape, S.P.; Pratap, U.; Maldhure, A.V.; Wankhade, A.V. Low temperature synthesis of pure anatase carbon doped titanium dioxide: An efficient visible light active photocatalyst. Mater. Sci. Semicond. Process. 2017, 63, 18-24. [CrossRef]

155. Jiang, W.J.; Zhu, Y.F.; Zhu, G.X.; Zhang, Z.J.; Chen, X.J.; Yao, W.Q. Three-dimensional photocatalysts with a network structure. J. Mater. Chem. A 2017, 5, 5661-5679. [CrossRef]

156. Williams, G.; Seger, B.; Kamat, P.V. $\mathrm{TiO}_{2}$-graphene nanocomposites. UV-assisted photocatalytic reduction of graphene oxide. ACS Nano 2008, 2, 1487-1491. [CrossRef] [PubMed]

157. Pan, X.; Yang, M.-Q.; Tang, Z.R.; Xu, Y.-J. Noncovalently functionalized graphene-directed synthesis of ultralarge graphene-based $\mathrm{TiO}_{2}$ nanosheet composites: Tunable morphology and photocatalytic applications. J. Phys. Chem. C 2014, 118, 27325-27335. [CrossRef]

158. Kamegawa, T.; Yamahana, D.; Yamashita, H. Graphene coating of $\mathrm{TiO}_{2}$ nanoparticles loaded on mesoporous silica for enhancement of photocatalytic activity. J. Phys. Chem. C 2010, 114, 15049-15053. [CrossRef] 
159. Bekyarova, E.; Itkis, M.E.; Ramesh, P.; Berger, C.; Sprinkle, M.; de Heer, W.A.; Haddon, R.C. Chemical modification of epitaxial graphene: Spontaneous grafting of aryl groups. J. Am. Chem. Soc. 2009, 131, 1336-1337. [CrossRef] [PubMed]

160. Zhang, Q.; Bao, N.; Wang, X.; Hu, X.; Miao, X.; Chaker, M.; Ma, D. Advanced fabrication of chemically bonded graphene $/ \mathrm{TiO}_{2}$ continuous fibers with enhanced broadband photocatalytic properties and involved mechanisms exploration. Sci. Rep. 2016, 6. [CrossRef] [PubMed]

161. Yao, Y.; Jie, G.; Bao, F.; Jiang, S.; Zhang, X.; Ma, R. Covalent functionalization of graphene with polythiophene through a Suzuki coupling reaction. RSC Adv. 2015, 5, 42754-42761. [CrossRef]

162. He, F.; Fan, J.; Ma, D.; Zhang, L.; Leung, C.; Chan, H.L. The attachment of $\mathrm{Fe}_{3} \mathrm{O}_{4}$ nanoparticles to graphene oxide by covalent bonding. Carbon 2010, 48, 3139-3144. [CrossRef]

163. Morawskia, A.W.; Kusiak-Nejmana, E.; Wanaga, A.; Kapica-Kozara, J.; Wróbela, R.J.; Ohtanib, B.; Aksienionekc, M.; Lipinska, L. Photocatalytic degradation of acetic acid in the presence of visiblelight-active $\mathrm{TiO}_{2}$-reduced graphene oxide photocatalysts. Catal. Today 2017, 280, 108-113. [CrossRef]

164. Liu, Y.; Zhang, D.; Shang, Y.; Zang, W.; Li, M. Construction of multifunctional films based on graphene-TiO 2 composite materials for strain sensing and photodegradation. RSC Adv. 2015, 5, 104785-104791. [CrossRef]

165. Raliya, R.; Avery, C.; Chakrabarti, S.; Biswas, P. Photocatalytic degradation of methyl orange dye by pristine titanium dioxide, zinc oxide, and graphene oxide nanostructures and their composites under visible light irradiation. Appl. Nanosci. 2017, 7, 253-259. [CrossRef]

166. Kuila, T.; Bose, S.; Mishra, A.K.; Kharna, P.; Kim, N.H.; Lee, J.H. Recent advances in graphene based polymer composites. Progress Mater. Sci. 2012, 57, 1061-1105. [CrossRef]

167. Huang, X.; Qi, X.; Freddy Boeyab, F.; Zhang, H. Graphene-based composites. Chem. Soc. Rev. 2011, 41, 666-686. [CrossRef] [PubMed]

168. Bai, H.; Li, C.; Shi, G. Functional composite materials based on chemically converted graphene. Adv. Mater. 2011, 23, 1089-1115. [CrossRef] [PubMed]

169. Sreeprasad, T.S.; Berry, V. How do the electrical properties of graphene change with its functionalization? Small 2013, 9, 341-350. [CrossRef] [PubMed]

170. Pan, X.; Zhao, Y.; Liu, S.; Korzeniewski, C.L.; Wang, S.; Fan, Z. Comparing graphene- $\mathrm{TiO}_{2}$ nanowire and graphene- $\mathrm{TiO}_{2}$ nanoparticle composite photocatalysts. ACS Appl. Mater. Interfaces 2012, 4, 3944-3950. [CrossRef] [PubMed]

171. Lee, J.S.; You, K.H.; Park, C.B. Highly photoactive, low bandgap $\mathrm{TiO}_{2}$ nanoparticles wrapped by graphene. Adv. Mater. 2012, 24, 1084-1088. [CrossRef] [PubMed]

172. Wang, J.; Salihi, E.C.; Šiller, L. Green reduction of graphene oxide using alanine. Mater. Sci. Eng. C 2017, 72, 1-6. [CrossRef] [PubMed]

173. Pei, S.; Cheng, H.-M. The reduction of graphene oxide. Carbon 2012, 50, 3210-3228. [CrossRef]

174. Bell, N.J.; Ng, Y.H.; Du, A.; Coster, H.; Smith, S.C.; Amal, R. Understanding the enhancement in photoelectrochemical properties of photocatalytically prepared $\mathrm{TiO}_{2}$ - reduced graphene oxide composite. J. Phys. Chem. C 2011, 115, 6004-6009. [CrossRef]

175. Zhang, Y.; Pan, $\mathrm{C}$. $\mathrm{TiO}_{2}$ /graphene composite from thermal reaction of graphene oxide and its photocatalytic activity in visible light. J. Mater. Sci. 2011, 46, 2622-2626. [CrossRef]

176. Zhang, X.-Y.; Li, H.-P.; Cui, X.-L.; Linb, Y. Graphene/ $\mathrm{TiO}_{2}$ nanocomposites: Synthesis, characterization and application in hydrogen evolution from water photocatalytic splitting. J. Mater. Chem. 2010, 20, 2801-2806. [CrossRef]

177. Zabihi, F.; Ahmadian-Yazdi, M.-R.; Eslamian, M. Photocatalytic graphene- $\mathrm{TiO}_{2}$ thin films fabricated by low-temperature ultrasonic vibration-assisted spin and spray coating in a sol-gel process. Catalysts 2017, 7 , 136. [CrossRef]

178. Gopalakrishnan, A.; Binitha, N.N.; Yaakob, Z. Excellent photocatalytic activity of titania-graphene nanocomposites prepared by a facile route. J. Sol-Gel Sci. Technol. 2016, 80, 189-200. [CrossRef]

179. Shao, L.; Quan, S.; Liu, Y.; Guo, Z.; Wang, Z. A novel "gel-sol" strategy to synthesize $\mathrm{TiO}_{2}$ nanorod combining reduced graphene oxide composites. Mater. Lett. 2013, 107, 307-310. [CrossRef]

180. Long, M.; Qin, Y.; Chen, C.; Guo, X.; Tan, B.; Cai, W. Origin of visible light photoactivity of reduced graphene oxide $/ \mathrm{TiO}_{2}$ by in situ hydrothermal growth of undergrown $\mathrm{TiO}_{2}$ with graphene oxide. J. Phys. Chem. C 2013, 117, 16734-16741. [CrossRef] 
181. Zhang, H.; Lv, X.; Li, Y.; Wang, Y.; Li, J. P25-graphene composite as a high performance photocatalyst. ACS Nano 2010, 4, 380-386. [CrossRef] [PubMed]

182. Hu, G.; Yang, J.; Zhao, D.; Chen, Y.; Cao, Y. Research on photocatalytic properties of $\mathrm{TiO}_{2}$-graphene composites with different morphologies. J. Mater. Eng. Perform. 2017, 26, 3263-3270. [CrossRef]

183. Hamandi, M.; Berhault, G.; Guillard, C.; Kochkar, H. Reduced graphene oxide/ $\mathrm{TiO}_{2}$ nanotube composites for formic acid photodegradation. Appl. Catal. B Environ. 2017, 209, 203-213. [CrossRef]

184. Lv, S.; Wan, J.; Shen, Y.; Hu, Z. Preparation of superlong $\mathrm{TiO}_{2}$ nanotubes and reduced graphene oxide composite photocatalysts with enhanced photocatalytic performance under visible light irradiation. J. Mater. Sci. Mater. Electron. 2017, 28, 14769-14776. [CrossRef]

185. Kusiak-Nejmana, E.; Wanaga, A.; Kowalczyka, L.; Kapica-Kozara, J.; Colbeau-Justinb, C.; Mendez Medrano, M.G.; Morawsk, A.W. Graphene oxide- $\mathrm{TiO}_{2}$ and reduced graphene oxide- $\mathrm{TiO}_{2}$ nanocomposites: Insight in charge-carrier lifetime measurements. Catal. Today 2017, 287, 189-195. [CrossRef]

186. Li, T.; Wang, T.; Qu, G.; Qu, G.; Liang, D.; Hu, S. Synthesis and photocatalytic performance of reduced graphene oxide- $\mathrm{TiO}_{2}$ nanocomposites for orange II degradation under UV light irradiation. Environ. Sci. Pollut. Res. 2017, 24, 12416-12425. [CrossRef] [PubMed]

187. Yadav, H.M.; Kim, J.-S. Solvothermal synthesis of anatase $\mathrm{TiO}_{2}$-graphene oxide nanocomposites and their photocatalytic performance. J. Alloys Compd. 2016, 688, 123-129. [CrossRef]

188. Hu, J.J.; Lia, H.; Muhammada, S.; Wua, Q.; Zhaoa, Y.; Jiaoa, Q. Surfactant-assisted hydrothermal synthesis of $\mathrm{TiO}_{2} /$ reduced graphene oxide nanocomposites and their photocatalytic performances. J. Solid State Chem. 2017, 253, 113-120. [CrossRef]

189. Ge, M.-Z.; Li, S.-H.; Huang, J.-Y.; Zhang, K.-Q.; Al-Deyabc, S.S.; Lai, Y.-K. $\mathrm{TiO}_{2}$ nanotube arrays loaded with reduced graphene oxide films: Facile hybridization and promising photocatalytic application. J. Mater. Chem. A 2015, 3, 3491-3499. [CrossRef]

190. De Oliveira, A.G.; Nascimento, J.P.; de Fátima Gorgulho, H.; Martelli, P.B.; Furtado, C.A.; Figueiredo, J.L. Electrochemical synthesis of $\mathrm{TiO}_{2} /$ Graphene oxide composite films for photocatalytic applications. J. Alloys Compd. 2016, 654, 514-522. [CrossRef]

191. Shanmugam, M.; Alsalme, A.; Alghamdi, A.; Jayavel, R. In-situ microwave synthesis of graphene-TiO 2 nanocomposites with enhanced photocatalytic properties for the degradation of organic pollutants. J. Photochem. Photobiol. B Biol. 2016, 163, 216-223. [CrossRef] [PubMed]

192. Wang, H.; Gao, H.; Chen, M.; Xu, X.; Wang, X.; Pan, C.; Gao, J. Microwave-assisted synthesis of reduced graphene oxide/titania nanocomposites as an adsorbent for methylene blue adsorption. J. Appl. Surf. Sci. 2016, 360, 840-848. [CrossRef]

193. Yang, Y.; Liu, E.; Fan, J.; Hu, X.; Hou, W.; Wu, F.; Ma, Y. Green and facile microwave-assisted synthesis of $\mathrm{TiO}_{2}$ /graphene nanocomposite and their photocatalytic activity for methylene blue degradation. Russ. J. Phys. Chem. A 2014, 88, 478-483. [CrossRef]

194. Pu, S.; Zhu, R.; Ma, H.; Deng, D.; Pei, X.; Qi, F.; Chu, W. Facile in-situ design strategy to disperse $\mathrm{TiO}_{2}$ nanoparticles on graphene for the enhanced photocatalytic degradation of rhodamine 6G. Appl. Catal. B Environ. 2017, 218, 208-219. [CrossRef]

195. Pokhrel, D.; Viraraghavan, T. Treatment of pulp and paper mill wastewater-A review. Sci. Total Environ. 2004, 333, 37-58. [CrossRef] [PubMed]

196. Liu, L.; Zhang, B.; Zhang, Y.; He, Y.; Huang, L.; Tan, S.; Cai, X. Simultaneous removal of cationic and anionic dyes from environmental water using montmorillonite-pillared graphene oxide. J. Chem. Eng. Data 2015, 60, 1270-1278. [CrossRef]

197. Bhullar, N.; Sharma, S.; Sud, D. Studies of adsorption for dye effluent and decolonization of methylene blue and methyl blue based on the surface of biomass adsorbent. Pollut. Res. 2012, 31, 681-686.

198. Hameed, B.H.; Din, A.T.M.; Ahmad, A.L. Adsorption of methylene blue onto bamboo-based activated carbon: Kinetics and equilibrium studies. J. Hazard. Mater. 2007, 141, 819-825. [CrossRef] [PubMed]

199. Mohamed, H.H. Biphasic TiO microspheres/reduced graphene oxide for effective simultaneous photocatalytic reduction and oxidation processes. Appl. Catal. A Gen. 2017, 541, 25-34. [CrossRef]

200. Zhang, N.; Li, B.; Li, S.; Yang, S. Graphene-supported mesoporous Titania nanosheets for efficient photodegradation. J. Colloid Interface Sci. 2017, 505, 711-718. [CrossRef] [PubMed] 
201. Najafi, M.; Kermanpur, A.; Rahimipour, M.R.; Najafizadeh, A. Effect of $\mathrm{TiO}_{2}$ morphology on structure of $\mathrm{TiO}_{2}$-graphene oxide nanocomposite synthesized via a one-step hydrothermal method. J. Alloys Compd. 2017, 722, 272-277. [CrossRef]

202. Divya, K.S.; Madhu, A.K.; Umadevi, T.U.; Suprabha, T.; Radhakrishnan Nair, P.; Suresh, M. Improving the photocatalytic performance of $\mathrm{TiO}_{2}$ via hybridizing with graphene. J. Semiconduct. 2017, 38. [CrossRef]

203. Sohail, M.; Xue, H.; Jiao, Q.; Li, H.; Khan, K.; Wang, S. Synthesis of well-dispersed $\mathrm{TiO}_{2} @$ reduced graphene oxide (rGO) nanocomposites and their photocatalytic properties. Mater. Res. Bull. 2017, 90, 125-130. [CrossRef]

204. Tseng, I.-H.; Sung, Y.-M.; Chang, P.-Y.; Lin, S.-W. Photocatalytic performance of Titania nanosheets templated by graphene oxide. J. Photochem. Photobiol. A Chem. 2017, 339, 1-11. [CrossRef]

205. Minella, M.; Sordello, F.; Minero, C. Photocatalytic process in $\mathrm{TiO}_{2}$ /graphene hybrid materials. Evidence of charge separation by electron transfer from reduced graphene oxide to $\mathrm{TiO}_{2}$. Catal. Today 2017, 281, $29-37$. [CrossRef]

206. Raja, V.; Shiamala, L. Biphasic $\mathrm{TiO}_{2}$ nanoparticles decorated graphene nanosheets for visible light driven photocatalytic degradation of organic dyes. Appl. Surf. Sci. 2017, 31. [CrossRef]

207. Verma, R.; Samdarshi, S.K.; Sagar, K. Nanostructured bi-phasic $\mathrm{TiO}_{2}$ nanoparticles grown on reduced graphene oxide with high visible light photocatalytic detoxification. Mater. Chem. Phys. 2017, 186, 202-211. [CrossRef]

208. Atchudan, R.; Jebakumar Immanuel Edison, T.N.; Perumal, S.; Karthikeyan, D.; Lee, Y.R. Effective photocatalytic degradation of anthropogenic dyes using graphene oxide grafting titanium dioxide nanoparticles under UV-light irradiation. J. Photochem. Photobiol. A Chem. 2017, 333, 92-104. [CrossRef]

209. Darvishi, M.; Seyed-Yazdi, J. Characterization and comparison of photocatalytic activities of prepared $\mathrm{TiO}_{2}$ /graphene nanocomposites using titanium butoxide and $\mathrm{TiO}_{2}$ via microwave irradiation method. Mater. Res. Express 2016, 3. [CrossRef]

210. Rezaei, M.; Salem, S. Photocatalytic activity enhancement of anatase-graphene nanocomposite for methylene removal: Degradation and kinetics. Spectrochim. Acta A Mol. Biomol. Spectrosc. 2016, 167, 41-49. [CrossRef] [PubMed]

211. Rezaei, M.; Salem, S. Optimal $\mathrm{TiO}_{2}$-graphene oxide nanocomposite for photocatalytic activity under sunlight condition: Synthesis, characterization, and kinetics. Int. J. Chem. Kinet. 2016, 48, 573-583. [CrossRef]

212. Charoensuk, J.; Charupongtawitch, R.; Usakulwattana, A. Kinetics of photocatalytic degradation of methylene blue by $\mathrm{TiO}_{2}$-graphene nanocomposites. J. Nanosci. Nanotechnol. 2016, 16, 296-302.

213. Wang, R.; Yang, R.; Wang, B. Efficient degradation of methylene blue by the nano $\mathrm{TiO}_{2}$-functionalized graphene oxide nanocomposite photocatalyst for wastewater treatment. Water Air Soil Pollut. 2016, 227. [CrossRef]

214. Liu, G.; Wang, R.; Liu, H.; Han, K.; Cui, H. Highly dispersive nano- $\mathrm{TiO}_{2}$ in situ growing on functional graphene with high photocatalytic activity. J. Nanopart. Res. 2016, 18, 1-8. [CrossRef]

215. Baldissarelli, V.Z.; De Souza, T.; Andrade, L.; Oliveira, L.F.C.D.; José, H.J. Preparation and photocatalytic activity of $\mathrm{TiO}_{2}$-exfoliated graphite oxide composite using an ecofriendly graphite oxidation method. Appl. Surf. Sci. 2015, 359, 868-874. [CrossRef]

216. Gu, L.; Zhang, H.; Jiao, Z.; Li, M.; Wu, M.; Lei, Y. Glucosamine-induced growth of highly distributed $\mathrm{TiO}_{2}$ nanoparticles on graphene nanosheets as high-performance photocatalysts. RSC Adv. 2016, 6, 67039-67048. [CrossRef]

217. Fan, J.; Liu, E.; Hu, X.; Ma, Y.; Fan, X.; Li, Y.; Tang, C. Facile hydrothermal synthesis of $\mathrm{TiO}_{2}$ nanospindles-reduced graphene oxide composite with a enhanced photocatalytic activity. J. Alloys Compd. 2015, 623, 298-303.

218. Sun, M.; Li, W.; Sun, S.; He, J.; Zhang, Q.; Shi, Y. One-step in situ synthesis of graphene-TiO ${ }_{2}$ nanorod hybrid composites with enhanced photocatalytic activity. Mater. Res. Bull. 2015, 61, 280-286. [CrossRef]

219. Rong, X.; Qiu, F.; Zhang, C.; Fu, L.; Wang, Y.; Yang, D. Preparation, characterization and photocatalytic application of $\mathrm{TiO}_{2}$-graphene photocatalyst under visible light irradiation. Ceram. Int. 2015, 41, 2502-2511. [CrossRef]

220. Gupta, B.K.; Kedawat, G.; Agrawal, Y.; Kumar, P.; Dwivedi, J. A novel strategy to enhance ultraviolet light driven photocatalysis from graphene quantum dots infilled $\mathrm{TiO}_{2}$ nanotube arrays. RSC Adv. 2015, 5, 10623-10631. [CrossRef] 
221. Sha, J.; Zhao, N.; Liu, E.; Shi, C.; He, C.; Li, J. In situ synthesis of ultrathin 2-D $\mathrm{TiO}_{2}$ with high energy facets on graphene oxide for enhancing photocatalytic activity. Carbon 2014, 68, 352-359. [CrossRef]

222. Yang, Y.; Xu, L.; Wang, H.; Wang, W.; Zhang, L. $\mathrm{TiO}_{2}$ /graphene porous composite and its photocatalytic degradation of methylene blue. Mater. Des. 2016, 108, 632-639. [CrossRef]

223. Suave, J.; Amorim, S.M.; Moreira, R.F.P.M. $\mathrm{TiO}_{2}$-graphene nanocomposite supported on floating autoclaved cellular concrete for photocatalytic removal of organic compounds. J. Environ. Chem. Eng. 2017, 5, 3215-3223. [CrossRef]

224. Ai, L.; Zhang, C.; Meng, L. Adsorption of methyl orange from aqueous solution on hydrothermal synthesized Mg-Al layered double hydroxide. J. Chem. Eng. Data 2011, 56, 4217-4225. [CrossRef]

225. Lavanya, T.; Dutta, M.; Ramaprabhu, S.; Satheesh, K. Superior photocatalytic performance of graphene wrapped anatase/rutile mixed phase $\mathrm{TiO}_{2}$ nanofibers synthesized by a simple and facile route. J. Environ. Chem. Eng. 2017, 5, 494-503. [CrossRef]

226. Hou, X.; Sun, T.; Zhao, X. Calcination of reduced graphene oxide decorated $\mathrm{TiO}_{2}$ composites for recovery and reuse in photocatalytic applications. Ceram. Int. 2017, 43, 1150-1159.

227. Zhao, F.; Dong, B.; Gao, R.; Su, G.; Liu, W.; Shi, L.; Xia, C. A three-dimensional graphene-TiO 2 nanotube nanocomposite with exceptional photocatalytic activity for dye degradation. Appl. Surf. Sci. 2015, 351, 303-308. [CrossRef]

228. Lu, Z.; Chen, G.; Hao, W.; Sun, G.; Li, Z. Mechanism of UV-assisted $\mathrm{TiO}_{2}$ / reduced graphene oxide composites with variable photodegradation of methyl orange. RSC Adv. 2015, 5, 72916-72922. [CrossRef]

229. Xia, H.Y.; He, G.Q.; Min, Y.L.; Liu, T. Role of the crystallite phase of $\mathrm{TiO}_{2}$ in graphene $/ \mathrm{TiO}_{2}$ photocatalysis. J. Mater. Sci. Mater. Electron. 2015, 26, 3357-3363. [CrossRef]

230. Jiang, Y.; Wang, W.-N.; Biswas, P.; Fortner, J.D. Facile aerosol synthesis and characterization of ternary crumpled graphene- $\mathrm{TiO}_{2}$-magnetite nanocomposites for advanced watertreatment. ACS Appl. Mater. Interfaces 2014, 6, 11766-11774. [CrossRef] [PubMed]

231. Han, W.; Ren, L.; Zhang, Z.; Qi, X.; Liu, Y.; Huang, Z.; Zhong, J. Graphene-supported flocculent-like $\mathrm{TiO}_{2}$ nanostructures for enhanced photoelectrochemical activity and photodegradation performance. J. Ceram. Int. 2015, 41, 7471-7477. [CrossRef]

232. Lavanya, T.; Satheesh, K.; Dutta, M.; Victor Jaya, N. Superior photocatalytic performance of reduced graphene oxide wrapped electrospun anatase mesoporous $\mathrm{TiO}_{2}$ nanofibers. J. Alloys Compd. 2014, 615, 643-650. [CrossRef]

233. Wang, Y.; Li, Z.; He, Y.; Li, F.; Liu, X. Low-temperature solvothermal synthesis of graphene-TiO nanocomposite and its photocatalytic activity for dye degradation. Mater. Lett. 2014, 134, 115-118. [CrossRef]

234. Athanasekou, C.P.; Morales-Torres, S.; Likodimos, V.; Romanos, G.E.; Pastrana-Martinez, L.M.; Falaras, P.; Faria, J.L.; Figueiredo, J.L. Prototype composite membranes of partially reduced graphene oxide $/ \mathrm{TiO}_{2}$ for photocatalytic ultrafiltration water treatment under visible light. Appl. Catal. B Environ. 2014, 158-159, 361-372. [CrossRef]

235. Liu, Y. Hydrothermal synthesis of $\mathrm{TiO}_{2}-\mathrm{RGO}$ composites and their improved photocatalytic activity in visible light. RSC Adv. 2014, 4, 36040-36045. [CrossRef]

236. Shakir, K.; Elkafrawy, A.F.; Ghoneimy, H.F.; Elrab Beheir, S.G.; Refaat, M. Removal of rhodamine B (a basic dye) and thoron (an acidic dye) from dilute aqueous solutions and wastewater simulants by ion flotation. Water Res. 2010, 44, 1449-1461. [CrossRef] [PubMed]

237. Chen, Q.; Zhou, M.; Zhang, Z.; Tang, T.; Wang, T. Preparation of $\mathrm{TiO}_{2}$ nanotubes/reduced graphene oxide binary nanocomposites enhanced photocatalytic properties. J. Mater. Sci. Mater. Electron. 2017, 28, 9416-9422. [CrossRef]

238. Chen, Y.; Dong, X.; Cao, Y.; Xiang, J. Enhanced photocatalytic activities of low-bandgap $\mathrm{TiO}_{2}$-reduced graphene oxide nanocomposites. J. Nanopart. Res. 2017, 19. [CrossRef]

239. Wang, W.; Huang, X.; Lai, M. RGO/ $\mathrm{TiO}_{2}$ nanosheets immobilized on magnetically actuated artificial cilia film: A new mode for efficient photocatalytic reaction. RSC Adv. 2017, 7, 10517-10523. [CrossRef]

240. Biris, A.R.; Toloman, D.; Popa, A.; Lazar, M.D.; Kannarpady, G.K.; Saini, V.; Watanabe, F.; Chhetri, B.P.; Ghosh, A. Synthesis of tunable core-shell nanostructures based on $\mathrm{TiO}_{2}$-graphene architectures and their application in the photodegradation of rhodamine dyes. Phys. E Low Dimens. Syst. Nanostruct. 2016, 81, 326-333. [CrossRef] 
241. Kim, T.-W.; Park, M.; Kim, H.Y.; Park, S.-J. Preparation of flower-like $\mathrm{TiO}_{2}$ sphere/reduced graphene oxide composites for photocatalytic degradation of organic pollutants. J. Solid State Chem. 2016, 239, 91-98. [CrossRef]

242. Liu, H.; Wang, Y.; Shi, L.; Xu, R.; Huang, L.; Tan, S. Utilization of reduced graphene oxide for the enhancement of photocatalytic property of $\mathrm{TiO}_{2}$ nanotube. Desalination Water Treat. 2016, 57, 13263-13272. [CrossRef]

243. Sedghi, R.; Heidari, F. A novel \& effective visible light-driven $\mathrm{TiO}_{2} /$ magnetic porous graphene oxide nanocomposite for the degradation of dye pollutants. RSC Adv. 2016, 6, 49459-49468.

244. Zhang, J.-J.; Wu, Y.-H.; Mei, J.-Y.; Zheng, G.-P.; Yan, T.-T.; Zheng, X.-C.; Liu, P.; Guan, X.-X. Synergetic adsorption and photocatalytic degradation of pollutants over $3 \mathrm{D} \mathrm{TiO}_{2}$-graphene aerogel composites synthesized: Via a facile one-pot route. Photochem. Photobiol. Sci. 2016, 15, 1012-1019. [CrossRef] [PubMed]

245. He, R.; He, W. Ultrasonic assisted synthesis of $\mathrm{TiO}_{2}$-reduced graphene oxide nanocomposites with superior photovoltaic and photocatalytic activities. Ceram. Int. 2016, 42, 5766-5771. [CrossRef]

246. Fang, R.; Liang, Y.; Ge, X.; Du, M.; Li, S.; Li, T. Preparation and photocatalytic degradation activity of $\mathrm{TiO}_{2} / \mathrm{rGO} /$ polymer composites. Colloid Polym. Sci. 2015, 293, 1151-1157. [CrossRef]

247. Liang, D.; Cui, C.; Hub, H.; Wang, Y.; Xu, S.; Ying, B.; Li, P.; Lu, B. One-step hydrothermal synthesis of anatase $\mathrm{TiO}_{2} /$ reduced graphene oxide nanocomposites with enhanced photocatalytic activity. J. Alloys Compd. 2014, 582, 236-240. [CrossRef]

248. Li, Q.; Bian, J.; Zhang, L.; Zhang, R.; Wang, G. Synthesis of carbon materials- $\mathrm{TiO}_{2}$ hybrid nanostructures and their visible-light photo-catalytic activity. Chem Plus Chem 2014, 79, 454-461.

249. Rajoriya, S.; Bargole, S.; Saharan, V.K. Degradation of a cationic dye (Rhodamine 6G) using hydrodynamic cavitation coupled with other oxidative agents: Reaction mechanism and pathway. Ultrason. Sonochem. 2017, 34, 183-194. [CrossRef] [PubMed]

250. Dai, B.; Tao, H.; Lin, Y.-J.; Chang, C.-T. Study of various nanostructures Titania with graphene composites: The preparation and photocatalytic activities. Nano 2016, 11. [CrossRef]

251. Liang, X.; Tao, H.; Zhang, Q. High performance photocatalytic degradation by graphene/titanium nanotubes under near visible light with low energy irradiation. J. Nanosci. Nanotechnol. 2015, 15, 4887-4894. [CrossRef] [PubMed]

252. Zhang, Q.; Liang, X.; Chen, B.-Y.; Chang, C. Deciphering effects of functional groups and electron density on azodyes degradation by graphene loaded $\mathrm{TiO}_{2}$. Appl. Surf. Sci. 2015, 357, 1064-1071. [CrossRef]

253. Posa, V.R.; Annavaram, V.; Somala, A.R. Fabrication of graphene- $\mathrm{TiO}_{2}$ nanocomposite with improved photocatalytic degradation for acid orange 7 dye under solar light irradiation. Bull. Mater. Sci. 2016, 39, 759-767. [CrossRef]

254. Gao, P.; Li, A.; Sun, D.D.; Ng, W.J. Effects of various $\mathrm{TiO}_{2}$ nanostructures and graphene oxide on photocatalytic activity of $\mathrm{TiO}_{2}$. J. Hazard. Mater. 2014, 279, 96-104. [CrossRef] [PubMed]

255. Muthirulan, P.; Devi, C.N.; Sundaram, M.M. $\mathrm{TiO}_{2}$ wrapped graphene as a high performance photocatalyst for acid orange 7 dye degradation under solar/UV light irradiations. Ceram. Int. 2014, 40, 5945-5957. [CrossRef]

(C) 2017 by the authors. Licensee MDPI, Basel, Switzerland. This article is an open access article distributed under the terms and conditions of the Creative Commons Attribution (CC BY) license (http:/ / creativecommons.org/licenses/by/4.0/). 


\title{
Article \\ Photocatalytic Reduction of $\mathrm{CO}_{2}$ from Simulated Flue Gas with Colored Anatase
}

\author{
Yebin Guan ${ }^{1,2}$, Ming Xia ${ }^{1}$, Alessandro Marchetti ${ }^{1}$, Xiaohong Wang ${ }^{2}$, Weicheng Cao ${ }^{1}$, \\ Hanxi Guan ${ }^{1}$ and Xueqian Kong ${ }^{1, *}$ \\ 1 Center for Chemistry of Novel \& High-Performance Materials, and Department of Chemistry, \\ Zhejiang University, Hangzhou 310027, China; guanyb@aqnu.edu.cn (Y.G.); xiaming301@126.com (M.X.); \\ alexmar983@yahoo.it (A.M.); caowc@zju.edu.cn (W.C.); guanhx0123@zju.edu.cn (H.G.) \\ 2 Anhui Key Laboratory of Functional Coordination Compounds, School of Chemistry and Chemical \\ Engineering, Anqing Normal University, Anqing 246011, China; wangxiaohong@aqnu.edu.cn \\ * Correspondence: kxq@zju.edu.cn; Tel.: +86-571-8795-3189
}

Received: 29 December 2017; Accepted: 9 February 2018; Published: 13 February 2018

\begin{abstract}
Photocatalytic reduction with sunlight is an economical and promising advanced approach for reducing the excessive emissions of $\mathrm{CO}_{2}$ from the combustion of fossil fuels. Aimed at practical applications, a type of inexpensive colored anatase material was used to evaluate $\mathrm{CO}_{2}$ photoreduction performance on a platform with a continuous flow of gas mixtures (10 vol $\% \mathrm{CO}_{2}, 90 \% \mathrm{~N}_{2}$ ), which resembles realistic flue gas conditions. The results showed an enhanced photocatalytic activity compared with standard P25 and significant improvement over pristine anatase. Based on a series of characterization techniques, we propose that the oxygen vacancies and surface hydroxyl groups on colored anatase can reduce the bandgap and assist the binding of $\mathrm{CO}_{2}$ molecules. Our results showed that photoreduction of $\mathrm{CO}_{2}$ is feasible under practical conditions, and the efficiency could be improved through modification of catalysts.
\end{abstract}

Keywords: photocatalytic reduction; $\mathrm{TiO}_{2}$; anatase; $\mathrm{CO}_{2}$; flue gas

\section{Introduction}

The excessive emissions of $\mathrm{CO}_{2}$ generated by the combustion of fossil fuels have a prolonged consequence on the global climate [1]. For instance, as one of the major contributors to $\mathrm{CO}_{2}$ emissions, thermal power stations emit 10-20 volume percent of $\mathrm{CO}_{2}$ in their flue gas. Although major research efforts have been aimed at $\mathrm{CO}_{2}$ capture and sequestration, direct conversion of $\mathrm{CO}_{2}$ into useable chemicals is a desired, yet more challenging approach. Various chemical or electrochemical processes have been developed to reduce $\mathrm{CO}_{2}$ to $\mathrm{CO}$ or hydrocarbon compounds [2-4]; however, due to the chemical inertness of $\mathrm{CO}_{2}$, most strategies for $\mathrm{CO}_{2}$ reduction can only be achieved at an unaffordable cost of energy or reagents. Alternatively, photocatalytic reduction of $\mathrm{CO}_{2}$ with sunlight would be much more economical, and it is being actively researched [5]. However, current photocatalytic processes either use strong ultraviolet light, or additional sacrificial agents, or conditions far from the industrial processes, while the development of solar-active photocatalysts is still at its early stage.

Till now, a great quantity of works has been endeavored to explore photocatalysts for selective $\mathrm{CO}_{2}$ transformations [6-9]. For instance, a novel molecular $\mathrm{Ru}(\mathrm{II})-\mathrm{Re}(\mathrm{I})$ dinuclear complex photocatalytic system with high reduction ability of $\mathrm{CO}_{2}$ and capture ability of $\mathrm{CO}_{2}$ has been developed [6]. Rosenthal et al. developed an inexpensive bismuth-carbon monoxide evolving catalyst (Bi-CMEC), which can selectively catalyze the conversion of $\mathrm{CO}_{2}$ to $\mathrm{CO}$ without the need for a costly supporting electrolyte [7]. $\mathrm{BiFeO}_{3}$ and $\mathrm{BiFeO}_{3}$ /single-walled carbon nanotubes (SWCNTs) were prepared by the sol-gel method, and the modification of the catalysts by single-walled carbon nanotubes not only greatly improved the response to visible light, but also doubled the catalytic reduction yield of 
$\mathrm{CO}_{2}$ [8]. Among these, $\mathrm{TiO}_{2}$-based photocatalysts have been most widely studied as photocatalyst with different crystalline forms or modifications [10-13], and they show considerable prospect for the selective transformation of $\mathrm{CO}_{2}$ to $\mathrm{CO}, \mathrm{HCOOH}, \mathrm{CH}_{3} \mathrm{OH}$ and $\mathrm{CH}_{4}$ [14]. The $\mathrm{P}_{25} \mathrm{TiO}_{2}$ nanoparticles branded by Degussa, which have mixed phases of rutile and anatase, are the benchmark material with high photocatalytic performance. However, P25 is relatively expensive, which precludes its use on the scale required for fuel production. Alternatively, loading noble metals such as $\mathrm{Pt}, \mathrm{Au}$ and $\mathrm{Ag}$ can enhance its activities of $\mathrm{CO}_{2}$ photoreduction for commercial anatase or rutile materials, but the cost is also high. Therefore, the development of inexpensive photocatalysts that can promote the reduction of $\mathrm{CO}_{2}$ to $\mathrm{CO}$ with high selectivity and efficiency is an important step for commercialization.

In this report, we evaluated the $\mathrm{CO}_{2}$ photoreduction performance on a platform with a continuous flow of gas mixtures $\left(10 \mathrm{vol} \% \mathrm{CO}_{2}, 90 \% \mathrm{~N}_{2}\right.$ at $\left.80{ }^{\circ} \mathrm{C}\right)$ that resembles realistic flue gas conditions. In such conditions, energy-intensive $\mathrm{CO}_{2}$ separation processes [15] may be avoided. The conversion of $\mathrm{CO}_{2}$ to $\mathrm{CO}$ can be achieved on titanium oxide catalysts with additional water under xenon light in the UV-visible or visible-only range. Carbon monoxide is a key chemical feedstock and a component of syngas, which can be further converted to liquid hydrocarbon fuels. In order to reduce the cost for large-scale application, a colored anatase (g-anatase) material has been prepared, which showed a comparable photocatalytic activity with standard P25 and significant improvement over pristine anatase. Based on characterizations by X-ray diffraction (XRD), transmission electron microscopy (TEM), X-ray photoelectron spectroscopy (XPS), electron paramagnetic resonance (EPR), Fourier transforming infrared spectroscopy (FT-IR) and solid-state nuclear magnetic resonance (SSNMR), we propose that oxygen vacancies and surface hydroxyl groups on colored anatase can reduce the bandgap and assist the binding of $\mathrm{CO}_{2}$ molecules. Our results showed that photo-reduction of $\mathrm{CO}_{2}$ is feasible under flue gas conditions, and the efficiency could be improved through modification of catalysts.

\section{Results and Discussion}

\section{1. $\mathrm{CO}_{2}$ Photoreduction Performance}

A number of photocatalysts has been reported for the conversion of $\mathrm{CO}_{2}$ into $\mathrm{CO}$ under continuous flow conditions (Table 1) $[11-13,16,17]$. However, for flue gas, $\mathrm{CO}_{2}$ concentration is around $10 \%$ in volume. If we used pure $\mathrm{CO}_{2}$ for reduction, this would demand either intensive energy or special adsorbents for $\mathrm{CO}_{2}$ separation [18]. For practical and economic considerations, we performed photocatalysis using low concentration $\mathrm{CO}_{2}$ just like flue gas (i.e., $90 \% \mathrm{~N}_{2}$ and $10 \% \mathrm{CO}_{2}$ ). Other features of flue gas such as temperature and humidity have also been simulated [19]. The temperature of the reaction chamber was maintained at $80^{\circ} \mathrm{C}$, which also approximates the temperature of flue gas. A certain degree of humidity was maintained with added water, and the gas in the reaction chamber was internally cycled with a pump to assist the flow of flue gas. We used xenon light with either the UV or UV-visible range to excite anatase and colored-anatase samples. Under our experimental conditions, $\mathrm{CO}$ is the primary product that we detected through an on-line gas chromatography. 


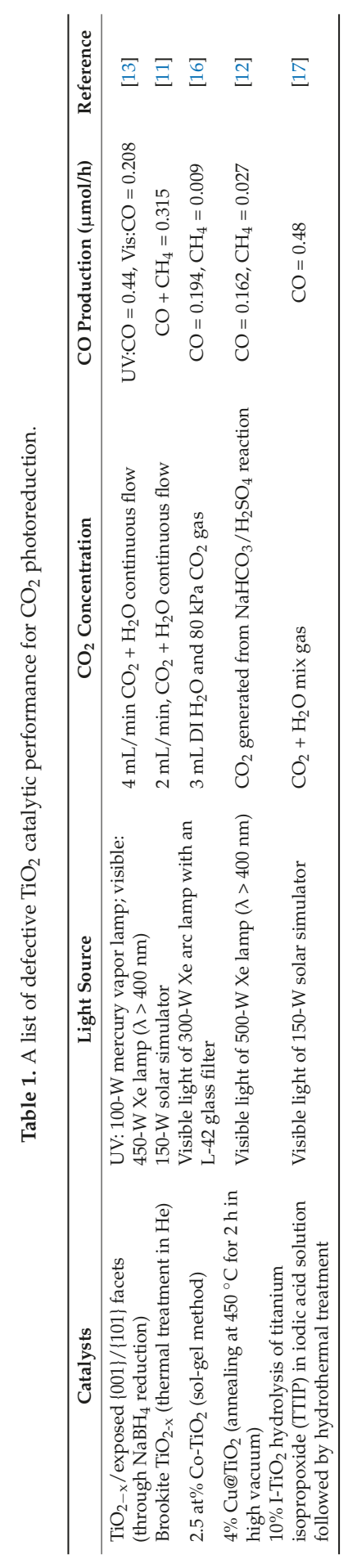


The production of $\mathrm{CO}(\mu \mathrm{mol} / \mathrm{g})$ during a 6-h photo-illumination period was calculated, as shown in Figure 1. It can be seen that the CO production on colored-anatase greatly increased; the maximum CO production rate was up to $4.99 \mu \mathrm{mol} \mathrm{g}{ }^{-1}$ (i.e., a rate of $0.83 \mu \mathrm{mol} \mathrm{g}^{-1} \mathrm{~h}^{-1}$ ) under UV-visible light irradiation (the UV-vis column in Figure 1), which is circa 10.7-times that of anatase and higher than P25 [20]. If the UV light (wavelength smaller than $400 \mathrm{~nm}$ ) was cut off, the overall production of CO decreased (the UV cut400 column in Figure 1), and this suggests that UV-light plays an important role in the catalyzing process. However, even with visible light, the colored anatase can still produce about $1.2 \mu \mathrm{mol} \mathrm{g}^{-1} \mathrm{CO}$ (i.e., a rate of $0.2 \mu \mathrm{mol} \mathrm{g}^{-1} \mathrm{~h}^{-1}$ ), which is $\sim 20 \%$ higher than P25. Although such a conversion rate of $\mathrm{CO}_{2}$ into $\mathrm{CO}$ does not seem so impressive compared to the literature, it should be pointed out that our experiments were performed with more stringent conditions at a much lower $\mathrm{CO}_{2}$ concentration. As a proof of concept experiment, our results have confirmed the feasibility of direct photocatalytic conversion of $\mathrm{CO}_{2}$ with flue gas for the first time. Our work also suggests that improvement of the existing catalysts can greatly benefit the conversion efficiency. Therefore, in the following section, we carried out further study on the colored anatase, which is also introduced in this work.

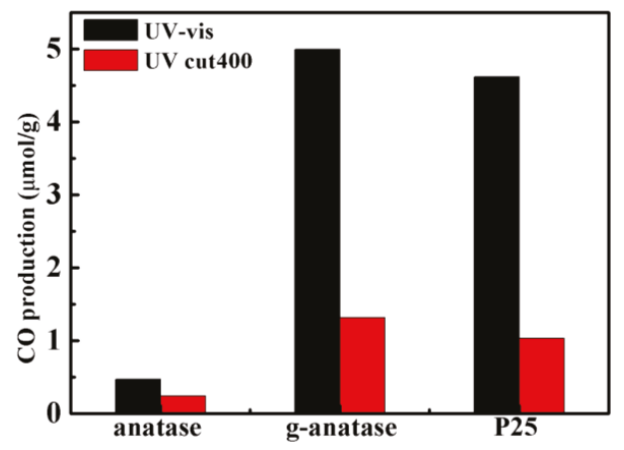

Figure 1. The histogram of CO maximum output with $6 \mathrm{~h}$ using anatase, colored anatase and P25 as the catalysts. g-anatase, gray anatase.

\subsection{Characterization of Colored Anatase}

It has been demonstrated that a higher density of oxygen vacancies in colored $\mathrm{TiO}_{2}$ could contribute to enhanced photocatalytic activity [21-23]. For example, black $\mathrm{TiO}_{2}$ nanoparticles with a defective core/disordered shell structure exhibited a bandgap of only $1.85 \mathrm{eV}$, and the bandgap narrowing is dictated by the synergistic presence of oxygen vacancies and surface disorder [22]. Figure 2a shows the commercial anatase (white color) and the treated anatase powder (gray color, named g-anatase). This distinct change of color indicates that the band structure of anatase nanocrystals has been modified by the $\mathrm{NaBH}_{4}$ reduction treatment. The XRD patterns in Figure $2 \mathrm{~b}$ showed that the gray $\mathrm{TiO} 2$ kept the anatase phase, suggesting this reduction treatment did not alter the crystalline core. The diffuse reflectance UV-Vis spectrum of colored anatase (Figure 2c) clearly shows a broad absorption from $400 \mathrm{~nm}$ to the near-infrared region. The relationship between absorbance $(\mathrm{Ah} v)^{1 / 2}$ and photo energy $(\mathrm{h} v)$ is shown in Figure $2 \mathrm{~d}$, and the bandgap of g-anatase is calculated to be $2.04 \mathrm{eV}$ (compared to $2.97 \mathrm{eV}$ for pristine anatase), which allows the adsorption of a large part of visible light. 
(a)

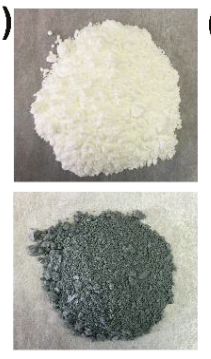

(b)

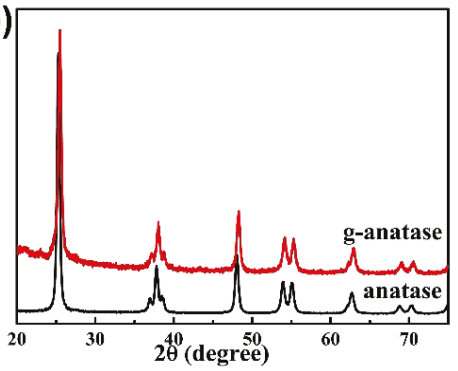

(c)

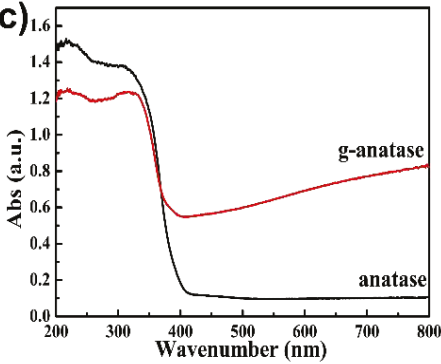

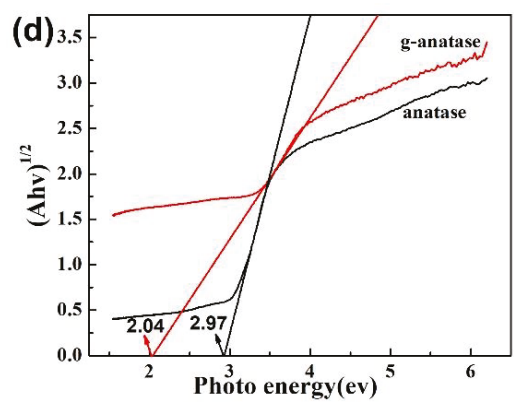

(e)

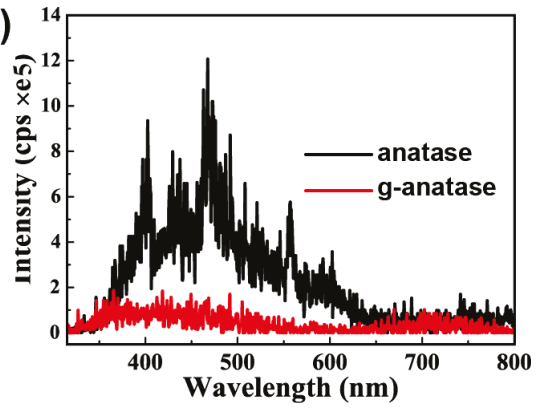

Figure 2. (a) Images of anatase (top) and colored anatase (bottom), (b) XRD patterns, (c) diffuse reflectance UV-Vis spectra, (d) relationship between (Ahv) ${ }^{1 / 2}$ and $\mathrm{h} v$ and (e) photoluminescence (PL) spectra of anatase and colored anatase.

A photoluminescence (PL) experiment was used to track the recombination of charged carriers freed by photo excitation $(325 \mathrm{~nm})[24,25]$. The PL intensity of colored anatase is much weaker compared to anatase, which indicates that the recombination rate of photo-generated electrons and holes had been reduced considerably (Figure 2e) [26]. Together, the UV-Vis and PL experiments explain the photoactivity of colored anatase in the visible and UV-visible range. In order to fully address the mechanism of its enhanced $\mathrm{CO}_{2}$ reduction performance, we conducted further structural characterizations by TEM, EDX, XPS, IR, SSNMR, TG and $\mathrm{CO}_{2}$ adsorption and desorption experiments.

TEM revealed that the average diameter of colored anatase nanocrystals is about $25 \mathrm{~nm}$ (Figure 3c), similar to pristine anatase (Figure 3a). Before the reduction treatment, $\mathrm{TiO}_{2}$ nanocrystals exhibit a highly crystalline nature and well resolved lattice features throughout the whole particles (Figure $3 b$ ). However, after the reduction treatment, the anatase nanocrystals show a crystallized core with a disordered outer layer, which forms a shell of about $1.5 \mathrm{~nm}$ in thickness, as shown by the black arrows in Figure 3d, and this confirms that the obtained sample has a $\mathrm{TiO}_{2} @ \mathrm{TiO}_{2-x}$ core/shell structure feature [27]. The corresponding EDX spectrum (Figure 4) showed that there are only Ti and O elements existing in the g-anatase ( $\mathrm{C}$ and $\mathrm{Cu}$ are from the supporting super-thin carbon-coated copper grid). In addition, the atomic ratio of Ti to $\mathrm{O}$ is below the stoichiometric ratio of two, which further proved the formation of the amorphous shell.

The high-resolution spectra of Ti2p XPS of commercial anatase and colored anatase are shown in Figure 5a. The Ti2p $3 / 2$ and Ti2p $1 / 2$ peaks centered at the binding energies of 460.5 and $466.2 \mathrm{eV}$ are typical characteristics of the $\mathrm{Ti}^{4+}-\mathrm{O}$ bonds in anatase. Such peaks shift nevertheless to lower binding energies of 460.0 and $465.9 \mathrm{eV}$ in the colored anatase, which indicates that $\mathrm{Ti}^{3+}$ species may have appeared in the colored anatase sample, as previously reported [28,29]. 

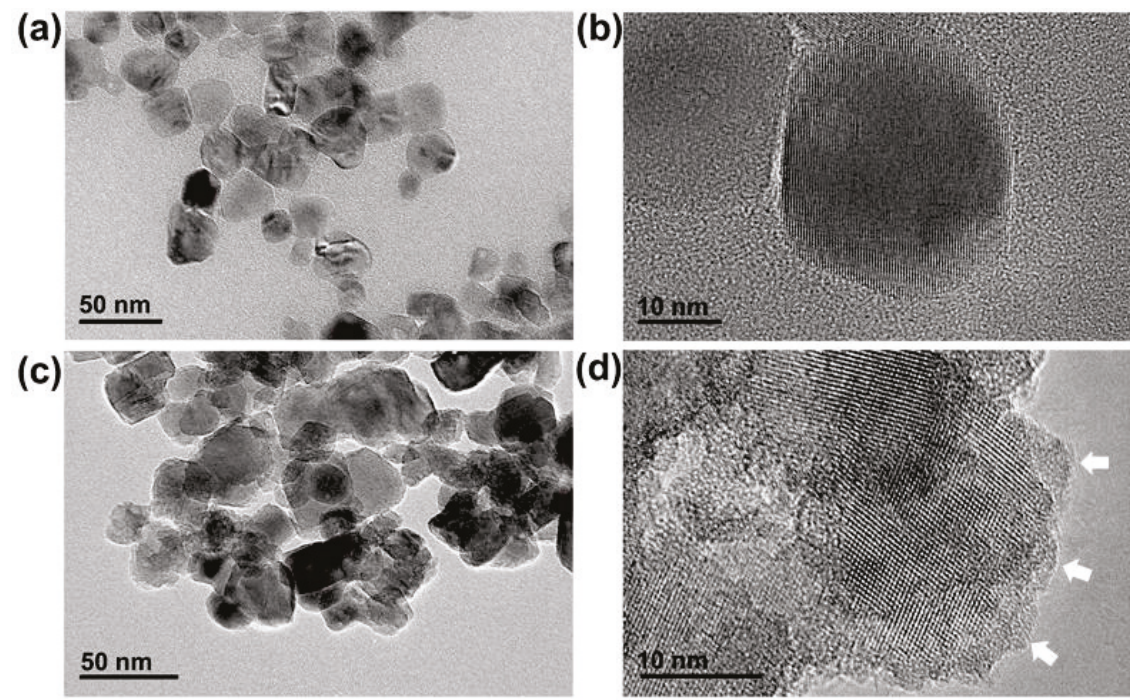

Figure 3. (a,c) TEM and (b,d) HRTEM images of anatase and colored anatase nanocrystals.

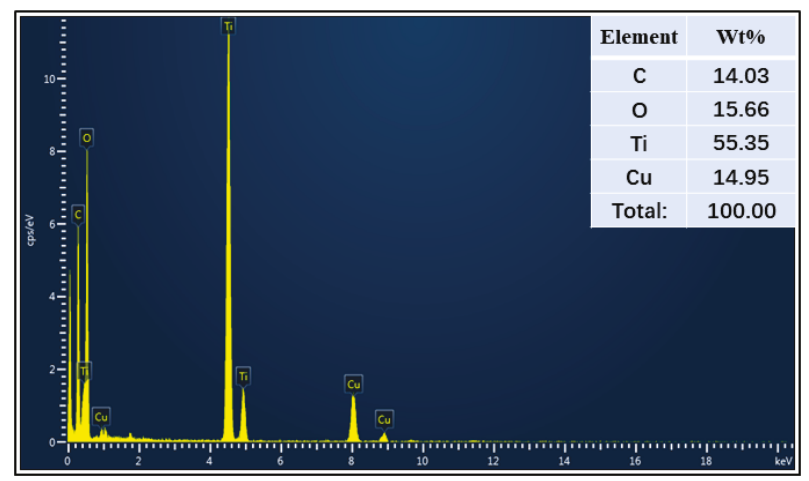

Figure 4. EDX of colored anatase nanocrystals.
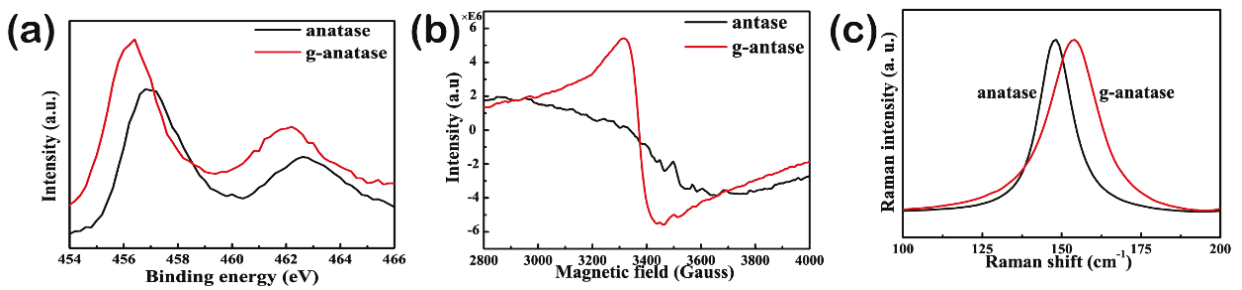

Figure 5. (a) High-resolution XPS spectra of Ti 2p, (b) electron paramagnetic resonance (EPR) and (c) Raman spectra of anatase and colored anatase.

The EPR technique was further employed to analyze the $\mathrm{Ti}^{3+}$-related vacancy defects. From Figure $5 b$, there is an obvious signal at $g=2.058$ for the g-anatase sample, which can be attributed to oxygen vacancy [30]; therefore, the defects probed from slow negative annihilation 
spectroscopy may be considered to be oxygen-related vacancy, which is consistent with the XPS results. Oxygen-related vacancy defects mainly exist in the bulk (or surface) lattice of the $\mathrm{TiO}_{2}$ samples after reduction treatment. Raman spectroscopy (Figure $5 \mathrm{c}$ ) reveals that the strongest vibration mode area (Eg) at $144 \mathrm{~cm}^{-1}$ had a significant peak broadening and blue shifting after reduction treatment, compared with commercial anatase. The peak broadening effect and shift have been observed in several recent studies on hydrogenated $\mathrm{TiO}_{2}$ [22,30-32], which are attributed to the presence of lattice disorder resulting from phonon confinement or nonstoichiometry as the result of oxygen vacancy (VO) doping.

FT-IR spectra (Figure 6a,b) of both white and colored anatase were recorded to investigate light absorption in the mid-infrared light region, from $400 \mathrm{~cm}^{-1}-4000 \mathrm{~cm}^{-1}$. This allowed gaining further insight into the molecular-level alterations induced by the hydrogenation process. Similar absorption features can be detected in the two samples, namely the $\mathrm{OH}$ of $\mathrm{H}_{2} \mathrm{O}$ bands near $1635 \mathrm{~cm}^{-1}$ and $3400 \mathrm{~cm}^{-1}$ and the characteristic wide band in the region $510 \sim 650 \mathrm{~cm}^{-1}$, which is due to the symmetric stretching vibrations of the $\mathrm{Ti}-\mathrm{O}$ bonds of the $\mathrm{TiO}_{4}$ tetrahedra. The differences between spectra (Figure 6b) reveal that hydrogenation leads to additional absorption peaks at 3648, 3672, and $3691 \mathrm{~cm}^{-1}$, which can be associated with tetrahedral coordinated vacancies and designated as $\mathrm{Ti}^{4+}-\mathrm{OH}$ [33]. Moreover, hydrogenation leads to another new absorbance at $3710 \mathrm{~cm}^{-1}$, corresponding to terminal $\mathrm{OH}$ groups [34], which could be attributed to the hydrogen atoms embedded in the $\mathrm{TiO}_{2}$ network.

(a)

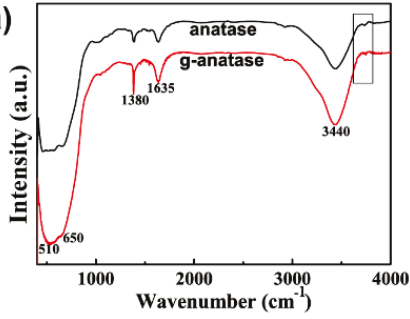

(b)

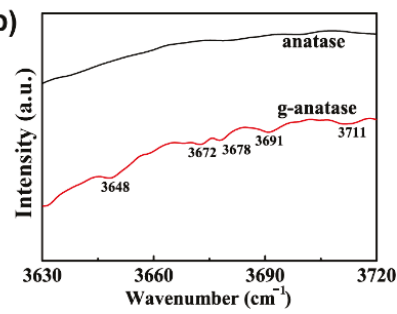

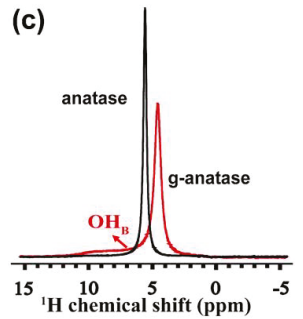

Figure 6. (a,b) FT-IR spectra and (c) ${ }^{1} \mathrm{H}$ solid-state NMR spectra of anatase and colored anatase.

Ultra-fast magic-angle spinning (MAS) solid-state NMR spectroscopy is a crucial tool for the effective characterization of the hydrogen species present on nanocrystals. We performed ${ }^{1} \mathrm{H}$ NMR measurements of anatase and colored anatase at an MAS rate of $60 \mathrm{kHz}$, as shown in Figure $6 \mathrm{c}$. The dominant peaks at 5.5 and $4.8 \mathrm{ppm}$ in anatase and colored anatase, respectively, can be assigned to the isolated water molecules trapped in anatase crystal defects. Such sharp ${ }^{1} \mathrm{H}$ peaks, which were also observed at the lower spinning speed of $12 \mathrm{kHz}$, are features of weak ${ }^{1} \mathrm{H}-{ }^{1} \mathrm{H}$ dipolar coupling. It is unlikely to be mobile water, however, as the sample has been treated in vacuum at elevated temperatures. Different from anatase, the colored anatase showed also a relatively broad signal at $6.7 \mathrm{ppm}$ corresponding to bridging (i.e., non-terminal) surface hydroxyl groups (marked in Figure $6 \mathrm{c}$ as $\mathrm{OH}_{\mathrm{B}}$ ), which is consistent with the $3648 \mathrm{~cm}^{-1}$ FT-IR signal [35].

$\mathrm{CO}_{2}$ adsorption and desorption curves of anatase and colored anatase are shown in Figure 7a. One can find that both $\mathrm{CO}_{2}$ adsorbed and desorbed capacities detected at the low pressure range $\left(\mathrm{P} / \mathrm{P}_{0}<0.2\right)$ on g-anatase nanocrystals are higher than those on anatase nanocrystals; this feature is probably closely related to the more exposed alkaline sites, namely $\mathrm{Ti}^{3+}$ vacancies on g-anatase nanocrystals, which can absorb more $\mathrm{CO}_{2}$ molecules [36]. The TGA curve reported in Figure $7 \mathrm{~b}$ shows that the continuous weight losses of the anatase and g-anatase samples are 2.36 and $3.65 \%$ before $350^{\circ} \mathrm{C}$, which can be ascribed to the adsorbed water evaporation. Obviously, the greater weight loss of g-anatase indicates that more water molecules are adsorbed on the surface of the crystals, which is probably closely associated with the amorphous shell of colored anatase [37]. 

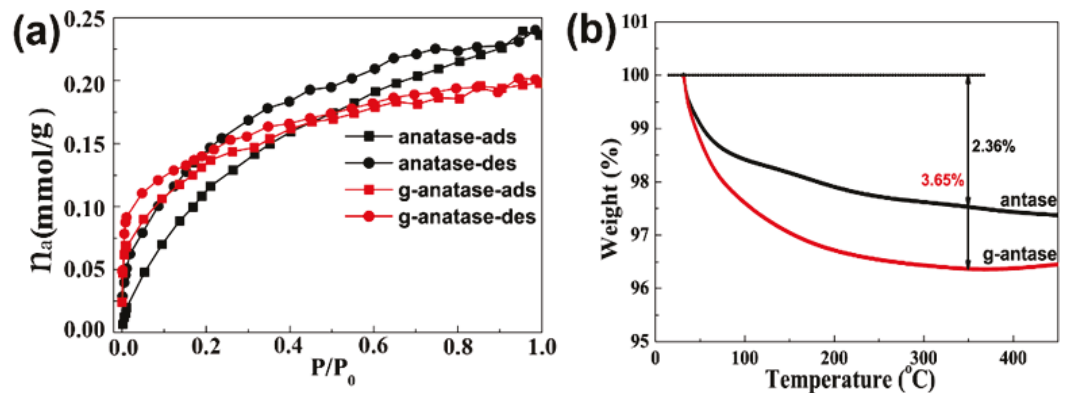

Figure 7. (a) $\mathrm{CO}_{2}$ adsorption and desorption curves and (b) TGA curves of anatase and colored anatase samples.

\section{Experimental Section}

\subsection{Surface Defective Anatase Preparation}

Anatase (99.8\%, $25 \mathrm{~nm}), \mathrm{NaBH}_{4}(98 \%)$ and ethanol (AR) were purchased from Aladdin Reagent Comp. (Shanghai, China) and used without purification. The surface defective anatase preparation process is reported elsewhere [20]. Typically, $2.40 \mathrm{~g}$ of anatase powder and $0.90 \mathrm{~g}$ of $\mathrm{NaBH}_{4}$ were mixed thoroughly with $20 \mathrm{~min}$ if grinding. The mixture was then placed into a porcelain capsule inside a tubular furnace in Ar atmosphere and heated from ambient temperature with a rate of $10^{\circ} \mathrm{C} / \mathrm{min}$ until it reached $400{ }^{\circ} \mathrm{C}$, then maintained at this level for $120 \mathrm{~min}$. After self-cooling to ambient temperature, the obtained gray powder was washed seven times alternately with deionized water and ethanol to remove unreacted $\mathrm{NaBH}_{4}$, then dried at $60{ }^{\circ} \mathrm{C}$ in air.

\subsection{Sample Characterization}

Diffraction patterns were collected using an X-ray diffractometer (XRD) (Bruker AXS D8 Focus, Karlsruhe, Germany) with $\mathrm{Cu}$ Ka radiation $(\lambda=1.54056 \mathrm{~A})$. The UV-Vis absorption spectra were recorded on a Shimadzu UV 2600 UV/Vis spectrophotometer (SHIMADZU Corporation, Kyoto, Japan). Transmission electron microscope (TEM) images were taken using a JEOL 2100 operating at 200 kV (Japan Electron Optics Laboratory Co., Ltd., Kyoto, Japan). X-ray photoelectron spectra (XPS) analyses were recorded using an ESCALABMKII spectrometer with an AlKa (1486.6 eV) achromatic X-ray source (VG Scienta, East Sussex, UK). The EPR spectra were acquired using a Bruker EMX-8 spectrometer at $9.36 \mathrm{GHz}$ at $298.5 \mathrm{~K}$ (Karlsruhe, Germany). Raman spectra were collected on a thermal dispersive spectrometer using laser light with an excitation wavelength of $532 \mathrm{~nm}$ at a laser power of $10 \mathrm{~mW} .{ }^{1} \mathrm{H}$ SSNMR experiments were conducted at a probe temperature of $302 \pm 1 \mathrm{~K}$ on an AVANCE $600-\mathrm{MHz}$ wide bore spectrometer (Bruker, Karlsruhe, Germany) operating at $14.1 \mathrm{~T}$ (the Larmor frequency was $599.80 \mathrm{MHz}$ for the proton) and equipped with a 1.3-mm triple-resonance magic angle spinning (MAS) probe. Free induction decays (FIDs) were not multiplied by an exponential anodization function before Fourier transformation. The spectrum of an empty NMR rotor was collected under the same conditions and subtracted to eliminate the contribution from background signals $[35,38,39]$. Chemical shifts were measured relative to secondary standard adamantane as an external reference [40,41].

\subsection{The Gas-Solid Reaction System}

The gas-solid reaction measurement is designed as shown in Scheme 1. A 300-W Xe lamp was used as the light source and eventually filtered to remove its UV part. As a preliminary step, we tested with GC/TCD-FID the eventual background level of carbon-containing products of a mixture of $\mathrm{H}_{2} \mathrm{O}$ and $\mathrm{He}$ passing through the catalyst with the lamp on. This confirmed that $\mathrm{CO}_{2}$ was indeed 
the only carbon source. The production of $\mathrm{CO}$ during a given period was calculated by measuring its concentrations at the reactor outlet.

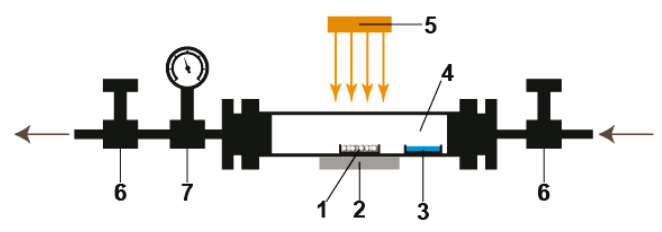

Scheme 1. Diagram of the photocatalytic equipment. (1) Quartz boat for the loading of the $\mathrm{TiO}_{2}$ catalyst, (2) external heating sleeve, (3) Petri dish containing deionized water, (4) main device constituted by a high-permeability quartz tube and stainless seal flanges, (5) xenon light source, (6) needle valve for the control of the gas flow rate, (7) air gauge displaying the pressure variation in the reaction device. The arrows indicate the flow direction.

\section{Conclusions}

In summary, we firstly prepared the core/shell structure of the $\mathrm{TiO}_{2} @ \mathrm{TiO}_{2-x}$ sample by mildly reducing commercial anatase. Such a colored anatase showed comparable photocatalytic activity towards $\mathrm{CO}_{2}$ reduction under a simulated flue gas system. The enhanced activity is attributed to the formation of oxygen vacancies and $\mathrm{Ti}^{3+}$ on the amorphous surface shell, which promotes $\mathrm{CO}_{2}$ activation under photo-illumination. Our work represents a further step to utilize post-combustion $\mathrm{CO}_{2}$ in a sustainable manner, i.e., using sunlight and without further processing. Further refinement of reaction conditions and catalytic supports is still possible in order to improve the overall efficiency of photocatalysis

Acknowledgments: This work was financially supported by the National Natural Science Foundation of China (No. 41402037, 21573197) and the State Key Laboratory of Chemical Engineering No. SKL-ChE-16D03.

Author Contributions: X.K., Y.G. and M.X. conceived and designed the experiments; Y.G., M.X. and W.C. performed the experiments; M.X. and A.M. analyzed the data; H.G. and X.M. contributed reagents/materials/ analysis tools; Y.G. and X.K. wrote the paper.

Conflicts of Interest: The authors declare no conflict of interest.

\section{References}

1. Yu, J.G.; Low, J.X.; Xiao, W.; Zhou, P.; Jaroniec, M. Enhanced photocatalytic $\mathrm{CO}_{2}$-reduction activity of anatase $\mathrm{TiO}_{2}$ by coexposed $\{001\}$ and $\{101\}$ facets. J. Am. Chem. Soc. 2014, 136, 8839-8842. [CrossRef] [PubMed]

2. Zhu, Z.; Qin, J.; Jiang, M.; Ding, Z.; Hou, Y. Enhanced selective photocatalytic $\mathrm{CO}_{2}$ reduction into $\mathrm{CO}$ over Ag/CdS nanocomposites under visible light. Appl. Surf. Sci. 2017, 391, 572-579. [CrossRef]

3. Tahir, M.; Tahir, B.; Amin, N.A.S.; Zakaria, Z.Y. Photo-induced reduction of $\mathrm{CO}_{2}$ to $\mathrm{CO}$ with hydrogen over plasmonic Ag-NPs/ $\mathrm{TiO}_{2}$ NWs core/shell hetero-junction under UV and visible light. J. CO2 Util. 2017, 18, 250-260. [CrossRef]

4. Tahir, M.; Tahir, B.; Amin, N.A.S. Synergistic effect in plasmonic Au/Ag alloy NPs co-coated $\mathrm{TiO}_{2} \mathrm{NWs}$ toward visible-light enhanced $\mathrm{CO}_{2}$ photoreduction to fuels. Appl. Catal. B Environ. 2017, 204, 548-560. [CrossRef]

5. House, R.L.; Tha, N.Y.M.; Coppo, R.L.; Alibabaei, L.; Sherman, B.D.; Kang, P.; Brennaman, M.K.; Hoertz, P.G.; Meyer, T.J. Artificial photosynthesis: Where are we now? Where can we go? J. Photochem. Photobiol. C Photochem. Rev. 2015, 25, 32-45. [CrossRef]

6. Nakajima, T.; Tamaki, Y.; Ueno, K.; Kato, E.; Nishikawa, T.; Ohkubo, K.; Yamazaki, Y.; Morimoto, T.; Ishitani, O. Photocatalytic reduction of low concentration of $\mathrm{CO}_{2}$. J. Am. Chem. Soc. 2016, 138, 13818-13821. [CrossRef] [PubMed] 
7. Medina-Ramos, J.; DiMeglio, J.L.; Rosenthal, J. Efficient reduction of $\mathrm{CO}_{2}$ to $\mathrm{CO}$ with high current density using in situ or ex situ prepared Bi-Based materials. J. Am. Chem. Soc. 2014, 136, 8361-8367. [CrossRef] [PubMed]

8. Li, X.; He, S.Y.; $\mathrm{Li}, \mathrm{Z}$. Methanol synthesis in the catalytic reduction of $\mathrm{CO}_{2}$ under the visible light by $\mathrm{BiFeO}_{3}$ modified with carbon nanotubes. J. Chin. Ceram. Soc. 2009, 37, 1869-1872.

9. Ponzoni, C.; Rosa, R.; Cannio, M.; Buscaglia, V.; Finocchio, E.; Nanni, P.; Leonelli, C. Electrophoretic deposition of multiferroic $\mathrm{BiFeO}_{3}$ submicrometric particles from stabilized suspensions. J. Eur. Ceram. Soc. 2012, 33, 1325-1333. [CrossRef]

10. Liu, G.D.; Xie, S.J.; Zhang, Q.H.; Tian, Z.F.; Wang, Y. Carbon dioxide-enhanced photosynthesis of methane and hydrogen from carbon dioxide and water over Pt-promoted polyaniline- $\mathrm{TiO}_{2}$ nanocomposites. Chem. Commun. 2015, 51, 13654-13657. [CrossRef] [PubMed]

11. Liu, L.J.; Zhao, H.L.; Andino, J.M.; Li, Y. Photocatalytic $\mathrm{CO}_{2}$ Reduction with $\mathrm{H}_{2} \mathrm{O}$ on $\mathrm{TiO}_{2}$ Nanocrystals: Comparison of Anatase, Rutile, and Brookite Polymorphs and Exploration of Surface Chemistry. ACS Catal. 2012, 2, 1817-1828. [CrossRef]

12. Zhao, J.; Li, Y.X.; Zhu, Y.; Wang, Y.; Wang, C. Enhanced $\mathrm{CO}_{2}$ photoreduction activity of black $\mathrm{TiO}_{2}$-coated $\mathrm{Cu}$ nanoparticles under visible light irradiation: Role of metallic Cu. Appl. Catal. A 2016, 510, 34-41. [CrossRef]

13. Liu, L.J.; Jiang, Y.Q.; Zhao, H.L.; Chen, J.T.; Cheng, J.L.; Yang, K.S.; Li, Y. Engineering co-exposed $\{001\}$ and $\{101\}$ facets in oxygen-deficient $\mathrm{TiO}_{2}$ nanocrystals for enhanced $\mathrm{CO}_{2}$ photoreduction under visible light. ACS Catal. 2016, 6, 1097-1108. [CrossRef]

14. Peng, C.; Reid, G.; Wang, H.F.; Hu, P. Perspective: Photocatalytic reduction of $\mathrm{CO}_{2}$ to solar fuels over semiconductors. J. Chem. Phys. 2017, 147, 030901. [CrossRef] [PubMed]

15. IPCC. Special Report on Carbon Dioxide Capture and Storage; Prepared by Working Group III of the Intergovernmental Panel on Climate Change; Metz, B., Davidson, O., de Coninck, H.C., Loos, M., Meyer, L.A., Eds.; Cambridge University Press: Cambridge, UK; New York, NY, USA, 2005.

16. Wang, T.; Meng, X.; Liu, G.G.; Chang, K.; Li, P.; Kang, Q.; Liu, L.Q.; Li, M.; Ouyang, S.X.; Ye, J.H. In situ synthesis of ordered mesoporous $\mathrm{Co}$-doped $\mathrm{TiO}_{2}$ and its enhanced photocatalytic activity and selectivity for the reduction of $\mathrm{CO}_{2}$. J. Mater. Chem. A 2015, 3, 9491-9501. [CrossRef]

17. Zhang, Q.Y.; Li, Y.; Ackerman, E.A.; Gajdardziska-Josifovska, M.; Li, H.L. Visible light responsive iodine-doped $\mathrm{TiO}_{2}$ for photocatalytic reduction of $\mathrm{CO}_{2}$ to fuels. Appl. Catal. A 2011, 400, 195-202. [CrossRef]

18. Sumida, K.; Rogow, D.L.; Mason, J.A.; McDonald, T.M.; Bloch, E.D.; Herm, Z.R.; Bae, T.H.; Long, J.R. Carbon Dioxide Capture in Metal-Organic Frameworks. Chem. Rev. 2012, 112, 724-781. [CrossRef] [PubMed]

19. McDonald, T.M.; Mson, J.A.; Kong, X.Q.; Bloch, E.D.; Gygi, D.; Dani, A.; Crocellà, V.; Giordanino, F.; Odoh, S.O.; Drisdell, W.S.; et al. Cooperative insertion of $\mathrm{CO}_{2}$ in diamine-appended metal-organic frameworks. Nature 2014, 519, 303-308. [CrossRef] [PubMed]

20. Tan, H.Q.; Zhao, Z.; Niu, M.; Mao, C.Y.; Cao, D.P.; Cheng, D.J.; Feng, P.Y.; Sun, Z.C. A facile and versatile method for preparation of colored $\mathrm{TiO}_{2}$ with enhanced solar-driven photocatalytic activity. Nanoscale 2014, 6, 10216-10223. [CrossRef] [PubMed]

21. Naldoni, A.; Allieta, M.; Santangelo, S.; Marelli, M.; Fabbri, F.; Cappelli, S.; Bianchi, C.L.; Psaro, R.; Santo, V.D. Effect of nature and location of defects on bandgap narrowing in black $\mathrm{TiO}_{2}$ nanoparticles. J. Am. Chem. Soc. 2012, 134, 7600-7603. [CrossRef] [PubMed]

22. Janotti, A.; Varley, J.B.; Rinke, P.; Umezawa, N.; Kresse, G.; van de Walle, C.G. Hybrid functional studies of the oxygen vacancy in $\mathrm{TiO}_{2}$. Phys. Rev. B Condens. Matter Mater. Phys. 2010, 81, 085212. [CrossRef]

23. Cronemeyer, D.C. Infrared absorption of reduced rutile $\mathrm{TiO}_{2}$ single crystals. Phys. Rev. 1959, 113, 1222-1226. [CrossRef]

24. Yu, J.C.; Yu, G.J.; Ho, W.K.; Jiang, Z.T.; Zhang, L.Z. Effects of F-doping on the photocatalytic activity and microstructures of nanocrystalline $\mathrm{TiO}_{2}$ powders. Chem. Mater. 2002, 14, 3808-3816. [CrossRef]

25. Xiang, Q.; Lv, K.; Yu, J. Pivotal role of fluorine in enhanced photocatalytic activity of anatase $\mathrm{TiO}_{2}$ nanosheets with dominant (001) facets for the photocatalytic degradation of acetone in air. Appl. Catal. B Environ. 2010, 96, 557-564. [CrossRef]

26. Jiang, X.D.; Zhang, Y.P.; Jiang, J.; Rong, Y.S.; Wang, Y.C.; Wu, Y.C.; Pan, C.X. Characterization of oxygen vacancy associates within hydrogenated $\mathrm{TiO}_{2}$ : A positron annihilation study. J. Phys. Chem. C 2012, 116, 22619-22624. [CrossRef] 
27. Chen, X.; Liu, L.; Peter, Y.Y.; Mao, S.S. Increasing solar absorption for photocatalysis with black hydrogenated titanium b nanocrystals. Science 2011, 331, 746-750. [CrossRef] [PubMed]

28. Zuo, F.; Bozhilov, K.; Dillon, R.J.; Wang, L.; Smith, P.; Zhao, X.; Bardeen, C.; Feng, P. Active facets on titanium(III)-doped $\mathrm{TiO}_{2}$ : An effective strategy to improve the visible-light photocatalytic activity. Angew. Chem. Int. Ed. 2012, 51, 6223-6226. [CrossRef] [PubMed]

29. Wang, Z.; Yang, C.; Lin, T.; Yin, H.; Chen, P.; Wan, D.; Xu, F.; Huang, F.; Lin, J.; Xie, X.; et al. H-doped black titania with very high solar absorption and excellent photocatalysis enhanced by localized surface plasmon resonance. Adv. Funct. Mater. 2013, 23, 5444-5450. [CrossRef]

30. Zou, X.X.; Liu, J.K.; Su, J.; Zuo, F.; Chen, J.S.; Feng, P.Y. Facile synthesis of thermal-and photostable titania with paramagnetic oxygen vacancies for visible-light photocatalysis. Chem. Eur. J. 2013, 19, 2866-2873. [CrossRef] [PubMed]

31. Venkatasubbu, G.D.; Ramakrishnan, V.; Sasirekha, V.; Ramasamy, S.; Kumar, J. Influence of particle size on the phonon confinement of $\mathrm{TiO}_{2}$ nanoparticles. J. Exp. Nanosci. 2014, 9, 661-668. [CrossRef]

32. Zhang, W.; He, Y.; Zhang, M.; Yin, Z.; Chen, Q. Raman scattering study on anatase $\mathrm{TiO}_{2}$ nanocrystals. J. Phys. D Appl. Phys. 2000, 33, 912-916. [CrossRef]

33. Kumar, P.M.; Badrinarayanan, S.; Sastry, M. Nanocrystalline $\mathrm{TiO}_{2}$ studied by optical, FTIR and X-ray photoelectron spectroscopy: Correlation to presence of surface states. Thin Solid Films 2000, 358, 122-130. [CrossRef]

34. Szczepankiewicz, S.H.; Colussi, A.J.; Hoffmann, M.R. Infrared spectra of photoinduced species on hydroxylated titania surfaces. J. Phys. Chem. B 2000, 104, 9842-9850. [CrossRef]

35. Ramesha, G.K.; Brennecke, J.F.; Kamat, P.V. Origin of catalytic effect in the reduction of $\mathrm{CO}_{2}$ at nanostructured $\mathrm{TiO}_{2}$ films. ACS Catal. 2014, 4, 3249-3254. [CrossRef]

36. Lindan, P.; Harrison, N.; Gillan, M. Mixed dissociative and molecular adsorption of water on the rutile (110) surface. Phys. Rev. Lett. 1998, 80, 762-765. [CrossRef]

37. Bavykin, D.V.; Lapkin, A.A.; Plucinski, P.K.; Friedrich, J.M.; Walsh, F.C. Reversible Storage of Molecular Hydrogen by Sorption into Multilayered $\mathrm{TiO}_{2}$ Nanotubes. J. Phys. Chem. B 2005, 109, 19422-19427. [CrossRef] [PubMed]

38. Nosaka, A.Y.; Fujiwara, T.; Yagi, H.; Akutsu, H.; Nosaka, Y. Photocatalytic Reaction Sites at the $\mathrm{TiO}_{2} \mathrm{Surface}$ as Studied by Solid-State 1H NMR Spectroscopy. Langmuir 2003, 19, 1935-1937. [CrossRef]

39. Murrell, J.N.; Sorbie, K.S. New analytic form for the potential energy curves of stable diatomic states. J. Chem. Soc. Faraday Trans. 1996, 92, 2791-2798. [CrossRef]

40. Morcombe, C.R.; Zilm, K.W. Chemical shift referencing in MAS solid state NMR. J. Magn. Reson. 2003, 162, 479-486. [CrossRef]

41. Hayashi, S.; Hayamizu, K. Chemical Shift Standards in High-Resolution Solid-State NMR (1) 13C, 29Si, and 1H Nuclei. Bull. Chem. Soc. Jpn. 1991, 64, 685-687. [CrossRef]

(C) 2018 by the authors. Licensee MDPI, Basel, Switzerland. This article is an open access article distributed under the terms and conditions of the Creative Commons Attribution (CC BY) license (http:/ / creativecommons.org/licenses/by/4.0/). 


\title{
Article \\ The Pros and Cons of Polydopamine-Sensitized Titanium Oxide for the Photoreduction of $\mathrm{CO}_{2}$
}

\author{
Tongyao Wang, Ming Xia and Xueqian Kong * \\ Center for Chemistry of Novel \& High-Performance Materials, and Department of Chemistry, \\ Zhejiang University, Hangzhou 310027, China; Wangtongyao@zju.edu.cn (T.W.); Xiam@zju.edu.cn (M.X.) \\ * Correspondence: kxq@zju.edu.cn; Tel.: +86-177-6715-0513
}

Received: 17 April 2018; Accepted: 15 May 2018; Published: 17 May 2018

\begin{abstract}
Photocatalytic reduction of $\mathrm{CO}_{2}$ into fuels is a promising route to reduce greenhouse gas emission, and it demands high-performance photocatalysts that can use visible light in the solar spectrum. Due to its broadband light adsorption, polydopamine (PDA) is considered as a promising photo-sensitization material for semiconductor photocatalysts. In this work, titanium oxides have been coated with PDA through an in-situ oxidation polymerization method to pursue $\mathrm{CO}_{2}$ reduction under visible light. We have shown that the surface coated PDA with a thickness of around $1 \mathrm{~nm}$ can enhance the photocatalytic performance of anatase under visible light to reduce $\mathrm{CO}_{2}$ into $\mathrm{CO}$. Assisted with additional UV-vis adsorption and photoluminescence characterizations, we confirmed the sensitization effect of PDA on anatase. Furthermore, our study shows that thicker PDA coating might not be favorable, as PDA could decompose under both visible and UV-vis light irradiations. ${ }^{13} \mathrm{C}$ solid-state nuclear magnetic resonance showed structural differences between thin and thick PDA coatings and revealed compositional changes of PDA after light irradiation.
\end{abstract}

Keywords: photocatalysis; $\mathrm{CO}_{2}$ reduction; anatase; polydopamine; sensitization

\section{Introduction}

The large-scale consumption of fossil fuels rapidly increases atmospheric $\mathrm{CO}_{2}$ concentration that leads to the consequence of climate change. Alongside technologies to capture and sequester $\mathrm{CO}_{2}[1,2]$, photocatalytic reduction of $\mathrm{CO}_{2}$ into fuels is a promising route to turn waste into resources $[3,4]$. Ultimately, the photocatalysts could turn into artificial leaves which utilize only solar light and minimal reagents to enable a sustainable carbon cycle. To reach such ambitious goal, semiconductor materials will play a very important role owing to their desired photocatalytic activity [5,6]. In 1979, Inoue et al. [7] initially reported semiconductor including $\mathrm{TiO}_{2}, \mathrm{WO}_{3}, \mathrm{ZnO}, \mathrm{CdS}, \mathrm{GaP}$ and $\mathrm{SiC}$ as photocatalysts on reduction of $\mathrm{CO}_{2}$ into organic compounds such as methane, methanol, and formic acid. Encouraged by this pioneering work, various kinds of semiconductor photocatalysts (e.g., $\mathrm{Fe}_{2} \mathrm{O}_{3}$, $\mathrm{Cu}_{2} \mathrm{O}, \mathrm{BiVO}_{4}, \mathrm{Zn}_{2} \mathrm{GeO}_{4}$ and $\mathrm{g}-\mathrm{C}_{3} \mathrm{~N}_{4}$ ) have been developed and tested, although overall their performance was far from satisfaction. The major reasons are their low chemical stability, rapid electron-hole recombination, low visible light adsorption and difficulty activating $\mathrm{CO}_{2}[8,9]$.

$\mathrm{TiO}_{2}$ is the most widely studied semiconductor photocatalyst due to its high chemical stability, low toxicity, commercial availability, and suitable energy levels of conduction and valance bands $[10,11]$. Three crystalline polymorphs of $\mathrm{TiO}_{2}$ exist in nature, anatase, rutile and brookite, which have different levels of photocatalytic activities. Limited by its wide bandgap (e.g., $3.2 \mathrm{eV}$ for anatase), however, $\mathrm{TiO}_{2}$ can only absorb UV light of the solar spectrum which is only $\sim 4 \%$ of the total solar energy. Various methods, including impurity doping, surface sensitization, oxygen vacancies, and the localized surface plasmon resonance (SPR) effect have been developed to improve the light-harvesting ability of $\mathrm{TiO}_{2}$ under visible light which accounts for $45 \%$ of energy in the solar spectrum [12-20]. Among them, 
surface sensitization is a frequently-used method that improves visible adsorption and electron/hole separation by transferring the photo-excited electron in photosensitizer to the conduction band of $\mathrm{TiO}_{2}$.

Compared to other photosensitizers such as pure organic dyes and organometallic complexes [15-20], polymer photosensitizers are more stable under photo-irradiation and in harsh environment. In this study, we focused on polydopamine (PDA), which is a polymer bioinspired by mussel adhesive proteins [21]. PDA not only is an effective surface-coating material, but also possesses unique optical and electronic properties such as broad-spectrum light adsorption and enhanced photoconductivity under the visible light irradiation [22-25]. Recently, it has been used to modify semiconductors such as $\mathrm{TiO}_{2}$ [26-28], g- $\mathrm{C}_{3} \mathrm{~N}_{4}[29,30], \mathrm{Cu}_{2} \mathrm{O}$ [31], and $\beta-\mathrm{FeOOH}$ [32] and metals such as Pd [33] and Ag [34] to improve their photocatalytic activities by the synergetic effect of $\pi-\pi^{*}$ transition. However, up to date, almost all the studies have only reported the photodegradation of organic dyes, i.e., the photo-oxidation reaction. $\mathrm{PDA}-\mathrm{TiO}_{2}$ inorganic-organic hybrid materials have not been applied to the photoreduction of $\mathrm{CO}_{2}$. More importantly, the control of PDA sensitizer, e.g., the coating thickness and surface bonding structure is critical for the resulting photocatalytic performance. Fundamental understanding of the surface chemistry in such composite systems, however, is still rather limited.

In this work, we evaluated the photocatalytic performance of anatase-PDA (A@PDA) under UV-vis or visible light. It was found that the surface sensitizing by PDA can lead to an improved $\mathrm{CO}_{2}$ conversion into $\mathrm{CO}$. Our results suggest PDA could be a promising photosensitizer for anatase targeted for $\mathrm{CO}_{2}$ reduction applications. However, we also noticed that, although the increased thickness of PDA apparently increases the CO production, part of the CO increase could come from the photo-degradation of PDA itself as indicated by solid state NMR (SSNMR) and thermogravimetric analysis (TGA) measurements before and after reaction. SSNMR also suggests the chemical structure surface coated PDA could be quite different from the bulk as the aliphatic portions significantly increase. Our experimental work shows that, for the purpose of surface sensitization, balancing the thickness of surface layer is extremely important. It is recommended that the photocatalytic performance (especially about the organic products) should be evaluated judiciously and careful characterization of photo-stability is necessary.

\section{Results and Discussions}

\subsection{Physical and Optical Properties}

X-ray diffraction (XRD) was performed to examine the crystal structure of A@PDA. As the results shown in Figure 1a, A@PDA shows a typical pattern of anatase, while the feature of disordered PDA is not observed due to limited thickness of the surface layer. To confirm the successful PDA coating on anatase, we carried out Raman spectroscopy and transmission electron microscopy (TEM) measurements. As shown in Figure 1b, besides the four main Raman vibration modes of anatase, i.e., $141 \mathrm{~cm}^{-1}\left(E_{\mathrm{g}}\right), 395 \mathrm{~cm}^{-1}\left(B_{1 \mathrm{~g}}\right), 516 \mathrm{~cm}^{-1}\left(A_{1 \mathrm{~g}}\right)$ and $638 \mathrm{~cm}^{-1}\left(E_{\mathrm{g}}\right)$ [35,36], A@PDA also showed two broad Raman bands at around $1354 \mathrm{~cm}^{-1}$ and $1585 \mathrm{~cm}^{-1}$ which match those of pure PDA. These broad bands originate from linear stretching of $\mathrm{C}-\mathrm{C}$ bonds within the rings and in-plane stretching of the aromatic rings, similar to the D and $G$ bands of carbon nanomaterials such as graphene and graphite [37]. Moreover, TEM images (Figure 1c) of A@PDA samples show a thin surface layer of PDA whose thickness ranges from $1 \mathrm{~nm}$ to $5 \mathrm{~nm}$ depending on the amount of dopamine hydrochloride precursor added. The presence of PDA may also be confirmed by ${ }^{13} \mathrm{C}$ SSNMR, as is mentioned below.

UV-vis diffraction reflectance spectroscopy measurement (Figure 1d) shows that the light adsorption of A@PDA is in general the superposition of A-Ti and PDA. Our calculation shows that the A-Ti has a band-gap of $3.06 \mathrm{eV}$ which is in agreement with typical anatase (Figure S1).

Time-resolved photoluminescence (PL) decay (Figure 1e) is employed to study the charge carrier recombination behavior of A@PDA with different thickness of PDA. In these A@PDA samples, the fluorescence life time is increased versus anatase itself which means a longer life time of excited state that potentially benefit electron transfer for $\mathrm{CO}_{2}$ reduction. 
We also compared the specific surface area and porosity of A@PDA with anatase with $\mathrm{N}_{2}$ adsorption measurements (Figure S2). According to the classification of International Union of Pure and Applied Chemistry (IUPAC) [38], A@PDA displays a type IV isotherm, suggesting the existence of mesopore structure. The specific surface area of A@PDA is somewhat larger than anatase, and this could contribute to a higher density of active sites (Table 1).
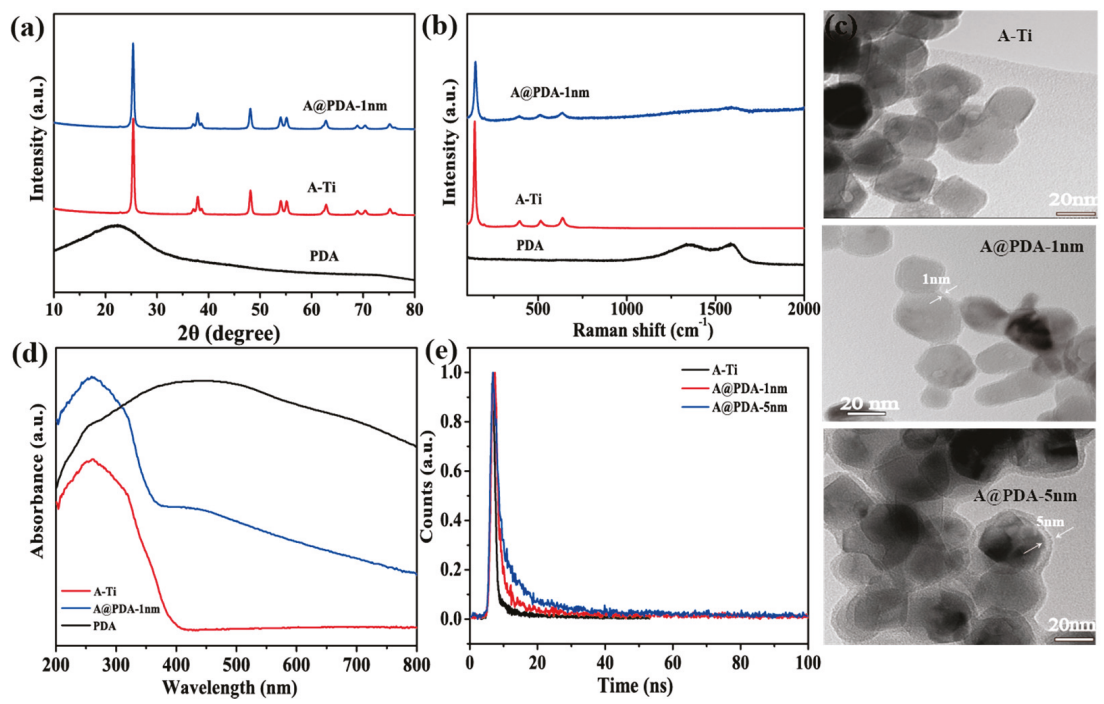

Figure 1. (a) XRD pattern and (b) Raman spectra of A@PDA-1 nm, A-Ti and PDA; (c) TEM images of A-Ti, A@PDA-1 nm, and A@PDA-5 nm; (d) UV-vis diffraction reflectance spectra of A-Ti, A@PDA-1 nm, and PDA; and (e) PL decay spectra of A-Ti, A@PDA-1 nm, and A@PDA-5 nm.

Table 1. Specific surface area, mean pore size and pore volume of the photocatalysts.

\begin{tabular}{cccc}
\hline Photocatalyst & $S_{\text {BET }}\left(\mathrm{m}^{2} / \mathrm{g}\right)$ & Mean Pore Size $(\mathrm{nm})$ & Pore Volume $\left(\mathrm{cm}^{3} / \mathrm{g}\right)$ \\
\hline A-Ti & 58.2 & 21.5 & 0.31 \\
A@PDA-1 $\mathrm{nm}$ & 60.1 & 23.7 & 0.36 \\
\hline
\end{tabular}

\subsection{Physical and Optical Properties}

We first evaluated the photocatalytic activity of A@PDA under visible light using the UV cut-off filter of the Xenon light. The PDA coated anatase shows an increased production of CO per gram of catalyst compared to anatase (Figure 2a). Reaction under such conditions i.e., visible light, no extra sacrificial agents, and a reduced pressure of $\mathrm{CO}_{2}$ is a viable pathway for the practical application of $\mathrm{CO}_{2}$ reduction. This again proves the sensitization effect of PDA which works through either direct electron injection [26,27], or more likely a sequential electron injection mechanism, as there is no new band in the adsorption spectrum [28].

In this work, we also tested rutile (R@PDA-1 nm) and brookite (B@PDA-1 nm) using the same PDA sensitization strategy. However, the $\mathrm{CO}_{2}$ reduction performance of R@PDA-1 nm and B@PDA-1 $\mathrm{nm}$ is worse than the pure $\mathrm{TiO}_{2}$ phases (Figures S3 and S4). It might be due to the mismatch of the excited state of PDA with the CB edge of rutile and brookite [39-41].

On the other hand, under the UV-vis range of Xenon light, the performance of anatase improves and reaches about the same level as A@PDA-1 nm (Figure 2b). By increasing the thickness of PDA, the $\mathrm{CO}$ production of A@PDA can be increased further. As the photo-generated electrons have 
a limited migration range, the photo-sensitization should take place at the shallow interface between PDA and anatase. It is not clear whether such increased CO production for the thicker PDA coating of A@PDA is due to the sensitization effect or other mechanisms such as photo-degradation of PDA itself. We therefore performed a series of control experiments and further characterized the A@PDA samples after photocatalytic reactions.
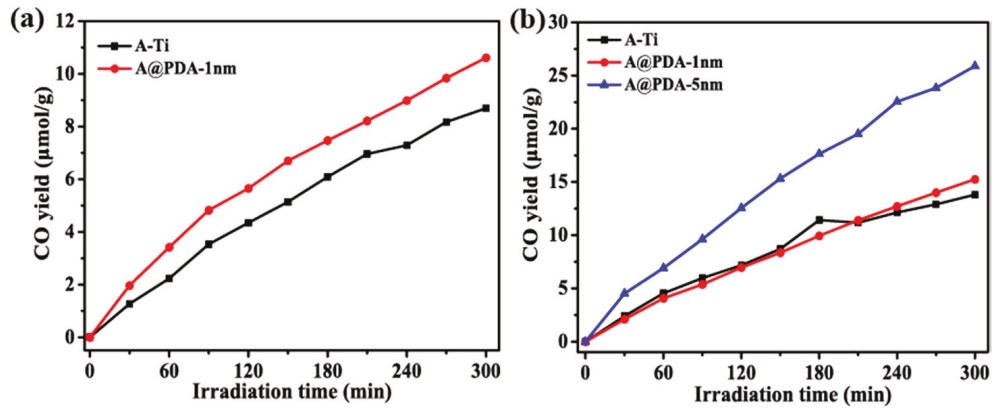

Figure 2. The comparison of CO yield for A-Ti and A@PDA-1 nm under visible light (a) and for the A-Ti, A@PDA-1 nm, and A@PDA-5 nm under UV-vis light (b) in $\mathrm{CO}_{2}$.

\subsection{Photo-Stability Evaluation}

In the literature [42,43], PDA is generally regarded as a stable compound under light irradiation and mild temperature. However, Proks et al. [44] reported that, under elevated temperatures, PDA produces a continuous evolution of $\mathrm{CO}_{2}$ and they observed that some aliphatic moieties convert into unsaturated species. Bearing this in mind, we were cautious about the extra $\mathrm{CO}$ generated by the A@PDA samples, even though it is mostly unexpected in the literature. Control experiments under UV-vis light and pure nitrogen show that both A@PDA samples can still generate $\mathrm{CO}$ without the reagent of $\mathrm{CO}_{2}$ (Figure 3a). The A@PDA with thicker coating generates significantly more $\mathrm{CO}$ than the thin one. As PDA is the only carbon source in the system, this inevitably proved that the surface covered PDA is not that stable under UV-vis light irradiation as people would expect. We then took a further step to study whether pure PDA itself can withstand light irradiation. As shown in Figure 3b, when the light was turned off, the PDA sample generated minimal CO suggesting it is relatively stable thermally. However, when light was on, no matter UV-vis or only visible light, extra $\mathrm{CO}$ was generated. This clearly indicates pure PDA also undergoes photo-degradation.

Further characterization was performed to analyze the structural evolution of A@PDA and PDA after light irradiation. Although no significant changes were detected in the TEM or XPS measurements for the PDA (Figures S5 and S6), clear changes were observed in TGA (Figure 3c) and SSNMR spectra (Figure $4 \mathrm{a}-\mathrm{c}$ ). In the TGA experiments, the A@PDA samples after light irradiation gave less weight loss, suggesting photo-degradation eliminated part of the uncrosslinked monomers or oligomers [45]. The difference in weight-loss of the A@PDA- $1 \mathrm{~nm}$ sample is much less before and after light irradiation which in good agreement with control experiments observed in Figure 3a.

Qualitatively, ${ }^{13} \mathrm{C}$ SSNMR provides a consistent story that PDA and A@PDA- $5 \mathrm{~nm}$ sample changed noticeably but not quite for the A@PDA-1 nm sample. More importantly, SSNMR can offer much more details on the changes in chemical structures [46]. In accordance to the literature [47-49], we assigned the resonances between 30 and $60 \mathrm{ppm}$ to the carbon atoms of partially saturated five-member rings and aliphatic $\mathrm{CH}_{2}-\mathrm{CH}_{2}-\mathrm{N}$ segments; the signals spanning from 110 to $150 \mathrm{ppm}$ to the aromatic species; and the peaks at between 170 and $180 \mathrm{ppm}$ to the quinones or carboxylate groups. For the PDA sample, the signals of aliphatic carbon (30-50 ppm), the protonated arene (114 ppm) and catecholic groups (145 ppm) decreased after UV-vis light irradiation (Figure 4a), whereas the spectrum of the A@PDA-1 nm sample did not vary much after irradiation despite that the signal-to-noise ratio is 
low due to the limited amount of surface coating (Figure 4b). In contrast, the signals of aliphatic carbon decreases noticeably for the A@PDA-5 nm sample, indicating a thicker layer of PDA is prone to photo-decomposition (Figure 4c). These findings agree with other measurements and provide more chemical insights on how the PDA degrades under light. We reason that the self-degradation of PDA is the primary effect under such low oxygen concentrations [50]. Interestingly, ${ }^{13} \mathrm{C}$ SSNMR also suggests that the chemical compositions of PDA between sample A@PDA-1 nm and A@PDA-5 $\mathrm{nm}$ are somewhat different as the A@PDA-1 nm seems to have more aliphatic portions. This could be due to either the disordered nature of the tightly bound surface structures or different polymerization mechanisms induced by the $\mathrm{TiO}_{2}$.
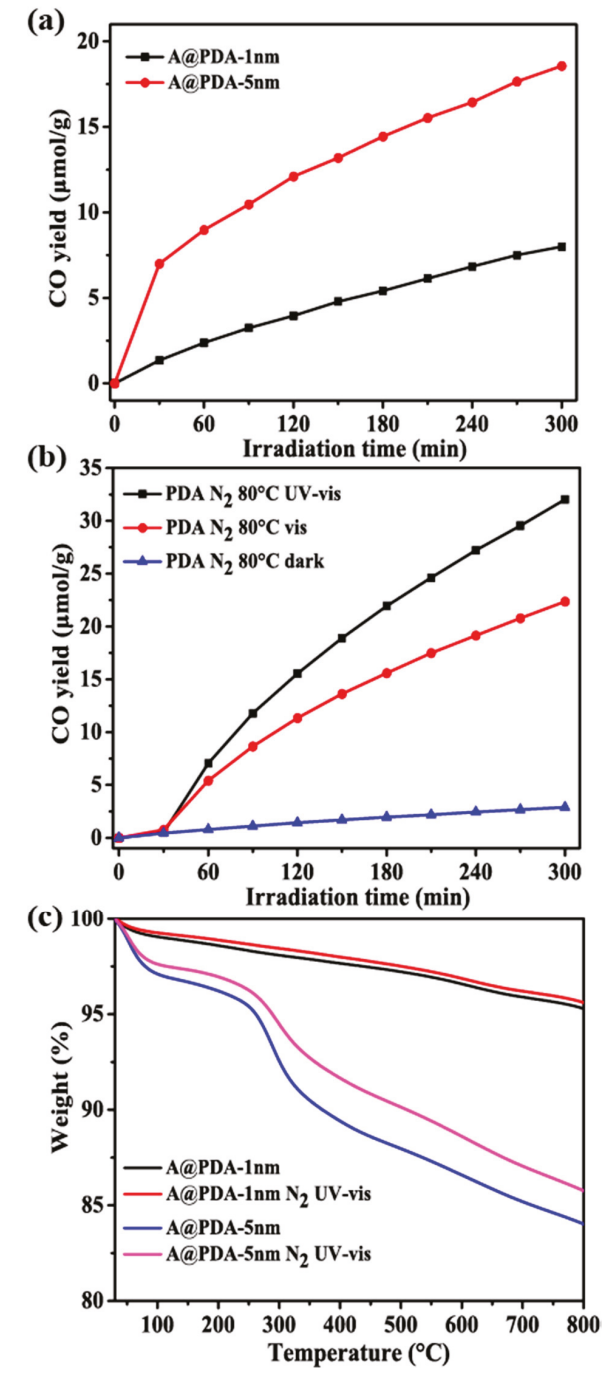

Figure 3. (a) The control experiments of A@PDA-1 nm and A@PDA-5 nm under UV-vis light in $\mathrm{N}_{2}$; (b) $\mathrm{CO}$ yields for the PDA in $\mathrm{N}_{2}$ under UV-vis light and visible light and in dark; and (c) TGA for the pristine A@PDA-1 nm and A@PDA-5 nm and them after illuminating under UV-vis light in $\mathrm{N}_{2}$ for $6 \mathrm{~h}$. 

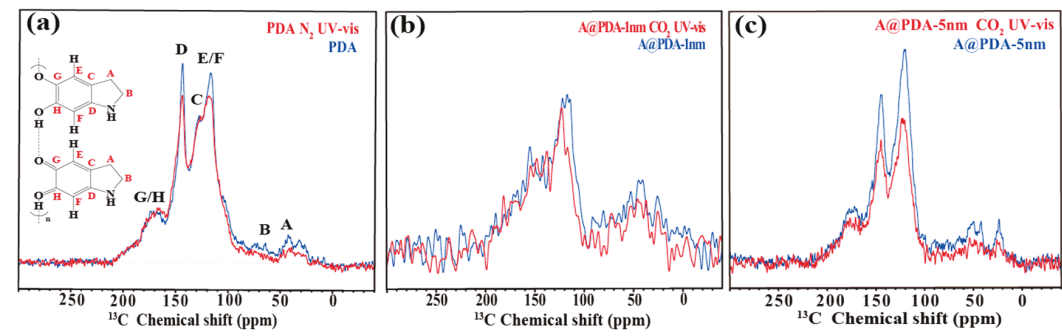

Figure 4. ${ }^{13} \mathrm{C}$ cross-polarization total suppression of spinning sidebands (CP-TOSS) spectrum of: pristine PDA and PDA after illuminating under $\mathrm{UV}$-vis light in the presence of $\mathrm{N}_{2}$ for $11 \mathrm{~h}$ (a); pristine A@PDA-1 nm and A@PDA-1 nm after illuminating in $\mathrm{CO}_{2}$ for $11 \mathrm{~h}(\mathbf{b})$; and pristine A@PDA-5 nm and A@PDA-5 nm after illuminating in $\mathrm{CO}_{2}$ for $11 \mathrm{~h}$ under UV-vis light (c).

\subsection{Proposed Reaction Mechanisms}

The mechanism of $\mathrm{CO}_{2}$ photoreduction with $\mathrm{H}_{2} \mathrm{O}$ using PDA-sensitized $\mathrm{TiO}_{2}$ under visible light is illustrated in Figure 5. According to the literature [28], the lowest unoccupied molecular orbital (LUMO) and the highest occupied molecular orbital (HOMO) of PDA are ca. -1.2 and $0.4 \mathrm{eV}$, respectively. The conduction band (CB) of anatase $\mathrm{TiO}_{2}$ is ca. $-0.5 \mathrm{eV}$ and valence band (VB) of $\mathrm{TiO}_{2}$ is at $2.56 \mathrm{eV}$. Under irradiation, the electrons on HOMO of surface-coated PDA are excited to LUMO by adsorbing a considerable amount of visible light. These photoelectrons are then transferred to the conduction band of $\mathrm{TiO}_{2}$, assisting the reduction of $\mathrm{CO}_{2}$ into $\mathrm{CO}$.

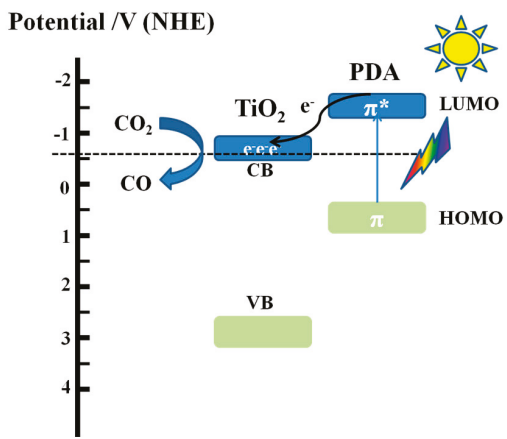

Figure 5. Illustration of the possible reaction mechanism for photoreduction of $\mathrm{CO}_{2}$ with $\mathrm{H}_{2} \mathrm{O}$ under visible light over $\mathrm{TiO}_{2} @ P D A$.

\section{Experimental Section}

\subsection{Materials and Methods}

Anatase $\mathrm{TiO}_{2}$ nano-powder $(25 \mathrm{~nm})$, named as A-Ti, and Dopamine hydrochloride were purchased from Aladdin Bio-chem Technology Co. Ltd. (Shanghai, China). Hexamethylenetetramine was purchased from Sinopharm Chemical Reagent Co. Ltd. (Shanghai, China). The anatase powder was calcinated at $450{ }^{\circ} \mathrm{C}$ for $3 \mathrm{~h}$ to improve the crystallinity and remove the organic impurity on the surface of the $\mathrm{TiO}_{2}$.

\subsubsection{Preparation of $\mathrm{TiO}_{2} @ P D A$ Composites}

The preparation of $\mathrm{TiO}_{2}-\mathrm{PDA}$ composites followed the procedures reported in the literature [26] with some modifications. First, $0.2 \mathrm{~g}$ of A-Ti and a calculated amount of dopamine hydrochloride 
were mixed with $50 \mathrm{~mL}$ of deionized water and the suspension was sonicated for $15 \mathrm{~min}$ before $0.4 \mathrm{~g}$ of hexamethylenetetramine was added. The above mixture was kept stirring for $3 \mathrm{~h}$ at $90^{\circ} \mathrm{C}$. The resulting product was obtained after centrifugation, washed thoroughly with water and dried overnight at $80^{\circ} \mathrm{C}$ in an oven. The as-prepared sample is denoted as A@PDA. For the comparison, we prepared different thickness of PDA on the anatase with added dopamine hydrochloride varying from $0.02 \mathrm{~g}$ to $0.12 \mathrm{~g}$, which resulted in samples A@PDA-1 nm and A@PDA-5 nm.

\subsubsection{Preparation of PDA}

Polydopamine was prepared according to the method reported in the literature [51]. First, $0.75 \mathrm{~mL}$ ammonia aqueous solution $\left(\mathrm{NH}_{4} \mathrm{OH}, 28-30 \%\right)$ was added to the mixture of ethanol $(40 \mathrm{~mL})$ and deionized water $(90 \mathrm{~mL})$ under mild stirring at room temperature for $30 \mathrm{~min}$. Second, $0.5 \mathrm{~g}$ of dopamine hydrochloride was dissolved in deionized water $(10 \mathrm{~mL})$ and then added to the mixture above under mild stirring. The mixture was kept for $30 \mathrm{~h}$ at room temperature. The resulting product was collected, washed thoroughly with water and dried overnight at $80^{\circ} \mathrm{C}$ in an oven.

\subsection{Characterizations}

X-ray diffraction (XRD) patterns of the materials were collected on an Ultima IV X-ray diffractometer (Rigaku, Tokyo, Japan) with $\mathrm{Cu} \mathrm{K} \alpha$ irradiation in the $2 \theta$ range of $10-80^{\circ}$. Raman spectra were recorded on a Labor Raman HR-800 (JobinYvon, Longjumeau, France) with an $\mathrm{Ar}^{+}$laser excitation at $514 \mathrm{~nm}$. Transmission electron microscopy (TEM) (Hitachi HT7700, Tokyo, Japan) was used to obtain the morphologies of the materials. The UV-vis diffuse reflectance spectra of the samples over the range of 200-800 nm were obtained on a Shimadzu UV-2600 UV-vis spectrophotometer with an integration sphere diffuse reflectance attachment using $\mathrm{BaSO}_{4}$ as the reference. The time-resolved photoluminescence (PL) decay measurements for the solid samples were investigated on an Edinburgh FLSP920 spectrometer, the laser device of $340 \mathrm{~nm}$ was used to get the laser beam. The surface area and porosity were analyzed by nitrogen adsorption at 77K on a gas adsorption apparatus (MicrotracBEL, BELSORP-max, Osaka, Japan). Thermogravimetric analysis (TGA) was performed in $\mathrm{N}_{2}$ using a SDT Q600 V20.9 Build 20 thermogravimetric analyzer (TA Instruments, New Castle, DE, USA) from $30^{\circ} \mathrm{C}$ to $800{ }^{\circ} \mathrm{C}$ with a heating rate of $10^{\circ} \mathrm{C} \mathrm{min}^{-1}$. X-ray photoelectron spectroscopy (XPS) measurements were conducted on an Esclab MARK II spectrometer (VG Scientific, West Sussex, UK). The solid-state NMR (SSNMR) experiments were performed on a Bruker 14.1T magnet in 3.2-mm $\mathrm{ZrO}_{2}$ rotors. The ${ }^{13} \mathrm{C}$ Cross-Polarization Total Suppression of Spinning Sidebands (CP-TOSS) NMR spectra were measured at a spinning rate of $10 \mathrm{kHz}$. The ${ }^{13} \mathrm{C}$ chemical shifts were referenced to adamantane at $38.4 \mathrm{ppm}$. A CP contact time was set to $2 \mathrm{~ms}$. A total of 10,240 scans were accumulated for each spectrum. All experiments were conducted at room temperature.

\subsection{Photocatalytic Reactions}

$\mathrm{CO}_{2}$ photocatalytic reduction in the presence of water was performed with a homemade stainless-steel photocatalytic reactor. The total volume of the reactor was about $415 \mathrm{~mL}$. A $300 \mathrm{~W}$ Xe arc lamp (PL-X300D, Beijing Precise Technology Co. Ltd., Beijing, China) equipped with a UV cut-off filter $(\lambda \geq 400 \mathrm{~nm})$ was used as the UV-vis light source and visible light source and it was positioned $\sim 7.5 \mathrm{~cm}$ above the quartz boat. The UV-vis light intensity measured using a radiometer was ca. $220 \mathrm{~mW} / \mathrm{cm}^{2}$ and the visible light intensity was ca. $150 \mathrm{~mW} / \mathrm{cm}^{2}$. In a typical experiment, $30 \mathrm{mg}$ solid photocatalyst was placed in a quartz boat inside the closed quartz tube. A culture dish containing $4 \mathrm{~mL}$ water was placed at the side of the quartz tube, which supplies water vapor to the system. Before light irradiation, the reactor was sealed and was subjected to vacuum degassing at room temperature and then backfilled the mixture of $\mathrm{N}_{2}$ and $\mathrm{CO}_{2}(v / v 90 / 10)$ until the pressure rose slightly above $1 \mathrm{bar}$. The temperature of the reactor was maintained at $80^{\circ} \mathrm{C}$. The gas products from the reactor were analyzed at a 30-min interval using an online gas chromatography (Fuli GC-9790, Wenling, China) equipped with a flame ionized detector (FID) and methanizer. 


\section{Conclusions}

In summary, core-shell structured $\mathrm{TiO}_{2} @ P D A$ samples were prepared and they exhibited improved $\mathrm{CO}$ yield under visible light, confirming the sensitization effect of PDA. On the other hand, even though thicker PDA coating may lead to higher CO yield, part of the CO product could come from the photodegradation of PDA itself, as indicated by SSNMR and TGA. To achieve better $\mathrm{CO}_{2}$ reduction performance, further investigations on polymer sensitized semiconductors are needed. Meanwhile, the photo-stability of the organic components has to be carefully evaluated and optimized.

Supplementary Materials: The following are available online at http:/ /www.mdpi.com/2073-4344/8/5/215/s1, Figure S1: The plot of $(\alpha \mathrm{h} v)^{1 / 2}$ versus $\mathrm{h} v$ for the bandgap calculation of A-Ti, Figure S2: (a) Nitrogen adsorption and desorption isotherms; and (b) pore size distribution curves of A-Ti and A@PDA-1 nm, Figure S3: CO yield comparison of R-Ti and R@PDA-1 nm under Visible light (a) and UV-vis light (b) for the photoreduction of $\mathrm{CO}_{2}$ Figure S4: CO yield comparison of B-Ti and B@PDA-1 nm under Visible light (a) and UV-vis light (b) for the photoreduction of $\mathrm{CO}_{2}$, Figure S5: TEM images of : (a) pristine PDA; and (b) PDA after illuminating under UV-vis light in $\mathrm{N}_{2}$ for $6 \mathrm{~h}$, Figure S6: XPS spectra of PDA and PDA after illuminating under UV-vis light in $\mathrm{N}_{2}$ for $6 \mathrm{~h}$ : (a) $\mathrm{C} 1 \mathrm{~s} ;$ (b) N1s; and (c) O1s.

Author Contributions: X.K. and T.W. conceived and designed the experiments; T.W. performed the experiments; T.W. analyzed the data; M.X. contributed reagents/materials/analysis tools; and T.W. and X.K. wrote the paper.

Acknowledgments: This work was financially supported by National Natural Science Foundation of China (No. 21573197) and State Key Laboratory of Chemical Engineering No. SKL-ChE-16D03. The authors are grateful to the School of Materials Science and Engineering of Zhejiang University for providing the characterizations of time-resolved PL decay in this paper.

Conflicts of Interest: The authors declare no conflict of interest.

\section{References}

1. D'Alessandro, D.M.; Smit, B.; Long, J.R. Carbon Dioxide Capture: Prospects for New Materials. Angew. Chem. Int. Ed. 2010, 49, 6058-6082. [CrossRef] [PubMed]

2. Yaumi, A.L.; Abu Bakar, M.Z.; Hameed, B.H. Recent advances in functionalized composite solid materials for carbon dioxide capture. Energy 2017, 124, 461-480. [CrossRef]

3. Lewis, N.S.; Nocera, D.G. Powering the planet: Chemical challenges in solar energy utilization. Proc. Natl. Acad. Sci. USA 2006, 103, 15729-15735. [CrossRef] [PubMed]

4. Habisreutinger, S.N.; Schmidt-Mende, L.; Stolarczyk, J.K. Photocatalytic Reduction of $\mathrm{CO}_{2}$ on $\mathrm{TiO}_{2}$ and Other Semiconductors. Angew. Chem. Int. Ed. 2013, 52, 7372-7408. [CrossRef] [PubMed]

5. Hoffmann, M.R.; Martin, S.T.; Choi, W.Y.; Bahnemann, D.W. Environmental applications of semiconductor photocatalysis. Chem. Rev. 1995, 95, 69-96. [CrossRef]

6. Zhou, Y.; Tu, W.G.; Zou, Z.G. New Materials for $\mathrm{CO}_{2}$ Photoreduction. In Photocatalysis: Fundamentals and Perspectives; Schneider, J., Bahnemann, D., Ye, J.H., Puma, G.L., Dionysiou, D.D., Eds.; The Royal Society of Chemistry: Cambridge, UK, 2016; pp. 318-322. ISBN 978-1-78262-041-9.

7. Inoue, T.; Fujishima, A.; Konishi, S.; Honda, K. Photoelectrocatalytic reduction of carbon dioxide in aqueous suspensions of semiconductor powders. Nature 1979, 277, 637-638. [CrossRef]

8. Li, X.; Wen, J.Q.; Low, J.X.; Fang, Y.P.; Yu, J.G. Design and fabrication of semiconductor photocatalyst for photocatalytic reduction of $\mathrm{CO}_{2}$ to solar fuel. Sci. China Mater. 2014, 57, 70-100. [CrossRef]

9. Chang, X.X.; Wang, T.; Gong, J.L. $\mathrm{CO}_{2}$ photo-reduction: Insights into $\mathrm{CO}_{2}$ activation and reaction on surfaces of photocatalysts. Energy Environ. Sci. 2016, 9, 2177-2196. [CrossRef]

10. Carp, O.; Huisman, C.L.; Reller, A. Photoinduced reactivity of titanium dioxide. Prog. Solid State Chem. 2004, 32, 33-177. [CrossRef]

11. Ma, Y.; Wang, X.L.; Jia, Y.S.; Chen, X.B.; Han, H.X.; Li, C. Titanium Dioxide-Based Nanomaterials for Photocatalytic Fuel Generations. Chem. Rev. 2014, 114, 9987-10043. [CrossRef] [PubMed]

12. Liu, G.H.; Hoivik, N.; Wang, K.Y.; Jakobsen, H. Engineering $\mathrm{TiO}_{2}$ nanomaterials for $\mathrm{CO}_{2}$ conversion/solar fuels. Sol. Energy Mater. Sol. Cells 2012, 105, 53-68. [CrossRef]

13. Das, S.; Daud, W. Photocatalytic $\mathrm{CO}_{2}$ transformation into fuel: A review on advances in photocatalyst and photoreactor. Renew. Sustain. Energy Rev. 2014, 39, 765-805. [CrossRef] 
14. Zhao, H.L.; Pan, F.P.; $\mathrm{Li}, \mathrm{Y}$. A review on the effects of $\mathrm{TiO}_{2}$ surface point defects on $\mathrm{CO}_{2}$ photoreduction with $\mathrm{H}_{2}$ O. J. Materiomics 2017, 3, 17-32. [CrossRef]

15. Ozcan, O.; Yukruk, F.; Akkaya, E.U.; Uner, D. Dye sensitized artificial photosynthesis in the gas phase over thin and thick $\mathrm{TiO}_{2}$ films under UV and visible light irradiation. Appl. Catal. B Environ. 2007, 71, 291-297. [CrossRef]

16. Nguyen, T.V.; Wu, J.C.S.; Chiou, C.H. Photoreduction of $\mathrm{CO}_{2}$ over Ruthenium dye-sensitized $\mathrm{TiO}_{2}$-based catalysts under concentrated natural sunlight. Catal. Commun. 2008, 9, 2073-2076. [CrossRef]

17. Qin, G.H.; Zhang, Y.; Ke, X.B.; Tong, X.L.; Sun, Z.; Liang, M.; Xue, S. Photocatalytic reduction of carbon dioxide to formic acid, formaldehyde, and methanol using dye-sensitized $\mathrm{TiO}_{2}$ film. Appl. Catal. B Environ. 2013, 129, 599-605. [CrossRef]

18. Won, D.I.; Lee, J.S.; Ji, J.M.; Jung, W.J.; Son, H.J.; Pac, C.; Kang, S.O. Highly Robust Hybrid Photocatalyst for Carbon Dioxide Reduction: Tuning and Optimization of Catalytic Activities of Dye $/ \mathrm{TiO}_{2} / \operatorname{Re}(\mathrm{I})$ Organic-Inorganic Ternary Systems. J. Am. Chem. Soc. 2015, 137, 13679-13690. [CrossRef] [PubMed]

19. Do, J.Y.; Tamilavan, V.; Agneeswari, R.; Hyun, M.H.; Kang, M. Synthesis and optical properties of TDQD and effective $\mathrm{CO}_{2}$ reduction using a TDQD-photosensitized $\mathrm{TiO}_{2}$ film. J. Photochem. Photobiol. A Chem. 2016, 330, 30-36. [CrossRef]

20. Huang, H.W.; Lin, J.J.; Zhu, G.B.; Weng, Y.X.; Wang, X.X.; Fu, X.Z.; Long, J.L. A Long-Lived Mononuclear Cyclopentadienyl Ruthenium Complex Grafted onto Anatase $\mathrm{TiO}_{2}$ for Efficient $\mathrm{CO}_{2}$ Photoreduction. Angew. Chem. Int. Ed. 2016, 55, 8314-8318. [CrossRef] [PubMed]

21. Lee, H.; Dellatore, S.M.; Miller, W.M.; Messersmith, P.B. Mussel-inspired surface chemistry for multifunctional coatings. Science 2007, 318, 426-430. [CrossRef] [PubMed]

22. Pezzella, A.; Iadonisi, A.; Valerio, S.; Panzella, L.; Napolitano, A.; Adinolfi, M.; d'Ischia, M. Disentangling Eumelanin "Black Chromophore": Visible Absorption Changes As Signatures of Oxidation State- and Aggregation-Dependent Dynamic Interactions in a Model Water-Soluble 5,6-Dihydroxyindole Polymer. J. Am. Chem. Soc. 2009, 131, 15270-15275. [CrossRef] [PubMed]

23. Liu, Y.L.; Ai, K.L.; Lu, L.H. Polydopamine and Its Derivative Materials: Synthesis and Promising Applications in Energy, Environmental, and Biomedical Fields. Chem. Rev. 2014, 114, 5057-5115. [CrossRef] [PubMed]

24. D'Ischia, M.; Napolitano, A.; Ball, V.; Chen, C.T.; Buehler, M.J. Polydopamine and Eumelanin: From Structure-Property Relationships to a Unified Tailoring Strategy. Acc. Chem. Res. 2014, 47, 3541-3550. [CrossRef] [PubMed]

25. Son, E.J.; Kim, J.H.; Kim, K.; Park, C.B. Quinone and its derivatives for energy harvesting and storage materials. J. Mater. Chem. A 2016, 4, 11179-11202. [CrossRef]

26. Mao, W.X.; Lin, X.J.; Zhang, W.; Chi, Z.X.; Lyu, R.W.; Cao, A.M.; Wan, L.J. Core-shell structured $\mathrm{TiO}_{2} @$ polydopamine for highly active visible-light photocatalysis. Chem. Commun. 2016, 52, 7122-7125. [CrossRef] [PubMed]

27. Zhou, X.S.; Jin, B.; Luo, J.; Xu, X.Y.; Zhang, L.L.; Li, J.J.; Guan, H.J. Dramatic visible light photocatalytic degradation due to the synergetic effects of $\mathrm{TiO}_{2}$ and PDA nanospheres. RSC Adv. 2016, 6, 64446-64449. [CrossRef]

28. Kim, S.; Moon, G.H.; Kim, G.; Kang, U.; Park, H.; Choi, W. TiO 2 complexed with dopamine-derived polymers and the visible light photocatalytic activities for water pollutants. J. Catal. 2017, 346, 92-100. [CrossRef]

29. He, F.; Chen, G.; Yu, Y.G.; Zhou, Y.S.; Zheng, Y.; Hao, S. The synthesis of condensed C-PDA-g-C $3 \mathrm{~N}_{4}$ composites with superior photocatalytic performance. Chem. Commun. 2015, 51, 6824-6827. [CrossRef] [PubMed]

30. Yu, Z.X.; Li, F.; Yang, Q.B.; Shi, H.; Chen, Q.; Xu, M. Nature-Mimic Method To Fabricate Polydopamine/Graphitic Carbon Nitride for Enhancing Photocatalytic Degradation Performance. ACS Sustain. Chem. Eng. 2017, 5, 7840-7850. [CrossRef]

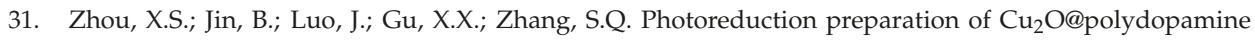
nanospheres with enhanced photocatalytic activity under visible light irradiation. J. Solid State Chem. 2017, 254, 55-61. [CrossRef]

32. Zhang, C.; Yang, H.C.; Wan, L.S.; Liang, H.Q.; Li, H.Y.; Xu, Z.K. Polydopamine-Coated Porous Substrates as a Platform for Mineralized beta-FeOOH Nanorods with Photocatalysis under Sunlight. ACS Appl. Mater. Interfaces 2015, 7, 11567-11574. [CrossRef] [PubMed]

33. Xie, A.M.; Zhang, K.; Wu, F.; Wang, N.N.; Wang, Y.; Wang, M.Y. Polydopamine nanofilms as visible light-harvesting interfaces for palladium nanocrystal catalyzed coupling reactions. Catal. Sci. Technol. 2016, 6, 1764-1771. [CrossRef] 
34. Feng, J.J.; Zhang, P.P.; Wang, A.J.; Liao, Q.C.; Xi, J.L.; Chen, J.R. One-step synthesis of monodisperse polydopamine-coated silver core-shell nanostructures for enhanced photocatalysis. New J. Chem. 2012, 36, 148-154. [CrossRef]

35. Ohsaka, T. Temperature dependence of the Raman spectrum in anatase $\mathrm{TiO}_{2}$. J. Phys. Soc. Jpn. 1980, 48, 1661-1668. [CrossRef]

36. Choi, H.C.; Jung, Y.M.; Kim, S.B. Size effects in the Raman spectra of $\mathrm{TiO}_{2}$ nanoparticles. Vib. Spectrosc. 2005, 37, 33-38. [CrossRef]

37. Ye, W.C.; Wang, D.A.; Zhang, H.; Zhou, F.; Liu, W.M. Electrochemical growth of flowerlike gold nanoparticles on polydopamine modified ITO glass for SERS application. Electrochim. Acta 2010, 55, 2004-2009. [CrossRef]

38. Thommes, M.; Kaneko, K.; Neimark, A.V.; Olivier, J.P.; Rodriguez-Reinoso, F.; Rouquerol, J.; Sing, K.S.W. Physisorption of gases, with special reference to the evaluation of surface area and pore size distribution (IUPAC Technical Report). Pure Appl. Chem. 2015, 87, 1051-1069. [CrossRef]

39. Magne, C.; Dufour, F.; Labat, F.; Lancel, G.; Durupthy, O.; Cassaignon, S.; Pauporte, T. Effects of $\mathrm{TiO}_{2}$ nanoparticle polymorphism on dye-sensitized solar cell photovoltaic properties. J. Photochem. Photobiol. A Chem. 2012, 232, 22-31. [CrossRef]

40. Akimov, A.V.; Neukirch, A.J.; Prezhdo, O.V. Theoretical Insights into Photoinduced Charge Transfer and Catalysis at Oxide Interfaces. Chem. Rev. 2013, 113, 4496-4565. [CrossRef] [PubMed]

41. Lin, H.; Fratesi, G.; Selcuk, S.; Brivio, G.P.; Selloni, A. Effects of Thermal Fluctuations on the Structure, Level Alignment, and Absorption Spectrum of Dye-Sensitized $\mathrm{TiO}_{2}$ : A Comparative Study of Catechol and Isonicotinic Acid on the Anatase (101) and Rutile (110) Surfaces. J. Phys. Chem. C 2016, 120, 3899-3905. [CrossRef]

42. Phua, S.L.; Yang, L.P.; Toh, C.L.; Ding, G.Q.; Lau, S.K.; Dasari, A.; Lu, X.H. Simultaneous Enhancements of UV Resistance and Mechanical Properties of Polypropylene by Incorporation of Dopamine-Modified Clay. ACS Appl. Mater. Interfaces 2013, 5, 1302-1309. [CrossRef] [PubMed]

43. Yang, X.; Duan, L.; Cheng, X.J.; Ran, X.Q. Effect of polydopamine coating on improving photostability of poly(1,3,4-oxadiazole)s fiber. J. Polym. Res. 2016, 23. [CrossRef]

44. Proks, V.; Brus, J.; Pop-Georgievski, O.; Vecernikova, E.; Wisniewski, W.; Kotek, J.; Urbanova, M.; Rypacek, F. Thermal-Induced Transformation of Polydopamine Structures: An Efficient Route for the Stabilization of the Polydopamine Surfaces. Macromol. Chem. Phys. 2013, 214, 499-507. [CrossRef]

45. Wang, Z.H.; Tang, F.; Fan, H.L.; Wang, L.; Jin, Z.X. Polydopamine Generates Hydroxyl Free Radicals under Ultraviolet-Light Illumination. Langmuir 2017, 33, 5938-5946. [CrossRef] [PubMed]

46. Marchetti, A.; Chen, J.E.; Pang, Z.F.; Li, S.H.; Ling, D.S.; Deng, F.; Kong, X.Q. Understanding Surface and Interfacial Chemistry in Functional Nanomaterials via Solid-State NMR. Adv. Mater. 2017, 29. [CrossRef] [PubMed]

47. Adhyaru, B.B.; Akhmedov, N.G.; Katritzky, A.R.; Bowers, C.R. Solid-state cross-polarization magic angle spinning ${ }^{13} \mathrm{C}$ and ${ }^{15} \mathrm{~N}$ NMR characterization of Sepia melanin, Sepia melanin free acid and Human hair melanin in comparison with several model compounds. Magn. Reson. Chem. 2003, 41, 466-474. [CrossRef]

48. Dreyer, D.R.; Miller, D.J.; Freeman, B.D.; Paul, D.R.; Bielawski, C.W. Elucidating the Structure of Poly(dopamine). Langmuir 2012, 28, 6428-6435. [CrossRef] [PubMed]

49. Liebscher, J.; Mrowczynski, R.; Scheidt, H.A.; Filip, C.; Hadade, N.D.; Turcu, R.; Bende, A.; Beck, S. Structure of Polydopamine: A Never-Ending Story? Langmuir 2013, 29, 10539-10548. [CrossRef] [PubMed]

50. Gaya, U.I.; Abdullah, A.H. Heterogeneous photocatalytic degradation of organic contaminants over titanium dioxide: A review of fundamentals, progress and problems. J. Photochem. Photobiol. C: Photochem. Rev. 2008, 9,1-12. [CrossRef]

51. Ai, K.L.; Liu, Y.L.; Ruan, C.P.; Lu, L.H.; Lu, G.Q. Sp2 C-Dominant N-Doped Carbon Sub-micrometer Spheres with a Tunable Size: A Versatile Platform for Highly Efficient Oxygen-Reduction Catalysts. Adv. Mater. 2013, 25, 998-1003. [CrossRef] [PubMed]

(C) 2018 by the authors. Licensee MDPI, Basel, Switzerland. This article is an open access article distributed under the terms and conditions of the Creative Commons Attribution (CC BY) license (http:/ / creativecommons.org/licenses/by/4.0/). 


\title{
Article \\ Photocatalytic Water Disinfection under Solar Irradiation by D-Glucose-Modified Titania
}

\author{
Agata Markowska-Szczupak ${ }^{1, *}$, Paulina Rokicka ${ }^{1}$, Kunlei Wang ${ }^{2}$, Maya Endo ${ }^{2}$, \\ Antoni Waldemar Morawski ${ }^{1}$ and Ewa Kowalska ${ }^{2}$ \\ 1 Institute of Inorganic Technology and Environment Engineering, \\ West Pomeranian University of Technology in Szczecin, Pulaskiego 10, \\ 70-322 Szczecin, Poland; rokicka16@poczta.onet.pl (P.R.); amor@zut.edu.pl (A.W.M.) \\ 2 Institute for Catalysis, Hokkaido University, N21, W10, Sapporo 001-0021, Japan; \\ kunlei@cat.hokudai.ac.jp (K.W.); m_endo@cat.hokudai.ac.jp (M.E.); kowalska@cat.hokudai.ac.jp (E.K.) \\ * Correspondence: Agata.Markowska@zut.edu.pl; Tel.: +48-91-449-42-30
}

Received: 18 July 2018; Accepted: 30 July 2018; Published: 1 August 2018

\begin{abstract}
Modified titania photocatalysts were synthesized by the pressure method using titanium(IV) oxide from Grupa Azoty Zakłady Chemiczne "Police" S.A., Police, Poland, and D-glucose solution. Characterization of obtained composites was performed by X-ray diffraction (XRD), X-ray photoelectron spectroscopy (XPS), elemental analysis, and measurements of zeta potential and specific surface area (SSA). The possibility of using glucose-titania composites as photocatalysts for simulated solar-assisted disinfection against gram-negative Escherichia coli and gram-positive Stapchyloccocus epidermidis bacteria were examined in two reaction systems, i.e., for suspended and immobilized photocatalysts (on the concrete). It was found that an increase in the D-glucose concentration, i.e., higher carbon content, led to a decrease in antibacterial properties. The sample obtained from $1 \%$ of $\mathrm{D}$-glucose solution at $100{ }^{\circ} \mathrm{C}\left(\mathrm{TiO}_{2}-1 \%-\mathrm{G}-100\right)$ showed superior photocatalytic activity under UV-Vis irradiation toward both bacteria species. Water disinfection was more efficient for suspended photocatalyst than that for supported one, where complete disinfection was reached during 55-70 $\mathrm{min}$ and $120 \mathrm{~min}$ of irradiation, respectively. For the first time, it has been shown that titania modified with monosaccharides can be efficiently used for water disinfection, and the immobilization of photocatalyst on the concrete might be a prospective method for public water supplies.
\end{abstract}

Keywords: $\mathrm{C} / \mathrm{TiO}_{2}$; photocatalysis; solar radiation; disinfection; immobilized catalyst

\section{Introduction}

In recent years, the intensification of research directed to delivery new, ecological, and cost-effective disinfection methods that are focused on increased water safety has taken place. It seems that the photocatalytic oxidation with titanium(IV) oxide $\left(\mathrm{TiO}_{2}\right.$, titania) fulfills above conditions. Unfortunately, the majority of commercially available titania photocatalysts are the first-generation catalyst, which means that their activity occurs only under UV irradiation, i.e., with wavelengths $(\lambda)$ shorter than $400 \mathrm{~nm}$. Therefore, the amount of solar radiation reaching Earth's surface might be insufficient for photocatalyst activation. In order to enhance the photocatalytic activity of $\mathrm{TiO}_{2}$ under solar radiation, what is essential from the economical point of view, different ways of titania modification have been widely studied, e.g., doping, surface modification, and heterojunction. Various physical and chemical strategies, and many kinds of modifiers, such as metals, metal oxides, and non-metals have been used for titania modification, particularly noble metals (e.g., Au, Ag) and nonmetals (e.g., S, C, N) [1-4]. Scientific studies on nonmetal modification started about two decades ago [5]. Among them, the aliphatic alcohols, urea, thiourea, calcium carbide, activated carbon, multi-wall carbon nanotubes, 
and graphene have been used. It has been shown that carbon modification of titania resulted in significant enhancement of photocatalytic activity under solar radiation and even under sole visible irradiation [5-9]. The main advantage of carbon modification of $\mathrm{TiO}_{2}$ is that the simple and fast methods of preparation can be used. It has been proved that $\mathrm{C} / \mathrm{TiO}_{2}$ demonstrates better photocatalytic activity than un-modified $\mathrm{TiO}_{2}$ for organic (including phenol and organic dyes) or inorganic (e.g., nitrogen oxides) compounds' degradation [6,8,10-12]. However, except our own research [13-15], only a few studies on disinfection using carbon-modified $\mathrm{TiO}_{2}$ have been performed [16-18]. For example, titania modified with carbon from coconut shell, alcohols, and carbide presents better biocidal properties than un-modified titania, even under irradiation with visible light. Moreover, it should be mentioned that preliminary results on antibacterial properties for other modified titania samples (with graphene oxide) were quite promising [15]. Therefore, the antibacterial properties of sunlight-activated D-glucose-modified titania was evaluated in the present study.

\section{Results}

\subsection{Characteristics of D-Glucose-Modified $\mathrm{TiO}_{2}$}

Starting material contained majority of amorphous titania (ca. 75.0\%, data from producer), and thus had very high specific surface area (SSA) of $312 \mathrm{~m}^{2} \mathrm{~g}^{-1}$, whereas crystalline part was composed mainly of anatase $(95.0 \%$ and $5 \%$ of rutile). Thermal treatment did not cause significant changes in the crystalline composition of titania, where only slight phase transition was noticed, i.e., from amorphous titania to anatase, resulting in a slight increase in anatase content to ca. $98 \%$ and a decrease in SSA from $312 \mathrm{~m}^{2} \mathrm{~g}^{-1}$ to 266,158 , and $88 \mathrm{~m}^{2} \mathrm{~g}^{-1}$ after annealing at $100{ }^{\circ} \mathrm{C}, 150{ }^{\circ} \mathrm{C}$, and $200^{\circ} \mathrm{C}$, respectively. Similarly, the presence of D-glucose practically did not influence the crystalline composition of photocatalysts, and anatase phase was predominant form of titania also in those samples (97.6-98.1\%), as shown in Table 1. The largest anatase crystallites and the smallest SSA were obtained for the sample that was prepared with the smallest content of D-glucose at the highest temperature $\left(\mathrm{TiO}_{2}-\mathrm{G}-1 \%-200\right)$. An increase in annealing temperature caused an increase in anatase crystallite size and a decrease in SSA (Figure 1a). It is well known that thermal treatment results in increases in both crystalline and particle sizes (a decrease in SSA), due to transformation of amorphous titania (e.g., amorphous layer on nano-crystals) and particle sintering/aggregation, respectively. In contrast, an influence of D-glucose on surface properties indicates that D-glucose restrains crystal growing (crystallite size of anatase in un-modified samples annealed at $100{ }^{\circ} \mathrm{C}, 150{ }^{\circ} \mathrm{C}$, and $200{ }^{\circ} \mathrm{C}$ were larger, i.e., 12.0, 16.3, and $21.9 \mathrm{~nm}$, respectively). It has been reported that titania modifiers could influence crystal growth either positively or negatively. For example, Grzybowska et al. found an increase in SSA after surface modification of titania with calcium, tungsten, iron, and aluminum, suggesting that adsorbed modifiers on titania surface disturbed in particles' sintering [19]. Usually, a decrease in crystallite size corresponds to an increase in SSA. Contrary, D-glucose-modification resulted in a decrease in both crystallite size and SSA for samples annealed at $100{ }^{\circ} \mathrm{C}$ (with an increase in D-glucose content), whereas higher temperatures of annealing resulted in a significant increase in SSA. Therefore, it is proposed that photocatalysts that were annealed at lower temperature could be composed of fine titania nanoparticles (NPs) covered with a thin layer of adsorbed D-glucose, whereas for those annealed at higher temperatures the presence of carbon (decomposed D-glucose) inhibited significantly particles' aggregation, as also proved by a decrease and an increase in micropore volume, respectively (Figure 1c). Interestingly, in the case of modified samples annealed at higher temperatures, the largest values of SSA were obtained for those with middle content of D-glucose (5\%), suggesting that smaller content (1\%) was not sufficient to prevent particles' aggregation, whereas too large content $(10 \%)$ could form a thick layer on titania surface, as confirmed by pore size distribution (a decrease in total pore volume and mesopore volumes, Figure 1b,d). The carbon content increased with an increase in D-glucose content, as shown in Table 1. 
Table 1. Physicochemical properties of photocatalysts used in this study (commercial photocatalysts: starting $\mathrm{TiO}_{2}$ (from Grupa Azoty Zakłady Chemiczne "Police" S.A., Police, Poland) and KRONOClean 7000), and starting $\mathrm{TiO}_{2}$ modified with D-glucose.

\begin{tabular}{|c|c|c|c|c|c|}
\hline Sample Name & $\begin{array}{c}\text { Anatase } \\
\text { Content }[\%]^{a}\end{array}$ & $\begin{array}{c}\text { Anatase Crystallite } \\
\text { Size [nm] }\end{array}$ & SBET $\left[\mathrm{m}^{2} / \mathrm{g}\right]$ & $\begin{array}{c}\text { Carbon } \\
\text { Content (wt \%) }\end{array}$ & $\begin{array}{c}\text { Zeta Potential } \\
\zeta[\mathrm{mV}]\end{array}$ \\
\hline Starting $\mathrm{TiO}_{2}$ & 95.0 & 11.0 & 312 & 0.0 & -24.13 \\
\hline KRONOClean7000 & 100.0 & 11.0 & 242 & 0.96 & -17.71 \\
\hline $\mathrm{TiO}_{2}-\mathrm{G}-1 \%-100$ & 97.8 & 11.7 & 268 & 0.59 & -13.49 \\
\hline $\mathrm{TiO}_{2}-\mathrm{G}-5 \%-100$ & 97.6 & 11.4 & 252 & 2.23 & -25.28 \\
\hline $\mathrm{TiO}_{2}-\mathrm{G}-10 \%-100$ & 97.6 & 11.2 & 214 & 4.49 & -26.49 \\
\hline $\mathrm{TiO}_{2}-\mathrm{G}-1 \%-150$ & 98.0 & 16.0 & 155 & 0.49 & -17.04 \\
\hline $\mathrm{TiO}_{2}-\mathrm{G}-5 \%-150$ & 98.1 & 13.4 & 206 & 2.10 & -20.24 \\
\hline $\mathrm{TiO}_{2}-\mathrm{G}-10 \%-150$ & 97.8 & 11.4 & 195 & 3.91 & -23.70 \\
\hline $\mathrm{TiO}_{2}-\mathrm{G}-1 \%-200$ & 98.0 & 21.8 & 87 & 0.29 & -16.80 \\
\hline $\mathrm{TiO}_{2}-\mathrm{G}-5 \%-200$ & 97.9 & 17.2 & 120 & 1.90 & -18.72 \\
\hline $\mathrm{TiO}_{2}-\mathrm{G}-10 \%-200$ & 97.9 & 17.3 & 110 & 3.37 & -23.34 \\
\hline
\end{tabular}

${ }^{\mathrm{a}}$ anatase content considering only crystalline forms (anatase + rutile).

a

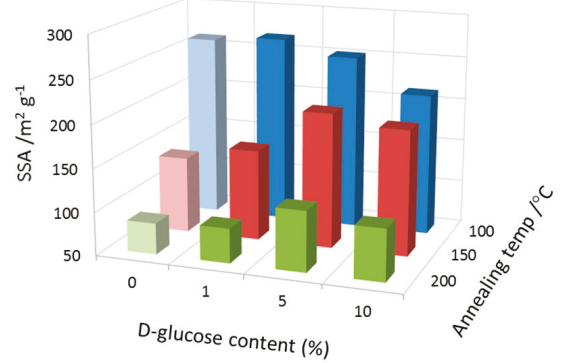

C

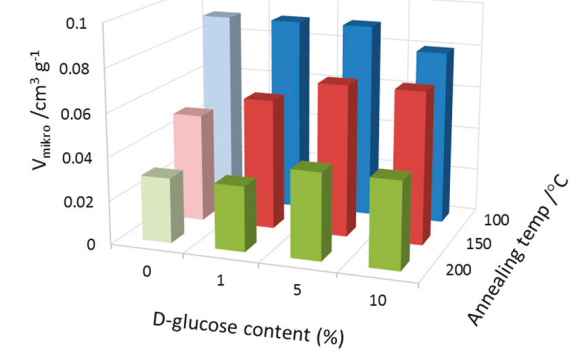

b
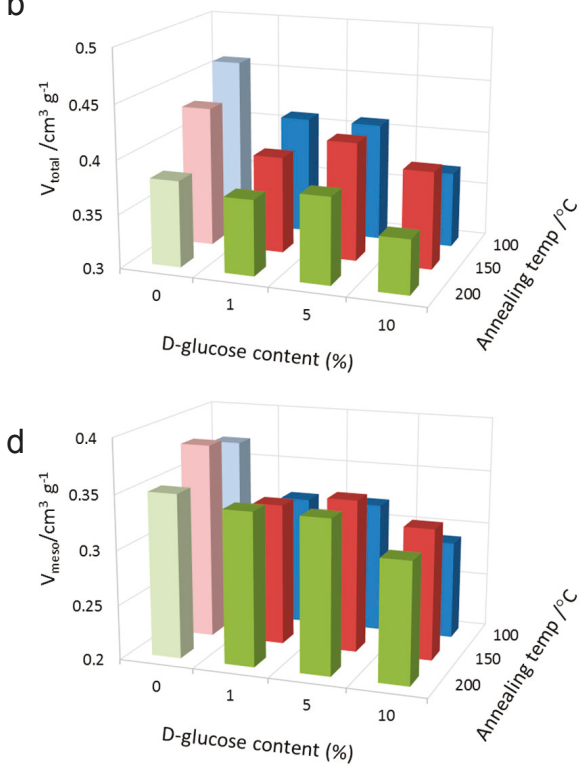

Figure 1. BET (Brunauer, Emmett and Teller) results for un-modified (D-glucose content: 0) and modified with D-glucose (1\%, 5\% and 10\%): (a) specific surface area (SSA), (b) total pore volume $\left(\mathrm{V}_{\text {total }}\right)$, (c) micropore volume $\left(\mathrm{V}_{\text {micro }}\right)$, and $(\mathrm{d})$ mesopore volume $\left(\mathrm{V}_{\text {meso }}\right)$.

However, an increase in annealing temperature resulted in a decrease in carbon content, especially for samples that were prepared at $200{ }^{\circ} \mathrm{C}$ (Table 1). This decrease in carbon content should be caused by thermal decomposition of D-glucose, which usually starts at ca. $165^{\circ} \mathrm{C}$ [20]. Therefore, it is proposed that high pressure in an autoclave could accelerate D-glucose decomposition (at lower temperatures), similarly as reported for D-glucose instability during HPLC analysis [21]. Obviously, the presence of D-glucose on titania surface resulted in changes of zeta potential from $-19.49,-21.09$ and $-21.44 \mathrm{mV}$ for samples annealed at $100^{\circ} \mathrm{C}, 150^{\circ} \mathrm{C}$, and $200^{\circ} \mathrm{C}$, respectively, to values shown in Table 1 . 
To investigate surface composition of titania after modification, $\mathrm{X}$-ray photoelectron spectroscopy (XPS) analysis has been performed for three samples: starting $\mathrm{TiO}_{2}, \mathrm{TiO}_{2}-100$ (starting $\mathrm{TiO}_{2}$ thermally treated at $100{ }^{\circ} \mathrm{C}$ ), and $\mathrm{TiO}_{2}-\mathrm{G}-1 \%-100$ (starting $\mathrm{TiO}_{2}$ modified with $1 \%$ of D-glucose and annealed at $100{ }^{\circ} \mathrm{C}$; the most active sample), and the obtained results are shown in Figure 2 and Table 2 . It was found that the surface of titania was enriched with oxygen as the ratio of oxygen to titanium exceeded the stoichiometric ratio (2) being 2.2, which is typical for various titania samples, due to adsorption of water and carbon dioxide on the titania surface. For example, oxygen enrichment of titania was reported for samples that were prepared by the laser ablation $(\mathrm{O} / \mathrm{Ti}=2.5)$ [22], the microemulsion $(\mathrm{O} / \mathrm{Ti}=4.6)$ [23], the hydrothermal $(\mathrm{O} / \mathrm{Ti}=5.2)[24]$ and the gas-phase $(\mathrm{O} / \mathrm{Ti}=7.7)$ [24] methods. Carbon is present in all titania samples (and also other oxides), mainly due to adsorption of carbon dioxide from air (forming bicarbonate and mono- and bidentate carbonate [25]), but also from precursors that are used for titania synthesis, such as titanium alcoholates. XPS analysis proved the surface modification of titania with D-glucose since the ratio of carbon to titanium increased by almost double after sample modification with $1 \mathrm{wt} \%$ of D-glucose. The banding energies of titanium, oxygen, and carbon were estimated by deconvolution of $\mathrm{Ti} 2 \mathrm{p}_{3 / 2}, \mathrm{O} 1 \mathrm{~s}$, and $\mathrm{C} 1$ s peaks, respectively, accordingly to published reports on XPS analysis of titania samples [26-31]. Titanium consisted mainly $\mathrm{Ti}^{4+}$, and the reduced form of titanium $\left(\mathrm{Ti}^{3+}\right)$ did not exceed 2.2\%. D-glucose presence and thermal treatment practically did not change form of titanium. Deconvolution of oxygen peak into three peaks at ca. $529.6 \mathrm{eV}$, $531.3 \mathrm{eV}$, and $533.3 \mathrm{eV}$, respectively, confirmed the co-existence of three forms of oxygen, i.e., (i) lattice oxygen in $\mathrm{TiO}_{2}$, (ii) oxygen bound to: carbon $(\mathrm{C}=\mathrm{O})$, titanium in $\mathrm{Ti}_{2} \mathrm{O}_{3}$, and hydroxyl groups bound to two titanium atoms, (iii) hydroxyl groups that were bound to titanium or carbon (Ti-OH/C-OH). A significant increase in the content of oxygen in the form of hydroxyl groups (from 1.4 to 6.8) and an increase in the carbon content in the form of carbon bound to carbon (C-C) for $\mathrm{TiO}_{2}-\mathrm{G}-1 \%-100$ sample confirmed the presence of adsorbed D-glucose on the titania surface.

To examine photocatalytic activity of prepared samples, the generation of hydroxyl radicals under irradiation was performed, and the obtained data are shown in Figure 3. It was found that titania modification with glucose resulted in a significant enhancement of photocatalytic activity (more than twice), where the most active sample contained the smallest content of glucose (1 wt \%) and was annealed at lowest temperature $\left(100{ }^{\circ} \mathrm{C}\right)$, i.e., $\mathrm{TiO}_{2}-\mathrm{G}-1 \%-100$. An increase in annealing temperature resulted in a decrease in activity, which is probably due to glucose decomposition, as discussed above.

Table 2. Surface composition and fraction of oxidation states of $\mathrm{Ti}, \mathrm{O}$, and $\mathrm{C}$ from deconvolution of X-ray photoelectron spectroscopy (XPS) peaks.

\begin{tabular}{|c|c|c|c|c|c|c|c|c|}
\hline \multirow{2}{*}{ Sample name } & \multicolumn{5}{|c|}{ Content (at. \%) } & \multicolumn{3}{|c|}{ Ratio } \\
\hline & \multicolumn{2}{|c|}{ Ti $2 p_{3 / 2}$} & \multicolumn{2}{|l|}{ O 1s } & C 1s & \multicolumn{2}{|l|}{$\mathrm{O} / \mathrm{Ti}$} & $\mathrm{C} / \mathrm{Ti}$ \\
\hline Starting $\mathrm{TiO}_{2}$ & \multicolumn{2}{|c|}{17.71} & \multicolumn{2}{|l|}{43.95} & 38.34 & \multicolumn{2}{|l|}{2.5} & 2.2 \\
\hline $\mathrm{TiO}_{2}-100$ & \multicolumn{2}{|c|}{15.05} & \multicolumn{2}{|l|}{43.3} & 41.65 & \multicolumn{2}{|l|}{2.9} & 2.8 \\
\hline $\mathrm{TiO}_{2}-\mathrm{G}-1 \%-100$ & \multicolumn{2}{|c|}{12.1} & \multicolumn{2}{|l|}{36.06} & 51.84 & 3.0 & & 4.3 \\
\hline \multicolumn{9}{|c|}{ Fraction of oxidation states } \\
\hline \multirow{2}{*}{ Sample name } & \multicolumn{2}{|c|}{$\operatorname{Ti} 2 \mathrm{p}_{3 / 2}(\%)$} & \multicolumn{3}{|c|}{ O 1s (\%) } & \multicolumn{3}{|c|}{ C 1s (\%) } \\
\hline & $\mathrm{Ti}^{4+}$ & $\mathrm{Ti}^{3+}$ & $\mathrm{TiO}_{2}$ & $=\mathrm{O}^{\mathrm{a}}$ & $-\mathrm{OH}^{\mathrm{b}}$ & C-C & $\mathrm{C}-\mathrm{OH}$ & $\mathrm{C}=\mathrm{O}$ \\
\hline Starting $\mathrm{TiO}_{2}$ & 97.9 & 2.1 & 47.2 & 50.0 & 2.8 & 58.7 & 30.1 & 11.2 \\
\hline $\mathrm{TiO}_{2}-100$ & 98.1 & 1.9 & 45.0 & 53.6 & 1.4 & 54.7 & 37.2 & 8.1 \\
\hline $\mathrm{TiO}_{2}-\mathrm{G}-1 \%-100$ & 97.8 & 2.2 & 46.0 & 47.2 & 6.8 & 61.5 & 28.5 & 10.0 \\
\hline
\end{tabular}


A

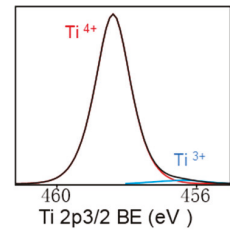

B

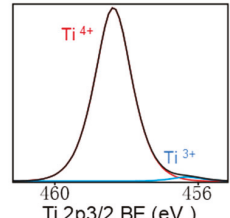

C

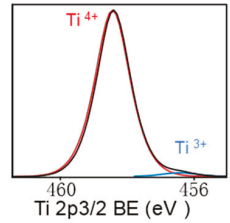

$\mathrm{TiO}_{2}$-starting

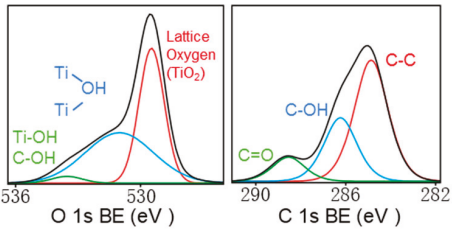

$\mathrm{TiO}_{2}-100$

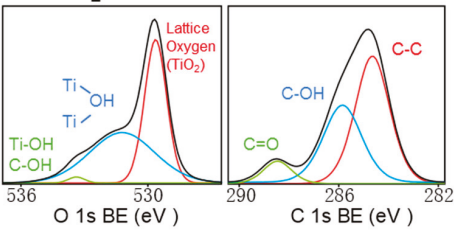

$\mathrm{TiO}_{2}-\mathrm{G}-1 \%-100$
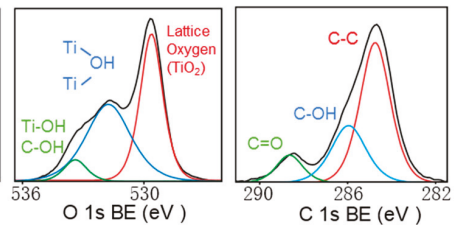

Figure 2. XPS results for $\mathrm{Ti} 2 \mathrm{p}_{3 / 2}, \mathrm{O} 1 \mathrm{~s}$, and $\mathrm{C} 1$ s for starting $\mathrm{TiO}_{2}$ (A; top), $\mathrm{TiO}_{2}-100$ (B; middle), and $\mathrm{TiO}_{2}-\mathrm{G}-1 \%-100$ (C; bottom).

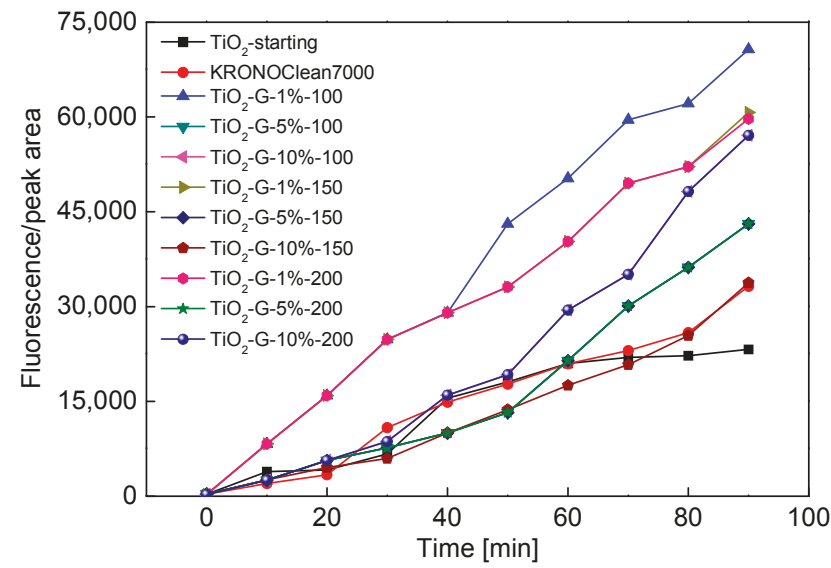

Figure 3. The amount of generated 2-hydroxyterephthalic acid (fluorescence intensity) during $90 \mathrm{~min}$ of UV-Vis irradiation.

\subsection{Dose-Dependent Photocatalytic Inactivation of Escherichia coli and Staphylococcus epidermidis}

The correlation between disinfection duration and dose of the glucose-modified photocatalyst with the highest photocatalytic activity (i.e., rate of hydroxyl radicals' formation), i.e., $\mathrm{TiO}_{2}-\mathrm{G}-1 \%-100$ sample, was examined. The fastest disinfection process under UV-Vis irradiation (after $70 \mathrm{~min}$ ) was obtained for photocatalyst dose of $0.1 \mathrm{~g} \times \mathrm{dm}^{-3}$ (Figure $4 \mathrm{a}$ ). It was found that both an increase and 
a decrease in $\mathrm{TiO}_{2}-\mathrm{G}-1 \%-100$ dose resulted in extension of disinfection duration. All of the differences were statistically significant (Table 3). Taken into account the obtained results, it was assumed that $0.1 \mathrm{~g}$ per $\mathrm{dm}^{3}$ was an optimal dose for photocatalytic disinfection. Next, the influence of bacteria concentration (E. coli and S. epidermidis) on disinfection duration was studied, and the obtained data are shown in Figure $4 \mathrm{~b}$. The necessary duration of disinfection did not differ significantly for both bacteria solutions in the case of their low concentration from $1.5 \times 10^{4} \mathrm{CFU} \times \mathrm{cm}^{-3}$ to $1.5 \times 10^{5} \mathrm{CFU} \times \mathrm{cm}^{-3}$ (Table 3), reaching complete disinfection during $60 \mathrm{~min}$ of UV-Vis irradiation (Figure 4b). However, an increase in bacteria concentration resulted in a significant extension of necessary disinfection time, even up to $120 \mathrm{~min}$ for concentration of $1.5 \times 10^{8} \mathrm{CFU}$.
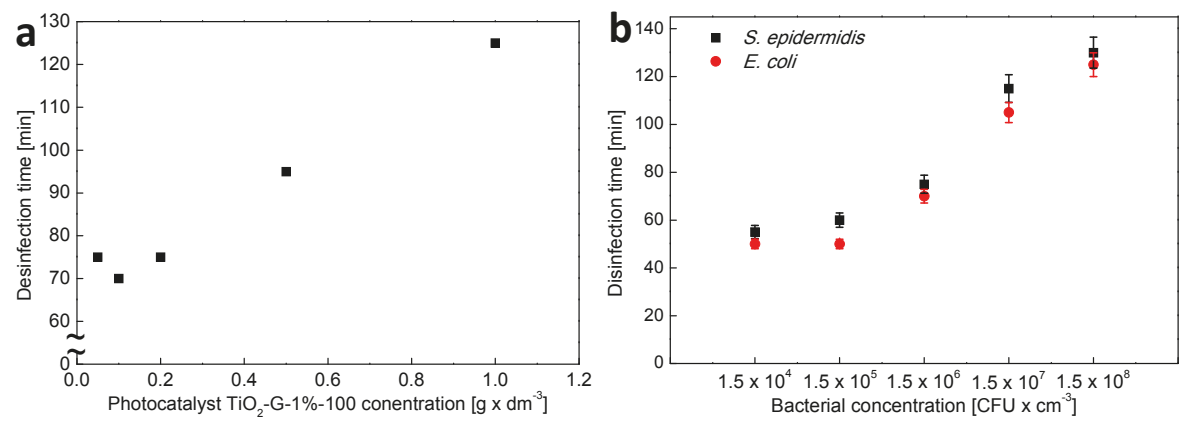

Figure 4. The correlations between disinfection time and: (a) photocatalyst $\mathrm{TiO}_{2}-\mathrm{G}-1 \%-100$ content, and (b) bacteria concentration.

Table 3. Statistical analysis for factors influencing E. coli disinfection time.

\begin{tabular}{|c|c|c|c|c|c|}
\hline Photocatalyst $\mathrm{TiO}_{2}-\mathrm{G}-1 \%-100$ Concentration $\left[\mathrm{g} \times \mathrm{dm}^{3}\right]$ & 0.05 & 0.1 & 0.2 & 0.5 & 1.0 \\
\hline 0.05 & - & SI & SI & * & $* * *$ \\
\hline 0.1 & SI & - & SI & * & $* * *$ \\
\hline 0.2 & * & * & * & - & $* * *$ \\
\hline 0.5 & * & 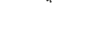 & 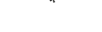 & - & $+x$ \\
\hline 1.0 & $* * *$ & $* * *$ & $* * *$ & $* * *$ & - \\
\hline Initial concentration of $E$. coli $\left[\mathrm{CFU} \times \mathrm{cm}^{3}\right]$ & $1.5 \times 10^{4}$ & $1.5 \times 10^{5}$ & $1.5 \times 10^{6}$ & $1.5 \times 10^{7}$ & $1.5 \times 10^{8}$ \\
\hline $1.5 \times 10^{4}$ & - & SI & SI & ** & $* * *$ \\
\hline $1.5 \times 10^{5}$ & SI & - & SI & $* *$ & $* * *$ \\
\hline $1.5 \times 10^{6}$ & SI & SI & - & ** & $* * *$ \\
\hline $1.5 \times 10^{7}$ & ** & $* *$ & ** & - & * \\
\hline $1.5 \times 10^{8}$ & $* * *$ & $* * *$ & $* * *$ & * & - \\
\hline Initial concentration of $S$. epidermidis $\left[\mathrm{CFU} \times \mathrm{cm}^{3}\right]$ & $1.5 \times 10^{4}$ & $1.5 \times 10^{5}$ & $1.5 \times 10^{6}$ & $1.5 \times 10^{7}$ & $1.5 \times 10^{8}$ \\
\hline $1.5 \times 10^{4}$ & - & SI & SI & $* *$ & $* * *$ \\
\hline $1.5 \times 10^{5}$ & SI & - & SI & $* *$ & $* * *$ \\
\hline $1.5 \times 10^{6}$ & SI & SI & - & ** & $* * *$ \\
\hline $1.5 \times 10^{7}$ & ** & $* *$ & $* *$ & - & $*$ \\
\hline $1.5 \times 10^{8}$ & $* * *$ & $* * *$ & $* * *$ & * & - \\
\hline
\end{tabular}

\subsection{Influenece of D-Glucose Content, Used for $\mathrm{TiO}_{2}$ Modification at $100^{\circ} \mathrm{C}$, on Disinfection Properties}

The influence of D-glucose content, used for titania modification at $100{ }^{\circ} \mathrm{C}$, was investigated. It was found that disinfection duration strongly depended on the D-glucose content, as shown in Figure 5. $\mathrm{TiO}_{2}-\mathrm{G}-1 \%-100$ photocatalyst led to the complete inactivation of gram-negative bacteria $E$. coli within $70 \mathrm{~min}$ (Figure 5a) and gram-positive bacteria S. epidermidis within 85 min (Figure 6a) under UV-Vis irradiation. Scanning electron microscopy (SEM) revealed the significant change in bacterial morphology (e.g., shape, disruption of outer membranes, etc.) after photocatalytic process, as shown 
in Figures $5 c$ and $6 c$. In contrast, all of the photocatalysts (commercial and modified) did not cause the change in bacterial number in dark conditions (Figures $5 \mathrm{~b}$ and $6 \mathrm{~b}$ ).
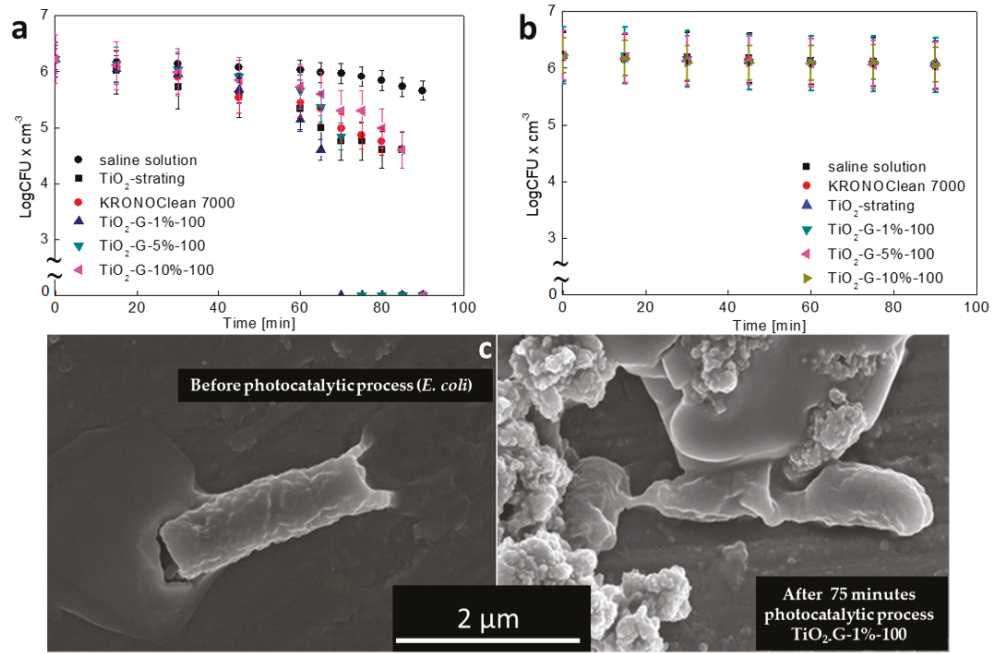

Figure 5. Antibacterial activity against $E$. coli of commercial and D-glucose-modified titania: (a) under UV-Vis irradiation, and (b) in dark conditions; and, (c) SEM images of E. coli before (left) and after $75 \mathrm{~min}$ of UV-Vis irradiation (right) in the presence of $0.1 \mathrm{~g} \times \mathrm{dm}^{3} \mathrm{TiO}_{2}-\mathrm{G}-1 \%-100$.
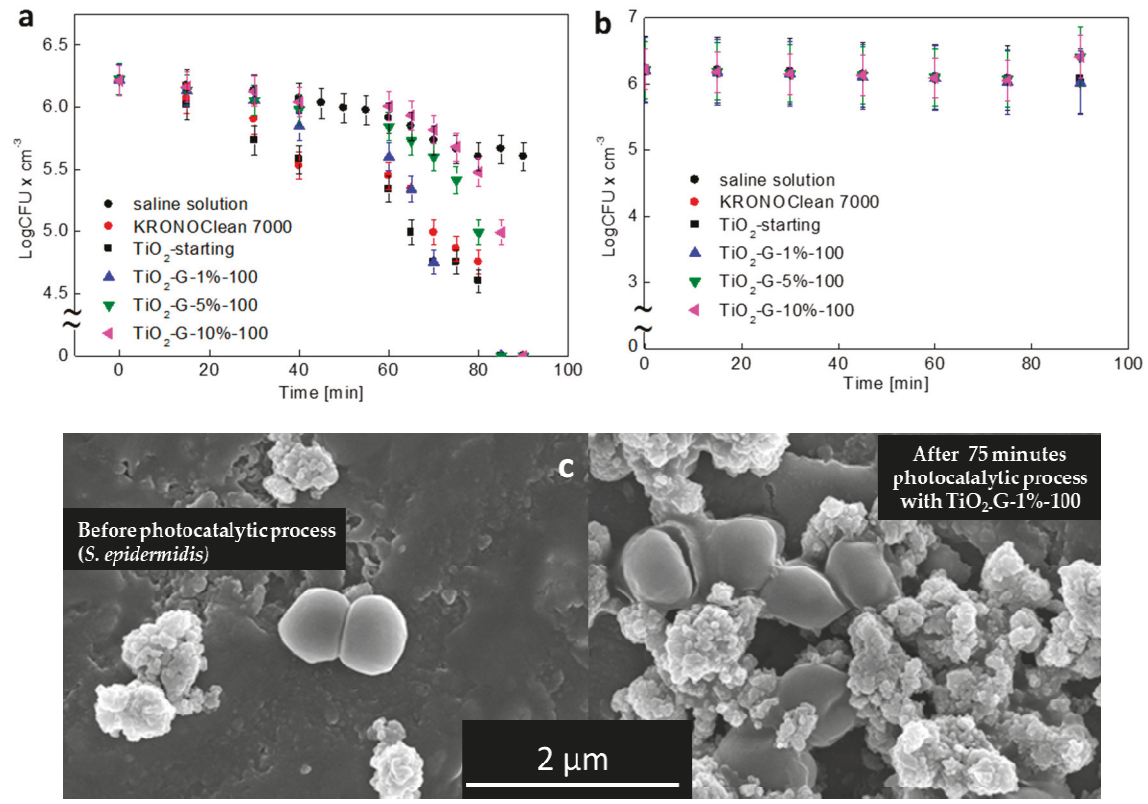

Figure 6. Antibacterial activity against S. epidermidis of commercial and D-glucose-modified titania: (a) under UV-Vis irradiation, and (b) in dark conditions; and, (c) SEM images of S. epidermidis before (left) and after $75 \mathrm{~min}$ of UV-Vis irradiation (right) in the presence of $0.1 \mathrm{~g} \times \mathrm{dm}^{3} \mathrm{TiO}_{2}-\mathrm{G}-1 \%-100$. 


\subsection{Influenece of D-Glucose Content, Used for $\mathrm{TiO}_{2}$ Modification at $100{ }^{\circ} \mathrm{C}$, on Enzymatic Activity}

The enzymatic activity, i.e., catalase activity (CAT) and superoxide dismutase activity (SOD), secreted by E. coli and S. epidermidis, under UV-Vis irradiation and in the dark, was investigated for commercial and D-glucose-modified (at $100{ }^{\circ} \mathrm{C}$ ) photocatalysts. The tests were performed before and after $30,60,90$, and $120 \mathrm{~min}$ of process. The enzymatic activity was not observed from $90 \mathrm{~min}$ of process, and thus the obtained results were only presented till $60 \mathrm{~min}$, as shown in Figures 7 and 8 . It was demonstrated that without activation (dark conditions) all of the photocatalysts did not influence the CAT and SOD activity (Figures 7 and 8). However, 30-min UV-irradiation caused an increase in CAT and SOD enzyme activities, whereas next 30-min UV-Vis irradiation resulted in a decrease in those activities below the initial levels.

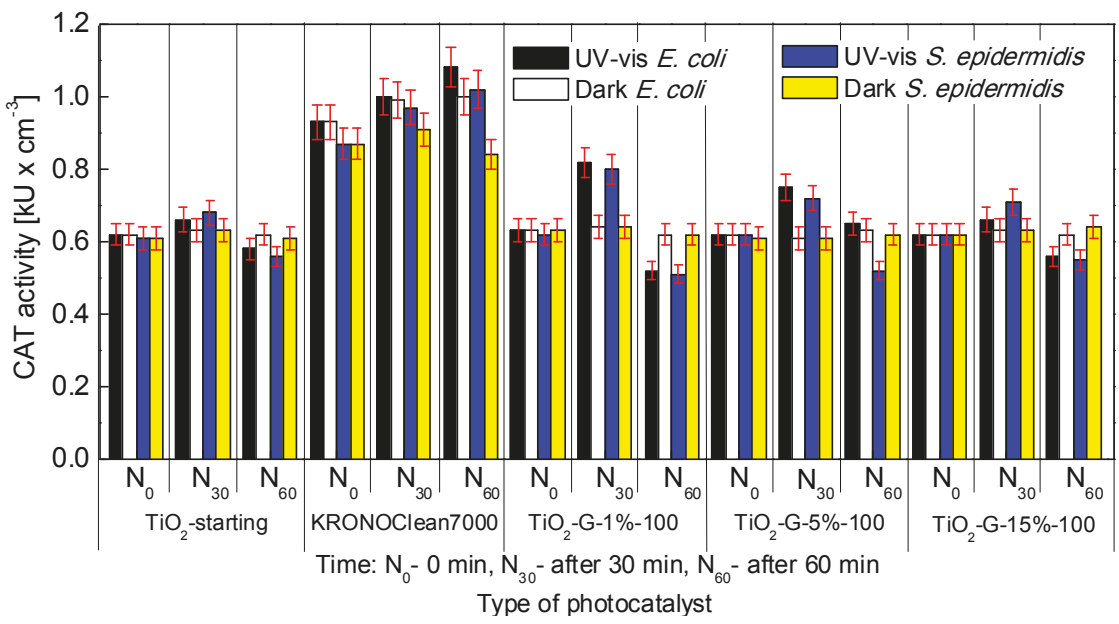

Figure 7. Influence of commercial and D-glucose-modified titania under UV-Vis irradiation and in dark conditions on E. coli and S. epidermidis catalase activity (CAT).

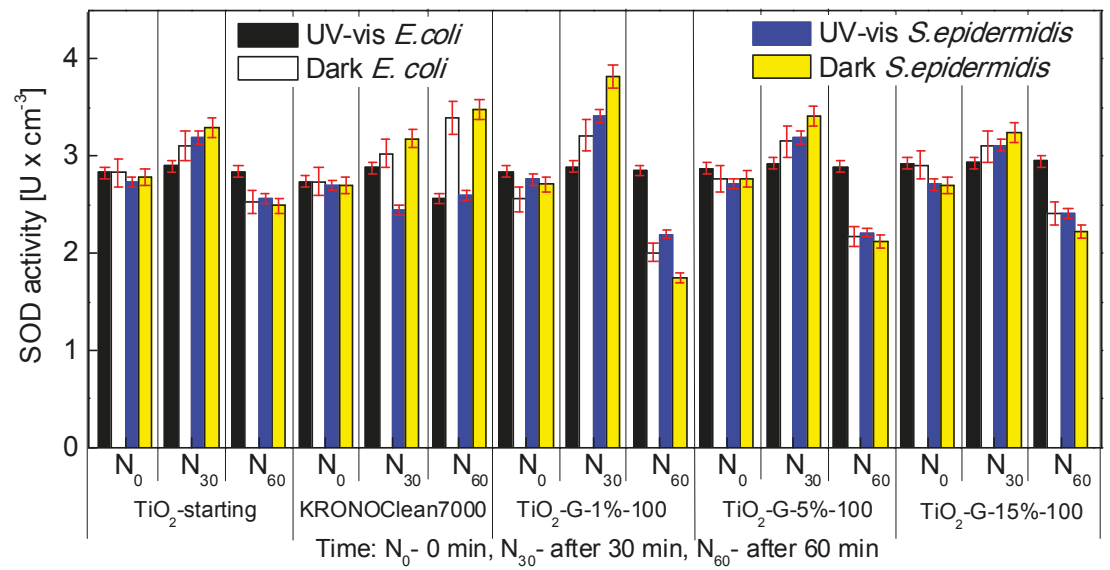

Type of photocatalyst

Figure 8. Influence of commercial and D-glucose-modified titania under UV-Vis irradiation and in dark conditions on E. coli and S. epidermidis superoxide dismutase activity (SOD). 


\subsection{Influenece of D-Glucose Content, Used for $\mathrm{TiO}_{2}$ Modification at $100{ }^{\circ} \mathrm{C}$, on Bacteria Mineralization}

To study the probability of complete decomposition of bacterial cells (mineralization), the liberation of carbon dioxide during UV-Vis irradiation and in the dark, were investigated. It was found that, indeed, bacterial cells could be efficiently decomposed only under photocatalytic process (Figures 9a and 10a), whereas no changes in carbon dioxide concentration were noticed in the dark (Figures $9 \mathrm{~b}$ and $10 \mathrm{~b}$ ). Moreover, the fastest evolution of carbon dioxide was observed for $\mathrm{TiO}_{2}-\mathrm{G}-1 \%-100$ sample with the lowest content of carbon among the modified samples, confirming its highest photocatalytic activity.
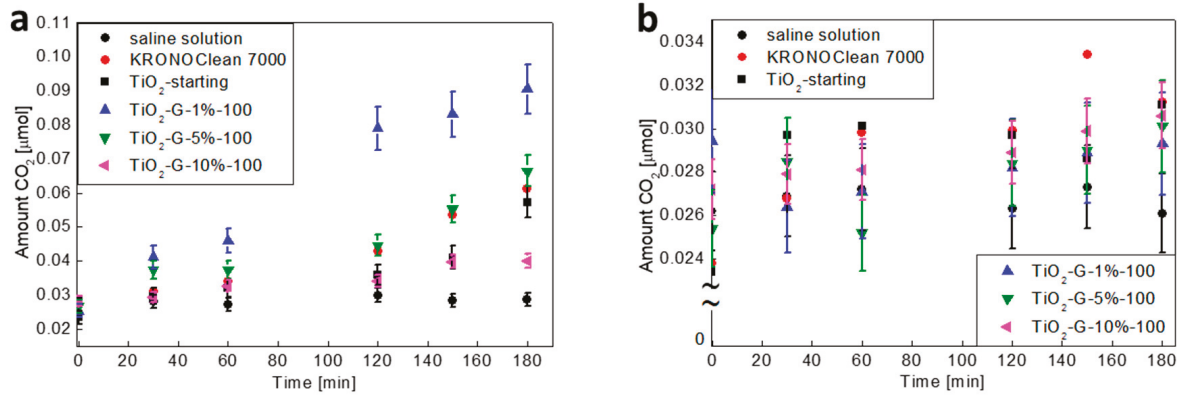

Figure 9. Evolution of $\mathrm{CO}_{2}$ during mineralization of E. coli cells under: (a) UV-Vis irradiation, and (b) in the dark on commercial and D-glucose-modified titania.
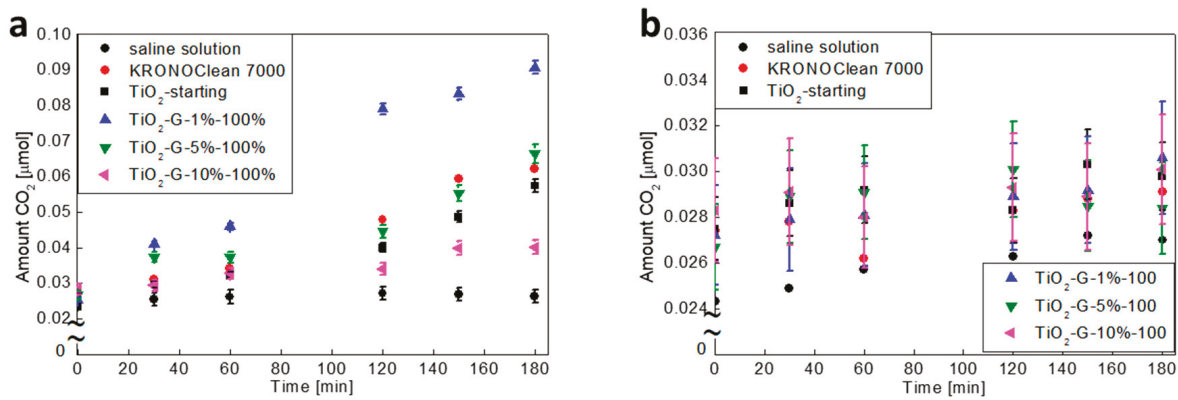

Figure 10. Evolution of $\mathrm{CO}_{2}$ during mineralization of S. epidermidis cells under: (a) UV-Vis irradiation, and $(\mathbf{b})$ in the dark on commercial and D-glucose-modified titania.

\subsection{Commercialization of Antimicrobial Photocatalysts for Building Materials}

To check the commercial feasibility of antimicrobial photocatalysts, cement mortars were supplemented with $10 \mathrm{wt} \%$ of $\mathrm{TiO}_{2}-\mathrm{G}-1 \%-100$ photocatalyst and tested for $E$. coli inactivation. It was clearly demonstrated that D-glucose-modified titania contributed to the additive benefits of the final product. Under UV-Vis irradiation the obtained concrete exhibited disinfection potential, as shown in Figure 11. The control experiments (concrete without photocatalyst) of E. coli inactivation did not show any significant differences in the number of bacteria after 120-min incubation in dark condition and under light irradiation. In contrast, in water being in contact with the plate, made of concrete supplemented with $\mathrm{TiO}_{2}-\mathrm{G}-1 \%-100$, the complete disinfection was achieved after only 120 min under UV-Vis irradiation (Figure 11). 


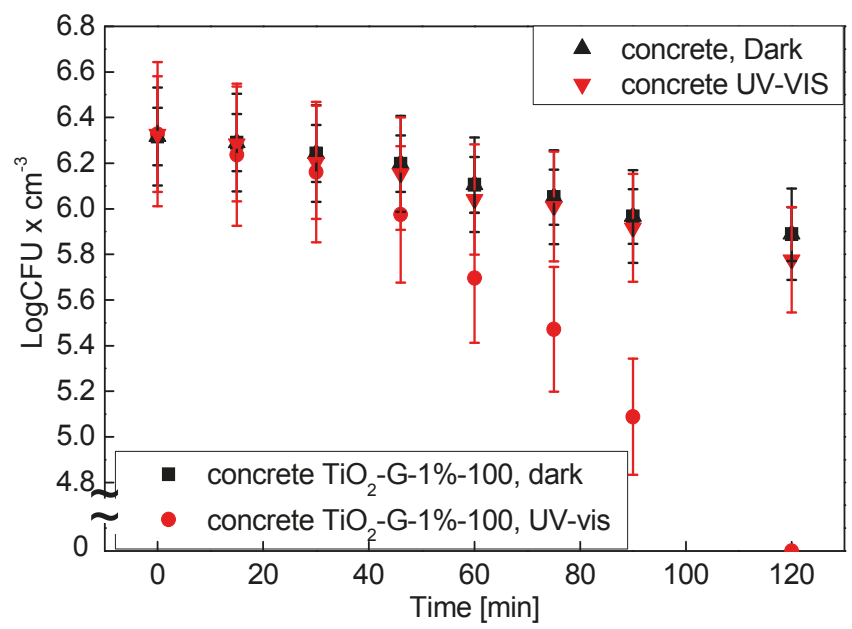

Figure 11. Antibacterial activity (against E. coli) of concrete supplemented with $10 \% \mathrm{TiO}_{2}-\mathrm{G}-1 \%-100$ and reference samples (concrete without $\mathrm{TiO}_{2}$ ) under UV-Vis irradiation and in dark condition.

\section{Discussion}

Antibacterial properties of titania have received a great attention by many researchers [2,14,18,32-34], and thus studies on $\mathrm{TiO}_{2}$ disinfection under solar radiation are mainstream research and development [33]. Therefore, in this study it has been hypothesized that surface modification of titania by D-glucose could result in development of antimicrobial agent towards both gram-negative (Escherichia coli) and gram-positive (Staphylococcus epidermidis) bacteria under solar radiation. Physicochemical characteristics of D-glucose-modified titania at $100^{\circ} \mathrm{C}$ showed that this group of samples has various advantageous, such as large SSA (214-268 $\left.\mathrm{m}^{2} \times \mathrm{g}^{-1}\right)$, large content of anatase (97.6-97.8\%), and small size of anatase crystallites $(11.2-11.7 \mathrm{~nm})$. The photocatalytic activity of the D-glucose-modified $\mathrm{TiO}_{2}$ was examined for the generation of $\bullet \mathrm{OH}$ radicals under UV-Vis light irradiation. The most reactive photocatalyst, inducing the fastest $E$. coli and S. epidermidis inactivation, was obtained by titania modification with $1 \%$ of D-glucose solution at $100{ }^{\circ} \mathrm{C}\left(\mathrm{TiO}_{2}-1 \%-100\right)$. The enhancement of photocatalytic activity (in the visible range of solar spectrum $(\lambda>400 \mathrm{~nm})$ ) has been reported for $\mathrm{TiO}_{2}$ modified with glucose by Kim at al. [35]. According to these studies, glucose-adsorbed $\mathrm{TiO}_{2}$ can form the charge transfer complex by ligand-to-metal charge transfer (LMCT) sensitization mechanism. Moreover, enhanced photocatalytic activity under UV irradiation could be achieved by the hindering of electron-hole recombination, since photogenerated holes could be trapped by hydroxyl groups [36]. Indeed, the enrichment of titania surface with hydroxyl groups was observed after its modification with D-glucose $\left(\mathrm{TiO}_{2}-1 \%-100\right)$, as shown in Table 2 .

In the literature, there are many reports concerning the optimization procedures for photocatalyst and bacterial doses used for water disinfection. The results that were obtained by various teams differ significantly. For example, Herrmann [37] found that $2.5 \mathrm{~g} \mathrm{TiO}_{2} \times \mathrm{dm}^{-3}$ was the best value corresponding to the maximal photon absorption (all of the particles could be illuminated). However, Cho et al. [38] determined that the bactericidal activity of P25 at concentration of $1.0 \mathrm{~g} \times \mathrm{dm}^{-3}$ was two times more effective than that at $0.1 \mathrm{~g} \times \mathrm{dm}^{-3}$, whereby increasing the $\mathrm{TiO}_{2}$ concentration from 1.0 to $2.0 \mathrm{~g} \times \mathrm{dm}^{-3}$ did not enhance the inactivation efficiency. Therefore, it is proposed that for disinfection process less content of titania is required than that for decomposition of organic compounds. The presented results in this report have confirmed this hypothesis, but much less content of titania $\left(0.1 \mathrm{~g} \times \mathrm{dm}^{-3}\right)$ than that by Cho et al. [38] appeared to be an optimal value. 
The most effective concentration of bacteria (E. coli and S. epidermidis) was in the range from $1.5 \times$ $10^{4} \mathrm{CFU} \times \mathrm{cm}^{-3}$ to $1.5 \times 10^{5} \mathrm{CFU} \times \mathrm{cm}^{-3}$, confirming the previous findings by Benabbou et al. [39]. Necessary time for complete inactivation of microorganisms was longer in the case of more concentrated bacterial suspension due to the shielding effect by bacteria cells. It was found that conditions of disinfection, such as photocatalyst content and bacterial concentration, have had a critical influence on the obtained results, and the optimal conditions must be experimentally determined.

Unfortunately, there are no reports on the antibacterial properties of glucose-modified titania prepared at temperatures lower than $300{ }^{\circ} \mathrm{C}$, and thus the direct comparison of our results with others was impossible. The best antibacterial activity was obtained for the sample that was modified with $1 \%$ of D-glucose at $100{ }^{\circ} \mathrm{C}\left(\mathrm{TiO}_{2}-1 \%-100\right)$. Under UV-Vis irradiation, the complete disinfection of E. coli and S. epidermidis was achieved after 70 and $75 \mathrm{~min}$, respectively, whereas carbon-modified commercial photocatalyst KRONOClean 7000 was less efficient, needing $85 \mathrm{~min}$ and $90 \mathrm{~min}$, respectively, of UV-Vis irradiation. Therefore, it is proposed that the form of carbon is crucial for antimicrobial properties, i.e., hydroxyl groups in glucose structure responsible for holes' trapping.

Antioxidant enzymes, secreted by bacteria, are considered to be important indicators for the oxidative stress. Catalase (CAT) and superoxide dismutase (SOD) are two commonly investigated intracellular enzymes $[35,40]$. CAT is an antioxidant enzyme catalyzing the decomposition of $\mathrm{H}_{2} \mathrm{O}_{2}$ to water and oxygen, whereas SOD is a metalloenzyme catalyzing the dismutation of $\bullet \mathrm{O}_{2}$ into $\mathrm{H}_{2} \mathrm{O}_{2}$ and $\mathrm{O}_{2}$. Accordingly, the loss of their activity accelerated the accumulation of reactive oxygen species (ROSs) and led to the deficiency of cell viability. On the basis of the obtained results, the two-step mechanism of response to the presence of photocatalyst, activated under UV-Vis irradiation, was described. It was found that the induced levels of these enzymes increased during the first $30 \mathrm{~min}$, and then decreased (after $60 \mathrm{~min}$ ). The changes in enzyme activity during the photocatalytic disinfection process indicated that defense capacity was overwhelmed by the rapidly created ROSs at the initial stage, and then suppressed gradually. The correlation between high amount of generated hydroxyl radicals (Figure 3) during $90 \mathrm{~min}$ of UV-Vis irradiation and the loss of enzymatic activity suggested that oxidative stress could act as an important pathway by which photocatalyst induced bacterial death. Interestingly, no significant differences in the oxidative stress response between two examined bacteria species was found. The protein nature of enzymes determines their quick and explicit reaction on various environmental factors whether naturally or artificially introduced, such as photocatalyst. Despite short lifetime of ROSs, generated on the surface of photoexcited photocatalyst, they may probably cause conformational changes (in secondary structure), damage of the active sites or irreversible loss of the activity.

It was found that carbon content was the main factor influencing antibacterial efficiency of D-glucose modified photocatalysts, and larger than $1 \%$ content of D-glucose was detrimental for activity. Similarly, it was reported that too high carbon content on the photocatalyst surface could block the active sites decreasing photocatalytic decomposition of organic compounds, such as phenol [41] and methylene blue [42]. The results of mineralization of the bacterial cells clearly indicated that the amount of $\mathrm{CO}_{2}$, liberated from $\mathrm{TiO}_{2}-1 \%-100$ suspension under UV-Vis irradiation, was 1.5 times higher than that from suspension containing commercial photocatalyst KRONOClean 7000 or starting $\mathrm{TiO}_{2}$. Although an increase of $\mathrm{CO}_{2}$ concentration proved the mineralization of bacteria cells, this did not guarantee water "microbial purity", as reported by Kacem at al. [43]. Photoexcited $\mathrm{TiO}_{2}$ could cause only the partial mineralization of bacterial cells that could lead to bacteria transition to viable, but nonculturable (VBNC) state. This apparent dormant state, in which bacterial cells are metabolically active, maintains their pathogenic features, but bacteria cannot grow on culture media. Therefore, it is necessary to introduce genetic methods, based on the quantification of DNA (e.g., polymerase chain reaction $\mathrm{PCR}$ ), which may justify the complete destruction of bacterial DNA.

The interaction between bacteria and photocatalyst was observed by SEM observations. It was found that modified samples with $1 \%$ of D-glucose showed stronger adhesion to the bacterial cells. The carbon content of $0.59\left(\mathrm{TiO}_{2}-\mathrm{G}-1 \%-100\right)$ and enrichment of the titania surface with hydroxyl groups, 
resulted in a significant modification of surface properties, as clearly shown by zeta potential changes, and thus increased bacterial adhesion to the photocatalyst surface. It is very important finding since, according to the literature reports, the titania NPs with particle sizes larger than $8 \mathrm{~nm}$ cannot penetrate bacteria through the cell-wall porins of ca. 1.2-nm diameters [44]. Accordingly, the electrostatic interaction between photocatalyst and bacteria has a crucial significance for antibacterial activity and should be extensively investigated in future. It is well-known that gram-negative bacteria contain both anionic and zwitterionic phospholipids, whereas gram-positive bacteria contain predominantly anionic lipids. When considering the observation that was made by Clogston and Patri [45], that NPs with a zeta potential between -10 and $+10 \mathrm{mV}$ were considered as neutral, whereas NPs with zeta potentials that were lower than $-30 \mathrm{mV}$ were strongly anionic, and thus cationic particles would attract negatively charged bacteria (e.g., E. coli $\zeta \sim 35 \mathrm{mV}$ ). The obtained results confirmed these findings since the best antibacterial properties were found for $\mathrm{TiO}_{2}-\mathrm{G}-1 \%-100$ photocatalyst with the least negative zeta potential of $-13.49 \mathrm{mV}$. Deterioration of antibacterial properties was observed for photocatalyst characterized by more negative $\zeta(<-20 \mathrm{mV})$, due to worse contact between bacterial cells and photocatalyst NPs. It is important to notice that bacteria cells are much larger than NPs of photocatalysts (approx. 180 times bigger), and thus stronger adsorption of photocatalyst on bacteria is advisable for better interaction. An attractive feature of this mechanism is that it can be used to design antimicrobial agents with selective toxicity against certain organisms.

The present work fulfilled previous studies on disinfection process. First time, the application of D-glucose-modified photocatalyst in a cement mortar for water disinfection was presented. The complete disinfection was achieved during 120-min contact of contaminated water with a small concrete plate, made of cement mortar and supplemented with $10 \mathrm{wt} \%$ of $\mathrm{TiO}_{2}-\mathrm{G}-1 \%-100$ photocatalyst. According to the obtained results, it would be possible to use solar energy to activate the D-glucose-modified photocatalyst, and thus disinfect water in a concrete container used for storage of drinking water or fish farms (e.g., trout ponds). Last mentioned application should improve health conditions in fish farms since the microbial purity of water is the most important factor affecting performance in aquaculture production systems.

\section{Materials and Methods}

\subsection{Preparation of $\mathrm{C} / \mathrm{TiO}_{2}$}

The intermediate product, taken directly from the production line of titanium(IV) oxide, from the Grupa Azoty Zakłady Chemiczne "Police" S.A., Police, Poland), was used as the starting material in the process of photocatalysts preparation. Titanium dioxide was treated with D-glucose (Chempur, Piekary Ślaskie, Poland) solutions of various concentrations $(1 \%, 5 \%, 10 \%)$ at various annealing temperature $\left(100{ }^{\circ} \mathrm{C}, 150^{\circ} \mathrm{C}\right.$, and $\left.200{ }^{\circ} \mathrm{C}\right)$ in a pressure autoclave BHL-800 (Berghof, Eningen, Germany).

\subsection{Characterisation of Photocatalyst}

The characteristic of commercial and obtained photocatalyst was studied by measurement of specific surface area (SSA) by the $\mathrm{N}_{2}$ adsorption-desorption method on a Quadrasorb SI analyzer (Quantachrome Instruments, Boynton Beach, FL, USA). The crystalline phase and crystal structures of prepared samples were identified by X-Ray Diffraction analysis (PANalytical Empyrean X-ray diffractometer, Malvern Panalytical Ltd., Melvern, UK) using Cu K $\alpha$ radiation $(\lambda=1.54056 \AA)$. Total carbon amount in the samples was calculated using CN628 elemental analyzer (LECO Corporation, St Joseph, MI, USA). Chemical composition of the surface (chemical state and content of titanium, oxygen, and carbon) was estimated by XPS JEOL JPC-9010MC with MgK $\alpha$ X-ray (JEOL, Tokyo, Japan). The zeta potential was determined by using ZetaSizerNanoSeries ZS (Malvern Instruments, Melvern, UK). 


\subsection{Antimicrobial Properties of Dispersed $\mathrm{C} / \mathrm{TiO}_{2}$}

D-glucose-modified titania, starting $\mathrm{TiO}_{2}$ (Grupa Azoty Zakłady Chemiczne "Police" S.A., Police, Poland), commercial photocatalyst KRONOClean 7000 (International Inc., Leverkusen, Germany) were dispersed in $10 \mathrm{~cm}^{-3}$ Escherichia coli (E. coli) K12 ATCC29425 or Staphylococcus epidermidis (S. epidermidis) ACCT 49461 suspension in a sterile sodium chloride aqueous solution $\left(8.5 \mathrm{~g} \mathrm{dm}^{-3}\right)$ in a glass test tube, and irradiated with lamp emitting artificial solar light (250 W OSRAM) under continuous stirring (using a magnetic stirrer at speed of $250 \mathrm{rpm}$ ) at $37^{\circ} \mathrm{C}$. The distance between the solution and the light source was fixed at ca. $15 \mathrm{~cm}$. The radiant flux was monitored with a Radiation Intensity Meter LB901/WCM3 \& PD204AB cos. sensor meter. The photocatalyst and bacterial cell concentration was adjusted, according to the results described in Section 2.2. The control experiments in darkness and for $\mathrm{NaCl}$ solution were also performed. Serial dilutions $\left(10^{-1}\right.$ to $\left.10^{-6}\right)$ were prepared in saline solution $(0.9 \%)$. The samples were placed on Plate Count Agar (PCA, BTL Polska Sp. z.o.o, Warszawa, Poland). The plates were incubated for $24 \mathrm{~h}$ at $37^{\circ} \mathrm{C}$ and then colony forming unit $\left(\mathrm{CFU} \times \mathrm{cm}^{-3}\right)$ was counted. Statistical analysis of obtained results was conducted using Excel spreadsheet. The comparisons among the means and the statistical significance of differences were evaluated by Tukey's test. Microscopic bacteria specimen were prepared according to general protocol and dehydrated by graded series of ethanol (30,50, 70, 90, 95, and 99.5\% $(v / v))$. Samples were sputtered with gold for $60 \mathrm{~s}$ from three-directions and observed by SEM (SU8020 UHR FE-SEM, Hitachi, Tokyo, Japan). The bacteria mineralization rate was calculated as amounts of liberated $\mathrm{CO}_{2}$ (gas chromatography; GC 8610C; SRI Instrument Inc., Torrance, CA, USA) after $180 \mathrm{~min}$ irradiation or under dark condition. The catalase (CAT) and superoxide dismutase (SOD) in bacterial suspension were determined before photocatalytic process $\left(\mathrm{N}_{0}\right)$ and after $30\left(\mathrm{~N}_{30}\right)$ and $60\left(\mathrm{~N}_{60}\right)$ min of irradiation and in dark conditions. Catalase activity was determined spectrophotometrically at $25^{\circ} \mathrm{C}(1-\mathrm{cm}$ cuvette, spectrophotometer F-2500, Hitachi, Tokyo, Japan) by monitoring the change in absorbance $\mathrm{A}(\lambda=374 \mathrm{~nm})$, according protocols that are given in [46] and own modification. One unit (U) of activity was defined as the amount of enzyme that catalyses the oxidation of $1 \mathrm{mmol} \mathrm{H}_{2} \mathrm{O}_{2}$ in 1 min under the assay conditions. Superoxidase dismutase activity was determined spectrophotometrically at $25{ }^{\circ} \mathrm{C}(1$-cm cuvette, spectrophotometer F-2500, Hitachi, Tokyo, Japan) by monitoring the change in absorbance A $(\lambda=420 \mathrm{~nm})$, according to [47] and own modification. One unit of SOD activity inhibits the rate of pyrogallol oxidation at $25^{\circ} \mathrm{C}$ by $50 \%$ in $1 \mathrm{~min}$.

\subsection{Antimicrobial Properties of Employed in Concrete $\mathrm{TiO}_{2}-\mathrm{G}-1 \%-100$}

The bactericidal properties of cement mortars supplemented with modified titania $\left(\mathrm{TiO}_{2}-\mathrm{G}-1 \%-100\right)$ were examined in an own-designed photoreactor according patented procedure [48]. Cement mortar Fix M-15 Kreisel (Kreisel Technika Budowlana Sp. z.o.o., Poznań, Poland) was used to prepare reference concrete plates. The same material was used to prepare concrete plated with $10 \%$ weight of $\mathrm{TiO}_{2}-\mathrm{G}-1 \%-100$. The antimicrobial activity was evaluated against Escherichia coli K12 (ATCC 25922) under artificial solar light (UV-Vis) and in dark condition. The bacterial concentration was calculated as CFU per milliliter according the procedure described in Section 4.3.

\section{Conclusions}

Titania modification with cheap carbon source, i.e., D-glucose, resulted in the appearance of high antimicrobial activity against both gram-positive and gram-negative bacteria. It is thought that strong interaction between bacterial cells and photocatalyst surface are responsible for inactivation and complete decomposition of bacteria cells. It is proposed that D-glucose-modified titania photocatalyst is highly prospective material, and may be commercially used for cheap and effective water disinfection and wastewater treatment since its immobilization on a concrete results in the efficient removal of bacteria under solar radiation. 
Author Contributions: A.M.-S. conceived and designed the experiments, and wrote the paper; P.R. performed the experiments; M.E. analyzed the data; K.W. performed XPS analysis and edited figures; A.W.M. corrected the manuscript; and E.K. analyzed the data and wrote the paper. All authors read and approved the final manuscript.

Acknowledgments: A.M.-S. acknowledges Institute for Catalysis, Hokkaido University for research stay in a framework of Fusion Emergent Research project by the MEXT program of Integrated Research Consortium on Chemical Sciences (IRCCS)

Conflicts of Interest: The author declares no conflict of interest.

\section{References}

1. Rengifo-Herrera, J.A.; Mielczarski, E.; Mielczarski, J.; Castillo, N.C.; Kiwi, J.; Pulgarin, C. Escherichia coli inactivation by $\mathrm{N}, \mathrm{S}$ co-doped commercial $\mathrm{TiO}_{2}$ powders under $\mathrm{UV}$ and visible light. Appl. Catal. B Environ. 2008, 84, 448-456. [CrossRef]

2. Kowalska, E.; Mahaney, O.O.P.; Abe, R.; Ohtani, B. Visible-light-induced photocatalysis through surface plasmon excitation of gold on titania surfaces. Phys. Chem. Chem. Phys. 2010, 12, 2344. [CrossRef] [PubMed]

3. Liu, G.; Han, C.; Pelaez, M.; Zhu, D.; Liao, S.; Likodimos, V.; Ioannidis, N.; Kontos, A.G.; Falaras, P.; Dunlop, P.S.M.; et al. Synthesis, characterization and photocatalytic evaluation of visible light activated c-doped $\mathrm{TiO}_{2}$ nanoparticles. Nanotechnology 2012, 23, 294003. [CrossRef] [PubMed]

4. Asahi, R.; Morikawa, T.; Irie, H.; Ohwaki, T. Nitrogen-doped titanium dioxide as visible-light-sensitive photocatalyst: Designs, developments, and prospects. Chem. Rev. 2014, 114, 9824-9852. [CrossRef] [PubMed]

5. Asahi, R.; Morikawa, T.; Ohwaki, T.; Aoki, K.; Taga, Y. Visible-light photocatalysis in nitrogen-doped titanium oxides. Science 2001, 293, 269-271. [CrossRef] [PubMed]

6. Palanivelu, K.; Im, J.-S.; Lee, Y.-S. Carbon doping of $\mathrm{TiO}_{2}$ for visible light photo catalysis-A review. Carbon Lett. 2007, 8, 214-224. [CrossRef]

7. Wu, G.; Nishikawa, T.; Ohtani, B.; Chen, A. Synthesis and characterization of carbon-doped $\mathrm{TiO}_{2}$ nanostructures with enhanced visible light response. Chem. Mater. 2007, 19, 4530-4537. [CrossRef]

8. Wu, Z.; Dong, F.; Zhao, W.; Wang, H.; Liu, Y.; Guan, B. The fabrication and characterization of novel carbon doped $\mathrm{TiO}_{2}$ nanotubes, nanowires and nanorods with high visible light photocatalytic activity. Nanotechnology 2009, 20, 235701. [CrossRef] [PubMed]

9. Zhong, J.; Chen, F.; Zhang, J. Carbon-deposited $\mathrm{TiO}_{2}$ : Synthesis, characterization, and visible photocatalytic performance. J. Phys. Chem. C 2010, 114, 933-939. [CrossRef]

10. Xie, C.; Yang, S.; Shi, J.; Niu, C. Highly crystallized C-doped mesoporous anatase $\mathrm{TiO}_{2}$ with visible light photocatalytic activity. Catalysts 2016, 6, 117. [CrossRef]

11. Morawski, A.W.; Janus, M.; Tryba, B.; Inagaki, M.; Kałucki, K. TiO ${ }_{2}$-anatase modified by carbon as the photocatalyst under visible light. Rendus Rendu Chim. 2006, 9, 800-805. [CrossRef]

12. Sakthivel, S.; Kisch, H. Daylight photocatalysis by carbon-modified titanium dioxide. Angew. Chem. Int. Ed. 2003, 42, 4908-4911. [CrossRef] [PubMed]

13. Janus, M.; Markowska-Szczupak, A.; Kusiak-Nejman, E.; Morawski, A.W. Disinfection of E. coli by carbon modified $\mathrm{TiO}_{2}$ photocatalysts. Environ. Prot. Eng. 2012, 38, 90-97. [CrossRef]

14. Wanag, A.; Rokicka, P.; Kusiak-Nejman, E.; Markowska-Szczupak, A.; Morawski, A.W. TiO 2 /glucose nanomaterials with enhanced antibacterial properties. Mater. Lett. 2016, 185, 264-267. [CrossRef]

15. Wanag, A.; Rokicka, P.; Kusiak-Nejman, E.; Kapica-Kozar, J.; Wrobel, R.J.; Markowska-Szczupak, A.; Morawski, A.W. Antibacterial properties of $\mathrm{TiO}_{2}$ modified with reduced graphene oxide. Ecotoxicol. Environ. Saf. 2018, 147, 788-793. [CrossRef] [PubMed]

16. Li, Y.; Ma, M.; Wang, X.; Wang, X. Inactivated properties of activated carbon-supported $\mathrm{TiO}_{2}$ nanoparticles for bacteria and kinetic study. J. Environ. Sci. 2008, 20, 1527-1533. [CrossRef]

17. McEvoy, J.G.; Cui, W.; Zhang, Z. Degradative and disinfective properties of carbon-doped anatase-rutile $\mathrm{TiO}_{2}$ mixtures under visible light irradiation. Catal. Today 2013, 207, 191-199. [CrossRef]

18. Sun, D.-S.; Kau, J.-H.; Huang, H.-H.; Tseng, Y.-H.; Wu, W.-S.; Chang, H.-H. Antibacterial properties of visible-light-responsive carbon-containing titanium dioxide photocatalytic nanoparticles against anthrax. Nanomaterials 2016, 6, 237. [CrossRef] [PubMed] 
19. Grzybowska, B.; Słoczyński, J.; Grabowski, R.; Samson, K.; Gressel, I.; Wcisło, K.; Gengembre, L.; Barbaux, Y. Effect of doping of $\mathrm{TiO}_{2}$ support with altervalent ions on physicochemical and catalytic properties in oxidative dehydrogenation of propane of vanadia-titania catalysts. Appl. Catal. A Gen. 2002, 230, 1-10. [CrossRef]

20. örsi, F. Kinetic studies on the thermal decomposition of glucose and fructose. J. Therm. Anal. 1973, 5, 329-335. [CrossRef]

21. Slimestad, R.; Vågen, I.M. Thermal stability of glucose and other sugar aldoses in normal phase high performance liquid chromatography. J. Chromatogr. Coruña 2006, 1118, 281-284. [CrossRef] [PubMed]

22. Siuzdak, K.; Sawczak, M.; Klein, M.; Nowaczyk, G.; Jurga, S.; Cenian, A. Preparation of platinum modified titanium dioxide nanoparticles with the use of laser ablation in water. Phys. Chem. Chem. Phys. 2014, 16, 15199-15206. [CrossRef] [PubMed]

23. Zielińska-Jurek, A.; Kowalska, E.; Sobczak, J.W.; Lisowski, W.; Ohtani, B.; Zaleska, A. Preparation and characterization of monometallic (au) and bimetallic (ag/au) modified-titania photocatalysts activated by visible light. Appl. Catal. B Environ. 2011, 101, 504-514. [CrossRef]

24. Wei, Z.; Janczarek, M.; Endo, M.; Balčytis, A.; Nitta, A.; Mendez Medrano, M.G.; Colbeau-Justin, C.; Juodkazis, S.; Ohtani, B.; Kowalska, E. Noble metal-modified faceted anatase titania photocatalysts: Octahedron versus decahedron. Appl. Catal. B Environ. 2018, 237, 574-587. [CrossRef]

25. Baltrusaitis, J.; Schuttlefield, J.; Zeitler, E.; Grassian, V.H. Carbon dioxide adsorption on oxide nanoparticle surfaces. Chem. Eng. J. 2011, 170, 471-481. [CrossRef]

26. Fleisch, T.H.; Mains, G.J. Reduction of copper oxides by uv radiation and atomic hydrogen studied by xps. Appl. Surf. Sci. 1982, 10, 51-62. [CrossRef]

27. Akhavan, O.; Ghaderi, E. Self-accumulated ag nanoparticles on mesoporous $\mathrm{TiO}_{2}$ thin film with high bactericidal activities. Surf. Coat. Technol. 2010, 204, 3676-3683. [CrossRef]

28. Kruse, N.; Chenakin, $\mathrm{S}$. Xps characterization of $\mathrm{Au} / \mathrm{TiO}_{2}$ catalysts: Binding energy assessment and irradiation effects. Appl. Catal. A Gen. 2011, 391, 367-376. [CrossRef]

29. Rossnagel, S.M.; Sites, J.R. X-ray photoelectron spectroscopy of ion beam sputter deposited $\mathrm{SiO}_{2}, \mathrm{TiO}_{2}$, and $\mathrm{Ta}_{2} \mathrm{O}_{5}$. J. Vac. Sci. Technol. A Vac. Surf. Films 1984, 2, 376-379. [CrossRef]

30. Jensen, H.; Soloviev, A.; Li, Z.; Søgaard, E.G. Xps and ftir investigation of the surface properties of different prepared titania nano-powders. Appl. Surf. Sci. 2005, 246, 239-249. [CrossRef]

31. Yu, J.; Zhao, X.; Zhao, Q. Effect of surface structure on photocatalytic activity of $\mathrm{TiO}_{2}$ thin films prepared by sol-gel method. Thin Solid Films 2000, 379, 7-14. [CrossRef]

32. Lonnen, J.; Kilvington, S.; Kehoe, S.C.; Al-Touati, F.; McGuigan, K.G. Solar and photocatalytic disinfection of protozoan, fungal and bacterial microbes in drinking water. Water Res. 2005, 39, 877-883. [CrossRef] [PubMed]

33. Wang, L.; Hu, C.; Shao, L. The antimicrobial activity of nanoparticles: Present situation and prospects for the future. Int. J. Nanomed. 2017, 12, 1227-1249. [CrossRef] [PubMed]

34. Maletić, M.; Vukčević, M.; Kalijadis, A.; Janković-Častvan, I.; Dapčević, A.; Laušević, Z.; Laušević, M. Hydrothermal synthesis of $\mathrm{TiO}_{2}$ /carbon composites and their application for removal of organic pollutants. Arab. J. Chem. 2016. [CrossRef]

35. Kim, G.; Lee, S.-H.; Choi, W. Glucose- $\mathrm{TiO}_{2}$ charge transfer complex-mediated photocatalysis under visible light. Appl. Catal. B Environ. 2015, 162, 463-469. [CrossRef]

36. Dong, F.; Wang, H.; Wu, Z. One-step "green" synthetic approach for mesoporous c-doped titanium dioxide with efficient visible light photocatalytic activity. J. Phys. Chem. C 2009, 113, 16717-16723. [CrossRef]

37. Herrmann, J. Heterogeneous photocatalysis: Fundamentals and applications to the removal of various types of aqueous pollutants. Catal. Today 1999, 53, 115-129. [CrossRef]

38. Cho, M.; Chung, H.; Choi, W.; Yoon, J. Linear correlation between inactivation of E. coli and OH radical concentration in $\mathrm{TiO}_{2}$ photocatalytic disinfection. Water Res. 2004, 38, 1069-1077. [CrossRef] [PubMed]

39. Benabbou, A.K.; Derriche, Z.; Felix, C.; Lejeune, P.; Guillard, C. Photocatalytic inactivation of escherischia coli. Appl. Catal. B Environ. 2007, 76, 257-263. [CrossRef]

40. Kumar, A.; Pandey, A.K.; Singh, S.S.; Shanker, R.; Dhawan, A. Engineered ZnO and TiO2 nanoparticles induce oxidative stress and dna damage leading to reduced viability of escherichia coli. Free. Radic. Biol. Med. 2011, 51, 1872-1881. [CrossRef] [PubMed] 
41. Wanag, A.; Morawski, A.W.; Kapica-Kozar, J.; Kusiak-Nejman, E. Photocatalytic performance of thermally prepared $\mathrm{TiO}_{2} / \mathrm{C}$ photocatalysts under artificial solar light. Micro Nano Lett. 2016, 11, 202-206. [CrossRef]

42. Cui, Y.; Li, H.; Hong, W.; Fan, S.; Zhu, L. The effect of carbon content on the structure and photocatalytic activity of nano-bi2wo6 powder. Powder Technol. 2013, 247, 151-160. [CrossRef]

43. Kacem, M.; Bru-Adan, V.; Goetz, V.; Steyer, J.P.; Plantard, G.; Sacco, D.; Wery, N. Inactivation of escherichia coli by TiO2-mediated photocatalysis evaluated by a culture method and viability-qpcr. J. Photochem. Photobiol. A Chem. 2016, 317, 81-87. [CrossRef]

44. Lin, X.; Li, J.; Ma, S.; Liu, G.; Yang, K.; Tong, M.; Lin, D. Toxicity of TiO2 nanoparticles to escherichia coli: Effects of particle size, crystal phase and water chemistry. PLoS ONE 2014, 9, e110247. [CrossRef] [PubMed]

45. Clogston, J.D.; Patri, A.K. Zeta potential measurement. Methods Mol. Biol. 2011, 697, 63-70. [CrossRef] [PubMed]

46. Hadwan, M.H.; Abed, H.N. Data supporting the spectrophotometric method for the estimation of catalase activity. Data Brief 2016, 6, 194-199. [CrossRef] [PubMed]

47. Marklund, S.; Marklund, G. Involvement of the superoxide anion radical in the autoxidation of pyrogallol and a convenient assay for superoxide dismutase. Eur. J. Biochem. 1974, 47, 469-474. [CrossRef] [PubMed]

48. Markowska-Szczupak, A.; Rokicka, P.; Janus, M.; Kusiak Najman, E.; Morawski, A.W. Method for Testing Antibacterial Properties of Materials Made from Cements Containing Titanium Dioxide. Patent Number 416,872, 19 April 2016.

(C) 2018 by the authors. Licensee MDPI, Basel, Switzerland. This article is an open access article distributed under the terms and conditions of the Creative Commons Attribution (CC BY) license (http:/ / creativecommons.org/licenses/by/4.0/). 


\title{
Article \\ Synergistic Effect of $\mathrm{Cu}_{2} \mathrm{O}$ and Urea as Modifiers of $\mathrm{TiO}_{2}$ for Enhanced Visible Light Activity
}

\author{
Marcin Janczarek ${ }^{1,2, *}$, Kunlei Wang ${ }^{1}$ and Ewa Kowalska ${ }^{1}$ \\ 1 Institute for Catalysis, Hokkaido University, N21, W10, Sapporo 001-0021, Japan; \\ kunlei@cat.hokudai.ac.jp (K.W.); kowalska@cat.hokudai.ac.jp (E.K.) \\ 2 Department of Chemical Technology, Gdansk University of Technology, Narutowicza Str. 11/12, \\ 80-233 Gdansk, Poland \\ * Correspondence: mjancz@pg.edu.pl; Tel.: +48-58-3472352
}

Received: 14 March 2018; Accepted: 1 June 2018; Published: 6 June 2018

\begin{abstract}
Low cost compounds, i.e., $\mathrm{Cu}_{2} \mathrm{O}$ and urea, were used as $\mathrm{TiO}_{2}$ modifiers to introduce visible light activity. Simple and cheap methods were applied to synthesize an efficient and stable nanocomposite photocatalytic material. First, the core-shell structure $\mathrm{TiO}_{2}$-polytriazine derivatives were prepared. Thereafter, $\mathrm{Cu}_{2} \mathrm{O}$ was added as the second semiconductor to form a dual heterojunction system. Enhanced visible light activity was found for the above-mentioned nanocomposite, confirming a synergistic effect of $\mathrm{Cu}_{2} \mathrm{O}$ and urea (via polytriazine derivatives on titania surface). Two possible mechanisms of visible light activity of the considered material were proposed regarding the type II heterojunction and Z-scheme through the essential improvement of the charge separation effect.
\end{abstract}

Keywords: photocatalysis; nanocomposites; heterojunction; $\mathrm{Cu}_{2} \mathrm{O}$; urea; polytriazine; Z-scheme

\section{Introduction}

Titanium dioxide $\left(\mathrm{TiO}_{2}\right.$, titania) is widely recognized as an efficient, stable, and green photocatalytic material (long term stability, chemical inertness and corrosion resistance). Therefore, its application potential in photocatalysis is still growing and presently focuses on emergency areas, such as environmental remediation (water treatment and air purification), renewable energy processes (i.e., photocurrent generation, water splitting for hydrogen production, conversion of $\mathrm{CO}_{2}$ to hydrocarbons) and self-cleaning surfaces [1-5]. However, the application of titania is still limited to regions with a high intensity of solar radiation due to its wide bandgap (ca. 3.0 to $3.2 \mathrm{eV}$ ). The following strategies of titania doping, modification, semiconductor coupling, and dye sensitization can be applied to incorporate visible light absorption to $\mathrm{TiO}_{2}$ [6-8]. The nature of electron transfer between $\mathrm{TiO}_{2}$ and other materials has been intensively studied and recognized as the origin of the high performances of $\mathrm{TiO}_{2}$-based composites [9]. The photocatalytic activity of $\mathrm{TiO}_{2}$ systems depend on the following properties, such as particle size, surface area, crystal phase, morphology, uncoordinated surface sites, defects in the lattice, and degree of crystallinity. Design of $\mathrm{TiO}_{2}$ composite structures based on the heterojunction between titania and other semiconducting materials can improve many of these properties. Moreover, this strategy can create and tune other properties, such as mid-band-gap electronic states, which can be responsible for the intensification of charge separation or incorporation of a red shift to the absorption spectrum $[7,9]$.

Copper oxides $\left(\mathrm{Cu}_{2} \mathrm{O}, \mathrm{CuO}\right)$ have been intensively studied as titania modifiers due to their intrinsic p-type configuration. $\mathrm{Cu}_{2} \mathrm{O}$ and $\mathrm{CuO}$ are inexpensive semiconductors with band gap energies of 2.1-2.2 eV and 1.2-1.7 eV, respectively. This fact makes both materials promising for research directed to solar energy utilization [10-12]. If the electronic properties of both oxides are compared, $\mathrm{CuO}$ has a significantly smaller band gap than $\mathrm{Cu}_{2} \mathrm{O}$, and thus can absorb more photons, 
but the positions of $\mathrm{CB}$ and $\mathrm{VB}$ for $\mathrm{CuO}$ are insufficient to catalyze the generation of hydroxyl and superoxide radicals, which are the primary initiators for the photocatalytic oxidation of organic compounds $[13,14]$. Therefore, the photocatalytic oxidation of organic compounds over $\mathrm{Cu}_{2} \mathrm{O} / \mathrm{TiO}_{2}$ composites has been of particular interest, especially to introduce visible light activity to $\mathrm{TiO}_{2}$-based systems [15-19]. For example, $\mathrm{Liu}$ et al. prepared $\mathrm{Cu}_{2} \mathrm{O} / \mathrm{TiO}_{2}$ composites where titania was in the form of nanosheets with exposed $\{001\}$ facets. They reported visible light photocatalytic activity for $\mathrm{Cu}_{2} \mathrm{O} / \mathrm{TiO}_{2}$ nanosheets three times higher than that for nitrogen-doped titania nanosheets. Owing to the type II heterojunction between $\mathrm{Cu}_{2} \mathrm{O}$ and $\mathrm{TiO}_{2}$, an efficient charge separation is observed and visible light induced electron transfer from $\mathrm{Cu}_{2} \mathrm{O}$ to $\mathrm{TiO}_{2}$ occurs, resulting in visible light photocatalytic performance of the system [17]. Furthermore, $\mathrm{Cu}_{2} \mathrm{O}$ possesses promising application potential because of its very good antipathogenic properties, even better than that of metallic copper [20-23].

Apart from p-type semiconducting metal oxides as composite junctions for titania, a promising option to prepare efficient and low cost visible light-active material based on $\mathrm{TiO}_{2}$ is the application of organic compounds like urea as a modifier. Urea-derived titania materials were initially recognized as nitrogen "doped" $\mathrm{TiO}_{2}$ photocatalysts [24-27]. Subsequently, the presence of nitridic and amidic species or nitrogen species with several oxidation states of nitrogen were suggested $[25,26]$. Finally, Mitoraj and Kisch proposed another explanation for the nature of urea-modification of titania including both nitrogen and carbon originating from urea as the elements building the chemical structure responsible for visible light-sensitization of $\mathrm{TiO}_{2}$ [28-30]. They reported that thermal processing of urea with titania at $400{ }^{\circ} \mathrm{C}$ produced poly(amino-tri-s-triazine) derivatives (shell) covalently attached to the semiconductor (core), i.e., a unique example of inorganic with an organic (polytriazine as a crystalline layer) semiconductor connected through the Ti-N-C bond. Titania acts as a catalyst in this urea transformation. Condensation between the triazine amino and titania hydroxy groups forms $\mathrm{Ti}-\mathrm{N}$ bonds. Considered chemical structures arise from condensed aromatic s-triazine compounds containing melem and melon (trimer of melem) units, which form a visible light absorbing semiconducting organic layer coupled with titania. Compared to unmodified $\mathrm{TiO}_{2}$, the prepared photocatalyst may exhibit a band-gap narrowing. It has been proposed that the absorption shoulder in the visible region corresponding to this material is a charge-transfer band enabling an optical transfer from polytriazine component to titania [29]. In contrast, it is known that prolonged heating of urea at $550{ }^{\circ} \mathrm{C}$ produces polycondensed s-triazines with a graphitic structure $\left(g-C_{3} \mathrm{~N}_{4}\right)$, which was recognized as a separate metal-free polymeric n-type semiconductor (band gap energy equal to $2.7 \mathrm{eV}$ ) with the possibility to create heterojunctions with other semiconductors, e.g., titania [31-34]. Therefore, thermal treatment of a $\mathrm{TiO}_{2}$ /urea composite at higher temperature results in the formation of a $\mathrm{TiO}_{2} / \mathrm{g}-\mathrm{C}_{3} \mathrm{~N}_{4}$ heterojunction, whereas at lower temperatures, novel electronic states responsible for visible light activity located near valence band of titania originating from the presence of poly(amino-s-triazine) shell are formed [6].

Herein, we demonstrate that titania with a polytriazine layer originated from urea, and modified with $\mathrm{Cu}_{2} \mathrm{O}\left(\mathrm{Cu}_{2} \mathrm{O} / \mathrm{PTr}-\mathrm{TiO}_{2}\right)$ becomes an efficient visible light photocatalyst, significantly more active than that of single modified titania, i.e., $\mathrm{PTr}-\mathrm{TiO}_{2}$ or $\mathrm{Cu}_{2} \mathrm{O} / \mathrm{TiO}_{2}$. The preparation method is economically and practically attractive by using low cost components such as urea and $\mathrm{Cu}_{2} \mathrm{O}$ and simple synthetic operations, i.e., lower temperatures of preparation in comparison with $g-C_{3} \mathrm{~N}_{4}$ synthesis $\left(400 \mathrm{v}\right.$. $\left.550{ }^{\circ} \mathrm{C}\right)$. The important issue is the probable proposition of the explanation of the synergistic behavior of two different modifiers with corresponding visible light activation mechanisms. There are only two studies describing combinations of $g-\mathrm{C}_{3} \mathrm{~N}_{4}$ with $\mathrm{Cu}_{2} \mathrm{O}$ [35] and additionally with $\mathrm{TiO}_{2}$ [36] showing improvements of visible light photocatalytic activity in comparison to single components (However, dyes have been used as test compounds, and thus origin of visible activity could not be unequivocally decided, i.e., dye sensitization could not be excluded [37,38]). Moreover, polycondensed $s$-triazines of graphitic structure were used, but not the non-graphitic forms obtained at lower temperature as proposed by Mitoraj and Kisch [29]. To the best of our knowledge, this report is the first study for this type of photocatalytic material. 


\section{Results and Discussion}

\subsection{Preparation Conditions and Visible Light Photocatalytic Efficiency}

Commercially available P25 titania was used as a base to prepare the final photocatalytic material $\left(\mathrm{Cu}_{2} \mathrm{O} / \mathrm{PTr}-\mathrm{TiO}_{2}\right)$. The first step of preparation was to obtain $\mathrm{PTr}-\mathrm{TiO}{ }_{2}$ with urea as a modifier (preparation details in Materials and Methods). "PTr" symbolizes the polytriazine shell. Different ratios between urea and P25 were investigated: 0.5:1, 1:1, 2:1 and 3:1 to find the material with the best photocatalytic efficiency under visible light irradiation. Samples with different shades of yellow color were obtained (more intensive yellow represents a higher amount of urea). 2-propanol oxidation to acetone was selected as the reaction system to test visible light photocatalytic activity $(\lambda>455 \mathrm{~nm})$. The sample prepared at 1:1 urea-P25 ratio possessed the highest photocatalytic activity (measured as the produced acetone amount) and was chosen for further research and marked as $\mathrm{PTr}-\mathrm{TiO}_{2}$ (see Figure 1). It was found that higher amounts of urea were not advantageous for the photocatalytic activity of the final product probably due to the detrimental influence of some not converted products of urea thermal transformation (excess of urea) on the semiconducting character of the polytriazine shell structure, as previously reported [29].

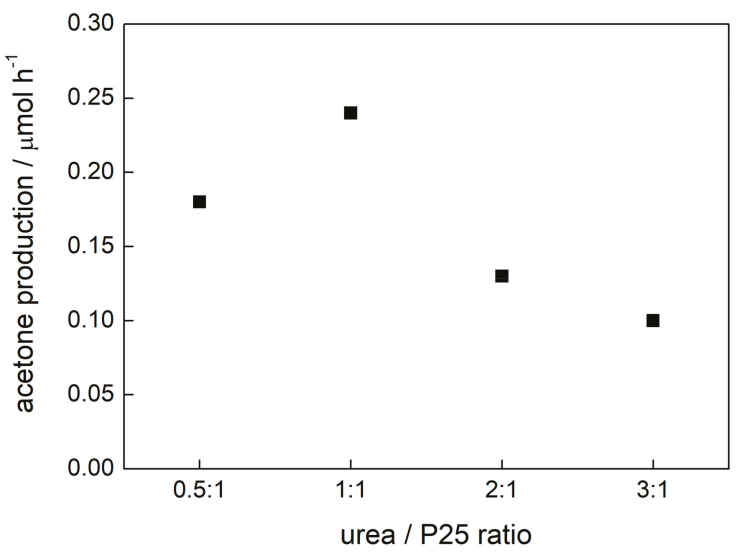

Figure 1. Visible light photocatalytic activity of the samples prepared with corresponding urea/P25 ratio.

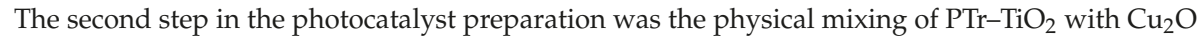
by using different contents of $\mathrm{Cu}_{2} \mathrm{O}$. Figure 2 shows the evidence of the advantageous role of the addition of cuprous oxide to the $\mathrm{PTr}-\mathrm{TiO}_{2}$ sample. The optimum $\mathrm{Cu}_{2} \mathrm{O}$ content was found to be in the range of ca. $5 \mathrm{wt} \%$, whereas $10 \mathrm{wt} \%$ and larger amounts were detrimental for photocatalytic efficiency. Detrimental influence of modifiers at their larger contents on photocatalytic activity is not surprising, and has already been reported for various systems. There are two main reasons for this behavior, i.e., (i) a shielding effect as $\mathrm{Cu}_{2} \mathrm{O}$ blocks $\mathrm{PTr}-\mathrm{TiO}_{2}$ for photon absorption; and (ii) competitive adsorption as the oxygen and/or organic compounds (here 2-propanol) could not adsorbed directly on the titania surface, occupied by its modifier. Based on the obtained results, $5 \mathrm{wt} \%$ was chosen the $\mathrm{Cu}_{2} \mathrm{O}$ content in the $\mathrm{Cu}_{2} \mathrm{O} / \mathrm{PTr}-\mathrm{TiO}_{2}$ sample. 


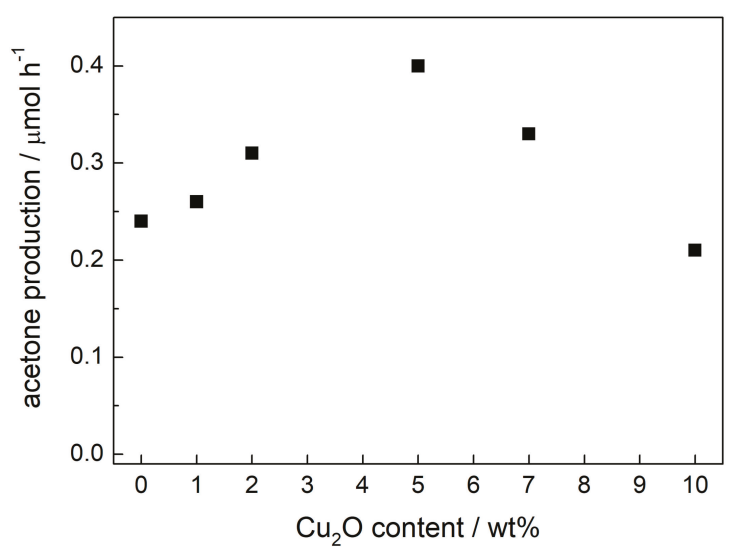

Figure 2. Visible light photocatalytic activity of the samples prepared with different $\mathrm{Cu}_{2} \mathrm{O}$ content.

\subsection{Characterization of Samples}

P25 is a well-known mixed-phase titania photocatalyst containing two crystalline phases: anatase $(86.4 \%)$ and rutile $(13.6 \%)$, and amorphous titania (exact composition using $\mathrm{NiO}$ as the internal standard was estimated previously showing the anatase/rutile/amorphous ratio to be 76-80/13-15/6-11 (P25 is not a uniform sample) [39]) with a $21 \mathrm{~nm}$ crystallite size of anatase (determined from XRD) and $59.1 \mathrm{~m}^{2} / \mathrm{g}$ specific surface area. After the thermal treatment with urea, the properties of the $\mathrm{PTr}-\mathrm{TiO}_{2}$ sample (1:1 urea-P25 ratio) changed slightly to a $23 \mathrm{~nm}$ crystallite size of anatase and $62.3 \mathrm{~m}^{2} \mathrm{~g}^{-1}$ specific surface area, but the crystalline phase content remained unchanged. It is proposed that an increase in crystallite size should result from amorphous titania conversion to anatase during calcination, whereas an increase in specific surface area comes from the adsorbed organic layer of poly(amino-tri-s-triazine) derivatives. $\mathrm{Cu}_{2} \mathrm{O}$, which was used as a component of the $\mathrm{Cu}_{2} \mathrm{O}-\mathrm{PTr}-\mathrm{TiO}_{2}$ mixture, was characterized by a $65 \mathrm{~nm}$ crystallite size and $23 \mathrm{~m}^{2} \mathrm{~g}^{-1}$ specific surface area. Therefore, the results stated that the $\mathrm{PTr}-\mathrm{TiO}_{2}$ crystallites were almost three times smaller than the $\mathrm{Cu}_{2} \mathrm{O}$ ones. These values were confirmed by XRD analysis of the $\mathrm{Cu}_{2} \mathrm{O} / \mathrm{PTr}-\mathrm{TiO}_{2}$ sample. Figure 3 shows the XRD diffractogram of $\mathrm{Cu}_{2} \mathrm{O} / \mathrm{PTr}-\mathrm{TiO}_{2}$ with peaks corresponding to anatase, rutile, and $\mathrm{Cu}_{2} \mathrm{O}$. An aromatic system of carbon nitrides should appear at around $27.4^{\circ}$, but a strong peak of rutile overlaps it. It was reported that in the case of a small fraction of polycondensed polytriazines, this peak would not be detected [29].

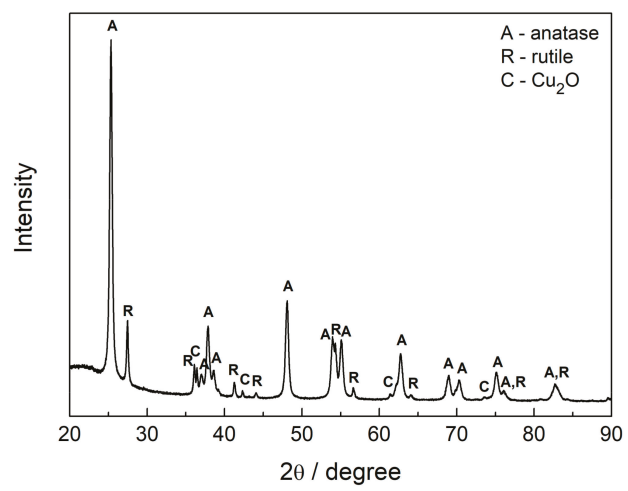

Figure 3. XRD diffractogram of $\mathrm{Cu}_{2} \mathrm{O} / \mathrm{PTr}-\mathrm{TiO}_{2}$ sample. 
The diffuse reflectance spectra of the $\mathrm{PTr}-\mathrm{TiO}_{2}$ and $\mathrm{Cu}_{2} \mathrm{O} / \mathrm{PTr}-\mathrm{TiO}_{2}$ samples (Figure 4) show the strong red shift originated from the absorption properties of the polytriazine layer on P25. The visible light absorption effect was stronger than that for similar samples reported by Mitoraj and Kisch $[28,30]$. However, a different type of titania was used as the base for synthesis in that study. Therefore, it was proposed that the content of the surface hydroxyl groups on the surfaces of the various $\mathrm{TiO}_{2}$ samples were responsible for better/worse ability of polytriazine layer formation (the issue of finishing the process of formation polytriazine layer by the reaction of amino groups of the relevant intermediates with titania surface $\mathrm{OH}$ groups [30]). To check this hypothesis, reference experiments were performed for own-prepared decahedral anatase particles (DAP) [40] modified with urea using the same conditions as for P25. Interestingly, it was observed that the DAP sample after this modification practically did not change, i.e., the color was still white and the visible light activity was not observed. Accordingly, it is proposed that the highly crystalline titania samples with low surface area (DAP as an example) possess too low number of surface $\mathrm{OH}$ groups to successfully introduce the polytriazine layer on their surfaces. It is also possible that surface defects, e.g., oxygen vacancy, play a crucial role in polytriazine layer formation since the DAP (well-crystallized faceted titania) possess an extremely low content of such defects (clarification of this phenomenon for other titania samples is under study). Mitoraj and Kisch proposed that the visible light absorption of urea-modified samples with a yellow color originated from the presence of poly(tri-s-triazine) centered intra-bandgap levels which may form (depending on PTr concentration) a narrow energy band in titania [29]. Additionally, in the case of the $\mathrm{Cu}_{2} \mathrm{O} / \mathrm{PTr}-\mathrm{TiO}_{2}$ photocatalyst, more intensive light absorption in the range 450-600 nm, as the consequence of the inherent light absorption properties of $\mathrm{Cu}_{2} \mathrm{O}$, was observed (Figure 3). The $\mathrm{Cu}_{2} \mathrm{O} / \mathrm{PTr}-\mathrm{TiO}_{2}$ sample had a reddish-yellow color.

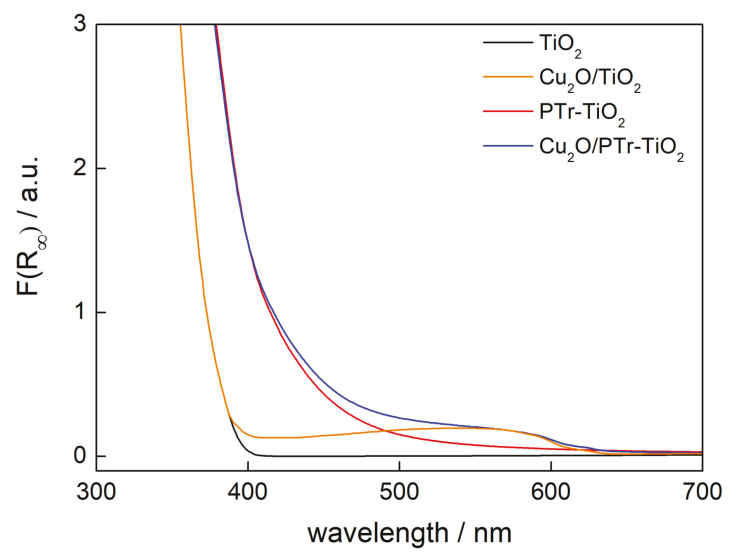

Figure 4. Diffuse reflectance spectra of $\mathrm{TiO}_{2}, \mathrm{PTr}-\mathrm{TiO}_{2}, \mathrm{Cu}_{2} \mathrm{O} / \mathrm{PTr}-\mathrm{TiO}_{2}$. The Kubelka-Munk function $\mathrm{F}\left(\mathrm{R}_{\infty}\right)$ is equivalent to absorbance.

XPS analysis of $\mathrm{PTr}-\mathrm{TiO}_{2}$ and $\mathrm{Cu}_{2} \mathrm{O} / \mathrm{PTr}-\mathrm{TiO}_{2}$ samples showed the presence of nitrogen $1 \mathrm{~s}$ with binding energies of 399.1 and $400.5 \mathrm{eV}$, which indicates the presence of $\mathrm{C}=\mathrm{N}-\mathrm{C}$ and $(-\mathrm{C}=\mathrm{N}-)_{\mathrm{x}}$ bonds, respectively, being in agreement with previously reported values [29,41,42]. XPS results showing the fractions of oxidation states of titanium, oxygen and copper are shown in Table 1. For samples modified with urea $\left(\mathrm{PTr}-\mathrm{TiO}_{2}\right.$ and $\left.\mathrm{Cu}_{2} \mathrm{O} / \mathrm{PTr}-\mathrm{TiO}_{2}\right)$, the content of oxygen related to hydroxyl groups bound to titanium and carbon was lower than for bare $\mathrm{TiO}_{2}$ due to the fact that surface hydroxyl groups participate in poly-s-triazine layer formation. In contrast, the content of $\mathrm{Ti}^{3+}$ increased after modification, which could confirm the participation of surface defects in the formation of $\mathrm{PTr}-\mathrm{TiO}_{2}$ (as discussed above for modified faceted titania (DAP)). It is proposed that thermal treatment could increase the formation of $\mathrm{Ti}^{3+}$. 
Therefore, it is also possible that a decrease in the content of hydroxyl groups after titania modification could result from their replacement by poly-s-triazine, similar to titania surface modification with nanoparticles of noble metals [43]. Moreover, samples with the poly-s-triazine layer also had a higher carbon content (higher C/Ti ratio). These results confirmed the presence of an organic layer on the titania surface consisting of poly-s-triazine derivatives, as reported previously [29].

Table 1. XPS analysis for $\mathrm{TiO}_{2}, \mathrm{PTr}-\mathrm{TiO}_{2}$ and $\mathrm{Cu}_{2} \mathrm{O} / \mathrm{PTR}-\mathrm{TiO}_{2}$ samples including fraction of oxidation states of Ti, $\mathrm{O}$, and $\mathrm{Cu}$ from the deconvolution of XPS peaks of Ti $2 \mathrm{p}_{3 / 2}, \mathrm{O}$ 1s and $\mathrm{Cu} 2 \mathrm{p}_{3 / 2}$.

\begin{tabular}{|c|c|c|c|c|c|c|c|c|c|c|}
\hline \multirow{2}{*}{ Samples } & \multicolumn{2}{|c|}{$\mathrm{Ti} 2 \mathrm{p}_{3 / 2}(\%)$} & \multicolumn{3}{|c|}{ O 1s (\%) } & \multicolumn{2}{|c|}{ Ratio } & \multicolumn{3}{|c|}{ Valent State (\%) } \\
\hline & $\mathrm{Ti}^{4+}$ & $\mathrm{Ti}^{3+}$ & $\mathrm{TiO}_{2}{ }^{\mathrm{a}}$ & $\mathrm{Ti}^{-\mathrm{OH}^{\mathrm{b}}}$ & $\mathrm{Ti}^{-O H}{ }^{\mathrm{c}}$ & $\mathrm{O} / \mathrm{Ti}$ & $\mathrm{C} / \mathrm{Ti}$ & $\mathrm{Cu}^{2+}$ & $\mathrm{Cu}^{+}$ & $\mathrm{Cu}(0)$ \\
\hline $\mathrm{TiO}_{2}$ & 98.5 & 1.5 & 57.9 & 26.7 & 15.4 & 2.6 & 3.5 & - & - & - \\
\hline PTr-TiO 2 & 97.2 & 2.8 & 62.3 & 23.7 & 14.0 & 2.5 & 4.1 & - & - & - \\
\hline $\mathrm{Cu}_{2} \mathrm{O} / \mathrm{PTr}-\mathrm{TiO}_{2}$ & 97.0 & 3.0 & 61.8 & 24.1 & 14.1 & 2.5 & 4.3 & 0.9 & 99.1 & - \\
\hline
\end{tabular}

To confirm the presence of the organic layer and possible formation of the $\mathrm{Cu} \mathrm{u}_{2} \mathrm{O} / \mathrm{PTr}-\mathrm{TiO}_{2}$ heterojunction, scanning transmission electron microscopy (STEM) observation was carried out. It was found that $\mathrm{Cu}_{2} \mathrm{O}$ existed in both crystalline and amorphous forms (large aggregates of very fine NPs). Moreover, two kinds of crystalline structures were noticed, i.e., large crystals of 100-150 nm and fine faceted nanocrystals of 10-30 nm (cubic and decahedral). For the $\mathrm{Cu}_{2} \mathrm{O} / \mathrm{PTr}-\mathrm{TiO}_{2}$ sample, titania particles were covered with a 5-10-nm layer of polytriazine located nearby larger $\mathrm{Cu}_{2} \mathrm{O}$ crystallites, as clearly shown in Figure 5 (respective SEM and TEM modes of the same image). Moreover, fine amorphous $\mathrm{Cu}_{2} \mathrm{O}$ interconnecting $\mathrm{PTr}-\mathrm{TiO}_{2}$ particles was also observed. Interestingly, it was found that long-term electron beam during STEM observations could destroy the polytriazine layer around the titania since new nanostructures were formed (gravitationally-formed honey-like tails).

(a)

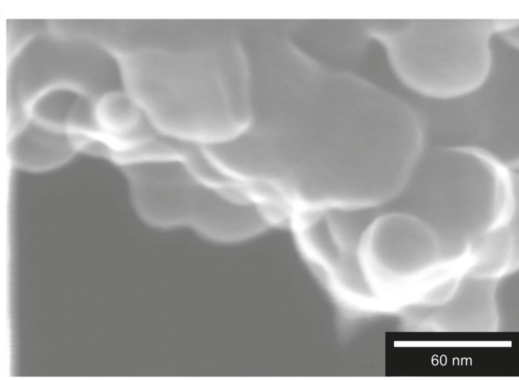

(b)

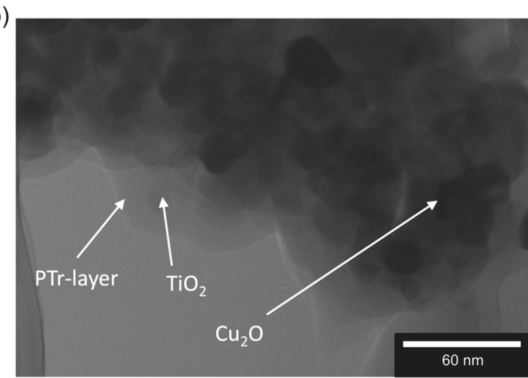

Figure 5. STEM images of $\mathrm{Cu}_{2} \mathrm{O} / \mathrm{PTr}-\mathrm{TiO}_{2}$ sample in SEM (a) and TEM (b) modes.

\subsection{Enhanced Visible Light Photocatalytic Activity as a Synergistic Effect of Two Modifiers}

Figure 6 shows the results of the photocatalytic activity tests of five photocatalysts: $\mathrm{TiO}_{2}$, $\mathrm{Cu}_{2} \mathrm{O}, \mathrm{Cu}_{2} \mathrm{O} / \mathrm{TiO}_{2}, \mathrm{PTr}_{-} \mathrm{TiO}_{2}$, and $\mathrm{Cu}_{2} \mathrm{O} / \mathrm{PTr}-\mathrm{TiO}_{2}$ in the visible light-induced 2-propanol oxidation. The highest activity was observed for $\mathrm{Cu}_{2} \mathrm{O} / \mathrm{PTr}-\mathrm{TiO}_{2}$ with $1.2 \mu \mathrm{mol}$ of acetone formation after $3 \mathrm{~h}$ of irradiation. The $\mathrm{Cu}_{2} \mathrm{O} / \mathrm{TiO}_{2}$ and $\mathrm{PTr}-\mathrm{TiO}_{2}$ samples were characterized by significantly lower photoactivity: 0.18 and $0.72 \mu \mathrm{mol}$ of acetone, respectively. The unmodified photocatalysts $\mathrm{TiO}_{2}$ (P25) and $\mathrm{Cu}_{2} \mathrm{O}$ were almost inactive in this reaction system. The improvement of visible light photocatalytic performance for the $\mathrm{Cu}_{2} \mathrm{O} / \mathrm{PTr}-\mathrm{TiO}_{2}$ sample in comparison to the $\mathrm{Cu}_{2} \mathrm{O} / \mathrm{TiO}_{2}$ and $\mathrm{PTr}-\mathrm{TiO}_{2}$ photocatalysts is evidence of the synergistic effect of urea (poly(tri-s-triazine)) and $\mathrm{Cu}_{2} \mathrm{O}$ modifiers for enhancing the visible light photocatalytic activity of titania. The photocatalytic activity test for the $\mathrm{Cu}_{2} \mathrm{O} / \mathrm{PTr}-\mathrm{TiO}_{2}$ sample was extended to $8 \mathrm{~h}$ to check the basic stability of the material. After $8 \mathrm{~h}$ of irradiation, a linear course of acetone production was still observed. 


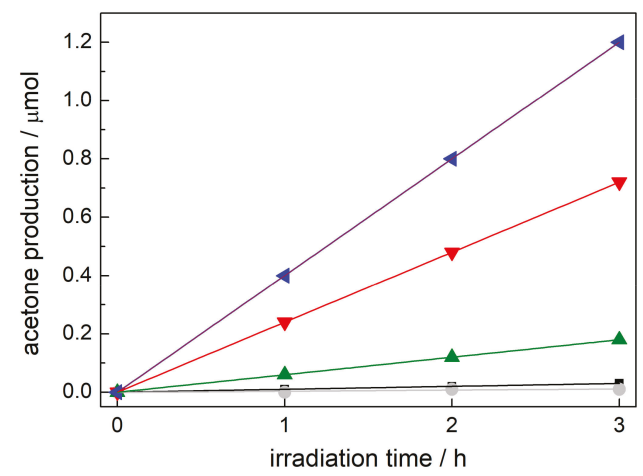

Figure 6. Visible light-induced $(\lambda>455 \mathrm{~nm})$ 2-propanol oxidation in the presence of $\mathrm{TiO}_{2},(\bullet) \mathrm{Cu}_{2} \mathrm{O}$, $(\Delta) \mathrm{Cu}_{2} \mathrm{O} / \mathrm{TiO}_{2},(\boldsymbol{\nabla}) \mathrm{PTr}^{-\mathrm{TiO}_{2}}$, and (४) $\mathrm{Cu}_{2} \mathrm{O} / \mathrm{PTr}-\mathrm{TiO}_{2}$.

A lack of visible light activity for a single $\mathrm{Cu}_{2} \mathrm{O}$, in spite of its good visible light absorption properties, can be explained by a strong photocorrosion effect and fast charge recombination $[44,45]$. It was reported that the coupling of cuprous oxide with titania reduced these detrimental effects by the heterojunction mechanism (type II) between the p- and n-type semiconductors introducing visible light activity and enhancing stability $[15-19,46]$.

The $\mathrm{PTr}-\mathrm{TiO}_{2}$ photocatalyst possesses significantly higher visible light activity for 2-propanol oxidation than $\mathrm{Cu}_{2} \mathrm{O} / \mathrm{TiO}_{2}$. The core-shell structure of titania-poly(tri-s-triazine) derivatives changes photoabsorption and electronic properties in comparison to the unmodified titania. Figure 7 shows a way to determine band gap energy and absorption onset for the $\mathrm{PTr}-\mathrm{TiO}_{2}$ sample. The band gap narrowing occurred from $3.17 \mathrm{eV}$ for bare $\mathrm{TiO}_{2}$ (P25) to $2.88 \mathrm{eV}$ for $\mathrm{PTr}_{-} \mathrm{TiO}_{2}$. The absorption onset is useful to determine the location of surface states in $\mathrm{PTr}-\mathrm{TiO}_{2}$ originating from the presence of an organic modifier (shaded area in the Figures 8 and 9) [6].

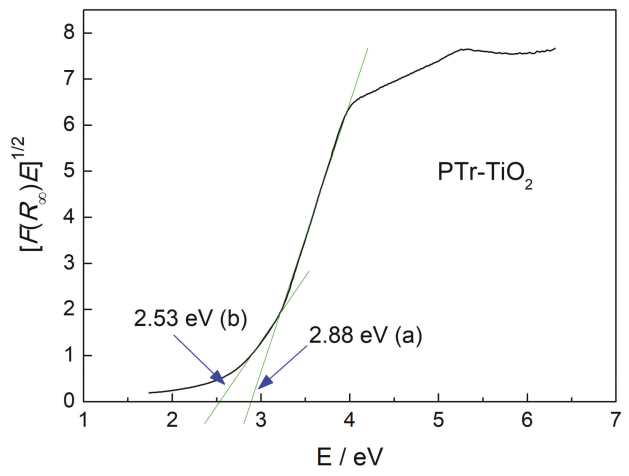

Figure 7. Plot of transformed Kubelka-Munk function vs. energy of light for the $\mathrm{PTr}-\mathrm{TiO}_{2}$ sample. Determination of band gap energy (a) and absorption onset (b).

Figures 8 and 9 illustrate the propositions of explanation for enhanced visible light photocatalytic activity of $\mathrm{Cu}_{2} \mathrm{O} / \mathrm{PTr}-\mathrm{TiO}_{2}$, a photocatalytic system with two main composites. In the first mechanistic variant (Figure 7), two semiconductors: p-type $\mathrm{Cu}_{2} \mathrm{O}$ and n-type titania (P25) with an organic sensitizer created a type II heterojunction. This system provided the optimum band positions for efficient charge carrier separation. Visible light photoexcited electrons were transferred from $\mathrm{CB}\left(\mathrm{Cu}_{2} \mathrm{O}\right)$ to 
$\mathrm{CB}\left(\mathrm{PTr}-\mathrm{TiO}_{2}\right)$ and this transfer could occur due to the favorable energetics of the relative positions of both $\mathrm{CBs}$, whereas holes were simultaneously transferred from $\mathrm{VB}\left(\mathrm{PTr}-\mathrm{TiO}_{2}\right)$ to $\mathrm{VB}\left(\mathrm{Cu}_{2} \mathrm{O}\right)$. The main consequence of such phenomenon is the separation of the photogenerated electrons and holes reducing the probability of recombination and increasing the lifetimes of the charge carriers [46]. $\mathrm{Cu}_{2} \mathrm{O}$ has a valence band potential of $1.07 \mathrm{~V}$ [47]. To form hydroxyl radicals, the valence band potential of $\mathrm{Cu}_{2} \mathrm{O}$ should be more positive than the following values at $\mathrm{pH}=7$ [7]:

$$
\begin{gathered}
h^{+}+\mathrm{H}_{2} \mathrm{O} \rightarrow \mathrm{OH}^{\bullet}+\mathrm{H}^{+}, \mathrm{E}_{0}=2.73 \mathrm{~V}(\text { vs. } \mathrm{NHE}) \\
h^{+}+\mathrm{OH}^{-} \rightarrow \mathrm{OH}^{\bullet}, \mathrm{E}_{0}=1.90 \mathrm{~V}(\text { vs. } \mathrm{NHE})
\end{gathered}
$$

Therefore, the formation of hydroxyl radicals may be thermodynamically unfavorable. It can be concluded that holes accumulated would be mostly consumed through the direct oxidation of 2-propanol. Electrons accumulated on $\mathrm{CB}\left(\mathrm{PTr}-\mathrm{TiO}_{2}\right)$ play a key role in the formation of reactive oxygen species. The properties of the $\mathrm{PTr}-\mathrm{TiO}_{2}$ component of the considered semiconductor composition by introduction of visible light activity into titania enabled the formation of this advantageous heterojunction functioning under visible light irradiation.

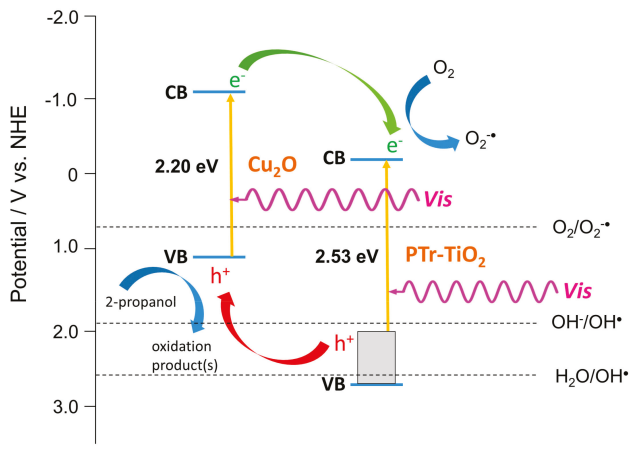

Figure 8. Energy diagram for the $\mathrm{Cu}_{2} \mathrm{O} / \mathrm{PTr}-\mathrm{TiO}_{2}$ photocatalytic system working under visible light, illustrating the coupling of two semiconductors as a type II heterojunction.

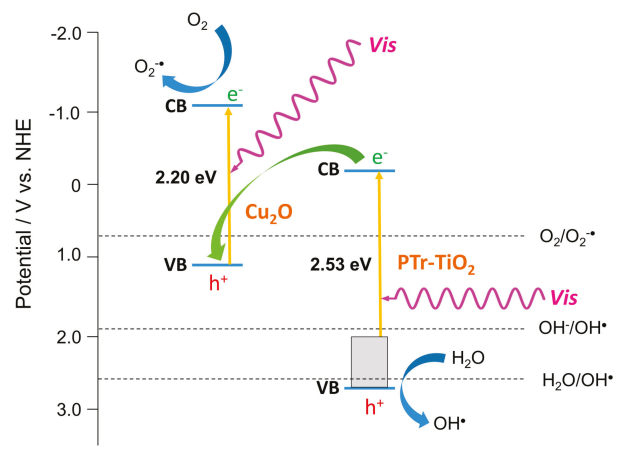

Figure 9. Energy diagram for $\mathrm{Cu}_{2} \mathrm{O} / \mathrm{PTr}-\mathrm{TiO}_{2}$ photocatalytic system working under visible light, illustrating the coupling of two semiconductors as a Z-scheme system.

Another mechanistic variant describing enhanced visible light activated $\mathrm{Cu}_{2} \mathrm{O} / \mathrm{PTr}-\mathrm{TiO}_{2}$ system relies on the Z-scheme concept $[48,49]$. As shown in Figure 9, photogenerated electrons in $\mathrm{PTr}^{\mathrm{T}} \mathrm{TiO} \mathrm{O}_{2}$ 
with a lower reduction ability recombined with the photogenerated holes in $\mathrm{Cu}_{2} \mathrm{O}$ with lower oxidation ability. Therefore, electrons accumulated on $\mathrm{CB}\left(\mathrm{Cu}_{2} \mathrm{O}\right)$ with a high reduction ability of holes accumulated on $\mathrm{VB}\left(\mathrm{PTr}-\mathrm{TiO}_{2}\right)$ with a high oxidation ability can be maintained. The occurrence of the second mechanistic variant might be even more possible due to the existence of optimal $\mathrm{Cu}_{2} \mathrm{O}$ content (Figure 2) and the low photocatalytic activity of the $\mathrm{Cu}_{2} \mathrm{O} / \mathrm{TiO}_{2}$ system.

In the case of both mechanisms, the efficient charge separation induced by visible light irradiation was the main reason of the exceptional photocatalytic activity of the proposed system and provides the explanation of the synergistic role of the two considered types of titania modifiers. Clarification of which mechanistic variant is responsible for enhanced photocatalytic properties of the $\mathrm{Cu}_{2} \mathrm{O} / \mathrm{PTr}-\mathrm{TiO}_{2}$ system in the visible light is necessary. Further studies including action spectrum analysis, photoactivity tests in the presence of scavengers, and detailed characterization of these materials (and other photocatalysts prepared with different titania photocatalysts, i.e., varied by surface properties and/or content of oxygen defects), such as the estimation of the quasi-Fermi level, are along this line.

\section{Materials and Methods}

\subsection{Preparation of $\mathrm{Cu}_{2} \mathrm{O} / \mathrm{PTr}-\mathrm{TiO}_{2}$}

P25 (AEROXIDE ${ }^{\circledR} \mathrm{TiO}_{2}$ P25, Nippon Aerosil, Tokyo, Japan), urea (Wako Pure Chemicals, Osaka, Japan) and $\mathrm{Cu}_{2} \mathrm{O}$ (Wako Pure Chemicals) were used for the study without purification. $\mathrm{PTr}-\mathrm{TiO}_{2}$ samples were prepared by the method based on the processes reported elsewhere $[26,29]$. Typically, $400 \mathrm{~g}$ of P25 powder and different amounts of urea corresponding to 0.5:1, 1:1, 2:1 and $3: 1(\mathrm{w} / \mathrm{w})$ ratios were ground in an agate mortar, followed by calcination in air at $400{ }^{\circ} \mathrm{C}$ for $30 \mathrm{~min}$. Powders were placed in the open test-tube with $15 \mathrm{~cm}$ of length. The resulting powders were washed five times with water to remove the excess of urea decomposition products and finally dried under air at $70{ }^{\circ} \mathrm{C}$. In the second step, $\mathrm{PTr}-\mathrm{TiO}_{2}$ sample and $\mathrm{Cu}_{2} \mathrm{O}$ powder (in different amounts: 1, 2, 5, 7, $10 \mathrm{wt} \%$ ) were mixed thoroughly with $5 \mathrm{~min}$ of grinding.

\subsection{Sample Characterization}

The UV-Vis diffuse reflectance spectra (DRS) were recorded on JASCO V-670 (JASCO, Tokyo, Japan) equipped with PIN-757 integrating sphere using $\mathrm{BaSO}_{4}$ as a reference. Gas-adsorption measurements of prepared titania samples were performed on a Yuasa Ionics Autosorb, 6AG (Yuasa Ionics, Osaka, Japan) surface area and pore size analyzer. Specific surface area (SSA) was calculated from nitrogen adsorption at $77 \mathrm{~K}$ using the Brunauer-Emmett-Teller equation. X-ray diffraction patterns (XRD) were collected using an X-ray diffractometer (Rigaku intelligent XRD SmartLab with a Cu target, Rigaku, Tokyo, Japan). X-ray photoelectron spectra (XPS) were recorded using a JEOL JPC-9010MC (JEOL, Tokyo, Japan) spectrometer with a MgKa X-ray source. Samples were also characterized by scanning transmission electron microscopy (STEM, HITACHI HD-2000, HITACHI, Tokyo, Japan).

\subsection{Photocatalytic Reaction}

The photocatalyst $(50 \mathrm{mg}$ ) was suspended in an aqueous solution of 2-propanol (5 vol \%, $5 \mathrm{~mL}$ ) and photoirradiated (120 W-xenon lamp) with a Y48 cut-off filter mounted in the irradiation window, therefore the light of wavelengths $>450 \mathrm{~nm}$ reached the suspension, which was under continuous magnetic stirring $(1000 \mathrm{rpm})$ in a thermostated bath. Generated acetone was detected using GC-FID (Shimadzu GC-14B (Shimadzu, Kyoto, Japan) equipped with a flame ionization detector). Before the injection of the liquid sample to GC, the photocatalyst was separated using a filter (Whatman Mini-UniPrep, PVDF, Whatman, Maidstone, UK). 


\section{Conclusions}

The results presented in this study clearly revealed that the application of both low cost- modifiers for titania: urea (first step of preparation) and $\mathrm{Cu}_{2} \mathrm{O}$ (second step), significantly enhanced the visible light photocatalytic properties of $\mathrm{TiO}_{2}$ in comparison to the single materials of urea-modified $\mathrm{TiO}_{2}$ and $\mathrm{Cu}_{2} \mathrm{O}$-modified titania. Therefore, it is possible to describe this phenomenon as a synergistic effect of urea (more detailed: the presence of polytriazine layer on titania originated from the thermal treatment of urea) and $\mathrm{Cu}_{2} \mathrm{O}$. The type II heterojunction or Z-scheme systems formed by two semiconductors, p-type $\mathrm{Cu}_{2} \mathrm{O}$ and n-type $\mathrm{PTr}-\mathrm{TiO}_{2}$, can be responsible for the improvement of photocatalytic activity through the intensification of visible light-induced charge separation and subsequent reduction of the electron-hole recombination effect. A preparation of composite photocatalysts based on titania and low-cost materials as modifiers, such as a precursor of the organic sensitizer of titania and metal oxide, to prepare the efficient and stable photocatalytic system operating in the visible light within heterojunction principles is a very promising direction for a wider practical application of photocatalysis given the preference for concomitantly cheap and efficient solutions.

Author Contributions: M.J. conceived, designed, performed the experiments and characterizations, interpreted the data, and wrote the paper. E.K. performed STEM, interpreted the data, and corrected the manuscript. K.W. performed STEM experiments. All authors read and approved the final manuscript.

Acknowledgments: M.J. acknowledges Hokkaido University for guest lecturer position (2016-2017).

Conflicts of Interest: The authors declare no conflict of interest.

\section{References}

1. Bahnemann, D.W. Photocatalytic water treatment: Solar energy applications. Solar Energy 2004, 77, 445-459. [CrossRef]

2. Chen, X.B.; Shen, S.H.; Guo, L.J.; Mao, S.S. Semiconductor-based photocatalytic hydrogen generation. Chem. Rev. 2010, 110, 6503-6570. [CrossRef] [PubMed]

3. Li, K.; Peng, B.S.; Peng, T.Y. Recent advances in heterogeneous photocatalytic $\mathrm{CO}_{2}$ conversion to solar fuels. ACS Catal. 2016, 6, 7485-7527. [CrossRef]

4. Pietron, J.J.; DeSario, P.A. Review of roles for photonic crystals in solar fuels photocatalysis. J. Photonics Energy 2016, 7, 012007. [CrossRef]

5. Ragesh, P.; Ganesh, V.A.; Nair, S.V.; Nair, A.S. A review on 'self-cleaning and multifunctional materials'. J. Mater. Chem. A 2014, 2, 14773-14797. [CrossRef]

6. Kisch, H. Semiconductor photocatalysis-Mechanistic and synthetic aspects. Angew. Chem. Int. Ed. 2013, 52, 812-847. [CrossRef] [PubMed]

7. Schneider, J.; Matsuoka, M.; Takeuchi, M.; Zhang, J.; Horiuchi, Y.; Anpo, M.; Bahnemann, D.W. Understanding $\mathrm{TiO}_{2}$ photocatalysis: Mechanisms and materials. Chem. Rev. 2014, 114, 9919-9986. [CrossRef] [PubMed]

8. Pelaez, M.; Nolan, N.T.; Pillai, S.C.; Seery, M.K.; Falaras, P.; Kontos, A.G.; Dunlop, P.S.M.; Hamilton, J.W.J.; Byrne, J.A.; O'Shea, K.; et al. A review on the visible light active titanium dioxide photocatalysts for environmental applications. Appl. Catal. B Environ. 2012, 125, 331-349. [CrossRef]

9. Dahl, M.; Liu, Y.; Yin, Y. Composite titanium dioxide nanomaterials. Chem. Rev. 2014, 114, 9853-9889. [CrossRef] [PubMed]

10. Bhanushali, S.; Ghosh, P.; Ganesh, A.; Cheng, W.L. 1D copper nanostructures: Progress, challenges and opportunities. Small 2015, 11, 1232-1252. [CrossRef] [PubMed]

11. Clarizia, L.; Spasiano, D.; Di Somma, I.; Marotta, R.; Andreozzi, R.; Dionysiou, D.D. Copper modified-TiO 2 catalysts for hydrogen generation through photoreforming of organics. A short review. Int. J. Hydrogen Energy 2014, 39, 16812-16831. [CrossRef]

12. Janczarek, M.; Kowalska, E. On the origin of enhanced photocatalytic activity of copper-modified titania in the oxidative reaction systems. Catalysts 2017, 7, 317. [CrossRef] 
13. Nguyen, M.A.; Bedford, N.M.; Ren, Y.; Zahran, E.M.; Goodin, R.C.; Chagani, F.F.; Bachas, L.G.; Knecht, M.R. Direct Synthetic Control over the Size, Composition, and Photocatalytic Activity of Octahedral Copper Oxide Materials: Correlation Between Surface Structure and Catalytic Functionality. ACS Appl. Mater. Interfaces 2015, 7, 13238-13250. [CrossRef] [PubMed]

14. Deng, X.L.; Wang, C.G.; Shao, M.H.; Xu, X.J.; Huang, J.Z. Low-temperature solution synthesis of CuO/Cu $2 \mathrm{O}$ nanostructures for enhanced photocatalytic activity with added $\mathrm{H}_{2} \mathrm{O}_{2}$ : Synergistic effect and mechanism insight. RSC Adv. 2017, 7, 4329-4338. [CrossRef]

15. Yang, L.; Luo, S.; Li, Y.; Xiao, Y.; Kang, Q.; Cai, Q. High efficient photocatalytic degradation of p-nitrophenol on a unique $\mathrm{Cu}_{2} \mathrm{O} / \mathrm{TiO}_{2}$ p-n heterojunction network catalyst. Environ. Sci. Technol. 2010, 44, 7641-7646. [CrossRef] [PubMed]

16. Chu, S.; Zheng, X.M.; Kong, F.; Wu, G.H.; Luo, L.L.; Guo, Y.; Liu, H.L.; Wang, Y.; Yu, H.X.; Zou, Z.G. Architecture of $\mathrm{Cu}_{2} \mathrm{O} @ \mathrm{TiO}_{2}$ core-shell heterojunction and photodegradation for 4-nitrophenol under simulated sunlight irradiation. Mater. Chem. Phys. 2011, 129, 1184-1188. [CrossRef]

17. Liu, L.; Gu, X.; Sun, C.; Li, H.; Deng, Y.; Gao, F.; Dong, L. In situ loading of ultra-small $\mathrm{Cu}_{2} \mathrm{O}$ particles on $\mathrm{TiO}_{2}$ nanosheets to enhance the visible-light photoactivity. Nanoscale 2012, 4, 6351-6359. [CrossRef] [PubMed]

18. Liu, L.M.; Yang, W.Y.; Li, Q.; Gao, S.A.; Shang, J.K. Synthesis of $\mathrm{Cu}_{2} \mathrm{O}$ nanospheres decorated with $\mathrm{TiO}_{2}$ nanoislands, their enhanced photoactivity and stability under visible light illumination, and their post-illumination catalytic memory. ACS Appl. Mater. Interfaces 2014, 6, 5629-5639. [CrossRef] [PubMed]

19. Xiong, L.B.; Yang, F.; Yan, L.L.; Yan, N.N.; Yang, X.; Qiu, M.Q.; Yu, Y. Bifunctional photocatalysis of $\mathrm{TiO}_{2} / \mathrm{Cu}_{2} \mathrm{O}$ composite under visible light: $\mathrm{Ti}^{3+}$ in organic pollutant degradation and water splitting. J. Phys. Chem. Solids. 2011, 72, 1104-1109. [CrossRef]

20. Qiu, X.; Miyauchi, M.; Sunada, K.; Minoshima, M.; Liu, M.; Lu, Y.; Li, D.; Shimodaira, Y.; Hosogi, Y.; Kuroda, Y.; et al. Hybrid $\mathrm{Cu}_{\mathrm{x}} \mathrm{O} / \mathrm{TiO}_{2}$ nanocomposites as risk-reduction materials in indoor environments. ACS Nano 2012, 6, 1609-1618. [CrossRef] [PubMed]

21. Hans, M.; Erbe, A.; Mathews, S.; Chen, Y.; Solioz, M.; Mucklich, F. Role of copper oxides in contact killing of bacteria. Langmuir 2013, 29, 16160-16166. [CrossRef] [PubMed]

22. Duan, W.; Zheng, M.; Li, R.; Wang, Y. Morphology transformation of $\mathrm{Cu}_{2} \mathrm{O}$ by adding TEOA and their antibacterial activity. J. Nanopart. Res. 2016, 18, 342. [CrossRef]

23. Lee, Y.J.; Kim, S.; Park, S.H.; Park, H.; Huh, Y.D. Morphology-dependent antibacterial activities of $\mathrm{Cu}_{2} \mathrm{O}$. Mater. Lett. 2011, 65, 818-820. [CrossRef]

24. Nosaka, Y.; Matsushita, M.; Nishino, J.; Nosaka, A.Y. Nitrogen-doped titanium dioxide photocatalysts for visible response prepared by using organic compounds. Sci. Technol. Adv. Mater. 2005, 6, 143-148. [CrossRef]

25. Bacsa, R.; Kiwi, J.; Ohno, T.; Albers, P.; Nadtochenko, V. Preparation, testing and characterization of doped $\mathrm{TiO}_{2}$ active in the peroxidation of biomolecules under visible light. J. Phys. Chem. B 2005, 109, 5994-6003. [CrossRef] [PubMed]

26. Kisch, H.; Sakthivel, S.; Janczarek, M.; Mitoraj, D. A low-band gap, nitrogen-modified titania visible-light photocatalyst. J. Phys. Chem. C 2007, 111, 11445-11449. [CrossRef]

27. Beranek, R.; Neumann, B.; Sakthivel, S.; Janczarek, M.; Dittrich, T.; Tributsch, H.; Kisch, H. Exploring the electronic structure of nitrogen-modified $\mathrm{TiO}_{2}$ photocatalysts through photocurrent and surface photovoltage studies. Chem. Phys. 2007, 339, 11-19. [CrossRef]

28. Mitoraj, D.; Kisch, H. The nature of nitrogen-modified titanium dioxide photocatalysts active in visible light. Angew. Chem. Int. Ed. 2008, 47, 9975-9978. [CrossRef] [PubMed]

29. Mitoraj, D.; Kisch, H. On the mechanism of urea-Induced titania modification. Chem. Eur. J. 2010, 16, 261-269. [CrossRef] [PubMed]

30. Mitoraj, D.; Kisch, H. Surface modified titania visible light photocatalyst powders. Solid State Phenom. 2010, 162, 49-75. [CrossRef]

31. Dong, G.; Zhang, Y.; Pan, Q.; Qiu, J. A fantastic graphitic carbon nitride $\left(\mathrm{g}-\mathrm{C}_{3} \mathrm{~N}_{4}\right)$ material: Electronic structure, photocatalytic and photoelectronic properties. J. Photochem. Photobiol. C Photochem. Rev. 2014, 20, 33-50. [CrossRef]

32. Liu, J.; Zhang, T.; Wang, Z.; Dawson, G.; Chen, W. Simple pyrolysis of urea into graphitic carbon nitride with recyclable adsorption and photocatalytic activity. J. Mater. Chem. 2011, 21, 14398-14401. [CrossRef] 
33. Lee, S.C.; Lintang, H.O.; Yuliati, L. A urea precursor to synthesize carbon nitride with mesoporosity for enhanced activity in the photocatalytic removal of phenol. Chem. Asian J. 2012, 7, 2139-2144. [CrossRef] [PubMed]

34. Senthil, R.A.; Theerthagiri, J.; Selvi, A.; Madhavan, J. Synthesis and characterization of low-cost g- $\mathrm{C}_{3} \mathrm{~N}_{4} / \mathrm{TiO}_{2}$ composite with enhanced photocatalytic performance under visible-light rradiation. Opt. Mater. 2017, 64, 533-539. [CrossRef]

35. Peng, B.; Zhang, S.; Yang, S.; Wang, H.; Yu, H.; Zhang, S.; Peng, F. Synthesis and characterization of g- $\mathrm{C}_{3} \mathrm{~N} 4 / \mathrm{Cu}_{2} \mathrm{O}$ composite catalyst with enhanced photocatalytic activity under visible light irradiation. Mater. Res. Bull. 2014, 56, 19-24. [CrossRef]

36. Min, Z.; Wang, X.; Li, Y.; Jiang, J.; Li, J.; Qian, D.; Li, J. A highly efficient visible-light-responding $\mathrm{Cu}_{2} \mathrm{O}-\mathrm{TiO}_{2} / \mathrm{g}-\mathrm{C}_{3} \mathrm{~N}_{4}$ photocatalyst for instantaneous discolorations of organic dyes. Mater. Lett. 2017, 193, 18-21. [CrossRef]

37. Kisch, H.; Macyk, W. Visible-light photocatalysis by modified titania. Chem. Phys. Chem. 2002, 3, 399-400. [CrossRef]

38. Yan, X.; Ohno, T.; Nishijima, K.; Abe, R.; Ohtani, B. Is methylene blue an appropriate substrate for a photocatalytic activity test? A study with visible-light responsive titania. Chem. Phys. Lett. 2006, 429, 606-610. [CrossRef]

39. Wang, K.; Wei, Z.; Ohtani, B.; Kowalska, E. Interparticle electron transfer in methanol dehydrogenation on platinum-loaded titania particles prepared from P25. Catal. Today 2018, 303, 327-333. [CrossRef]

40. Janczarek, M.; Kowalska, E.; Ohtani, B. Decahedral-shaped anatase titania photocatalyst particles: Synthesis in a newly developed coaxial-flow gas-phase reactor. Chem. Eng. J. 2016, 289, 502-512. [CrossRef]

41. Dementjev, A.P.; de Graaf, A.; van den Sanden, M.C.M.; Maslakov, K.I.; Naumkin, A.V.; Serov, A.A. $\mathrm{X}$-Ray photoelectron spectroscopy reference data for identification of the $\mathrm{C}_{3} \mathrm{~N}_{4}$ phase in carbon-nitrogen films. Diam. Relat. Mater. 2000, 9, 1904-1907. [CrossRef]

42. Guo, X.; Xie, Y.; Wang, X.; Zhang, S.; Hou, T.; Lv, S. Synthesis of carbon nitride nanotubes with the $\mathrm{C}_{3} \mathrm{~N}_{4}$ stoichiometry via a benzene-thermal process at low temperatures. Chem. Commun. 2004, 26-27. [CrossRef] [PubMed]

43. Janczarek, M.; Wei, Z.; Endo, M.; Ohtani, B.; Kowalska, E. Silver- and copper-modified decahedral anatase titania particles as visible light-responsive plasmonic photocatalyst. J. Photonics Energy 2017, 7, 012008. [CrossRef]

44. Bessekhouad, Y.; Robert, D.; Weber, J.-V. Photocatalytic activity of $\mathrm{Cu}_{2} \mathrm{O} / \mathrm{TiO}_{2}, \mathrm{Bi}_{2} \mathrm{O}_{3} / \mathrm{TiO}_{2}$ and $\mathrm{ZnMn}_{2} \mathrm{O}_{4} / \mathrm{TiO}_{2}$ heterojunctions. Catal. Today 2005, 101, 315-321. [CrossRef]

45. Huang, L.; Peng, F.; Yu, H.; Wang, H. Preparation of cuprous oxides with different sizes and their behaviors of adsorption, visible-light driven photocatalysis and photocorrosion. Solid State Sci. 2009, 11, 129-138. [CrossRef]

46. Marschall, R. Semiconductor Composites: Strategies for Enhancing Charge Carrier Separation to Improve Photocatalytic Activity. Adv. Funct. Mater. 2014, 24, 2421-2440. [CrossRef]

47. Luna, A.L.; Valenzuela, M.A.; Colbeau-Justin, C.; Vazquez, P.; Rodriguez, J.; Avendano, J.R.; Alfaro, S.; Tirado, S.; Garduno, A.; De la Rosa, J.M. Photocatalytic degradation of gallic acid over $\mathrm{CuO}-\mathrm{TiO}_{2}$ composites under UV/Vis LEDs irradiation. Appl. Catal. A Gen. 2016, 521, 140-148. [CrossRef]

48. Li, H.; Tu, W.; Zhou, Y.; Zou, Z. Z-scheme photocatalytic systems for promoting photocatalytic performance: Recent progress and future challenges. Adv. Sci. 2016, 3, 1500389. [CrossRef] [PubMed]

49. Low, J.; Jiang, C.; Cheng, B.; Wageh, S.; Al-Ghamdi, A.A.; Yu, J. A review of direct Z-scheme photocatalysts. Small Methods 2017, 1, 1700080. [CrossRef] 


\title{
Article \\ Highly Active $\mathrm{TiO}_{2}$ Microspheres Formation in the Presence of Ethylammonium Nitrate Ionic Liquid
}

\author{
Anna Gołąbiewska ${ }^{1}$, Micaela Checa-Suárez ${ }^{1,2}$, Marta Paszkiewicz-Gawron ${ }^{1}$, \\ Wojciech Lisowski ${ }^{3}$, Edyta Raczuk ${ }^{1}$, Tomasz Klimczuk ${ }^{4}$, Żaneta Polkowska ${ }^{5}$, \\ Ewelina Grabowska ${ }^{1}$, Adriana Zaleska-Medynska ${ }^{1}$ and Justyna Luczak ${ }^{6, *}$ \\ 1 Faculty of Chemistry, University of Gdansk, 80-308 Gdansk, Poland; anna.golabiewska@ug.edu.pl (A.G.); \\ micaela.checa@epn.edu.ec (M.C.-S.); marta.paszkiewicz@phdstud.ug.edu.pl (M.P.-G.); \\ edyta.raczuk@gmail.com (E.R.); ewelina.grabowska@ug.edu.pl (E.G.); adriana.zaleska@ug.edu.pl (A.Z.-M.) \\ 2 Faculty of Civil and Environmental Engineering, Escuela Politécnica Nacional, Quito 170525, Ecuador \\ 3 Institute of Physical Chemistry, Polish Academy of Sciences, 01-224 Warsaw, Poland; wlisowski@ichf.edu.pl \\ 4 Faculty of Applied Physics and Mathematics, Gdansk University of Technology, 80-233 Gdansk, Poland; \\ t.klimczuk@gmail.com \\ 5 Department of Analytical Chemistry, Faculty of Chemistry, Gdansk University of Technology, \\ 80-233 Gdańsk, Poland; zanpolko@pg.gda.pl \\ 6 Department of Chemical Technology, Faculty of Chemistry, Gdansk University of Technology, \\ 80-233 Gdansk, Poland \\ * Correspondence: justyna.luczak@pg.gda.pl; Tel.: +48-58-347-13-65
}

Received: 14 May 2018; Accepted: 13 June 2018; Published: 11 July 2018

\begin{abstract}
Spherical microparticles of $\mathrm{TiO}_{2}$ were synthesized by the ionic liquid-assisted solvothermal method at different reaction times $(3,6,12$, and $24 \mathrm{~h})$. The properties of the prepared photocatalysts were investigated by means of UV-VIS diffuse-reflectance spectroscopy (DRS), Brunauer-Emmett-Teller (BET) surface area measurements, scanning electron microscopy (SEM), X-ray diffraction analysis (XRD), and X-ray photoelectron spectroscopy (XPS). The results indicated that the efficiency of the phenol degradation was related to the time of the solvothermal synthesis, as determined for the $\mathrm{TiO}_{2}$ EAN(1:1)_24h sample. The microparticles of $\mathrm{TiO}_{2}$ EAN(1:1)_3h that formed during only $3 \mathrm{~h}$ of the synthesis time revealed a really high photoactivity under visible irradiation (75\%). This value increased to $80 \%$ and $82 \%$ after $12 \mathrm{~h}$ and $24 \mathrm{~h}$, respectively. The photoactivity increase was accompanied by the increase of the specific surface area, thus the poresize as well as the ability to absorb UV-VIS irradiation. The high efficiency of the phenol degradation of the ionic liquid (IL)- $\mathrm{TiO}_{2}$ photocatalysts was ascribed to the interaction between the surface of the $\mathrm{TiO}_{2}$ and ionic liquid components (carbon and nitrogen).
\end{abstract}

Keywords: ionic liquids; ionic liquid-assisted solvothermal reaction; reaction time; titanium dioxide; heterogeneous photocatalysis; visible light

\section{Introduction}

A number of recent studies have explored the applications of photosensitized titanium dioxide photocatalysts inter alia in solar cells, energy storage, hydrogen production via the water-splitting process, and the photocatalytic degradation of organic pollutants for water/air purification [1-5]. Expected low exploitation costs, prevalence in utility, and safety has created the motivation for intensified research in the field of solar to chemical energy conversion. The photoactive performance of the pristine $\mathrm{TiO}_{2}$ nano- and micro-particles is limited by its $3.2 \mathrm{eV}$ bandgap to the absorption of UV light. As the UV light range constitutes the total radiant energy in only as diminutive an amount as $5 \%$, harvesting a greater range of the solar spectrum is considered vital for achieving the significant 
effectiveness of the photocatalysis [5,6]. The extension of the $\mathrm{TiO}_{2}$ spectral response range to absorb the photons under visible ( $43 \%$ ) or/and near infrared ( $49 \%$ of solar spectrum energy) irradiation is crucial for this purpose. The $\mathrm{TiO}_{2}$ photocatalytic properties can be controlled and their optical response can be expanded to absorb photons under visible or/and near infrared light irradiation through the alteration of the $\mathrm{TiO}_{2}$ bandgap via morphology engineering [7-10].

It was found that, after excitation, the electrons and holes propagate to the nano- and micro-particles surface where they react with electron acceptors and donors, respectively $[6,9,11,12]$. Additionally, it has been noted that a slower recombination rate and a larger surface area accounted for more active adsorption/desorption reactions and the surface transfer of photoexcited electrons $[9,12,13]$, whereas the potential adverse effects that originate in the highly defective sites, typically developing with the growth of a large surface area, may be rectified by a higher crystallization of the particles [9].

Ionic liquids (ILs) have gained increasing attention in terms of their assistance in $\mathrm{TiO}_{2}$ synthesis as solvents as well as spatial and, perhaps, band structuring agents. Their high viscosity, dielectric constant, and thus polarity and dispersal capacity are widely recognized as the properties responsible for the charge, steric, and viscous stabilization of small-sized slow-growing crystallites, as well as the hindrance of aggregation and agglomeration processes that are disadvantageous for photocatalytic $[7,10,11,14-23]$.

The synthesized photocatalysts in the presence of ILs nano- and microparticles are characterized by a larger specific surface area, higher crystallization level, and less crystalline defects [17]. Hence, with the assistance of ILs, the formation of the particles of the beneficial surface reactivity is promoted, inducing a more effective photon absorption, trapping, and their migration to the surface. Moreover, an energetically simplified pathway of excited electrons through an ionic liquid's HOMO and LUMO orbitals [16], along with prolonged stabilized charge separation was revealed to result in the formation of a greater amount of reactive oxygen species (ROS) in the subsequent reaction of electrons and holes with oxygen and water, respectively. The generated reactive oxygen species $\left(\bullet \mathrm{OH}\right.$ and $\left.\mathrm{O}_{2} \bullet{ }^{-}\right)$are crucial reagents in the photodegradation of pollutants $[16,17,24]$.

Notwithstanding, the direct relationship between the structure of the ILs and the size/morphology of the nano- and microparticles of the semiconductors, such as the $\mathrm{TiO}_{2}$ photocatalysts, still remains ambiguous. Up until now, the following factors had been reported as predominant in effectuating the structure, and thus the activity of said particles, as follows: (1) IL anion type (the number of atoms it is composed o growth; apart from this, $\pi-\pi$ stacking of imidazolium cations promotes the ILs role as templating agents); (3) cation-anion interaction energy where the frailer, the weaker the cation-anion interactions, the firmer the capping on growing the $\mathrm{TiO}_{2}$ particles and the more efficient the inhibition/hampering of the unfavorable Ostwald ripening process; and (4) the type of overall interactions ( $\pi-\pi$, van der Waals, coulomb and electrostatic forces, and hydrogen bonding) $[15,16,21,25]$.

Furthermore, the proposed fons et orgio of the influences on the $\mathrm{TiO}_{2}$ photoactivity are tenable, as follows: (1) doping with N, C, and F elements after ILs thermal decomposition; (2) directly sensitizing the $\mathrm{TiO}_{2}$ particles; (3) affecting the transfer of photo-generated charges through the bulk of particles; and (4) favoring oxygen vacancies and $\mathrm{Ti}^{3+}$ species formation during synthesis [26-28]. However, an up to date kinetics of the formation of the $\mathrm{TiO}_{2}$ particles during ionic liquid-assisted synthesis has not been presented and discussed.

In this regard, in this study, the $\mathrm{TiO}_{2}$ particles were synthesized solvothermally, with the assistance of the selected ionic liquid, ethylammonium nitrate $[\mathrm{EAN}]\left[\mathrm{NO}_{3}\right]$, which is one of the earliest reported in the literature of protic ionic liquid $[29,30]$.

Apart from prevailing in studies on the topics of the synthesis process and characterization of the IL-assisted $\mathrm{TiO}_{2}$ microparticles [22,30-32], we focused on evaluating the functional properties of the obtained micro-particles, namely, their photoactivity. Alongside this, we strived to infer the 
mechanisms of the ILs assistance through exploring the influence of selected ILs, illustrated with the example of ethylammonium nitrate [EAN][NO 3 [29].

We placed an emphasis on the essentiality of (1) researching VIS-light induced photoactivity in comparison to the already researched UV-induced photoactivity [19,25,33-35]; and (2) conducting research in the presence of a model pollutant (2a), neutral in terms of the photosensitization of $\mathrm{TiO}_{2}$, (2b) proposing a simple mechanism of degradation and mineralization, and (2c) with a low photoabsorption coefficient $[27,36,37]$. In contrast to the common choice of organic dyes (methylene blue, methyl orange, and rhodamine B) $[7,10,13,18,19,25,38,39]$, we applied phenol. Another imperative was that we excluded the minor ones in facilitating the photocatalysis reaction active species, while exposing the substantial ones through the active species scavenger tests.

In this article, we present the results of the previously non-analyzed and non-reviewed comprehensively $[\mathrm{EAN}]\left[\mathrm{NO}_{3}\right]$-assisted $\mathrm{TiO}_{2}$ microparticles, where the photocatalytic effect on the degradation and mineralization of phenol in aqueous solution vastly exceeded our expectations, reaching as high as an $82 \%$ degradation rate in our tests, which are described below. Moreover, for the first time, we have examined the kinetics of the $\mathrm{TiO}_{2}$ microsphere formation in the presence of ethylammonium nitrite ionic liquid.

\section{Results}

First of all, a set of samples with selected IL to titanium (IV) butoxide (TBOT) molar ratios were synthesized and characterized, taking into account the surface area and photoactivity. The sample labeling and the amount of ILs to the precursor used during the preparation procedure, as well as the specific surface area, pore volume of the obtained photocatalysts, and their photocatalytic activity under VIS irradiation are given in Table 1. On the basis of the photocatalytic effect, we chose the sample with the highest activity in order to examine the kinetics of the $\mathrm{TiO}_{2}$ microsphere formation in the presence of ethylammonium nitrite ionic liquid, which is shown in Figure 1. As presented in Table 1, the effect of the solvothermal synthesis duration $(3,6,12$, and $24 \mathrm{~h})$ on the surface properties as well as the photoactivity for the IL:TBOT ratio equaled to 1:1 were also investigated.

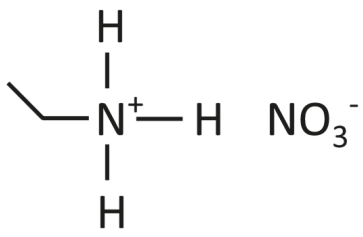

Figure 1. The structure of ethylammonium nitrite $[\mathrm{EAN}]\left[\mathrm{NO}_{3}\right]$ ionic liquid (IL).

\subsection{The BET Surface Area and SEM Analysis}

The results listed in Table 1 revealed the influence of the ionic liquid content on the specific surface area and the pore volume of the synthesized samples. All of the samples presented a higher specific surface area in comparison with the $\mathrm{TiO}_{2}$ synthesized without IL $\left(184 \mathrm{~m}^{2} \cdot \mathrm{g}^{-1}\right)$, and also than that reported for the commercially available P25 $\left(50 \mathrm{~m}^{2} \cdot \mathrm{g}^{-1}\right)[10,40]$. The values of the specific surface area for $\mathrm{TiO}_{2}$ prepared in the presence of $[\mathrm{EAN}]\left[\mathrm{NO}_{3}\right]$ ranged from $190 \mathrm{~m}^{2} \cdot \mathrm{g}^{-1}$ (sample prepared with the lowest IL:TBOT molar ratio, 1:10) to $233 \mathrm{~m}^{2} \cdot \mathrm{g}^{-1}$ for the sample obtained with IL:TBOT, with a molar ratio of 1:2. In this regard, the direct relation between the amount of the IL in the reaction mixture and the specific surface area for these photocatalysts was detected. However, a further increase in the IL content taken for the synthesis (up to IL:TBOT molar ratio of 1:1) resulted in a decrease of the pore volume, thus, the specific surface area was due, most probably, to the overloading of the $\mathrm{TiO}_{2}$ surface with organic salt. This might indicate that the ILs work like a designer agent of the microstructures' physical and structural properties. 
The scanning electron microscopy images of the pure $\mathrm{TiO}_{2}$ and IL-assisted $\mathrm{TiO}_{2}$ particles obtained for various molar ratios of IL:TBOT in the presence of [EAN] $\left[\mathrm{NO}_{3}\right]$ are presented in Figure 2. The pristine $\mathrm{TiO}_{2}$ exhibited a smooth surface with an average size from $0.5-4 \mu \mathrm{m}$. In the case of the $\mathrm{IL}-\mathrm{TiO}_{2}$ samples, it showed that the sample with the molar ratio 1:1 and the sample with a low amount of IL (1:8) presented a spherical structure and did not change in relation to the pristine $\mathrm{TiO}_{2}$.

Table 1. Characteristics of the $\mathrm{TiO}_{2}$ particles obtained by ethylammonium nitrite [EAN][ $\left.\mathrm{NO}_{3}\right]$ assisted solvothermal synthesis. IL-ionic liquid; TBOT_titanium (IV) butoxide.

\begin{tabular}{|c|c|c|c|c|c|c|}
\hline Sample & $\begin{array}{l}\text { Time of the } \\
\text { Synthesis }\end{array}$ & $\begin{array}{l}\text { Molar Ratio } \\
\text { (IL:TBOT) }\end{array}$ & $\begin{array}{c}\text { Specific } \\
\text { Surface Area } \\
\left(\mathrm{m}^{2} \cdot \mathrm{g}^{-1}\right)\end{array}$ & $\begin{array}{c}\text { Pore } \\
\text { Volume } \\
\left(\mathrm{cm}^{3} \cdot \mathrm{g}^{-1}\right)\end{array}$ & $\begin{array}{c}\text { Phenol } \\
\text { Degradation } \\
\text { Efficiency under } \\
60 \text { min of VIS } \\
\text { Irradiation } \\
(\%)\end{array}$ & $\begin{array}{c}\text { Rate of Phenol } \\
\text { Degradation under } \\
\text { Visible Light } \\
(\lambda>420) \\
{\left[\mu \mathrm{mol} \cdot \mathrm{dm}^{-3} \cdot \mathrm{min}^{-1} \text { ] }\right.}\end{array}$ \\
\hline $\mathrm{TiO}_{2 \_ \text {pristine }}$ & 24 & - & 184 & 0.069 & 7 & 0.18 \\
\hline $\mathrm{TiO}_{2}$ EAN $(1: 10) \_24 \mathrm{~h}$ & 24 & $1: 10$ & 190 & 0.093 & 28 & 1.01 \\
\hline $\mathrm{TiO}_{2}$ EAN $(1: 8) \_24 \mathrm{~h}$ & 24 & $1: 8$ & 211 & 0.102 & 19 & 0.55 \\
\hline $\mathrm{TiO}_{2 \_} \mathrm{EAN}(1: 5) \_24 \mathrm{~h}$ & 24 & $1: 5$ & 216 & 0.105 & 33 & 1.11 \\
\hline $\mathrm{TiO}_{2} \_\mathrm{EAN}(1: 3) \_24 \mathrm{~h}$ & 24 & $1: 3$ & 216 & 0.105 & 36 & 1.17 \\
\hline $\mathrm{TiO}_{2} \_\mathrm{EAN}(1: 2) \_24 \mathrm{~h}$ & 24 & $1: 2$ & 233 & 0.113 & 41 & 1.32 \\
\hline $\mathrm{TiO}_{2 \_} \mathrm{EAN}(1: 1) \_24 \mathrm{~h}$ & 24 & $1: 1$ & 221 & 0.108 & 82 & 3.12 \\
\hline $\mathrm{TiO}_{2} \_\mathrm{EAN}(1: 1) \_3 \mathrm{~h}$ & 3 & $1: 1$ & 239 & 0.12 & 75 & 2.28 \\
\hline $\mathrm{TiO}_{2}$ EAN(1:1)_6h & 6 & $1: 1$ & 207 & 0.101 & 75 & 2.38 \\
\hline $\mathrm{TiO}_{2}$ EAN(1:1)_12h & 12 & $1: 1$ & 209 & 0.102 & 80 & 2.53 \\
\hline
\end{tabular}
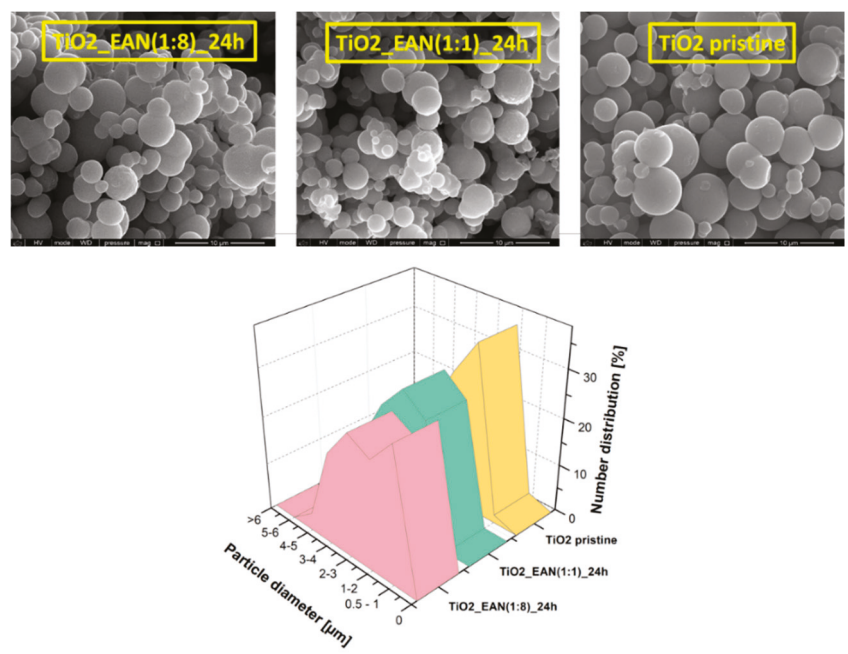

Figure 2. SEM images of $\mathrm{TiO}_{2}$ obtained from IL-assisted solvothermal synthesis, $\mathrm{TiO}_{2}$ EAN(1:8)_24h, $\mathrm{TiO}_{2}$ EAN(1:1)_24h, and reference $\mathrm{TiO}_{2}$.

The experiments of the $\mathrm{TiO}_{2} \mathrm{EAN}(1: 1) \_24 \mathrm{~h}$ sample preparation performed at different time regimes revealed that $3 \mathrm{~h}$ of solvothermal synthesis was enough to obtain the $\mathrm{TiO}_{2}$ microspheres (see SEM images, presented in Figure 3 below). However, the reaction yield was relatively low (only 19\%) and increased with the increasing reaction time ( $38 \%$ for $6 \mathrm{~h}, 65 \%$ for $12 \mathrm{~h}$, and $93 \%$ for $24 \mathrm{~h}$ ). Moreover, the elongation of the synthesis time resulted, at first, in the decrease of the specific surface area from $239 \mathrm{~m}^{2} \cdot \mathrm{g}^{-1}$ (after $3 \mathrm{~h}$ ) to $207 \mathrm{~m}^{2} \cdot \mathrm{g}^{-1}$ (after $6 \mathrm{~h}$ ), and then in the enlargement of the specific surface area to $221 \mathrm{~m}^{2} \cdot \mathrm{g}^{-1}$ (after $24 \mathrm{~h}$ ).

An explanation of this observation may be found in the SEM images of the microparticles prepared with the same amount of substrates (molar ratio of TBOT to ILs equaling 1:1), however, with different 
times of thermal treatment $(3,6,12$, and $24 \mathrm{~h})$ presented in Figure 3. In all of the introduced variations, the majority of the particles lay within the scope of $1-3 \mu \mathrm{m}$ for $3 \mathrm{~h}(48 \%), 2-3 \mu \mathrm{m}$ for $6(24 \%)$ and $24 \mathrm{~h}(28 \%)$, and $3-4 \mu \mathrm{m}$ for $12 \mathrm{~h}(19 \%)$. The percentage contribution of the particles with a diameter above $4 \mu \mathrm{m}$ was rarely reached and never exceeded $15 \%$ for all of the obtained samples. In the image sequences presented below, we noted that the sample subjected to thermal treatment for $3 \mathrm{~h}$ was mainly composed of a large number of small spherical particles with a range of $1-3 \mu \mathrm{m}$. Nonetheless, between the particles synthesized in 6, 12, and $24 \mathrm{~h}$ regimes, less of a difference was recognized. In this regard, the high surface area of the particles prepared within $3 \mathrm{~h}$ may be related to a higher contribution of the smallest particles.

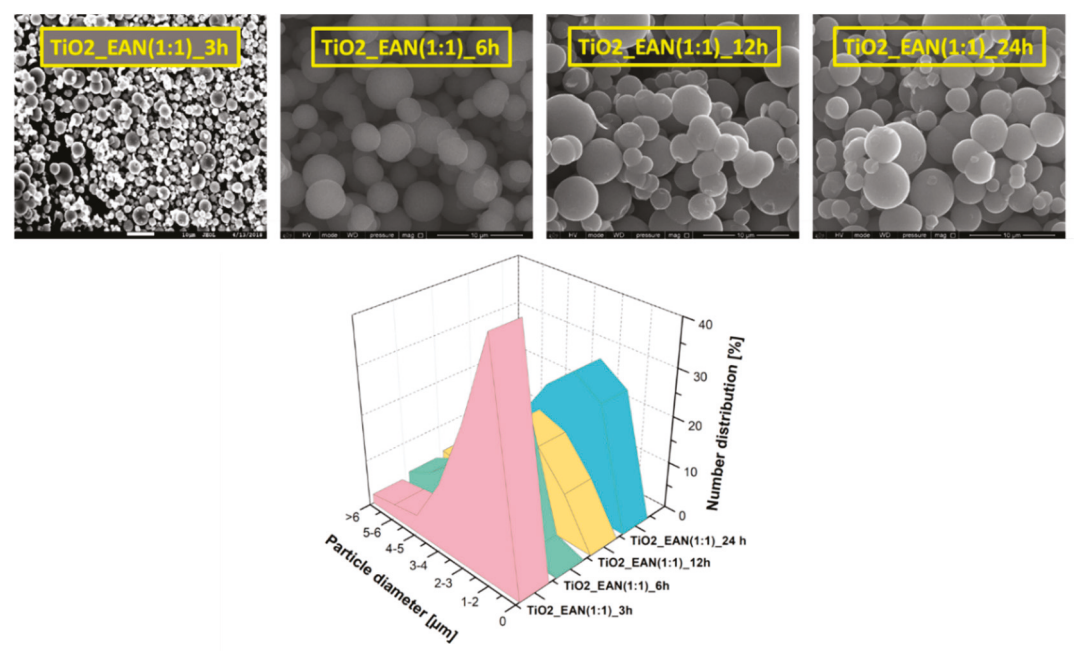

Figure 3. SEM images of $\mathrm{TiO}_{2}$ EAN(1:1) obtained in different synthesis times of 3, 6, 12, and $24 \mathrm{~h}$.

\subsection{XRD Analysis}

The PXRD patterns for the series of $\mathrm{TiO}_{2}$ EAN are presented in Figures 4 and 5 . All of the patterns looked similar as the samples only contained the anatase $\left(\mathrm{TiO}_{2}\right)$ phase. The open circles represent the experimental data points, a solid red line is a profile fitting (LeBail method), and the vertical bars mark the positions of the expected Bragg reflections for the used model (I 41/a m d, s.g. \#141). The LeBail fit given lattice parameters for $\mathrm{TiO}_{2}$ are gathered in Table 2. The lattice parameters were similar and are close to those reported by Djerdj and Tonejc [41]. The PXRD reflections were broad, which indicated a small crystallite size estimated to be between 5.0 and $6.5 \mathrm{~nm}$. However, no correlation was observed between the amount of ionic liquid taken for the synthesis nor for the preparation time and the crystallite size.

Table 2. Lattice parameters and average crystallite size of the $\mathrm{TiO}_{2} \_\mathrm{EAN}$ photocatalysts.

\begin{tabular}{|c|c|c|c|}
\hline Sample & a (§̊) & c (@) & d (Å) \\
\hline $\mathrm{TiO}_{2}$ EAN(1:1)_3h & $3.8051(3)$ & $9.554(2)$ & 65 \\
\hline $\mathrm{TiO}_{2}$ EAN $(1: 1)_{6} 6 \mathrm{~h}$ & $3.7907(7)$ & $9.504(3)$ & 50 \\
\hline $\mathrm{TiO}_{2}$ EAN(1:1)_12h & $3.7892(6)$ & $9.507(3)$ & 55 \\
\hline $\mathrm{TiO}_{2}$ EAN(1:1)_24h & $3.7890(6)$ & $9.502(3)$ & 60 \\
\hline $\mathrm{TiO}_{2}$ EAN(1:2)_24h & $3.7899(7)$ & $9.499(3)$ & 55 \\
\hline $\mathrm{TiO}_{2} \mathrm{EAN}(1: 3) \_24 \mathrm{~h}$ & $3.7926(8)$ & $9.506(4)$ & 60 \\
\hline $\mathrm{TiO}_{2}$ EAN(1:5)_24h & $3.7814(11)$ & $9.472(6)$ & 65 \\
\hline $\mathrm{TiO}_{2} \_\mathrm{EAN}(1: 8) \_24 \mathrm{~h}$ & $3.7953(9)$ & $9.483(5)$ & 55 \\
\hline $\mathrm{TiO}_{2}$ EAN(1:10)_24h & $3.7942(12)$ & $9.476(7)$ & 55 \\
\hline
\end{tabular}




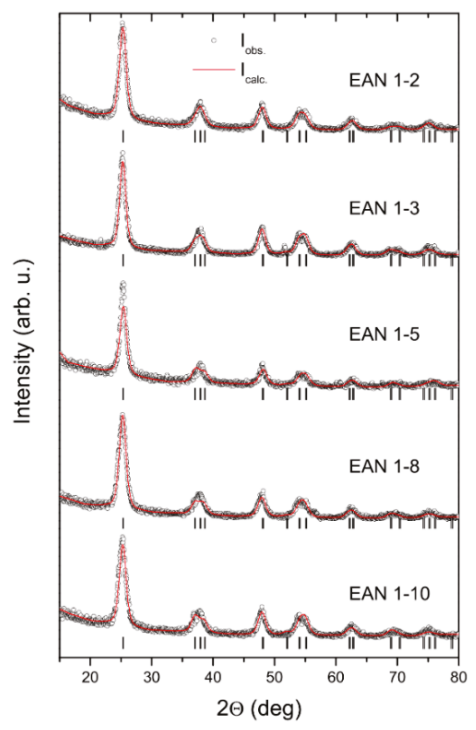

Figure 4. XRD pattern of $\mathrm{TiO}_{2}$ EAN prepared with different IL-titanium (IV) butoxide (TBOT) molar ratios. A solid line is a profile fit to the experimental data (open circles). The Bragg reflections are marked by vertical bars.

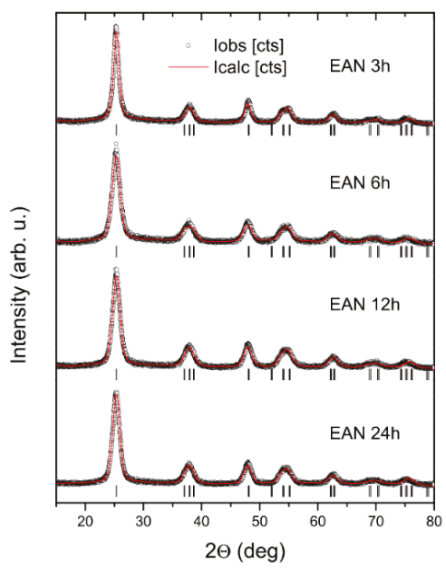

Figure 5. XRD pattern of the $\mathrm{TiO}_{2}$ EAN prepared with the IL-TBOT molar ratio of 1:1, synthesized at different synthesis times. A solid line is a profile fit to the experimental data (open circles). The Bragg reflections are marked by vertical bars.

\subsection{X-ray Photoelectron Spectroscopy (XPS) Analysis}

The elemental surface composition of the selected $\mathrm{IL}-\mathrm{TiO}_{2}$ specimens, evaluated by XPS, is shown in Table 3. Titanium, oxygen, carbon, and nitrogen were detected and the corresponding high-resolution (HR) XPS spectra of Ti 2p, O 1s, C 1s, and N 1s are presented in Figure 6. The chemical character of the elements is identified in the deconvoluted spectra in Figure 6 and Table 3. The Ti 2p, $\mathrm{O} 1 \mathrm{~s}$, and $\mathrm{C} 1 \mathrm{~s}$ spectra exhibited features that were characteristic of the $\mathrm{IL}^{-} \mathrm{TiO}_{2}$ specimens $[16,42]$. The $\mathrm{N} 1 \mathrm{~s}$ signal at $400 \mathrm{eV}$ is commonly interpreted as the surface $\mathrm{C}-\mathrm{N}$ bond. Only for the $\mathrm{TiO}_{2}$ EAN(1:1) 
sample thermally treated for $24 \mathrm{~h}$ was the additional signal that appeared at about $402.8 \mathrm{eV}$ observed, which may be assigned to the oxidized nitrogen surface species.

The XPS data collected in Table 3 revealed that the surface chemical composition of the $\mathrm{TiO}_{2} \_\mathrm{EAN}(1: 1) \_24 \mathrm{~h}$ samples were different than the sample of the lower amount of $\mathrm{TiO}_{2}$ EAN(1:8)_24h. For the last one, the contribution of the $\mathrm{Ti}^{(3+)}$ fraction was about $30 \%$ smaller and the nitrogen amount was evidently lower than for the $\mathrm{TiO}_{2}$ EAN(1:1)_24h sample. These observations confirmed a higher amount of IL on the $\mathrm{TiO}_{2}$ EAN(1:1)_24h sample surface (an analogous relation was also observed for the carbon atom). In the series of $\mathrm{TiO}_{2} \mathrm{EAN}(1: 1)$ samples, differing by the time of thermal treatment, we noted a systematic decrease in the oxygen of the Ti- $\mathrm{O}_{\text {surf }}$ fraction, with an increasing time of the thermal treatment from 6 to $24 \mathrm{~h}$, and a significantly smaller surface concentration of nitrogen for the $24 \mathrm{~h}$ synthesized sample (Table 3). Moreover, for the last sample, the oxidized form of the nitrogen species appeared in addition to the main nitrogen $\mathrm{N}-\mathrm{C}$ surface fraction (Figure 6). These observations indicated the surface transformation of the IL-assisted $\mathrm{TiO}_{2}$ with the prolonged time of thermal treatment.

To elucidate the effect of the phenol-degradation processing on the chemical composition of the $\mathrm{TiO}_{2}$ EAN photocatalyst, we analyzed both the sample after three cycles of photocatalytic processing and the same sample washed with deionized water. The results are compared in Figure 6 and Table 3 . One can see that the nitrogen atom concentration was similar for both of the samples. However, the water washed sample exhibited a significantly larger surface amount of titanium faction $\mathrm{Ti}^{(3+)}$ and a relatively higher contribution of $-\mathrm{OH}$ surface species (see $\mathrm{O} 1 \mathrm{~s}$ and $\mathrm{C} 1 \mathrm{~s}$ fractions in Table 3 ).

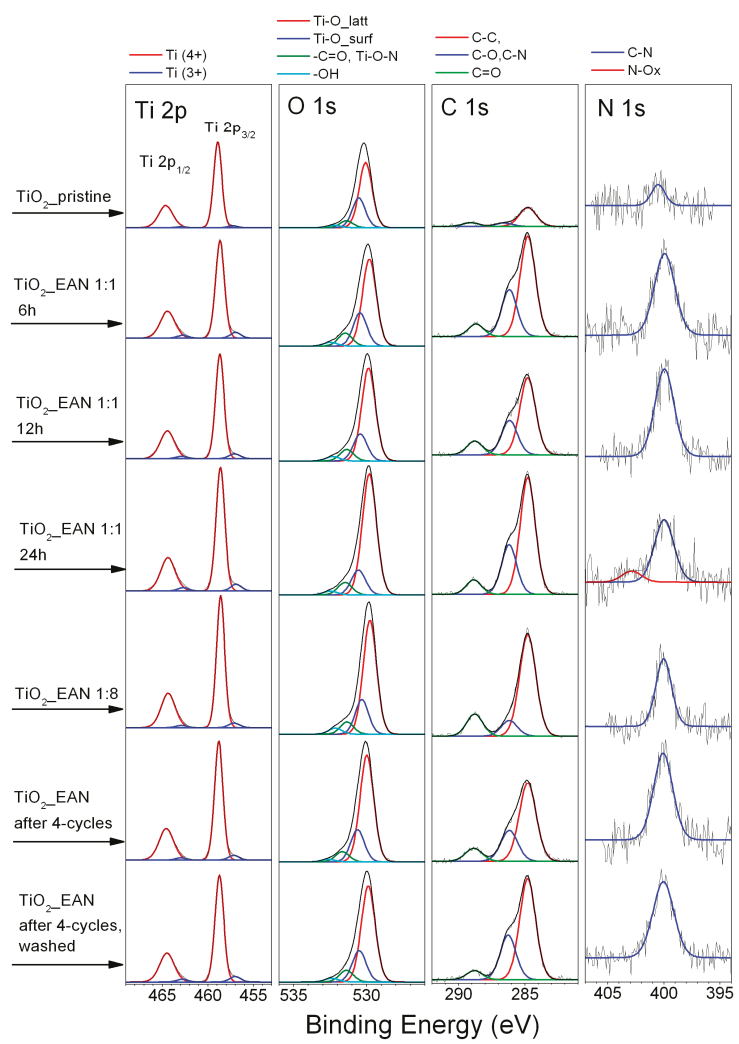

Figure 6. High resolution X-ray photoelectron spectroscopy (XPS) spectra of elements detected in the surface layer of the $[\mathrm{EAN}]\left[\mathrm{NO}_{3}\right]$-modified $\mathrm{TiO}_{2}$ particles. 


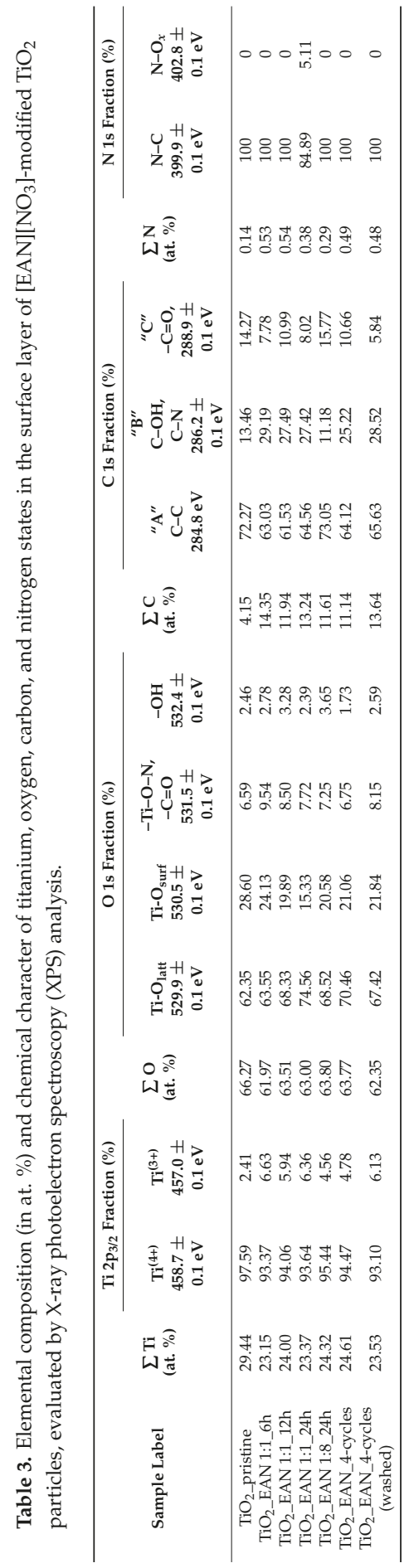




\subsection{UV-VIS Spectrum}

The UV-VIS adsorption spectra of the $\mathrm{TiO}_{2}$ synthesized with various molar ratios of [EAN] $\left[\mathrm{NO}_{3}\right]$ to TBOT are presented in Figure 7. Pristine $\mathrm{TiO}_{2}$ was only photoactive under the UV region $(\lambda<400 \mathrm{~nm})$. The addition of the ionic liquid to the $\mathrm{TiO}_{2}$ synthesis environment increased the absorption range of $\mathrm{IL}-\mathrm{TiO}_{2}$, being noticeably photoactive at above $420 \mathrm{~nm}$. The absorption properties of the samples prepared with IL were superior in comparison with the pristine $\mathrm{TiO}_{2}$ in the visible light range, whereas all of the samples showed a similar UV absorption. Generally, a higher IL amount used for synthesis resulted in the enhancement of the VIS light absorption by the IL- $\mathrm{TiO}_{2}$ photocatalysts.

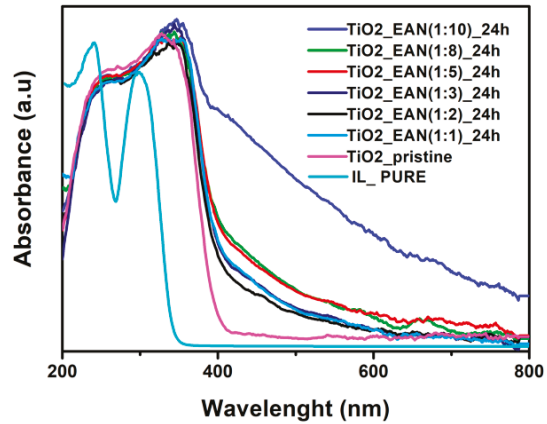

Figure 7. UV-VIS adsorption spectra of $\mathrm{TiO}_{2}$ synthesized using various molar ratios of [EAN][ $\left.\mathrm{NO}_{3}\right]$ to TBOT.

Interesting results were also obtained for the experiments where the influence of the reaction time was taken into account (Figure 8). When increasing the reaction time, the enhancement of the visible light absorption by $\mathrm{IL}-\mathrm{TiO}_{2}$ was observed. Thereby, the sample prepared during $24 \mathrm{~h}$ was characterized by a significantly broader absorption as well as the highest red shift of the absorption edge; thus, there was a higher effectiveness in creating the electron-hole pairs.

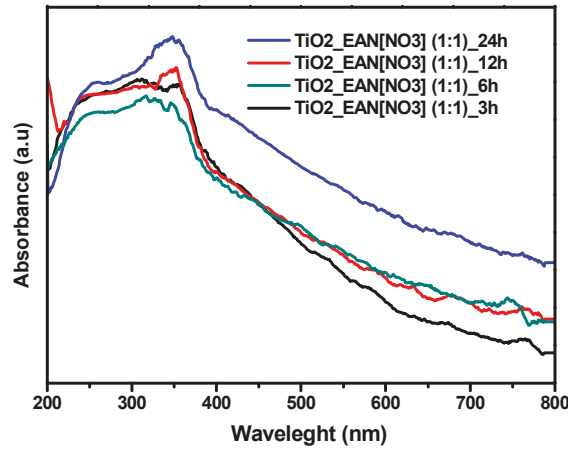

Figure 8. UV-VIS adsorption spectra of $\mathrm{TiO}_{2}$ EAN(1:1) photocatalyst prepared in 3, 6, 12, and $24 \mathrm{~h}$.

According to the literature, a significant increase in the absorption of visible light by $\mathrm{TiO}_{2}$ can be related with the presence of carbon atoms in the sample [43-47]. As the carbon species exist mainly on the $\mathrm{TiO}_{2}$ surface rather than occupying the lattice of $\mathrm{TiO}_{2}$, the visible light response of the samples was attributed to the formation of the inter band C2p states [48]. However, our observations revealed that a correlation between the content of the IL used for the sample preparation and the apparent enhanced absorption of visible light was not observed. Additionally, based on the XPS analysis, a similar amount 
of at. \% of carbon was observed for the samples containing small amounts of IL, as well as the sample with a higher IL content.

\subsection{Photocatalytic Activity of $\mathrm{IL}-\mathrm{TiO}_{2}$ in Phenol Decomposition Model Reaction}

The photocatalytic activity of the $\mathrm{IL}-\mathrm{TiO}_{2}$ samples was evaluated by the degradation of the phenol model compound under visible light $(\lambda>420 \mathrm{~nm})$ irradiation. The obtained results are summarized in Table 1 and presented in Figure 9. As above-mentioned, before illumination, the solution was stirred for $30 \mathrm{~min}$ in the dark to establish a molecular adsorption equilibrium. Pristine $\mathrm{TiO}_{2}$ synthesized by the solvothermal method, without addition of the ionic liquid, was used as the reference sample. For comparison purposes, the photocatalytic activity result of $\mathrm{P} 25 \mathrm{TiO}_{2}$ under UV-VIS irradiation was also shown.

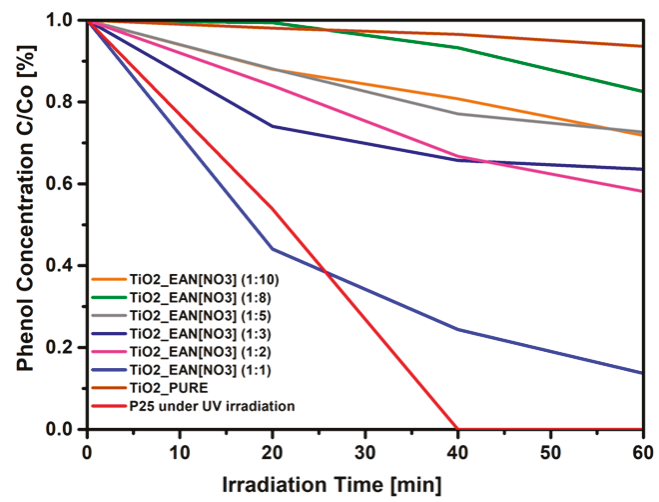

Figure 9. Efficiency of phenol degradation under visible light $(\lambda>420 \mathrm{~nm})$ in the presence of $\mathrm{TiO}_{2}$ prepared in $[\mathrm{EAN}]\left[\mathrm{NO}_{3}\right]$ and under UV-VIS light for P25.

It was found that the $\mathrm{TiO}_{2}$ EAN microparticles exhibited a higher photoefficiency than the pristine $\mathrm{TiO}_{2}$, which is also consistent with the higher BET specific surface areas and enhanced optical properties. After 60 min of the photocatalytic process, $7 \%$ of the phenol was degraded using unmodified $\mathrm{TiO}_{2}$, however, the $\mathrm{TiO}_{2}$ EAN efficiency was higher, and was strongly influenced by the amount of ILs that were used during the synthesis. For example, up to $82 \%$ of the phenol was degraded in the presence of photocatalyst $\mathrm{TiO}_{2}$ EAN(1:1)_24h, where the molar ratio of $[\mathrm{EAN}]\left[\mathrm{NO}_{3}\right]$ to $\mathrm{TBOT}$ taken for synthesis was 1:1. This value was about 5.5 times higher when compared to the pristine $\mathrm{TiO}_{2}$, indicating its excellent photocatalytic activity. This observation was correlated with the UV-VIS adsorption spectra, where the $\mathrm{TiO}_{2} \_\mathrm{EAN}(1: 1) \_24 \mathrm{~h}$ sample showed the highest extension of the absorption edge to the visible light region. It was found that the samples prepared with IL:TBOT molar ratios of 1:10 and 1:8 revealed the lowest photoactivity among the photocatalysts that were obtained in the presence of ethylammonium nitrate IL. In this regard, the photodegradation efficiency increased with the increase in the quantity of ionic liquid taken to synthesis (thereby, the IL present at the $\mathrm{TiO}_{2}$ surface).

In addition, the efficiency of the phenol total mineralization by the sample with the highest photoactivity was also determined. The total organic carbon measurements confirmed $20 \%$ of the total mineralization of the phenol after $60 \mathrm{~min}$ of irradiation in a presence of the $\mathrm{TiO}_{2}[\mathrm{EAN}](1: 1) \_24 \mathrm{~h}$ sample that was performed under VIS irradiation and $48 \%$ under UV-VIS irradiation.

Moreover, the efficiency of the phenol degradation was also related with the time of the solvothermal synthesis, as determined for the $\mathrm{TiO}_{2}$ EAN(1:1) sample. The microparticles of $\mathrm{TiO}_{2}$ EAN(1:1)_3h formed during only $3 \mathrm{~h}$ of the synthesis time revealed a really high photoactivity under visible irradiation at $75 \%$. This value increased to $80 \%$ and $82 \%$ after $12 \mathrm{~h}$ and $24 \mathrm{~h}$, respectively. The photoactivity increase was accompanied by an increase in the specific surface area, thus the 
pore sizes as well as the ability to absorb UV-VIS irradiation. Additionally, based on the XPS measurements, it was concluded that the increase in the visible light absorption and the enhancement of the photocatalytic activity may be related to the highest quantity of the carbon and $\mathrm{Ti}^{(+3)}$ defects at the $\mathrm{TiO}_{2}$ surface.

To investigate the degradation/regeneration capacity and the structural stability during the entire process, we performed stability tests for the sample characterized by the best photocatalytic activity under VIS light irradiation. In the stability tests, the same sample was repeatedly used in the phenol photodegradation reaction three times. As shown in Figure 10, a significant drop in the phenol removal, from $84 \%$ to $33 \%$, was found.

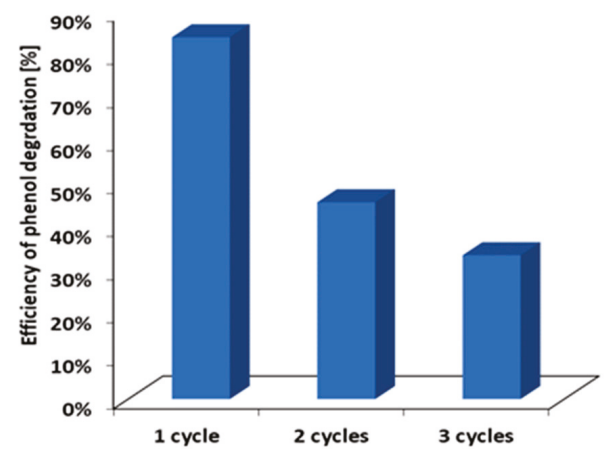

Figure 10. Phenol removals in the photodegradation using the $\mathrm{TiO}_{2}$ microspheres in a cycled mode.

In order to further clarify the possible mechanism of phenol degradation, reactive species trapping tests were designed. Controlled photoactivity experiments using different radical scavengers (ammonium oxalate as a scavenger for $\mathrm{h}^{+}, \mathrm{AgNO}_{3}$ as a scavenger for $\mathrm{e}^{-}$, benzoquinone as a scavenger for $\mathrm{O}_{2} \bullet^{-}$radical species, and tert-butyl alcohol as a scavenger for $\bullet \mathrm{OH}$ species) were carried out similarly to the above described photocatalytic degradation process. The only exception was that the radical scavengers were added to the reaction system. The addition of ammonium oxalate and $\mathrm{AgNO}_{3}$ had a weak inhibition efficiency of the phenol degradation, indicating that $\mathrm{h}^{+}$and $\mathrm{e}^{-}$had a negligibly small effect on the mechanism of photocatalytic degradation. The photocatalytic conversion fell by approximately half when the tert-butyl alcohol (TBA) as the scavenger for the hydroxyl radicals was used. As shown in Figure 11, when benzoquinone as the trapping agent of $\mathrm{O}_{2} \bullet^{-}$was added into the phenol solution under visible irradiation, the photodegradation of phenol significantly declined to about $7 \%$. These results clearly suggest that the photocatalytic degradation of phenol under VIS irradiation in the presence of $\mathrm{TiO}_{2}$ EAN(1:1) was mainly intimate, with the photogenerated superoxide radical species. Secondly, the photogenerated $\mathrm{OH}$ radicals were also involved in the decomposition of phenol.

To explain what might have contributed to the increase in the photoactivity of $\mathrm{TiO}_{2} \mathrm{ILs}$, the decomposition level of the ionic liquid cations was investigated using chromatography techniques. It was demonstrated that the ethylammonium nitrate ionic liquid was degraded in $97 \%$ after $24 \mathrm{~h}$ of the solvothermal reaction. Therefore, it is most likely that $\mathrm{TiO}_{2}$ could be doped with nitrogen and carbon, and/or surface-modified by carbon species. However, based on the XPS analysis, the Ti-N interactions between the released nitrogen atoms, resulting from the IL's thermal decomposition, and the $\mathrm{TiO}_{2}$ matrix, have not been observed. Thus, although we could expect the incorporation of nitrogen and carbon atoms in a crystalline lattice of $\mathrm{TiO}_{2}$, the performed analysis did not confirm it. Nevertheless, it should be remembered that because of the low ionic liquid content on the $\mathrm{TiO}_{2}$ surface, a low level of XPS detection (d.1. = 0.1 at. \%) could affect the results. According to the literature, it could be generally stated that if $\mathrm{TiO}_{2}$ particles grow in the presence of the $\mathrm{N}$ and $\mathrm{C}$ precursors and under 
elevated temperature conditions, usually, the $\mathrm{N}$ and $\mathrm{C}$ atoms are incorporated into the crystal lattice of the semiconductors [49-51].

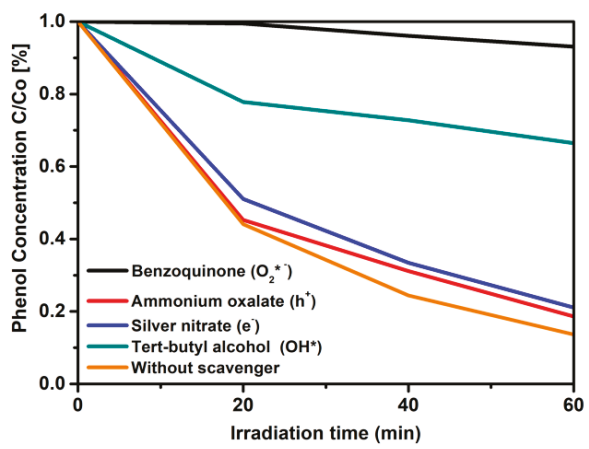

Figure 11. Effect of the addition of different radical scavengers on the phenol degradation over $\mathrm{TiO}_{2}$ EAN(1:1)_24h composites under visible light irradiation. Initial pH 6.5, $20 \mathrm{mg} / \mathrm{L}$, light intensity 3 $\mathrm{mW} / \mathrm{cm}^{2}$.

To identify the origin of visible light-induced activity, the phenol degradation rate was plotted depending on the surface area values as well as the carbon and nitrogen content in the surface layer. The data presented in Figure 12 suggests that the observed increase in photoactivity could be most interpreted by the presence of nitrogen in the surface layer. Although the origin of photoactivity is not clear at this moment, it is crucial to note that the preparation of highly active $\mathrm{TiO}_{2}$ spheres was developed.

(a)

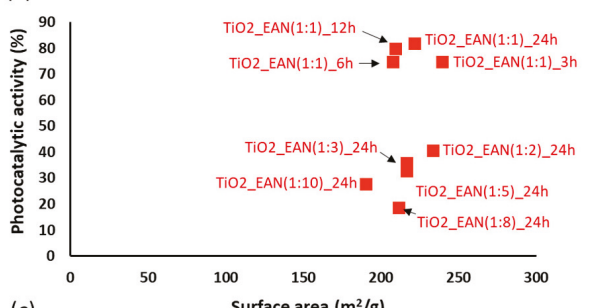

(c)

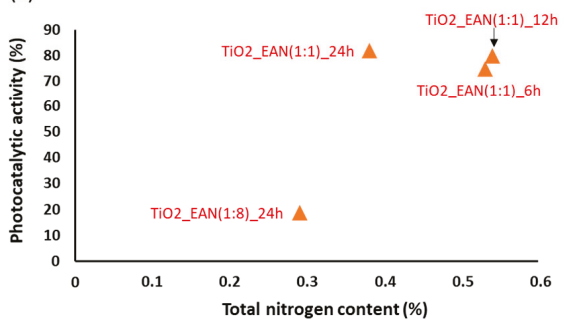

(b)
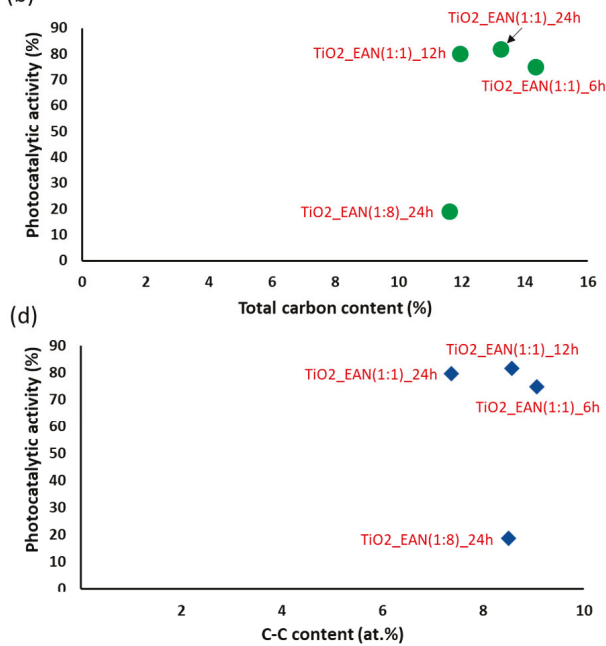

Figure 12. Dependence of the (a) surface area, (b) total carbon content, (c) total nitrogen content (d) C-C content of the photocatalytic activity. 


\section{Materials and Methods}

\subsection{Materials}

For the aforementioned synthesis' purpose, the following reagents were applied: (1) titanium (IV) butoxide (TBOT) as the $\mathrm{TiO}_{2}$ micro-particles direct precursor, and (2) 36\% hydrochloric acid $(\mathrm{HCl})$ as a pH stabilizer, sourced from Sigma-Aldrich; (3) anhydrous ethyl alcohol (99.8\% ethanol) as the reaction medium (from POSCH S.A., Troine, Luxembourg); (4) ethylammonium nitrate (from IOLITEC, Heilbronn, Germany, purveyed with $\geq 97 \%$ of purity) as the assisting ionic liquid; and (5) deionized water, provided locally.

\subsection{Preparation of IL-Assisted $\mathrm{TiO}_{2}$ Particles}

The preparation of the $\mathrm{TiO}_{2}$ micro-particles was carried out emulating the method reported by Paszkiewicz et al. [16], summarized as follows: (1) TBOT was dispersed in ethanol through dropwise pouring under constant vigorous stirring; and (2) $\mathrm{HCl}$, deionized water, and the due amount of IL-adequate to the applied molar ratio of TBOT to IL-were dissolved under unchanged conditions, to the point of attaining a pellucid solution. Afterwards, the ensuing mixture was transferred into an inner Teflon and an outer stainless steel autoclave, to be incubated at $180{ }^{\circ} \mathrm{C}$ for $24 \mathrm{~h}$ (for various TBOT to IL molar ratios) and for 6, 12, and $24 \mathrm{~h}$ (for 1:1 TBOT to IL molar ratio) for the purpose of the kinetics of the crystal growth evaluation. Subsequently, the autoclaves were cooled down to room temperature and the obtained precipitate was cleansed through numerous washings with deionized water and ethanol, and then dried at $60^{\circ} \mathrm{C}$ for $4 \mathrm{~h}$. The preparation ended with the $2 \mathrm{~h}$ calcination of plateau at $200{ }^{\circ} \mathrm{C}$, which was reached at the $2{ }^{\circ} \mathrm{C} / \mathrm{min}$ slope. For reference, the pristine $\mathrm{TiO}_{2}$ was as-synthetized, with the exception of the IL presence.

\subsection{Surface Properties Characterization}

The Brunauer-Emmett-Teller (BET) surface area was calculated by the $\mathrm{N}_{2}$ absorption-desorption isotherms at $77 \mathrm{~K}$ on a Micromeritics Gemini V200 Shimadzu analyzer (equipped with the VacPrep 061 Degasser) (Norcross, GA, USA). The morphology of the $\mathrm{TiO}_{2}$ micro-particles was studied by scanning electron microscopy (SEM) analysis, performed under a Hitachi TM-1000 microscope (Tokyo, Japan). The chemistry of the surface was researched by X-ray photoelectron spectroscopy (XPS), the results were obtained with a PHI 5000 VersaProbeTM (ULVAC-PHI, Chigasaki, Japan) spectrometer of monochoromatic $\mathrm{Al} \mathrm{K} \alpha$ radiation $(\mathrm{h}=1486.6 \mathrm{eV})$. The phase purity of the samples was determined by powder X-ray diffraction (PXRD) using a PANalytical X'Pert Plus diffractometer (Almelo, The Netherlands) with $\mathrm{Cu} \mathrm{K} \alpha$ radiation. To determine the unit cell parameters, the profile fits were performed on the powder diffraction data through the use of the HighScore program using Thompson-Cox-Hastings pseudo-Voigt peak shapes. The average crystallite size was calculated using the Scherrer equation.

The decomposition level of the ionic liquid cations was analyzed using a Dionex ICS 1100 liquid chromatograph. Deionized water containing 0.21\% (v/v) of methanesulfonic acid (Sigma Aldrich, St. Louis, MO, USA) was used as a mobile phase. The separation was carried out isocratically using a Dionex (Sunnyvale, CA, USA) ION PAC, CS16 column $(3 \times 250 \mathrm{~mm}$ Dionex $)$ at $35^{\circ} \mathrm{C}$. The flow rate was $0.36 \mathrm{~mL} \mathrm{~min}^{-1}$. Each sample (before and after solvothermal reaction) was measured in triplicate. The decomposition level was calculated as follows:

$$
\mathrm{nIL}(\%)=100 \times \mathrm{C}_{0}-\mathrm{C} / \mathrm{C}_{0}
$$

where $\mathrm{C}_{0}$ is the initial concentrations of the cations of the ILs; and $\mathrm{C}$ is the concentrations of the cations of the ILs after the solvothermal reaction. 


\subsection{Evaluation of Photocatalytic Activity}

The photocatalytic activity was measured through the phenol decomposition rate under visible-light irradiation. For this aim, we dispersed $0.125 \mathrm{~g}$ of the obtained photocatalyst in $25 \mathrm{~mL}$ of phenol aqueous solution $\left(C_{0}=25 \mathrm{mg} / \mathrm{L}\right)$, inside a cylindrical reactor with a circular quartz window. In use, there was a reactor fitted with a cooling jacket; during the reaction, it was cooled by the constant flow of water at $\leq 10^{\circ} \mathrm{C}$, supplied in aeration at $5 \mathrm{dm}^{3} / \mathrm{h}$. The reactor's quartz-windowed side was exposed to the illumination of intensity equaling to $3 \mathrm{~mW} / \mathrm{cm}^{2}$ (by $1000 \mathrm{~W}$ Xenon lamp, 6271H Oriel; optical filter $>420 \mathrm{~nm}$, GG 420).

In order to establish the absorption-desorption equilibrium between the phenol and photocatalyst prior to the reaction, the suspension was allocated to $30 \mathrm{~min}$ long stirring in the dark, preliminarily to the photo-initiation of the catalysis; then, about $1 \mathrm{~mL}$ of the suspension was sampled from the reactor. During the irradiation, the samples were taken in 3 and $20 \mathrm{~min}$ intervals. Each sample was filtered through syringe filters $(\Phi=0.2 \mu \mathrm{m})$ for the removal of the photocatalyst micro-particles, anterior to the due evaluation. The concentration of the remaining phenol was measured colorimetrically $(\lambda \max =480 \mathrm{~nm})$, after the derivatization with diazo-p-nitroaniline with a UV-VIS spectrometer (Evolution 220, Thermo-Scientific, Waltham, MA, USA).

The controlled photoactivity experiments were carried out using different scavengers (ammonium oxalate as a scavenger of photogenerated holes, $\mathrm{AgNO}_{3}$ for electrons, benzoquinone for superoxide radical species, and tert-butyl alcohol for hydroxyl radical species). The scavenger concentration was equal to the phenol content, and experiments were performed analogously to the photocatalytic degradation of the phenol described in the manuscript, except that the scavengers were added to the reaction system.

\section{Conclusions}

This study is the first step towards enhancing our understanding of the effect of ethylammonium nitrate ionic liquids on the surface properties of the $\mathrm{TiO}_{2}$ spheres formed in the solvothermal synthesis. In summary, the $\mathrm{TiO}_{2}$ microspheres with a superior visible-light photocatalytic activity were prepared in the presence of the ethylammonium nitrate ionic liquid, using a solvothermal method followed by a calcination process. It should be highlighted that the most active $\mathrm{TiO}_{2}$ samples formed in the presence of $[\mathrm{EAN}]\left[\mathrm{NO}_{3}\right]$ possessed almost the same activity induced by visible light than $\mathrm{P}_{2} 5 \mathrm{TiO}_{2}$ under UV radiation. The phenol degradation rate was equal to $3.12 \mu \mathrm{mol} / \mathrm{dm}^{3} / \mathrm{min}$ for the $\mathrm{TiO}_{2}$ EAN/Vis system, and $3.46 \mu \mathrm{mol} / \mathrm{dm}^{3} / \mathrm{min}$ for the P25/UV system. In this paper, the kinetics of the highly active $\mathrm{TiO}_{2}$ microsphere formation in the presence of ethylammonium nitrate ionic liquid was examined. The obtained results revealed that the micro-particles of $\mathrm{TiO}_{2}$ EAN(1:1)_3h that formed during only $3 \mathrm{~h}$ of synthesis time revealed a really high photoactivity under visible irradiation at $75 \%$. This value increased to $80 \%$ and $82 \%$ after 12 and $24 \mathrm{~h}$, respectively. However, the reaction yield for the $3 \mathrm{~h}$ synthesis time was relatively low (only 19\%) and significantly increased with the increasing reaction time ( $38 \%$ for $6 \mathrm{~h}, 65 \%$ for $12 \mathrm{~h}$, and $93 \%$ for $24 \mathrm{~h}$ ). The photoactivity increase was accompanied by an increase in the specific surface area, thus the pore sizes as well as the ability to absorb the VIS irradiation.

The effective interactions between the ionic liquid components, mainly carbon, nitrogen, and the micro-particles surface of $\mathrm{TiO}_{2}$, were clearly demonstrated by the XPS analysis. This factor could result in excellent visible-light photocatalytic activity for the $\mathrm{IL}-\mathrm{TiO}_{2}$ samples prepared. The radical trapping experiments revealed that $\mathrm{O}_{2} \bullet$ and $\mathrm{OH} \bullet$ were the main active species during the degradation process.

Author Contributions: Conceptualization, A.Z.-M. and J.Ł.; funding acquisition, J.Ł.; investigation, A.G., M.C.-S., M.P.-G., W.L., E.R., T.K., Ż.P., and J.Ł.; project administration, E.G.; supervision, A.Z.-M. and J.Ł.; writing (original draft), A.G., W.L., E.R., T.K., E.G., and J.Ł.; writing (review and editing), A.Z.-M. and J.Ł.

Funding: This research was funded by the National Science Center within the program SONATA 8, research grant: 'Influence of the ionic liquid structure on interactions with $\mathrm{TiO}_{2}$ particles in ionic liquid assisted hydrothermal synthesis', contract No. 2014/15/D/ST5/02747. 
Conflicts of Interest: The authors declare no conflict of interest.

\section{References}

1. Hoffmann, M.R.; Martin, S.T.; Choi, W.; Bahnemann, D.W. Environmental applications of semiconductor photocatalysis. Chem. Rev. 1995, 95, 69-96. [CrossRef]

2. Fujishima, A.; Rao, T.N.; Tryk, D.A. Titanium dioxide photocatalysis. J. Photochem. Photobiol. C Photochem. Rev. 2000, 1, 1-21. [CrossRef]

3. Pelaez, M.; Nolan, N.T.; Pillai, S.C.; Seery, M.K.; Falaras, P.; Kontos, A.G.; Dunlop, P.S.M.; Hamilton, J.W.J.; Byrne, J.A.; O'Shea, K.; et al. A review on the visible light active titanium dioxide photocatalysts for environmental applications. Appl. Catal. B Environ. 2012, 125, 331-349. [CrossRef]

4. Fox, M.A.; Dulay, M.T. Heterogeneous photocatalysis. Chem. Rev. 1993, 93, 341-357. [CrossRef]

5. Thompson, T.L.; Yates, J.T. Surface science studies of the photoactivation of $\mathrm{TiO}_{2}$ new photochemical processes. Chem. Rev. 2006, 106, 4428-4453. [CrossRef] [PubMed]

6. Zhang, B.; Xue, Z.; Xue, Y.; Huang, Z.; Li, Z.; Hao, J. Ionic liquid-assisted synthesis of morphology-controlled $\mathrm{TiO}_{2}$ particles with efficient photocatalytic activity. RSC Adv. 2015, 5, 81108-81114. [CrossRef]

7. Ramanathan, R.; Bansal, V. Ionic liquid mediated synthesis of nitrogen, carbon and fluorine-codoped rutile $\mathrm{TiO}_{2}$ nanorods for improved UV and visible light photocatalysis. RSC Adv. 2015, 5, 1424-1429. [CrossRef]

8. Xu, H.; Ouyang, S.; Liu, L.; Reunchan, P.; Umezawa, N.; Ye, J. Recent advances in $\mathrm{TiO}_{2}$-based photocatalysis. J. Mater. Chem. A 2014, 2, 12642-12661. [CrossRef]

9. Zhang, F.; Sun, D.; Yu, C.; Yin, Y.; Dai, H.; Shao, G. A sol-gel route to synthesize $\mathrm{SiO}_{2} / \mathrm{TiO}_{2}$ well-ordered nanocrystalline mesoporous photocatalysts through ionic liquid control. New J. Chem. 2015, 39, 3065-3070. [CrossRef]

10. Alammar, T.; Noei, H.; Wang, Y.; Mudring, A.-V. Mild yet phase-selective preparation of $\mathrm{TiO}_{2}$ nanoparticles from ionic liquids-A critical study. Nanoscale 2013, 5, 8045-8055. [CrossRef] [PubMed]

11. Ahmed, E.; Breternitz, J.; Groh, M.F.; Ruck, M. Ionic liquids as crystallisation media for inorganic materials. CrystEngComm 2012, 14, 4874-4885. [CrossRef]

12. Bhattacharyya, K.; Majeed, J.; Dey, K.K.; Ayyub, P.; Tyagi, A.K.; Bharadwaj, S.R. Effect of Mo-Incorporation in the $\mathrm{TiO}_{2}$ Lattice: A mechanistic basis for photocatalytic dye degradation. J. Phys. Chem. C 2014, 118, 15946-15962. [CrossRef]

13. Yu, S.; Liu, B.; Wang, Q.; Gao, Y.; Shi, Y.; Feng, X.; An, X.; Liu, L.; Zhang, J. Ionic Liquid Assisted Chemical Strategy to $\mathrm{TiO}_{2}$ Hollow Nanocube Assemblies with Surface-Fluorination and Nitridation and High Energy Crystal Facet Exposure for Enhanced Photocatalysis. ACS Appl. Mater. Interfaces 2014, 6, 10283-10295. [CrossRef] [PubMed]

14. Gindri, I.M.; Frizzo, C.P.; Bender, C.R.; Tier, A.Z.; Martins, M.A.P.; Villetti, M.A.; Machado, G.; Rodriguez, L.C.; Rodrigues, D.C. Preparation of $\mathrm{TiO}_{2}$ nanoparticles coated with ionic liquids: A supramolecular approach. ACS Appl. Mater. Interfaces 2014, 6, 11536-11543. [CrossRef] [PubMed]

15. Łuczak, J.; Paszkiewicz, M.; Krukowska, A.; Malankowska, A.; Zaleska-Medynska, A. Ionic liquids for nano-and microstructures preparation. Part 1: Properties and multifunctional role. Adv. Colloid Interface Sci. 2016, 230, 13-28. [CrossRef] [PubMed]

16. Paszkiewicz, M.; Łuczak, J.; Lisowski, W.; Patyk, P.; Zaleska-Medynska, A. The ILs-assisted solvothermal synthesis of $\mathrm{TiO}_{2}$ spheres: The effect of ionic liquids on morphology and photoactivity of $\mathrm{TiO}_{2}$. Appl. Catal. B Environ. 2016, 184, 223-237. [CrossRef]

17. Kaur, N.; Singh, V. Current status and future challenges in ionic liquids, functionalized ionic liquids and deep eutectic solvent-mediated synthesis of nanostructured $\mathrm{TiO}_{2}$ : A review. New J. Chem. 2017, 41, 2844-2868. [CrossRef]

18. Wender, H.; Feil, A.F.; Diaz, L.B.; Ribeiro, C.S.; Machado, G.J.; Migowski, P.; Weibel, D.E.; Dupont, J.; Teixeira, S.R. Self-organized $\mathrm{TiO}_{2}$ nanotube arrays: Synthesis by anodization in an ionic liquid and assessment of photocatalytic properties. ACS Appl. Mater. Interfaces 2011, 3, 1359-1365. [CrossRef] [PubMed]

19. Qi, L.; Yu, J.; Jaroniec, M. Enhanced and suppressed effects of ionic liquid on the photocatalytic activity of $\mathrm{TiO}_{2}$. Adsorption 2013, 19, 557-561. [CrossRef]

20. Marr, P.C.; Marr, A.C. Ionic liquid gel materials: Applications in green and sustainable chemistry. Green Chem. 2016, 18, 105-128. [CrossRef] 
21. Chang, S.-M.; Lee, C.-Y. A salt-assisted approach for the pore-size-tailoring of the ionic-liquid-templated $\mathrm{TiO}_{2}$ photocatalysts exhibiting high activity. Appl. Catal. B Environ. 2013, 132, 219-228. [CrossRef]

22. Lopes, C.W.; Finger, P.H.; Mignoni, M.L.; Emmerich, D.J.; Mendes, F.M.T.; Amorim, S.; Pergher, S.B.C. $\mathrm{TiO}_{2}-\mathrm{TON}$ zeolite synthesis using an ionic liquid as a structure-directing agent. Microporous Mesoporous Mater. 2015, 213, 78-84. [CrossRef]

23. Yu, N.; Gong, L.; Song, H.; Liu, Y.; Yin, D. Ionic liquid of $[\mathrm{Bmim}]^{+} \mathrm{Cl}^{-}$for the preparation of hierarchical nanostructured rutile titania. J. Solid State Chem. 2007, 180, 799-803. [CrossRef]

24. Gołąbiewska, A.; Paszkiewicz-Gawron, M.; Sadzińska, A.; Lisowski, W.; Grabowska, E.; Zaleska-Medynska, A.; Łuczak, J. Fabrication and photoactivity of ionic liquid- $\mathrm{TiO}_{2}$ structures for efficient visible-light-induced photocatalytic decomposition of organic pollutants in aqueous phase. Beilstein J. Nanotechnol. 2018, 9, 580-590. [CrossRef] [PubMed]

25. Han, C.-C.; Ho, S.-Y.; Lin, Y.-P.; Lai, Y.-C.; Liang, W.-C.; Chen-Yang, Y.-W. Effect of $\pi-\pi$ stacking of water miscible ionic liquid template with different cation chain length and content on morphology of mesoporous $\mathrm{TiO}_{2}$ prepared via sol-gel method and the applications. Microporous Mesoporous Mater. 2010, 131, 217-223. [CrossRef]

26. Chen, Y.; Li, W.; Wang, J.; Gan, Y.; Liu, L.; Ju, M. Microwave-assisted ionic liquid synthesis of $\mathrm{Ti}^{3+}$ self-doped $\mathrm{TiO}_{2}$ hollow nanocrystals with enhanced visible-light photoactivity. Appl. Catal. B Environ. 2016, 191, 94-105. [CrossRef]

27. Łuczak, J.; Paszkiewicz-Gawron, M.; Długokęcka, M.; Lisowski, W.; Grabowska, E.; Makurat, S.; Rak, J.; Zaleska-Medynska, A. Visible light photocatalytic activity of ionic liquid- $\mathrm{TiO}_{2}$ spheres: Effect of the ionic liquid's anion structure. ChemCatChem 2017, 9, 4377-4388. [CrossRef]

28. Kim, S.; Ko, K.C.; Lee, J.Y.; Illas, F. Single oxygen vacancies of $\left(\mathrm{TiO}_{2}\right) 35$ as a prototype reduced nanoparticle: Implication for photocatalytic activity. Phys. Chem. Chem. Phys. 2016, 18, 23755-23762. [CrossRef] [PubMed]

29. Jiang, Y.; Zhu, Y.J.; Cheng, G.F. Synthesis of $\mathrm{Bi}_{2} \mathrm{Se}_{3}$ Nanosheets by Microwave Heating Using an Ionic Liquid. Cryst. Growth Des. 2006, 6, 2174-2176. [CrossRef]

30. Kaper, H.; Sallard, S.B.; Djerdj, I.; Antonietti, M.; Smarsly, B.M. Toward a Low-Temperature Sol-Gel Synthesis of $\mathrm{TiO}_{2}$ (B) Using Mixtures of Surfactants and Ionic Liquids. Chem. Mater. 2010, 22, 3502-3510. [CrossRef]

31. Verma, Y.L.; Tripathi, A.K.; Singh, V.K.; Balo, L.; Gupta, H.; Singh, S.K.; Singh, R.K. Preparation and properties of titania based ionogels synthesized using ionic liquid 1-ethyl-3-methyl imidazolium thiocyanate. Mater. Sci. Eng. B 2017, 220, 37-43. [CrossRef]

32. Jing, L.; Wang, M.; Li, X.; Xiao, R.; Zhao, Y.; Zhang, Y.; Yan, Y.-M.; Wu, Q.; Sun, K. Covalently functionalized $\mathrm{TiO}_{2}$ with ionic liquid: A high-performance catalyst for photoelectrochemical water oxidation. Appl. Catal. B Environ. 2015, 166, 270-276. [CrossRef]

33. Ravishankar, T.N.; Nagaraju, G.; Dupont, J. Photocatalytic activity of Li-doped $\mathrm{TiO}_{2}$ nanoparticles: Synthesis via ionic liquid-assisted hydrothermal route. Mater. Res. Bull. 2016, 78, 103-111. [CrossRef]

34. Liu, H.; Liang, Y.; Hu, H.; Wang, M. Hydrothermal synthesis of mesostructured nanocrystalline $\mathrm{TiO}_{2}$ in an ionic liquid-water mixture and its photocatalytic performance. Solid State Sci. 2009, 11, 1655-1660. [CrossRef]

35. Shahi, S.K.; Kaur, N.; Singh, V. Fabrication of phase and morphology controlled pure rutile and rutile/anatase $\mathrm{TiO}_{2}$ nanostructures in functional ionic liquid/water. Appl. Surf. Sci. 2016, 360, 953-960. [CrossRef]

36. Yan, X.; Ohno, T.; Nishijima, K.; Abe, R.; Ohtani, B. Is methylene blue an appropriate substrate for a photocatalytic activity test? A study with visible-light responsive Titania. Chem. Phys. Lett. 2006, 429, 606-610. [CrossRef]

37. Ohtani, B. Photocatalysis A to Z-What we know and what we do not know in a scientific sense. J. Photochem. Photobiol. C Photochem. Rev. 2010, 11, 157-178. [CrossRef]

38. Li, F.-T.; Wang, X.-J.; Zhao, Y.; Liu, J.-X.; Hao, Y.-J.; Liu, R.-H.; Zhao, D.-S. Ionic-liquid-assisted synthesis of high-visible-light-activated $\mathrm{N}-\mathrm{B}-\mathrm{F}-$ tri-doped mesoporous $\mathrm{TiO}_{2}$ via a microwave route. Appl. Catal. B Environ. 2014, 144, 442-453. [CrossRef]

39. Mirhoseini, F.; Salabat, A. Ionic liquid based microemulsion method for the fabrication of poly (methyl methacrylate) $-\mathrm{TiO}_{2}$ nanocomposite as a highly efficient visible light photocatalyst. RSC Adv. 2015, 5, 12536-12545. [CrossRef]

40. Raj, K.J.A.; Viswanathan, B. Effect of surface area, pore volume and particle size of P25 titania of the phase transformation of anatase to rutile. Indian J. Chem. 2009, 48A, 1378-1382. 
41. Djerdj, I.; Tonejc, A.M. Structural investigations of nanocrystalline $\mathrm{TiO}_{2}$ samples. J. Alloys Compd. 2006, 413, 159-174. [CrossRef]

42. Naumkin, A.V.; Kraut-Vass, A.; Gaarenstroom, S.W.; Powell, C.J. NIST X-ray Photoelectron Spectroscopy Database, NIST Standard Reference Database 20, Version 4.1. 2012. Available online: http:/ / srdata.nist.gov/ xps / (accessed on 25 March 2013).

43. Hu, X.; Zhang, T.; Jin, Z.; Zhang, J.; Xu, W.; Yan, J.; Zhang, J.; Zhang, L.; Wu, Y. Fabrication of carbon-modified $\mathrm{TiO}_{2}$ nanotube arrays and their photocatalytic activity. Mater. Lett. 2008, 62, 4579-4581. [CrossRef]

44. Janus, M.; Inagaki, M.; Tryba, B.; Toyoda, M.; Morawski, A.W. Carbon-modified $\mathrm{TiO}_{2}$ photocatalyst by ethanol carbonisation. Appl. Catal. B Environ. 2006, 63, 272-276. [CrossRef]

45. Kusiak-Nejman, E.; Janus, M.; Grzmil, B.; Morawski, A.W. Methylene Blue decomposition under visible light irradiation in the presence of carbon-modified $\mathrm{TiO}_{2}$ photocatalysts. J. Photochem. Photobiol. A Chem. 2011, 226, 68-72. [CrossRef]

46. Li, Y.; Wang, Y.; Kong, J.; Jia, H.; Wang, Z. Synthesis and characterization of carbon modified $\mathrm{TiO}_{2}$ nanotube and photocatalytic activity on methylene blue under sunlight. Appl. Surf. Sci. 2015, 344, 176-180. [CrossRef]

47. Wei, X.-N.; Wang, H.-L.; Wang, X.-K.; Jiang, W.-F. Facile synthesis of tunable carbon modified mesoporous $\mathrm{TiO}_{2}$ for visible light photocatalytic application. Appl. Surf. Sci. 2017, 412, 357-365. [CrossRef]

48. Qi, H.-P.; Liu, Y.-Z.; Chang, L.; Wang, H.-L. In-situ one-pot hydrothermal synthesis of carbon- $\mathrm{TiO}_{2}$ nanocomposites and their photocatalytic applications. J. Environ. Chem. Eng. 2017, 5, 6114-6121. [CrossRef]

49. Wu, D.; Long, M.; Cai, W.; Chen, C.; Wu, Y. Low temperature hydrothermal synthesis of N-doped $\mathrm{TiO}_{2}$ photocatalyst with high visible-light activity. J. Alloys Compd. 2010, 502, 289-294. [CrossRef]

50. Dolat, D.; Quici, N.; Kusiak-Nejman, E.; Morawski, A.W.; Puma, G.L. One-step, hydrothermal synthesis of nitrogen, carbon co-doped titanium dioxide $\left(\mathrm{N}, \mathrm{CTiO}_{2}\right)$ photocatalysts. Effect of alcohol degree and chain length as carbon dopant precursors on photocatalytic activity and catalyst deactivation. Appl. Catal. B Environ. 2012, 115, 81-89. [CrossRef]

51. Peng, F.; Cai, L.; Huang, L.; Yu, H.; Wang, H. Preparation of nitrogen-doped titanium dioxide with visible-light photocatalytic activity using a facile hydrothermal method. J. Phys. Chem. Solids 2008, 69, 1657-1664. [CrossRef] 
Article

\title{
Electrochemically Obtained $\mathrm{TiO}_{2} / \mathrm{Cu}_{x} \mathrm{O}_{y}$ Nanotube Arrays Presenting a Photocatalytic Response in Processes of Pollutants Degradation and Bacteria Inactivation in Aqueous Phase
}

\author{
Magda Kozak ${ }^{1, *}$, Paweł Mazierski ${ }^{1}$, Joanna Żebrowska ${ }^{2}$, Marek Kobylański ${ }^{1}$, \\ Tomasz Klimczuk ${ }^{3}$, Wojciech Lisowski ${ }^{4}$, Grzegorz Trykowski ${ }^{5}$, Grzegorz Nowaczyk ${ }^{6}$ \\ and Adriana Zaleska-Medynska ${ }^{1}$ \\ 1 Department of Environmental Technology, Faculty of Chemistry, University of Gdansk, \\ 80-308 Gdansk, Poland; pawel.mazierski@phdstud.ug.edu.pl (P.M.); \\ marek.kobylanski@phdstud.ug.edu.pl (M.K.); adriana.zaleska@ug.edu.pl (A.Z.-M.) \\ 2 Department of Molecular Biotechnology, Faculty of Chemistry, University of Gdansk, \\ 80-308 Gdansk, Poland; joanna.zebrowska@ug.edu.pl \\ 3 Faculty of Applied Physics and Mathematics, Gdansk University of Technology, 80-233 Gdansk, Poland; \\ tomek@mif.pg.gda.pl \\ 4 Institute of Physical Chemistry, Polish Academy of Sciences, 01-224 Warsaw, Poland; wlisowski@ichf.edu.pl \\ 5 Faculty of Chemistry, Nicolaus Copernicus University, 87-100 Torun, Poland; tryki@umk.pl \\ 6 NanoBioMedical Centre, Adam Mickiewicz University, Umultowska 85, 61-614 Poznan, Poland; \\ nowag@amu.edu.pl \\ * Correspondence: magda.kozak@ug.edu.pl; Tel.: +48-58-523-5159
}

Received: 15 May 2018; Accepted: 2 June 2018; Published: 5 June 2018

\begin{abstract}
TiO}_{2} / \mathrm{Cu}_{x} \mathrm{O}_{y}$ nanotube (NT) arrays were synthesized using the anodization method in the presence of ethylene glycol and different parameters applied. The presence, morphology, and chemical character of the obtained structures was characterized using a variety of methods-SEM (scanning electron microscopy), XPS (X-ray photoelectron spectroscopy), XRD (X-ray crystallography), PL (photoluminescence), and EDX (energy-dispersive X-ray spectroscopy). A p-n mixed oxide heterojunction of Ti-Cu was created with a proved response to the visible light range and the stable form that were in contact with $\mathrm{Ti}$. $\mathrm{TiO}_{2} / \mathrm{Cu}_{x} \mathrm{O}_{y}$ NTs presented the appearance of both $\mathrm{Cu}_{2} \mathrm{O}$ (mainly) and $\mathrm{CuO}$ components influencing the dimensions of the NTs $(1.1-1.3 \mu \mathrm{m})$. Additionally, changes in voltage have been proven to affect the NTs' length, which reached a value of $3.5 \mu \mathrm{m}$ for $\mathrm{Ti}_{90} \mathrm{Cu}_{10} 50 \mathrm{~V}$. Degradation of phenol in the aqueous phase was observed in $16 \%$ of $\mathrm{Ti}_{85} \mathrm{Cu}_{15} 30 \mathrm{~V}$ after $1 \mathrm{~h}$ of visible light irradiation $(\lambda>420 \mathrm{~nm})$. Scavenger tests for phenol degradation process in presence of NT samples exposed the responsibility of superoxide radicals for degradation of organic compounds in Vis light region. Inactivation of bacteria strains Escherichia coli (E. coli), Bacillus subtilis (B. subtilis), and Clostridium sp. in presence of obtained $\mathrm{TiO}_{2} / \mathrm{Cu}_{x} \mathrm{O}_{y}$ NT photocatalysts, and Vis light has been studied showing a great improvement in inactivation efficiency with a response rate of $97 \%$ inactivation for E. coli and $98 \%$ for Clostridium sp. in $60 \mathrm{~min}$. Evidently, TEM (transmission electron microscopy) images confirmed the bacteria cells' damage.
\end{abstract}

Keywords: heterogeneous photocatalysis; $\mathrm{TiO}_{2} / \mathrm{Cu}_{2} \mathrm{O}$ nanotubes; anodization; nanomaterials fabrication; removal of microbiological pollutants

\section{Introduction}

Processes connected with the photocatalysis phenomenon are in area that is receiving great attention nowadays. Once we add nanomaterials to this combination, we will produce an interesting 
mix that not only scientists but also industry have been paying attention to lately. The main reason for this interest is the scope of application-i.e., the healthy nature of the environmental engineering and car industries.

Intensive studies on nanomaterials_-research on properties, attempts to reduce their size or modifications-lead to the extension of the application possibilities. In recent years, more attention has been directed towards transformation processes that involve a light source-i.e., solve energy and pollution problems in the presence of semiconductors (photocatalysts). One of the semiconductors, considered as the most attractive photocatalyst in previous research, is $\mathrm{TiO}_{2}$, which is characterized by a wide range of advantages, i.e., high chemical stability and relatively low price, and it is not toxic. It has been confirmed that it is applicable to the degradation of pollutants in both the gaseous and liquid phases [1,2], as well as in many different areas such as $\mathrm{CO}_{2}$ reduction [3], water splitting [4], or antibacterial activity [5]. There is also one main disadvantage of $\mathrm{TiO}_{2}$ photocatalysts, which is their minimal energy value (Eg, c.a $3.2 \mathrm{eV}$ ), which is necessary for the electron excitation that needed to generate holes in the valence band and carry on photocatalytic reactions. This value corresponds to $388 \mathrm{~nm}$, so it can be activated in the UV irradiation range (300-380 nm), which really limits its applications [6].

The limitations have led to worldwide research focusing on $\mathrm{TiO}_{2}$ modifications to extend its activity to the range of light irradiation of the Vis, such as sensitization with a semiconductor with a narrow band gap, metal ion doping, or nonmetal doping or dye sensitization [7]. These processes not only increase the activity but also modify the active surface area. There are two approaches in terms of the nanofabrication process: "top-down" and "bottom-up." The first represents the idea of using larger structures, which can be further controlled in the nanoscale, whereas the second includes the miniaturization of components with the self-assembly process. There are a variety of forms of modified nanostructures_-nanoparticles, nanotubes (NTs), nanosheets, or nanocubes obtained using many methods such as electrodeposition [6], self-assembly examples, atomic layer deposition, or anodization [8-10].

Anodization of titanium and its alloys was performed in many environments [3,11], but modification of Ti alloys with this method was not so common. During the oxidation process, a big influence on the results of the experiment had some parameters such as applied voltage, the composition of the electrolyte, or the time of the process [12]. The anodic growth of compact oxides in metal surfaces and the formation of tubes are governed by a competition between anodic oxide formation and chemical dissolution of the oxide as a soluble fluoride complex. In 2001, Grimes et al. first reported the influence of hydrofluoric (HF) acid in the anodic oxidation process on the porosity of the titanium NT arrays [13]. It is proved that longer NTs are formed in electrolytes based on organic compounds like ethylene glycol or glycerol. Studies on literature show that usage of viscous solvents for anodization results in smooth wall structures of the NTs [14,15].

One promising aspect of $\mathrm{TiO}_{2}$ modification is its ability to combine with $\mathrm{Cu}$, including $\mathrm{Cu}_{2} \mathrm{O}$ and $\mathrm{CuO}$ species, which can function as an electron mediator to widen the wavelength region for absorption [16]; however, $\mathrm{Cu}$ is not stable in terms of nano-scale size [17]. Furthermore, $\mathrm{Cu}_{2} \mathrm{O}$ is also promising with regard to the formation of p-n heterojunctions with $\mathrm{TiO}_{2}$ [18], which can lead to the improvement of the modified photocatalysts features. It was already reported that photocatalysts containing titanium and copper have the ability to cause pollutant degradation $[19,20]$; what is more, there is great potential in these materials in terms of inactivation of bacteria that has studied since 1985. Metsunga et al. were among the pioneers who studied the application of titanium dioxide $\left(\mathrm{TiO}_{2}\right)$ as a promising photocatalyst in terms of antimicrobial reactions [21]. Copper possesses high antimicrobial features [22] with the potential for drug degradation [23] and, due to lower toxicity, price, and increased cytocompatibility [24], it is more favorable than silver or gold. This is the reason why it has been more intensively studied among other catalysts nowadays. $\mathrm{Cu}$ and $\mathrm{TiO}_{2}$ combinations were studied in different modifications including photodeposition of copper [25], microwave co-precipitation technique [26], layer films [27], alloy rods [28], nanocrystals [19], composite 
coating on wooden substrate [29], copper decorated $\mathrm{TiO}_{2}$ nanorods [30], combination of magnetron sputtering and annealing treatment [31], doped nanoparticles [32] or radiolytic deposition of copper species at the surface of $\mathrm{TiO}_{2}$ nanotubes [33]. However, properties of nanostructures containing copper obtained via anodic oxidation using alloys are still rather unknown, and very little research has been undertaken to understand the quantity influence of copper in the $\mathrm{Cu}-\mathrm{TiO}_{2}$ nanostructured composite regarding the photocatalytic activities of $\mathrm{Cu}$-doped $\mathrm{TiO}_{2}$. Furthermore, the influence of different parameters on oxidation processes such as voltage, time, and electrolyte composition has not been fully studied yet. In view of this, in this work, it was decided to extend knowledge about the anodized Ti-Cu alloys while considering different parameters of the process. Moreover, the impact of anodized Ti-Cu alloys on bacteria inactivation (E. coli, B. subtilis, Clostridium sp.) in Vis light was investigated for the first time. The expected outcomes are as follows: (a) the anodic oxidation of Ti-Cu alloys will form $\mathrm{TiO}_{2} \mathrm{NT}$ arrays in various production conditions, (b) $\mathrm{TiO}_{2} / \mathrm{Cu}_{x} \mathrm{O}_{y}$ will show increased activity under Vis light, and (c) $\mathrm{TiO}_{2} / \mathrm{Cu}_{x} \mathrm{O}_{y}$ will present intense bacteria inactivation features.

\section{Results and Discussion}

\subsection{Morphology and Formation of $\mathrm{TiO}_{2} / \mathrm{Cu}_{x} \mathrm{O}_{y} \mathrm{NTs}$}

The surface morphology of obtained $\mathrm{TiO}_{2} / \mathrm{Cu}_{x} \mathrm{O}_{y}$ NTs was determined by SEM (scanning electron microscopy) and is presented in Figure 1a-e, while SEM images of references samples, namely, pristine $\mathrm{TiO}_{2}$, are displayed in Figure S1 (Supplementary Materials). The upper layer of NTs remains unveiled, and only a small amount of initial barrier layer is visible, which suggests that cleaning the surface of samples after anodization in an ultrasonic bath was effective. Characteristic dimensions of NTs such as length, diameter, and wall thickness were calculated based on SEM images and are gathered in Table 1. Among the $\mathrm{TiO}_{2} / \mathrm{Cu}_{x} \mathrm{O}_{y} \mathrm{NTs}$, the length of tubes and external diameter varied from 1.1 to $3.5 \mu \mathrm{m}$ and $83-98 \mathrm{~nm}$, respectively, indicating that the shape of NTs strictly depends on applied voltage during anodization process and amount of $\mathrm{Cu}$ in the Ti-Cu alloys. In general, the length of all $\mathrm{TiO}_{2} / \mathrm{Cu}_{x} \mathrm{O}_{y}$ NTs is shorter than pristine $\mathrm{TiO}_{2}$ NTs prepared from Ti foil under the same anodization conditions. Additionally, the length $\mathrm{TiO}_{2} / \mathrm{Cu}_{x} \mathrm{O}_{y}$ NTs decreased with the increase of $\mathrm{Cu}$ content in the Ti-Cu alloy. These phenomena have already been observed for the anodization of titanium alloys $[34,35]$ and can be ascribed to the accelerated dissolution of $\mathrm{TiO}_{2} / \mathrm{Cu}_{x} \mathrm{O}_{y}$ NTs $[28,34]$.

As will be described later (in XPS (X-ray photoelectron spectroscopy) part) by anodizing Ti-Cu alloys, we obtained p-n heterojunction consisting of $\mathrm{TiO}_{2} \mathrm{NTs}_{\mathrm{s}} \mathrm{Cu}_{x} \mathrm{O}_{y}$ species, in which $\mathrm{Cu}$ species appear in the form of $\mathrm{Cu}_{2} \mathrm{O}$ (mostly) and $\mathrm{CuO}$. Based on TEM image depicted in Figure 1f, we can conclude that $\mathrm{Cu}_{x} \mathrm{O}_{y}$ species are evenly spaced along the NTs, and no nanoparticles formation was observed. On the other hand, the formation of copper oxides inside $\mathrm{TiO}_{2} \mathrm{NTs}$ at various oxidation states $\left(\mathrm{Cu}^{1+}\right.$ and $\left.\mathrm{Cu}^{2+}\right)$ can be represented by the following reactions [36,37]:

$$
\begin{aligned}
& \mathrm{Cu}-\mathrm{e}^{-} \rightarrow \mathrm{Cu}^{+}, 2 \mathrm{Cu}^{+}+2 \mathrm{OH}^{-} \rightarrow \mathrm{Cu}_{2} \mathrm{O}+\mathrm{H}_{2} \mathrm{O} \\
& \mathrm{Cu}-2 \mathrm{e}^{-} \rightarrow \mathrm{Cu}^{2+}, \mathrm{Cu}^{2+}+2 \mathrm{OH}^{-} \rightarrow \mathrm{CuO}+\mathrm{H}_{2} \mathrm{O}
\end{aligned}
$$

These reactions occur simultaneously with the formation of $\mathrm{TiO}_{2}$, which can be represented as

$$
\begin{gathered}
\mathrm{Ti}+2 \mathrm{H}_{2} \mathrm{O} \rightarrow \mathrm{TiO}_{2}+4 \mathrm{H}^{+}+4 \mathrm{e}^{-} \\
\mathrm{TiO}_{2}+4 \mathrm{H}^{+}+6 \mathrm{~F}^{-} \rightarrow \mathrm{TiF}_{6}^{2-}+2 \mathrm{H}_{2} \mathrm{O}
\end{gathered}
$$

Reaction (4) affects the anodization process and is responsible for the growth of $\mathrm{TiO}_{2}$ in the form of NTs $[38,39]$. 

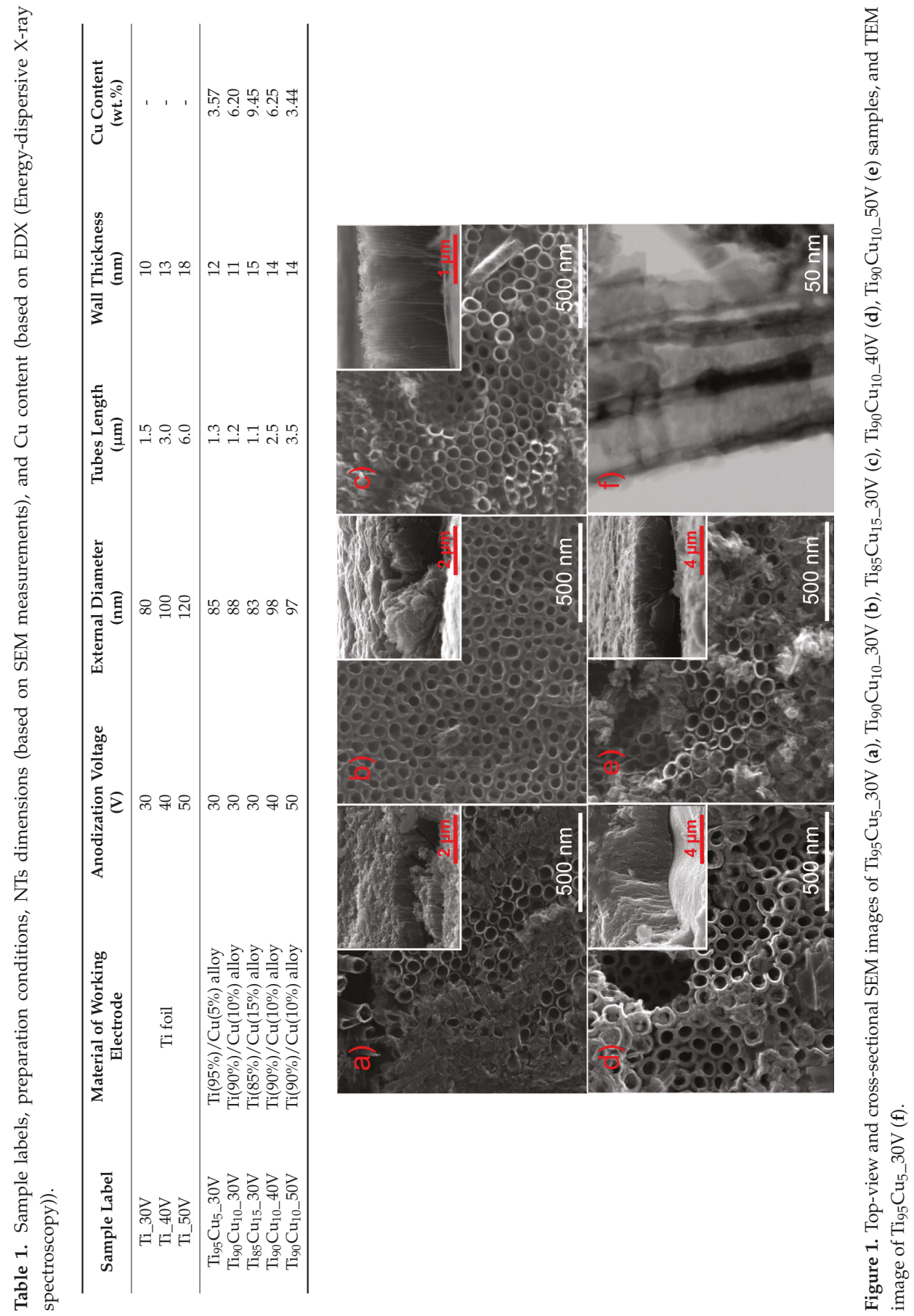


\subsection{XRD Analysis}

Phase composition of the tested samples was checked by using powder X-ray diffractometer (X'Pert Pro MPD, PANalytical, Almelo, The Netherlands). Figure 2 details diffraction patterns for Ti-Cu alloys after the anodic oxidation process. The patterns for Ti anodized samples are in Table S1 and Figure S2 (supplementary materials). The experimental data and refined model (LeBail) are represented by circles and a solid red line, respectively. The sets of vertical bars show expected positions for $\mathrm{TiO}_{2}$-anatase (black), $\mathrm{Ti}$ (red), and $\mathrm{CuTi}_{2}$ alloy (olive). The Miller indices for the anatase are shown in panel (d). The strongest reflection (101) is observed at around $25.3 \mathrm{deg}$. Ti foil is always observed with the strongest reflection at $40.3 \mathrm{deg}$. Foils with $\mathrm{Cu}$ concentration $10 \%$ and $15 \%$ reveal presence of $\mathrm{CuTi}_{2}$ alloy_clearly seen by growing reflection near $16.6 \mathrm{deg}$. (Figure 2a,b). Interestingly, a relative signal of $\mathrm{CuTi}_{2}$ is weaker for $\mathrm{Ti}_{90} \mathrm{Cu}_{10}$ samples anodized in $40 \mathrm{~V}$ and $50 \mathrm{~V}$, compared to the one anodized in $30 \mathrm{~V}\left(\mathrm{Ti}_{90} \mathrm{Cu}_{10} \_30 \mathrm{~V}\right)$. It is likely caused by thicker film of anatase on the surface for $\mathrm{Ti}_{90} \mathrm{Cu}_{10} 40 \mathrm{~V}$ and $\mathrm{Ti}_{90} \mathrm{Cu}_{10} \_50 \mathrm{~V}$. We do not observe neither $\mathrm{Cu}$ metal, nor $\mathrm{Cu}$ oxides.

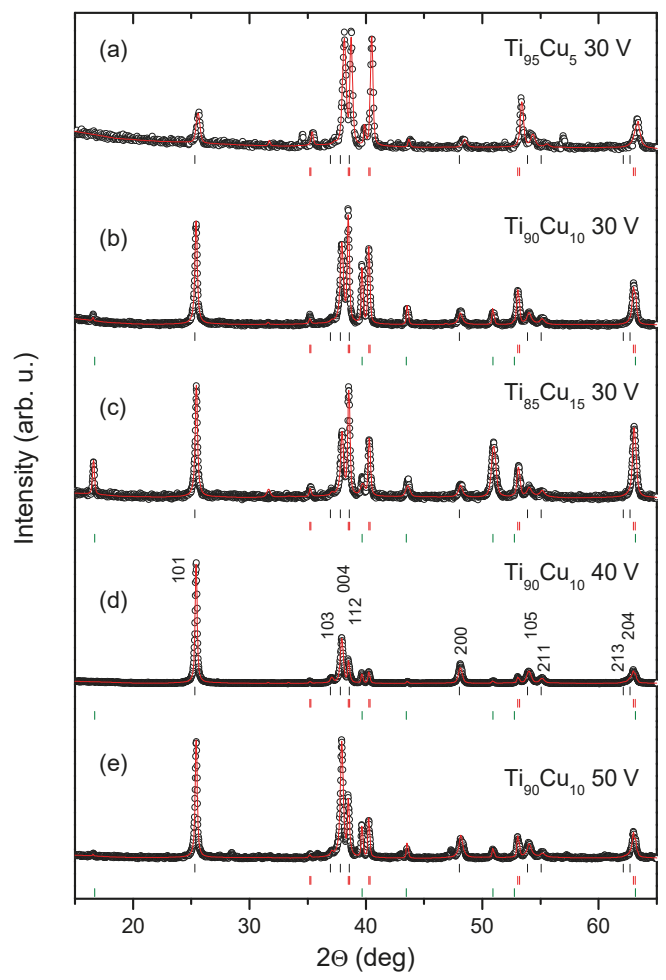

Figure 2. X-ray diffraction patterns for Ti-Cu alloys. A red solid line is a LeBail fit to the experimental data (open circles). Vertical bars represent positions of expected Bragg peaks for (from top): $\mathrm{TiO}_{2}$-anatase (black), $\mathrm{Ti}$ (red), and $\mathrm{CuTi}_{2}$ alloy (olive), respectively.

More qualitative results were obtained by using LeBail refinement. Table S1 contains obtained lattice parameters for $\mathrm{TiO}_{2}$ - anatase (tetragonal I41/amd, ICSD code: 063711), Ti-metal (hexagonal P63/mmc, ICSD code: 076265 ), and $\mathrm{CuTi}_{2}$ (tetragonal I4/mmm, ICSD code: 015807) compounds. A corrected full width at half maximum (FWHM) of the strongest (101) anatase reflection was used for calculations of the average crystallite size using the Scherrer equation. The estimated size is between $250 \AA$ and $460 \AA$ for $\mathrm{Ti}_{95} \mathrm{Cu}_{5} \_30 \mathrm{~V}$ and $\mathrm{Ti}_{90} \mathrm{Cu} 10 \_50 \mathrm{~V}$, respectively. However, because of complexity of 
studied photocatalysts, presence of three oxides $\left(\mathrm{TiO}_{2}, \mathrm{Cu}_{2} \mathrm{O}, \mathrm{CuO}\right)$, and different wall thickness of NTs, it is hard to obtain more information about the crystallite size. There is no obvious change of the anatase lattice parameters with the increasing voltage. The a and c parameters for Ti_30V, Ti_40V, and Ti_50V, as well as for $\mathrm{Ti}_{90} \mathrm{Cu}_{10} \_30 \mathrm{~V}$, $\mathrm{Ti}_{90} \mathrm{Cu}_{10} 40 \mathrm{~V}$, and $\mathrm{Ti}_{90} \mathrm{Cu}_{10} \_50 \mathrm{~V}$ series, remain almost the same. However, for the samples anodized in $30 \mathrm{~V}$, with different $\mathrm{Cu}$ content, there is increase in both a and c values. It is reflected also by increase in unit cell volume from $136.0 \AA^{3}\left(\mathrm{Ti}_{95} \mathrm{Cu}_{5} \_30 \mathrm{~V}\right)$ to $136.6 \AA^{3}$ $\left(\mathrm{Ti}_{90} \mathrm{Cu}_{10} 30 \mathrm{~V}\right)$ and $136.0 \AA^{3}\left(\mathrm{Ti}_{85} \mathrm{Cu}_{15} 30 \mathrm{~V}\right)$. Higher $\mathrm{Cu}$ concentration is likely responsible for larger crystallite size: $250 \AA, 360 \AA$, and $390 \AA$ for $5 \%, 10 \%$, and $15 \% \mathrm{Cu}$, respectively.

\subsection{XPS Analysis}

Elemental composition (in at.\%) in the surface layer of $\mathrm{Cu}$-modified $\mathrm{TiO}_{2} \mathrm{NTs}$ was evaluated by XPS analysis and reported in Table 2 and Table S2. Detection of $\mathrm{Cu}$ in addition to Ti and O confirm the effective modification of this element in all $\mathrm{TiO}_{2}$ NTs. Carbon, nitrogen, and fluorine species were also detected. Results obtained in different studies by our group and also knowledge gathered from literature confirm that source of fluoride, carbon, and nitrogen species lies in electrolyte used in NTs preparation. Level of contamination depends on porosity and thickness of the films used in experiment, as well as composition of electrolyte and time of the anodization. However, it was confirmed by D. Regonini et al. that these species do not influence the degradation process [40,41]. They are common contaminants of $\mathrm{TiO}_{2}$ nanotubes obtained by anodic oxidation, and all derive from the electrolyte [40,42].

The chemical character of Ti originating from pristine $\mathrm{TiO}_{2}$ and $\mathrm{Cu}$ from the $\mathrm{Cu}$-modified $\mathrm{TiO}_{2}$ NTs were identified from the Ti $2 p$ and $\mathrm{Cu} 2 \mathrm{p}$ HR XPS spectra, respectively. The selected spectra for $30 \mathrm{~V}$ are summarized in Table 2 and shown in Figure 3. The Ti $2 \mathrm{p}$ spectrum is resolved into two doublet-components at $\mathrm{BE}$ of Ti $2 \mathrm{p}_{3 / 2}$ signal at 458.7 and $457.3 \mathrm{eV}$ and are assigned to $\mathrm{Ti}^{4+}$ and $\mathrm{Ti}^{3+}$, respectively (Figure 3a). The $\mathrm{Ti}^{4+}$ is the dominant surface state and relative contribution of the $\mathrm{Ti}^{3+}$ species is similar for all NTs (Table 2). Following the curve-fitting procedure of $\mathrm{Cu} 2 \mathrm{p}_{3 / 2}$ spectra (Figure 3b), we separated the XPS peaks at the BE of 932.1 and $933.8 \mathrm{eV}$, which are characteristic of $\mathrm{Cu}(\mathrm{I})$ and $\mathrm{Cu}(\mathrm{II})$ oxide species, respectively $[27,40,43-45]$. The $\mathrm{Cu}(\mathrm{I})$ composites are the dominant $\mathrm{Cu}$ fraction for all samples, and their relative contribution depends on applied voltage during anodization process and amount of $\mathrm{Cu}$ in the Ti-Cu alloys (Table 2).

Inspection of the data presented in Table 2 reveal the relative contribution of $\mathrm{Cu}(\mathrm{I})$ fraction to be systematically increased as the $\mathrm{Cu}$ amount in the Ti-Cu alloys increased (see the XPS data for TiCu alloys anodized at $30 \mathrm{~V}$ ). 


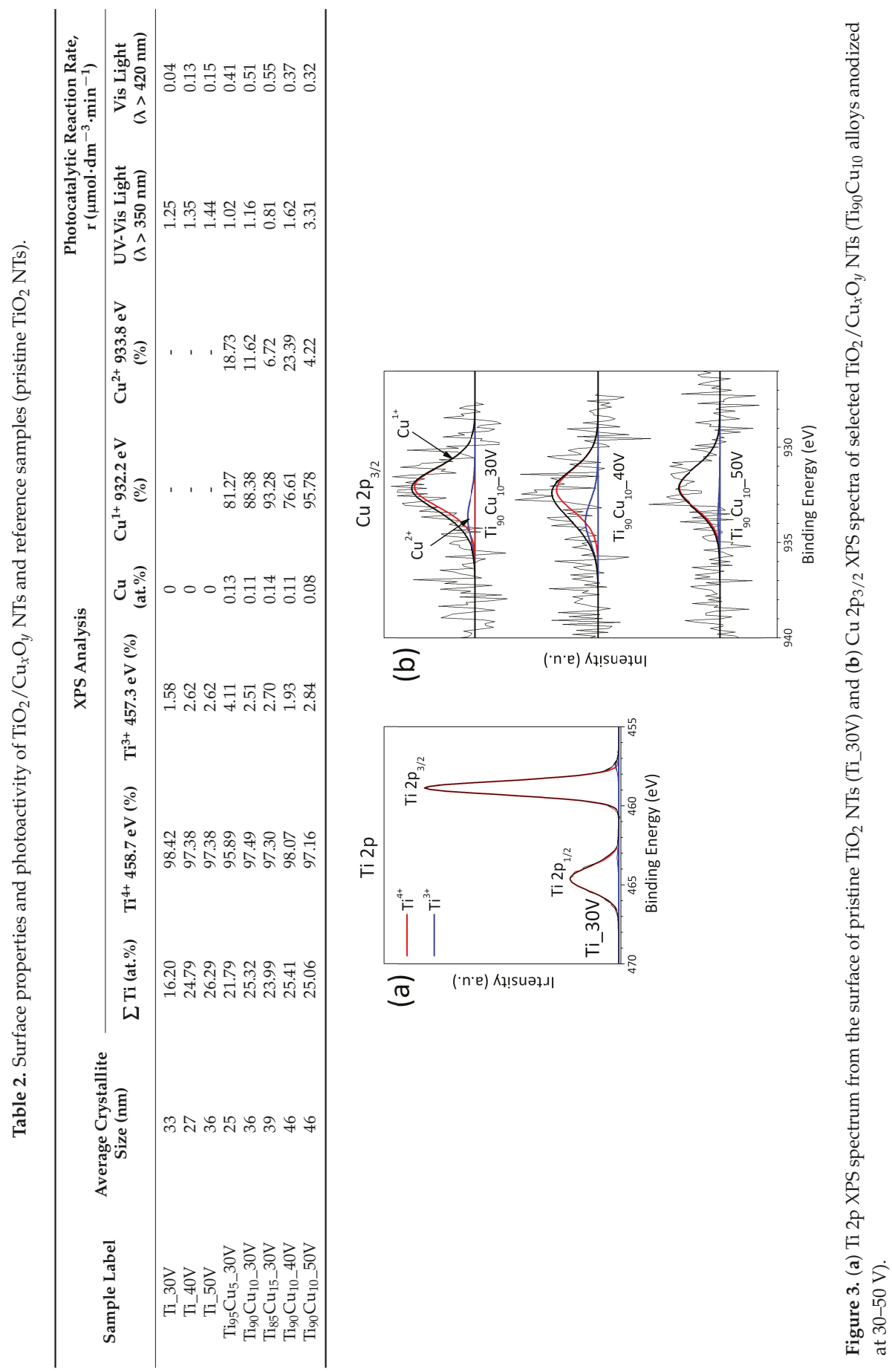




\subsection{UV-Vis Spectra and Photoluminescence Properties}

Figure 4a demonstrates UV-Vis spectra that were prepared for all investigated samples, not only alloys but also pristine NTs. The analysis results indicate clearly UV signals at the region 300-390 nm, which are strictly connected with the excitation state of the electrons and the movement from valence to conduction band [17]. Ti ${ }_{95} \mathrm{Cu}_{5} \_30 \mathrm{~V}$ reflects high absorbance of UV light $(\lambda<380 \mathrm{~nm})$ in comparison to pristine NTs. All modified NTs generally present more intensive absorbance in Vis irradiation range than pristine NTs, which can lead to intensified response during experiments in visible light. Maximum absorbance was observed at $600 \mathrm{~nm}$ with $\mathrm{Ti}_{90} \mathrm{Cu}_{10} \_30 \mathrm{~V}$, $\mathrm{Ti}_{95} \mathrm{Cu}_{5} \_30 \mathrm{~V}$, and $\mathrm{Ti}_{85} \mathrm{Cu}_{15} \_30 \mathrm{~V}$, and stands for red shift compared to pristine NTs. For Ti ${ }_{90} \mathrm{Cu}_{10} 40 \mathrm{~V}$ alloy, the absorbance maximum was not registered. Increased absorption values in Vis range in comparison to pristine NTs is a result of $\mathrm{Cu}_{x} \mathrm{O}_{y}$ appearance in the system and their narrower band gap $\left(\mathrm{Cu}_{2} \mathrm{O}=2.1 \mathrm{eV} ; \mathrm{CuO}=1.7 \mathrm{eV}\right)$, which work as a photo sensitizer that broadens the photo response of $\mathrm{TiO}_{2} \mathrm{NTs}$ to the visible region. The wide absorption band could have occurred because of inter-band transition in the $\mathrm{Ti}_{x} \mathrm{Cu}_{y}$ alloys. Figure $4 \mathrm{a}$ reveals a slight shift in band-gap transition of modified NTs to longer wavelengths. This effect can be assigned to stronger stabilization of the conduction band of $\mathrm{TiO}_{2}, \mathrm{Cu}_{2} \mathrm{O}$, and $\mathrm{CuO}$ than their valence band [17].
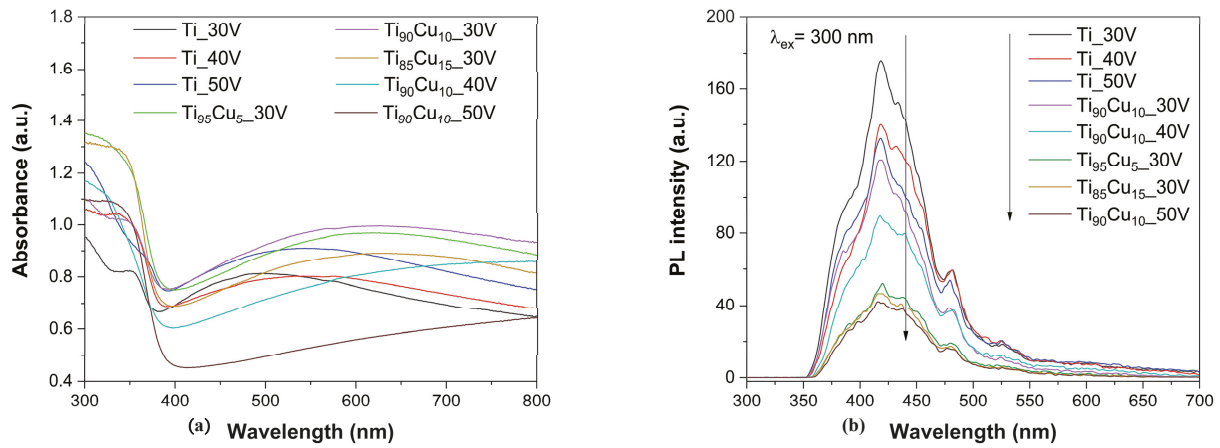

Figure 4. Absorbance (a) and photoluminescence (b) spectra of pristine $\mathrm{TiO}_{2}$ and $\mathrm{TiO}_{2} / \mathrm{Cu}_{x} \mathrm{O}_{y} \mathrm{NTs}_{\text {s }}$

The photoluminescence (PL) is a nondestructive spectroscopic technique often applied in study of intrinsic and extrinsic properties of both bulk semiconductors and nanostructures [46]. Mainly, the analysis of spectra of nanostructures can help in the characterization of the structure, providing information on the interface morphology and the quality of the materials. Photoluminescence (PL) signals and their intensity are closely related to photocatalytic activity. Possibly, the lower the PL intensity, the higher the separation rate of photo-induced charges, and, possibly, the higher the photocatalytic activity [47]. There are three intensive bands presented in Figure $4 \mathrm{~b}$, which can be distinguished. Two of them lie in the range between 400 and $440 \mathrm{~nm}$ and originate from charge recombination in the surface state defects [48]. The bands at $445-500 \mathrm{~nm}$ are attributed to different intrinsic defects in the $\mathrm{TiO}_{2}$ lattice such as oxygen vacancies, titanium vacancies, and interstitial defects [49]. Because of different thicknesses of obtained NTs, the recombination rate intensity may be highly influenced. Figure $4 \mathrm{~b}$ reveals $\mathrm{TiO}_{2}-\mathrm{Cu}_{\mathrm{x}} \mathrm{O}_{\mathrm{y}} \mathrm{NTs}$ and pristine $\mathrm{TiO}_{2}$ NTs response on PL, showing that $\mathrm{TiO}_{2}-\mathrm{Cu}_{\mathrm{x}} \mathrm{O}_{\mathrm{y}}$ NTs were more efficient than pristine $\mathrm{TiO}_{2}$ NTs because of better charge carriers separation ability, which leads to improved photocatalytic properties.

\subsection{Photodegradation Ability in Aqueous Phase}

Photodegradation ability of obtained NTs was studied in phenol degradation process proceed in two different light sources: UV-Vis $(\lambda>350 \mathrm{~nm})$ and Vis $(\lambda>420 \mathrm{~nm})$ conditions. At the beginning, 
a direct photolysis was performed to confirm the necessity of photocatalyst appearance. In case of UV-Vis irradiation, $3 \%$ of phenol was degraded, and in Vis light no action was observed. The significant results for UV-Vis were presented by samples with applied voltage above $30 \mathrm{~V}$. Ti ${ }_{90} \mathrm{Cu}_{10} \_50 \mathrm{~V}$ and $\mathrm{Ti}_{90} \mathrm{Cu}_{10} \_40 \mathrm{~V}$ have degradation efficiencies close to $85 \%$ and $45 \%$, respectively, while pristine NTs showed efficiency between $35-40 \%$ (Figure $5 \mathrm{a}$ ). NTs obtained with voltage equal to $30 \mathrm{~V}$ revealed the efficiency lower than pristine NTs under UV-Vis light. The reason of obtained results is strictly connected with length of the NTs, as pristine NTs are longer $(1.5-6 \mu \mathrm{m})$ than NTs from copper alloys anodized in $30 \mathrm{~V}$, while in terms of $\mathrm{Ti}_{90} \mathrm{Cu}_{10} 40 \mathrm{~V}$ and $\mathrm{Ti}_{90} \mathrm{Cu}_{10} 50 \mathrm{~V}$, NTs are just a little shorter $(2.5-3.5 \mu \mathrm{m})$ than pristine NTs but sufficient for conducting the degradation process. Combination of length and $\mathrm{Cu}_{2} \mathrm{O}$ and $\mathrm{CuO}$ species in total gives higher activity compering to pristine NTs. In terms of Vis light irradiation (Figure $5 b$ ), whose results were the main area of interest, the outcome appears to be different. The efficiency increased in the following order: Ti_30V $<\mathrm{Ti} \_40 \mathrm{~V}<\mathrm{Ti} \_50 \mathrm{~V}<\mathrm{Ti}_{90} \mathrm{Cu}_{10} \_50 \mathrm{~V}$ $<\mathrm{Ti}_{90} \mathrm{Cu}_{10} \_40 \mathrm{~V}<\mathrm{Ti}_{95} \mathrm{Cu}_{5} \_30 \mathrm{~V}<\mathrm{Ti}_{90} \mathrm{Cu}_{10} \_30 \mathrm{~V}<\mathrm{Ti}_{85} \mathrm{Cu}_{15} \_30 \mathrm{~V}$ showing that NTs obtained with $30 \mathrm{~V}$ presents the best results, reaching a value of $16 \%$ for the $\mathrm{Ti}_{85} \mathrm{Cu}_{15} 30 \mathrm{~V}$ sample. Obtained result can relate to the correlance of penetration depth of visible light and thickness of the NTs, in which only small amounts of photons can reach lower parts of the NTs. The level of influence on phenol degradation in terms of Vis light can lay also in amount of $\mathrm{Cu}$ in the sample. EDX results presented in Table 1 show that in $\mathrm{Ti}_{85} \mathrm{Cu}_{15} 30 \mathrm{~V}$ the highest amount of $\mathrm{Cu}$ was measured with the value of 9.45 (wt.\%). The same results were obtained by XPS measurements (Table 2). Similar effect was observed during our previous work with the NTs obtained by anodic oxidation of Ti-Ag alloys [50].

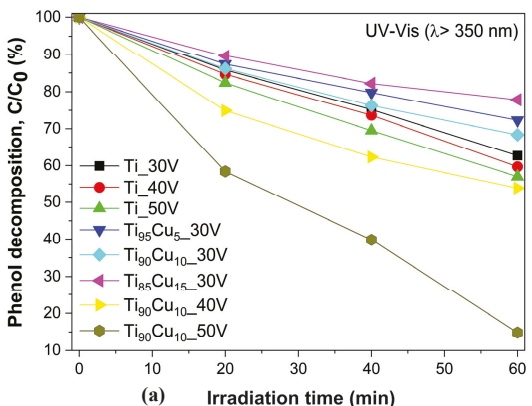

(a) Irradiation time $(\mathrm{min})$

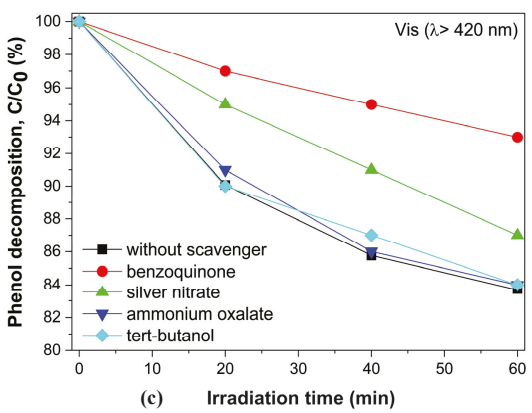

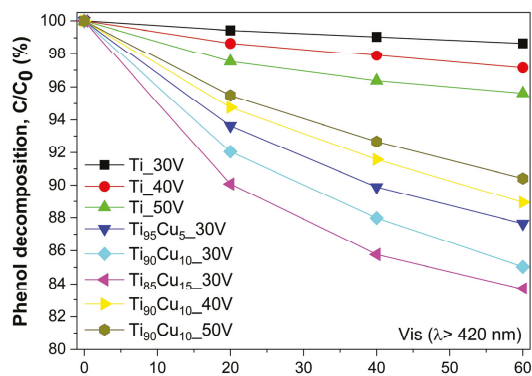

(b) Irradiation time ( $\mathrm{min})$

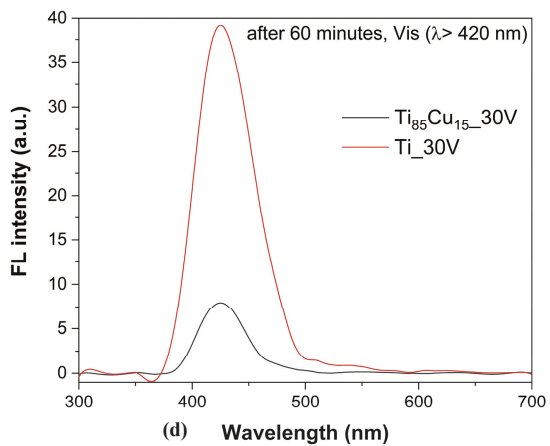

Figure 5. Kinetics of photocatalytic degradation of phenol under UV-Vis (a) and Vis (b) irradiation, photocatalytic decomposition of phenol under visible light irradiation in the presence of scavengers, and $\mathrm{Ti}_{95} \mathrm{Cu}_{15} \_30 \mathrm{~V}$ sample (c) and $\bullet \mathrm{OH}$ radical generation efficiency under Vis irradiation (d) in the presence of selected samples. 


\subsection{The Excitation Mechanism of $\mathrm{TiO}_{2}-\mathrm{Cu}_{x} \mathrm{O}_{y} \mathrm{NTs}$}

For better understanding of the visible light excitation mechanism of $\mathrm{TiO}_{2}, \mathrm{NTs}$ modified with $\mathrm{Cu}$ species additional experiments were performed. First of all, to confirm phenol degradation mechanism, reactions with different scavengers-benzoquinone (for $\mathrm{O}_{2} \bullet-$ radicals), silver nitrate (for $\mathrm{e}^{-}$), ammonium oxalate (for $\mathrm{h}^{+}$), and tert-butanol (for hydroxyl radicals) were performed for the most active sample $\mathrm{Ti}_{85} \mathrm{Cu}_{15} \_30 \mathrm{~V}$, as shown in Figure $5 \mathrm{c}$. The photocatalytic efficiency of phenol degradation for benzoquinone was $13 \%$ and for silver nitrate $6 \%$. In terms of other scavengers, the degradation was negligible in comparison with the reaction without scavengers what can lead to conclusions that $\mathrm{O}_{2} \bullet-$ radicals are the main initiator of photocatalytic degradation under visible light irradiation. Secondly, to confirm above results, the $\bullet \mathrm{OH}$ radical generation tests were taken (see Figure $5 \mathrm{~d}$ ), confirming that larger amounts of $\bullet \mathrm{OH}$ radicals were produced in case of pristine NTs than in presence of $\mathrm{TiO}_{2}-\mathrm{Cu}_{x} \mathrm{O}_{y}$ NTs. It can incline that other forms of reactive oxygen species are the source of phenol degradation under Vis light (as demonstrated in Figure 6a).

a)

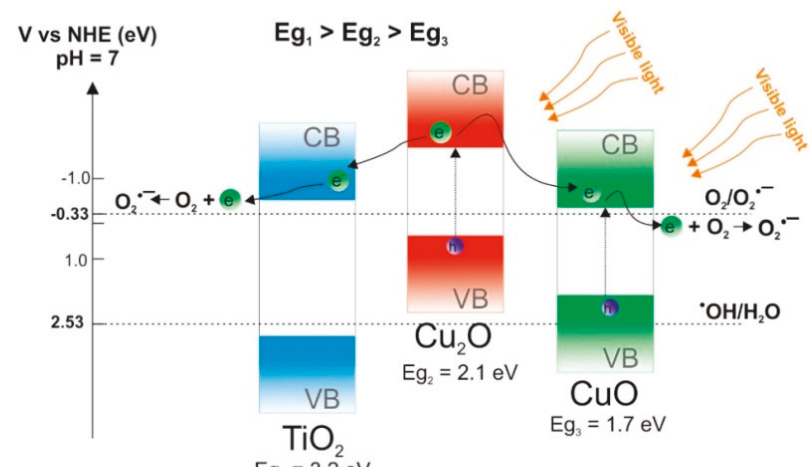

b)

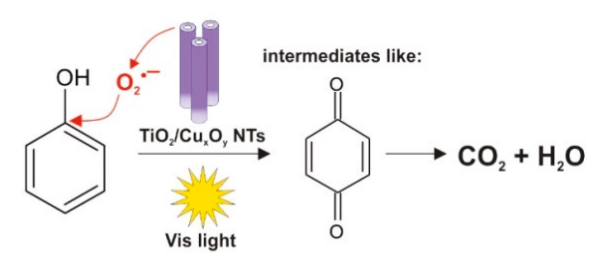

c)

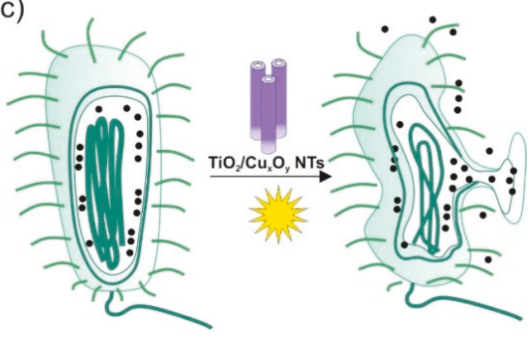

Figure 6. A suggested scheme of (a) visible light excitation mechanism in presence of $\mathrm{TiO}_{2}-\mathrm{Cu}_{2} \mathrm{O}$ and $\mathrm{CuO}$ NTs, (b) phenol degradation pathway under Vis light, and (c) inactivation of bacterial cell by $\mathrm{O}_{2} \bullet-$ radicals.

As the results of XPS showed division of the $\mathrm{TiO}_{2}-\mathrm{Cu}_{\mathrm{x}} \mathrm{O}_{\mathrm{y}} \mathrm{NT}$ in terms of $\mathrm{Cu}$ type, the Vis light photocatalytic mechanism (Figure 6a) and the stability of heterojunctions should be considered for both types $\mathrm{Cu}^{+}$and $\mathrm{Cu}^{2+}$. As the $\mathrm{TiO}_{2} \mathrm{NTs}$ band gap (3.2 eV) is too wide to absorb Vis light, $\mathrm{TiO}_{2}-\mathrm{Cu}_{2} \mathrm{O}$ were investigated for band gaps much narrower $2.1 \mathrm{eV}$ and $1.7 \mathrm{eV}$, respectively, to confirm the application of materials in Vis light. $\mathrm{TiO}_{2}-\mathrm{Cu}_{2} \mathrm{O}$ and $\mathrm{TiO}_{2}-\mathrm{CuO}$ NTs with the Vis light conditions can activate electrons and create the pair electron-hole [51]. In terms of $\mathrm{TiO}_{2}-\mathrm{Cu}_{2} \mathrm{O}$ NTs, electron from $\mathrm{CB} \mathrm{Cu}_{2} \mathrm{O}$ is transferred to the conduction band of $\mathrm{TiO}_{2} \mathrm{NTs}$, whereas holes from valence band of $\mathrm{Cu}_{2} \mathrm{O}$ remain immobile and are unable to generate $\bullet \mathrm{OH}$ radicals, because the band edge potential is lower than edge for $\bullet \mathrm{OH}$ radical generation with potential of $2.53 \mathrm{eV}$. The electron path from $\mathrm{CB}$ of $\mathrm{TiO}_{2} \mathrm{NTs}$ 
transfers further to the environment reacting with the oxygen and creating superoxide anion radicals $\mathrm{O}_{2} \bullet-$ and then $\mathrm{H}_{2} \mathrm{O}_{2}$ and $\mathrm{HO}_{2} \bullet$. When analyzing the reaction with $\mathrm{TiO}_{2}-\mathrm{CuO}$ NTs, the situation is very much different. As the band gap of $\mathrm{CuO}(1.7 \mathrm{eV})$ enables electrons to move conduction band of $\mathrm{CuO}$, the electrons react with oxygen forming superoxide anion radicals $\mathrm{O}_{2} \bullet-$ and then $\mathrm{H}_{2} \mathrm{O}_{2}$ and $\mathrm{HO}_{2} \bullet$. Furthermore, the reaction with pollutant (phenol) after several processes led to formation of intermediates and finally $\mathrm{H}_{2} \mathrm{O}$ and $\mathrm{CO}_{2}$ (as shown in Figure 6b).

Moreover, it is confirmed that redox potentials for the reduction of $\mathrm{Cu}_{2} \mathrm{O}$ to $\mathrm{Cu}$ and for oxidation $\mathrm{Cu}_{2} \mathrm{O}$ to $\mathrm{CuO}$ occur and should be taken into consideration. However, Weng et al reported that in presence of even small amount of $\mathrm{CuO}$, which works as a protection shield, the possibility of $\mathrm{Cu}_{2} \mathrm{O}$ photocorrosion is less probable [52]. XPS analysis showed (Table 2) that there are trace amounts of CuO in tested NTs alloys that can lead to the conclusion that $\mathrm{Cu}_{2} \mathrm{O}$ is resistant to photocorrosion process. All results above and analysis presented by Luna et al. [53] can lead to proposed $\mathrm{Cu}_{2} \mathrm{O}-\mathrm{CuO}-\mathrm{TiO}_{2}$ complex mechanism (Figure 6a).

\subsection{Assessment of Antibacterial Properties of $\mathrm{TiO}_{2} / \mathrm{Cu}_{x} \mathrm{O}_{y}$ NTs}

Microbial contamination of the environment can be a critical issue for many aspects of our lives. That is why the modification of surface with different additives, which can foster the process of bacterial inactivation, is important [54]. The assessment of the antibacterial properties of photocatalytic layer- $-\mathrm{TiO}_{2} / \mathrm{Cu}_{x} \mathrm{O}_{y}$ NTs obtained from $\mathrm{Ti}_{95} \mathrm{Cu}_{5}$ alloy in Vis light-was investigated in three different configurations in presence of microorganisms, Ti-Cu NTs, Vis light, microorganisms and Vis light only, and microorganisms and Ti-Cu NTs in the dark. Three different bacterial strain were used: E. coli, B. subtilis, and Clostridium sp. The amount of bacteria after the process was measured quantitatively (CFU/mL (colony-forming unit)) and with usage of TEM (Table 3 and Figure 7, respectively).

Table 3. Efficiency of bacteria inactivation in aqueous phase in the presence of the $\mathrm{Ti}_{95} \mathrm{Cu}_{5}$ 30V sample and visible light $(\lambda>420 \mathrm{~nm})$.

\begin{tabular}{|c|c|c|}
\hline Bacterial Strain & Experimental Conditions & Efficiency after $60 \mathrm{~min}$ \\
\hline \multirow{9}{*}{$\begin{array}{l}\text { E. coli }- \text { OD }=0.09 \\
\text { STARTING CFU/mL: } 3.3 \times 10^{2}\end{array}$} & Light source: switched on & \multirow{3}{*}{$97 \%$} \\
\hline & Bacteria: present & \\
\hline & Photocatalytic layer: present & \\
\hline & Light source: switched off & \multirow{3}{*}{$12 \%$} \\
\hline & Bacteria: present & \\
\hline & Photocatalytic layer: present & \\
\hline & Light source: switched on & \multirow{3}{*}{$3 \%$} \\
\hline & Bacteria: present & \\
\hline & Photocatalytic layer: absent & \\
\hline \multirow{9}{*}{$\begin{array}{l}\text { B. subtilis - OD = } 0.09 \\
\text { STARTING CFU/mL: } 2.5 \times 10^{2}\end{array}$} & Light source: switched on & \multirow{2}{*}{ Did not grow } \\
\hline & Bacteria: present & \\
\hline & Photocatalytic layer: present & \multirow{4}{*}{ Did not grow } \\
\hline & Light source: switched off & \\
\hline & Bacteria: present & \\
\hline & Photocatalytic layer: present & \\
\hline & Light source: switched on & \multirow{3}{*}{$16 \%$} \\
\hline & Bacteria: present & \\
\hline & Photocatalytic layer: absent & \\
\hline \multirow{9}{*}{$\begin{array}{l}\text { Clostridium sp. }- \text { OD }=0.1 \\
\text { STARTING CFU/mL: } 3.8 \times 10^{2}\end{array}$} & Light source: switched on & \multirow{3}{*}{$98 \%$} \\
\hline & Bacteria: present & \\
\hline & Photocatalytic layer: present & \\
\hline & Light source: switched off & \multirow{3}{*}{$0 \%$} \\
\hline & Bacteria: present & \\
\hline & Photocatalytic layer: present & \\
\hline & Light source: switched on & \multirow{3}{*}{$5 \%$} \\
\hline & Bacteria: present & \\
\hline & Photocatalytic layer: absent & \\
\hline
\end{tabular}


The quantitative analysis shows that correlation between efficiency of the process and experimental conditions are clearly noticeable. The significant results were obtained for measurements in presence of Vis light source and photocatalytic layers in case of two strains: E. coli (97\% damage in $60 \mathrm{~min}$ ) and Clostridium sp. (98\% damage in $60 \mathrm{~min}$ ). What is more, in example of B. subtilis there was no response of bacteria and it never grew (all results presented in Table S3). The lack of B. subtilis growth can be related to conditions of the experiment or the influence of $\mathrm{Cu}^{2+}$ ions leached from surface of nanotubes.

B. subtilis can form endospores which are small, metabolically dormant cells remarkably resistant to heat, desiccation, radiation, and chemical insult. Sporulation is the last response to nutrient starvation or other stressful conditions. Alternative condition to forming the spores is high cell density favors sporulation. The process of endospore formation has profound morphological and physiological consequences $[55,56]$. Endospores are produced in a process called sporulation, which is reversible, because the vegetative cell can be regenerated again when only in the environment there will be favorable conditions. This reverse process to sporulation is called germination of spores. This process requires a number of spore specific proteins. Most proteins are associated with the inner spore membrane [57]. Germination of spores depends on many conditions present in bacterial growth and formulation way of spores. Stress conditions for bacteria (irradiation of the catalytic layer connected radiation) led to the formation of spores, which under normal conditions of Bacillus sp. growth were unable to undergo germination.

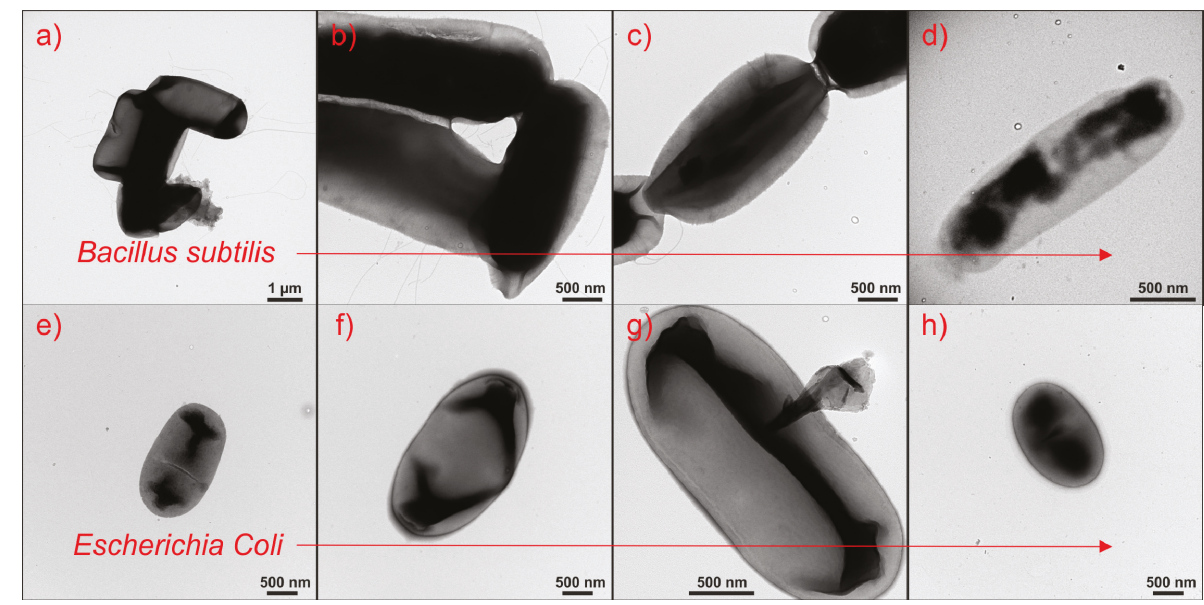

Figure 7. TEM images of bacteria after $60 \mathrm{~min}$ of various processes: $(\mathbf{a}, \mathbf{e})$ reference bacteria $(\mathbf{b}, \mathbf{f})$ light switched off, bacteria present, photocatalyst present, (c,g) light switched on, bacteria present, photocatalyst absent and $(\mathbf{d}, \mathbf{h})$ light switched on, bacteria present, photocatalyst present.

However, there are also differences between germination of Bacillus spores and Clostridium spores. First, while germinant receptor (GR) function in germination Bacillus sp. requires all three GR subunits. It appears that only a GRc subunit alone can facilitate Clostridia spore germination. Second, spores of some Clostridia lack GRs with any similarity to those in spores of bacilli, likely a reflection of the great diversity in the Clostridia. However, C. difficile spores do germinate well with specific bile salts and also respond to various amino acids [57]. In the case of E. coli, these types of processes are not observed because they do not sporulate.

For confirmation of previous analysis, the effect of $\mathrm{Cu}^{2+}$ on the growth of E. coli and B. subtilis was investigated (Figure S3 and Table S4). The growth of bacterial cultures (with the addition of $\mathrm{Cu}^{2+}$ ions) was controlled by measuring the optical density at $600 \mathrm{~nm}$. Growth inhibition was found for 
both strains in the first two dilutions. The minimal inhibitory concentration (MIC) is $0.1 \mathrm{mM}$ of $\mathrm{Cu}^{2+}$ ions. A similar effect was observed by Zong et al. [34]. After obtaining above results, only E. coli and B. subtilis were sent for TEM analysis to confirm the transformation of bacteria. Images revealed changes in bacteria shape in every tested configuration with the biggest influence of photocatalytic layer on B. subtilis (clear damage of the inside structure) and light source on E. coli (whole deformation of bacteria). Deformed bacterial cell cannot grow and is no longer a serious environmental problem. Finally, it is likely that the cell membrane will undergo complete mineralization [58]. In summary, the as-prepared photocatalyst irradiated with Vis light has very high, indisputable bactericidal effects (in both cases, efficiency of bacteria inactivation reached 97\%). E. coli, Clostridium sp., and B. subtilis are removed from water and the surface of the photocatalysts within $60 \mathrm{~min}$. of irradiation.

\subsection{Suggested Mechanism of Bacteria Inactivation}

A full knowledge about the mechanism of bacteria inactivation is essential for further development of nanocomposites involved in disinfection processes. Matsunga et al. were the pioneers with hypothesis in which Coenzyme A is degraded by ROS in the presence of light [21]. The enzyme cut off can cause respiration problems, possibly leading to death. However further research performed by Saito et al. confirmed that main reason for cell death is the burst of the cell wall membrane leading to leakages [59]. Obtained TEM images (Figure 7) for experiment with $\mathrm{Ti}_{95} \mathrm{Cu}_{5}{ }_{30 \mathrm{~V}}$ confirmed the destruction of bacteria cell structure and wall membrane in presence of photocatalyst and light, which led to conclusion that copper as a component photocatalyst influenced the process. Moreover, based on analysis made by Kikuchi et al., who confirmed the role of the ROS by addition of hydroxyl scavengers to the reaction system [60], it can be concluded that for $\mathrm{TiO}_{2}-\mathrm{Cu}_{x} \mathrm{O}_{y}$, another source of bacteria inactivation lies in oxygen radicals. The suggested scheme presenting damage of bacteria cell during the inactivation process is presented in Figure 6c.

\section{Materials and Methods}

\subsection{Materials}

The titanium foils and alloys were purchased from HMW Hauner (Röttenbach, Germany). Isopropanol, acetone, and methanol (p.a., POCh S.A., Gliwice, Poland) were used for cleaning Ti foil and alloys surface. $\mathrm{NH}_{4} \mathrm{~F}$ (p.a.) and ethylene glycol (99.0\%, p.a.) purchased from POCh S.A. were the components of the electrolyte, which were used for preparation of the $\mathrm{TiO}_{2}$ nanotubes. Deionized water used during experiments had conductivity of $0.05 \mu \mathrm{S}$.

The following bacterial strains were used in this work: E. coli DSMZ collection no 1116, B. subtilis DSMZ collection no 347, and Clostridium sp. DSMZ collection no 2634. E. coli is a Gram-negative, facultatively anaerobic, rod-shaped bacteria. E. coli is found in the gut of animals, including human gut, as well as commonly in soil and water. Bacteria does not create endospores. B. subtilis is Gram-positive, facultative anaerobe, and rod-shaped found in soil and the gastrointestinal tract of ruminants and humans. It can form a tough, protective endospore, allowing it to tolerate extreme environmental conditions. Clostridium sp. is Gram-positive, obligate anaerobes, rod-shaped bacteria. They are producing endospores commonly found mainly in the soil and digestive tract of animals, including humans, female reproductive organs, as well as in water and sewage. These bacteria are characterized by the possibility of binding atmospheric nitrogen and reduction of sulphites [61].

To measure the copper influence on growth of bacteria cultures, the bacterial cultures mentioned above were conducted in LB medium (1\% tryptone, $0.5 \%$ yeast extract, $1 \% \mathrm{NaCl}, \mathrm{pH} 7.0$ ), supplemented with $98 \%$ copper acetate $\left(\mathrm{C}_{4} \mathrm{H}_{6} \mathrm{CuO}_{4} \times \mathrm{H}_{2} \mathrm{O}\right)$ from Avantor Performance Materials S.A. (Gliwice, Poland). 


\subsection{Preparation of NTs}

Ti and Ti-Cu alloys containing different amounts of copper (5, 10, 15 wt.\%) in the form of sheets were cut into pieces of size $2 \times 3 \mathrm{~cm}$. In the first step, experiment samples were cleaned with usage of acetone, isopropanol, methanol, and deionized water separately, one by one, in ultrasonic bath for $10 \mathrm{~min}$. Cleaning process was finalized with drying alloys in the air steam. In the second step, the set up for anodization process was established with two electrodes-platinum mesh as the cathode and $\mathrm{Ti} / \mathrm{Ti}-\mathrm{Cu}$ alloy as a working electrode. Moreover, the $\mathrm{Ag} / \mathrm{AgCl}$ reference electrode was incorporated into the system to gather information about the definite potential of the electrode. The anodic oxidation process was performed in the presence of electrolyte solution ( $98 \mathrm{vol} \%$ ethylene glycol, $2 \mathrm{vol} \%$ water and $0.09 \mathrm{M} \mathrm{NH}_{4} \mathrm{~F}$ ) for $60 \mathrm{~min}$ with applied voltage in a range between 30 and $50 \mathrm{~V}$. The anodization was monitored with DC power supply (MANSON SDP 2603, Hong Kong, China). After all, in third step, samples were sonicated in deionized water for $5 \mathrm{~min}$, dried in air stream at $80^{\circ} \mathrm{C}$ for $24 \mathrm{~h}$, and calcinated at $450{ }^{\circ} \mathrm{C}$ (heating rate of $2{ }^{\circ} \mathrm{C} / \mathrm{min}$ ) for $1 \mathrm{~h}$.

\subsection{Characterization Systems}

To understand the morphology of NTs obtained by electrochemical method, scanning electron microscopy was performed (SEM-FEI Quanta 250 FEG FEI Company, Brno, Czech Republic). To locate the anomalies, structure high-resolution transmission electron microscopy (HRTEM Jeol ARM 200F, Akishama, Tokio, Japan)) was carried out. The X-Ray photoelectron spectroscopy (XPS) measurements were completed at PHI 5000 VersaProbeTM (ULVAC-PHI, Chigasaki, Japan) spectrometer with monochromatic $\mathrm{Al} \mathrm{K} \lambda$ radiation $(\mathrm{h} v=1486.6 \mathrm{eV})$. Phase composition on the surface was checked using a room temperature powder X-ray X'Pert Pro MPD diffractometer (PANalytical, Almelo, The Netherlands)(CuK $\alpha \lambda 1.5406 \AA)$. A LeBail refinement was performed using the HighScore software (Ver. 3.0d, PANanalytical, Almelo, The Netherlands). The binding energy (BE) scale of all detected high resolution (HR) spectra was referenced by setting the BE of the aliphatic carbon peak (C-C) signal to $284.6 \mathrm{eV}$. The photoluminescence (PL) measurements were taken at room temperature with LS-50B Luminescence Spectrophotometer with Xenon discharge lamp as an excitation source and special detector-a R928 photomultiplier (HAMAMATSU, Hamamatsu, Japan). The excitation radiation $(360 \mathrm{~nm})$ was directed on the sample's surface at an angle of $90^{\circ}$. The UV-Vis reflectance and absorbance spectra of pure and copper doped NTs were obtained with usage of Shimadzu UV-Vis. Spectrophotometer (UV 2600) (SHIMADZU, Kioto, Japan), with reference samples of barium sulphate. The range for the spectra registration was between 300 and $800 \mathrm{~nm}$ in room temperature and set scanning speed of $250 \mathrm{~nm} / \mathrm{min}$.

\subsection{Photocatalytic Activity}

The equipment used for all photocatalytic activity measurements was as follows: a quartz reactor with the capacity of $10 \mathrm{~mL}, 1000 \mathrm{~W}$ Xenon Lamp (Oriel 66021 Stratford, CT, USA), and cut off filters. Light intensity was measured for both filters with value of $40 \mathrm{~mW} / \mathrm{cm}^{2}$ for UV-Vis and $2 \mathrm{~mW} / \mathrm{cm}^{2}$ for Vis range.

\subsubsection{Phenol Degradation Process}

The process of photocatalytic degradation in model reaction with usage of phenol for two light sources was performed. The irradiation was controlled by two cut off filters GG350 (UV-Vis $\lambda>350 \mathrm{~nm}$ ) and GG 420 (Vis $\lambda>420 \mathrm{~nm}$ ). To perform the experiment, prepared phenol solution ( $20 \mathrm{mg} / \mathrm{L}$ ) in amount of $8 \mathrm{~mL}$ was applied to the reactor, followed by immersing the examined alloy. Prepared sample was placed on a stirrer $(500 \mathrm{rpm})$ and irradiated with preferable light for $60 \mathrm{~min}$. Not only reference phenol solution $(0.5 \mathrm{~mL})$ was taken before the beginning of procedure, but also samples $(0.5 \mathrm{~mL})$ after each $20 \mathrm{~min}$ of the irradiated process were collected. We chose colorimetric method in the 
presence of p-nitroaniline and with usage of UV-Vis spectrophotometer $\left(\lambda_{\max }=480 \mathrm{~nm}\right)$ to investigate the phenol concentration.

\subsubsection{Microorganisms Inactivation Process}

The experiment connected with bacteria inactivation process was performed with application of three microorganisms species-E. coli, B. subtilis, and Clostridium sp. All vessels and media used in bacterial experiments were pre-sterilized by steam. The preparation of bacteria were harvested in LB medium by shaken in air shaker at $37^{\circ} \mathrm{C}$ for $16 \mathrm{~h}$. The bacteria pellet was isolated from medium by centrifugation at $2739 \times g$ for $10 \mathrm{~min}$. The resulting pellet was resuspended in sterile water to final concentration E. coli $3.3 \times 10^{2}$, B. subtilis $2.5 \times 10^{2}$, Clostridium sp. $3.8 \times 10^{2}\left(\mathrm{OD}_{600 \mathrm{~nm}}=0.1\right)$. As it is proven that microorganisms die in UV irradiation range, the Vis range with the cut off filter GG420 was used. As a photocatalyst, $\mathrm{Ti}_{95} \mathrm{Cu}_{5}$ alloy was applied.

The idea of the experiment was to check the inactivation process in three control tests-in presence of microorganisms, Ti-Cu NTs, and Vis light; in presence of microorganisms and Vis light only; and in the presence of microorganisms and Ti-Cu NTs in the dark. To perform the experiment, the suspension of bacteria $(8 \mathrm{~mL})$ was applied in the same reactor as in phenol degradation process. Depending on the configuration, Ti-Cu NTs were immersed in bacteria suspension or not. Prepared set up (with or without NTs) was placed on a stirrer $(500 \mathrm{rpm})$ and irradiated with preferable light or kept in the dark for $60 \mathrm{~min}$. Reference samples $(1 \mathrm{~mL})$ were collected just before each experiment, and consecutive samples $(1 \mathrm{~mL})$ were taken every $20 \mathrm{~min}$. After the complete process there were two procedures of measurements. First, the collected samples were prepared by serial dilution (100 $\mu \mathrm{L}$ of sample in $900 \mu \mathrm{L}$ of sterile $1 \times$ PBS (phosphate-buffered saline)) and subsequent $10 \mu \mathrm{L}$ of each were seeded on agar plate PCA (Plate Count Agar). The plates were incubated at $37^{\circ} \mathrm{C}$ in an incubator for $16 \mathrm{~h}$. Grown bacteria were counted, along with the amount of microorganisms in $1 \mathrm{~mL}$ of the dilution with the formula CFU $=$ number of colonies $\times$ dilution/volume of inoculum. Second time, more diluted consecutive samples ( $1 \mathrm{~mL}$ taken every $20 \mathrm{~min}$ ) were put in the ice and sent to resolution transmission electron microscopy.

\subsubsection{Measurement of Copper $\mathrm{Cu}^{2+}$ Influence on Growth of Bacterial Cultures}

The aim of the measurement was to check the influence of $\mathrm{Cu}^{2+}$ on the growth of bacterial cultures. This method was chosen to identify if the copper alone influenced the bacteria. The diluted solution of copper actetite was used to perform this measurement. The bacteria were harvested in LB medium by shaken in air shaker at $37^{\circ} \mathrm{C}$ for $16 \mathrm{~h}$. B. subtilis was added to LB medium to $\mathrm{OD}_{600 \mathrm{~nm}}=0.13$ and E. coli to $\mathrm{OD}_{600 \mathrm{~nm}}=0.1$ and were harvested in air shaker at $37^{\circ} \mathrm{C}$ for $30 \mathrm{~min}$. In the test tube, serial dilution of $\mathrm{Cu}^{2+}$ ions were prepared from 1-1 $\times 10^{-9} \mathrm{mM}$. Then, $\mathrm{OD}_{600 \mathrm{~nm}}$ was measured; the negative control was LB medium, and the positive control was LB medium with bacteria with appropriate $\mathrm{OD}_{600 \mathrm{~nm}}$.

To determine the influence of $\mathrm{Cu}^{2+}$ ions on B. subtilis culture, the 2-fold serial dilution test of ions was tested. The B. subtilis was culture in LB medium by shaken in air shaker at $37^{\circ} \mathrm{C}$ for $16 \mathrm{~h}$. B. subtilis was added to $\mathrm{LB}$ medium to $\mathrm{OD}_{600 \mathrm{~nm}}=0.1$ and harvested in air shaker at $37^{\circ} \mathrm{C}$ for $1.5 \mathrm{~h}$. In the test tube 2-fold serial dilution of $\mathrm{Cu}^{2+}$, ions were prepared from 10-1.9 $\times 10^{-2}$. The $\mathrm{OD}_{600 \mathrm{~nm}}$ was measured every $30 \mathrm{~min}$; the negative control was LB medium, and the positive control was LB medium with bacteria with appropriate $\mathrm{OD}_{600 \mathrm{~nm}}$

\subsubsection{Measurement of Hydroxyl Radicals}

As $\bullet \mathrm{OH}$ radicals are considered the most powerful in the oxidation process of many organic compounds [62], the role and amount was determined to understand the photocatalytic properties. A terephthalic acid, as a substance which effectively captures $\bullet \mathrm{OH}$ radicals and generates highly fluorescent product, was used and investigated for photoluminescence intensity. The tests were performed in the same laboratorium set up as in the phenol degradation process with the initial concentration of terephthalic acid equal Co. $=0.5 \mathrm{mM}$. The reactor was irradiated for $60 \mathrm{~min}$, 
with 20 min intervals for sample collection. The photoluminescence spectra of all collected samples were measured at LS-50 B luminescence spectrophotometer (HAMAMATSU, Hamamatsu, Japan) with lamp with excitation wavelength at $315 \mathrm{~nm}$ and photomultiplier detector.

\subsubsection{Investigation of Photodegradation Mechanism}

In order to understand the mechanism of photodegradation of phenol solution silver nitrate, ammonium oxalate, tert-buthyl alcohol, and benzoquinone were applied, which are scavengers for $\mathrm{e}^{-}, \mathrm{h}^{+}, \bullet \mathrm{OH}$, and $\mathrm{O}_{2} \bullet-$ radicals, respectively. The photodegradation experiment conditions were the same as in phenol degradation process.

\section{Conclusions}

The analysis of new spectra of nanostructures developed by electrochemical method $\mathrm{TiO}_{2} / \mathrm{Cu}_{x} \mathrm{O}_{y}$ NT arrays due to their unique features can be used not only in the photodegradation process but also in bacteria inactivation. In this study, the influence of copper amount and applied voltage in NTs formation was investigated, as well as the correlation of NTs composition with the efficiency of the photodegradation of pollutants in the aqueous phase. All prepared $\mathrm{Ti}_{x} \mathrm{Cu}_{y}$ foils after the anodization process have proved to be self-organized nanotubes arrays with external diameter of 85-97 $\mathrm{nm}$ and length 1.1-3.5 $\mu \mathrm{m}$. The dimensions were directly induced by applied voltage, as the NTs were usually shorter and thicker than pristine $\mathrm{TiO}_{2}$ NTs. Furthermore, photodegradation of phenol in the aqueous phase with the presence of NT photocatalysts was performed under Vis light irradiation $(\lambda>420 \mathrm{~nm})$. The best performance was marked in the case of $\mathrm{TiO}_{2} / \mathrm{Cu}_{x} \mathrm{O}_{y}$ NTs arrays with a Cu content of 15 wt. $\%$. Additionally, PL analysis and absorbance measurements were performed that revealed promising results in terms of NTs application in Vis light region. It was proved that oxygen vacancies activated by $\mathrm{Cu}$ dopant in the NTs could be the main factor in the phase stabilization of the anataze phase.

Moreover, the assessment of the antibacterial properties of new NTs was performed with very promising results regarding the efficiency of bacteria degradation in terms of E. coli (97\% degradation in $60 \mathrm{~min}$ ) and Clostridium sp. (98\% degradation in $60 \mathrm{~min}$ ) under visible light irradiation (using low $\mathrm{CFU} / \mathrm{mL}$ of bacteria).

The anodization method with $\mathrm{Cu}$-Ti alloys developed in this study is a simple and effective method that can be implemented on a larger scale, not only in environmental applications but also in medical industry. Our results are encouraging and should be continued in the study of complexes with more than two components during anodization. Further work needs to be carried out in direction of creating nanomaterials with cascade heterojunctions possessing accurate photoelectrochemical characterization, which can be cheaper and more controlled in comparison to two composite photocatalysts. Research in this area was already undertaken by analyzing $\mathrm{Cu}$-Ag-Ti alloys. It is also a challenge to consider the antibiotic resistant strains of mutant microbs, which are a growing problem nowadays. Finally, what seems to be an important matter is the variety of standards used by research group to measure the efficiency of the photocatalysts and their influence on microorganisms.

Supplementary Materials: The following are available online at http:/ /www.mdpi.com/2073-4344/8/6/237/s1, Figure S1: Top-view and cross-sectional SEM images of pristine $\mathrm{TiO}_{2}$ NTs, Figure S2: X-ray diffraction patterns for pristine $\mathrm{TiO}_{2}$ NTs, Table S1: Refined lattice parameters for $\mathrm{TiO}_{2}$ —anatase, $\mathrm{Ti}$-metal and $\mathrm{CuTiO}_{2}$-alloy. The crystallite size was calculated for the anatase only, Table S2: Elemental composition (in at.\%) in the surface layer of $\mathrm{TiO}_{2}$ and $\mathrm{Cu}$-modified $\mathrm{TiO}_{2} \mathrm{NTs}$, evaluated by XPS analysis, Table S3: Efficiency of bacteria inactivation after 20, 40 and $60 \mathrm{~min}$ of various processes, Figure S3: Image of influence of $\mathrm{Cu}^{2+}$ ions on the growth of B.Subtilis, Table S4: The influence of $\mathrm{Cu}^{2+}$ ions on the growth of E. coli and B. subtilis. (a) OD measurements at $600 \mathrm{~nm}$ of E. coli and $B$. subtilis cultures with the addition of $\mathrm{Cu}^{2+}$ ions from $1-1 \times 10^{-9} \mathrm{mM}$ (serial dilution), (b) OD measurements at $600 \mathrm{~nm}$ of $B$. subtilis culture with addition of $\mathrm{Cu}^{2+}$ ions from $10-1.9 \times 10^{-2}$ from $1-10^{-9} \mathrm{mM}$. To, T1, T2-the subsequent measurement points; $\mathrm{Kp}-$ positive control, culture of strain without $\mathrm{Cu}^{2+}$ ions; $\mathrm{Kn}-$ negative control, the medium.

Author Contributions: Conceptualization: A.Z.-M. and P.M.; methodology: A.Z.-M. and P.M.; investigation: M.K. (Magda Kozak), P.M., J.Ż., M.K. (Marek Kobylański), T.K., W.L., G.T., and G.N.; visualization: M.K. (Magda Kozak) 
and P.M.; writing-original draft preparation: M.K. (Magda Kozak) ; writing review \& reediting: P.M and A.Z.-M.; supervision: A.Z.-M.; funding acquisition: A.Z.-M.

Funding: This research was financially supported by the Polish National Science Center (grant No. NCN 2014/15/B/ST5/00098, ordered $\mathrm{TiO}_{2} / \mathrm{M}_{\mathrm{x}} \mathrm{O}_{\mathrm{y}}$ nanostructures obtained by electrochemical method).

Conflicts of Interest: The authors declare no conflict of interest.

\section{References}

1. Hoffmann, M.R.; Martin, S.T.; Choi, W.; Bahnemann, D.W. Environmental Applications of Semiconductor Photocatalysis. Chem. Rev. 1995, 95, 69-96. [CrossRef]

2. Fujishima, A.; Rao, T.N.; Tryk, D.A. Titanium dioxide photocatalysis. J. Photochem. Photobiol. C Photochem. Rev. 2000, 1, 1-21. [CrossRef]

3. Low, J.; Cheng, B.; Yu, J. Surface modification and enhanced photocatalytic $\mathrm{CO}_{2}$ reduction performance of $\mathrm{TiO}_{2}$ : A review. Appl. Surf. Sci. 2017, 392, 658-686. [CrossRef]

4. Ni, M.; Leung, M.K.H.; Leung, D.Y.C.; Sumathy, K. A review and recent developments in photocatalytic water-splitting using $\mathrm{TiO}_{2}$ for hydrogen production. Renew. Sustain. Energy Rev. 2007, 11, 401-425. [CrossRef]

5. Yadav, H.M.; Kim, J.-S.; Pawar, S.H. Developments in photocatalytic antibacterial activity of nano $\mathrm{TiO}_{2}$ : A review. Korean J. Chem. Eng. 2016, 33, 1989-1998. [CrossRef]

6. Zhang, S.; Zhang, S.; Peng, F.; Zhang, H.; Liu, H.; Zhao, H. Electrodeposition of polyhedral $\mathrm{Cu}_{2} \mathrm{O}_{\text {on }} \mathrm{TiO}_{2}$ nanotube arrays for enhancing visible light photocatalytic performance. Electrochem. Commun. 2011, 13, 861-864. [CrossRef]

7. Pelaez, M.; Nolan, N.T.; Pillai, S.C.; Seery, M.K.; Falaras, P.; Kontos, A.G.; Dunlop, P.S.M.; Hamilton, J.W.J.; Byrne, J.A.; O'Shea, K.; et al. A review on the visible light active titanium dioxide photocatalysts for environmental applications. Appl. Catal. B Environ. 2012, 125, 331-349. [CrossRef]

8. Nevárez-Martínez, M.; Kobylański, M.; Mazierski, P.; Wółkiewicz, J.; Trykowski, G.; Malankowska, A.; Kozak, M.; Espinoza-Montero, P.; Zaleska-Medynska, A. Self-Organized $\mathrm{TiO}_{2}-\mathrm{MnO}_{2}$ Nanotube Arrays for Efficient Photocatalytic Degradation of Toluene. Molecules 2017, 22, 564. [CrossRef]

9. Daraio, C.; Jin, S. Synthesis and Patterning Methods for Nanostructures Useful for Biological Applications. In Nanotechnology for Biology and Medicine; Silva, G.A., Parpura, V., Eds.; Springer: New York, NY, USA, 2012; pp. 27-44. ISBN 978-0-387-31282-8.

10. Nevárez-Martínez, M.; Mazierski, P.; Kobylański, M.; Szczepańska, G.; Trykowski, G.; Malankowska, A.; Kozak, M.; Espinoza-Montero, P.; Zaleska-Medynska, A. Growth, Structure, and Photocatalytic Properties of Hierarchical $\mathrm{V}_{2} \mathrm{O}_{5}-\mathrm{TiO}_{2}$ Nanotube Arrays Obtained from the One-step Anodic Oxidation of Ti-V Alloys. Molecules 2017, 22, 580. [CrossRef]

11. Mohammed, M.T.; Khan, Z.A.; Siddiquee, A.N. Surface Modifications of Titanium Materials for developing Corrosion Behavior in Human Body Environment: A Review. Procedia Mater. Sci. 2014, 6, 1610-1618. [CrossRef]

12. Jung, M.; Scott, J.; Ng, Y.H.; Jiang, Y.; Amal, R. CuO x dispersion and reducibility on $\mathrm{TiO}_{2}$ and its impact on photocatalytic hydrogen evolution. Int. J. Hydrogen Energy 2014, 39, 12499-12506. [CrossRef]

13. Gong, D.; Grimes, C.A.; Varghese, O.K.; Hu, W.; Singh, R.S.; Chen, Z.; Dickey, E.C. Titanium oxide nanotube arrays prepared by anodic oxidation. J. Mater. Res. 2001, 16, 3331-3334. [CrossRef]

14. Macak, J.M.; Schmuki, P. Anodic growth of self-organized anodic $\mathrm{TiO}_{2}$ nanotubes in viscous electrolytes. Electrochim. Acta 2006, 52, 1258-1264. [CrossRef]

15. Xie, Z.B.; Blackwood, D.J. Effects of anodization parameters on the formation of titania nanotubes in ethylene glycol. Electrochim. Acta 2010, 56, 905-912. [CrossRef]

16. Erjavec, B.; Tišler, T.; Tchernychova, E.; Plahuta, M.; Pintar, A. Self-Doped Cu-Deposited Titania Nanotubes as Efficient Visible Light Photocatalyst. Catal. Lett. 2017, 147, 1686-1695. [CrossRef]

17. Hai, Z.; EL Kolli, N.; Chen, J.; Remita, H. Radiolytic synthesis of Au-Cu bimetallic nanoparticles supported on $\mathrm{TiO}_{2}$ : Application in photocatalysis. New J. Chem. 2014, 38, 5279-5286. [CrossRef]

18. Lalitha, K.; Sadanandam, G.; Kumari, V.D.; Subrahmanyam, M.; Sreedhar, B.; Hebalkar, N.Y. Highly Stabilized and Finely Dispersed CuO/TiO: A Promising Visible Sensitive Photocatalyst for Continuous Production of Hydrogen from Glycerol:Water Mixtures. J. Phys. Chem. C 2010, 114, 22181-22189. [CrossRef] 
19. Geng, Z.; Zhang, Y.; Yuan, X.; Huo, M.; Zhao, Y.; Lu, Y.; Qiu, Y. Incorporation of $\mathrm{Cu}_{2} \mathrm{O}$ nanocrystals into $\mathrm{TiO}_{2}$ photonic crystal for enhanced UV-visible light driven photocatalysis. J. Alloys Compd. 2015, 644, 734-741. [CrossRef]

20. Colón, G.; Maicu, M.; Hidalgo, M.C.; Navío, J.A. Cu-doped $\mathrm{TiO}_{2}$ systems with improved photocatalytic activity. Appl. Catal. B Environ. 2006, 67, 41-51. [CrossRef]

21. Matsunaga, T.; Tomoda, R.; Nakajima, T.; Wake, H. Photoelectrochemical sterilization of microbial cells by semiconductor powders. FEMS Microbiol. Lett. 1985, 29, 211-214. [CrossRef]

22. Polymeric Materials with Antimicrobial Activity: From Synthesis to Applications; Muñoz-Bonilla, A.; Cerrada, M.; Fernández-García, M. (Eds.) Polymer Chemistry Series; Royal Society of Chemistry: Cambridge, UK, 2013; ISBN 978-1-84973-807-1.

23. Chen, L.; Luo, T.; Yang, S.; Xu, J.; Liu, Z.; Wu, F. Efficient metoprolol degradation by heterogeneous copper ferrite/sulfite reaction. Environ. Chem. Lett. 2018, 16, 599-603. [CrossRef]

24. Wojcieszak, D.; Mazur, M.; Kaczmarek, D.; Poniedziałek, A.; Osękowska, M. An impact of the copper additive on photocatalytic and bactericidal properties of $\mathrm{TiO}_{2}$ thin films. Mater. Sci. Pol. 2017, 35. [CrossRef]

25. Reilche, H.; Dunn, W.W.; Bard, J.A. Allen Heterogeneous photocatalytic and photosynthetic deposition of copper on $\mathrm{TiO}_{2}$ and $\mathrm{WO}_{3}$ powders. J. Phys. Chem. 1979, 83, 2248-2251.

26. Moniz, S.J.A.; Tang, J. Charge Transfer and Photocatalytic Activity in $\mathrm{CuO} / \mathrm{TiO}_{2}$ Nanoparticle Heterojunctions Synthesised through a Rapid, One-Pot, Microwave Solvothermal Route. ChemCatChem 2015, 7, 1659-1667. [CrossRef]

27. Hu, Q.; Huang, J.; Li, G.; Chen, J.; Zhang, Z.; Deng, Z.; Jiang, Y.; Guo, W.; Cao, Y. Effective water splitting using $\mathrm{CuO} x / \mathrm{TiO}_{2}$ composite films: Role of $\mathrm{Cu}$ species and content in hydrogen generation. Appl. Surf. Sci. 2016, 369, 201-206. [CrossRef]

28. Ma, Q.; Liu, S.J.; Weng, L.Q.; Liu, Y.; Liu, B. Growth, structure and photocatalytic properties of hierarchical $\mathrm{Cu}-\mathrm{Ti}-\mathrm{O}$ nanotube arrays by anodization. J. Alloys Compd. 2010, 501, 333-338. [CrossRef]

29. Gao, L.; Qiu, Z.; Gan, W.; Zhan, X.; Li, J.; Qiang, T. Negative Oxygen Ions Production by Superamphiphobic and Antibacterial $\mathrm{TiO}_{2} / \mathrm{Cu}_{2} \mathrm{O}$ Composite Film Anchored on Wooden Substrates. Sci. Rep. 2016, 6. [CrossRef]

30. Cheng, M.; Yang, S.; Chen, R.; Zhu, X.; Liao, Q.; Huang, Y. Copper-decorated $\mathrm{TiO}_{2}$ nanorod thin films in optofluidic planar reactors for efficient photocatalytic reduction of $\mathrm{CO}_{2}$. Int. J. Hydrogen Energy 2017, 42, 9722-9732. [CrossRef]

31. He, X.; Zhang, G.; Wang, X.; Hang, R.; Huang, X.; Qin, L.; Tang, B.; Zhang, X. Biocompatibility, corrosion resistance and antibacterial activity of $\mathrm{TiO}_{2} / \mathrm{CuO}$ coating on titanium. Ceram. Int. 2017, 43, 16185-16195. [CrossRef]

32. Yadav, H.M.; Otari, S.V.; Koli, V.B.; Mali, S.S.; Hong, C.K.; Pawar, S.H.; Delekar, S.D. Preparation and characterization of copper-doped anatase $\mathrm{TiO}_{2}$ nanoparticles with visible light photocatalytic antibacterial activity. J. Photochem. Photobiol. A Chem. 2014, 280, 32-38. [CrossRef]

33. Nischk, M.; Mazierski, P.; Wei, Z.; Siuzdak, K.; Kouame, N.A.; Kowalska, E.; Remita, H.; Zaleska-Medynska, A. Enhanced photocatalytic, electrochemical and photoelectrochemical properties of $\mathrm{TiO}_{2}$ nanotubes arrays modified with $\mathrm{Cu}, \mathrm{AgCu}$ and $\mathrm{Bi}$ nanoparticles obtained via radiolytic reduction. Appl. Surf. Sci. 2016, 387, 89-102. [CrossRef]

34. Zong, M.; Bai, L.; Liu, Y.; Wang, X.; Zhang, X.; Huang, X.; Hang, R.; Tang, B. Antibacterial ability and angiogenic activity of Cu-Ti-O nanotube arrays. Mater. Sci. Eng. C 2017, 71, 93-99. [CrossRef]

35. Kim, D.; Fujimoto, S.; Schmuki, P.; Tsuchiya, H. Nitrogen doped anodic $\mathrm{TiO}_{2}$ nanotubes grown from nitrogen-containing Ti alloys. Electrochem. Commun. 2008, 10, 910-913. [CrossRef]

36. He, J.-B.; Lu, D.-Y.; Jin, G.-P. Potential dependence of cuprous/cupric duplex film growth on copper electrode in alkaline media. Appl. Surf. Sci. 2006, 253, 689-697. [CrossRef]

37. Jiang, X.; Herricks, T.; Xia, Y. CuO Nanowires Can Be Synthesized by Heating Copper Substrates in Air. Nano Lett. 2002, 2, 1333-1338. [CrossRef]

38. Mazierski, P.; Nadolna, J.; Lisowski, W.; Winiarski, M.J.; Gazda, M.; Nischk, M.; Klimczuk, T.; Zaleska-Medynska, A. Effect of irradiation intensity and initial pollutant concentration on gas phase photocatalytic activity of $\mathrm{TiO}_{2}$ nanotube arrays. Catal. Today 2017, 284, 19-26. [CrossRef]

39. Roy, P.; Berger, S.; Schmuki, P. $\mathrm{TiO}_{2}$ Nanotubes: Synthesis and Applications. Angew. Chem. Int. Ed. 2011, 50, 2904-2939. [CrossRef] 
40. Regonini, D.; Bowen, C.R.; Jaroenworaluck, A.; Stevens, R. A review of growth mechanism, structure and crystallinity of anodized $\mathrm{TiO}_{2}$ nanotubes. Mater. Sci. Eng. R Rep. 2013, 74, 377-406. [CrossRef]

41. Grimes, C.A.; Mor, G.K. TiO 2 Nanotube Arrays: Synthesis, Properties, and Applications; Springer: Dordrecht, The Netherlands; New York, NY, USA, 2009; ISBN 978-1-4419-0067-8.

42. Valota, A.; LeClere, D.J.; Hashimoto, T.; Skeldon, P.; Thompson, G.E.; Berger, S.; Kunze, J.; Schmuki, P. The efficiency of nanotube formation on titanium anodized under voltage and current control in fluoride/glycerol electrolyte. Nanotechnology 2008, 19, 355701. [CrossRef]

43. Biesinger, M.C.; Lau, L.W.M.; Gerson, A.R.; Smart, R.S.C. Resolving surface chemical states in XPS analysis of first row transition metals, oxides and hydroxides: Sc, Ti, V, Cu and Zn. Appl. Surf. Sci. 2010, 257, 887-898. [CrossRef]

44. Naumkin, A.V.; Kraut-Vass, A.; Gaarenstroom, S.W.; Powell, C.J. NIST X-ray Photoelectron Spectroscopy Database. 2012. Available online: https://srdata.nist.gov/xps/ (accessed on 4 June 2018).

45. Suzuki, S.; Hirabayashi, K.; Mimura, K.; Okabe, T.; Isshiki, M.; Waseda, Y. Surface Layer Formed by Selective Oxidation in High-Purity Copper-Titanium Binary Alloys. Mater. Trans. 2002, 43, 2303-2308. [CrossRef]

46. Sanguinetti, S.; Guzzi, M.; Gurioli, M. Accessing structural and electronic properties of semiconductor nanostructures via photoluminescence. In Characterization of Semiconductor Heterostructures and Nanostructures; Elsevier: New York, NY, USA, 2008; pp. 175-208. ISBN 978-0-444-53099-8.

47. Liqiang, J.; Yichun, Q.; Baiqi, W.; Shudan, L.; Baojiang, J.; Libin, Y.; Wei, F.; Honggang, F.; Jiazhong, S. Review of photoluminescence performance of nano-sized semiconductor materials and its relationships with photocatalytic activity. Sol. Energy Mater. Sol. Cells 2006, 90, 1773-1787. [CrossRef]

48. Garlisi, C.; Szlachetko, J.; Aubry, C.; Fernandes, D.L.A.; Hattori, Y.; Paun, C.; Pavliuk, M.V.; Rajput, N.S.; Lewin, E.; Sá, J.; Palmisano, G. N-TiO $/ 2 \mathrm{Cu}-\mathrm{TiO}_{2}$ double-layer films: Impact of stacking order on photocatalytic properties. J. Catal. 2017, 353, 116-122. [CrossRef]

49. Beltran-Huarac, J.; Guinel, M.J.-F.; Weiner, B.R.; Morell, G. Bifunctional $\mathrm{Fe}_{3} \mathrm{O}_{4} / \mathrm{ZnS}$ :Mn composite nanoparticles. Mater. Lett. 2013, 98, 108-111. [CrossRef]

50. Mazierski, P.; Malankowska, A.; Kobylański, M.; Diak, M.; Kozak, M.; Winiarski, M.J.; Klimczuk, T.; Lisowski, W.; Nowaczyk, G.; Zaleska-Medynska, A. Photocatalytically Active $\mathrm{TiO}_{2} / \mathrm{Ag}_{2} \mathrm{O}$ Nanotube Arrays Interlaced with Silver Nanoparticles Obtained from the One-Step Anodic Oxidation of Ti-Ag Alloys. ACS Catal. 2017, 7, 2753-2764. [CrossRef]

51. Park, S.-M.; Razzaq, A.; Park, Y.H.; Sorcar, S.; Park, Y.; Grimes, C.A.; In, S.-I. Hybrid $\mathrm{Cu}_{x} \mathrm{O}_{-} \mathrm{TiO}_{2}$ Heterostructured Composites for Photocatalytic $\mathrm{CO}_{2}$ Reduction into Methane Using Solar Irradiation: Sunlight into Fuel. ACS Omega 2016, 1, 868-875. [CrossRef]

52. Zhang, Z.; Wang, P. Highly stable copper oxide composite as an effective photocathode for water splitting via a facile electrochemical synthesis strategy. J. Mater. Chem. 2012, 22, 2456-2464. [CrossRef]

53. Luna, A.L.; Valenzuela, M.A.; Colbeau-Justin, C.; Vázquez, P.; Rodriguez, J.L.; Avendaño, J.R.; Alfaro, S.; Tirado, S.; Garduño, A.; De la Rosa, J.M. Photocatalytic degradation of gallic acid over $\mathrm{CuO}-\mathrm{TiO}_{2}$ composites under UV/Vis LEDs irradiation. Appl. Catal. A Gen. 2016, 521, 140-148. [CrossRef]

54. Chen, L.; Tang, M.; Chen, C.; Chen, M.; Luo, K.; Xu, J.; Zhou, D.; Wu, F. Efficient Bacterial Inactivation by Transition Metal Catalyzed Auto-Oxidation of Sulfite. Environ. Sci. Technol. 2017, 51, 12663-12671. [CrossRef]

55. Stephens, C. Bacterial sporulation: A question of commitment? Curr. Biol. 1998, 8, R45-R48. [CrossRef]

56. Grossman, A.D.; Losick, R. Extracellular control of spore formation in Bacillus subtilis. Proc. Natl. Acad. Sci. USA 1988, 85, 4369-4373.

57. Setlow, P. Germination of Spores of Bacillus Species: What We Know and Do Not Know. J. Bacteriol. 2014, 196, 1297-1305. [CrossRef]

58. Jacoby, W.A.; Maness, P.C.; Wolfrum, E.J.; Blake, D.M.; Fennell, J.A. Mineralization of Bacterial Cell Mass on a Photocatalytic Surface in Air. Environ. Sci. Technol. 1998, 32, 2650-2653. [CrossRef]

59. Saito, T.; Iwase, T.; Horie, J.; Morioka, T. Mode of photocatalytic bactericidal action of powdered semiconductor $\mathrm{TiO}_{2}$ on mutans streptococci. J. Photochem. Photobiol. B Biol. 1992, 14, 369-379. [CrossRef]

60. Kikuchi, Y.; Sunada, K.; Iyoda, T.; Hashimoto, K.; Fujishima, A. Photocatalytic bactericidal effect of $\mathrm{TiO}_{2}$ thin films: Dynamic view of the active oxygen species responsible for the effect. J. Photochem. Photobiol. A Chem. 1997, 106, 51-56. [CrossRef] 
61. Kunicki-Goldfinger, W.; Baj, J.; Markiewicz, Z.; Kobyliński, S. Życie Bakterii; Wydawnictwo Naukowe PWN: Warszawa, Poland, 2008; ISBN 978-83-01-14378-7.

62. Bubacz, K.; Kusiak-Nejman, E.; Tryba, B.; Morawski, A.W. Investigation of OH radicals formation on the surface of $\mathrm{TiO}_{2} / \mathrm{N}$ photocatalyst at the presence of terephthalic acid solution. Estimation of optimal conditions. J. Photochem. Photobiol. A Chem. 2013, 261,7-11. [CrossRef]

(C) 2018 by the authors. Licensee MDPI, Basel, Switzerland. This article is an open access article distributed under the terms and conditions of the Creative Commons Attribution (CC BY) license (http:// creativecommons.org/licenses/by/4.0/). 


\title{
Article \\ Synthesis of Rectorite $/ \mathrm{Fe}_{3} \mathrm{O}_{4} / \mathrm{ZnO}$ Composites and Their Application for the Removal of Methylene Blue Dye
}

\author{
Huanhuan Wang ${ }^{1}$, Peijiang Zhou ${ }^{1, *}$, Rui Guo ${ }^{1}$, Yifei Wang ${ }^{1}$, Hongju Zhan ${ }^{2}$ and Yunfei Yuan ${ }^{1}$ \\ 1 School of Resources and Environmental Science, Hubei Biomass-Resource Chemistry and Environmental \\ Biotechnology Key Laboratory, Eco-Environment Technology R\&D and Service Center, Wuhan University, \\ Wuhan 430079, China; doublewhh@163.com (H.W.); gregoryguo@163.com (R.G.); \\ yifeiwangzyh@gmail.com (Y.W.); yuanyunfei0523@126.com (Y.Y.) \\ 2 Chemical Engineering and Pharmaceutical Department, Jingchu University of Technology, Jingmen 448000, \\ China; blackcat927@tom.com \\ * Correspondence: zhoupj@whu.edu.cn; Tel.: +86-027-6876-6930
}

Received: 10 February 2018; Accepted: 6 March 2018; Published: 9 March 2018

\begin{abstract}
A novel series of rectorite-based magnetic zinc oxide ( $\mathrm{ZnO}$ ) photocatalysts $\left(\mathrm{REC} / \mathrm{Fe}_{3} \mathrm{O}_{4} / \mathrm{ZnO}\right)$ was synthesized and characterized in the present work. The fabricated $\mathrm{REC} / \mathrm{Fe}_{3} \mathrm{O}_{4} / \mathrm{ZnO}$ composite possessed a high specific surface area and high capacity of adsorption and photocatalysis toward methylene blue (MB) dye. The adsorption isotherm of the dye on the composite fitted well to the Langmuir model, with a maximum adsorption of $35.1 \mathrm{mg} / \mathrm{g}$. The high adsorption capacity increased the interactions between the dye and the $\mathrm{REC} / \mathrm{Fe}_{3} \mathrm{O}_{4} / \mathrm{ZnO}$, which enabled efficient decomposition of the dye under simulated solar radiation using $\mathrm{REC} / \mathrm{Fe}_{3} \mathrm{O}_{4} / \mathrm{ZnO}$ as the photocatalyst. The degradation kinetics of $\mathrm{MB}$ dye followed the Langmuir-Hinshelwood model. More importantly, the degradation of $\mathrm{MB}$ dye and the mass loss of $\mathrm{REC} / \mathrm{Fe}_{3} \mathrm{O}_{4} / \mathrm{ZnO}$ after three repetitive experiments were quite small. This suggests that the magnetic composite has great potential as an effective, stable, and easily recovered catalyst. Four major intermediates were detected during the degradation of $\mathrm{MB}$ dye and the degradation pathway was proposed.
\end{abstract}

Keywords: adsorption; magnetic $\mathrm{ZnO}$; methylene blue; photodegradation; rectorite

\section{Introduction}

Synthetic dyes are used in a wide range of industries, including textiles, cosmetics, printing, pharmaceuticals, and food. Of these dyes, approximately $1-2 \%$ and $1-10 \%$, are discharged into the environment by manufacturing processes and end-users, respectively [1-5], which poses a serious threat to human health and the environment. Several physical, chemical and biological techniques have been used to treat dyestuff waste, but the high cost, formation of hazardous coproducts, and intensive energy requirements have limited their extensive application [6]. Additionally, traditional wastewater treatment processes are inefficient in handling dye pollutants because of their biological resistance and chemical stability [7-9]. The removal of dyestuff waste from aqueous solutions is technically very challenging.

Photocatalysis could be an effective wastewater treatment technology for dye pollutants because of its potential high activity, low energy consumption, mild treatment conditions, and ease of handling [10-16]. The irradiation of wide bandgap semiconductors by ultraviolet light produces various reactive oxygen species (ROS) including hydroxyl radicals $(\bullet \mathrm{OH})$ and singlet oxygen $\left({ }^{1} \mathrm{O}_{2}\right)$, which can efficiently oxidize or mineralize organic compounds. Moreover, direct reaction between valence-band holes and organic pollutants could induce oxidation or decomposition of these target 
pollutants. The contributions of ROS and holes toward the degradation of pollutants depend on the electronic properties of the target substance and the photocatalyst $[17,18]$. Photocatalysis can degrade organic dyes into water, carbon dioxide, and other non-toxic inorganic compounds without causing secondary pollution.

Complementary metal-oxide semiconductors have received significant attention because of their efficient application in photocatalysis such as titanium dioxide $\left(\mathrm{TiO}_{2}\right)$, cuprous oxide $\left(\mathrm{Cu}_{2} \mathrm{O}\right)$, and so on $[19,20]$. Zinc oxide $(\mathrm{ZnO})$ is a well-known photocatalyst with a bandgap of $3.37 \mathrm{eV}$ that permits the absorption of ultraviolet (UV)-visible light. It also has the advantages of high photoactivity, non-toxicity, and low manufactured cost [21-26]. Photocatalysis using $\mathrm{ZnO}$ has been used to remove many pollutants from aqueous solutions because $\mathrm{ZnO}$ is effective in producing -OH [27-29]. However, the application of such photocatalysis to wastewater treatment is limited because of the difficulty in separating and recovering $\mathrm{ZnO}$ powder from the treated solutions. Using magnetic heterogeneous catalysts could facilitate efficient, rapid, and economical separation of the photocatalyst [30]. Water treatment agents modified with magnetic nanoparticles are particularly interesting; examples of these materials include magnetic iron oxide/clay composite materials such as magnetite $\left(\mathrm{Fe}_{3} \mathrm{O}_{4}\right)[31-38]$ and maghemite $\left(\gamma-\mathrm{Fe}_{2} \mathrm{O}_{3}\right)[35,39]$.

One strategy to improve $\mathrm{ZnO}$ performance has focused on the development of $\mathrm{ZnO}$ composites that enhance the photocatalytic efficiency via improved adsorption [40-45]. Rectorite (REC), a silicate clay mineral, is composed of alternating pairs of nonexpandable dioctahedral mica-like and expandable dioctahedral smectite-like layers [46]. REC efficiently adsorbs organic compounds both on its external surfaces and within its interlaminar spaces because of its high specific surface area and ion exchange properties [47]. This mineral is also of considerable interest as a catalyst support because of its low cost, small size, and unusual intercalated structure. Consequently, considerable research has been devoted to exploring the use of REC-based materials to adsorb or catalytically decompose environmental pollutants [48-51].

In this study, $\mathrm{REC} / \mathrm{Fe}_{3} \mathrm{O}_{4}$ was prepared by mixing $\mathrm{REC}$ with $\mathrm{Fe}_{3} \mathrm{O}_{4}$. This was further mixed with $\mathrm{ZnO}$ to obtain a $\mathrm{REC} / \mathrm{Fe}_{3} \mathrm{O}_{4} / \mathrm{ZnO}$ composite via an improved hydrothermal process. The composite was characterized by transmission electron microscopy (TEM), scanning electron microscopy (SEM), X-ray powder diffraction (XRD) and Fourier transform-infrared (FT-IR). The absorption and photocatalytic properties of $\mathrm{REC} / \mathrm{Fe}_{3} \mathrm{O}_{4} / \mathrm{ZnO}$ were evaluated by the decomposition of methylene blue (MB) dye under simulated sunlight irradiation. Such a composite material has potential as a new low-cost and recyclable agent for the efficient eliminate treatment of dyestuff wastewater.

\section{Results and Discussion}

\subsection{Morphology and BET Surface Area of the $\mathrm{REC} / \mathrm{Fe}_{3} \mathrm{O}_{4} / \mathrm{ZnO}$ Composites}

The morphologies of the various $\mathrm{REC} / \mathrm{Fe}_{3} \mathrm{O}_{4} / \mathrm{ZnO}$ composites were investigated by SEM and TEM (Figure 1). REC is an interstratified clay mineral (Figure 1a,d). Breakage of the structure (Figure 1b) formed particles having diameters of ca. 6-35 nm (Figure 1e), in which $\mathrm{Fe}_{3} \mathrm{O}_{4}$ was integrated with the mineral. The structure became further disrupted with the deposition of $\mathrm{ZnO}$ (Figure 1c) when many more particles were found with the REC (Figure 1f).

BET surface area of REC applied in this study was $11.7 \mathrm{~m}^{2} \mathrm{~g}^{-1}$ (Table 1), which is $25 \%$ smaller than that of $\mathrm{REC} / \mathrm{Fe}_{3} \mathrm{O}_{4}$. The increase of $\mathrm{BET}$ after magnetization was mainly because of the breakage of REC as shown in Figure 1e. BET surface area was approximately 16.8 and 16.0 for REC/ZnO and $\mathrm{REC} / \mathrm{Fe}_{3} \mathrm{O}_{4} / \mathrm{ZnO}$ composites, respectively. 
Table 1. Specific surface area of $\mathrm{ZnO}, \mathrm{REC}, \mathrm{REC} / \mathrm{Fe}_{3} \mathrm{O}_{4}$ (1:0.3), $\mathrm{REC} / \mathrm{ZnO}(1: 0.5), \mathrm{REC} / \mathrm{Fe}_{3} \mathrm{O}_{4} / \mathrm{ZnO}$ (1:0.3:0.5) powder.

\begin{tabular}{lccccc}
\hline \multirow{2}{*}{ BET Surface Area $\left(\mathrm{m}^{2} \cdot \mathrm{g}^{-1}\right)$} & $\mathrm{ZnO}$ & $\mathrm{REC}$ & $\mathrm{REC} / \mathrm{Fe}_{3} \mathrm{O}_{4}$ & $\mathrm{REC} / \mathrm{ZnO}$ & $\mathrm{ZnO} / \mathrm{REC} / \mathrm{Fe}_{3} \mathrm{O}_{4}$ \\
\cline { 2 - 6 } & 5.3 & 11.7 & 15.6 & 16.8 & 16.0 \\
\hline
\end{tabular}

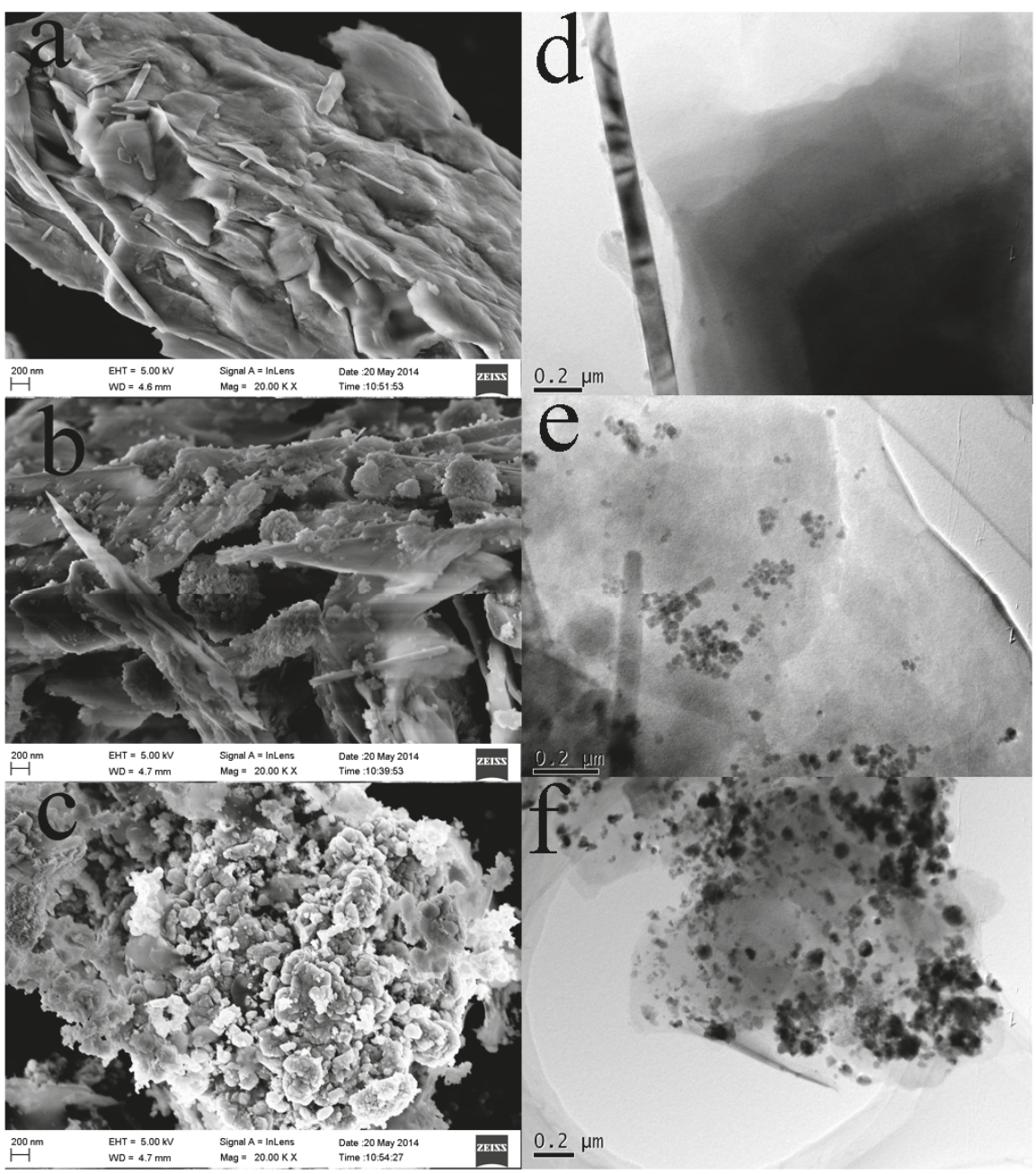

Figure 1. Scanning electron microscopy (SEM) images of (a) rectorite (REC), (b) REC/magnetite $\left(\mathrm{Fe}_{3} \mathrm{O}_{4}\right)$ (1:0.3), and (c) $\mathrm{REC} / \mathrm{Fe}_{3} \mathrm{O}_{4} /$ zinc oxide $(\mathrm{ZnO})$ (1:0.3:0.5) and transmission electron microscopy (TEM) images of (d) REC, (e) REC/ $\mathrm{Fe}_{3} \mathrm{O}_{4}$ (1:0.3), and (f) $\mathrm{REC} / \mathrm{Fe}_{3} \mathrm{O}_{4} / \mathrm{ZnO}(1: 0.3: 0.5)$.

\subsection{Structural Characterization of the $\mathrm{REC} / \mathrm{Fe}_{3} \mathrm{O}_{4} / \mathrm{ZnO}$ Composites}

Figure 2 shows the XRD patterns of $\mathrm{ZnO}, \mathrm{REC}$ and their composite materials for $2 \theta$ ranging from 10 to $70^{\circ}$. The diffraction peak at $2 \theta=19.8^{\circ}$ was a characterized peak of REC [52], which was also observed in $\mathrm{REC} / \mathrm{ZnO}, \mathrm{REC} / \mathrm{Fe}_{3} \mathrm{O}_{4}$ and $\mathrm{REC} / \mathrm{Fe}_{3} \mathrm{O}_{4} / \mathrm{ZnO}$. The relative intensities of diffraction peak at $2 \theta=19.8^{\circ}$ was changed in composites, compared with that in pure REC. The finding indicates that 
the structure of rectorite distorted to some extents during the synthesis of composites. Similar results were also reported during the synthesis of other REC-based photocatalyst [52]. Peaks observed at $31.7^{\circ}, 34.4^{\circ}, 36.2^{\circ}, 47.5^{\circ}, 56.5^{\circ}, 62.8^{\circ}, 66.3^{\circ}, 67.9^{\circ}$, and $69.0^{\circ}$ were indexed to hexagonal wurtzite $(\mathrm{ZnO}$; JCPDS Data Card no. 36-1451). Diffraction peaks at $33.1^{\circ}, 35.7^{\circ}, 40.8^{\circ}, 54.1^{\circ}$, and $64.0^{\circ}$, characteristic of $\mathrm{Fe}_{3} \mathrm{O}_{4}$ were observed for the $\mathrm{REC} / \mathrm{Fe}_{3} \mathrm{O}_{4}$ and $\mathrm{REC} / \mathrm{Fe}_{3} \mathrm{O}_{4} / \mathrm{ZnO}$ composites [48]. The diameters of $\mathrm{ZnO}$ and $\mathrm{Fe}_{3} \mathrm{O}_{4}$ were approximately 45.7 and $22.4 \mathrm{~nm}$ in $\mathrm{REC} / \mathrm{Fe}_{3} \mathrm{O}_{4} / \mathrm{ZnO}$, putting diffraction peaks at $2 \theta=36.3^{\circ}$ and $19.8^{\circ}$ and the corresponding FWHM (full width at half maxima) into Scherrer equation. The relative size between $\mathrm{ZnO}$ and $\mathrm{Fe}_{3} \mathrm{O}_{4}$ was correlated with that shown in Figure 1e,f.

Figure 3 compares the Fourier transform-infrared (FT-IR) spectra of REC and its composites. The spectra of $\mathrm{REC}, \mathrm{ZnO} / \mathrm{REC}$, and $\mathrm{REC} / \mathrm{Fe}_{3} \mathrm{O}_{4} / \mathrm{ZnO}$ were quite similar, with only small differences in band locations and intensities. The bands at 3645-3647 and 3429-3440 $\mathrm{cm}^{-1}$ were attributed to the hydrogen-bonding bending vibration of water and hydroxyl stretching vibration in all three samples [53]. Bands observed at 1635 and $1386 \mathrm{~cm}^{-1}$ in $\mathrm{ZnO}$ were attributed to the asymmetrical and symmetrical stretching of the zinc carboxylate [54], respectively. The band at $1635 \mathrm{~cm}^{-1}$ overlapped with the band at $1640 \mathrm{~cm}^{-1}$, which was assigned to a water bending vibration in REC [55,56]. Bands at 1021 and $1053 \mathrm{~cm}^{-1}$ were assigned as In-plane Si-O-Si stretching [56], which was found to be 1012 and $1047 \mathrm{~cm}^{-1}$ in $\mathrm{REC} / \mathrm{ZnO}$ and $\mathrm{REC} / \mathrm{Fe}_{3} \mathrm{O}_{4} / \mathrm{ZnO}$ in this study. Bands at 478 and $545 \mathrm{~cm}^{-1}$ were assigned as $\mathrm{Si}-\mathrm{O}$ bending and $\mathrm{Si}-\mathrm{O}-\mathrm{Al}$ bending [56], which was 486 and $548 \mathrm{~cm}^{-1}$ in $\mathrm{REC} / \mathrm{ZnO}$, and 490 and $552 \mathrm{~cm}^{-1}$ in $\mathrm{REC} / \mathrm{Fe}_{3} \mathrm{O}_{4} / \mathrm{ZnO}$, respectively. Notably, band at approximately $530-580 \mathrm{~cm}^{-1}$ was also reported to $\mathrm{Fe}-\mathrm{O}$ bond [57] in $\mathrm{Fe}_{3} \mathrm{O}_{4}$, which could be emerged in $\mathrm{Si}-\mathrm{O}-\mathrm{Al}$ bending band.

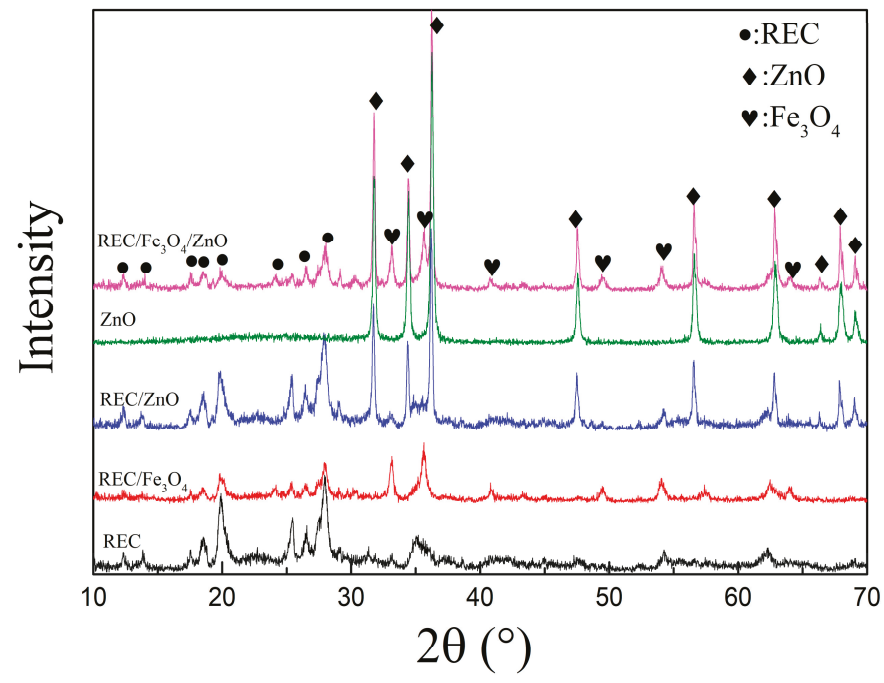

Figure 2. X-ray diffraction (XRD) patterns of REC, $\mathrm{ZnO}, \mathrm{REC} / \mathrm{ZnO}(1: 0.5), \mathrm{REC} / \mathrm{Fe}_{3} \mathrm{O}_{4}(1: 0.3)$ and $\mathrm{REC} / \mathrm{Fe}_{3} \mathrm{O}_{4} / \mathrm{ZnO}(1: 0.3: 0.5)$. 


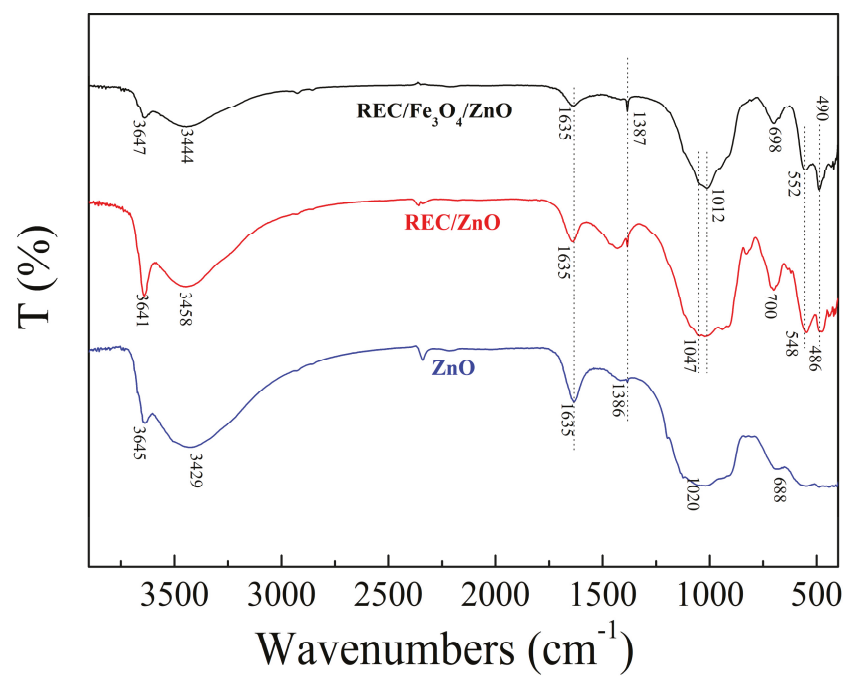

Figure 3. Fourier transform-infrared (FT-IR) spectra of $\mathrm{ZnO}, \mathrm{REC} / \mathrm{ZnO}(1: 0.5)$, and $\mathrm{ZnO} / \mathrm{REC} / \mathrm{Fe}_{3} \mathrm{O}_{4}$ (1:0.3:0.5).

\subsection{Thermogravimetric Analysis (TGA) Analysis REC and $\mathrm{REC} / \mathrm{Fe}_{3} \mathrm{O}_{4} / \mathrm{ZnO}$}

TGA analysis was investigated to investigate the stability of ternary composite. As shown in Figure 4, REC barely lose its weight up to $800^{\circ} \mathrm{C}$ mainly because of the loss of binding water. As for $\mathrm{REC} / \mathrm{Fe}_{3} \mathrm{O}_{4} / \mathrm{ZnO}$, the loss of weight could be divided into two regions. Loss of water could result in the loss weight below $200{ }^{\circ} \mathrm{C}$. Decomposition of $\mathrm{ZnCO}_{3} \cdot 2 \mathrm{Zn}(\mathrm{OH})_{2}$ impurity could lead to the loss of weight at approximately $600{ }^{\circ} \mathrm{C}$.

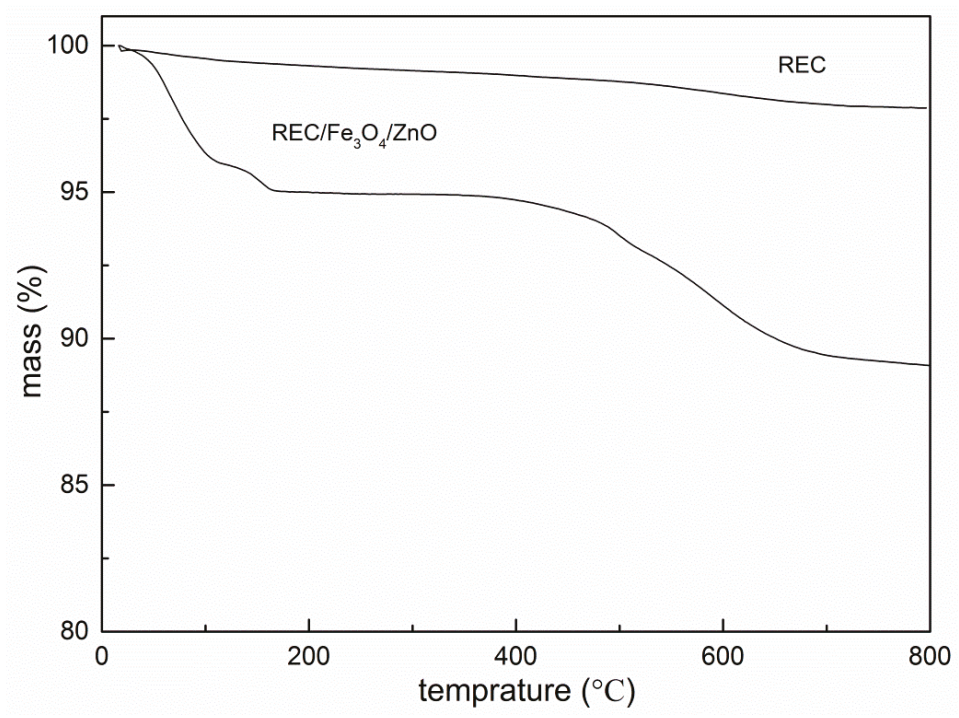

Figure 4. TGA of REC and $\mathrm{REC} / \mathrm{Fe}_{3} \mathrm{O}_{4} / \mathrm{ZnO}(1: 0.3: 0.5)$. 


\subsection{Adsorption Equilibrium and Isotherm of $\mathrm{MB}$ Dye on $\mathrm{REC} / \mathrm{Fe}_{3} \mathrm{O}_{4} / \mathrm{ZnO}$}

Figure $5 \mathrm{a}$ illustrates the results of equilibrium adsorption studies. The adsorption of $\mathrm{MB}$ dye increased with increasing time to $50 \mathrm{~min}$, reaching equilibrium within $60 \mathrm{~min}$ for $\mathrm{REC} / \mathrm{Fe}_{3} \mathrm{O}_{4} / \mathrm{ZnO}$. The adsorption kinetics were fitted using different equations including pseudo-first-order, pseudo-second-order and Elovich models; the adjusted $R$-squared (adj. $r^{2}$ ) values were $0.98,0.98$, and 0.93 , respectively. The calculated equilibrium adsorption was 1.5 and $2.2 \mathrm{mg} / \mathrm{g}$ from the pseudo-first-order and pseudo second-order models, respectively. The experimental equilibrium adsorption of $1.2 \mathrm{mg} / \mathrm{g}$ of $\mathrm{MB}$ dye on $\mathrm{REC} / \mathrm{Fe}_{3} \mathrm{O}_{4} / \mathrm{ZnO}$ was thus consistent with pseudo-first-order kinetics.

The Freundlich and Langmuir isotherms are commonly used to describe the adsorption properties of pollutants. Figure $5 \mathrm{~b}$ shows that the adsorption data fitted the Langmuir (adj. $r^{2}=0.999$ ) better than the Freundlich isotherm model (adj. $r^{2}=0.974$ ). The Langmuir isotherm is typically used to model monolayer adsorption on adsorbents having homogeneous and energetically uniform surfaces. Thus, our MB dye adsorption data are consistent with adsorption on the outer layer of the composites. The estimated recovered maximum adsorption capacity of $\mathrm{MB}$ dye on $\mathrm{REC} / \mathrm{Fe}_{3} \mathrm{O}_{4} / \mathrm{ZnO}$ was $35.1 \mathrm{mg} / \mathrm{g}$, which was $13 \%$ and $72 \%$ larger than that of $\mathrm{REC} / \mathrm{ZnO}(31.1 \mathrm{mg} / \mathrm{g})$ and $\mathrm{ZnO}(20.4 \mathrm{mg} / \mathrm{g})$. These data clearly showed REC component contributed significantly to the adsorption of $\mathrm{MB}$ to $\mathrm{REC} / \mathrm{Fe}_{3} \mathrm{O}_{4} / \mathrm{ZnO}$.
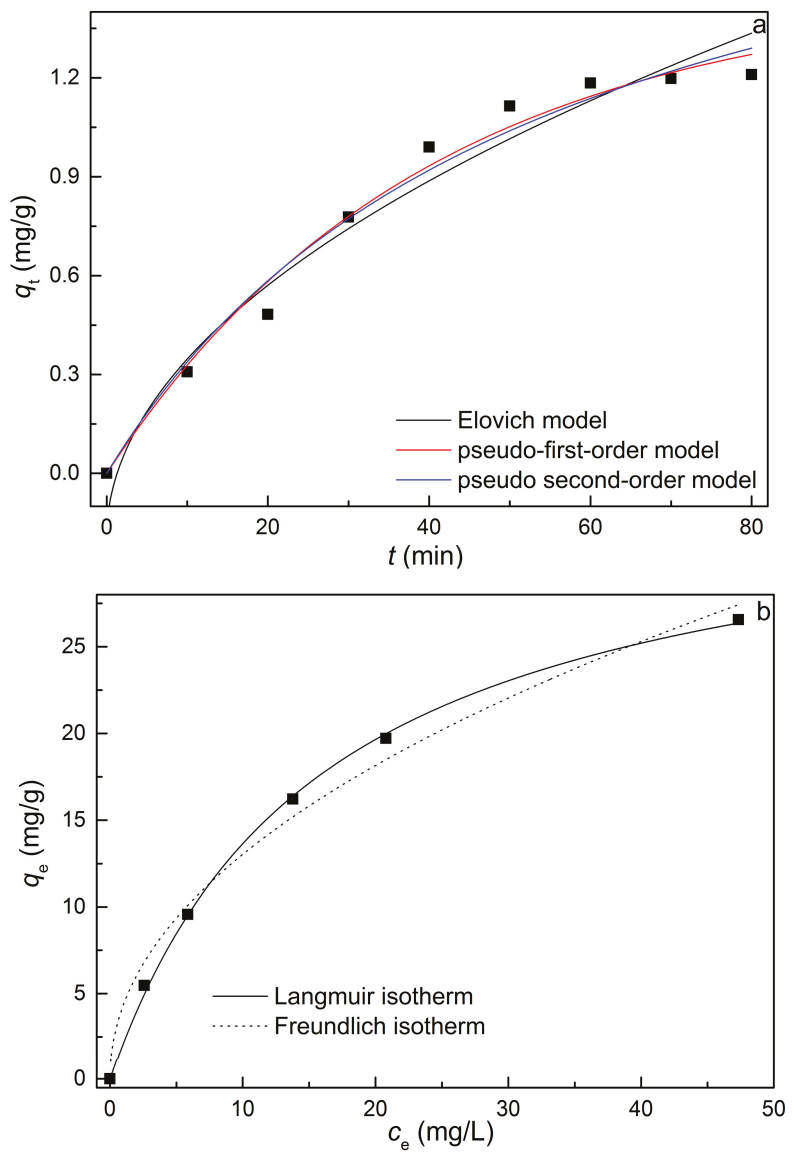

Figure 5. (a) Adsorption kinetics and (b) isotherm of methylene blue (MB) dye on $\mathrm{REC} / \mathrm{Fe}_{3} \mathrm{O}_{4} / \mathrm{ZnO}$ (1:0.3:0.5). 


\subsection{Effect of Component Mass Ratio on the Degradation of MB Dye}

The fabricated composites contained $\mathrm{REC}, \mathrm{Fe}_{3} \mathrm{O}_{4}$, and $\mathrm{ZnO}$. The impact of the component mass ratio on the removal of $\mathrm{MB}$ dye was investigated to obtain the optimal composition. Figure 6a shows that the dark adsorption of $\mathrm{MB}$ dye on $\mathrm{REC} / \mathrm{Fe}_{3} \mathrm{O}_{4} / \mathrm{ZnO}$ was only slightly influenced by the $\mathrm{ZnO}$ content. After a 60-min adsorption period, the MB dye concentration in the bulk phase decreased to $4.2,4.0$, and $4.0 \mathrm{mg} / \mathrm{L}$ for $\mathrm{ZnO}$ contents of $1.5,1.0$, and 0.5 , respectively. Control experiment showed that degradation of MB was negligible by direct photolysis in the absence of catalysts because of the low irradiance $\left(1.9 \mathrm{~mW} / \mathrm{cm}^{2}\right)$. However, photodegradation of the MB dye was greatly influenced by the $\mathrm{ZnO}$ content, with the degradation clearly decreasing with increasing $\mathrm{ZnO}$ content. The observed degradation kinetic constant $\left(k_{\mathrm{obs}}\right)$ for the degradation of MB dye was 0.0056, 0.0086, and $0.012 \mathrm{~min}^{-1}$ for $\mathrm{ZnO}$ contents of 1.5, 1.0, and 0.5, respectively. A plausible explanation for the decreased photoactivity with increasing $\mathrm{ZnO}$ content is that larger $\mathrm{ZnO}$ particles were formed, which may render the $\mathrm{REC} / \mathrm{Fe}_{3} \mathrm{O}_{4} / \mathrm{ZnO}$ less photoactive.
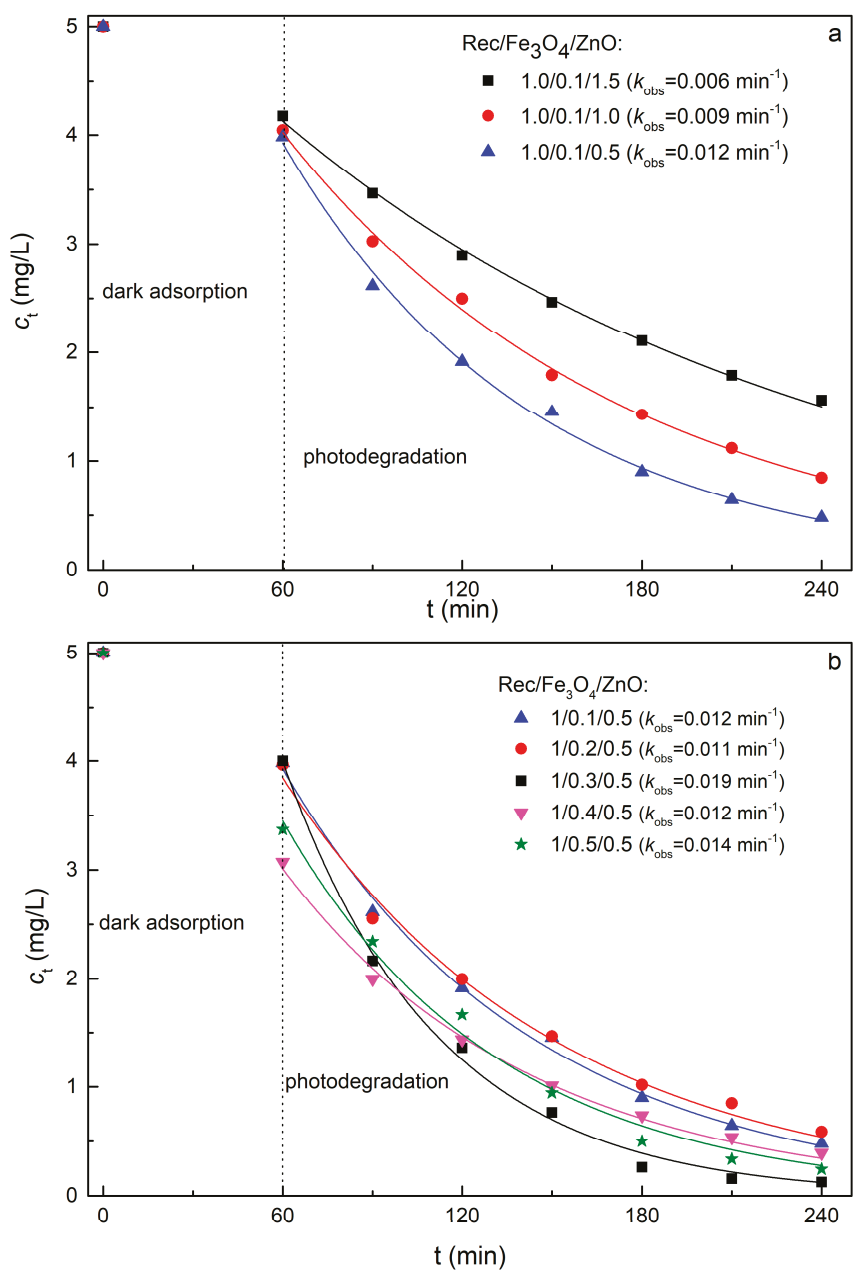

Figure 6. Effects of (a) $\mathrm{ZnO}$ and (b) $\mathrm{Fe}_{3} \mathrm{O}_{4}$ mass contents of $\mathrm{REC} / \mathrm{Fe}_{3} \mathrm{O}_{4} / \mathrm{ZnO}$ on the adsorption and photodegradation of MB dye. 
Figure $6 \mathrm{~b}$ shows that the dark adsorption of $\mathrm{MB}$ dye was highly influenced by the $\mathrm{Fe}_{3} \mathrm{O}_{4}$ content of $\mathrm{REC} / \mathrm{Fe}_{3} \mathrm{O}_{4} / \mathrm{ZnO}$. The adsorption ratio first increased from 20 to $45 \%$ as the $\mathrm{Fe}_{3} \mathrm{O}_{4}$ content increased from 0.1 to 0.3 ; it then decreased to $33 \%$ as the $\mathrm{Fe}_{3} \mathrm{O}_{4}$ content increased to 0.5 . However, $k_{\text {obs }}$ for the $\mathrm{MB}$ photodegradation only slightly increased, from 0.012 to $0.015 \mathrm{~min}^{-1}$, as the $\mathrm{Fe}_{3} \mathrm{O}_{4}$ content increased from 0.1 to 0.3 , which indicated that the photodegradation was not significantly affected by the $\mathrm{Fe}_{3} \mathrm{O}_{4}$ content. Figure 1 shows that the layered structure of REC was damaged by the introduction of $\mathrm{Fe}_{3} \mathrm{O}_{4}$, which was detrimental to $\mathrm{MB}$ dye adsorption. However, $\mathrm{Fe}_{3} \mathrm{O}_{4}$ was not an effective catalyst even under simulated solar radiation, particularly at neutral $\mathrm{pH}$ values. Therefore, the photoactivity of $\mathrm{REC} / \mathrm{Fe}_{3} \mathrm{O}_{4} / \mathrm{ZnO}$ (as indicated by the degradation of adsorbed $\mathrm{MB}$ dye) was likely not greatly influenced by the $\mathrm{Fe}_{3} \mathrm{O}_{4}$ content. These results established that $\mathrm{REC}$ and $\mathrm{ZnO}$ acted mainly as adsorbent and photocatalyst, respectively, for the removal of $\mathrm{MB}$ dye by $\mathrm{REC} / \mathrm{Fe}_{3} \mathrm{O}_{4} / \mathrm{ZnO}$.

\subsection{Effect of $\mathrm{REC} / \mathrm{Fe}_{3} \mathrm{O}_{4} / \mathrm{ZnO}$ Dosage on the Degradation of $\mathrm{MB}$ Dye}

Figure 7 shows that the dark adsorption of $\mathrm{MB}$ dye on $\mathrm{REC} / \mathrm{Fe}_{3} \mathrm{O}_{4} / \mathrm{ZnO}$ slightly increased as the composite dosage increased from 0.3 to $1.1 \mathrm{~g} / \mathrm{L}$; this was attributed to increasing availability of adsorption sites. The photodegradation of $\mathrm{MB}$ dye also greatly increased with increasing dosage up to $0.9 \mathrm{~g} / \mathrm{L}$. The $k_{\text {obs }}$ for the photodegradation of the MB dye increased from 0.0084 to $0.019 \mathrm{~min}^{-1}$ as the $\mathrm{REC} / \mathrm{Fe}_{3} \mathrm{O}_{4} / \mathrm{ZnO}$ dosage increased from 0.3 to $0.9 \mathrm{~g} / \mathrm{L}$. These results are consistent with many studies where the reaction accelerates with increasing catalyst dosage when the amount of reactive species, such as $\bullet \mathrm{OH}$, is determined by the concentration of the catalyst in the bulk solution. However, a dosage of $1.1 \mathrm{~g} / \mathrm{L}$ had an inhibitory effect on the degradation of the dye. This was attributed to agglomeration of $\mathrm{REC} / \mathrm{Fe}_{3} \mathrm{O}_{4} / \mathrm{ZnO}$ particles at the high concentration, which reduced light transmission. The optimal amount of added $\mathrm{REC} / \mathrm{Fe}_{3} \mathrm{O}_{4} / \mathrm{ZnO}$ is the least amount required for complete photon absorption for the photodegradation reaction; in our experiments, we fixed the $\mathrm{REC} / \mathrm{Fe}_{3} \mathrm{O}_{4} / \mathrm{ZnO}$ concentration at $0.9 \mathrm{~g} / \mathrm{L}$.

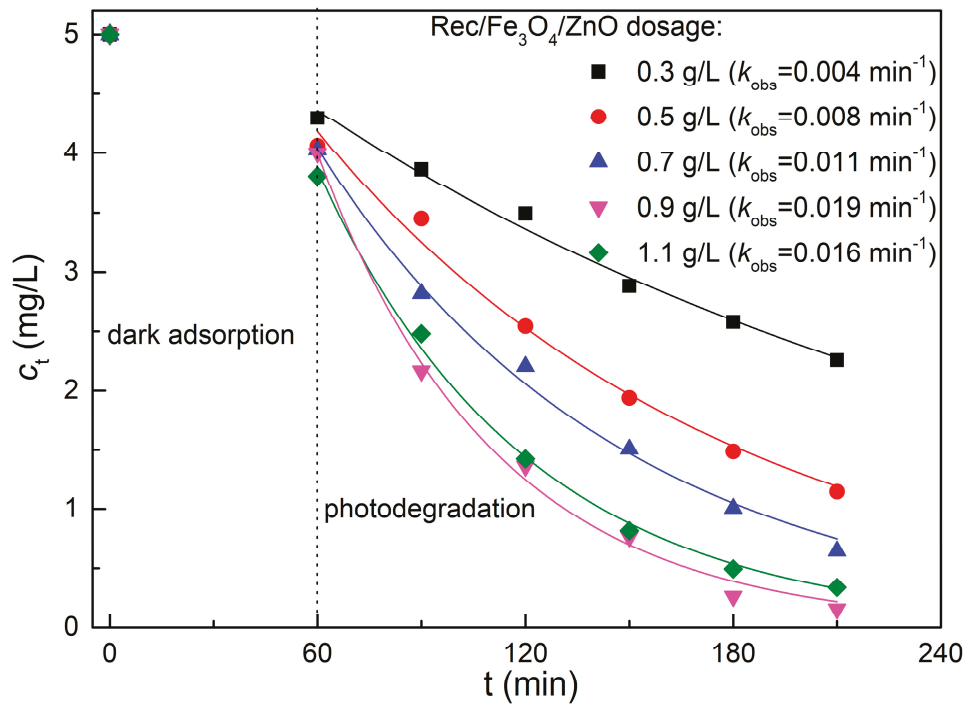

Figure 7. Effect of $\mathrm{REC} / \mathrm{Fe}_{3} \mathrm{O}_{4} / \mathrm{ZnO}$ (1:0.3:0.5) dosage on the adsorption and photodegradation of MB dye.

\subsection{Effect of Solution $\mathrm{pH}$ on the Degradation of $M B$ Dye}

The impact of solution $\mathrm{pH}$ on the adsorption and photodegradation of $\mathrm{MB}$ dye on $\mathrm{REC} / \mathrm{Fe}_{3} \mathrm{O}_{4} / \mathrm{ZnO}$ is shown in Figure 8. It clearly shows that acidic solution favored the adsorption 
of the dye and that the adsorption ratio at $\mathrm{pH} 5.0$ was about twice that at other $\mathrm{pH}$ values. Conversely, degradation of the dye in acidic solution was much slower below $\mathrm{pH}$ 6.0. The rate constant $k_{\mathrm{obs}}$ increased from 0.011 to $0.019 \mathrm{~min}^{-1}$ as the solution $\mathrm{pH}$ increased from 5.0 to 6.0 , and then decreased to $0.0076 \mathrm{~min}^{-1}$ at $\mathrm{pH}$ 8.0. These findings demonstrated that the solution $\mathrm{pH}$ had variable effect on the adsorption and degradation process of $\mathrm{MB}$ dye on $\mathrm{REC} / \mathrm{Fe}_{3} \mathrm{O}_{4} / \mathrm{ZnO}$. This variable effect of $\mathrm{pH}$ is related to its multiple roles in electrostatic interactions with the catalyst surface and substrate, and to the formation of charged radicals during the reaction process. This makes the interpretation of $\mathrm{pH}$ effects on the photodegradation of organic pollutants very difficult. The $\mathrm{REC} / \mathrm{Fe}_{3} \mathrm{O}_{4} / \mathrm{ZnO}$ surface was negatively charged and the $\mathrm{MB}$ dye was present in its cationic form at $\mathrm{pH}$ 5.0. Therefore, the electrostatic attraction generated between cationic dye molecules and the negative surface charge contributed to the high adsorption ratio measured in acidic solutions. Typically, $\mathrm{ZnO}$ exhibits higher photoactivity at neutral $\mathrm{pH}$. The degradation of $\mathrm{MB}$ dye on $\mathrm{REC} / \mathrm{Fe}_{3} \mathrm{O}_{4} / \mathrm{ZnO}$ was faster at $\mathrm{pH} 6.0$ because $\mathrm{ZnO}$ was the most important photocatalyst present in the composite at that $\mathrm{pH}$.

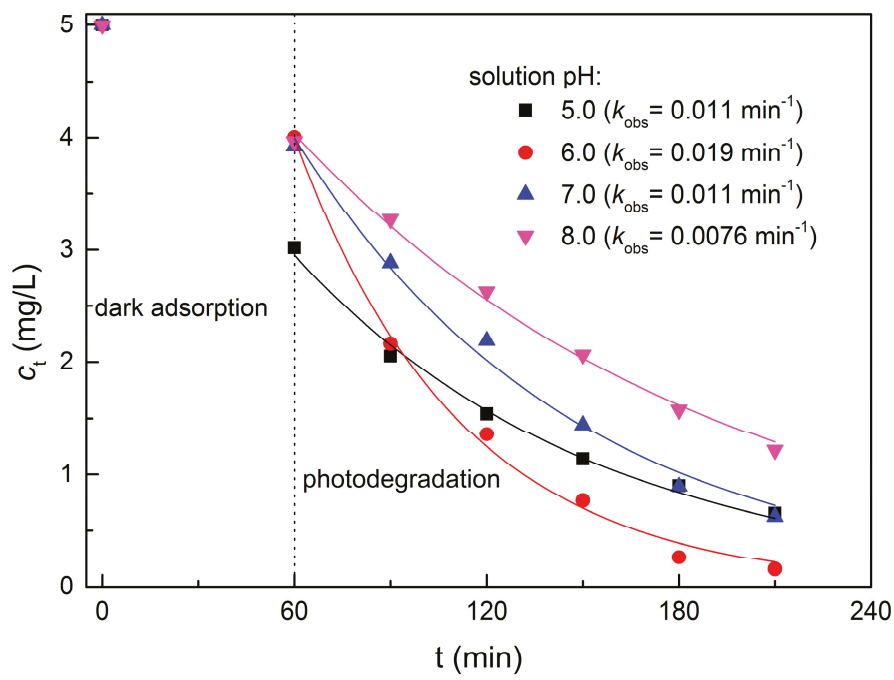

Figure 8. Effect of solution $\mathrm{pH}$ on the adsorption and photodegradation of $\mathrm{MB}$ dye on $\mathrm{REC} / \mathrm{Fe}_{3} \mathrm{O}_{4} / \mathrm{ZnO}$ (1:0.3:0.5).

\subsection{Kinetics for the Degradation of $\mathrm{MB}$ Dye on $\mathrm{REC} / \mathrm{Fe}_{3} \mathrm{O}_{4} / \mathrm{ZnO}$}

The effect of initial $\mathrm{MB}$ dye concentration on its degradation was investigated for initial concentrations ranging from 5.0 to $30.0 \mathrm{mg} / \mathrm{L}$ (Figure 9a). After reaching adsorption equilibrium, the dye gradually decomposed with increasing irradiation time. The initial rate of photodegradation increased and reached a plateau with increasing initial dye concentration (Figure 9b). The data were fitted to the Langmuir-Hinshelwood kinetic model, which is frequently used to model the initial photocatalytic degradation rates of organic compounds. The rate law is given by Equation (1):

$$
r_{0}=-\frac{d c}{d t}=k_{r e} K_{s} c_{0} /\left(1+K_{s} c_{0}\right),
$$

where $r_{0}$ is the initial rate of disappearance of $\mathrm{MB}$ dye, $c_{0}$ is the initial concentration of the dye, $k_{r e}$ is the reaction rate constant, and $K_{S}$ is the Langmuir adsorption constant. The calculated values for $k_{r e}$ and $K_{s}$ were $0.122 \mathrm{mg} /(\mathrm{L} \cdot \mathrm{min})$ and $0.069 \mathrm{~L} / \mathrm{mg}$, respectively. 

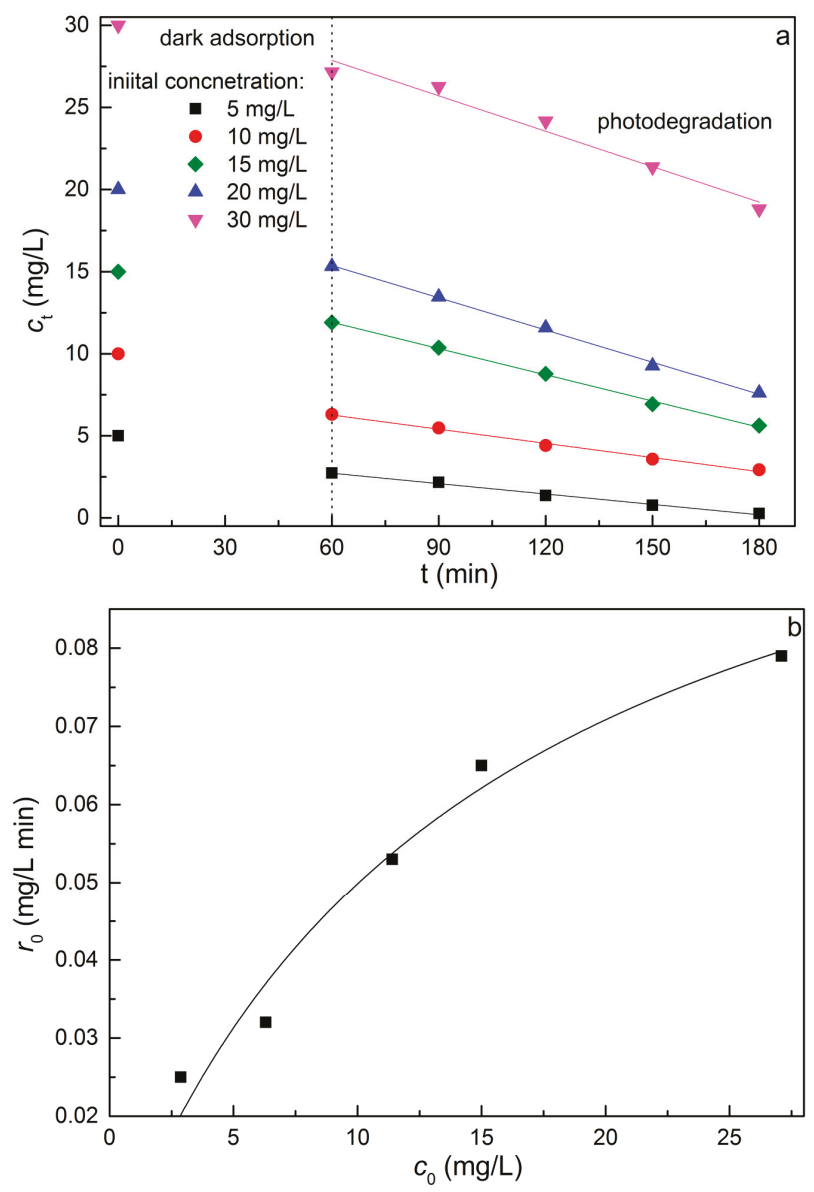

Figure 9. (a) Correlation between the initial rate of loss of $\mathrm{MB}$ dye on $\mathrm{REC} / \mathrm{Fe}_{3} \mathrm{O}_{4} / \mathrm{ZnO}$ (1:0.3:0.5) and the initial dye concentration. (b) The solid line represents fitting of the data to the Langmuir-Hinshelwood kinetic model.

\subsection{Recovery and Stability of $\mathrm{REC} / \mathrm{Fe}_{3} \mathrm{O}_{4} / \mathrm{ZnO}$}

The performance of a single catalyst sample for the removal of MB dye over several cycles was determined to assess the photostability and possible reuse of $\mathrm{REC} / \mathrm{Fe}_{3} \mathrm{O}_{4} / \mathrm{ZnO}$. After 1-h adsorption and 5-h irradiation sequences, the composite was recovered from the reaction solution using an external magnet and redispersed in fresh 5-mg/L MB dye solution. Figure 10 shows that a noticeable decrease in the removal ratio of the dye occurred during repeated use of the $\mathrm{REC} / \mathrm{Fe}_{3} \mathrm{O}_{4} / \mathrm{ZnO}$ catalyst. Only $80 \%$ remained after three cycles, corresponding to a mass loss of $14 \%$. The results demonstrated satisfactory photostability of the $\mathrm{REC} / \mathrm{Fe}_{3} \mathrm{O}_{4} / \mathrm{ZnO}$ catalyst. 


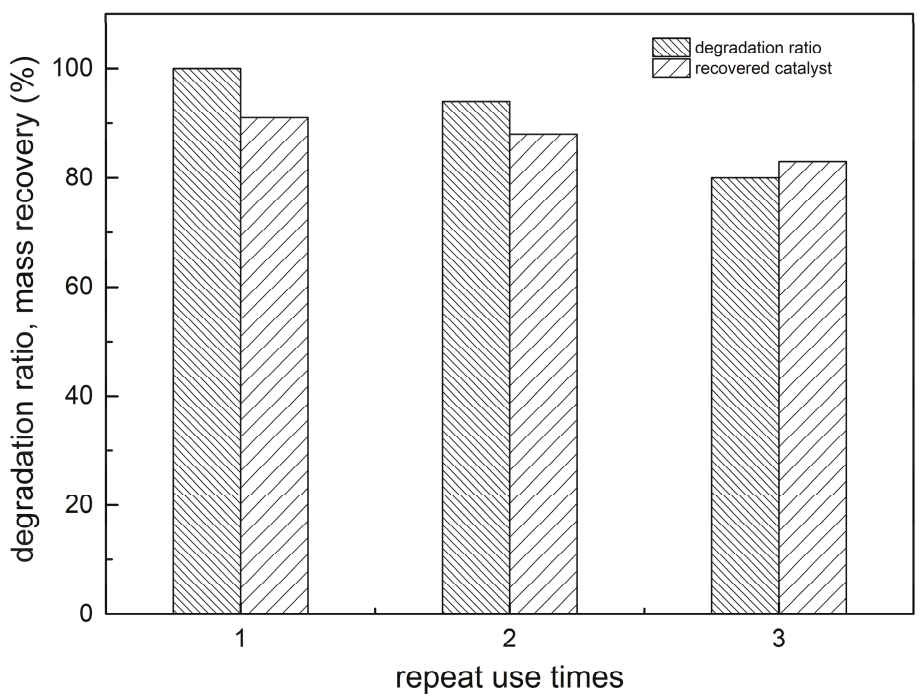

Figure 10. Performance and recovery of $\mathrm{REC} / \mathrm{Fe}_{3} \mathrm{O}_{4} / \mathrm{ZnO}$ (1:0.3:0.5) during repeated use.

\subsection{Mechanism for the Degradation of $\mathrm{MB}$ Dye on $\mathrm{REC} / \mathrm{Fe}_{3} \mathrm{O}_{4} / \mathrm{ZnO}$}

The degradation intermediates were identified by liquid chromatography-mass spectrometry (LC-MS). The signal at $m / z=284$ present before degradation was assigned to the MB dye molecule (Scheme 1). Oxidation of MB dye could follow different paths. Addition of $\bullet \mathrm{OH}$ to $\mathrm{MB}$ dye molecules would lead to the formation of an intermediate with $m / z=300$ [58]. Oxidation of sulfur atoms and bond cleavage at nitrogen-bridged sites would lead to the formation of a sulfoxide intermediate having $m / z=303$ [59]. However, neither $m / z=300$ nor 303 was detected in the present study. Instead, signals were found at $m / z=317,274,138$, and 345. An intermediate with $m / z=317$ could be formed through the addition of two $\bullet \mathrm{OH}$ radicals per MB dye molecule, or through oxidation of methyl $\left(-\mathrm{CH}_{3}\right)$ groups of the sulfoxide intermediate, and the oxidation of more methyl groups would lead to the formation of a species having $m / z=345$. Addition of $\bullet \mathrm{OH}$ to an intermediate of $m / z=317$ and cleavage at a sulfur-bridged site might lead to the formation of an intermediate with $m / z=138$. Additionally, loss of a methyl group could produce an intermediate with $m / z=274$. Contribution of - $\mathrm{OH}$ to the degradation of $\mathrm{MB}$ was proved by a much smaller degradation kinetic constant in the presence of isopropanol acting as $\bullet \mathrm{OH}$ scavenger. Oxidation of these intermediates could form ring cleavage products, and even mineralization to $\mathrm{CO}_{2}$ and $\mathrm{H}_{2} \mathrm{O}$ is plausible. The chemical structures of any intermediates were not identified because of the complexity of the degradation process. 


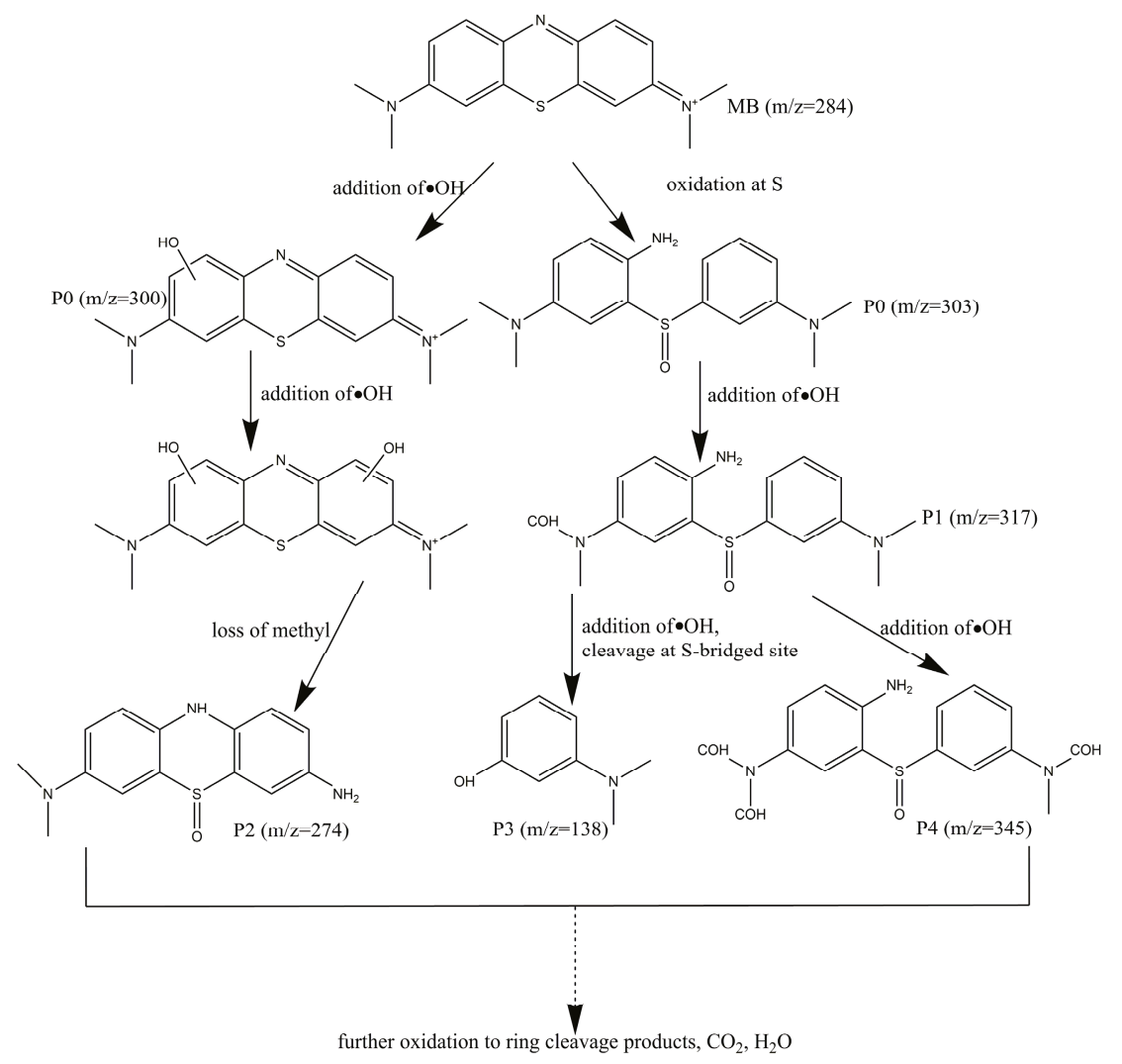

Scheme 1. Proposed pathway for the degradation of $\mathrm{MB}$ dye on $\mathrm{REC} / \mathrm{Fe}_{3} \mathrm{O}_{4} / \mathrm{ZnO}$ (1:0.3:0.5).

\section{Materials and Methods}

\subsection{Chemicals}

Ferric chloride, ferric sulfate, $\mathrm{MB}$, zinc acetate dihydrate $\left(\mathrm{Zn}\left(\mathrm{CH}_{3} \mathrm{COO}\right)_{2} \cdot 2 \mathrm{H}_{2} \mathrm{O}\right)$ (purity: 99.9\%), hydrazine hydrate, dimethyl benzene, ethylene glycol, ethyl alcohol, and sodium hydroxide were purchased from Alpha-Aesar (Shanghai, China) and used as-received. They were of analytical grade. Refined REC was provided by Hubei Mingliu Inc. Co. (Wuhan, China). The water used in the experiments had been pretreated with an ultrapure water system (Liyuan Electric Instrument Co., Beijing, China).

\subsection{Synthesis of $\mathrm{REC} / \mathrm{Fe}_{3} \mathrm{O}_{4} / \mathrm{ZnO}$}

\subsubsection{Synthesis of Magnetic REC}

$\mathrm{Fe}_{3} \mathrm{O}_{4}$ was prepared by a co-precipitation method as follows. A solution of $\mathrm{FeCl}_{3}(1.625 \mathrm{~g})$ and $\mathrm{FeSO}_{4}(1.219 \mathrm{~g})$ was prepared at a molar ratio of $4: 3$, and $1 \mathrm{~mol} / \mathrm{L}$ of $\mathrm{NaOH}$ solution $(250 \mathrm{~mL})$ was quickly added to the mixture while mixing at high speed with a magnetic mixer to adjust the $\mathrm{pH}$ to 11 . Mixing was continued at $60^{\circ} \mathrm{C}$ for $1.5 \mathrm{~h}$, and then the solution was placed in a thermostated water bath at $80^{\circ} \mathrm{C}$ for $1.5 \mathrm{~h}$ to crystallize the product. The $\mathrm{Fe}_{3} \mathrm{O}_{4}$ product was isolated by filtration, rinsed with pure water until the $\mathrm{pH}$ of the filtrate was neutral, dried at $105^{\circ} \mathrm{C}$ for $6 \mathrm{~h}$, and finally ground to a particle size of $74 \mu \mathrm{m}$. 
Magnetic REC was prepared as follows. A mixture of REC in water was sonicated to provide a uniform suspension. A ferrofluid containing $50 \mathrm{wt}$. \% of the $\mathrm{Fe}_{3} \mathrm{O}_{4}$ described above was slowly dropped into REC suspensions to provide $\mathrm{REC} / \mathrm{Fe}_{3} \mathrm{O}_{4}$ mixtures having weight ratios of 1:0.1, 1:0.2, 1:0.3, 1:0.4, and 1:0.5. Each mixture was ultrasonically dispersed for $60 \mathrm{~min}$. The product was recovered by filtration, dried at $105^{\circ} \mathrm{C}$ for $6 \mathrm{~h}$, and ground to a particle size of $74 \mu \mathrm{m}$.

\subsubsection{Synthesis of $\mathrm{REC} / \mathrm{Fe}_{3} \mathrm{O}_{4} / \mathrm{ZnO}$}

The $\mathrm{REC} / \mathrm{Fe}_{3} \mathrm{O}_{4} / \mathrm{ZnO}$ nanocomposites were prepared via a mild liquid-phase synthesis method. The reaction of zinc acetate dihydrate $\left(\mathrm{Zn}\left(\mathrm{CH}_{3} \mathrm{COO}\right)_{2} \cdot 2 \mathrm{H}_{2} \mathrm{O} ; 2.1951 \mathrm{~g}(10 \mathrm{mmol})\right)$ with hydrazine hydrate $\left(\mathrm{N}_{2} \mathrm{H}_{4} \cdot \mathrm{H}_{2} \mathrm{O} ; 80 \% ; 0.726 \mathrm{~mL}(15 \mathrm{mmol})\right.$ ) provided a theoretical yield of $0.8137 \mathrm{~g}$ of $\mathrm{ZnO}$. Based on this calculation, appropriate amounts of the magnetic REC were added to form $\mathrm{REC} / \mathrm{Fe}_{3} \mathrm{O}_{4} / \mathrm{ZnO}$ suspensions having weight ratios of 1:0.1:0.5, 1:0.2:0.5, 1:0.3:0.5, 1:0.4:0.5, 1:0.5:0.5, 1:0.1:0.5, 1:0.1:1.0 and 1:0.1:1.5. In the experiments, $2.1951 \mathrm{~g}(10 \mathrm{mmol})$ of $\mathrm{Zn}\left(\mathrm{CH}_{3} \mathrm{COO}\right)_{2} \cdot 2 \mathrm{H}_{2} \mathrm{O}$ and the appropriate calculated weights of magnetic REC were dissolved in $200 \mathrm{~mL}$ of a mixed solvent of dimethyl benzene and ethylene glycol under vigorous stirring for $30 \mathrm{~min}$. Then, a solution of hydrazine hydrate $(0.726 \mathrm{~mL}$, $15 \mathrm{mmol})$ in anhydrous ethanol $(30 \mathrm{~mL})$ was added dropwise to the suspension. The resulting dispersion was vigorously stirred for $5 \mathrm{~h}$ at room temperature, and then transferred to a separating funnel and allowed to stand for $1.5 \mathrm{~h}$. Centrifugation provided the $\mathrm{REC} / \mathrm{Fe}_{3} \mathrm{O}_{4} / \mathrm{ZnO}$ nanocomposites as gray solids. These were isolated by filtration, rinsed three times with anhydrous ethanol, and calcined for $6 \mathrm{~h}$ in a muffle furnace at temperatures of 200, 300, 400, 500, and $600{ }^{\circ} \mathrm{C}$.

\subsection{Characterization of the Synthesized Magnetic Materials}

The Brunauer-Emmett-Teller (BET) surface area was determined using a Micromeritics model ASAP 2020 Instrument (Micromeritics, Norcross, GA, USA). The XRD patterns of the products were determined using a Dmax-rA powder diffractometer (Rigaku, Akishima, Japan), which used $\mathrm{Cu}$ $\mathrm{K} \alpha$ radiation source at a scanning rate of $2^{\circ} \mathrm{min}^{-1}$. SEM images were acquired using a QUANTA 200 instrument (FEI, Hillsboro, OR, USA). Transmission electron microscopy (TEM) images were obtained with a JEM 2010HT instrument (JEOL, Akishima, Japan) at an accelerating voltage of $200 \mathrm{kV}$. Thermogravimetric analysis (TGA) was conducted on a TGA 2050 thermogravimetric analyzer with a heating rate of $10^{\circ} \mathrm{C} / \mathrm{min}$ from 50 to $800^{\circ} \mathrm{C}$ under a nitrogen atmosphere (TA Instruments, NewCastle, $\mathrm{DE}, \mathrm{USA}$ ). The Brunauer-Emmett-Teller (BET) surface areas of the two $\mathrm{TiO}_{2}$ were determined using a Micromeritics ASAP 2020 setup (Micromeritics, Norcross, GA, USA).

\subsection{Adsorption of $M B$ Dye on $\mathrm{REC} / \mathrm{Fe}_{3} \mathrm{O}_{4} / \mathrm{ZnO}$}

Adsorption kinetics: A dispersion of $\mathrm{REC} / \mathrm{Fe}_{3} \mathrm{O}_{4} / \mathrm{ZnO}(0.9 \mathrm{~g} / \mathrm{L})$ was prepared by adding $\mathrm{REC} / \mathrm{Fe}_{3} \mathrm{O}_{4} / \mathrm{ZnO}$ to $100 \mathrm{~mL}$ of an aqueous $\mathrm{MB}$ solution (concentration: $5 \mathrm{mg} / \mathrm{L}$ ) and the dispersion was shaken at $25{ }^{\circ} \mathrm{C}$. Samples $(2 \mathrm{~mL})$ were withdrawn from the flask at different time intervals. The adsorbent and $\mathrm{MB}$ dye solution were quickly separated by a magnet, and the concentration of dye in the supernatant was analyzed by UV-visible spectroscopy.

Adsorption isotherms: Batch adsorption studies were performed using aqueous suspensions containing $\mathrm{MB}$ dye at different initial concentrations; the dosage of $\mathrm{REC} / \mathrm{Fe}_{3} \mathrm{O}_{4} / \mathrm{ZnO}, \mathrm{REC} / \mathrm{Fe}_{3} \mathrm{O}_{4}$ or $\mathrm{ZnO}$ as adsorbent was held at $0.9 \mathrm{~g} / \mathrm{L}$. The suspension was continuously stirred at constant temperature using a mechanical stirrer for $2 \mathrm{~h}$. After reaching equilibrium, a 2-mL aliquot of the suspension was withdrawn to determine the equilibrium concentration, $c_{t}$. Adsorption isotherm experiments were carried out at $\mathrm{pH} 6.0$ in the absence of electrolytes.

\subsection{Photocatalytic Degradation of MB Dye under Simulated Solar Radiation}

Photodegradation of MB dye was carried out in a home-made photoreactor. The radiation source was an incandescent light bulb lamp that provided radiation at $\geq 350 \mathrm{~nm}$ with an irradiance of $1900 \mu \mathrm{W} / \mathrm{cm}^{2}$ (Figure 11). Aqueous solutions of MB dye (200 mL; initial concentration: 5 to $20 \mathrm{mg} / \mathrm{L}$ ) 
were mixed magnetically with the various catalysts in a $250 \mathrm{~mL}$ Pyrex beaker. After equilibrating in the dark for $1 \mathrm{~h}$, aliquots $(2 \mathrm{~mL})$ of those suspensions were withdrawn to determine the initial $\mathrm{MB}$ concentration, $c_{0}$. Aliquots $(2 \mathrm{~mL})$ were also collected at selected time intervals as the MB degraded; these were magnetically separated and used to determine $c_{t}$. The degradation of the MB dye was monitored using a 2550 UV-visible spectrophotometer (Shimadzu, Kyoto, Japan) with a 10-mm cuvette. The slope of a linear fit of the data provided the initial photodegradation rate, $R_{0}$.

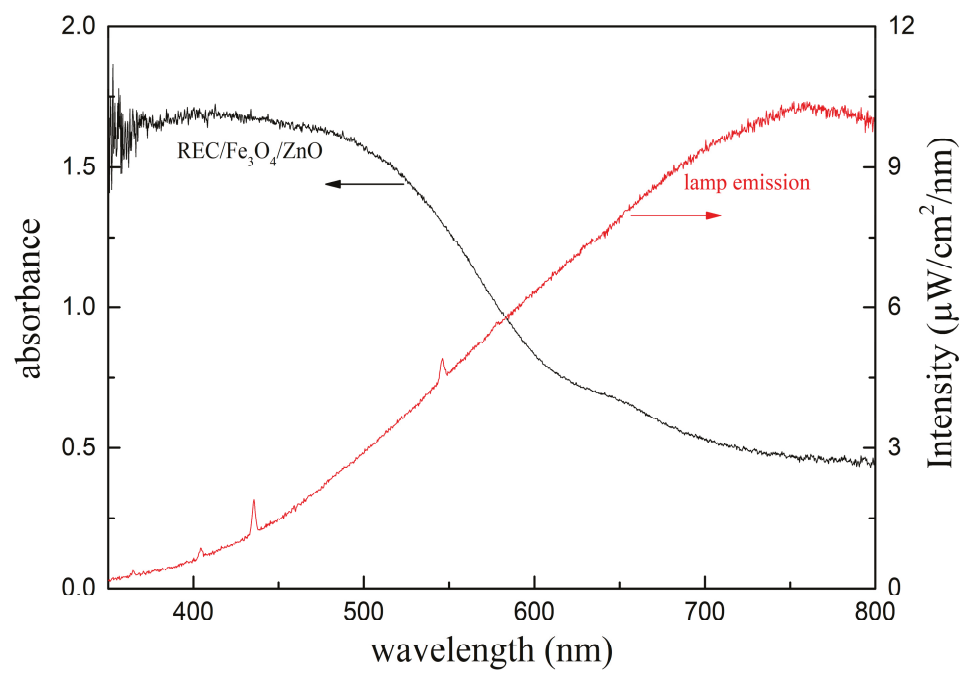

Figure 11. Absorption spectrum of $\mathrm{REC} / \mathrm{Fe}_{3} \mathrm{O}_{4} / \mathrm{ZnO}$ (1:0.3:0.5) and the irradiance of lamp using in this study.

\subsection{Sample and Data Analyses}

Sample analysis: The MB dye concentration was determined according to its absorbance at $665 \mathrm{~nm}$.

Data analysis: The mass of MB dye adsorbed per gram of adsorbent at different times $\left(q_{t}, \mathrm{mg} / \mathrm{g}\right)$ and at equilibrium ( $q_{\mathrm{e}}, \mathrm{mg} / \mathrm{g}$ ) were calculated using Equations (2) and (3), respectively:

$$
\begin{aligned}
& q_{t}=\frac{\left(c_{0}-c_{t}\right) \times V}{m}, \\
& q_{\mathrm{e}}=\frac{\left(c_{0}-c_{\mathrm{e}}\right) \times V}{m},
\end{aligned}
$$

where $c_{0}, c_{t}$, and $c_{\mathrm{e}}$ are the initial concentration, concentration at time $t$, and equilibrium concentration of the $\mathrm{MB}$ dye (all in $\mathrm{mg} / \mathrm{g}$ ), respectively.

The adsorption ratio (\%) of the MB dye was then calculated using Equation (4):

$$
R=\left(1-\frac{c_{\mathrm{e}}}{c_{0}}\right) \times 100 \%,
$$

The Freundlich (Equation (5)) and Langmuir (Equation (6)) isotherms were applied to describe the adsorption properties of the $\mathrm{MB}$ dye on $\mathrm{REC} / \mathrm{Fe}_{3} \mathrm{O}_{4} / \mathrm{ZnO}, \mathrm{REC} / \mathrm{Fe}_{3} \mathrm{O}_{4}$ and $\mathrm{ZnO}$, as follows [60]:

$$
q_{\mathrm{e}}=K_{\mathrm{F}} \times c_{\mathrm{e}}^{1 / n},
$$


where $K_{\mathrm{F}}\left((\mathrm{mg} / \mathrm{g}) \times(\mathrm{L} / \mathrm{g})^{1 / n}\right)$ is the Freundlich affinity coefficient and $1 / n$ is the Freundlich exponential coefficient. Additionally:

$$
q_{\mathrm{e}}=\frac{q_{\max } \times K_{L} \times c_{\mathrm{e}}}{1+K_{L} \times c_{\mathrm{e}}},
$$

where $q_{\max }(\mathrm{mg} / \mathrm{g})$ is the maximum adsorption of MB dye on the adsorbents and $K_{L}(\mathrm{~L} / \mathrm{mg})$ is the Langmuir adsorption constant.

\section{Conclusions}

A series of $\mathrm{REC} / \mathrm{Fe}_{3} \mathrm{O}_{4} / \mathrm{ZnO}$ composites was synthesized and characterized. The $\mathrm{Fe}_{3} \mathrm{O}_{4}$ phase destroyed the layered structure of REC and increased the adsorption of MB dye. The $\mathrm{ZnO}$ component greatly assisted the degradation of the dye, with the activity of $\mathrm{REC} / \mathrm{Fe}_{3} \mathrm{O}_{4} / \mathrm{ZnO}$ decreasing with increasing $\mathrm{ZnO}$ content. $\mathrm{REC} / \mathrm{Fe}_{3} \mathrm{O}_{4} / \mathrm{ZnO}$ exhibited the highest photoactivity for the removal of $\mathrm{MB}$ dye at $\mathrm{pH}$ 6.0. The adsorption isotherm and degradation kinetics followed the Langmuir and Langmuir-Hinshelwood models, respectively. The mass loss and photoactivity of $\mathrm{REC} / \mathrm{Fe}_{3} \mathrm{O}_{4} / \mathrm{ZnO}$ only slightly decreased after three cycles. The primary degradation mechanism was also proposed based on the detected intermediates. Our study demonstrated that $\mathrm{REC} / \mathrm{Fe}_{3} \mathrm{O}_{4} / \mathrm{ZnO}$ composites have great potential as catalysts for the treatment of dye pollutants in aqueous solutions.

Acknowledgments: This research is supported by the National High Technology Research and Development Program of China (No. 2007AA06Z418), the National Natural Science Foundation of China (Nos. 20577036, 20777058, 20977070), the National Natural Science Foundation of Hubei province in China (No. 2015CFA137), and the Open Fund of Hubei Biomass-Resource Chemistry and Environmental Biotechnology Key Laboratory, and the Fund of Eco-environment Technology R\&D and Service Center (Wuhan University).

Author Contributions: Peijiang Zhou and Huanhuan Wang conceived and designed the experiments; Rui Guo, Yifei Wang and Yunfei Yuan performed the experiments; Huanhuan Wang and Hongju Zhan analyzed the data; Peijiang Zhou contributed reagents/materials/analysis tools; Huanhuan Wang wrote the paper.

Conflicts of Interest: The authors declare no conflict of interest.

\section{References}

1. Forgacs, E.; Cserhati, T.; Oros, G. Removal of synthetic dyes from wastewaters: A review. Environ. Int. 2004, 30, 953-971. [CrossRef] [PubMed]

2. An, A.K.; Guo, J.; Lee, E.J.; Jeong, S.; Zhao, Y.; Wang, Z.; Leiknes, T. PDMS/PVDF hybrid electrospun membrane with superhydrophobic property and drop impact dynamics for dyeing wastewater treatment using membrane distillation. J. Membr. Sci. 2017, 525, 57-67. [CrossRef]

3. Zinatloo-Ajabshir, S.; Salavati-Niasari, M.; Zinatloo-Ajabshir, Z. Facile size-controlled preparation of highly photocatalytically active praseodymium zirconate nanostructures for degradation and removal of organic pollutants. Sep. Purif. Technol. 2017, 177, 110-120. [CrossRef]

4. Giannakoudakis, D.A.; Kyzas, G.Z.; Avranas, A.; Lazaridis, N.K. Multi-parametric adsorption effects of the reactive dye removal with commercial activated carbons. J. Mol. Liq. 2016, 213, 381-389. [CrossRef]

5. Spagnoli, A.A.; Giannakoudakis, D.A.; Bashkova, S. Adsorption of methylene blue on cashew nut shell based carbons activated with zinc chloride: The role of surface and structural parameters. J. Mol. Liq. 2017, 229, 465-471. [CrossRef]

6. Chang, S.H.; Wang, K.S.; Chao, S.J.; Peng, T.H.; Huang, L.C. Degradation of azo and anthraquinone dyes by a low-cost $\mathrm{Fe}^{0}$ /air process. J. Hazard. Mater. 2009, 166, 1127-1133. [CrossRef] [PubMed]

7. Ganesh, R.; Boardman, G.D.; Michelsen, D. Fate of azo dyes in sludges. Water Res. 1994, 28, 1367-1376. [CrossRef]

8. Razo-Flores, E.; Luijten, M.; Donlon, B.; Lettinga, G.; Field, J. Biodegradation of selected azo dyes under methanogenic conditions. Water Sci. Technol. 1997, 36, 65-72.

9. Lucas, M.; Peres, J. Decolorization of the azo dye reactive black 5 by Fenton and photo-Fenton oxidation. Dyes Pigment. 2006, 71, 236-244. [CrossRef] 
10. Zhang, X.; Wang, Y.; Liu, B.; Sang, Y.; Liu, H. Heterostructures construction on $\mathrm{TiO}_{2}$ nanobelts: A powerful tool for building high-performance photocatalysts. Appl. Catal. B Environ. 2017, 202, 620-641. [CrossRef]

11. Tan, C.; Cao, X.; Wu, X.J.; He, Q.; Yang, J.; Zhang, X.; Chen, J.; Zhao, W.; Han, S.; Nam, G.H.; et al. Recent advances in ultrathin two-dimensional nanomaterials. Chem. Rev. 2017, 117, 6225-6331. [CrossRef] [PubMed]

12. Pirhashemi, M.; Habibi-Yangjeh, A. Ultrasonic-assisted preparation of plasmonic $\mathrm{ZnO} / \mathrm{Ag} / \mathrm{Ag}_{2} \mathrm{WO}_{4}$ nanocomposites with high visible-light photocatalytic performance for degradation of organic pollutants. J. Colloid Interface Sci. 2017, 491, 216-229. [CrossRef] [PubMed]

13. Karunakaran, C.; Dhanalakshmi, R. Photocatalytic performance of particulate semiconductors under natural sunshine-Oxidation of carboxylic acids. Sol. Energy Mater. Sol. Cells 2008, 92, 588-593. [CrossRef]

14. Madhavan, J.; Muthuraaman, B.; Murugesan, S.; Anandan, S.; Maruthamuthu, P. Peroxomonosulphate, an efficient oxidant for the photocatalysed degradation of a textile dye, acid red 88. Sol. Energy Mater. Sol. Cells 2006, 90, 1875-1887. [CrossRef]

15. Kumar, S.; Karthikeyan, S.; Lee, A. G- $\mathrm{C}_{3} \mathrm{~N}_{4}$-based nanomaterials for visible light-driven photocatalysis. Catalysts 2018, 8, 74. [CrossRef]

16. Jelle, A.A.; Hmadeh, M.; O’Brien, P.G.; Perovic, D.D.; Ozin, G.A. Photocatalytic properties of all four polymorphs of nanostructured iron oxyhydroxides. ChemNanoMat 2016, 2, 1047-1054. [CrossRef]

17. Zhang, G.; Lan, Z.A.; Wang, X. Conjugated polymers: Catalysts for photocatalytic hydrogen evolution. Angew. Chem.-Int. Ed. 2016, 55, 15712-15727. [CrossRef] [PubMed]

18. Zhang, L.; Li, J.; Chen, Z.; Tang, Y.; Yu, Y. Preparation of fenton reagent with $\mathrm{H}_{2} \mathrm{O}_{2}$ generated by solar light-illuminated nano-Cu ${ }_{2} \mathrm{O} / \mathrm{MWNTs}$ composites. Appl. Catal. A Gen. 2006, 299, 292-297. [CrossRef]

19. Ali, I.; Kim, J.O. Continuous-flow photocatalytic degradation of organics using modified $\mathrm{TiO}_{2}$ nanocomposites. Catalysts 2018, 8, 43. [CrossRef]

20. Ho, W.; Tay, Q.; Qi, H.; Huang, Z.; Li, J.; Chen, Z. Photocatalytic and adsorption performances of faceted cuprous oxide $\left(\mathrm{Cu}_{2} \mathrm{O}\right)$ particles for the removal of methyl orange (MO) from aqueous media. Molecules 2017, 22, 677. [CrossRef] [PubMed]

21. Mohd Hir, Z.; Abdullah, A.; Zainal, Z.; Lim, H. Photoactive hybrid film photocatalyst of polyethersulfone- $\mathrm{ZnO}$ for the degradation of methyl orange dye: Kinetic study and operational parameters. Catalysts 2017, 7, 313. [CrossRef]

22. Shu, H.Y.; Chang, M.C.; Tseng, T.H. Solar and visible light illumination on immobilized nano zinc oxide for the degradation and mineralization of orange $G$ in wastewater. Catalysts 2017, 7, 164.

23. Sharma, D.; Sharma, S.; Kaith, B.S.; Rajput, J.; Kaur, M. Synthesis of zno nanoparticles using surfactant free in-air and microwave method. Appl. Surf. Sci. 2011, 257, 9661-9672. [CrossRef]

24. Giannakoudakis, D.A.; Arcibar-Orozco, J.A.; Bandosz, T.J. Key role of terminal hydroxyl groups and visible light in the reactive adsorption/catalytic conversion of mustard gas surrogate on zinc (hydr)oxides. Appl. Catal. B Environ. 2015, 174-175, 96-104. [CrossRef]

25. Ullah, R.; Dutta, J. Photocatalytic degradation of organic dyes with manganese-doped zno nanoparticles. J. Hazard. Mater. 2008, 156, 194-200. [CrossRef] [PubMed]

26. Chava, R.K.; Im, Y.; Kang, M. Nitrogen doped carbon quantum dots as a green luminescent sensitizer to functionalize zno nanoparticles for enhanced photovoltaic conversion devices. Mater. Res. Bull. 2017, 94, 399-407. [CrossRef]

27. He, W.; Jia, H.; Cai, J.; Han, X.; Zheng, Z.; Wamer, W.G.; Yin, J.-J. Production of reactive oxygen species and electrons from photoexcited zno and zns nanoparticles: A comparative study for unraveling their distinct photocatalytic activities. J. Phys. Chem. C 2016, 120, 3187-3195. [CrossRef]

28. Lakshmi Prasanna, V.; Vijayaraghavan, R. Insight into the mechanism of antibacterial activity of zno: Surface defects mediated reactive oxygen species even in the dark. Langmuir ACS J. Surf. Colloids 2015, 31, 9155-9162. [CrossRef] [PubMed]

29. Sun, L.; Shao, R.; Chen, Z.; Tang, L.; Dai, Y.; Ding, J. Alkali-dependent synthesis of flower-like zno structures with enhanced photocatalytic activity via a facile hydrothermal method. Appl. Surf. Sci. 2012, 258, 5455-5461. [CrossRef]

30. Mahmoodi, V.; Bastami, T.R.; Ahmadpour, A. Solar energy harvesting by magnetic-semiconductor nanoheterostructure in water treatment technology. Environ. Sci. Pollut. Res. Int. 2018. [CrossRef] [PubMed] 
31. Riahi-Madvaar, R.; Taher, M.A.; Fazelirad, H. Synthesis and characterization of magnetic halloysite-iron oxide nanocomposite and its application for naphthol green B removal. Appl. Clay Sci. 2017, 137, 101-106. [CrossRef]

32. Middea, A.; Spinelli, L.S.; Souza, F.G., Jr.; Neumann, R.; Fernandes, T.L.A.P.; Gomes, O.D.F.M. Preparation and characterization of an organo-palygorskite- $\mathrm{Fe}_{3} \mathrm{O}_{4}$ nanomaterial for removal of anionic dyes from wastewater. Appl. Clay Sci. 2017, 139, 45-53. [CrossRef]

33. Mu, B.; Tang, J.; Zhang, L.; Wang, A. Preparation, characterization and application on dye adsorption of a well-defined two-dimensional superparamagnetic clay/polyaniline/ $\mathrm{Fe}_{3} \mathrm{O}_{4}$ nanocomposite. Appl. Clay Sci. 2016, 132-133, 7-16. [CrossRef]

34. Chang, J.; Ma, J.; Ma, Q.; Zhang, D.; Qiao, N.; Hu, M.; Ma, H. Adsorption of methylene blue onto $\mathrm{Fe}_{3} \mathrm{O}_{4}$ /activated montmorillonite nanocomposite. Appl. Clay Sci. 2016, 119, 132-140. [CrossRef]

35. Hu, L.; Tang, X.; Wu, Z.; Lin, L.; Xu, J.; Xu, N.; Dai, B. Magnetic lignin-derived carbonaceous catalyst for the dehydration of fructose into 5-hydroxymethylfurfural in dimethylsulfoxide. Chem. Eng. J. 2015, 263, 299-308. [CrossRef]

36. Nur'aeni; Chae, A.; Jo, S.; Choi, Y.; Park, B.; Park, S.Y.; In, I. Synthesis of $\beta-\mathrm{FeOOH} / \mathrm{Fe}_{3} \mathrm{O}_{4}$ hybrid photocatalyst using catechol-quaternized poly( $N$-vinyl pyrrolidone) as a double-sided molecular tape. J. Mater. Sci. 2017, 52, 8493-8501.

37. Shi, Z.; Yang, X.; Yao, S. Photocatalytic activity of cerium-doped mesoporous $\mathrm{TiO}_{2}$ coated $\mathrm{Fe}_{3} \mathrm{O}_{4}$ magnetic composite under uv and visible light. J. Rare Earths 2012, 30, 355-360. [CrossRef]

38. Shekofteh-Gohari, M.; Habibi-Yangjeh, A. Novel magnetically separable $\mathrm{Fe}_{3} \mathrm{O}_{4} @ \mathrm{ZnO} / \mathrm{AgCl}$ nanocomposites with highly enhanced photocatalytic activities under visible-light irradiation. Sep. Purif. Technol. 2015, 147, 194-202. [CrossRef]

39. Majidnia, Z.; Idris, A. Combination of maghemite and titanium oxide nanoparticles in polyvinyl alcohol-alginate encapsulated beads for cadmium ions removal. Korean J. Chem. Eng. 2015, 32, 1094-1100. [CrossRef]

40. Jo, W.K.; Clament Sagaya Selvam, N. Enhanced visible light-driven photocatalytic performance of $\mathrm{ZnO}-\mathrm{g}-\mathrm{C}_{3} \mathrm{~N}_{4}$ coupled with graphene oxide as a novel ternary nanocomposite. J. Hazard. Mater. 2015, 299, 462-470. [CrossRef] [PubMed]

41. Gu, N.; Gao, J.; Wang, K.; Yang, X.; Dong, W. ZnO-montmorillonite as photocatalyst and flocculant for inhibition of cyanobacterial bloom. Water Air Soil Pollut. 2015, 226, 136. [CrossRef]

42. Kolodziejczak-Radzimska, A.; Jesionowski, T. Zinc oxide-from synthesis to application: A review. Materials 2014, 7, 2833-2881. [CrossRef] [PubMed]

43. Feng, X.; Guo, H.; Patel, K.; Zhou, H.; Lou, X. High performance, recoverable $\mathrm{Fe}_{3} \mathrm{O}_{4} / \mathrm{ZnO}$ nanoparticles for enhanced photocatalytic degradation of phenol. Chem. Eng. J. 2014, 244, 327-334. [CrossRef]

44. Ökte, A.N.; Karamanis, D. A novel photoresponsive ZnO-flyash nanocomposite for environmental and energy applications. Appl. Catal. B Environ. 2013, 142-143, 538-552. [CrossRef]

45. Ahmad, M.; Ahmed, E.; Hong, Z.L.; Xu, J.F.; Khalid, N.R.; Elhissi, A.; Ahmed, W. A facile one-step approach to synthesizing $\mathrm{ZnO} /$ graphene composites for enhanced degradation of methylene blue under visible light. Appl. Surf. Sci. 2013, 274, 273-281. [CrossRef]

46. Bailey, S.W.; Brindley, G.W.; Kodama, H.; Martin, R.T. Report of the clay-minerals-society nomenclature committee for 1980-1981-Nomenclature for regular interstratifications. Clays Clay Miner. 1982, 30, 76-78. [CrossRef]

47. Guo, Y.; Zhang, G.; Gan, H. Synthesis, characterization and visible light photocatalytic properties of $\mathrm{Bi}_{2} \mathrm{WO}_{6} /$ rectorite composites. J. Colloid Interface Sci. 2012, 369, 323-329. [CrossRef] [PubMed]

48. Lu, Y.; Chang, P.R.; Zheng, P.; Ma, X. Rectorite- $-\mathrm{TiO}_{2}-\mathrm{Fe}_{3} \mathrm{O}_{4}$ composites: Assembly, characterization, adsorption and photodegradation. Chem. Eng. J. 2014, 255, 49-54. [CrossRef]

49. Li, S.Q.; Zhou, P.J.; Zhang, W.S.; Chen, S.; Peng, H. Effective photocatalytic decolorization of methylene blue utilizing $\mathrm{ZnO} /$ rectorite nanocomposite under simulated solar irradiation. J. Alloys Compd. 2014, 616, 227-234. [CrossRef]

50. Wu, S.; Fang, J.; Xu, W.; Cen, C. Bismuth-modified rectorite with high visible light photocatalytic activity. J. Mol. Catal. A Chem. 2013, 373, 114-120. [CrossRef]

51. Zhang, Y.; Guo, Y.; Zhang, G.; Gao, Y. Stable $\mathrm{TiO}_{2}$ /rectorite: Preparation, characterization and photocatalytic activity. Appl. Clay Sci. 2011, 51, 335-340. [CrossRef] 
52. Bu, X.Z.; Zhang, G.K.; Gao, Y.Y.; Yang, Y.Q. Preparation and photocatalytic properties of visible light responsive n-doped $\mathrm{TiO}_{2}$ /rectorite composites. Microporous Mesoporous Mater. 2010, 136, 132-137. [CrossRef]

53. Yang, L.; Liang, G.; Zhang, Z.; He, S.; Wang, J. Sodium alginate/ $\mathrm{Na}^{+}$-rectorite composite films: Preparation, characterization, and properties. J. Appl. Polym. Sci. 2009, 114, 1235-1240. [CrossRef]

54. Xiong, G.; Pal, U.; Serrano, J.G.; Ucer, K.B.; Williams, R.T. Photoluminesence and ftir study of ZnO nanoparticles: The impurity and defect perspective. Phys. Status Solid 2006, 3, 3577-3581. [CrossRef]

55. Wang, X.; Liu, B.; Ren, J.; Liu, C.; Wang, X.; Wu, J.; Sun, R. Preparation and characterization of new quaternized carboxymethyl chitosan/rectorite nanocomposite. Compos. Sci. Technol. 2010, 70, 1161-1167. [CrossRef]

56. Li, Z.; Jiang, W.T.; Hong, H. An ftir investigation of hexadecyltrimethylammonium intercalation into rectorite. Spectrochim. Acta Part A 2008, 71, 1525-1534. [CrossRef] [PubMed]

57. Nguyen, H.D.; Nguyen, T.D.; Nguyen, D.H.; Nguyen, P.T. Magnetic properties of $\mathrm{Cr}$ doped $\mathrm{Fe}_{3} \mathrm{O}_{4}$ porous nanoparticles prepared through a co-precipitation method using surfactant. Adv. Nat. Sci. Nanosci. Nanotechnol. 2014, 5, 035017. [CrossRef]

58. Oliveira, L.C.A.; Gonçalves, M.; Guerreiro, M.C.; Ramalho, T.C.; Fabris, J.D.; Pereira, M.C.; Sapag, K. A new catalyst material based on niobia/iron oxide composite on the oxidation of organic contaminants in water via heterogeneous fenton mechanisms. Appl. Catal. A Gen. 2007, 316, 117-124. [CrossRef]

59. Shirafuji, T.; Nomura, A.; Hayashi, Y.; Tanaka, K.; Goto, M. Matrix-assisted laser desorption ionization time-of-flight mass spectrometric analysis of degradation products after treatment of methylene blue aqueous solution with three-dimensionally integrated microsolution plasma. Jpn. J. Appl. Phys. 2016, 55. [CrossRef]

60. Yang, K.; Zhu, L.; Xing, B. Adsorption of polycyclic aromatic hydrocarbons by carbon nanomaterials. Environ. Sci. Technol. 2006, 40, 1855-1861. [CrossRef] [PubMed]

(C) 2018 by the authors. Licensee MDPI, Basel, Switzerland. This article is an open access article distributed under the terms and conditions of the Creative Commons Attribution (CC BY) license (http:/ / creativecommons.org/licenses/by/4.0/). 


\title{
Article \\ Cu Nanoparticles/Fluorine-Doped Tin Oxide (FTO) Nanocomposites for Photocatalytic $\mathrm{H}_{2}$ Evolution under Visible Light Irradiation
}

\author{
Hui Liu, An Wang, Quan Sun, Tingting Wang * and Heping Zeng * \\ Key Laboratory of Functional Molecular Engineering of Guangdong Province, School of Chemistry \& Chemical \\ Engineering, South China University of Technology, Guangzhou 510640, China; \\ cehuiliu@mail.scut.edu.cn (H.L.); ceakwong@mail.scut.edu.cn (A.W.); boldymansun@163.com (Q.S.) \\ * Correspondence: ttwang@scut.edu.cn (T.W.); hpzeng@scut.edu.cn (H.Z.); \\ Tel.: +86-208-711-2631 (T.W.); +86-208-711-2631 (H.Z.)
}

Received: 12 August 2017; Accepted: 29 September 2017; Published: 12 December 2017

\begin{abstract}
Copper nanoparticles/fluorine-doped tin oxide (FTO) nanocomposites were successfully prepared by a simple hydrothermal method. The synthesized nanocomposites were characterized by X-ray diffraction (XRD), UV-visible diffuse-reflectance spectrum (UV-VIS DRS), energy dispersive X-ray (EDX), transmission electron microscopy (TEM), Raman spectra, and X-ray photoelectron spectroscopy (XPS). The obtained $\mathrm{Cu} / \mathrm{FTO}$ nanocomposites exhibit high photocatalytic activity for $\mathrm{H}_{2}$ evolution under visible light $(\lambda>420 \mathrm{~nm})$ irradiation. When the content of $\mathrm{Cu}$ is $19.2 \mathrm{wt} \%$ for FTO, the $\mathrm{Cu} / \mathrm{FTO}$ photocatalyst shows the highest photocatalytic activity and the photocatalytic $\mathrm{H}_{2}$ evolution rate is up to $11.22 \mu \mathrm{mol} \cdot \mathrm{h}^{-1}$. Meanwhile, the photocatalyst exhibits excellent stability and repeatability. It is revealed that the transfer efficiency of the photogenerated electrons is improved greatly because of the intense interaction between $\mathrm{Cu}$ NPs and FTO. Furthermore, a possible mechanism is proposed for enhanced photocatalytic $\mathrm{H}_{2}$ evolution of $\mathrm{Cu}$ /FTO photocatalysts under visible light irradiation.
\end{abstract}

Keywords: $\mathrm{Cu}$ nanoparticles; $\mathrm{Cu} / \mathrm{FTO}$ nanocomposites; $\mathrm{H}_{2}$ evolution; visible light; transfer efficiency

\section{Introduction}

Hydrogen $\left(\mathrm{H}_{2}\right)$ is regarded as one of the most promising energy sources because of its high energy content per mass. Photocatalytic $\mathrm{H}_{2}$ evolution using solar energy has attracted much attention, which is a feasible method to solve energy shortages and environmental crises [1-3]. Since Fujishima and Honda firstly reported the photolysis of water based on $\mathrm{TiO}_{2}$ electrodes in 1972 [4], semiconductor materials as photocatalysts have been extensively studied for highly-efficient solar water splitting. Subsequently, many semiconductor materials have been developed as efficient photocatalystys to make the utmost of solar energy for photocatalytic $\mathrm{H}_{2}$ evolution $[5,6]$.

It is well known that tin oxide $\left(\mathrm{SnO}_{2}\right)$ is one of the most promising semiconductors for photocatalytic $\mathrm{H}_{2}$ evolution due to its excellent chemical and physical properties [7]. In the past few decades, $\mathrm{SnO}_{2}$ has been extensively used in gas sensing, photoelectric conversion and photcatalysis, etc. However, because of the intrinsic band gap (ca. $3.6 \mathrm{eV}$ ), $\mathrm{SnO}_{2}$ cannot fully use solar radiation in visible spectrum [8]. Many researchers have been trying to modify $\mathrm{SnO}_{2}$ to increase its absorption of visible light, which accounts for $45 \%$ of sunlight [9]. Many different approaches can be used to promote visible light absorption, such as metal doping, ion doping, carbon materials doping, etc. [10-12]. Especially, fluorine (F) has been considered as one of the most effective dopants for enhancing light absorption. Fluorine-doped tin oxide (FTO) is widely used as conducting electrodes for photoelectrochemical reactions [13]. However, owing to the rapid recombination that photoinduction carries, the photocatalytic activity of fluorine-doped tin oxide (FTO) for $\mathrm{H}_{2}$ evolution is usually very low, or non-existent, in the presence of a sacrificial agent [14]. 
As it is well known, loading metal nanoparticles (NPs) as co-catalysts on the surface of catalysts is one of the most effective ways to increase the separation efficiency of photoinduced electron-hole pairs [15]. Many researchers reported that metals, such as $\mathrm{Au}, \mathrm{Ag}, \mathrm{Pt}, \mathrm{Cu}$, and $\mathrm{Pd}$, could be used to promote the migration efficiency of electrons [16-20]. Among of them, $\mathrm{Cu}$ has attracted much more attention because of its low cost and abundance [21]. Additionally, $\mathrm{Cu}$ NPs can generate the localized surface plasmon resonance (LSPR) effect and it is beneficial for the separation of photoinduced electron-hole pairs, which can greatly enhance the photocatalytic activity [22]. Therefore, $\mathrm{Cu}$ NPs as co-catalyst-modified semiconductor photocatalysts may be a promising system to promote the migration of photoinduced electrons for enhancing photocatalytic $\mathrm{H}_{2}$ evolution. Though there are many reports about growth of copper or copper oxides on FTO for photoelectrochemical hydrogen evolution reaction (HER) and oxygen evolution reaction (OER) $[23,24]$. To the best of our knowledge, there is no report about Cu NP-modified FTO (Cu/FTO) nanocomposites for photocatalytic $\mathrm{H}_{2}$ evolution under visible light irradiation.

Here, based on our previous research $[15,22,25,26]$, we reported that FTO nanopowders were fabricated by a typical sol-gel method and then modified with $\mathrm{Cu}$ further by a facile hydrothermal method. The $\mathrm{Cu} /$ FTO nanocomposites were characterized by X-ray diffraction (XRD), UV-VIS, energy dispersive X-ray (EDX), transmission electron microscopy (TEM), X-ray photoelectron spectroscopy (XPS) and so forth. The photacatalytic $\mathrm{H}_{2}$ evolution of $\mathrm{Cu}$ /FTO nanocomposites was evaluated under visible light illumination. The F dopant can greatly enhance the absorption ability of the visible light of $\mathrm{SnO}_{2}$ and the $\mathrm{Cu} / \mathrm{FTO}$ nanocomposites exhibit high photocatalytic activity for $\mathrm{H}_{2}$ evolution. Furthermore, the possible factors in the improvement of photocatalytic activity were also investigated and discussed in this paper.

\section{Results}

\subsection{Crystal Structure and Composition}

Figure 1 shows the XRD patterns of as-prepared samples. For pure $\mathrm{SnO}_{2}$, the diffraction peaks are indexed to the crystalline tetragonal structure of $\mathrm{SnO}_{2}$ (JCPDS No. 41-1445) [27]. The FTO sample exhibits similar diffraction peaks with pure $\mathrm{SnO}_{2}$, which indicates FTO has the similar crystal structure with pure $\mathrm{SnO}_{2}$. For $\mathrm{Cu} / \mathrm{FTO}$ samples, the diffraction peaks at $43.3^{\circ}, 50.5^{\circ}$, and $74.1^{\circ}$ are assigned to the (111), (200), and (220) planes of face-centered cubic Cu (JCPDS No. 04-0836) [26]. As the content of $\mathrm{Cu}$ increases, the intensity of characteristic peaks becomes stronger. No diffraction peak of $\mathrm{CuO}$ or $\mathrm{Cu}_{2} \mathrm{O}$ is observed, which is in agreement with the result of the XPS analysis below. Additionally, the XRD patterns of FTO after the introduction of $\mathrm{Cu}$ show no significant change indicating that the introduction of $\mathrm{Cu}$ does not influence the crystal structure of FTO.

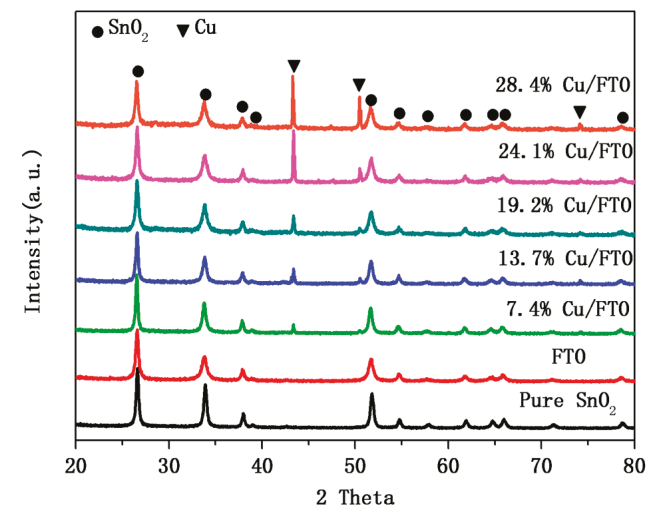

Figure 1. XRD (X-ray diffraction) patterns of pure $\mathrm{SnO}_{2}$, FTO (Fluorine-doped tin oxide), and $\mathrm{Cu} / \mathrm{FTO}$ samples with different contents of $\mathrm{Cu}$. 
To elaborate on the information of the as-prepared samples, Fourier transform infrared spectroscopy (FTIR) was carried out. Figure 2 depicts the FTIR spectra of pure $\mathrm{SnO}_{2}, \mathrm{FTO}$, and $19.2 \%$ $\mathrm{Cu} / \mathrm{FTO}$. The peaks at $924 \mathrm{~cm}^{-1}$ and $1530 \mathrm{~cm}^{-1}$ can be ascribed to the $\mathrm{N}-\mathrm{H}$ out-of-plane bending vibration and in-plane bending vibration. The peak at $1678 \mathrm{~cm}^{-1}$ is attributed to the $\mathrm{C}=\mathrm{O}$ stretching vibration [28]. The peaks around $3400-3800 \mathrm{~cm}^{-1}$ correspond to the $\mathrm{N}-\mathrm{H}$ stretching vibration of amino groups and the $\mathrm{O}-\mathrm{H}$ stretching vibrations of absorbed molecular water [6]. The characteristic peaks at $495 \mathrm{~cm}^{-1}$ and $642 \mathrm{~cm}^{-1}$ are ascribed to the $\mathrm{O}-\mathrm{Sn}-\mathrm{O}$ stretching vibration and the $\mathrm{Sn}-\mathrm{O}$ stretching vibration, respectively [29]. The main characteristic peaks of $\mathrm{SnO}_{2}$ are apparent in $\mathrm{Cu}$ /FTO nanocomposites, indicating the structure of $\mathrm{SnO}_{2}$ remains relatively intact. Moreover, no peak of $\mathrm{Cu}$ is observed because $\mathrm{Cu}$ is not active for infrared spectra.

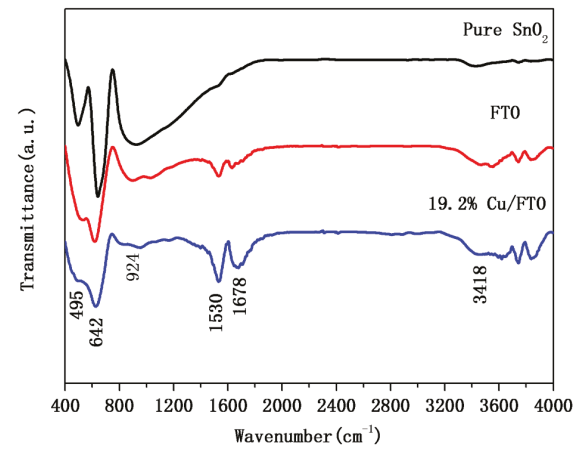

Figure 2. FTIR (Fourier transform infrared spectroscopy) spectra of pure $\mathrm{SnO}_{2}, \mathrm{FTO}$, and $\mathrm{Cu} / \mathrm{FTO}$ samples.

Figure 3 displays the Raman spectra of pure $\mathrm{SnO}_{2}, \mathrm{FTO}$, and $\mathrm{Cu} / \mathrm{FTO}$. There are three fundamental Raman scattering peaks in good agreement with those of rutile $\mathrm{SnO}_{2}$ single crystal [7]. For pure $\mathrm{SnO}_{2}$, the characteristic and strong band at $625 \mathrm{~cm}^{-1}$ is attributed to $\mathrm{A}_{1 \mathrm{~g}}$ vibration mode of $\mathrm{SnO}_{2}$. The weak bands around $478 \mathrm{~cm}^{-1}$ and $772 \mathrm{~cm}^{-1}$ correspond to $\mathrm{E}_{\mathrm{g}}$ and $\mathrm{B}_{2 \mathrm{~g}}$ vibration modes of $\mathrm{SnO}_{2}$ [30]. After doping $\mathrm{F}$ ions, the dominant bands of $\mathrm{SnO}_{2}$ broaden and have a slight shift, which might be evidence that $\mathrm{F}$ ions have substituted for a portion of $\mathrm{O}^{2-}$ in the $\mathrm{SnO}_{2}$. Compared with FTO, the intensity of $\mathrm{Cu} / \mathrm{FTO}$ samples become stronger, indicating that there may be an intense interaction between $\mathrm{Cu}$ NPs and FTO [22]. Especially, the 19.2\% Cu/FTO sample exhibits the strongest intensity and this SERS enhancement may be due to surface plasmon resonance [31]. Moreover, Figure S1 shows the Raman spectra at low wavelength region. Compared with FTO, there is no other band appearing for $19.2 \% \mathrm{Cu} / \mathrm{FTO}$, which may exclude the presence of oxidized $\mathrm{Cu}$ [32].

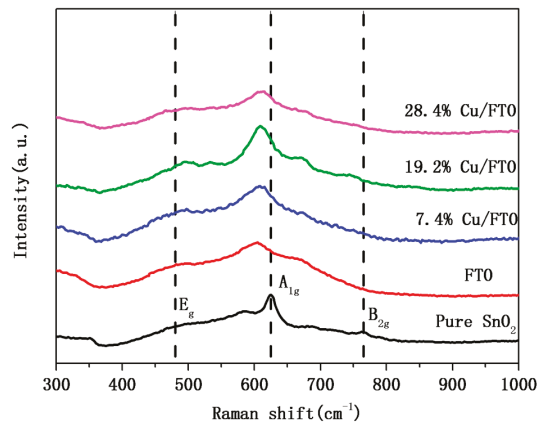

Figure 3. Raman spectra of pure $\mathrm{SnO}_{2}, \mathrm{FTO}$ and $\mathrm{Cu} / \mathrm{FTO}$ samples. 
Morphologies and microstructures of the samples were studied by scanning electron microscopy (SEM), transmission electron microscopy (TEM), and high resolution TEM (HRTEM). Figure 4a shows the SEM image of the FTO sample. The morphology looks like irregular particles and many aggregations exist. Figure $4 \mathrm{~b}-\mathrm{e}$ shows the SEM images of $\mathrm{Cu} / \mathrm{FTO}(7.4 \%, 19.2 \%$, and $28.4 \%)$ samples, respectively. After the introduction of $\mathrm{Cu}$, the particle size of $\mathrm{Cu} / \mathrm{FTO}$ samples seems to be larger and there appear to be more aggregations. Especially for the $28.4 \% \mathrm{Cu} / \mathrm{FTO}$ sample, bulk agglomeration appears in the image (Figure 4e). The EDX spectrum (Figure 4f) and the elemental mapping patterns (Figure 4g) confirm that $\mathrm{C}, \mathrm{O}, \mathrm{Sn}, \mathrm{Cu}$, and F exist, which is consistent with the result of XPS below. Meanwhile, we can see that the main elements are uniformly distributed. The TEM images (Figure S2a-c) shows that the size distribution of $19.2 \% \mathrm{Cu} / \mathrm{FTO}$ sample is about $40-80 \mathrm{~nm}$ and there are some particles joining together. The HRTEM image of $19.2 \% \mathrm{Cu} / \mathrm{FTO}$ is presented in Figure S2d. The lattice spacing of $\mathrm{d}=0.209 \mathrm{~nm}$ corresponds to the (111) plane of $\mathrm{Cu}$ [15]. The lattice spacing of $\mathrm{d}=0.237 \mathrm{~nm}$ and $0.335 \mathrm{~nm}$ are attributed to the (200) plane and the (110) plane of $\mathrm{SnO}_{2}$ (JCPDS No. 41-1445), respectively [33]. It can be found that $\mathrm{Cu}$ NPs and FTO have a close contact for developing the heterogeneous interface and this can promote the migration efficiency of photoinduced electrons.

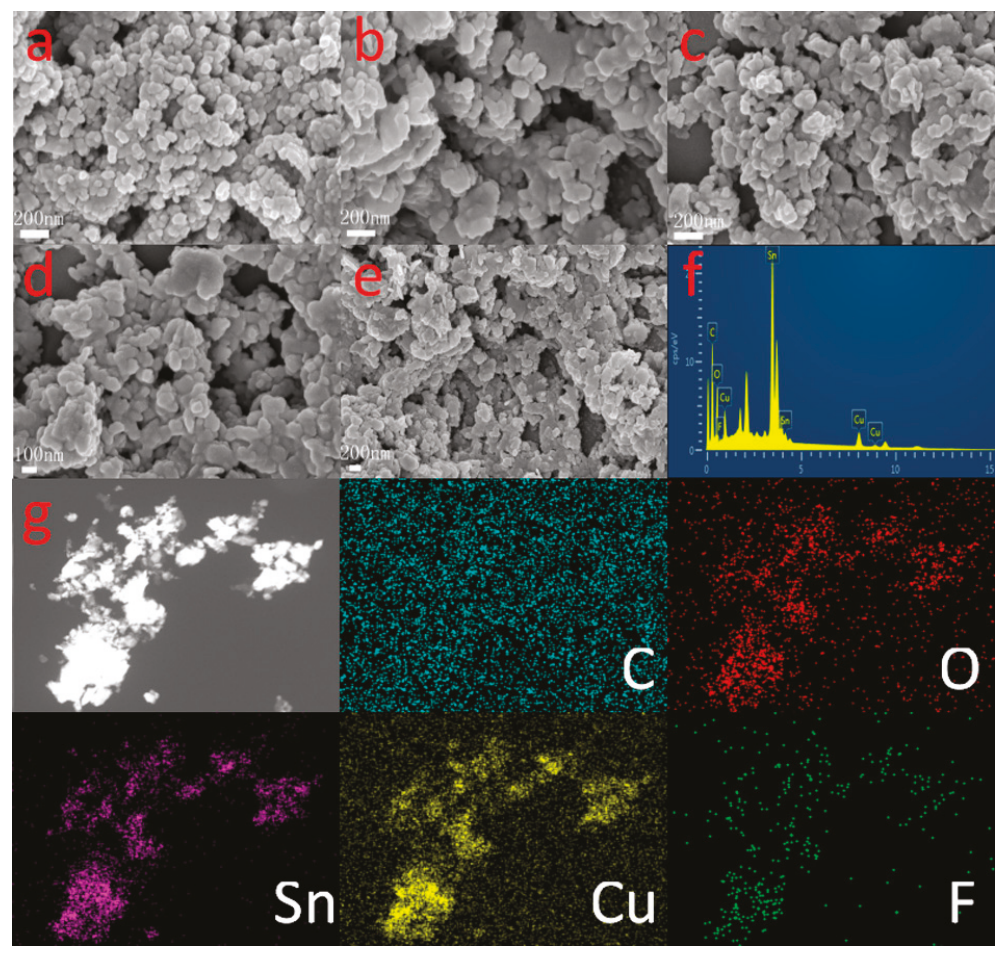

Figure 4. SEM (scanning electron microscopy) images (a) FTO; (b) 7.4\% Cu/FTO; (c,d) 19.2\% Cu/FTO; (e) $28.4 \% \mathrm{Cu} / \mathrm{FTO}$; EDX (energy dispersive X-ray) spectrum (f); and elemental mapping patterns (g) of the $19.2 \% \mathrm{Cu} / \mathrm{FTO}$ sample.

The XPS spectra of the as-prepared $19.2 \% \mathrm{Cu} / \mathrm{FTO}$ sample were analyzed to further determine the chemical composition and the chemical state of elements. The results are shown in Figure 5. The standard C 1 s peak at $284.8 \mathrm{eV}$ was used as a reference to correct the peak shifts. The survey spectra of $\mathrm{Cu} / \mathrm{FTO}$ sample (Figure 5a) suggest the presence of C, O, F, Sn, and Cu elements. Figure 5b shows the high-resolution XPS spectra of $\mathrm{C}$ 1s, the peaks at $284.8 \mathrm{eV}, 285.9 \mathrm{eV}$, and $288.6 \mathrm{eV}$ correspond 
to $\mathrm{C}-\mathrm{C}, \mathrm{C}-\mathrm{O}$, and $\mathrm{O}-\mathrm{C}=\mathrm{O}$, respectively [34]. The XPS spectrum of $\mathrm{O}$ 1s (Figure 5c) exhibits two fitted peaks located at $531.1 \mathrm{eV}$ and $532.2 \mathrm{eV}$, which are assigned to $\mathrm{Sn}-\mathrm{O}$ and C-O. The XPS spectrum of Sn $3 d$ (Figure $5 d$ ) shows two peaks attributed to $S n 3 d_{5 / 2}$ and $S n 3 d_{3 / 2}$. The first signal peak can be fitted into two peaks at $486.9 \mathrm{eV}$ and $487.4 \mathrm{eV}$, which can be ascribed to $\mathrm{Sn}-\mathrm{O}$ and $\mathrm{Sn}-\mathrm{F}$, respectively. The F $1 \mathrm{~s}$ spectrum (Figure S3) exhibits only one major peak, which is assigned to F-Sn bond [14,35]. As shown in Figure $5 \mathrm{f}$, the characteristic peaks of $\mathrm{Cu} 2 \mathrm{p}$ at $932.5 \mathrm{eV}$ and $952.6 \mathrm{eV}$ correspond to the binding energy of $\mathrm{Cu} 2 \mathrm{p}_{3 / 2}$ and $\mathrm{Cu} 2 \mathrm{p}_{1 / 2}$, respectively. The characteristic satellite peaks are not observed, suggesting that the high value state of $\mathrm{Cu}^{2+}$ is inexistence. Giving that the XPS spectra of $\mathrm{Cu} 2 \mathrm{p}$ is not able to distinguishing $\mathrm{Cu}^{+}$or $\mathrm{Cu}^{0}, \mathrm{Cu} 2 \mathrm{p}$ Auger electron spectroscopy (AES) was carried out by XPS. As illustrated in Figure $5 f$, the only peak at $918.6 \mathrm{eV}$ is assigned to $\mathrm{Cu}^{0}$ rather than $\mathrm{Cu}^{+}$, which is accordance with the result of the XRD analysis $[15,25,27]$. The abovementioned results show that the $\mathrm{Cu}^{2+}$ species are fully reduced to $\mathrm{Cu}^{0}$ rather than $\mathrm{Cu}^{+}$, which is consistent with the results of the XRD and Raman analysis.
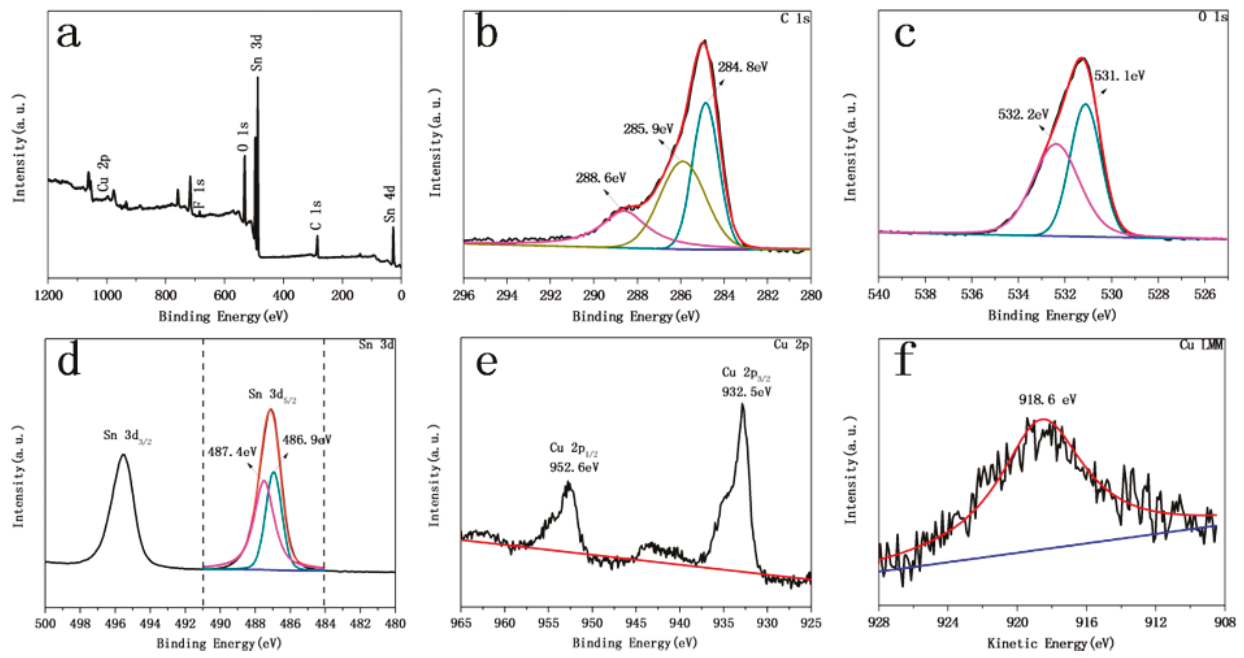

Figure 5. XPS (X-ray photoelectron spectroscopy) spectra of 19.2\% Cu/FTO sample. (a) Survey spectra; (b) C 1s; (c) O 1s; (d) Sn 3d; (e) Cu 2p; and (f) Cu 2p AES (Auger electron spectroscopy).

\subsection{Optical and Photoelectrochemical Properties}

To investigate the optical property of pure $\mathrm{SnO}_{2}, \mathrm{FTO}$, and $\mathrm{Cu} / \mathrm{FTO}$ samples, UV-VIS diffuse reflectance spectra was carried out. As displayed in Figure S4a, pure $\mathrm{SnO}_{2}$ has a limited visible light absorption for itself because of its intrinsic band gap. However, after doping F ions, FTO exhibits strong absorption in the visible light range, which is beneficial for enhancing the $\mathrm{H}_{2}$ evolution under visible light irradiation.

The optical band gap of semiconductors was determined by the Tauc equation [36]:

$$
(\alpha \mathrm{hv})^{\mathrm{n}}=\mathrm{A}\left(\mathrm{hv}-\mathrm{E}_{\mathrm{g}}\right)
$$

where $\alpha$ is the absorption coefficient, hv is the photon energy, $\mathrm{A}$ and $\mathrm{n}$ are constant, $\mathrm{E}_{\mathrm{g}}$ is the optical band energy. The value of $\mathrm{n}$ is 0.5 and 2 for the indirect and direct band gap, respectively [37]. The $\mathrm{E}_{\mathrm{g}}$ was calculated by the intercept of the extrapolated linear part of the curve with the energy axis. As presented in Figure S4b, the value of $\mathrm{n}$ is 2 and the band gap values of pure $\mathrm{SnO}_{2}$ and FTO are $3.51 \mathrm{eV}$ and $2.26 \mathrm{eV}$, respectively. As depicted in Figure 6, after the introduction of $\mathrm{Cu}$, the absorption 
intensity of $\mathrm{Cu}$ /FTO samples is improved greatly in the visible light region. Furthermore, the 19.2\% $\mathrm{Cu} / \mathrm{FTO}$ sample exhibits the best absorption in the visible light region.

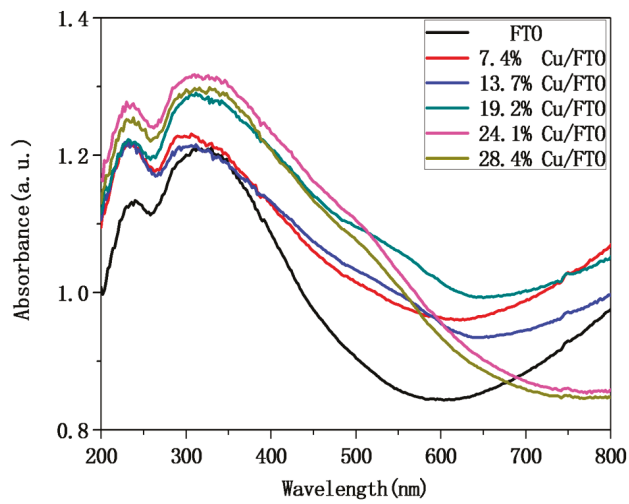

Figure 6. UV-VIS DRS (UV-visible diffuse-reflectance spectrum) of FTO and Cu/FTO samples.

To study the interaction between $\mathrm{Cu}$ NPs and FTO, we performed photoluminescence (PL) spectra and the results are presented in Figure 7. As displayed, all the samples of FTO and Cu/FTO exhibit a similar emission spectra shape with different intensities. The FTO shows the highest emission peak attributed to its higher recombination of the photogenerated electron-hole pairs. The emission intensity decreases with the introduction of $\mathrm{Cu}$, indicating that the recombination of photogenerated electron-hole pairs is restrained in the $\mathrm{Cu} / \mathrm{FTO}$. This phenomenon could be due to the fast transfer of electrons from the FTO to the $\mathrm{Cu}$ and this could enhance the photocatalytic activity. Especially, the $19.2 \% \mathrm{Cu} / \mathrm{FTO}$ sample has the lowest emission intensity, suggesting that it may have the optimal content of $\mathrm{Cu}$ to inhibit carrier recombination, and this is consistent with the result of the photocatalytic $\mathrm{H}_{2}$ evolution experiment. Due to the lower charge's recombination, more electrons will participate in photacatalytic reaction and, thus, enhance photocatalytic $\mathrm{H}_{2}$ evolution. However, when further increasing the content of $\mathrm{Cu}$, the $\mathrm{Cu} / \mathrm{FTO}$ samples exhibit an increase tendency in emission intensity. The reason may be that the introduction of excessive $\mathrm{Cu}$ results in serious agglomeration, which could inhibit the fast migration of electrons [11].

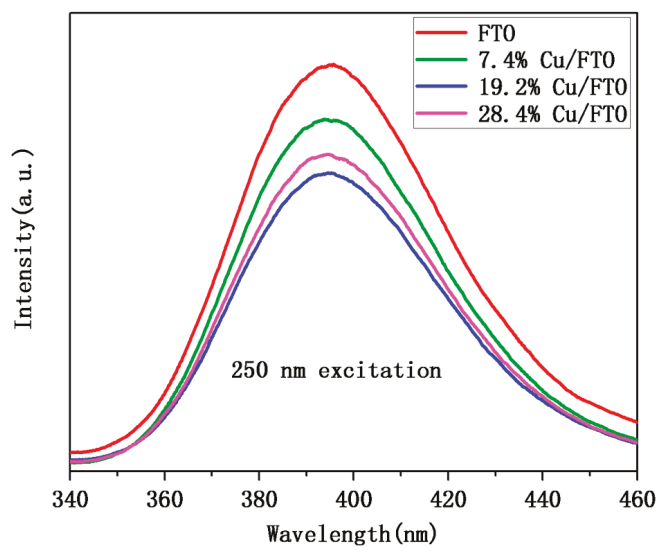

Figure 7. PL (photoluminescence) spectra of FTO and $\mathrm{Cu} /$ FTO samples with different contents of $\mathrm{Cu}$. 
As we know, the photocurrent test of semiconductors can be used to evaluate the separation and transfer efficiency of photogenerated electron-hole pairs. Figure 8a shows the transient photocurrent response of FTO and $\mathrm{Cu} /$ FTO film electrodes for six on-off cycles under visible light irradiation. Upon light irradiation, the photocurrent response appears in all FTO and $\mathrm{Cu}$ /FTO samples, but when the light is turned off, the value of the photocurrent decreases quickly to zero, which is reproducible in the six on-off cycles. The Cu/FTO samples show higher photocurrent density than that of FTO, indicating that there is less carrier recombination and much faster transfer of charges due to the intense surface interaction between $\mathrm{Cu}$ and FTO. Moreover, the 19.2\% Cu/FTO sample exhibits the highest photocurrent density and the value is about 4.5 times as high as that of bare FTO. All these results evidently indicate the separation efficiency and transfer of the photogenerated electron-hole pairs are enhanced significantly by the introduction of $\mathrm{Cu}$.

In order to further investigate the charge transfer capability, the EIS (electrochemical impedance spectra) Nyquist plots of both FTO and Cu/FTO samples were obtained and presented in Figure $8 \mathrm{~b}$. Generally, the smaller the diameter is, the lower charge transfer resistance and the faster interface charge transfer are. Compared with FTO, the $\mathrm{Cu}$ /FTO samples show smaller diameter, indicating that the introduction of $\mathrm{Cu}$ can diminish the impedance. Furthermore, the $19.2 \% \mathrm{Cu} / \mathrm{FTO}$ sample shows the smallest diameter due to its lower impedance. This result is consistent with that received by the photocurrent analysis.
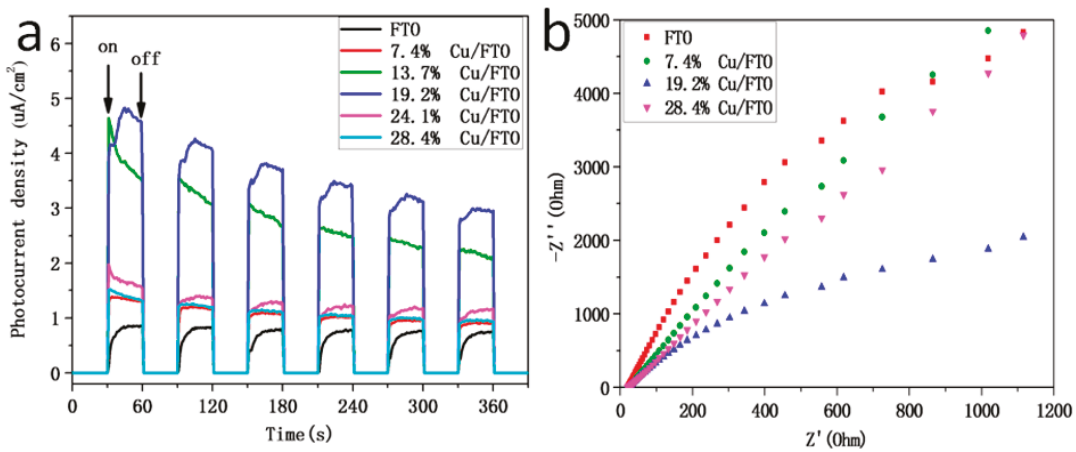

Figure 8. (a) The transient photocurrent of FTO and $\mathrm{Cu} / \mathrm{FTO}$ samples with different contents of $\mathrm{Cu}$ and (b) EIS (electrochemical impedance spectra) Nyquist plots of FTO and Cu/FTO samples with different contents of $\mathrm{Cu}$ under visible light irradiation.

\subsection{Photocatalytic Hydrogen Evolution}

The photocatalytic hydrogen evolution of samples is evaluated under visible light irradiation with lactic acid as the sacrificial agent. There is no $\mathrm{H}_{2}$ evolution of all samples to be detected without light irradiation, suggesting that $\mathrm{H}_{2}$ evolution arises from photocatalytic reactions.

On one hand, when the content of $\mathrm{Cu}$ is $19.2 \%$, we performed a series of photocatalytic $\mathrm{H}_{2}$ evolution experiments under visible light irradiation to determine the optimal content of F. Figure 9 shows photocatalytic $\mathrm{H}_{2}$ evolution rates of $19.2 \% \mathrm{Cu} / \mathrm{SnO}_{2}$ and $19.2 \% \mathrm{Cu} / \mathrm{FTO}$ with different $\mathrm{Sn} / \mathrm{F}$ molar ratios under visible light irradiation. Compared with $19.2 \% \mathrm{Cu} / \mathrm{SnO}_{2}$, all the $19.2 \% \mathrm{Cu} / \mathrm{FTO}$ samples with different $\mathrm{Sn} / \mathrm{F}$ molar ratios exhibit higher photocatalytic activity of $\mathrm{H}_{2}$ evolution. Moreover, when the Sn/F molar ratios is $10: 5$, the $19.2 \% \mathrm{Cu} / \mathrm{FTO}$ sample achieves the highest photocatalytic $\mathrm{H}_{2}$ evolution rate $\left(11.22 \mu \mathrm{mol} \mathrm{h}^{-1}\right)$, which could be ascribed to the appropriate band gap and fewer defect sites of FTO $(\mathrm{Sn} / \mathrm{F}=10: 5)$ than other FTO samples [37]. 


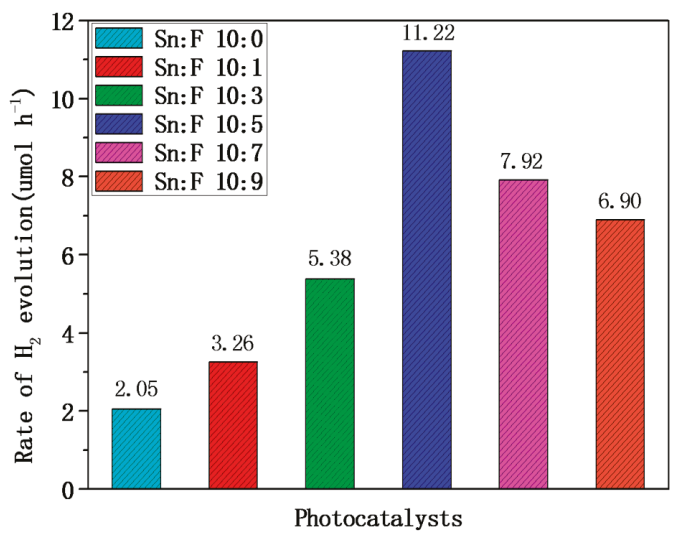

Figure 9. Photocatalytic $\mathrm{H}_{2}$ evolution rates of $19.2 \% \mathrm{Cu} / \mathrm{SnO}_{2}$ and $19.2 \% \mathrm{Cu} / \mathrm{FTO}$ samples with different Sn/F molar ratios under visible light irradiation.

On the other hand, when the Sn/F molar ratio is 10:5, we performed a series of photocatalytic $\mathrm{H}_{2}$ evolution experiments under visible light irradiation to determine the optimal content of $\mathrm{Cu}$ in the $\mathrm{Cu} /$ FTO samples and the results were shown in Figure 10. The bare FTO sample does not show any photocatalytic activity of $\mathrm{H}_{2}$ evolution, which may be due to the fast recombination of photoinduced electron-hole pairs. However, after the introduction of $\mathrm{Cu}$, the $\mathrm{Cu}$ /FTO samples exhibit excellent photocatalytic activity of $\mathrm{H}_{2}$ evolution. The $\mathrm{H}_{2}$ evolution rate of $\mathrm{Cu} / \mathrm{FTO}$ samples increases with the content of $\mathrm{Cu}$ and the highest photocatalytic $\mathrm{H}_{2}$ evolution rate is up to $11.22 \mu \mathrm{mol} \cdot \mathrm{h}^{-1}$ when the content of $\mathrm{Cu}$ is $19.2 \mathrm{wt} \%$ for FTO. However, when the content of $\mathrm{Cu}$ reach $19.2 \%$, the $\mathrm{H}_{2}$ evolution rate of $\mathrm{Cu} / \mathrm{FTO}$ decreases with further increasing content of $\mathrm{Cu}$. The results suggest the appropriate content of $\mathrm{Cu}$ can enhance photocatalytic activity because of the high absorption of light and the faster transfer of electrons. However, the introduction of excessive $\mathrm{Cu}$ may aggregate together and become new recombination centers of photogenerated electron-hole pairs, which could inhibit the photocatalytic activity of $\mathrm{H}_{2}$ evolution [38]. This result is consistent with the result of the PL spectra (Figure 7).

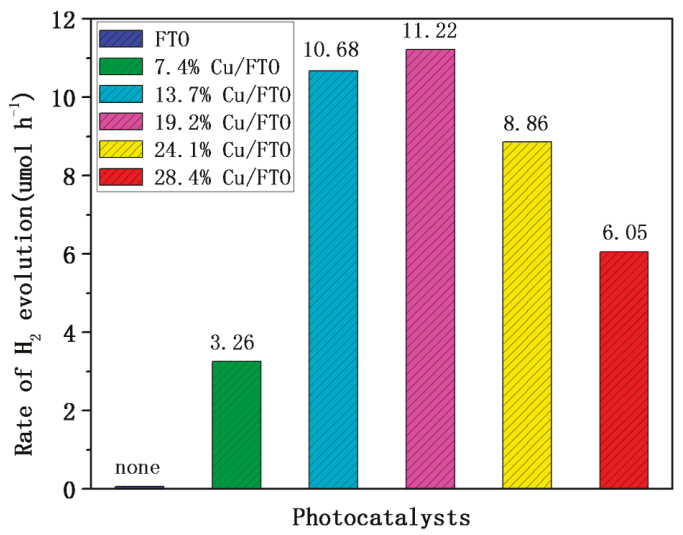

Figure 10. Photocatalytic $\mathrm{H}_{2}$ evolution rate of FTO $(\mathrm{Sn} / \mathrm{F}=10 / 5)$ and $\mathrm{Cu} / \mathrm{FTO}(\mathrm{Sn} / \mathrm{F}=10 / 5)$ with different contents of $\mathrm{Cu}$. 
Considering practical applications, the representative $19.2 \% \mathrm{Cu} / \mathrm{FTO}$ sample was selected to investigate the recycling and stability of $\mathrm{Cu}$ /FTO samples. As shown in Figure 11, the recycling photocatalytic test was carried out for six runs under the same condition. The photocatalytic $\mathrm{H}_{2}$ evolution of the sample is steady for six repeated runs under visible light irradiation, suggesting that the as-prepared $\mathrm{Cu} / \mathrm{FTO}$ samples have excellent stability and repeatability. Furthermore, no obvious change of XRD patterns (Figure S5) before and after the stability test is observed, indicating the photocatalysts have good stability during photocatalytic $\mathrm{H}_{2}$ evolution [34].

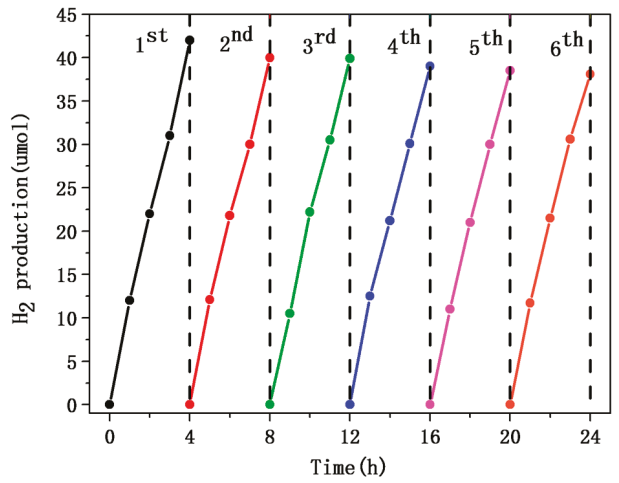

Figure 11. Recycling test of as-prepared $19.2 \% \mathrm{Cu} / \mathrm{FTO}(\mathrm{Sn} / \mathrm{F}=10 / 5)$ under visible light irradiation for $\mathrm{H}_{2}$ evolution (irradiation time $=24 \mathrm{~h}$ ).

\subsection{Mechanism}

On the basis of all the above results and discussions, the proposed schematic mechanism of photocatalytic $\mathrm{H}_{2}$ evolution of $\mathrm{Cu} /$ FTO photocatalyst is illustrated in Figure 12. Upon visible light irradiation, the electrons $\left(\mathrm{e}^{-}\right)$of the valence band (VB) can be excited to the conduction band (CB) and the holes $\left(\mathrm{h}^{+}\right)$remain in the valence band (VB). Due to the fast recombination of photogenerated electron-hole pairs, the photocatalytic activity of naked FTO is very low. However, after the introduction of $\mathrm{Cu}$ NPs, the recombination of photogenerated electron-hole pairs is greatly inhibited. Due to the existence of trapping centers ( $\mathrm{Cu} \mathrm{NPs})$, the electrons $\left(\mathrm{e}^{-}\right)$from the conduction band (CB) are tend to transfer quickly to $\mathrm{Cu} N P s$ and then react with $\mathrm{H}^{+}$for $\mathrm{H}_{2}$ more easily. Meanwhile, the holes $\left(\mathrm{h}^{+}\right)$are consumed by the sacrificial reagents (lactic acid). Thereby, the as-prepared $\mathrm{Cu} /$ FTO photocatalyst is beneficial for photocatalytic $\mathrm{H}_{2}$ evolution.

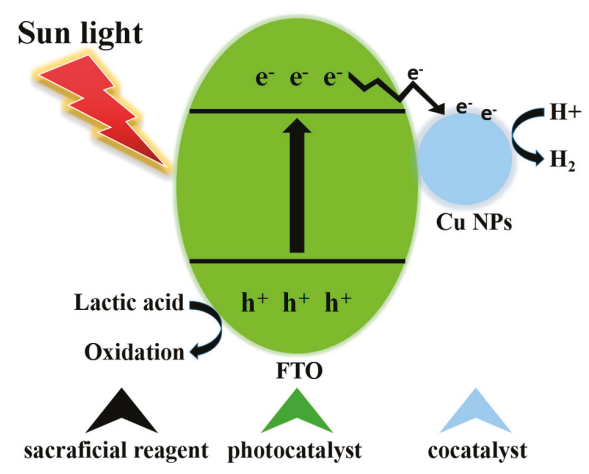

Figure 12. Schematic mechanism for photocatalytic $\mathrm{H}_{2}$ evolution on the $\mathrm{Cu} / \mathrm{FTO}$ system. 


\section{Materials and Methods}

\subsection{Materials}

All the chemical reagents and solvents were analytical grade and used without further purification. Deionized water was supplied by a Millipore Milli-Q system (Millipore, Suzhou, China). Copper acetate hydrate $\left(\mathrm{Cu}\left(\mathrm{CH}_{3} \mathrm{COO}\right)_{2} \cdot \mathrm{H}_{2} \mathrm{O}, \geq 99.0 \%\right)$, tin chloride dehydrate $\left(\mathrm{SnCl}_{2} \cdot 2 \mathrm{H}_{2} \mathrm{O}, \geq 98.0 \%\right)$, hydrofluoric acid $(\mathrm{HF}, \geq 40 \%)$, ammonium hydroxide $\left(\mathrm{NH}_{3} \cdot \mathrm{H}_{2} \mathrm{O}, \geq 25 \%\right)$, lactic acid $\left(\mathrm{C}_{3} \mathrm{H}_{6} \mathrm{O}_{3}, \geq 97.0 \%\right)$ and glucose $\left(\mathrm{C}_{6} \mathrm{H}_{12} \mathrm{O}_{6}, \geq 98.0 \%\right)$ were purchased from Sinopharm Chemical Reagent Co. Ltd. (Dalian, China).

\subsection{Synthesis of FTO Nanopowders}

A typical synthesis process is as following. Firstly, $15 \mathrm{~g}$ of tin chloride dehydrate $\left(\mathrm{SnCl}_{2} \cdot 2 \mathrm{H}_{2} \mathrm{O}\right)$ was dissolved in $10 \mathrm{~mL}$ of deionized water and then ammonium hydroxide $\left(\mathrm{NH}_{3} \cdot \mathrm{H}_{2} \mathrm{O}\right)$ was added dropwise into the solution under vigorous stirring until the $\mathrm{pH}$ value of the solution was up to 7 . The solution was centrifuged at $9000 \mathrm{rpm}$ to obtain the precipitation and the precipitation was washed three times with deionized water. Secondly, a certain amount of hydrofluoric acid (HF) was slowly dropped into the precipitation under vigorous stirring and obtained the sol mixture. Then the sol mixture was dried in a drying oven at $200{ }^{\circ} \mathrm{C}$ for $4 \mathrm{~h}$ and the gel mixture obtained. Finally, the gel mixture was calcined at $450{ }^{\circ} \mathrm{C}$ for $2 \mathrm{~h}$ under air in a muffle furnace and subsequently ground into fine nanopowders. Similarly, The FTO nanopowders with different Sn/F molar ratios (10:0, 10:1, 10:3, 10:5, 10:7, 10:9) were synthesized by following the same method. The Sn/F molar ratios (10:0, 10:1, 10:3, 10:5, $10: 7,10: 9)$ are theoretical values calculated by the precursor ratios. If there is no special instructions in the paper, the $\mathrm{Sn} / \mathrm{F}$ molar ratio of FTO is 10:5.

\subsection{Synthesis of Cu/FTO Nanocomposites}

In a typical synthesis process, $10 \mathrm{~mL}$ of deionized water, $15 \mathrm{~mL}$ of copper acetate $(0.2 \mathrm{M}$ $\left.\mathrm{Cu}\left(\mathrm{CH}_{3} \mathrm{COO}\right)_{2}\right), 1.2 \mathrm{~g}$ of glucose $\left(\mathrm{C}_{6} \mathrm{H}_{12} \mathrm{O}_{6}\right)$ and $800 \mathrm{mg}$ of FTO nanopowders were mixed together to form a homogeneous suspension by sonicating for $30 \mathrm{~min}$. Then the suspension was transferred to a Teflon-lined autoclave (SX2-12-10Q, Suzhou Jiangdong Precision Instrument Co. Ltd., Shanghai, China) and heated at $120{ }^{\circ} \mathrm{C}$ for $12 \mathrm{~h}$. Finally, the resulting solution was centrifuged to obtain the solid product. The solid product was washed three times by deionized water and ethanol, respectively. The obtained product was dried in a vacuum drying oven at $50{ }^{\circ} \mathrm{C}$ for $5 \mathrm{~h}$. The $\mathrm{Cu} / \mathrm{FTO}$ nanocomposites with different contents of $\mathrm{Cu}(0 \%, 7.4 \%, 13.7 \%, 19.2 \%, 24.1 \%, 28.4 \%)$ were prepared by following the same method. Cu wt \% (0\%, 7.4\%, 13.7\%, 19.2\%, 24.1\%, 28.4\%) is the theoretical value calculated by the precursor ratios.

\subsection{Characterization}

The crystalline structure of the samples was characterized by using D8 Advantage X-ray diffraction (XRD, Bruker, Beijing, China) with $\mathrm{Cu} \mathrm{K} \alpha$ radiation. Fourier transform infrared spectroscopy (FTIR) was recorded in the wave number range from $400 \mathrm{~cm}^{-1}$ to $4000 \mathrm{~cm}^{-1}$ by a FTIR spectrometer (Nicolet 670, Bruker, Beijing, China). The morphology of the samples was characterized by scanning electron microscopy (Merlin, Zeiss, Beijing, China). Transmission electron microscopy (TEM) test was conducted by an electron microscope (JEOL, JEM-2100, Bruker, Beijing, China) equipped with energy dispersive X-ray (EDX) spectrometer. X-ray photoelectron spectroscopy (XPS) was recorded on a Kratos Axis-Ultra DLD (Axis Ultra DLD, Bruker, Beijing, China). UV-VIS diffuse reflectance absorption spectra were obtained by a Hitachi U-3010 spectrophotometer (Shimadzu, Beijing, China). The photoluminescence spectra (PL) was conducted on a Hitachi F-4500 fluorescence spectrophotometer (Shimadzu, Beijing, China). Raman spectra were obtained by Laser Confocal Raman Microscopy system (LabRAM Aramis, H.J.Y, Beijing, China). The photocurrents and electrochemical impedance spectra (EIS) were recorded on an electrochemical workstation (CHI660C, CH Instruments, Inc., Beijing, China). 


\subsection{Photocatalytic Hydrogen Evolution Experiment}

The photocatalytic experiment was performed by using a Xe lamp with an ultraviolet cut-off filter (PLS-SXE300CUV, Perfect light Co. Ltd., Beijing, China) $(\lambda>420 \mathrm{~nm})$ as a light source in a quartz reaction cell, which was connected to a closed gas circulation. Based on our previous research, the as-synthesized photocatalyst $(50 \mathrm{mg})$, lactic acid $(10 \mathrm{~mL})$, and water $(60 \mathrm{~mL})$ were mixed together by constant magnetic stirring (85-2, Gongyi yuhua Instrument Co. Ltd., Zhengzhou, China) to form a homogeneous suspension. The solution was evacuated with $\mathrm{N}_{2}$ before every photocatalytic reaction. The evolved $\mathrm{H}_{2}$ under irradiation was analyzed by online gas chromatography (GC-7900, Tianmei Co. Ltd., Beijing, China) with a thermal conductivity detector (TCD).

\subsection{Photoelectrochemical Measurements}

Electrochemical measurements were performed by using an electrochemical workstation (CHI660C Instruments, Shanghai, China). FTO and Cu/FTO electrodes served as the working electrode, platinum wire was used as the counter electrode, and $\mathrm{Ag} / \mathrm{AgCl}$ as the reference electrode. The $0.5 \mathrm{M}$ $\mathrm{Na}_{2} \mathrm{SO}_{4}$ aqueous solution served as the electrolyte and a $300 \mathrm{~W}$ Xe lamp was used as the light source. The working electrode was prepared as follows: $0.1 \mathrm{~g}$ of as-synthesized catalyst was dispersed in $1 \mathrm{~mL}$ of ethanol solution by sonication to get slurry. Then the slurry was spread onto the cleaned ITO glass and the as-prepared electrolyte was dried at $323 \mathrm{~K}$ for $4 \mathrm{~h}$ under vacuum.

\section{Conclusions}

In summary, we prepared a series of FTO nanopowders with different Sn/F molar ratios by a typical sol-gel method and then they were modified with different contents of $\mathrm{Cu}$ via a facile hydrothermal method. Compared with pure $\mathrm{SnO}_{2}$, the fluorine-doped tin oxide (FTO) exhibits stronger absorption in the visible light range, but it does not show any photocatalytic activity for $\mathrm{H}_{2}$ evolution because of the fast recombination of photogenerated electron-hole pairs. However, after the introduction of $\mathrm{Cu}$, the $\mathrm{Cu} / \mathrm{FTO}$ nanocomposites show excellent photocatalytic activity for $\mathrm{H}_{2}$ evolution. When the loading content of $\mathrm{Cu}$ is $19.2 \mathrm{wt} \%$ for FTO, the highest $\mathrm{H}_{2}$ evolution rate is up to $11.22 \mu \mathrm{mol} \mathrm{h}{ }^{-1}$ under visible light irradiation. The photocatalysts exhibit excellent stability and repeatability for $\mathrm{H}_{2}$ evolution. Moreover, the introduction of $\mathrm{Cu}$ could greatly promote the separation and transfer efficiency of the photogenerated electron-hole pairs and, thus, can enhance photocatalytic $\mathrm{H}_{2}$ evolution. This work provides an insight for developing effective photocatalysts, which could be used for the conversion of solar energy to new energy sources.

Supplementary Materials: The following are available online at www.mdpi.com/2073-4344/7/12/385/s1, Figure S1. Raman spectra of FTO and 19.2\% Cu/FTO. Figure S2. TEM (a) and HRTEM (b) of as-prepared $19.2 \% \mathrm{Cu} /$ FTO sample. Figure S3. F 1s spectra of 19.2\% Cu/FTO with XPS characterization. Figure S4. UV-VIS diffuse reflectance spectra (a) and optical band gap spectra (b) of pure $\mathrm{SnO}_{2}$ and FTO. Figure S5. XRD patterns of $19.2 \% \mathrm{Cu} / \mathrm{FTO}$ before and after the stability test of hydrogen evolution.

Acknowledgments: We gratefully acknowledge financial support from the National Natural Science Foundation of China (Nos. 21571064, 21371060) and the Fundamental Research Funds for the Central Universities (No. 2015ZM162).

Author Contributions: Heping Zeng and Hui Liu conceived and designed the experiments; Hui Liu performed the experiments; Hui Liu, An Wang, Quan Sun and Tingting Wang analyzed the data; Hui Liu wrote the paper.

Conflicts of Interest: The authors declare no conflict of interest.

\section{References}

1. Wang, Y.; Wang, Q.; Zhan, X.; Wang, F.; Safdar, M.; He, J. Visible light driven type II heterostructures and their enhanced photocatalysis properties: A review. Nanoscale 2013, 5, 8326-8339. [CrossRef] [PubMed]

2. Jafari, T.; Moharreri, E.; Amin, A.; Miao, R.; Song, W.Q.; Suib, S. Photocatalytic Water Splitting-The Untamed Dream: A Review of Recent Advances. Molecules 2016, 21, 900. [CrossRef] [PubMed] 
3. Huo, J.P.; Zeng, H.P. A novel triphenylamine functionalized bithiazole-metal complex with $\mathrm{C}_{60}$ for photocatalytic hydrogen production under visible light irradiation. J. Mater. Chem. A 2015, 3, 6258-6264. [CrossRef]

4. Fujishima, A.; Honda, K. Photolysis-decomposition of water at the surface of an irradiated semiconductor. Nature 1972, 238, 37-38. [CrossRef] [PubMed]

5. Huo, J.P.; Fang, L.T.; Lei, Y.L.; Zeng, G.C.; Zeng, H.P. Facile preparation of yttrium and aluminum co-doped $\mathrm{ZnO}$ via a sol-gel route for photocatalytic hydrogen production. J. Mater. Chem. A 2014, 2, 11040-11044. [CrossRef]

6. Qin, J.Y.; Huo, J.P.; Zhang, P.Y.; Zeng, J.; Wang, T.T.; Zeng, H.P. Improving the photocatalytic hydrogen production of $\mathrm{Ag} / \mathrm{g}-\mathrm{C}_{3} \mathrm{~N}_{4}$ nanocomposites by dye-sensitization under visible light irradiation. Nanoscale 2016, 8, 2249-2259. [CrossRef] [PubMed]

7. Chen, Z.W.; Pan, D.Y.; Li, Z.; Jiao, Z.; Wu, M.H.; Shek, C.; Wu, C.M.L.; Lai, J.K.L. Recent Advances in Tin Dioxide Materials: Some Developments in Thin Films, Nanowires, and Nanorods. Chem. Rev. 2014, 114, 7442-7486. [CrossRef] [PubMed]

8. Khan, M.M.; Ansari, S.A.; Khan, M.E.; Ansari, M.O.; Min, B.K. Visible light-induced enhanced photoelectrochemical and photocatalytic studies of gold decorated $\mathrm{SnO}_{2}$ nanostructures. New J. Chem. 2015, 39, 2758-2766. [CrossRef]

9. Babu, B.; Kadam, A.N.; Ravikumar, R.; Chan, B. Enhanced visible light photocatalytic activity of Cu-doped $\mathrm{SnO}_{2}$ quantum dots by solution combustion synthesis. J. Alloys Compd. 2017, 703, 330-336. [CrossRef]

10. Ghimbeu, C.M.; Lumbreras, M.; Siadat, M.; van Landschoot, R.C.; Schoonman, J. Electrostatic sprayed $\mathrm{SnO}_{2}$ and $\mathrm{Cu}$-doped $\mathrm{SnO}_{2}$ films for $\mathrm{H}_{2} \mathrm{~S}$ detection. Sens. Actuators B Chem. 2008, 133, 694-698. [CrossRef]

11. Chandra, S.; George, G.; Ravichandran, K.; Thirumurugan, K. Influence of simultaneous cationic (Mn) and anionic (F) doping on the magnetic and certain other properties of $\mathrm{SnO}_{2}$ thin films. Surf. Interface 2017, 7, 39-46. [CrossRef]

12. Seema, H.; Christian, K.K.; Chandra, V.; Kim, K.S. Graphene-SnO 2 composites for highly efficient photocatalytic degradation of methylene blue under sunlight. Nanotechnology 2012, 23, 355705. [CrossRef] [PubMed]

13. Kent, C.A.; Concepcion, J.J.; Dares, C.J.; Torelli, D.A.; Rieth, A.J.; Miller, A.S.; Meyer, T.J. Water Oxidation and Oxygen Monitoring by Cobalt-Modified Fluorine-Doped Tin Oxide Electrodes. J. Am. Chem. Soc. 2013, 135, 8432-8435. [CrossRef] [PubMed]

14. Samad, W.Z.; Goto, M.; Kanda, H.; Nordin, N.; Liew, K.H.; Yarmo, M.A.; Yusop, M.R. Fluorine-doped tin oxide catalyst for glycerol conversion to methanol in sub-critical water. J. Supercrit. Fluids 2017, 120, 366-378. [CrossRef]

15. Zhang, P.Y.; Song, T.; Wang, T.T.; Zeng, H.P. In-situ synthesis of Cu nanoparticles hybridized with carbon quantum dots as a broad spectrum photocatalyst for improvement of photocatalytic $\mathrm{H}_{2}$ evolution. Appl. Catal. B Environ. 2017, 206, 328-335. [CrossRef]

16. He, W.; Kim, H.K.; Wamer, W.G.; Melka, D.; Callahan, J.H. Photogenerated Charge Carriers and Reactive Oxygen Species in ZnO/Au Hybrid Nanostructures with Enhanced Photocatalytic and Antibacterial Activity. J. Am. Chem. Soc. 2014, 136, 750-757. [CrossRef] [PubMed]

17. Logar, M.; Jancar, B.; Sturm, S.; Suvorov, D. Weak polyion multilayer-assisted in situ synthesis as a route toward a plasmonic $\mathrm{Ag} / \mathrm{TiO}_{2}$ photocatalyst. Langmuir 2010, 26, 12215-12224. [CrossRef] [PubMed]

18. Shiraishi, Y.; Kofuji, Y.; Kanazawa, S.; Sakamoto, H.; Ichikawa, S.; Tanaka, S.; Hirai, T. Platinum nanoparticles strongly associated with graphitic carbon nitride as efficient co-catalysts for photocatalytic hydrogen evolution under visible light. Chem. Commun. 2014, 50, 15255-15258. [CrossRef] [PubMed]

19. Zou, Y.L.; Kang, S.; Li, X.Q.; Qin, L.X.; Mu, J. $\mathrm{TiO}_{2}$ nanosheets loaded with Cu: A low-cost efficient photocatalytic system for hydrogen evolution from water. Int. J. Hydrog. Energy 2014, 39, 15403-15410. [CrossRef]

20. Han, C.; Yang, M.Q.; Zhang, N.; Xu, Y.J. Enhancing the visible light photocatalytic performance of ternary CdS-(graphene-Pd) nanocomposites via a facile interfacial mediator and co-catalyst strategy. J. Mater. Chem. A 2014, 2, 19156-19166. [CrossRef]

21. Liu, E.Z.; Qi, L.L.; Bian, J.J.; Chen, Y.H.; Hu, X.Y.; Fan, J.; Liu, H.C.; Zhu, C.J.; Wang, Q.P. A facile strategy to fabricate plasmonic $\mathrm{Cu}$ modified $\mathrm{TiO}_{2}$ nano-flower films for photocatalytic reduction of $\mathrm{CO}_{2}$ to methanol. Mater. Res. Bull. 2015, 68, 203-209. [CrossRef] 
22. Huo, J.P.; Zeng, H.P. Copper nanoparticles embedded in the triphenylamine functionalized bithiazole-metal complex as active photocatalysts for visible light-driven hydrogen evolution. J. Mater. Chem. A 2015, 3, 17201-17208. [CrossRef]

23. Yang, Y.; $\mathrm{Xu}, \mathrm{D}$;; $\mathrm{Wu}, \mathrm{Q}$. Y.; Diao, P. $\mathrm{Cu}_{2} \mathrm{O} / \mathrm{CuO}$ Bilayered Composite as a High-Efficiency Photocathode for Photoelectrochemical Hydrogen Evolution Reaction. Sci. Rep. 2016, 6, 35158. [CrossRef] [PubMed]

24. Liu, X.; Cui, S.S.; Sun, Z.J.; Du, P.W. Copper oxide nanomaterials synthesized from simple copper salts as active catalysts for electrocatalytic water oxidation. Electrochim. Acta 2015, 160, 202-208. [CrossRef]

25. Zhang, P.Y.; Wang, T.T.; Zeng, H.P. Design of $\mathrm{Cu}-\mathrm{Cu}_{2} \mathrm{O} / \mathrm{g}-\mathrm{C}_{3} \mathrm{~N}_{4}$ nanocomponent photocatalysts for hydrogen evolution under visible light irradiation using water-soluble Erythrosin B dye sensitization. Appl. Surf. Sci. 2017, 391, 404-414. [CrossRef]

26. Liu, H.Y.; Wang, T.T.; Zeng, H.P. CuNPs for Efficient Photocatalytic Hydrogen Evolution. Part. Part. Syst. Charact. 2015, 32, 869-873. [CrossRef]

27. Zheng, L.R.; Zheng, Y.H.; Chen, C.Q.; Zhan, Y.Y.; Lin, X.Y.; Zheng, Q.; Wei, K.M.; Zhu, J.F. Network Structured $\mathrm{SnO}_{2} / \mathrm{ZnO}$ Heterojunction Nanocatalyst with High Photocatalytic Activity. Inorg. Chem. 2009, 48, 1819-1825. [CrossRef] [PubMed]

28. Zhu, S.J.; Meng, Q.N.; Wang, L.; Zhang, J.H.; Song, Y.B.; Jin, H.; Zhang, K.; Sun, H.C.; Wang, H.Y.; Yang, B. Highly Photoluminescent Carbon Dots for Multicolor Patterning, Sensors, and Bioimaging. Angew. Chem. Int. Ed. 2013, 52, 3953-3957. [CrossRef] [PubMed]

29. Zhang, B.; Tian, Y.; Zhang, J.X.; Cai, W. The characterization of fluorine doped tin oxide films by Fourier Transformation Infrared spectrum. Appl. Phys. Lett. 2011, 98, 021906. [CrossRef]

30. Noor, N.; Parkin, I.P. Enhanced transparent-conducting fluorine-doped tin oxide films formed by Aerosol-Assisted Chemical Vapour Deposition. J. Mater. Chem. C 2013, 1, 984-996. [CrossRef]

31. Liu, E.; Kang, L.; Yang, Y.; Sun, T.; Hu, X. Plasmonic Ag deposited $\mathrm{TiO}_{2}$ nano-sheet film for enhanced photocatalytic hydrogen production by water splitting. Nanotechnology 2014, 25, 165401-165410. [CrossRef] [PubMed]

32. Deng, Y.L.; Handoko, A.D.; Do, Y.H.; Xi, S.B.; Yeo, B.S. In Situ Raman Spectroscopy of Copper and Copper Oxide Surfaces during Electrochemical Oxygen Evolution Reaction: Identification of $\mathrm{Cu}^{\mathrm{III}}$ Oxides as Catalytically Active Species. ACS Catal. 2016, 6, 2473-2481. [CrossRef]

33. Chen, X.; Zhou, B.; Yang, S.; Wu, H.; Wu, Y. In situ construction of an $\mathrm{SnO}_{2} / g-\mathrm{C}_{3} \mathrm{~N}_{4}$ heterojunction for enhanced visible-light photocatalytic activity. RSC Adv. 2015, 5, 68953-68963. [CrossRef]

34. Song, T.; Huo, J.P.; Liao, T.; Zeng, J.; Qin, J.Y.; Zeng, H.P. Fullerene $\left[\mathrm{C}_{60}\right]$ modified $\mathrm{Cr}_{2-\mathrm{x}} \mathrm{Fe}_{\mathrm{x}} \mathrm{O}_{3}$ nanocomposites for enhanced photocatalytic activity under visible light irradiation. Chem. Eng. J. 2016, 287, 359-366. [CrossRef]

35. Wu, S.S.; Yuan, S.; Shi, L.Y.; Zhao, Y.; Fang, J.H. Preparation, characterization and electrical properties of fluorine-doped tin dioxide nanocrystals. J. Colloid Interface Sci. 2010, 346, 12-16. [CrossRef] [PubMed]

36. Chu, D.M.; Zhang, C.Y.; Yang, P.; Du, Y.K.; Lu, C. WS 2 as an Effective Noble-Metal Free Cocatalyst Modified $\mathrm{TiSi}_{2}$ for Enhanced Photocatalytic Hydrogen Evolution under Visible Light Irradiation. Catalysts 2016, 6, 136. [CrossRef]

37. Yu, J.C.; Yu, J.G.; Ho, W.K.; Jiang, Z.T.; Zhang, L.Z. Effects of $\mathrm{F}^{-}$Doping on the Photocatalytic Activity and Microstructures of Nanocrystalline $\mathrm{TiO}_{2}$ Powders. Chem. Mater. 2002, 14, 3808-3816. [CrossRef]

38. Chao, Y.G.; Zheng, J.F.; Chen, J.Z.; Wang, Z.J.; Jia, S.P.; Zhang, H.X.; Zhu, Z.P. Highly efficient visible light-driven hydrogen production of precious metal-free hybrid photocatalyst: CdS@NiMoS core-shell nanorods. Catal. Sci. Technol. 2017, 7, 2798-2804. [CrossRef] 
Article

\title{
Synthesis, Characterization of Nanosized $\mathrm{ZnCr}_{2} \mathrm{O}_{4}$ and Its Photocatalytic Performance in the Degradation of Humic Acid from Drinking Water
}

\author{
Raluca Dumitru ${ }^{1, *}$, Florica Manea ${ }^{1}$, Cornelia Păcurariu ${ }^{1}$, Lavinia Lupa ${ }^{1}$, Aniela Pop ${ }^{1}$, \\ Adrian Cioablă ${ }^{2, *}$, Adrian Surdu ${ }^{3}$ and Adelina Ianculescu ${ }^{3}$ \\ 1 Faculty for Industrial Chemistry and Environmental Engineering, Politehnica University Timisoara, \\ Piata Victoriei No. 2, Timisoara 300006, Romania; florica.manea@upt.ro (F.M.); \\ cornelia.pacurariu@upt.ro (C.P.); lavinia.lupa@upt.ro (L.L.); aniela.pop@upt.ro (A.P.) \\ 2 Faculty of Mechanical Engineering, Politehnica University Timisoara, 1 Mihai Viteazu Blv., \\ Timisoara 300222, Romania \\ 3 Department of Oxide Materials Science and Engineering, Faculty of Applied Chemistry and Materials \\ Science, Polytehnic University of Bucharest, Gh. Polizu Street No.1-7, Bucharest 011061, Romania; \\ adrian.surdu@live.com (A.S.); a_ianculescu@yahoo.com (A.I.) \\ * Correspondence: ralucadumitru2002@yahoo.com (R.D.); adrian.cioabla@upt.ro (A.C.); \\ Tel.: +40-256-404-188 (R.D.)
}

Received: 31 March 2018; Accepted: 12 May 2018; Published: 15 May 2018

\begin{abstract}
Zinc chromite $\left(\mathrm{ZnCr}_{2} \mathrm{O}_{4}\right)$ has been synthesized by the thermolysis of a new $\mathrm{Zn}$ (II)-Cr(III) oxalate coordination compound, namely $\left[\mathrm{Cr}_{2} \mathrm{Zn}\left(\mathrm{C}_{2} \mathrm{O}_{4}\right)_{4}\left(\mathrm{OH}_{2}\right)_{6}\right] \cdot 4 \mathrm{H}_{2} \mathrm{O}$. The coordination compound has been characterized by chemical analysis, infrared spectroscopy (IR), and thermal analysis. The zinc chromite obtained after a heating treatment of the coordination compound at $450{ }^{\circ} \mathrm{C}$ for $1 \mathrm{~h}$ has been investigated by XRD, FE-SEM, TEM/HR-TEM coupled with selected area electron diffraction (SAED) measurements. The photocatalytic performance of nanosized zinc chromite was assessed for the degradation and mineralization of humic acid (HA) from a drinking water source, envisaging the development of the advanced oxidation process for drinking water treatment technology. A mineralization efficiency of $60 \%$ was achieved after $180 \mathrm{~min}$ of $50 \mathrm{mg} \mathrm{L}^{-1}$ HA photocatalysis using zinc chromite under UV irradiation, in comparison with $7 \%$ efficiency reached by photolysis.
\end{abstract}

Keywords: zinc chromite; photocatalysis activity; oxalate; humic acid

\section{Introduction}

Zinc chromite $\left(\mathrm{ZnCr}_{2} \mathrm{O}_{4}\right)$, a mixed oxide that exhibits a normal spinel structure and crystallizes in the cubic system, has attracted considerable interest in material science, due to its physical-chemical properties suitable for various applications. Many applications of the nanocrystalline $\mathrm{ZnCr}_{2} \mathrm{O}_{4}$ spinel have been reported, e.g., as catalytic material for a variety of reactions [1-3], a photocatalyst [4-7], a sensor for toxic gases [8], and for humidity [9,10].

The solid state reactions that consist of the mixing of oxides or carbonates, followed by calcination and grinding, are considered the most general method for preparing spinel [11-13]. A higher temperature of calcination $\left(>1000{ }^{\circ} \mathrm{C}\right)$ is needed for the reactions' completion, which leads to the obtaining of spinel powder with a small surface area $[14,15]$. Various synthesis methods, such as co-precipitation [16,17], sol-gel [6,18], thermolysis of polymer-metal complex [19], microwave [14,20], and hydrothermal methods $[15,21,22]$ have been investigated in order to obtain spinel powders with higher specific surface areas. Among all these methods, the most efficient one, which considers the lack of stoichiometry control and allows the formation of homogeneous nanoparticles with very good 
properties for catalytic and photocatalytic usage, is considered to be synthesis at a low temperature, starting from different precursors [23-25].

In recent years, photocatalytic oxidation as an advanced oxidation process with semiconducting materials has been studied for both water and wastewater treatment. The most studied research has considered $\mathrm{TiO}_{2}$-based materials [26-28], and recently, cromite-type materials have raised a high interest due to their certain peculiarities for photocatalysis applications, e.g., small band-gap energy and chemical stability [29,30]. $\mathrm{ZnCr}_{2} \mathrm{O}_{4}$ is considered a very important spinel compound, due to its potential application as an efficient catalyst, and its photocatalytic activity has been reported for the removal of organic dyes from wastewaters [6,31].

The goal of this research is to obtain nanosized $\mathrm{ZnCr}_{2} \mathrm{O}_{4}$ through this new and efficient method, based on the thermal conversion at $450{ }^{\circ} \mathrm{C}$ of the $\left[\mathrm{Cr}_{2} \mathrm{Zn}\left(\mathrm{C}_{2} \mathrm{O}_{4}\right)_{4}\left(\mathrm{OH}_{2}\right)_{6}\right] \cdot 4 \mathrm{H}_{2} \mathrm{O}$ precursor, and to study the compound's photocatalytic activity during the removal process of humic acid from drinking waters. This proposed method of zinc chromite spinel synthesis exhibits the advantages of a short reaction time, low reaction temperatures, no by-product generation, environmentally friendliness, and the ability to be easily scaled up due to its simplicity and low costs, compared to the conventional methods. The catalytic activity of synthesized $\mathrm{ZnCr}_{2} \mathrm{O}_{4}$ was studied under UV irradiation for colour removal, degradation, and the mineralization of humic acids from water. Humic acids are considered to be the main component of natural organic matters (NOMs) from drinking water sources, which should be eliminated due to their potential toxicity and carcinogeneous character in particular, during the disinfection step. The photocatalytic study was conducted in comparison with the photolysis process, and considered a prior sorption step before photocatalysis to assess the contribution of each process.

\section{Results and Discussion}

\subsection{Synthesis and Characterization of the $\mathrm{Cr}^{3+}-\mathrm{Zn}^{2+}$ Coordination Compound}

The synthetic route developed for the synthesis of the coordination compound precursor is based on the redox reaction between 1,2-ethanediol and a nitrate ion in the presence of nitric acid (2M):

$$
\begin{gathered}
12 \mathrm{C}_{2} \mathrm{H}_{4}(\mathrm{OH})_{2}+6\left(\left[\mathrm{Cr}\left(\mathrm{OH}_{2}\right)_{6}\right]^{3+}+3 \mathrm{NO}_{3}^{-}\right)+3\left(\left[\mathrm{Zn}\left(\mathrm{OH}_{2}\right)_{6}\right]^{2+}+2 \mathrm{NO}_{3}^{-}\right)+8\left(\mathrm{H}^{+}+\mathrm{NO}_{3}^{-}\right) \\
\left.\stackrel{\Delta t^{\circ}}{\longrightarrow} 3 \mathrm{Cr}_{2} \mathrm{Zn}\left(\mathrm{C}_{2} \mathrm{O}_{4}\right)_{4}\left(\mathrm{OH}_{2}\right)_{6}\right] \cdot 4 \mathrm{H}_{2} \mathrm{O}_{(\mathrm{s})}+32 \mathrm{NO}_{(\mathrm{g})}+76 \mathrm{H}_{2} \mathrm{O}_{(\mathrm{g})}
\end{gathered}
$$

The IR spectrum of the oxalate precursor (Figure 1a and Table S1 Electronic Supplementary

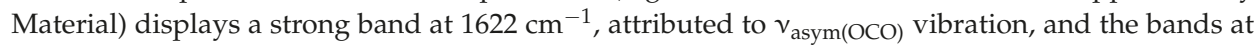
$1391 \mathrm{~cm}^{-1}$ and $910 \mathrm{~cm}^{-1}$ attributed to $v_{\text {sym(OCO) }}$ confirm that the ligand acts as a bidentate $[32,33]$.

The strong band at $1719 \mathrm{~cm}^{-1}$, assigned to the $v_{\text {asym }(\mathrm{O}=\mathrm{C}-\mathrm{O})}$ vibration, as well as the band at

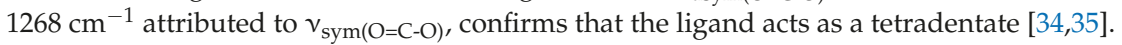

The broad and intense band with the maximum at $3565 \mathrm{~cm}^{-1}$ assigned to vibration $v_{(\mathrm{OH})}$ confirms the presence of water in the $\mathrm{Cr}(\mathrm{III})-\mathrm{Zn}(\mathrm{II})$ oxalate [34-36].

The IR spectrum of the ligand (Figure 1b and Table S2 Electronic Supplementary Material) is similar to the one reported by the literature for oxalic acid [33].

The thermal decomposition of the coordination compound (Figure 2) occurs in the $25-450{ }^{\circ} \mathrm{C}$ temperature range, and is characterized by a four-stage mass loss. During the first endothermic step $\left(25-150{ }^{\circ} \mathrm{C}\right.$, mass loss (found /calc.) $\left.=9.75 / 10.26 \%\right)$ is eliminated the lattice water. The second decomposition stage $\left(150-321^{\circ} \mathrm{C}\right.$, mass loss (found/calc.) $=14.83 / 15.39 \%$ ) corresponds to the removal of the six coordinated molecules of water. The oxidative degradation of oxalate occurs in the third step $\left(321-406^{\circ} \mathrm{C}\right)$, and the mass loss ((found/calc.) $\left.=40.69 / 41.06 \%\right)$ indicates the obtaining of a mixture of oxides: zinc oxide and nonstoichiometric oxide $\mathrm{Cr}_{2} \mathrm{O}_{3+\mathrm{x}}, \mathrm{x}=0.25$. This assumption is supported by the existence of the fourth decomposition stage $\left(406-450{ }^{\circ} \mathrm{C}\right)$. In this decomposition process, the continuous mass loss assigned to oxygen evolving is in agreement with the data from literature $[35,37]$, and represents the formation of $\mathrm{Cr}_{2} \mathrm{O}_{3}$ followed by obtaining the zinc chromite. 


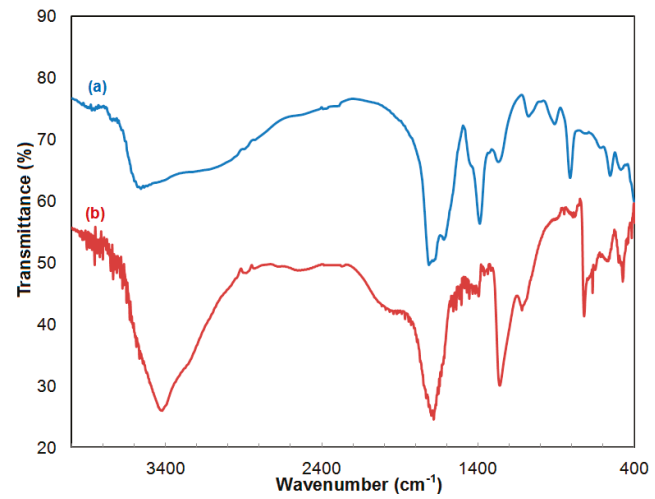

Figure 1. IR vibrational spectra of (a) the $\left[\mathrm{Cr}_{2} \mathrm{Zn}\left(\mathrm{C}_{2} \mathrm{O}_{4}\right)_{4}\left(\mathrm{OH}_{2}\right)_{6}\right] \cdot 4 \mathrm{H}_{2} \mathrm{O}$ compound and (b) isolated oxalic acid.

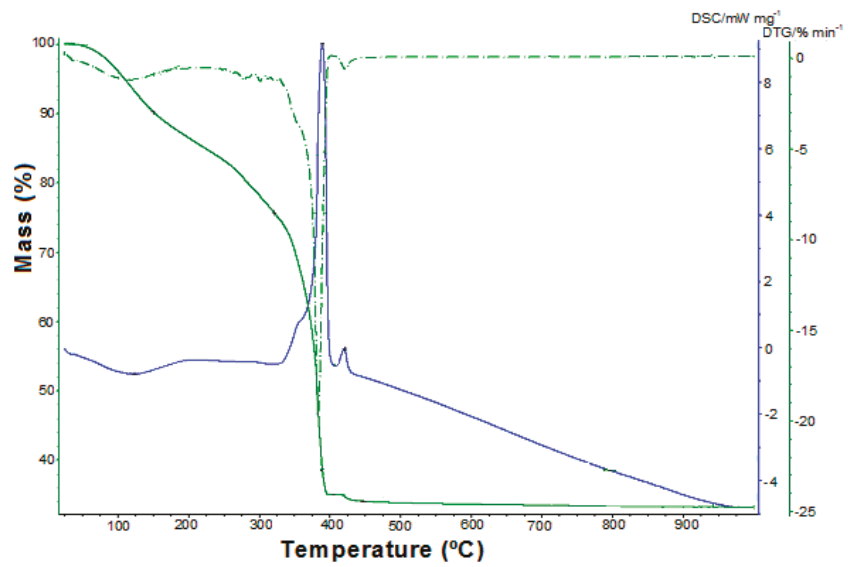

Figure 2. Thermal curves (TG, DTG and DSC) of $\left[\mathrm{Cr}_{2} \mathrm{Zn}\left(\mathrm{C}_{2} \mathrm{O}_{4}\right)_{4}\left(\mathrm{OH}_{2}\right)_{6}\right] \cdot 4 \mathrm{H}_{2} \mathrm{O}$ in air atmosphere.

Based on TG, DTG and DSC curves analysis, the thermal decomposition of $\left[\mathrm{Cr}_{2} \mathrm{Zn}\left(\mathrm{C}_{2} \mathrm{O}_{4}\right)_{4}\left(\mathrm{OH}_{2}\right)_{6}\right] \cdot 4 \mathrm{H}_{2} \mathrm{O}$ in air atmosphere can be represented by the following sequence:

$$
\begin{gathered}
{\left[\mathrm{Cr}_{2} \mathrm{Zn}\left(\mathrm{C}_{2} \mathrm{O}_{4}\right)_{4}\left(\mathrm{OH}_{2}\right)_{6}\right] \cdot 4 \mathrm{H}_{2} \mathrm{O}_{(\mathrm{s})} \stackrel{(I)}{\longrightarrow} 4 \mathrm{H}_{2} \mathrm{O}_{(\mathrm{g})}+\left[\mathrm{Cr}_{2} \mathrm{Zn}\left(\mathrm{C}_{2} \mathrm{O}_{4}\right)_{4}\left(\mathrm{OH}_{2}\right)_{6}\right]_{(\mathrm{s})}} \\
{\left[\mathrm{Cr}_{2} \mathrm{Zn}\left(\mathrm{C}_{2} \mathrm{O}_{4}\right)_{4}\left(\mathrm{OH}_{2}\right)_{6}\right]_{(\mathrm{s})} \stackrel{(I I)}{\longrightarrow} 6 \mathrm{H}_{2} \mathrm{O}_{(\mathrm{g})}+\mathrm{Cr}_{2} \mathrm{Zn}\left(\mathrm{C}_{2} \mathrm{O}_{4}\right)_{4(\mathrm{~s})}} \\
\mathrm{Cr}_{2} \mathrm{Zn}\left(\mathrm{C}_{2} \mathrm{O}_{4}\right)_{4(\mathrm{~s})} \stackrel{+(1 / 2+1 / 8) \mathrm{O}_{2} ; \quad \stackrel{(I I I)}{\longrightarrow} 4 \mathrm{CO}_{2(\mathrm{~g})}+4 \mathrm{CO}_{(\mathrm{g})}+\mathrm{ZnO}_{(\mathrm{s})}+\mathrm{Cr}_{2} \mathrm{O}_{3,25(\mathrm{~s})}}{\mathrm{Cr}_{2} \mathrm{O}_{3,25(\mathrm{~s})} \stackrel{(I V)}{\longrightarrow} 1 / 8 \mathrm{O}_{2(\mathrm{~g})}+\mathrm{Cr}_{2} \mathrm{O}_{3(\mathrm{~s})}} \\
\mathrm{ZnO}+\mathrm{Cr}_{2} \mathrm{O}_{3} \rightarrow \mathrm{ZnCr}_{2} \mathrm{O}_{4}
\end{gathered}
$$

The obtained zinc chromite at $480{ }^{\circ} \mathrm{C}$ was confirmed through elemental analysis $\left(\mathrm{ZnCr}_{2} \mathrm{O}_{4}\right.$, calc. /found: $\mathrm{Zn} \%=28.01 / 28.24 ; \mathrm{Cr} \%=44.55 / 44.48)$. 


\subsection{Characterization of $\mathrm{ZnCr}_{2} \mathrm{O}_{4}$ Powders}

XRD investigations at room temperature performed on the powders resulting after calcination at various temperatures indicate that the crystallization process is already in progress starting with temperatures above $450{ }^{\circ} \mathrm{C}$ (Figure 3). Thus, the powder obtained after calcination at $450{ }^{\circ} \mathrm{C}$ is already crystallized, consisting of $\mathrm{ZnCr}_{2} \mathrm{O}_{4}$ with the typical cubic spinel structure (space group $\mathrm{Fd}-3 \mathrm{~m}$ ), identified as a unique phase with the ICCD card no. 01-079-5291. The diffraction peaks of $\mathrm{ZnCr}_{2} \mathrm{O}_{4}$ become sharper as the calcination temperature increases (Figure 3). This evolution is very similar to that reported by Gingasu et al. for their zinc chromite powders, synthesized by using the precursor method via thermal decomposition of tartarte/gluconate compounds [24].

From the structural point of view, an obvious increase of lattice parameter $a$ and unit cell volume $V$ takes place with the increase of the thermal treatment temperature from 450 to $600{ }^{\circ} \mathrm{C}$, when the crystallization process is still in progress. A further rise in calcination temperature seems to no longer significantly affect the network, so that only a slight variation of the unit cell parameters and volume was observed (Table 1, Figure 3).

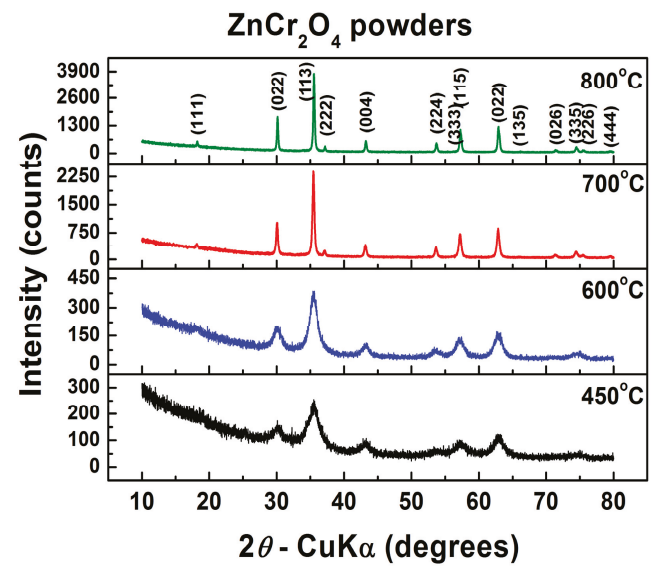

Figure 3. XRD patterns at room temperature for $\mathrm{ZnCr}_{2} \mathrm{O}_{4}$ powders annealed at various temperatures.

Table 1. Structural parameters obtained from XRD data by Rietveld refinement (ICCD no. 01-079-5291).

\begin{tabular}{ccccc}
\hline $\begin{array}{c}\text { Calcination } \\
\text { Temperature }\end{array}$ & $\mathbf{4 5 0}{ }^{\circ} \mathbf{C}$ & $\mathbf{6 0 0}{ }^{\circ} \mathbf{C}$ & $\mathbf{7 0 0}{ }^{\circ} \mathbf{C}$ & $\mathbf{8 0 0}{ }^{\circ} \mathbf{C}$ \\
\hline Structure/Space group & \multicolumn{4}{c}{ Cubic/Fd-3m } \\
\hline$a(\AA)$ & $8.3181 \pm 0.0028$ & $8.3296 \pm 0.0065$ & $8.3258 \pm 0.0009$ & $8.3295 \pm 0.0005$ \\
$V\left(\AA^{3}\right)$ & 575.54 & 577.92 & 577.14 & 577.90 \\
$<D>(\mathrm{nm})$ & $3.54 \pm 0.34$ & $5.20 \pm 0.39$ & $23.4 \pm 2.26$ & $45.79 \pm 11.6$ \\
$<S>(\%)$ & $2.85 \pm 1.65$ & $1.91 \pm 0.64$ & $0.41 \pm 0.20$ & $0.20 \pm 0.04$ \\
$\mathrm{R}_{\mathrm{e}}$ & 17.43 & 17.60 & 12.88 & 12.44 \\
$\mathrm{R}_{\mathrm{p}}$ & 8.02 & 8.83 & 6.50 & 6.46 \\
$\mathrm{R}_{\mathrm{wp}}$ & 11.30 & 11.98 & 8.65 & 8.73 \\
Goodness of fit (GOF) & 0.42 & 0.46 & 3.15 & 0.49 \\
\hline
\end{tabular}

As expected, the increase of the calcination temperature influenced the crystallite size $D$ and lattice strain $S$. Thus, the average crystallite size increased from $3.5 \mathrm{~nm}$ to $45.8 \mathrm{~nm}$ for the $\mathrm{ZnCr}_{2} \mathrm{O}_{4}$ powders that were thermally treated in the temperature range of $450-800{ }^{\circ} \mathrm{C}$ (Table 1 ). The coarsening process evolves faster at annealing temperatures above $600^{\circ} \mathrm{C}$. However, the value of the average crystallite 
size was maintained in the nanometric range even for the powder calcined at $800^{\circ} \mathrm{C}$. Concurrently, the increase of the crystallite sizes induced by higher annealing temperatures led to a structural relaxation, pointed out by the decreasing trend of the values of the lattice strains (Table 1).

The morphology of the synthesized powders calcined at various temperatures is presented in the FE-SEM images of Figure 4a-d. Figure 4a,b show that nanosized particles were obtained for the powders thermally treated at temperatures ranging between $450-600{ }^{\circ} \mathrm{C}$. In this case, the estimation of the shape and average size of particles is almost impossible, because they are very small and not well-defined, exhibiting a high agglomeration tendency. The $\mathrm{ZnCr}_{2} \mathrm{O}_{4}$ powder annealed at $700{ }^{\circ} \mathrm{C}$ exhibits a duplex morphology, consisting of a large fraction of rounded, small particles of a few tens of nanometers (10-30 nm), as well as a lower proportion of polyhedral particles of 70-120 nm with well-defined edges and corners, most with an almost octahedral shape (Figure 4c). This kind of morphology was maintained in the powder calcined at $800^{\circ} \mathrm{C}$, when the coarsening process occurs for both smaller and larger particles. One can notice that, in spite of their size (of 40-50 nm), the smaller particles seem also to evolve toward a well-faceted, polyhedral shape (Figure 4d).

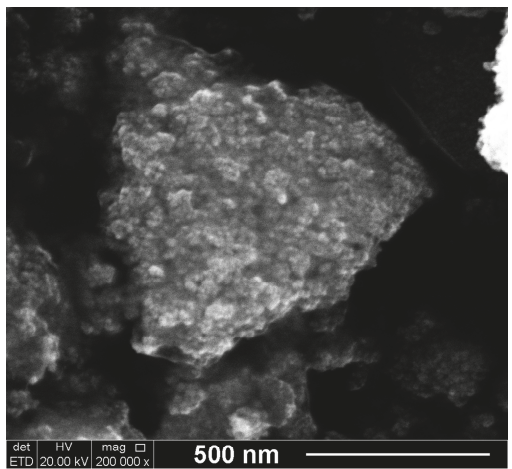

(a)

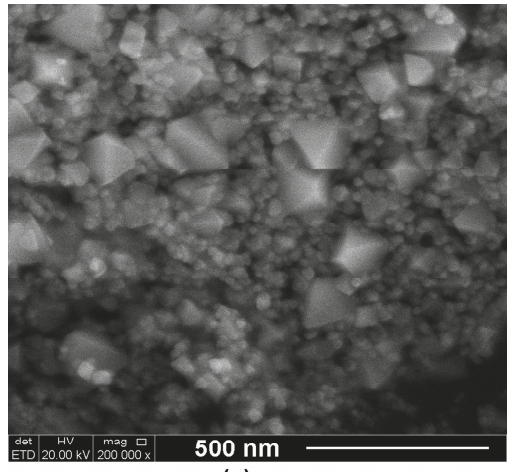

(c)

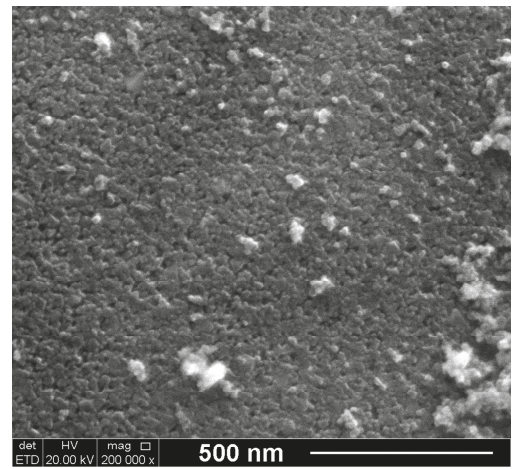

(b)

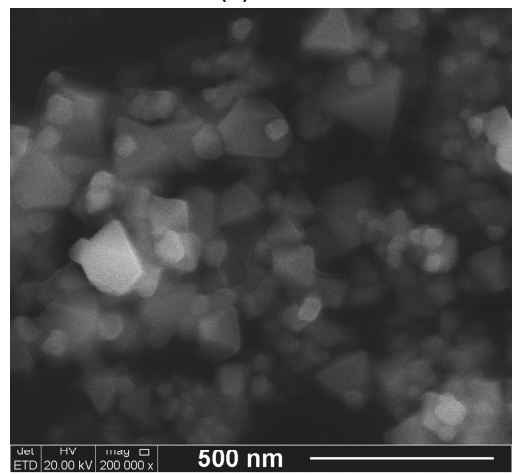

(d)

Figure 4. FE-SEM images showing some morphological features and the agglomeration tendency of $\mathrm{ZnCr}_{2} \mathrm{O}_{4}$ powders calcined at different temperatures: (a) $450{ }^{\circ} \mathrm{C}$; (b) $600{ }^{\circ} \mathrm{C}$; (c) $700{ }^{\circ} \mathrm{C}$; and (d) $800^{\circ} \mathrm{C}$.

In order to have a more realistic view of the size and morphology of the $\mathrm{ZnCr}_{2} \mathrm{O}_{4}$ particles, TEM investigations are required. Thus, the TEM images of the powders annealed at lower temperatures indicate that, in both cases, the individual particles exhibit sizes of only a few nanometers. Average particle size values $\left\langle d_{\text {TEM }}>\right.$ of $4.7 \mathrm{~nm}$ and $6.9 \mathrm{~nm}$ were estimated for the powders obtained after annealing at 400 and $600{ }^{\circ} \mathrm{C}$, respectively (Figures $5 \mathrm{a}, \mathrm{b}$ and $6 \mathrm{a}$ ). These $\left\langle d_{\mathrm{TEM}}>\right.$ values fit quite well the average crystallite size values $<D>$ calculated from the XRD data ( $3.54 \mathrm{~nm}$ and $5.20 \mathrm{~nm}$, respectively), 
proving the single-crystalline nature of the $\mathrm{ZnCr}_{2} \mathrm{O}_{4}$ particles, which each consist of 6-8 spinel unit cells. For the powder annealed at $700{ }^{\circ} \mathrm{C}$, the TEM image of Figure 7a reveals the two types of particles also emphasized by the FE-SEM investigations. One can observe that some of the smaller particles already exhibit well-faceted morphology, while the larger particles seem also to be single crystals. An overall $<d_{\text {TEM }}>$ value of $32.5 \mathrm{~nm}$ was estimated for the average particle size, taking into account the two types of particles. The same tendency toward a bimodal particle size distribution was also observed in the case of the powder thermally treated at $800^{\circ} \mathrm{C}$, where a few larger octahedral particles of 120-200 nm coexist with the major fraction of smaller particles of 30-50 nm (Figure $8 \mathrm{a}, \mathrm{b}$ ). The overall value of the average particle size is $66.3 \mathrm{~nm}$.

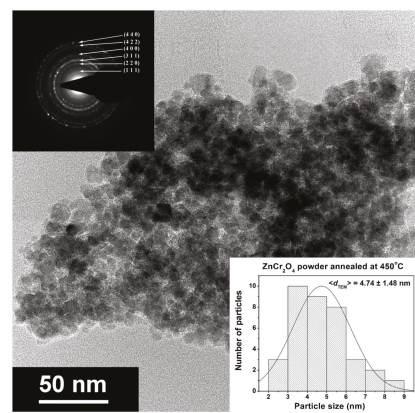

(a)

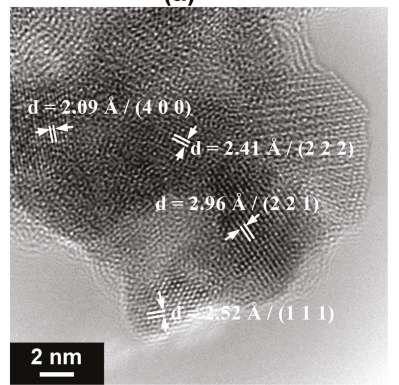

(c)
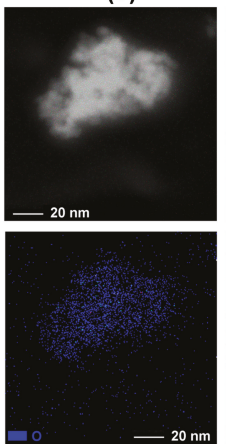

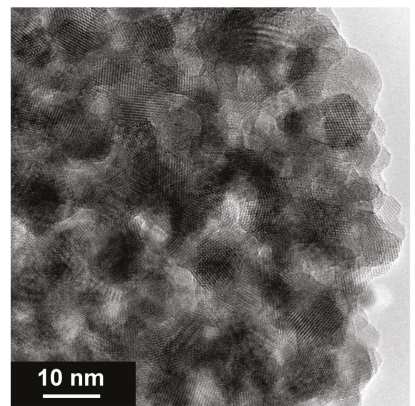

(b)

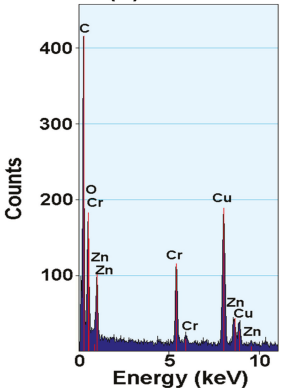

(d)

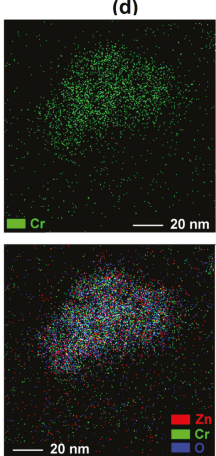

$\operatorname{Ban}_{0}^{2 \pi}$

(e)

Figure 5. Morphology, crystallinity, and compositional uniformity of $\mathrm{ZnCr}_{2} \mathrm{O}_{4}$ powder calcined at $450{ }^{\circ} \mathrm{C}$ : (a) TEM image showing a general view of a large aggregate of nanosized particles-insets show the SAED pattern and histogram indicating the particle size distribution; (b) TEM image showing a detail inside an agglomerate; (c) HR-TEM image; (d) EDX spectrum; (e) STEM image and elemental (at. \%) mapping performed on a small agglomerate of a few $\mathrm{ZnCr}_{2} \mathrm{O}_{4}$ particles. 


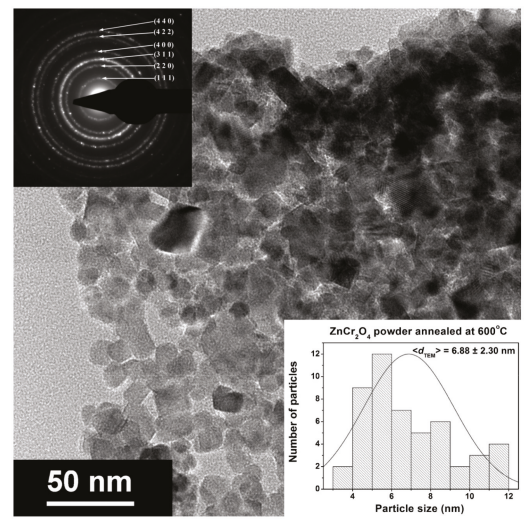

(a)

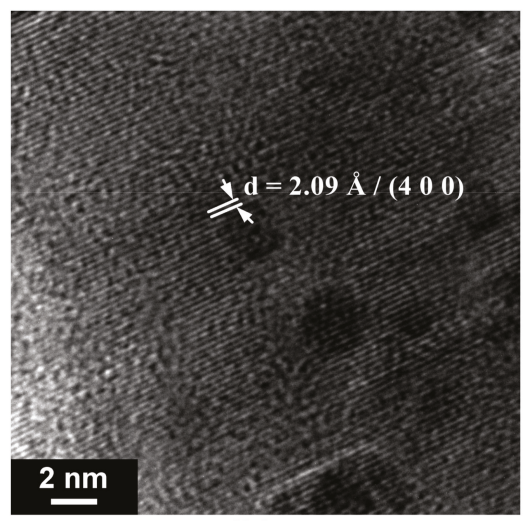

(b)

Figure 6. Morphology and crystallinity of $\mathrm{ZnCr}_{2} \mathrm{O}_{4}$ powder calcined at $600^{\circ} \mathrm{C}$ : (a) TEM image showing a general view of a large aggregate of nanosized particles-insets show the SAED pattern and histogram indicating the particle size distribution; (b) HR-TEM image.

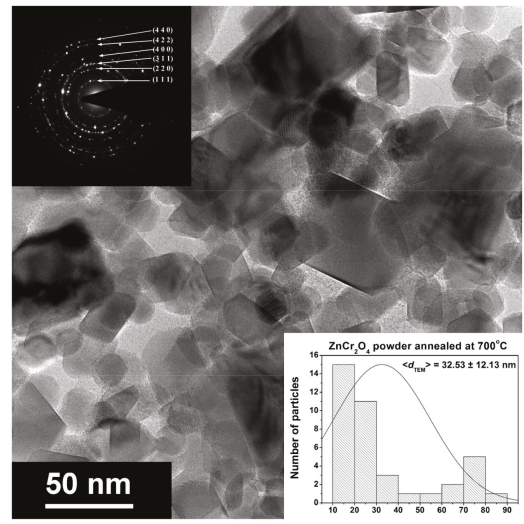

(a)

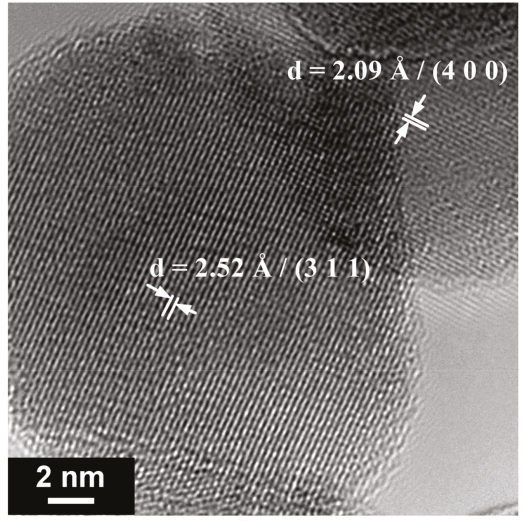

(b)

Figure 7. Morphology and crystallinity of $\mathrm{ZnCr}_{2} \mathrm{O}_{4}$ powder calcined at $700{ }^{\circ} \mathrm{C}$ : (a) TEM image showing a duplex morphology consisting of a large fraction of nanosized, equiaxial particles and a small fraction of submicron, polyhedral, well-faceted particles-insets show the SAED pattern and histogram indicating the particle size distribution; (b) HR-TEM image.

Despite the small size, especially in the case of the powders thermally treated at lower temperatures $\left(450\right.$ and $600{ }^{\circ} \mathrm{C}$ ), the particles exhibit a high crystallinity degree, proved by the HR-TEM images of Figures $5 c, 6 b, 7 b$ and $8 c$, which clearly show highly-ordered fringes spaced at specific distances corresponding to various crystalline planes of the spinel structure, as well as the bright spots that form well-defined diffraction rings in the SAED patterns (insets of Figures 5a, 6a, 7a and 8a).

EDX spectra of Figures $5 \mathrm{~d}$ and $8 \mathrm{~d}$ reveal only the presence of the $\mathrm{Zn}, \mathrm{Cr}$, and $\mathrm{O}$ species. No other foreign cations were identified, which proves the lack of any contamination during the synthesis process and the high purity degree of the as-prepared powdered samples. 


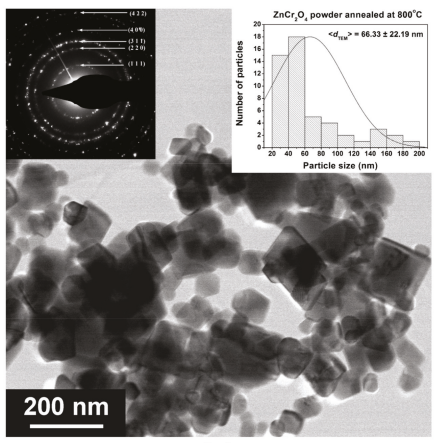

(a)

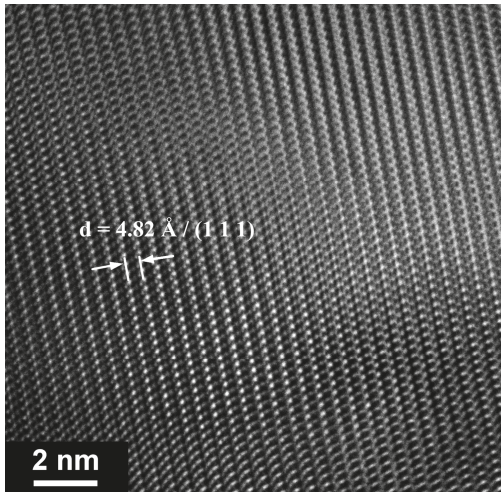

(c)
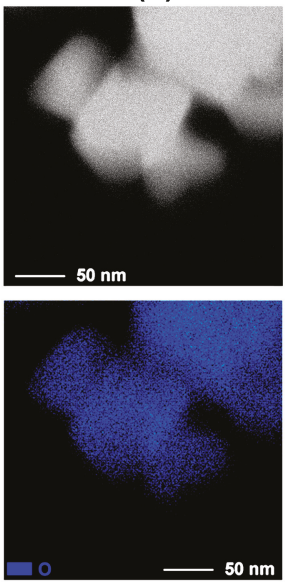

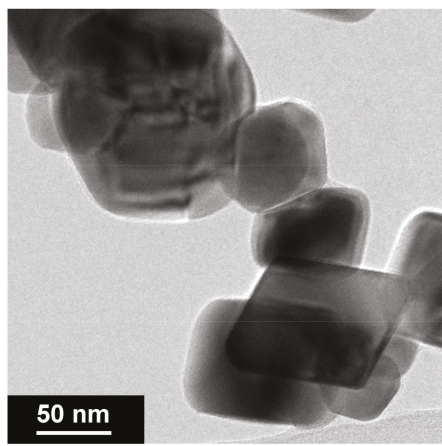

(b)

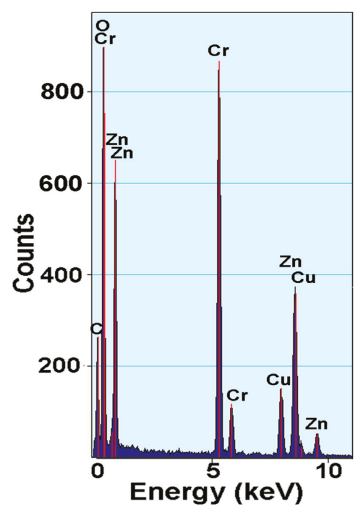

(d)
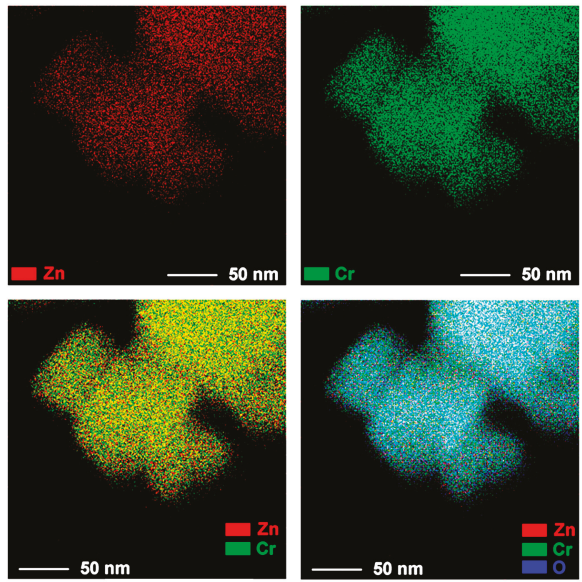

(e)

Figure 8. Morphology, crystallinity, and compositional uniformity of $\mathrm{ZnCr}_{2} \mathrm{O}_{4}$ powder calcined at $800^{\circ} \mathrm{C}$ : (a) TEM image showing a general view of several particles of different size and shape-insets show the SAED pattern and histogram indicating the particle size distribution; (b) TEM image showing details of a few polyhedral particles; (c) HR-TEM image; (d) EDX spectrum; (e) STEM image and elemental (at. \%) mapping performed on five $\mathrm{ZnCr}_{2} \mathrm{O}_{4}$ particles. 
EDX mapping was carried out in order to investigate the compositional homogeneity of a small agglomerate of particles of the powder annealed at $450^{\circ} \mathrm{C}$, as well as of five larger $\mathrm{ZnCr}_{2} \mathrm{O}_{4}$ particles of the powder annealed at $800{ }^{\circ} \mathrm{C}$. The superposition of the maps corresponding to all three elemental species of the $\mathrm{ZnCr}_{2} \mathrm{O}_{4}$ compound indicates a uniform distribution of $\mathrm{Zn}$ and $\mathrm{Cr}$ cations and oxygen anions, with respect to their atomic ratio in the spinel structure. This suggests that some compositional gradients or segregation of some potential secondary phases, undetected by XRD investigations, appear in the powders under investigation (Figures $5 \mathrm{e}$ and $8 \mathrm{e}$ ).

Figure 9 represents, as an example, the UV-VIS diffuse reflectance spectrum of $\mathrm{ZnCr}_{2} \mathrm{O}_{4}\left(450{ }^{\circ} \mathrm{C}\right)$, and a broad absorption band within a $200-650 \mathrm{~nm}$ wavelength can be seen. The band gap energy was determined using the Kubelka-Munk equation [38]:

$$
F(R)=(1-R)^{2} / 2 R,
$$

where $\mathrm{R}$ is reflectance.

To determine the band gap energy, the $(F(R) h v)^{2}-h v$ dependence is presented in the inset of Figure 6, where $\mathrm{hv}=1240 / \lambda$, which determines the band gap energy value of $2.45 \mathrm{eV}$, lower than the $2.9 \mathrm{eV}$ reported by Abbasi et al., [17] for $\mathrm{ZnCr}_{2} \mathrm{O}_{4}$ and $\mathrm{ZnCr}_{2} \mathrm{O}_{4} / \mathrm{Ag}$. Therefore, the results of the band gap energy values for the $\mathrm{ZnCr}_{2} \mathrm{O}_{4}$ powder calcinated at 600,700 , and $800{ }^{\circ} \mathrm{C}$ are gathered in Table 2, and the values are larger in comparison to $\mathrm{ZnCr}_{2} \mathrm{O}_{4}\left(450{ }^{\circ} \mathrm{C}\right)$. The particle size affects the band gap energy value in relation to composition, crystallinity, and crystallite size. The band gap energy decreasing as crystallite size decreases has been also reported by Irfan et al. [39]. This result showed the high photocatalytic potential of the material under both UV and VIS irradiation up to the $650 \mathrm{~nm}$ wavelength.

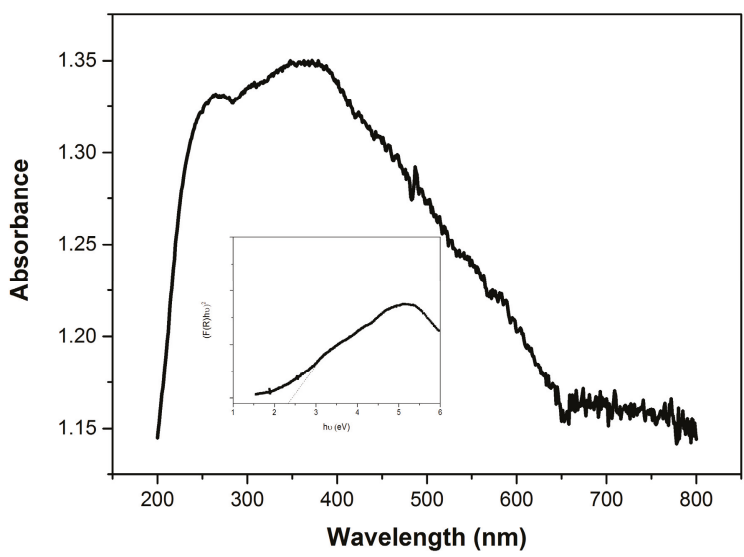

Figure 9. DRUV-VIS diffuse reflectance spectrum of $\mathrm{ZnCr}_{2} \mathrm{O}_{4}$. The inset shows the $(\mathrm{F}(\mathrm{R}) \mathrm{h} v)^{2}-\mathrm{h} v$ plot.

Table 2. The band gap energy values of $\mathrm{ZnCr}_{2} \mathrm{O}_{4}$.

\begin{tabular}{cc}
\hline Calcination Temperature $/{ }^{\circ} \mathrm{C}$ & The Band Gap Energy Values/eV \\
\hline 450 & 2.90 \\
600 & 3.19 \\
700 & 3.22 \\
800 & 3.25 \\
\hline
\end{tabular}




\subsection{Photocatalysis Activity}

The initial UV-VIS spectrum profile for $50 \mathrm{mg} / \mathrm{L} \mathrm{HA}$ and its evolution during the photocatalysis using $\mathrm{ZnCr}_{2} \mathrm{O}_{4}\left(450{ }^{\circ} \mathrm{C}\right)$ is shown in Figure $10 \mathrm{a}$, in comparison to the photolysis process (inset of Figure 10a). Absorbance recorded at wavelengths $254 \mathrm{~nm}$ and $365 \mathrm{~nm}$ is considered to be a suitable parameter for the characterization of aquatic humic substances, selected due to the fact that they indicate the presence of aromatic compounds. The aromatic compounds derived from an aquatic heterotrophic metabolism consist of nitrogen-based functions characterized by the chromophore characteristics. The comparative results of photocatalysis involving the prior sorption step for $30 \mathrm{~min}$, photolysis under UV irradiation, and sorption under dark conditions, as well as the application results applied for HA removal from water expressed as RE (\%), are shown in Figure 10b.

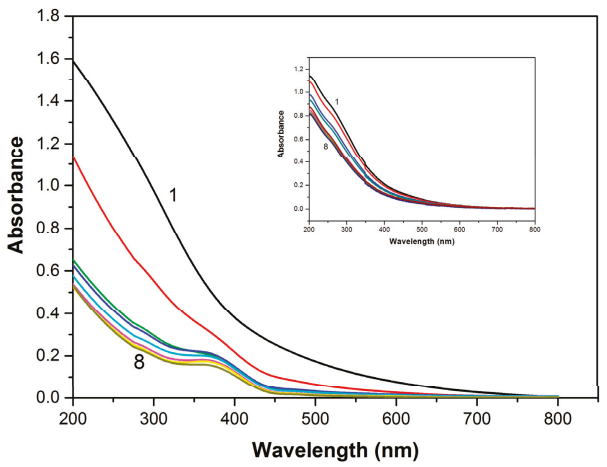

(a)

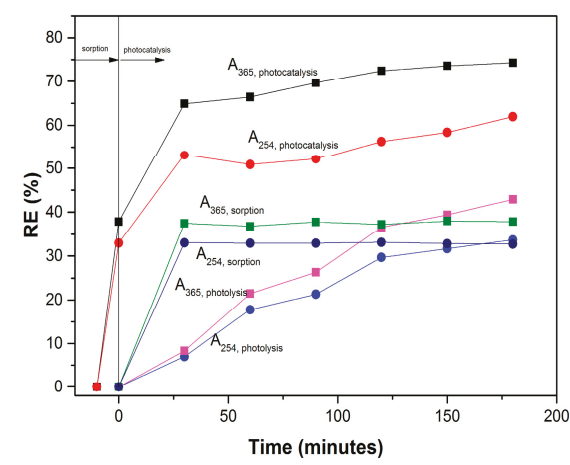

(b)

Figure 10. Evolution of UV-VIS spectrum profile of $50 \mathrm{mg} / \mathrm{L}$ humic acid (HA) during photocatalysis using $\mathrm{ZnCr}_{2} \mathrm{O}_{4}$. Inset shows the evolution of UV-VIS spectrum profile of $50 \mathrm{mg} / \mathrm{L} \mathrm{HA}$ during the photocatalysis (a) and the removal efficiency (RE) evolution for $50 \mathrm{mg} / \mathrm{L} \mathrm{HA}$ removal from water by application of sorption-based photocatalysis (solid line) and photolysis (dash line), assessed in terms of $\mathrm{A}_{254}$ and $\mathrm{A}_{365}$ (b).

It is obvious that $\mathrm{ZnCr}_{2} \mathrm{O}_{4}$-based photocatalysis enhanced the humic acid (HA) degradation in comparison with photolysis. Also, it can be seen that after adsorption for 30 min, the HA removal efficiency of about $30 \%$ was reached. Once the UV irradiation process started, a very significant decrease in the HA spectrum intensity was observed. It is noteworthy that during photocatalysis application, two distinct rate steps were delimited, except the sorption stage. The first one was characterised by a fast kinetics rate until $30 \mathrm{~min}$ of photocatalysis, followed by slower kinetics rate. Thus, for $30 \mathrm{~min}$ of the photocatalysis, a synergic effect regarding removal efficiency was found that was related to the sorption and the photolysis effect. This aspect denoted a good photocatalytic capacity of $\mathrm{ZnCr}_{2} \mathrm{O}_{4}$ for HA degradation that also considers the sorption effect as a compulsory stage in the photocatalytic mechanism. A different behaviour is observed for the photolysis application, which is characterised by a constant slow kinetics rate. The sorption characteristics of the $\mathrm{ZnCr}_{2} \mathrm{O}_{4}$ photocatalyst have been proved by kinetics modelling. The pseudo-first kinetics model was used to fit the experimental results for both photolysis and the photocatalysis, but the low correlation coefficient obtained for the photocatalysis showed that this model did not describe precisely. The second-order kinetics model better fit the experimental results for the photocatalysis application, which corresponded mainly to the sorption process, thus indicating a major contribution of sorption within the photocatalysis. A longer irradiation time in the presence of $\mathrm{ZnCr}_{2} \mathrm{O}_{4}$ indicated the slow kinetics of the photocatalysis process, and at its peak the cumulating effect of sorption and 
photolysis processes was noticed. The first-order kinetics model described the photocatalysis very well, and the results related to the rate constants are given in Table 3.

Table 3. Apparent rate constants calculated by fitting experimental data through the pseudo-second-order kinetics model for photocatalysis and the pseudo-first-order kinetics model for photolysis.

\begin{tabular}{cccc}
\hline \multirow{2}{*}{ Process/Catalyst } & Parameters & \multicolumn{2}{c}{ Value/Absorbance } \\
\cline { 3 - 4 } & & $\mathbf{A}_{\mathbf{2 5 4}}$ & $\mathbf{A}_{\mathbf{3 6 5}}$ \\
\hline \multirow{2}{*}{ Photocatalysis/ZnCr ${ }_{2} \mathrm{O}_{4}$} & $\mathrm{~K}_{\mathrm{app}}\left(\mathrm{g} \mathrm{mg}^{-1} \mathrm{~min}^{-1}\right)$ & $4 \cdot 10^{-3}$ & $16.2 \cdot 10^{-3}$ \\
& $\mathrm{R}^{2}$ & 0.997 & 0.988 \\
\hline \multirow{2}{*}{ Photolysis } & $\mathrm{K}_{\mathrm{app}}\left(\mathrm{min}^{-1}\right)$ & $2.1 \cdot 10^{-3}$ & $2.9 \cdot 10^{-3}$ \\
& $\mathrm{R}^{2}$ & 0.923 & 0.937 \\
\hline
\end{tabular}

As we mentioned already, based on the RE the kinetics results sustained $\mathrm{ZnCr}_{2} \mathrm{O}_{4}$ as a photocatalyst for UV irradiation for humic acid removal. Moreover, to support this statement, the mineralization degree was assessed by the total organic carbon (TOC) parameter for both photocatalysis and photolysis. The mineralization degree was about $60 \%$ for photocatalysis, compared to $7 \%$ for photolysis and $30 \%$ for sorption, which showed a net superiority of $\mathrm{ZnCr}_{2} \mathrm{O}_{4}$ for $\mathrm{HA}$ mineralization. Also, the mineralization degree is very close to the degradation efficiency that confirmed the effectiveness of the HA mineralization through photocatalysis, using the $\mathrm{ZnCr}_{2} \mathrm{O}_{4}$ photocatalyst. Based on these results, it can be concluded that a complex mechanism of HA degradation is based on sorption in the first stage and on mineralization through hydroxyl radicals generated under UV irradiation [26].

\section{Materials and Methods}

For the synthesis of the $\mathrm{Zn}(\mathrm{II})-\mathrm{Cr}(\mathrm{III})$ oxalate coordination compound, $\mathrm{Cr}\left(\mathrm{NO}_{3}\right)_{3} \cdot 9 \mathrm{H}_{2} \mathrm{O}$, $\mathrm{Zn}\left(\mathrm{NO}_{3}\right)_{2} \cdot 6 \mathrm{H}_{2} \mathrm{O}$, 1,2-ethanediol, and $2 \mathrm{M}$ nitric acid (Merck) were employed.

A water solution containing 1,2-ethanediol, chromium nitrate, zinc nitrate, and nitric acid (2M) in a molar ratio 2:1:0.5:1.3 was used. This mixture was heated in a water bath for about $40 \mathrm{~min}$. The reaction was finished when no more gas evolved. The resulting solid product was purified by washing with acetone and dried under a room temperature environment. The metal content was determined by the atomic absorption spectrophotometry (VARIAN Spectra 110 spectrophotometer). Carbon and hydrogen were analyzed using a Carlo Erba 1108 elemental analyzer. The data of the elemental analysis for the oxalate precursor is indicated in the Table 4.

Table 4. Composition and elemental analysis data.

\begin{tabular}{cccccccccc}
\hline Compound & \multicolumn{2}{c}{$\mathrm{Cr}(\mathrm{III}) \%$} & \multicolumn{2}{c}{$\mathrm{Zn}(\mathrm{II}) \%$} & \multicolumn{2}{c}{$\mathrm{C} \%$} & \multicolumn{2}{c}{$\mathbf{H} \%$} \\
\hline (composition formula) & calc. & found & calc. & found & calc. & found & calc. & found \\
$\mathrm{Cr}_{2} \mathrm{Zn}\left(\mathrm{C}_{2} \mathrm{O}_{4}\right)_{4} \cdot 10 \mathrm{H}_{2} \mathrm{O}$ & 14.82 & 14.90 & 9.32 & 9.25 & 13.68 & 13.70 & 2.85 & 2.91 \\
\hline
\end{tabular}

In order to identify the ligand, the $\mathrm{Cr}^{3+}-\mathrm{Zn}^{2+}$ oxalate was treated with $\mathrm{R}-\mathrm{H}$ cationite (Purolite $\mathrm{C}-100)$. After the metallic cations were retained and the remained solution evaporated, the solid oxalic acid $\left(\mathrm{H}_{2} \mathrm{C}_{2} \mathrm{O}_{4} \cdot 2 \mathrm{H}_{2} \mathrm{O}\right)$ was obtained. The isolated ligand was identified through three procedures: elemental analysis $\left(\mathrm{H}_{2} \mathrm{C}_{2} \mathrm{O}_{4} \cdot 2 \mathrm{H}_{2} \mathrm{O}\right.$, calc. / found: $\left.\mathrm{C} \%=19.04 / 19.22 ; \mathrm{H} \%=4.76 / 4.98\right)$, FTIR spectroscopy (Figure $1 \mathrm{~b}$ and Table $\mathrm{S} 2$ Electronic Supplementary Material), and specific reactions [32].

FTIR spectra (KBr pellets) of the compound and of the decomposition product were recorded on a Jasco FT-IR spectrophotometer, in the range of $4000-400 \mathrm{~cm}^{-1}$. Thermal measurements (TG, DTG, and DSC) were performed using a NETZSCH-STA $449 \mathrm{C}$ instrument, in the range of $25-1000{ }^{\circ} \mathrm{C}$, using alumina crucibles. The experiments were carried out in artificial air flow of $20 \mathrm{~mL} \mathrm{~min}{ }^{-1}$ and a heating 
rate of $10 \mathrm{~K} \mathrm{~min}^{-1}$. The phase purity and crystal structure of $\mathrm{ZnCr}_{2} \mathrm{O}_{4}$ powders were determined by $\mathrm{X}$-ray diffraction (XRD) investigations, performed at room temperature by means of a Rigaku Ultima IV multipurpose diffraction system (Rigaku Co., Tokyo, Japan). The diffractometer was set in a parallel beam geometry, using Ni-filtered CuK $\alpha$ radiation $(\lambda=1.5418 \AA$ ) , CBO optics, and a graphite monochromator, operated at $40 \mathrm{kV}$ and $40 \mathrm{~mA}$. The measurements were performed in $\theta-2 \theta$ mode, with a scan step increment of $0.01^{\circ}$, in the $2 \theta$ range of $\left(10^{\circ}-80^{\circ}\right)$. Phase identification was performed using HighScore Plus 3.0e software, connected to the ICDD PDF-4+ 2017 database. Lattice parameters were refined by the Rietveld method. After removing the instrumental contribution, the full-width at half-maximum (FWHM) of the diffraction peaks can be interpreted in terms of crystallite size and lattice strain. A pseudo-Voigt function was used to refine the shapes of the $\mathrm{ZnCr}_{2} \mathrm{O}_{4}$ peaks, and a Caglioti function was used for FWHM approximation. The size and the agglomeration tendency of the $\mathrm{ZnCr}_{2} \mathrm{O}_{4}$ particles was assessed by scanning electron microscopy (FE-SEM), using a high-resolution FEI QUANTA INSPECT F microscope with field emission gun (FEI Co., Eindhoven, The Netherlands). For a high-accuracy estimation of the morphology and crystallinity degree of the $\mathrm{ZnCr}_{2} \mathrm{O}_{4}$ particles, additional transmission electron microscopy (TEM/HR-TEM) and selected area electron diffraction (SAED) investigations were performed. The bright-field and high resolution images, as well as the SAED patterns, were collected by means of a TecnaiTM G ${ }^{2}$ F30 S-TWIN transmission electron microscope (FEI Co., Eindhoven, The Netherlands). An image-corrected 80-200 kV Titan Themis transmission and scanning transmission electron microscope (S/TEM), equipped with a high brightness Schottky field emission gun (X-FEG) tip and a four diode Super X-ray energy dispersive spectroscopy (X EDS) detector (Thermo Fisher Scientific, former FEI Co., Eindhoven, Netherlands) was used for rapid compositional analyses (acquisition of STEM images and EDX mappings). For these purposes, small amounts of powdered samples were suspended in ethanol by $15 \mathrm{~min}$ ultrasonication. For FE-SEM analyses, a drop of the suspension was put on a carbon tape stuck on a stub and dried under an IR lamp for $5 \mathrm{~min}$. Finally, the sample was sputtered with a gold film. For TEM observations, a drop of suspension was put onto a 400 mesh holey carbon-coated film $\mathrm{Cu}$ grid and dried. The average particle size for the $\mathrm{ZnCr}_{2} \mathrm{O}_{4}$ powders was determined using the OriginPro 9.0 software, by taking into account size measurements on 50-60 particles (from TEM images of appropriate magnifications obtained from various microscopic fields), performed by means of the microscope software DigitalMicrograph 1.8.0. The UV-Vis diffuse reflectance spectrum of the zinc chromite was obtained on a UV-VIS Carry 100 Varian spectrophotometer.

The photocatalytic experiments were carried out under magnetic stirring at $20^{\circ} \mathrm{C}$ into a RS- 1 photocatalytic reactor (Heraeus, Hanau, Germany), which consisted of a submerged UV lamp surrounded by a quartz shield. For each experiment, an adsorption step of $30 \mathrm{~min}$ was assured under the same hydrodynamic conditions without UV irradiation. At a certain running time, the suspension was sampled and filtered through a $0.4 \mu \mathrm{m}$ membrane filter. The concentration of humic acid was measured in terms of absorbance at $254 \mathrm{~nm}\left(\mathrm{~A}_{254}\right)$ and at $345 \mathrm{~nm}\left(\mathrm{~A}_{345}\right)$, in order to evaluate the decolorizing and respective degradation degrees, using a Carry 100 Varian spectrophotometer. Humic acid has a very complex structure, containing heterogeneous mixtures of small molecules, which usually result from the biological transformations of dead cells associated with a supramolecular structure that can be separated into smaller molecules by chemical fractionation.

To assess the mineralization degree, the total organic carbon (TOC) parameter was measured for initial and final HA concentration, using the TOC analyzer from Shimadzu (Tokyo, Japan). The HA removal efficiency was calculated using the following equation:

$$
\text { Removal efficiency }(\mathrm{RE})=\frac{C_{0}-C_{t}}{C_{0}} \times 100(\%)
$$


where $C_{0}$ and $C_{t}$ are the concentrations of HA in aqueous solution, in terms of the $A_{254}, A_{345}$, and TOC parameters at initial time and certain time $t$, respectively $\left(\mathrm{mg} \mathrm{L}^{-1}\right)$. Kinetics data were fitted with the pseudo-second-order kinetic model [28], and expressed as:

$$
\frac{t}{q_{t}}=\frac{1}{k_{2} \cdot q_{e}^{2}}+\frac{t}{q_{e}},
$$

where $k_{2}$ is the rate constant of the pseudo-second-order adsorption kinetics $\left(\mathrm{g} \mathrm{mg}^{-1} \mathrm{~min}^{-1}\right)$ and $q_{e}$ is the equilibrium adsorption capacity $\left(\mathrm{mg} \mathrm{g}^{-1}\right)$. The simplified pseudo-first-order equation was used also, to fit the kinetics data:

$$
\ln \left(C_{0} / C_{t}\right)=k K t=k_{a p p} t
$$

where $r$ is the rate of humic acid degradation and colour removal $\left(\mathrm{mg} \mathrm{L}^{-1} \mathrm{~min}^{-1}\right), C_{0}$ is the initial humic acid concentration $\left(\mathrm{mg} \mathrm{L}^{-1}\right), C_{t}$ is the concentration of the humic acid at time $t\left(\mathrm{mg} \mathrm{L}^{-1}\right), t$ is the irradiation time $(\mathrm{min})$, and $k$ is the reaction rate constant $\left(\mathrm{min}^{-1}\right)$.

\section{Conclusions}

Nanospinel zinc chromite was successfully synthesized using a new method, via thermal decomposition of the $\left[\mathrm{Cr}_{2} \mathrm{Zn}\left(\mathrm{C}_{2} \mathrm{O}_{4}\right)_{4}\left(\mathrm{OH}_{2}\right)_{6}\right] \cdot 4 \mathrm{H}_{2} \mathrm{O}$ oxalate compound at the temperature of $450{ }^{\circ} \mathrm{C}$. XRD investigations, FE-SEM, and TEM/HR-TEM analyses indicated that phase-pure $\mathrm{ZnCr}_{2} \mathrm{O}_{4}$ nanoparticles were obtained after calcination at temperatures ranging between $450-800{ }^{\circ} \mathrm{C}$. The average particle size values increased with increasing temperature, from $4.7 \mathrm{~nm}\left(450{ }^{\circ} \mathrm{C}\right)$ to $66.3 \mathrm{~nm}\left(800{ }^{\circ} \mathrm{C}\right)$, which affected the band gap energy value. The lowest band gap energy value of $2.45 \mathrm{eV}$ was determined for the $\mathrm{ZnCr}_{2} \mathrm{O}_{4}$ powder after calcination at $450{ }^{\circ} \mathrm{C}$, which exhibited photocatalytic activity towards the degradation and the mineralization of humic acids (HAs) from water. The sorption efficiency of this spinel for HAs was about 30\% after $30 \mathrm{~min}$, and the photocatalytic efficiency for HA degradation was about $60 \%$, which was similar to the mineralization degree, thus confirming the effectiveness of photocatalysis for mineralization while avoiding the generation of by-products. The sorption step was confirmed by the pseudo-second-order kinetics model to fit the experimental results best, which is characteristic to sorption in comparison with the photocalysis process, which was described as the best by the pseudo-first kinetics model. Two steps of the photocatalysis process using nanosized $\mathrm{ZnCr}_{2} \mathrm{O}_{4}$ spinel were found: the first step was characterized by the fast rate, while the second step occurred at the slow rate. In comparison with the photolysis and sorption process, a synergic effect was found for the photocatalysis process during the first $30 \mathrm{~min}$. Then, a maximum cumulative effect was found until $180 \mathrm{~min}$. Taking into account the energy consumption that corroborates these study results, the optimum irradiation time of the photocatalysis with $\mathrm{ZnCr}_{2} \mathrm{O}_{4}$ is $30 \mathrm{~min}$. This study informed about the great potential of this spinel to be used for drinking water treatment via its photocatalytic application.

Supplementary Materials: The following are available online at http:/ / www.mdpi.com/2073-4344/8/5/210/ s1, Table S1: Characteristic IR absorption bands of the compound $\left[\mathrm{Cr}_{2} \mathrm{Zn}\left(\mathrm{C}_{2} \mathrm{O}_{4}\right)_{4}\left(\mathrm{OH}_{2}\right)_{6}\right] \cdot 4 \mathrm{H}_{2} \mathrm{O}$, Table S2: Characteristic IR absorption bands of the oxalic acid.

Author Contributions: In this paper, R.D. and F.M. conceived and designed the experiments; C.P., L.L., A.P. and A.S. performed the experiments; R.D., F.M., A.P., A.C. and A.I. analyzed the data; A.C. contributed reagents/materials/analysis tools; R.D., F.M. and A.I. wrote the paper.

Acknowledgments: This work was partially supported by a grant of the Romanian National Authority for Scientific Research and Innovation, CNCS-UEFISCDI, project number PN-II-RU-TE-2104-4-1043. The TEM characterization was possible due to EU-funding project POSCCE-A2-O2.2.1-2013-1/Priority Axe 2, Project No. 638/12.03.2014, ID 1970, SMIS-CSNR code 48652. The contribution of Bogdan Vasile in performing some TEM/EDX investigations is highly acknowledged.

Conflicts of Interest: The authors declare no conflict of interest. 


\section{References}

1. Gabr, R.M.; Girgis, M.M.; El-Awad, A.M. Formation, conductivity and activity of zinc chromite catalyst. Mater. Chem. Phys. 1992, 30, 6619-6623. [CrossRef]

2. Epling, W.S.; Hoflund, G.B.; Minahan, D.M. Reaction and surface characterization study of higher alcohol synthesis catalysts: VII Cs- and Pd-promoted 1:1 Zn/Cr spinel. J. Catal. 1998, 175, 175-184. [CrossRef]

3. El-Sharkawy, E.A. Textural, structural and catalytic properties of $\mathrm{ZnCr}_{2} \mathrm{O}_{4} / \mathrm{Al}_{2} \mathrm{O}_{3}$ catalysts. Adsorpt. Sci. Technol. 1998, 6, 193-216. [CrossRef]

4. Peng, C.; Gao, L. Optical and photocatalytic properties of spinel $\mathrm{ZnCr}_{2} \mathrm{O}_{4}$ nanoparticles synthesized by a hydrothermal route. J. Am. Soc. 2008, 91, 2388-2390. [CrossRef]

5. Thennarasu, G.; Sivasamy, A. Synthesis and characterization of nanolayered $\mathrm{ZnO} / \mathrm{ZnCr}_{2} \mathrm{O}_{4}$ metal oxide composites and its photocatalytic activity under visible light irradiation. J. Chem. Technol. Biotechnol. 2015, 90, 514-524. [CrossRef]

6. Yazdanbakhsh, M.; Khosravi, I.; Goharshadi, E.K.; Youssefi, A. Fabrication of nanospinel $\mathrm{ZnCr}_{2} \mathrm{O}_{4}$ using sol-gel method and its application on removal of azo-dye from aqueous solutions. J. Hazard. Mater. 2010, 184, 684-689. [CrossRef] [PubMed]

7. He, H.Y. Catalytic and photocatalytic activity of $\mathrm{ZnCr}_{2} \mathrm{O}_{4}$ particle synthesized using metallo-organic precursor. Mater. Technol. 2008, 23, 110-113. [CrossRef]

8. Niu, X.; Du, W.; Du, W. Preparation and gas sensing properties of $\mathrm{ZnM}_{2} \mathrm{O}_{4}(\mathrm{M}=\mathrm{Fe}, \mathrm{Co}, \mathrm{Cr})$. Sens. Actuators $B$ 2004, 99, 405-409. [CrossRef]

9. Pokhrel, S.; Jeyaraj, B.; Nagaraja, K.S. Humidity-sensing properties of $\mathrm{ZnCr}_{2} \mathrm{O}_{4}-\mathrm{ZnO}$ composites. Mater. Lett. 2003, 57, 3534-3548. [CrossRef]

10. Bayahn, M.; Hashemi, T.; Brinkman, A.W. Sintering and humidity-sensitive behavior of the $\mathrm{ZnCr}_{2} \mathrm{O}_{4}-\mathrm{K}_{2} \mathrm{CrO}_{4}$ ceramic system. J. Mater. Sci. 1997, 32, 6619-6623. [CrossRef]

11. Marinkovic Stanojevic, Z.V.; Mancic, L.; Marcic, L.; Milosevici, O. Microstructural characterization of mechanically activated $\mathrm{ZnO}-\mathrm{Cr}_{2} \mathrm{O}_{3}$ sysstem. J. Eur. Ceram. Soc. 2005, 25, 2081-2084. [CrossRef]

12. Marinkovic Stanojevic, Z.V.; Romcevic, N.; Stoganovic, B. Spectroscopic study of spinel $\mathrm{ZnCr}_{2} \mathrm{O}_{4}$ obtained

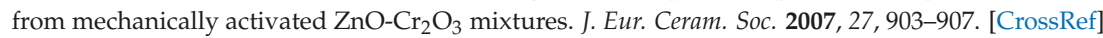

13. Imelda, E.; Myriam, P.; Roberto, M.; Adriana, G.C.; Guadalupe, S.L.; Luisa, M.F.V.; Octavia, D. Solid state reaction in $\mathrm{Cr}_{2} \mathrm{O}_{3}-\mathrm{ZnO}$ nanoparticles synthesized by triethanolamine chemical precipitation. Mater. Sci. Appl. 2011, 2, 1584-1592. [CrossRef]

14. Mousavi, Z.; Esmaeili-Zare, M.; Salavati-Niasari, M. Magnetic and optical properties of zinc chromite nanostructures prepared by microwave method. Trans. Nonferr. Met. Soc. China 2015, 25, 3980-3986. [CrossRef]

15. Naz, S.; Durrani, S.K.; Mehmood, M.; Nadeem, M. Hydrothermal synthesis, structural and impedance studies of nanocrystalline zinc chromite spinel oxide material. J. Saudi. Chem. Soc. 2016, 20, 585-593. [CrossRef]

16. Mousavi, Z.; Soofivand, F.; Esmaeili-Zare, M.; Salavati-Niasari, M.; Bagheri, S. $\mathrm{ZnCr}_{2} \mathrm{O}_{4}$ nanoparticles: Facile synthesis, characterization and photocatalytic properties. Sci. Rep. 2016, 6, 20071. [CrossRef] [PubMed]

17. Babar, A.R.; Kumbhar, S.B.; Shinde, S.S.; Moholkar, A.V.; Kim, J.H.; Rajpure, K.Y. Structural, compositional and electrical properties of co-precipitated zinc stannate. J. Alloy. Comp. 2011, 509, 7508-7514. [CrossRef]

18. Cui, H.; Zayat, M.; Levy, D. Sol-gel synthesis of nanoscaled spinel using propylene oxide as a gelation agent. Sol-Gel Sci. Technol. 2005, 35, 175-181. [CrossRef]

19. Gene, S.A.; Saion, E.; Shaari, A.H.; Kamarudin, M.A.; Al-Hada, N.M.; Kharazmi, A. Structural, optical and magnetic characterization of spinel zinc chromite nanocrystallines synthesized by thermal treatment methods. J. Nanomater. 2014, 2014, 416765. [CrossRef]

20. Hailiang, L.; Wenling, M.; Xiaohua, Y.; Jungi, L. Preparation and characterization of $\mathrm{MgCr}_{2} \mathrm{O}_{4}$ nanocrystals by microwave method. Adv. Mater. Res. 2011, 152, 1000-1003. [CrossRef]

21. Durani, S.K.; Hussain, S.Z.; Saeed, K.; Khan, Y.; Arif, M.; Ahmed, H. Hydrothermal synthesis and characterization of nanosized transition metal chromite spinels. Turk. J. Chem. 2012, 36, 111-120. [CrossRef]

22. Durani, S.K.; Naz, S.; Hayat, K. Thermal analysis and phase evolution of nanocrystalline perovskite oxide materials synthesized via hydrothermal and self-combustion methods. J. Therm. Anal. Calorim. 2014, 115, 1371-1380. [CrossRef] 
23. Stefanescu, M.; Barbu, M.; Vlase, T.; Barvinschi, P.; Barbu-Tudoran, L.; Stoia, M. Novel low temperature synthesis method for nanocrystalline zinc and magnesium chromites. Thermochim. Acta 2011, 526, 130-136. [CrossRef]

24. Gingasu, D.; Mindru, I.; Patron, L.; Culita, D.C.; Calderon-Moreno, J.M.; Diamandescu, L.; Feder, M.; Oprea, O. Precursor method-A nonconventional route for the synthesis of $\mathrm{ZnCr}_{2} \mathrm{O}_{4}$ spinel. J. Phys. Chem. Solid 2013, 74, 1295-12302. [CrossRef]

25. Gingasu, D.; Mindru, I.; Culita, D.C.; Patron, L.; Calderon-Moreno, J.M.; Preda, S.; Oprea, O.; Osiceanu, P.; Pineda, E.M. Investigation of nanocrystalline zinc chromite obtained by two soft chemical routes. Mater. Res. Bull. 2014, 49, 151-159. [CrossRef]

26. Fujishima, A.; Rao, T.N.; Tryk, D.A. Titanium Dioxide Photocatalysis. J. Photochem. Photobiol. C Photochem. Rev. 2000, 1, 1-21. [CrossRef]

27. Orha, C.; Pode, R.; Manea, F.; Lazau, C.; Bandas, C. Titanium dioxide-modified activated carbon for advanced drinking water treatment. Process Saf. Environ. Prot. 2017, 108, 26-33. [CrossRef]

28. Orha, C.; Manea, F.; Pop, A.; Bandas, C.; Lazau, C. TiO 2 -nanostructured carbon composite sorbent/photocatalyst for humic acid removal from water. Desalin. Water Treat. 2016, 57, 14178-14187. [CrossRef]

29. Yuan, W.; Liu, X.; Li, L. Synthesis, characterization and photocatalytic activity of cubic-like $\mathrm{CuCr}_{2} \mathrm{O}_{4}$ for dye degradation under visible light irradiation. Appl. Surf. Sci. 2014, 319, 350-357. [CrossRef]

30. Vader, V.T. Ni and Co substituted zinc ferri-chromite: A study of their influence in photocatalytic performance. Mater. Res. Bull. 2017, 85, 18-22. [CrossRef]

31. Abbasi, A.; Hamadanian, M.; Salavati-Niasari, M.; Mortazavi-Derazkola, S. Facile size-controlled preparation of highly photocatalytically active $\mathrm{ZnCr}_{2} \mathrm{O}_{4}$ and $\mathrm{ZnCr}_{2} \mathrm{O}_{4} / \mathrm{Ag}$ nanostructures for removal of organic contaminants. J. Colloid Interface Sci. 2017, 500, 276-284. [CrossRef] [PubMed]

32. Dumitru, R.; Papa, F.; Balint, I.; Culita, D.; Munteanu, C.; Stanica, N.; Ianculescu, A.; Diamandescu, L.; Carp, O. Mesoporous cobalt ferrite: A rival of platinum catalyst in methane combustion reaction. Appl. Catal. A Gen. 2013, 467, 178-186. [CrossRef]

33. Nakamoto, K. Infrared and Raman Spectra of Inorganic and Coordination Compounds; Wiley: New York, NY, USA, 1986; ISBN 0471010669.

34. Fujita, J.; Nakamoto, K.; Kobayshi, M. Infrared Spectra of Metallic Complexes. II. The Absorption Bands of Coördinated Water in Aquo Complexes. J. Am. Chem. Soc. 1956, 78, 3963-3965. [CrossRef]

35. Bîrzescu, M.; Niculescu, M.; Dumitru, R.; Carp, O.; Segal, E. Synthesis, structural characterization and thermal analysis of the cobalt(II) oxalate obtained through the reaction of 1,2-ethanediol with $\mathrm{Co}\left(\mathrm{NO}_{3}\right)_{2} \cdot 6 \mathrm{H}_{2} \mathrm{O}$. J. Therm. Anal. Calorim. 2009, 96, 979-986. [CrossRef]

36. Bîrzescu, M. Combinations with Ethyleneglycol and Their Oxidation Products. Ph.D. Thesis, University of Bucharest, Bucharest, Romania, 1998.

37. Stefãnescu, M.; Sasca, V.; Bîrzescu, M. Thermal behaviour of the homopolynuclear glyoxylate complex combinations with $\mathrm{Cu}(\mathrm{II})$ and $\mathrm{Cr}(\mathrm{III})$. J. Therm. Anal. Calorim. 2003, 72, 515-524. [CrossRef]

38. Kubelka, P.; Munk, F. Ein Beitrag Zur Optik Der Farbanstriche. Z. Tech. Phys. 1931, 12, 593-601.

39. Irfan, S.; Shen, Y.; Rizwan, S.; Wang, H.C.; Khan, S.B.; Nan, C.W. Band-gap engineering and enhanced photocatalytic activity of $\mathrm{Sm}$ and $\mathrm{Mn}$ doped $\mathrm{BiFeO}_{3}$ nanoparticles. J. Am. Ceram. Soc. 2016, 100, 31-40. [CrossRef]

(C) 2018 by the authors. Licensee MDPI, Basel, Switzerland. This article is an open access article distributed under the terms and conditions of the Creative Commons Attribution (CC BY) license (http:/ / creativecommons.org/licenses/by/4.0/). 


\title{
Article \\ Synthesis of $\mathrm{NaOH}-M o d i f i e d \mathrm{TiOF}_{2}$ and Its Enhanced Visible Light Photocatalytic Performance on RhB
}

\author{
Chentao Hou *, Wenli Liu and Jiaming Zhu \\ College of Geology and Environment, Xi'an University of Science and Technology, Xi'an 710054, China; \\ 13572955186@163.com (W.L.); XRD610@126.com (J.Z.) \\ * Correspondence: houct@xust.edu.cn; Tel.: +86-029-8558-3188
}

Received: 16 July 2017; Accepted: 16 August 2017; Published: 22 August 2017

\begin{abstract}
NaOH}$-modified $\mathrm{TiOF}_{2}$ was successfully prepared using a modified low-temperature hydrothermal method. Scanning electron microscopy shows that $\mathrm{NaOH}$-modified $\mathrm{TiOF}_{2}$ displayed a complex network shape with network units of about $100 \mathrm{~nm}$. The structures of $\mathrm{NaOH}$-modified $\mathrm{TiOF}_{2}$ have not been reported elsewhere. The network shape permits the $\mathrm{NaOH}$-modified $\mathrm{TiOF}_{2}$ a $\mathrm{S}_{\mathrm{BET}}$ of $36 \mathrm{~m}^{2} \cdot \mathrm{g}^{-1}$ and a pore diameter around $49 \mathrm{~nm}$. X-ray diffraction characterization shows that $\mathrm{TiOF}_{2}$ and $\mathrm{NaOH}$-modified $\mathrm{TiOF}_{2}$ are crystallized with a pure changed cubic phase which accords with the $\mathrm{SEM}$ results. Fourier transform infrared spectroscopy characterization shows that $\mathrm{NaOH}$-modified $\mathrm{TiOF}_{2}$ has more $\mathrm{O}-\mathrm{H}$ groups to supply more lone electron pairs to transfer from $\mathrm{O}$ of $\mathrm{O}-\mathrm{H}$ to $\mathrm{Ti}$ and $\mathrm{O}$ of $\mathrm{TiOF}_{2}$. UV-vis diffuse reflectance spectroscopy (DRS) shows that the $\mathrm{NaOH}$-modified $\mathrm{TiOF}_{2}$ sample has an adsorption plateau rising from 400 to $600 \mathrm{~nm}$ in comparison with $\mathrm{TiOF}_{2}$, and its band gap is $2.62 \mathrm{eV}$, lower than that of $\mathrm{TiOF}_{2}$. Due to the lower band gap, more $\mathrm{O}-\mathrm{H}$ groups adsorption, network morphologies with larger surface area, and sensitization progress, the $\mathrm{NaOH}$-modified $\mathrm{TiOF}_{2}$ exhibited much higher photocatalytic activity for Rhodamine B (RhB) degradation. In addition, considering the sensitization progress, $\mathrm{O}-\mathrm{H}$ groups on $\mathrm{TiOF}_{2}$ not only accelerated the degradation rate of $\mathrm{RhB}$, but also changed its degradation path. As a result, the $\mathrm{NaOH}$-modified $\mathrm{TiOF}_{2}$ exhibited much higher photocatalytic activity for $\mathrm{RhB}$ degradation than the $\mathrm{TiOF}_{2}$ in references under visible light. This finding provides a new idea to enhance the photocatalytic performance by $\mathrm{NaOH}$ modification of the surface of $\mathrm{TiOF}_{2}$.
\end{abstract}

Keywords: $\mathrm{TiOF}_{2} ; \mathrm{NaOH}$-modified $\mathrm{TiOF}_{2}$; network shape; photocatalysis; $\mathrm{RhB}$

\section{Introduction}

Nowadays, environmental pollution is affecting human survival and development. Photocatalysis is considered an efficient, stable, and environmentally friendly method for controlling environmental pollution [1]. In the past, $\mathrm{TiO}_{2}$ has been widely used as a photocatalyst in the photo-degradation of organic pollutants. However, it has a wide energy band gap (3.1-3.2 eV) which only permit its UV light response and can easily cause electron-hole recombination [1-4]. Thus, studies on changing morphology [1-3], modification [1,4,5], and other methods were conducted to decrease its band gap or inhibit its electron-hole recombination. The discovery of non-titanium semiconductor photocatalysts with a narrow intrinsic energy band gap, efficiently driven by visible light, may also attract much attention [5-13].

Recently, Li's research group found that $\mathrm{TiOF}_{2}$ cubes—considered a promising anode material for lithium ion batteries (LIBs) [14-19]—showed visible-light driven property and exhibited excellent performance in photodegradation of Rhodamine $\mathrm{B}(\mathrm{RhB})$ and 4-chlorophenol (4-CP) [7]. $\mathrm{TiOF}_{2}$ is also proven to be more active and durable at room temperature due to the covalent bonds of $\mathrm{F}$ species with Ti [8,9]. Only a few studies focused on the photocatalytic activity of $\mathrm{TiOF}_{2}$ have been reported [7-9]. 
As usual, $\mathrm{TiOF}_{2}$ nanoparticles were synthesized via hydrothermal $[10,14-18]$ and solvothermal $[7,11,12]$ methods from titanium (IV) isopropoxide (TIP), and have a cubic shape [7-18]. The size of $\mathrm{TiOF}_{2}$ nanocubes could be affected by alcoholysis time, alcohol kind, solvothermal temperature, different $\mathrm{H}_{2} \mathrm{O}$ production rate and amount $[7,17]$. While the photocatalytic activity of $\mathrm{TiOF}_{2}$ is still unsatisfactory, it is necessary to explore novel approaches to improve its photocatalytic performance.

Alkali modification is proven to be an effective method to enhance the catalytic performance for $\alpha$-pinene isomerization, formaldehyde oxidation, and benzene hydroxylation [20-23]. Thus, it stimulated us to modify the $\mathrm{TiOF}_{2}$ catalyst obtained from our earlier studies. In this study, we firstly reported a network-shaped $\mathrm{NaOH}$-modified $\mathrm{TiOF}_{2}$ treated by a hydrothermal process under low temperature. The FTIR measurement showed that more associated $\mathrm{O}-\mathrm{H}$ exists on the surface of $\mathrm{TiOF}_{2}$, which can remarkably enhance the catalytic activity of $\mathrm{TiOF}_{2}$ toward $\mathrm{RhB}$ oxidation under visible light. The $\mathrm{NaOH}$-modified $\mathrm{TiOF}_{2}$ had better photocatalytic performance than $\mathrm{TiOF}_{2}$ in $\mathrm{Li}^{\prime}$ s research [7].

\section{Results and Discussion}

\subsection{Phase Structures and Morphology}

The phase and crystallinity of the as-prepared $\mathrm{TiOF}_{2}$ and $\mathrm{NaOH}$-modified $\mathrm{TiOF}_{2}$ samples were tested by XRD analysis. It can be seen from Figure 1, the patterns of as-prepared $\mathrm{TiOF}_{2}$ and $\mathrm{NaOH}$-modified $\mathrm{TiOF}_{2}$ samples all have sharp peaks at $2 \theta=23.6^{\circ}, 48.1^{\circ}$, and $54.2^{\circ}$, corresponding to the (100), (200), and (210) planes of the cubic $\mathrm{TiOF}_{2}$ phase (JCPDS no. 08-0060) $[7,13]$ and no peak of any anatase $\mathrm{TiO}_{2}$ (JCPDS no. 21-1272) [24,25] crystal appears, indicating that the as-prepared samples have high crystallinity and pure phase of cubic $\mathrm{TiOF}_{2}$. It also indicates that the height of the (100) crystal planes of the $\mathrm{TiOF}_{2}$ and $\mathrm{NaOH}$-modified $\mathrm{TiOF}_{2}$ are higher, and the (200) and (210) crystal planes are lower than that of the standard cubic $\mathrm{TiOF}_{2}$, indicating a new shape of the as-prepared $\mathrm{TiOF}_{2}$ and $\mathrm{NaOH}$-modified $\mathrm{TiOF}_{2}$. The Scherrer formula was used to calculate the normal distance of certain crystal surfaces of $\mathrm{TiOF}_{2}$ and $\mathrm{NaOH}$-modified $\mathrm{TiOF}_{2}$

$$
\tau=\kappa \lambda /(\beta \cos \theta)
$$

where $\tau, \kappa, \lambda, \beta$, and $\theta$ are the mean normal distance of certain crystal surfaces, the shape constant with a value of 0.89 when $\beta$ is the half width of the diffraction peak (FWHM), the diffracted ray wavelength $(0.15418 \mathrm{~nm}$ for $\mathrm{Cu}-\mathrm{Ka})$, and the diffraction angle in radians, respectively [26].

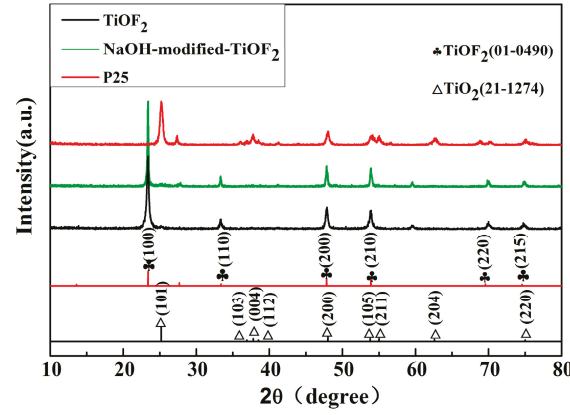

(a)

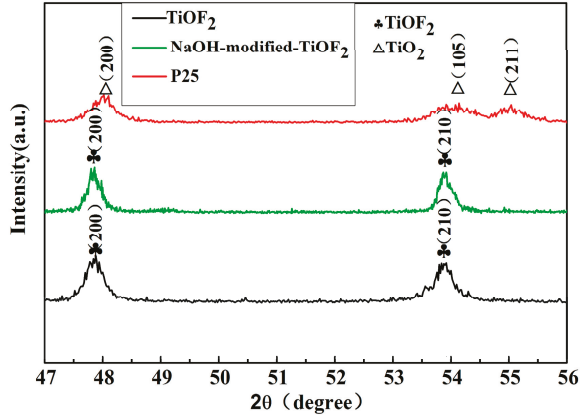

(b)

Figure 1. XRD pattern with $2 \theta$ from $10^{\circ}$ to $80^{\circ}$ (a) and partial enlarged detail of $2 \theta$ from $47^{\circ}$ to $56^{\circ}$ (b) of as-prepared $\mathrm{TiOF}_{2}, \mathrm{NaOH}$-modified $\mathrm{TiOF}_{2}$, commercial P25 and a standard card of $\mathrm{TiOF}_{2}$ and $\mathrm{TiO}_{2}$.

The normal distances of $\mathrm{TiOF}_{2}$ are $7.26,17.81,11.67,10.77,17.38$, and $16.98 \mathrm{~nm}$ along the (100), (110), (200), (210), (220), and (215) planes [7,13], respectively, while the distanced of crystal 
$\mathrm{NaOH}$-modified $\mathrm{TiOF}_{2}$ change to $15.99,42.18,26.26,30.78,40.80$, and $48.39 \mathrm{~nm}$ along the corresponding planes, respectively. It can be seen that the normal distance of the crystalline phase of $\mathrm{NaOH}$-modified $\mathrm{TiOF}_{2}$ shrunk $8.88 \%$ and $3.72 \%$ along (100) and (110) planes. However, an increase was observed along (200), (210), and (215) planes. This can be explained in that $\mathrm{NaOH}$-modifying induces more $\mathrm{O}-\mathrm{H}$ adsorbed onto (100) and (110) planes of $\mathrm{TiOF}_{2}$ and, thus, induces the planes' exposure.

Morphologies and microstructure of original $\mathrm{TiOF}_{2}$ and $\mathrm{NaOH}$-modified $\mathrm{TiOF}_{2}$ were checked by SEM characterization. In Figure $2 \mathrm{a}, \mathrm{b}, \mathrm{TiOF}_{2}$ crystals displayed a mixture of the cubic image which is accords with the cubic image in [7-18]. Each individual particle crystal is about $50-300 \mathrm{~nm}$ and tends to aggregate, forming larger particles while-in Figure $2 \mathrm{c}, \mathrm{d}$ - the $\mathrm{NaOH}$-modified $\mathrm{TiOF}_{2}$ displayed a more complex network shape with network units in about $100 \mathrm{~nm}$. The NaOH-modified $\mathrm{TiOF}_{2}$ shows phases assembling along certain directions. This accords with the XRD results. The network shape permits much more surface area for photocatalysis. These structures of $\mathrm{NaOH}$-modified $\mathrm{TiOF}_{2}$ have not been reported elsewhere. The Barrett-Joyner-Halenda (BJH) method was used to analyze the pore size distribution and pore volume and the surface area $\left(\mathrm{S}_{\mathrm{BET}}\right)$ was calculated using the BET method. The Figure 3 a demonstrated that the $\mathrm{NaOH}$-modified $\mathrm{TiOF}_{2}$ showed a typical IV type $\mathrm{N}_{2}$ adsorption-desorption isotherm and mesoporous structure with an average pore diameter of about $49 \mathrm{~nm}$. Thus, its $\mathrm{S}_{\mathrm{BET}}$ can reach as high as $36 \mathrm{~m}^{2} \cdot \mathrm{g}^{-1}$, while the average pore diameter and $\mathrm{S}_{\mathrm{BET}}$ of $\mathrm{TiOF}_{2}$ are only $3 \mathrm{~nm}$ and $2.7 \mathrm{~m}^{2} \cdot \mathrm{g}^{-1}$, which is much lower than that of $\mathrm{NaOH}$-modified $\mathrm{TiOF}_{2}$. The larger surface area permits more $\mathrm{O}-\mathrm{H}$ and pollutant adsorption and the formation of additional mesopores affects the improvement of mass transfer, enhancing photocatalytic performance accordingly [21,22].
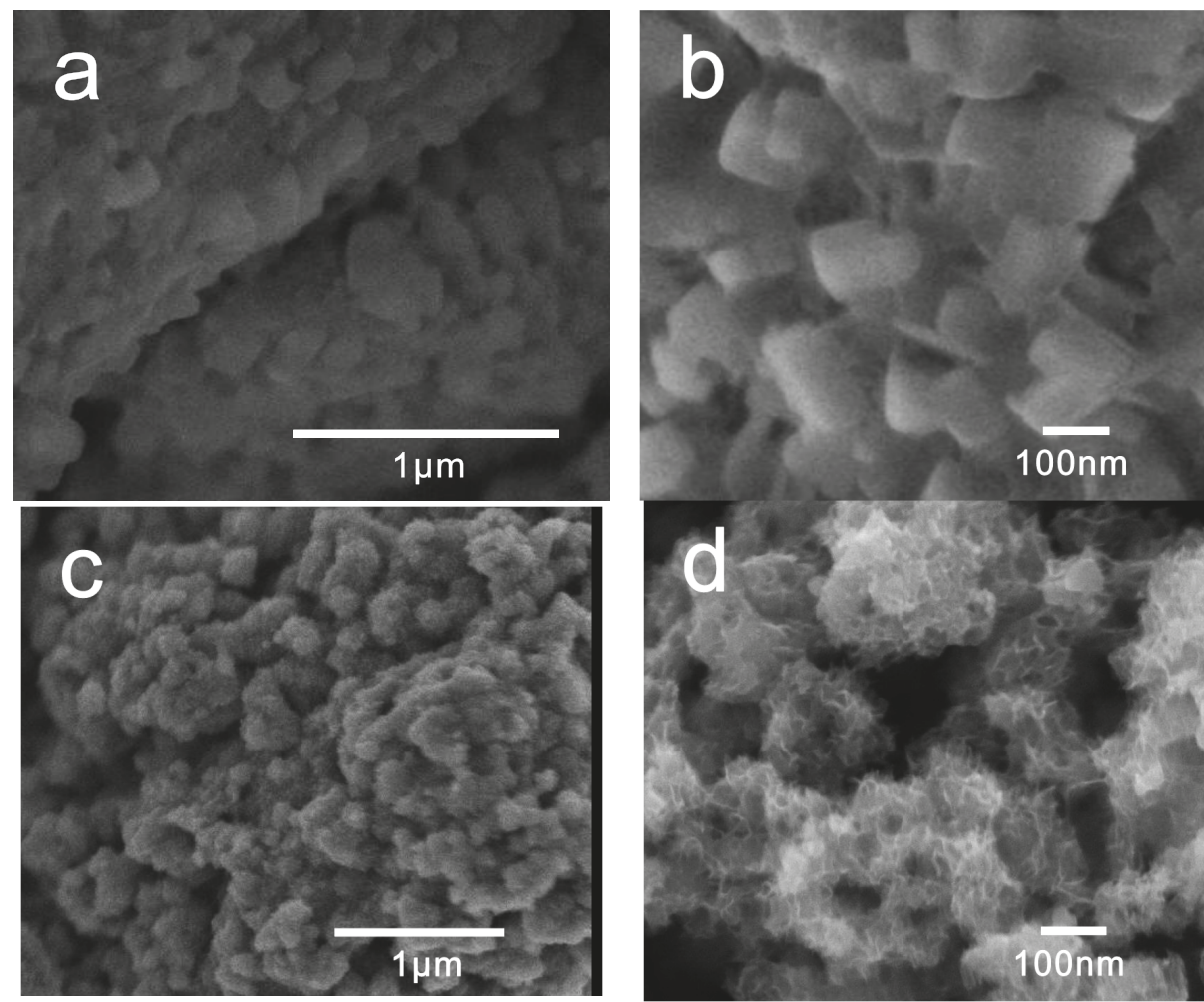

Figure 2. SEM of as-synthesized samples: (a,b) $\mathrm{TiOF}_{2}$; and (c,d) $\mathrm{NaOH}$-modified $\mathrm{TiOF}_{2}$. 


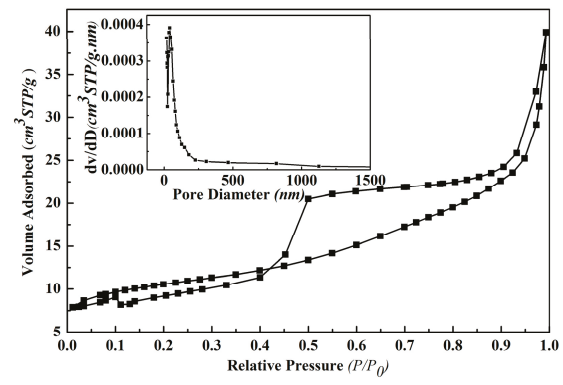

(a)

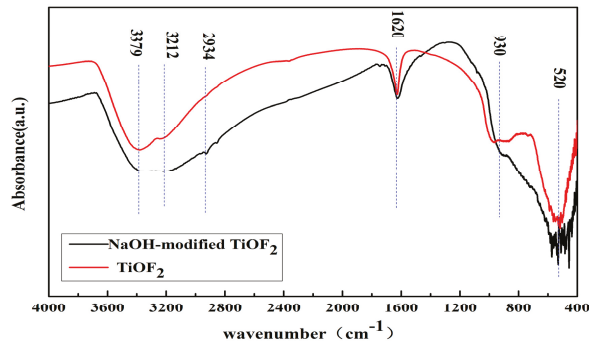

(b)

Figure 3. $\mathrm{N}_{2}$ adsorption-desorption isotherm of the $\mathrm{NaOH}$-modified $\mathrm{TiOF}_{2}$ (a) and the FTIR spectra for $\mathrm{TiOF}_{2}$ and $\mathrm{NaOH}$-modified $\mathrm{TiOF}(\mathbf{b})$.

\subsection{FTIR Analysis}

Figure $3 \mathrm{~b}$ shows the FTIR spectra of $\mathrm{TiOF}_{2}$ and $\mathrm{NaOH}$-modified $\mathrm{TiOF}_{2}$. The strong band around $700-500 \mathrm{~cm}^{-1}$ could contribute to the Ti-O-Ti stretching vibration [22-24]. The peak around $3379 \mathrm{~cm}^{-1}$ and the broad band centered around $3212 \mathrm{~cm}^{-1}$ were due to the free and bonding $\mathrm{O}-\mathrm{H}$ stretching vibration of Ti- $\mathrm{OH}$, respectively $[27,28]$. The peak at $1620 \mathrm{~cm}^{-1}$ was due to the $\mathrm{O}-\mathrm{H}$ bending vibration of $\mathrm{Ti}-\mathrm{OH}[16,22,29-33]$. The broad band centered around $3212 \mathrm{~cm}^{-1}$ in $\mathrm{NaOH}$-modified $\mathrm{TiOF}_{2}$ becomes broader than that in $\mathrm{TiOF}_{2}$, meaning that more $\mathrm{O}-\mathrm{H}$ bonds or associated $\mathrm{O}-\mathrm{H}$ appeared in $\mathrm{NaOH}$-modified $\mathrm{TiOF}_{2}$. According to previous work, the free $\mathrm{O}-\mathrm{H}$ stretching vibration used to appear at about $3600 \mathrm{~cm}^{-1}$ without bonding $\mathrm{O}-\mathrm{H}[27,28]$. It can be seen that the $\mathrm{O}-\mathrm{H}$ frequency for $\mathrm{TiOF}_{2}$ and $\mathrm{NaOH}$-modified $\mathrm{TiOF}_{2}$ is $221 \mathrm{~cm}^{-1}$ and $388 \mathrm{~cm}^{-1}$ lower than $3600 \mathrm{~cm}^{-1}$, indicating a strong hydrogen bond impact $[27,28]$. The $\mathrm{O}-\mathrm{H}$ on the $\mathrm{TiO}_{2}$ surface can enhance the transference of photo-generated electrons and then enhance photocatalytic performance [29]. The peaks around $930 \mathrm{~cm}^{-1}$ were due to the Ti-F vibrations in the $\mathrm{TiOF}_{2}$ [16]. The peak intensity decreased from $\mathrm{TiOF}_{2}$ to $\mathrm{NaOH}$-modified $\mathrm{TiOF}_{2}$, indicating $\mathrm{F}$ was exchanged by $\mathrm{O}-\mathrm{H}$ after $\mathrm{NaOH}$ modification. All of these show that the $\mathrm{NaOH}$-modified $\mathrm{TiOF}_{2}$ samples contain more O-H groups than $\mathrm{TiOF}_{2}$. It can be explained that $\mathrm{TiOF}_{2}$ was modified in $\mathrm{NaOH}$ solution, thus, more $\mathrm{O}-\mathrm{H}$ would be chemisorbed onto $\mathrm{TiOF}_{2}$, and further exchanged with $\mathrm{F}$. Then, more lone pair electrons in the $\mathrm{O}-\mathrm{H}$ groups transferring from the $\mathrm{O}$ of $\mathrm{O}-\mathrm{H}$ to $\mathrm{Ti}$ and the $\mathrm{O}$ of $\mathrm{TiOF}_{2}$, the performance of $\mathrm{TiOF}_{2}$ can be enhanced accordingly [21]. In addition, because $\mathrm{RhB}$ is a cationic dye, $\mathrm{NaOH}$ brings more $\mathrm{O}-\mathrm{H}$ onto the surface of $\mathrm{TiOF}_{2}$ to hold more $\mathrm{RhB}$ and accelerate its degradation rate $[34,35]$.

\subsection{UV-Vis Analysis}

Figure 4 shows that the UV-vis absorption spectroscopy and band gap of as-prepared $\mathrm{TiOF}_{2}$ and $\mathrm{NaOH}$-modified $\mathrm{TiOF}_{2}$ samples. The $\mathrm{NaOH}$-modified $\mathrm{TiOF}_{2}$ has a raised adsorption plateau from 400 to $600 \mathrm{~nm}$, which indicates stronger visible light absorption than that of $\mathrm{TiOF}_{2}$ (Figure 4a). Band gap estimation can be seen in Figure $4 \mathrm{~b}$ showing that the band gap of $\mathrm{NaOH}$-modified $\mathrm{TiOF}_{2}$ is $2.62 \mathrm{eV}$, which is lower than that of $\mathrm{TiOF}_{2}(2.80 \mathrm{eV})$ and lower than anatase $\mathrm{TiO}_{2}(3.2 \mathrm{eV})[1-4], \mathrm{NiO}$ $(4.0 \mathrm{eV})[6]$, and other oxides, indicating easier excitation by visible light. This can be explained in that $\mathrm{NaOH}$ treatment causes certain facet exposure and network morphologies of $\mathrm{TiOF}_{2}$, changing its light absorption properties. Thus, the $\mathrm{NaOH}$ treatment lowered the band gap of $\mathrm{TiOF}_{2}$, enhanced its visible light absorption, and further enhanced its visible light photocatalytic properties. 


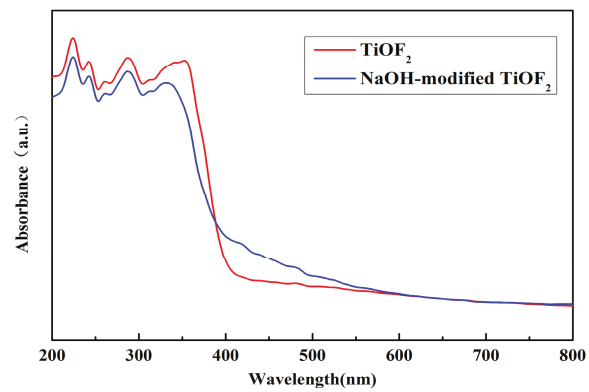

(a)

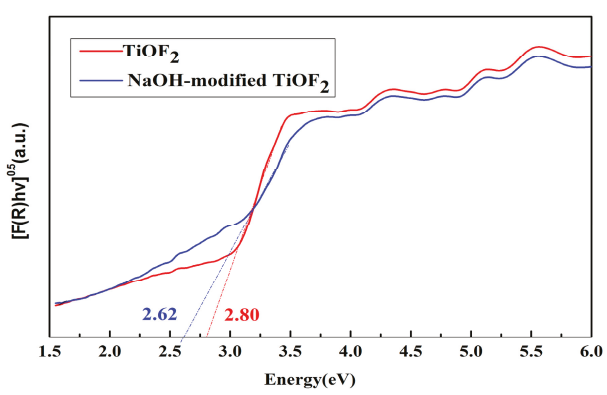

(b)

Figure 4. UV-vis DRS spectra (a) and band gap (b) of $\mathrm{TiOF}_{2}$ and $\mathrm{NaOH}$-modified $\mathrm{TiOF}_{2}$.

\subsection{Catalytic Activity}

Figure 5 shows the visible light photcatalytic properties of $\mathrm{TiOF}_{2}, \mathrm{NaOH}$-modified $\mathrm{TiOF}_{2}, \mathrm{TiOF}_{2}$ in reference $\left(\mathrm{TiOF}_{2}-\mathrm{Ref}\right)[7,13], \mathrm{TiOF}_{2}$-crushed in reference ( $\mathrm{TiOF}_{2}$-crushed-Ref) [7], and P25. It can be seen in Figure 5a that, in the adsorption test in dark and in light on the process without the catalyst for $\mathrm{RhB}$, the decrease of $\mathrm{RhB}$ is very small. It can be concluded that the adsorption and sensitization mechanisms can be negligible in the degradation process. Thus, the degradation of RhB was a photocatalytic process. The concentration of RhB decreased under the same conditions, which means that all samples are visible-light active. It also shows that $\mathrm{NaOH}$-modified $\mathrm{TiOF}_{2}$ can cause almost complete decomposition of $\mathrm{RhB}$ in $3 \mathrm{~h}$, having better photocatalytic performance than all of the $\mathrm{TiOF}_{2}$ in reference $[7,13]$. While $\mathrm{P} 25$ and $\mathrm{TiOF}_{2}$ performed poorly compared to $\mathrm{NaOH}$-modified $\mathrm{TiOF}_{2}$ and $\mathrm{TiOF}_{2}-$ Ref. The reaction rate of all of the samples are shown in Figure $5 \mathrm{~b}$. It can be seen that the data was fitted with the first-order reaction equation as

$$
\ln \left(C_{0} / C\right)=k t
$$

where $t$ is the reaction time, $C_{0}$ is concentration of $\mathrm{RhB}$ at time $0, C$ is the concentration of $\mathrm{RhB}$ at time $t$, and $k$ is the reaction rate constant.

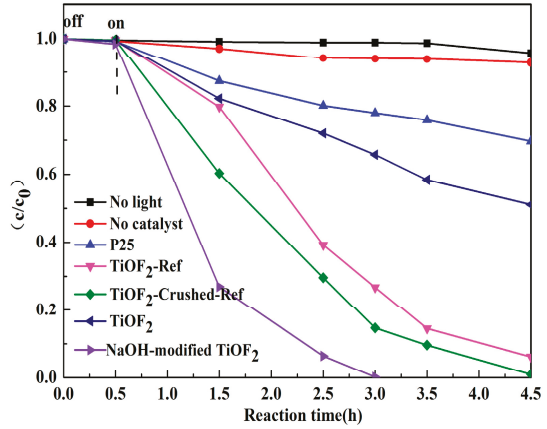

(a)

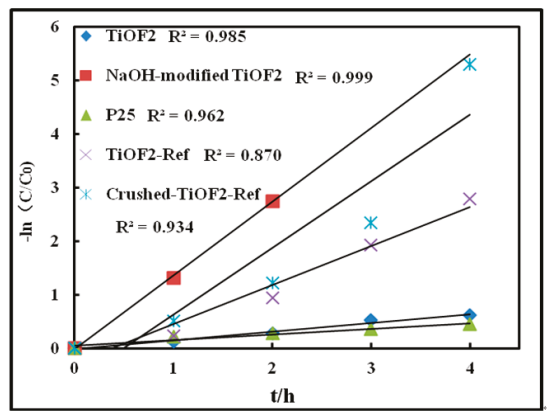

(b)

Figure 5. Catalytic activity of RhB under visible light: (a) concentration dependent on time and (b) kinetic fit for the degradation of RhB.

It can be seen that $\mathrm{P} 25$ and $\mathrm{TiOF}_{2}$ had rate constants of only 0.10 and $0.16 \mathrm{~h}^{-1}$, indicating poor photocatalytic performance. The result is consistent with previous work $[8,20]$. The calculated rate 
constants are $1.37,0.73$, and $1.24 \mathrm{~h}^{-1}$ for $\mathrm{NaOH}$-modified $\mathrm{TiOF}_{2}$, $\mathrm{TiOF}_{2}$-Ref, and $\mathrm{TiOF}_{2}$-crushed-Ref, respectively. The $\mathrm{NaOH}$-modified $\mathrm{TiOF}_{2}$ sample shows the best performance among all the photocatalysts, whose degradation rates are much higher than that of $\mathrm{P} 25$ and $\mathrm{TiOF}_{2}$ in our samples and $10.4 \%$ higher than that of $\mathrm{TiOF}_{2}$-crushed-Ref The excellent performance could be mainly attributed to its larger $\mathrm{S}_{\mathrm{BET}}\left(32 \mathrm{~m}^{2} \cdot \mathrm{g}^{-1}\right.$ for $\mathrm{TiOF}_{2}$-crushed-Ref) and more bonding $\mathrm{O}-\mathrm{H}[7,21]$.

\subsection{Effect of the Sensitization Mechanism}

According to previous studies, dyes can be degraded on $\mathrm{TiO}_{2}$ through a sensitized process under visible light $[34,35]$. In order to know whether there is a similar path on $\mathrm{TiOF}_{2}$ and $\mathrm{NaOH}$-modified $\mathrm{TiOF}_{2}, \mathrm{UV}$-vis absorption spectral changes of $\mathrm{RhB}$ with visible light irradiation time in the suspension of $\mathrm{TiOF}_{2}$ and $\mathrm{NaOH}$-modified $\mathrm{TiOF}_{2}$ were tested. The results are shown in Figure 6. It can be seen in Figure 6 that the spectral change of $\mathrm{RhB}$ with the irradiation time on $\mathrm{NaOH}$-modified $\mathrm{TiOF}_{2}$ is quite different from that on $\mathrm{TiOF}_{2}$. There is a blue-shift from 558 to $498 \mathrm{~nm}$ in the absorption maximum with irradiation time for $\mathrm{NaOH}$-modified $\mathrm{TiOF}_{2}$, while none in that of $\mathrm{TiOF}_{2}$. This is attributed to the $\mathrm{N}$-deethylation products of $\mathrm{RhB}$, which confirms the possibility of the sensitization mechanism $[34,35]$. Thus, $\mathrm{NaOH}$ treatment can induce the sensitization process and change the degradation path of $\mathrm{TiOF}_{2}$.

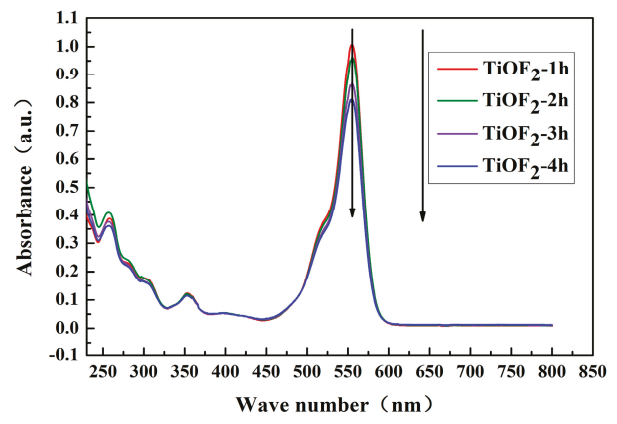

(a)

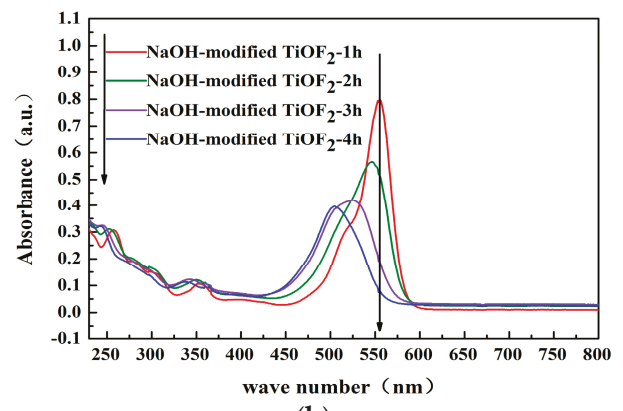

(b)

Figure 6. UV-vis absorption spectra of $\mathrm{RhB}$ in (a) $\mathrm{TiOF}_{2}$ and (b) $\mathrm{NaOH}$-modified $\mathrm{TiOF}_{2}$ suspension under visible light.

\section{Materials and Methods}

Tetrabutyl titanate (TBOT, A.R. grade) was purchased from Fu Chen Chemical Reagent Factory, Tianjin, China. Absolute ethyl alcohol $\left(\mathrm{C}_{2} \mathrm{H}_{5} \mathrm{OH}\right.$, A.R. grade) and sodium hydroxide $(\mathrm{NaOH}, \mathrm{A} . \mathrm{R}$. grade) was purchased from Fuyu Fine Chemical Co., Ltd., Tianjin, China. Hydrofluoric acid (HF, A.R. grade) was purchased from Xilong Chemical Industry Co., Ltd., Chengdu, China. All reagents are used without further purification. Ultrapure water was used as the experimental water.

$\mathrm{NaOH}$-modified $\mathrm{TiOF}_{2}$ was synthesized via a modified low-temperature hydrothermal method. In a typical synthesis, $30.4 \mathrm{~mL}$ absolute ethyl alcohol was added into $35.2 \mathrm{~mL}$ TBOT, which was named solution A. Absolute ethyl alcohol (30.4 mL) and $20.2 \mathrm{~mL}$ HF were added into $180 \mathrm{~mL}$ ultrapure water, which was named solution B. Solution A was dropped into solution B under medium-speed magnetic stirring at $20^{\circ} \mathrm{C}$ for $1.5 \mathrm{~h}$ to obtain a faint yellow sol. The sol was aged at room temperature for 2 days to change to a gel. The gel was then transferred into a 50-mL Teflon-lined stainless steel autoclave. When sealed, the autoclave was placed at $100{ }^{\circ} \mathrm{C}$ for $2 \mathrm{~h}$ in a drying box, then was naturally cooled to room temperature. Ultra-pure water and absolute ethanol were used to wash the obtained white precipitates several times to reach a $\mathrm{pH}$ of 7 , and then the precipitates were dried at $100{ }^{\circ} \mathrm{C}$. The as-prepared sample was $\mathrm{TiOF}_{2}$. One gram of the $\mathrm{TiOF}_{2}$ precursor was dispersed in $100 \mathrm{~mL} 5 \mathrm{~mol} \cdot \mathrm{L}^{-1} \mathrm{NaOH}$ solution under magnetic stirring with a speed of $4000 \mathrm{r} \cdot \mathrm{min}^{-1}$ for $1 \mathrm{~h}$, then the suspension was also washed with ultra-pure water and absolute ethanol to reach a $\mathrm{pH}$ 
of 7 . The product was dried at $100{ }^{\circ} \mathrm{C}$ for $12 \mathrm{~h}$. The sample was denoted as $\mathrm{NaOH}$-modified $\mathrm{TiOF}_{2}$. The crystal structure as analyzed by a XD-2 X-ray diffractometer (Beijing Purkinje, Beijing, China) with $\mathrm{Cu}$ K $\alpha$ radiation with a scan rate of $4.0000^{\circ} \cdot \mathrm{min}^{-1}$. The morphology was examined by field emission scanning electron microscopy (FESEM, JEOL JSM6700, Tokyo, Japan). Fourier transform infrared (FTIR) spectra were recorded using a Bruker TENSOR27 (Karlsurhe, Germeny) using the KBr method. The optical properties were determined by UV-vis diffuse reflectance spectroscopy (UV-vis DRS: (Shimadzu 2600, Beijing, China). $\mathrm{N}_{2}$ adsorption-desorption isotherms were measured at $77 \mathrm{~K}$ and the BET method was used to calculate the surface area $\left(\mathrm{S}_{\mathrm{BET}}\right)$ by a JW-BK122F (Beijing, China).

The degradation of $\mathrm{RhB}$ was conducted at room temperature in a $150 \mathrm{~mL}$ double-layered quartz reactor containing $50 \mathrm{mg}$ catalyst and $50 \mathrm{~mL} 5.0 \mathrm{mg} \cdot \mathrm{L}^{-1} \mathrm{RhB}$ solution. A $300 \mathrm{~W}$ Xe lamp (Jiguang-300, Shanghai, China) was located at a distance of $15 \mathrm{~cm}$ from the RhB solution to simulate solar light. A cutoff filter (JB-420, Shanghai, China) was chosen to filter off the light whose wavelength was less than $420 \mathrm{~nm}$ to simulate visible light. The solution was magnetically stirred for $30 \mathrm{~min}$ to ensure the adsorption-desorption equilibrium, then the xenon lamp was turned on to start the photocatalytic degradation. At $30 \mathrm{~min}$ time intervals, about $5.0 \mathrm{~mL} \mathrm{RhB}$ solution was extracted and centrifuged at high-speed $\left(11,000 \mathrm{r} \cdot \mathrm{min}^{-1}\right)$ to remove catalysts. Then the concentration of the remaining RhB solutions were analyzed with a Purkinje UV1901 UV-vis spectrophotometer at $554 \mathrm{~nm}$. The photocatalyst was separated from the RhB solution and another run of the reaction was started to investigate the durability of the catalysts.

\section{Conclusions}

$\mathrm{NaOH}$-modified $\mathrm{TiOF}_{2}$ was successfully prepared via a modified low-temperature solvothermal method. It exhibited much better photocatalytic performance for $\mathrm{RhB}$ degradation. XRD characterization shows that $\mathrm{TiOF}_{2}$ and $\mathrm{NaOH}$-modified $\mathrm{TiOF}_{2}$ are crystallized with a pure changed cubic phase which is accord with the SEM results. SEM shows that $\mathrm{TiOF}_{2}$ crystals displayed a mixture of the cubic images, while the $\mathrm{NaOH}$-modified $\mathrm{TiOF}_{2}$ displayed a more complex network shape with network units in about $100 \mathrm{~nm}$. These structures of $\mathrm{NaOH}$-modified $\mathrm{TiOF}_{2}$ have not been reported elsewhere. The network shape permits the $\mathrm{NaOH}$-modified $\mathrm{TiOF}_{2}$ a surface area of $36 \mathrm{~m}^{2} \cdot \mathrm{g}^{-1}$ and a pore diameter about $49 \mathrm{~nm}$, which will enhance the adsorption of $\mathrm{O}-\mathrm{H}$ groups and pollutants. FTIR characterization shows that $\mathrm{NaOH}$-modified $\mathrm{TiOF}_{2}$ has more $\mathrm{O}-\mathrm{H}$ groups to supply more lone electron pairs transferring from $\mathrm{O}$ of the $\mathrm{O}-\mathrm{H}$ groups to $\mathrm{Ti}$ and $\mathrm{O}$ of $\mathrm{TiOF}_{2}$, in accordance with the BET analysis. UV-vis absorption spectroscopy shows that the $\mathrm{NaOH}$-modified $\mathrm{TiOF}_{2}$ samples have an adsorption plateau rising from 400 to $600 \mathrm{~nm}$ in comparison with $\mathrm{TiOF}_{2}$ and its band gap is $2.62 \mathrm{eV}$, lower than that of $\mathrm{TiOF}_{2}$. Due to the lower band gap, more $\mathrm{O}-\mathrm{H}$ groups adsorption, network morphologies with larger surface area, and sensitization process, the $\mathrm{NaOH}$-modified $\mathrm{TiOF}_{2}$ exhibited much higher photocatalytic activity for RhB degradation. In addition, considering the sensitization process, $\mathrm{O}-\mathrm{H}$ on $\mathrm{TiOF}_{2}$ not only accelerated the degradation rate of $\mathrm{RhB}$, but also changed its degradation path. This finding provides a new idea to enhance the photocatalytic performence by $\mathrm{NaOH}$ modification of the surface of $\mathrm{TiOF}_{2}$. Considering its synthesizing process, the $\mathrm{NaOH}$-modified $\mathrm{TiOF}_{2}$ needs much lower temperature and shorter time than $\mathrm{TiOF}_{2}$-crushed-Ref, but has much better photocatalytic performance, which provides a more economic choice.

Acknowledgments: Financial support was provided by Shaanxi Key Industrial Projects (2014GY2-07) and the Shaanxi Province Education Department Science and Technology Research Plan (15JK1460).

Author Contributions: In this paper, Chentao Hou and Wenli Liu designed the experiments; Wenli Liu and Jiaming Zhu conducted the experiments; Chentao Hou and Wenli Liu analyzed the data; and Chentao Hou wrote the article.

Conflicts of Interest: There is no conflict of interest existing in the manuscript submission, and it is approved by all of the authors for publication. All the authors listed have approved the manuscript to be enclosed. 


\section{References}

1. Chen, X.; Mao, S.S. Titanium dioxide nanomaterials: Synthesis, properties, modifications, and applications. Chem. Rev. 2007, 107, 2891-2959. [CrossRef] [PubMed]

2. Nunes, D.; Pimentel, A.; Santos, L.; Barquinha, P.; Fortunato, E.; Martins, R. Photocatalytic $\mathrm{TiO}_{2} \mathrm{Nanorod}$ Spheres and Arrays Compatible with Flexible Applications. Catalysts 2017, 7, 60. [CrossRef]

3. Zuo, S.; Jiang, Z.; Liu, W.; Yao, C.; Chen, Q.; Liu, X. Synthesis and Characterization of Urchin-like Mischcrystal $\mathrm{TiO}_{2}$ and Its Photocatalysis. Mater. Charact. 2014, 96, 177-182. [CrossRef]

4. Xie, C.; Yang, S.; Shi, J.; Niu, C. Highly Crystallized C-Doped MesoporousAnatase $\mathrm{TiO}_{2}$ with Visible Light Photocatalytic Activity. Catalysts 2016, 6, 117. [CrossRef]

5. Cherian, C.T.; Reddy, M.V.; Magdaleno, T.; Sow, C.-H.; Ramanujachary, K.V.; Rao, G.V.S.; Chowdari, B.V.R. (N,F)-Co-doped $\mathrm{TiO}_{2}$ : Synthesis, anatase-rutile conversion and Li-cycling properties. CrystEngComm 2012, 14, 978-986. [CrossRef]

6. Ramasami, A.K.; Reddy, M.V.; Balakrishna, G.R. Combustion synthesis and characterization of $\mathrm{NiO}$ nanoparticles. Mater. Sci. Semicond. Process. 2015, 40, 194-202. [CrossRef]

7. Wang, J.; Cao, F.; Bian, Z.; Leung, M.K.H.; Li, H. Ultrafine single-crystal TiOF 2 nanocubes with mesoporous structure, high activity and durability in visible light driven photocatalysis. Nanoscale 2014, 6, 897-902. [CrossRef] [PubMed]

8. Wang, Z.; Ana, C.; Zhang, J. Synthesis of heterostructured $\mathrm{Pd@TiO} 2 / \mathrm{TiOF}_{2}$ nanohybrids with enhanced photocatalytic performance. Mater. Res. Bull. 2016, 80, 337-343.

9. Dongn, P.; Cui, E.; Hou, G.; Guan, R.; Zhang, Q. Synthesis and photocatalytic activity of $\mathrm{Ag}_{3} \mathrm{PO}_{4} / \mathrm{TiOF}_{2}$ composites with enhanced stability. Mater. Lett. 2015, 143, 20-23. [CrossRef]

10. Lv, K.; Yu, J.; Cui, L.; Chen, S.; Li, M. Preparation of thermally stable anatase $\mathrm{TiO}_{2}$ photocatalyst from $\mathrm{TiOF}_{2}$ precursor and its photocatalytic activity. J. Alloys Compd. 2011, 509, 4557-4562. [CrossRef]

11. Wang, Z.; Huang, B.; Dai, Y.; Zhang, X.; Qin, X.; Li, Z.; Zheng, Z.; Cheng, H.; Guo, L. Topotactic transformation of single-crystalline $\mathrm{TiOF}_{2}$ nanocubes to ordered arranged $3 \mathrm{D}$ hierarchical $\mathrm{TiO}_{2}$ nanoboxes. CrystEngComm 2012, 14, 4578-4581. [CrossRef]

12. Huang, Z.; Wang, Z.; Lv, K.; Zheng, Y.; Deng, K. Transformation of TiOF 2 cube to a hollow nanobox assembly from anatase $\mathrm{TiO}_{2}$ nanosheets with exposed $\{001\}$ facets via solvothermal strategy. ACS Appl. Mater. Interfaces 2013, 5, 8663-8669. [CrossRef] [PubMed]

13. Wen, C.Z.; Hu, Q.H.; Guo, Y.N.; Gong, X.Q.; Qiao, S.Z.; Yang, H.G. From titanium oxydifluoride $\left(\mathrm{TiOF}_{2}\right)$ to titania $\left(\mathrm{TiO}_{2}\right)$ : Phase transition and non-metal doping with enhanced photocatalytic hydrogen $\left(\mathrm{H}_{2}\right)$ evolution properties. Chem. Commun. 2011, 47, 6138-6140. [CrossRef] [PubMed]

14. Jung, M.; Kim, Y.; Lee, Y. Enhancement of the electrochemical capacitance of $\mathrm{TiOF}_{2}$ obtained via control of the crystal structure. J. Ind. Eng. Chem. 2017, 47, 187-193. [CrossRef]

15. Louvain, N.; Karkar, Z.; El-Ghozzi, M.; Bonnet, P.; Gúerin, K.; Willmann, P. Fluorinationof anatase $\mathrm{TiO}_{2}$ towards titanium oxyfluoride $\mathrm{TiOF}_{2}$ : A novel synthesis approach and proof of the Li-insertion mechanism. J. Mater. Chem. A 2014, 2, 15308-15315. [CrossRef]

16. Li, W.; Body, M.; Legein, C.; Dambournet, D. Identify $\mathrm{OH}$ groups in $\mathrm{TiOF}_{2}$ and their impact on the lithium intercalation properties. J. Solid State Chem. 2017, 246, 113-118. [CrossRef]

17. Chen, L.; Shen, L.; Nie, P.; Zhang, X.; Li, H. Facile hydrothermal synthesis of single crystalline $\mathrm{TiOF}_{2}$ nanocubes and their phase transitions to $\mathrm{TiO}_{2}$ hollow nanocages as anode materials for lithium-ion battery. Electrochim. Acta 2012, 62, 408-415. [CrossRef]

18. Reddy, M.V.; Madhavi, S.; Rao, G.V.S.; Chowdari, B.V.R. Metal oxyfluorides $\mathrm{TiOF}_{2}$ and $\mathrm{NbO}_{2} \mathrm{~F}$ as anodes for Li-ion batteries. J. Power Sources 2006, 162, 1312-1321. [CrossRef]

19. Reddy, M.V.; Rao, G.V.S.; Chowdari, B.V.R. Metal Oxides and Oxysalts as Anode Materials for Li Ion Batteries. Chem. Rev. 2013, 113, 5364-5457. [CrossRef] [PubMed]

20. Zhou, P.; Yu, J.; Nie, L.; Jaroniec, M. Dual-dehydrogenation-promoted catalytic oxidation of formaldehyde on alkali-treated Pt clusters at room temperature. J. Mater. Chem. A 2015, 3, 10432-10438. [CrossRef]

21. Nie, L.; Yu, J.; Li, X.; Cheng, B.; Liu, G.; Jaroniec, M. Enhanced Performance of NaOH-Modified Pt/TiO 2 toward Room Temperature Selective Oxidation of Formaldehyde. Environ. Sci. Technol. 2013, 47, 2777-2783. [CrossRef] [PubMed] 
22. Gopalakrishnan, S.; Zampieri, A.; Schwieger, W. Mesoporous ZSM-5 zeolites via alkali treatment for the direct hydroxylation of benzene to phenol with $\mathrm{N}_{2}$ O. J. Catal. 2008, 260, 193-197. [CrossRef]

23. Wu, Y.; Tian, F.; Liu, J.; Song, D.; Jia, C.; Chen, Y. Enhanced catalytic isomerization of $\alpha$-pinene over mesoporous zeolite beta of low Si / Al ratio by NaOH treatment. Microporous Mesoporous Mater. 2012, 162, 168-174. [CrossRef]

24. Wang, Z.; Lv, K.; Wang, G.; Deng, K.; Tang, D. Study on the shape control and photocatalytic activity of high-energy anatasetitania. Appl. Catal. B Environ. 2010, 100, 378-385. [CrossRef]

25. Niu, L.; Zhang, Q.; Liu, J.; Qian, J.; Zhou, X. $\mathrm{TiO}_{2}$ nanoparticles embedded in hollow cube with highly exposed $\{001\}$ facets: Facile synthesis and photovoltaic applications. J. Alloys Compd. 2016, 656, 863-870. [CrossRef]

26. He, M.; Wang, Z.; Yan, X.; Tian, L.; Liu, G.; Chen, X. Hydrogenation effects on the lithium ion battery performance of $\mathrm{TiOF}_{2}$. J. Power Sources 2016, 306, 309-316. [CrossRef]

27. Iwata, T.; Watanabe, A.; Iseki, M.; Watanabe, M.; Kandor, H. Strong Donation of the Hydrogen Bond of Tyrosine during Photoactivation of the BLUF Domain. J. Phys. Chem. Lett. 2011, 2, 1015-1019. [CrossRef]

28. Ning, Y. Structural Identification of Organic Compounds and Organic Spectroscopy; Science Press: Beijing, China, 2000; ISBN 978-7-03-0074-126.

29. Zhang, Y.; Zhang, Q.; Xia, T.; Zhu, D.; Chen, Y.; Chen, X. The influence of reaction temperature on the formation and photocatalytic hydrogen generation of (001) faceted $\mathrm{TiO}_{2}$ nanosheets. ChemNanoMat 2015, 1, 270-275. [CrossRef]

30. Vaiano, V.; Sannino, D.; Almeida, A.R.; Mul, G.; Ciambelli, P. Investigation of the Deactivation Phenomena Occurring in the Cyclohexane Photocatalytic Oxidative Dehydrogenation on $\mathrm{MoOx} / \mathrm{TiO}_{2}$ through Gas Phase and in situ DRIFTS Analyses. Catalysts 2013, 3, 978-997. [CrossRef]

31. Samsudin, E.M.; Hamid, S.B.A.; Basirun, W.J.; Centi, G. Synergetic effects in novel hydrogenated F-doped $\mathrm{TiO}_{2}$ photocatalysts. Appl. Surf. Sci. 2016, 370, 380-393. [CrossRef]

32. Ding, X.; Hong, Z.; Wang, Y.; Lai, R.; Wei, M. Synthesis of square-like anatase $\mathrm{TiO}_{2}$ nanocrystals based on $\mathrm{TiOF}_{2}$ quantum dots. J. Alloys Compd. 2013, 550, 475-478. [CrossRef]

33. Nishikiori, H.; Hayashibe, M.; Fujii, T. Visible Light-Photocatalytic Activity of Sulfate-Doped Titanium Dioxide Prepared by the Sol-Gel Method. Catalysts 2013, 3, 363-377. [CrossRef]

34. Kowalska, E.; Remita, H.; Colbeau-Justin, C.; Hupka, J.; Belloni, J. Modification of Titanium Dioxide with Platinum Ions and Clusters: Application in Photocatalysis. J. Phys. Chem. C 2008, 112, 1124-1131. [CrossRef]

35. Park, H.; Choi, W. Photocatalytic Reactivities of Nafion-Coated $\mathrm{TiO}_{2}$ for the Degradation of Charged Organic Compounds under UV or Visible Light. J. Phys. Chem. B 2005, 109, 11667-11674. [CrossRef] [PubMed]

(C) 2017 by the authors. Licensee MDPI, Basel, Switzerland. This article is an open access article distributed under the terms and conditions of the Creative Commons Attribution (CC BY) license (http:/ / creativecommons.org/licenses/by/4.0/). 

MDPI

St. Alban-Anlage 66

4052 Basel

Switzerland

Tel. +41616837734

Fax +41 613028918

www.mdpi.com

Catalysts Editorial Office

E-mail: catalysts@mdpi.com

www.mdpi.com/journal/catalysts

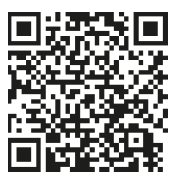



MDPI

St. Alban-Anlage 66

4052 Basel

Switzerland

Tel: +4161 6837734

Fax: +41 613028918

www.mdpi.com 